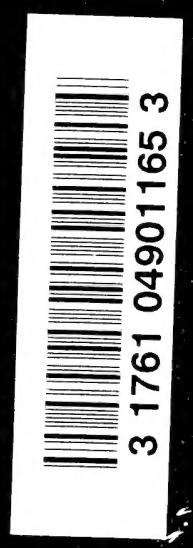

Umiv. of:

Tonorto

LIORARY 




$$
\text { . }
$$




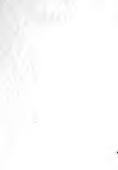


Number Io

MAY, 1923

\section{MEMOIRS}

THE AMERICAN ANATOMICAL

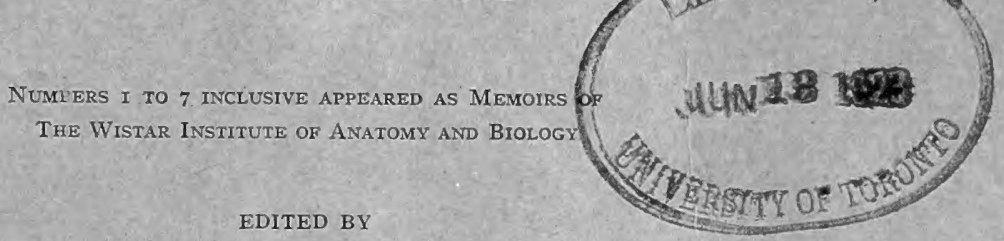

GEORGE S. HUNTINGTON

Columbia Untversity

WITH THE COLLABORATION OF

CHARLES R. STOCKARD

Cornell Untversity Medical School
AND

HERBERT M. EVANS

UnIVERSTIY OF CALIFornIA, BERKELEX

\section{ANATOMICAL AND PHYSIOLOGICAL STUDIES} ON THE GROWTH OF THE INNER EAR OF THE ALBINO RAT

TOKUJIRO WADA

THE WISTAR INSTITUTE OF ANATOMY AND BIOLOGY

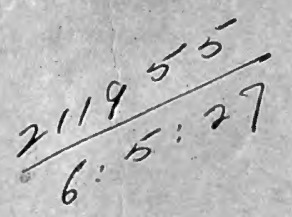

PUBLISHED BY

THE WISTAR INSTITUTE OF ANATOMY AND BIOLOGY PHILADELPHIA, PA., U. S. A. 


\section{THE AMERICAN ANATOMICAL MEMOIRS}

This series of Monographs was begun for the purpose of presenting the results of original investigations which were too extensive for incorporation in the current periodicals.

Since the early issues of the series the demands of biological science in our country for a publication of this type have become more urgent and more clearly defined. It is the intention of The Wistar Institute and of the Editors to provide, as far as possible, for these needs and to continue in a more formal manner the publication of the series which is intended to receive extensive original monographs based on either experimental or deseriptive investigations in the field of Anatomy.

This series is open to all qualified investigators in Anatomy. The journal is edited by Dr. George S. Huntington with the collaboration of Dr. Charles R. Stockard and Dr. Herbert M. Evans.

The publication will appear as consecutive numbers of varying sizes issued at irregular intervals, each number containing but one monograph. Bibliographic eards, with authors' abstracts, are issued in advance of each number.

The first seven numbers of the series appeared under the title of "Memoirs of The Wistar Institute of Anatomy and Biology."

They are as follows:

No. 1. The Anatomy and Development of the Systemic Lymphatic Vessels in the Domestic Cat, by George S. Huntington, Professor of Anatomy, Columbia University, New York City 175 pages of text, 8 text figures (two in color), 254 Photomicrographs and 21 colored plates. Sent postpaid to any country for $\$ 5.00$.

No. 2. Contribution to the Study of the Hypophysis Cerebri with Especial Reference to its Comparative Histology, by Frederick Tilney, Associate in Anatomy, Columbia University New York City. 72 pages of text, 2 text figures, 60 photomicrographs and plates, (Out of print.) 1911.

No. 3. Early Stages of Vasculogenesis in the Cat (Fells domestica) with Especial Reference to the Mesenchymal Origin of Endothelium, by $H$. Von W. Schulte, Department of Anatomy Columbia University, New York City. 90 pages of text and 33 figures, of which 14 are in colors. Sent postpaid to any country for $\$ 1.50$.

1914.

No. 4. The Development of the Lymphatic System in Fishes, with Especial Reference to hts Development in the Trout. by C. F. W. Mcolure, Department of Comparative Anatomy, Princeton University. 140 pages, 41 figures, 11 of which are in colors. Sent postpaid to any country for $\$ 2.50$.

No. 5. The Development of the Albino Rat, Mus norvegicus albinus, by G. Carl Iruber; Derartment of Antomy. University of Michigan and The Wistar Institute of Anatomy and Biology Philadelnhia. 142 pages of text and 42 figures from drawings by the author. (Out of print.) 1915

No. 6. The Rat, compiled and edited by Henry H. Donaldson. Reference tables and d to for the (Ajbino Rat Mus norvegicus albinus), and the Norway Rat (Mus norvegicus), 280 pages. (Out of print New edition in preparation.)

1915.

No. 17. An Experimental Analysis of the Origin of Blood and Vascular Endothelium, by Cirarles R. Stockard, Department of Anatomy, Cornell University Medical Sehool, New York City, 174 pages. Sent postpaid to any country for $\$ 2.50$.

1915.

No. 8. On the Behavior of Bufo and Rana toward Colloidal Dyes of the Acid Azo Group (trypan blue and dye No. 161), by Charles F. W. McClure, Laboratory of Comparative Anatomy, Princeton University. 64 pages. Sent postpaid to any country for \$1.25.

1918.

No. 9. The Morphology and Evolutional Significance of the Pineal Body, by Frederick Tilney, M. D.. Ph.D., Professor of Neurology, Columbia University, New York, and Luther F. Warren, A. B., M. D. Professor of Medicine, Long Island College Hospital, N. Y. Part 1. A contribution to the study of the epiphysis cerebri with an interpretation of the morphological, physiological, and clinical evidence. 258 pages, 97 flgures. Price, $\$ 3.00$.

No. 10. Anatomical and Physiological Studies on the Growth of the Inner Ear of the Albino Rat, by Tokujiro Wada, The Wistar Institute of Anatomy and Biology. 174 pages, 124 tables, 42 charts, 12 figures and 2 plates. Price, postpaid to any country, \$4.00.

No. 11. The Pigmentary, Growth and Endocrine Disturbances induced in the Anuran Tadpole by the Early Ablation of the Pars Buccalis of the Hypophysis, by P. E. Smith, Assistant Professor of Anatomy, University of California. 112 pages of text, 40 pages of illustrations, including 2 colored figures and 7 Heliotype plates. Price, postpaid, \$3.00. 1920 .

No. 8 of the series is the first to appear under the new title.

The price of each number will vary with its size and the number and kind of illustrations contained.

In the past the actual printing eost of each paper has been paid by the author or his laboratory, while The Wistar Institute has managed the details of publication and distribution, using its organization for placing the publication in the public and private libraries of the world.

Popers intended for publication in THe American ANatomcal Memorrs should be submifted to the Editor, Dr. George S. Huntington, College of Physicians and Surgeons, 437 West 59 th Street, New York City, or to either of the Collaborators, Dr. Charles R. Stockard, Cornell University Medical College, 28th St. and 1st Ave., New York City, and Dr. Herbert M. Evans, University of California, Berkeley, Cal. 


\section{MEMOIRS}

OF

THE WISTAR INSTITUTE OF ANATOMY AND BIOLOGY No. 10

ANATOMICAL AND PHYSIOLOGICAL STUDIES ON THE GROWTH OF THE INNER EAR OF THE ALBINO RAT

TOKUJIRO WADA

THE WISTAR INSTITUTE OF ANATOMY AND BIOLOGY

1923

PUBLISHED BY

THE WISTAR INSTITUTE OF ANATOMY AND BIOLOGY PHILADELPHIA 
$\therefore$

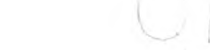

147
$N 3=$ 


\section{CONTENTS}

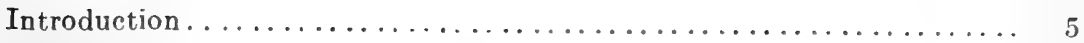

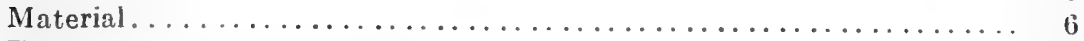

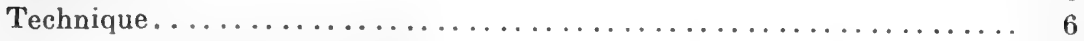

I. On the growth of the cochlea....................... 12

A. On the growth of the radial distance between the two spiral

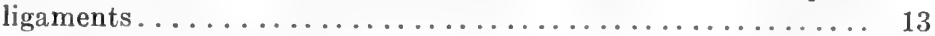

B. On the growth of the tympanic wall of the ductus cochlearis... 16

1. Membrana tectoria..................... 28

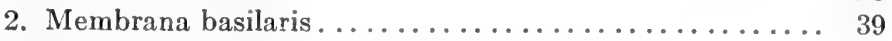

3. The radial distance between the habenula perforata and the inner corner of the inner pillar cell at base........ 47

4. The radial distance between the habenula perforata and the outer corner of the inner pillar cell (resp., the inner corner of the outer pillar cell) at base..............

5. The radial basal breadth of the outer pillar cell (including

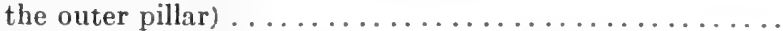

6. The radial distance between the habenula perforata and the outer border of the foot of the outer pillar cell.....

7. The greatest height of the greater epithelial ridge (dem grossen Epithelwulst Böttcher's s. Organon Köllikeri) resp. of the inner supporting cells. . . . . . . . . . . . 63

8. The radial distance between the labium vestibulare and the habenula perforata..................... 68

9. The radial distance between the labium vestibulare and the inner edge of the head of the inner pillar cell...... 71

10. Vertical distance from the membrana basilaris to the summit of the pillar cells.................. 75

11. The greatest height of the tunnel of Corti........ 77

12. The height of the papilla spiralis at the third series of the outer hair cells....................... 77

13. The greatest height of Hensen's supporting cells ....... 83

14. The angle suttended by the extension of the surface of the lamina reticularis with the extended plane of the membrana basilaris .................... 84

15. Lengths of the inner and outer pillar cells ......... 85

16. Inner and outer hair cells................. 94

17. Deiter's cells ......................... 109

18. Summary and discussion................ 116

C. On the growth of the largest nerve cells in the ganglion spirale. 124

observations . . . . . . . . . . . . . . . . . . . . . . 124

Discussion . . . . . . . . . . . . . . . . . . . . . . 136

Conclusions ................................. 143 
11. Correlation between the inception of hearing and the gromth of the

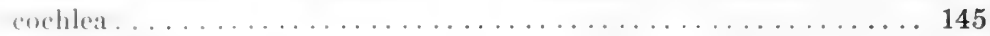

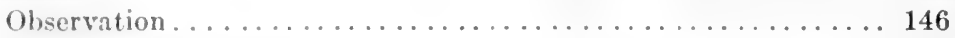

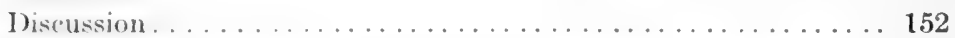

Conclusions............................ 155

III. On the growth of the largest nerve cells in the ganglion restibulare. . 156

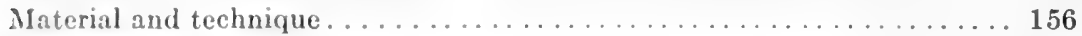

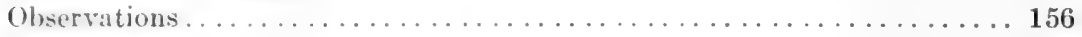

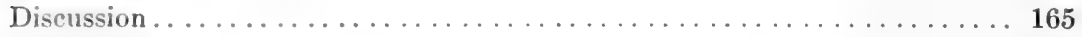

Conclusions ................................ 168

Final summary ............................... 169

Literature cited . . . . . . . . . . . . . . . . . . . . . 171 


\title{
ANATOMICAL AND PHYSIOLOGICAL STUDIES ON THE GROWTH OF THE INNER EAR OF THE ALBINO RAT
}

\author{
INTRODUCTION
}

Since Alphonse Corti, in 1851, published his famous work on the cochlea of mammals, studies on this organ have been made by many authors and have produced fairly concordant results. Concerning the postnatal growth of the internal ear, however, systematic studies are lacking. Especially is there no investigation, so far as I know, on the growth of the nerve cells in the ganglion spiral, not even in the great work of Retzius. ('84).

It was the special object of these studies, therefore, to follow the growth of the cells forming the spiral ganglion from birth to maturity and to correlate the changes in them with the appearance of the functional responses and with the structural changes in the membranous cochlea. In the course of this investigation studies were made also on the cells of the ganglion vestibulare, in order to see whether these cells differed in their growth from the cells in the spiral ganglion. Both of these ganglia are situated in the course of nervus acusticus, but have, as is well known, entirely different functions.

Thus determinations have been made on the diameters of the cells of the ganglion spirale and of their nuclei at different ages; of the nucleus-plasma ratios and of their growth in relation to those of other portions of the membranous cochlea. For the cells of the vestibular ganglion similar determinations were also made. Finally, these results have been compared with those obtained trom the study of other craniospinal ganglia in the albino rat.

In presenting my results I shall begin with a description of the changes in the larger portions of the membranous cochlea and pass from these to the cell elements themselves, and then to the observations on the ganglion cells and to the correlation between hearing and the growth of the cochlea. 


\section{MATERIAL}

For the present studies forty male and thirty female albino rats were used, representing every phase of postnatal growth and having approximately standard body weights. These were all from the colony of The Wistar Institute, and were sometimes from the same, and sometimes from different litters.

At first all these rats were tested for their ability to hear and their equilibrium, and it was ascertained that after about twelve days of age, or somewhat earlier, they responded positively to the test for hearing. Such examinations were deemed necessary, to make certain that the rats used were normal.

I have arranged the animals thus tested in fourteen groups according to age, each group having five individuals in it. Serial sections from all these cochleas were made by methods to be given later. Most of them were in the plane of the vertical axis of the cochlea, but some were at right angles to it.

From the former I selected four ears in each group for the study of the growth of the cochlea. For the study of the growth of the ganglion vestibulare, I have used for the most part the same specimens. For the study of the sections at right angles to the vertical axis of the cochlea, sections from one ear of each group were used.

\section{TECHNIQUE}

In order to obtain good preparations of this delicate organ, the method of vital fixation (injection under anaesthesia) was used. The method employed, and which proved almost ideal, was that introduced by Metzner and Yoshii ('09), Siebenmann and Yoshii ('08) and somewhat improved by Sato ('17). After the animals had been tested to make sure that they were quite normal, the fixing solution was injected through the aorta under ether. The brain was then carefully removed, care being taken not to drag the trunk of the nervus acusticus, as noted by Nager ('05), and the bulla tympanica was opened to allow the further penetration of the fluid. 
The bony labyrinth with its surrounding bones was then placed in the fixing solution for two weeks, the fluid being renewed every day.

The fixing solution which I used consists, according to Yoshii ('09), of-

10 per cent formol $\ldots \ldots \ldots \ldots \ldots \ldots \ldots \ldots \ldots \ldots \ldots \ldots \ldots \ldots$ parts

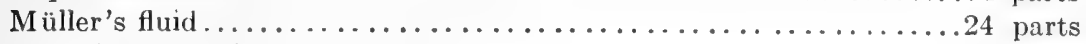

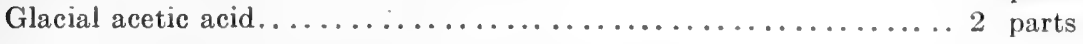

According to Tadokoro and Watanabe ('20), this solution is one of the best, ranking with that of Wittmaack ('04, '06) and that of Nakamura ('14).

This injection method is sometimes difficult to apply to very young rats on account of the small size and the delicacy of the vessels. When injection failed in very young animals, then immediately the head was cut off and put directly in the fixing fluid. Owing to the incomplete calcification of the very young cochlea, the fixing solution enters rapidly and fixes the deepseated organs in good condition. Since the parts of the internal ear are not yet well developed in the very young rats, they do not suffer from this method of fixation as do the older cochleas.

Indeed, no differences are to be seen between the sections prepared by vital fixation and by decapitation in very young rats.

For decalcification I have employed the following solution during three days, renewing it every day.

Decalcifying fluid

5 per cent aqueous nitric acid..................... 49 parts

10 per cent formol............................... parts

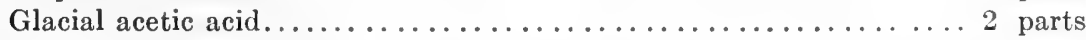

After the specimens had been washed in running water for three days, they were passed through the alcohols from 50 to 97 per cent. For the imbedding I have used 'parlodion' with good results. Here it is to be mentioned that all the cochleas were treated in the same way, even unossified cochlea being passed through the decalcifying fluid, so that there should be absolutely no differences in treatment. 
The next important matter is the determination of the plane of the section. For the measurement of growth changes it was necessary to obtain corresponding sections from the several cochleas. In an organ like that of Corti, which changes in its details from one end to the other, however, it is very difficult to accomplish this, but I believe that I have overcome most of the difficulties.

After much testing, I found that a section parallel to the under surface of os occipitale in the fronto-occipital direction runs nearly exactly parallel to the axis of the modiolus of the cochlea. In order to get the same direction from right to left, I have taken as the standard the transverse plane of the under surface of the os occipitale, controlling the direction of the section with a magnifying glass. Thus nearly the same radial direction and nearly corresponding places in the cochlea were obtained in the several series of sections. This makes possible a trustworthy comparison of the measurements and drawings.

The cross-section of the cochlea was gotten by making the plane of the cut transverse to the axis of the modiolus. To get the corresponding levels is difficult. At first I divided all the serial sections by $2 \frac{1}{2}$, which is the number of complete turns in the cochlea of the albino rat. Next, from the number of the slides representing each turn, I determined nearly the corresponding level in the cochlea according to age.

All the sections were $10 \mu$ in thickness. The sections were stained for the most part with haematoxylin and eosin, but sometimes by Heidenhain's iron haematoxylin or the iron haematoxylin and Van Gieson's stain. For the measurements, however, only the sections stained with haematoxylin and eosin were used.

For the examination of the larger parts of the cochlea and their relations, the sections were projected on a sheet of paper by the I.eitz-lidinger projection apparatus, at a magnification of exictly a hundred diameters, and the outline of the image arcuratcly traced. The remaining measurements of the ganglion cells and the smaller portions of the cochlea were made directly under the microscope. The measurements made on the tympanic 
wall of the cochlea are somewhat complicated, but by the aid of figures 1 and 2 they may be explained. In figure 1 lines 1-1, 1-1'. 2-2, 3-3 indicate, respectively, the height of the arch of Corti, of the tunnel of Corti, of the papilla spiralis (Huschke) at the third series of outer hair cells, and of Hensen's supporting cells, respectively, above the plane of the membrana basilaris.

Lines $4-4^{\prime}$ which are the extensions of the surface of the lamina reticularis and of the membrana basilaris, subtend the angle $\theta$.

To get the exact measurements of the radial breadth of the membrana tectoria is very difficult, if not impossible, because it is sinuous in its course; moreover, it differs in thickness from point to point. Therefore, it has been variously described by different authors. Intra vitam fixation tends to prevent distortion. We divide the membrana tectoria, figure 1 , into two portions, the first or inner $\left(7-7^{\prime}-9-9^{\prime}\right)$ and the second or outer $\left(5-5^{\prime}-7-7^{\prime}\right)$ or outer zones of Retzius; each of these is again divided in two at $6-6^{\prime}$ and $8-8^{\prime}$, as shown in figure 1 .

I have measured the radial distance of each portion and added all four together. This total approximates the natural radial breadth of this membrane, and since the sections have all been prepared in the same way and examined by the same method, the relations during growth can be followed.

In figure 2, 1-1 and 2-2, mark the length of the inner and outer pillar cells, respectively, from base to the point, which is situated just under their junction. It is to be noted here that the term 'pillar cell' here applies to the pillars in the strict sense and does not include the associated cells.

Distances 3 and 7 in figure 2 show the basal breadth of the inner and outer pillars, respectively. The former is identical with the distance between the habenula perforata and the outer corner of the inner pillar after the inner corner of the pillar has reached the habenula perforata, but there is some difference between the two distances in very young rats. Distance 4 is that between the habenula perforata and the inner corner of the outer pillar; distance 5 is that between the habenula perforata and the outer corner of the outer pillar. The latter represents at the same time the radial breadth of the zona arcuata of the membrana basilaris. 
Fig. 1 Showing the localities for the measurement of each part of the tympanic wall of ductus cochlearis in the albino rat, 100 days old-radial vertical section. 1-1, height from the basal plane to the surface of pillar cells; $1-1^{\prime}$, greatest height of the tunnel of Corti; $2-2$, height of papilla spiralis at the third scries of the outer hair cells; $3-3$, height of Hensen's supporting cells; $4-4^{\prime}, 4$ indicates the extension of the membrana basilaris and $4^{\prime}$ the extension of the lamina reticularis. The two lines subtend the angle $\theta$. The radial breadth of the membrana tectoria is taken as the sum of the four segments between the lines $\tilde{j}-5^{\prime}$ and $9-9^{\prime}$.

Fig. 2 Showing the method of measurement for several parts of the tympanic wall of the ductus cochlearis in the albino rat, 100 days old. 1-1, length of inner pillar cell without head; 2-2, length of outer pillar cell without head Distance 3 shows radial distance between habenula perforata and the outer corner of inner pillar at base-after twelve days of age this equals the radial basal breadth of inner pillar. Distance 4, radial distance between habenula perforata and the inner corner of outer pillar at base. Distance 5, radial breadth of the zona arcuata (Deiters') of membrana basilaris, and at the same time it indicates radial distance between habenula perforata and the outer corner of outer pillar at base. Distance 6, radial distance between the outer corner of inner pillar and the inner corner of outer pillar at base. Distance 7, radial basal breadth of outer pillar. Distance 8 , radial distance between the habenula perforata and outer corner of inner pillar cell at base. Distance 9, radial basal breadth of the outer pillar cell. Distance 10, radial breadth of zona pectinata of the membrana basilaris. Distance 11 , radial breadth of entire membrana basilaris.

Fig. 3 Showing the general outline of the cochlea in the radial vertical section-albino rat, 100 days of age.

\section{ABBREVIATIONS}

Line 1, 1, distance between two basal spiral ligaments

Line 2,2 , distance between two apical spiral ligaments

$I$, first turn

$I I$, second turn

$I I I$, third turn

$I V$, fourth turn

D.C., ductus cochlearis

G.S., ganglion spirale

Ci. $V$., ganglion vestibulare

L.L.S., limbus laminae spiralis

L.S., ligamentum spirale

L.S.O., lamina spiralis ossea

M.T., membrana tectoria

N.C., nervus cochlearis

$O$., bone

P.S., papilla spiralis

$S .$, stria vascularis

S.T., scala tympani

$S . V$., scala vestibuli 

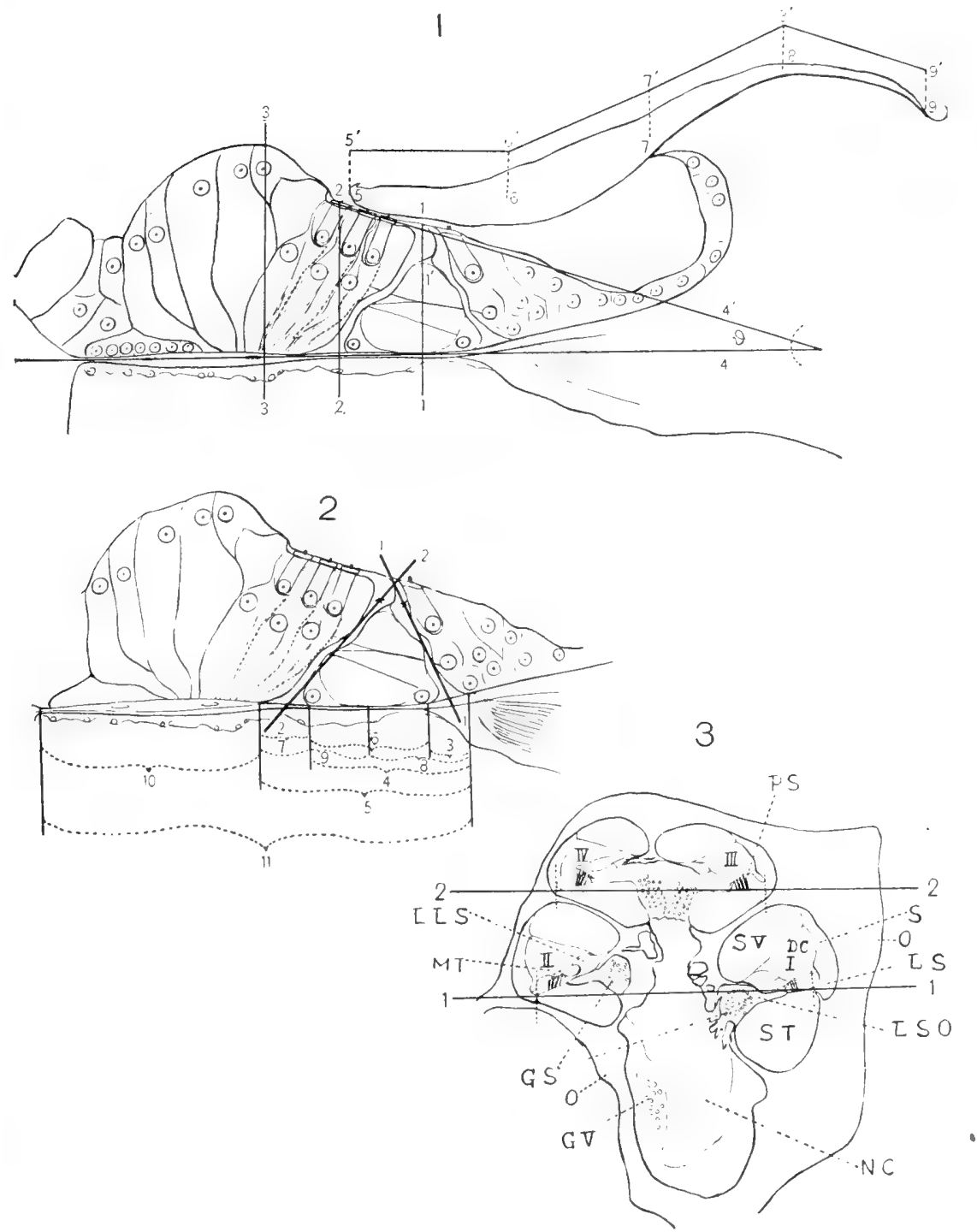
1)istance 6 is that between the outer corner of the inner pillar and the inner corner of the outer pillar. Distance 8 is that between the habenula perforata and the outer corner of the inner pillar cell. Distance 9 shows the radial basal breadth of the outer pillar cell plus the outer pillar. Distance 11 shows the radial breadth of the membrane basilaris comprising distance 5 (zona arcuata) and 10 , which is the radial breadth of the zona pectinata of the membrana basilaris.

\section{ON THE GROWTH OF THE COCHLEA}

As noted above, I have selected from at least seven serially sectioned cochleas in each age group, four for this study, taking one section in good condition from each labyrinth. From these four sections the average values were taken for each age. Table 1 gives the data for the rats used here. As we see, sometimes two, sometimes three animals were used at each age to get the four best-prepared sections which corresponded. Determinations accordingly to sex and side, therefore, cannot be based on like numbers.

In the following text we shall often refer to the I, II, III and IV turns of the cochlea. This calls for a word of explanation. As the cochlea of the rat has nearly $2 \frac{1}{2}$ complete turns, four cochlear canals are usually obtained in the radial vertical sections, as prepared by me (fig. 3). Therefore, turn I does not mean the first complete turn, but about the middle part of the basal turn; turn II about the beginning of the middle turn; turn III about the middle part of the middle turn, and turn IV about the beginning of the apical turn of the cochlea. Usually the cochlea has been divided for description by the authors into the first, second, and third turns, or more definitely into the basal, middle, and apical turns. For the purpose of this study, however, it is desirable to adopt the divisions given above, because here measurements are largely employed, and there are some differmoes in size, volume, and arrangement of structures, even between the beginning and end of the same turn.

It all erents, it is to be kept in mind that such divisions are arbitrary, as the changes in the elements take place in a graded manner. 


\section{A. On the growth of the radial distance between the two} spiral ligaments ( $f i g .3,1-1,2-2)$

As we have usually four sections of the ductus cochlearis, therefore four spiral ligaments in one radial vertical section, there are two radial distances presented, the first, figure 3, 1-1, connecting the two basal sections of the ductus on opposite sides, and the second, figure $3,2-2$, connecting the two apical

TABLE 1

Data on the albino rats used for the study of the cochlea

\begin{tabular}{|c|c|c|c|c|c|}
\hline $\mathbf{A G E}$ & BODY WEIGHT & BODY LENGTH & $\operatorname{sex}$ & SIDE & HEARING \\
\hline days & grams & $m m$. & & & \\
\hline 1 & 5.3 & 48 & $0^{7}$ & R. L. & - \\
\hline 1 & 4.2 & 47 & $0^{7}$ & R. L. & - \\
\hline 3 & 8.8 & 60 & $0^{\pi}$ & R. & - \\
\hline 3 & 7.1 & 54 & $0^{7}$ & R. L. & - \\
\hline 3 & 8.2 & 56 & 우 & $\mathrm{R}$. & - \\
\hline 6 & 10.2 & 64 & f & R. L. & - \\
\hline 6 & 11.0 & 62 & $0^{7}$ & R. L. & - \\
\hline 9 & 9.1 & 58 & 우 & R. L. & - \\
\hline 9 & 9.8 & 57 & $\sigma^{7}$ & R. L. & \pm \\
\hline 12 & 13.0 & 70 & $\sigma^{7}$ & L. & $\bar{t}$ \\
\hline 12 & 11.9 & 68 & 앙 & R. L. & + \\
\hline 12 & 14.8 & 72 & $\sigma^{7}$ & L. & + \\
\hline 15 & 13.0 & 74 & $\sigma^{7}$ & R. & + \\
\hline 15 & 13.5 & 75 & \% & $\mathrm{R}$. & + \\
\hline 15 & 13.0 & 74 & \% & R. L. & + \\
\hline 20 & 30.0 & 96 & $\sigma^{7}$ & R. L. & + \\
\hline 20 & 28.0 & 94 & $\sigma^{7}$ & R. L。 & + \\
\hline 25 & 38.4 & 107 & 우 & R. L. & + \\
\hline 25 & 34.2 & 101 & \& & R. L. & + \\
\hline 50 & 60.0 & 128 & $\%$ & R. L. & + \\
\hline 50 & 57.5 & 121 & ф & R. L. & + \\
\hline 100 & 145.6 & 176 & $\sigma^{7}$ & L. & + \\
\hline 100 & 102.5 & 154 & 우 & $\mathrm{R}$. & + \\
\hline 100 & 100.5 & 152 & $q_{+}^{+}$ & R. L. & + \\
\hline 150 & 153.5 & 184 & 우 & R. & + \\
\hline 150 & 188.9 & 191 & $\sigma^{7}$ & R. L. & + \\
\hline 150 & 198.8 & 192 & $\sigma^{7}$ & $\mathrm{R}$ & + \\
\hline 250 & 133.5 & 178 & o & R. L. & + \\
\hline 263 & 140.3 & 171 & \% & R. L. & + \\
\hline 365 & 205.4 & 202 & $\sigma^{7}$ & L. & + \\
\hline 365 & 170.4 & 182 & 우 & R. L。 & + \\
\hline 368 & 179.0 & 196 & 우 & R. & + \\
\hline 546 & 282.1 & 222 & $\sigma^{7}$ & R. L. & + \\
\hline 546 & 227.1 & 204 & $\sigma^{7}$ & R. L. & + \\
\hline
\end{tabular}


scetions. These distances measure the radial breadth of the membranous cochlea and of the modiolus combined at these levels.

In table 2 (chart 1 ) are entered the values for the radial distances found between the two spiral ligaments in fourteen

TABLE 2

Radial distance between the two spiral ligaments in radial-vertical section (chart 1, figure 3)

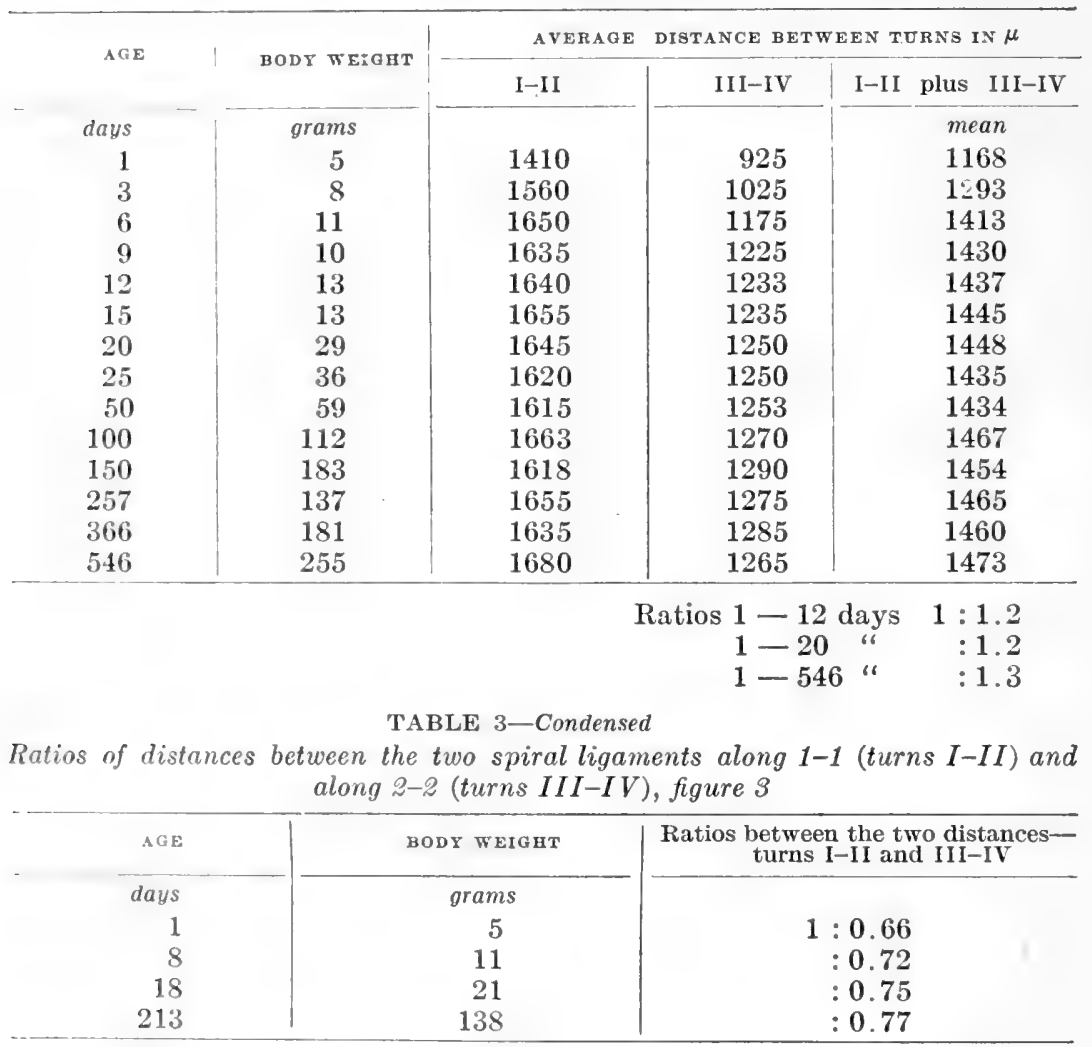

age groups), from one to 546 days. As we see, the average value of the two distances grows rapidly from birth till six days of age. Ifter that period the value increases gradually till twenty day's, while after twenty days the increase is very slight indeed. The ratios between 1 and 12, 1 and 20, and 1 and 546 days show these relations. 
In table 3 are given the average ratios between two radial distances between I-II and III-IV at four ages. Here we can also see a rapid increase in the ratio from one to eight days of age, while afterwards the ratios rise very gradually. The data in table 2 show that at nine days the mean diameter of the bony cochlea as thus measured is approximately 97 per cent of the value at maturity. The cochlea thus attains nearly its full size at an early age. Chart 1 illustrates this point.

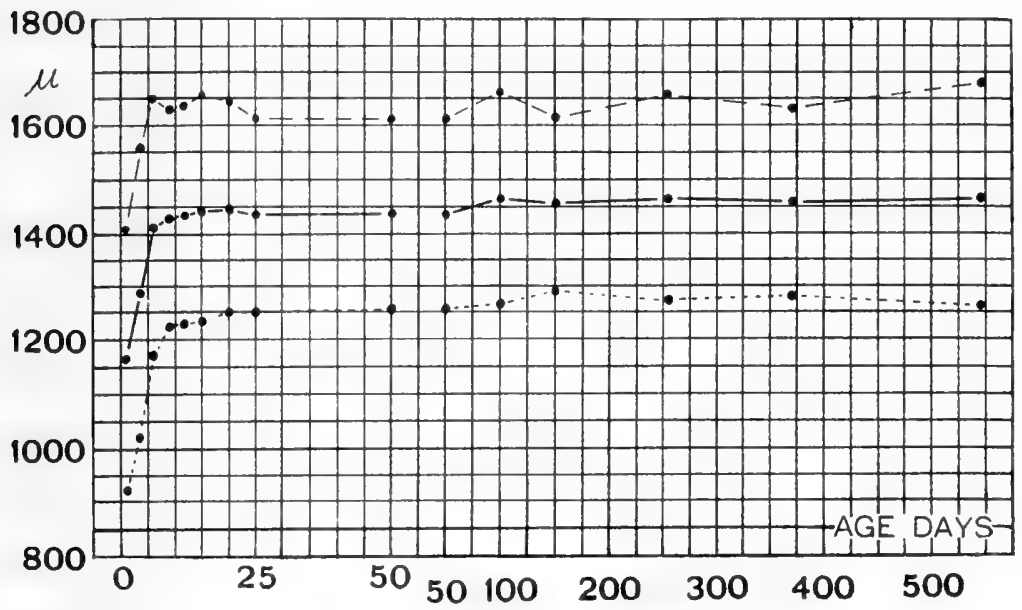

Chart 1 The radial distance between the spiral ligaments, turns I-II and III-IV, table 2, figure $3(1-1)$ and (2-2).

-...- Radial distance at turns I-II.

....... Radial distance at turns III-IV.

Average radial distance for the two foregoing measurements.

All the charts are plotted on age.

The scale for age changes at 50 days. From 0 to 50 days one interval is equal to five days. From 50 days on, one interval is equal to twenty-five days.

Unless otherwise stated, the measurements recorded in these charts have been made on radial-vertical sections. 
13. (In the grouth of the tympanic wall of the ductus cochlearis

Figures 4 to 12 show the appearance in outline at birth, at three six, nine (not hearing), nine (hearing), twelve, twenty one hundred, and 546 days, respectively. These figures have been drawn from the best corresponding sections at the beginning of the middle turn of the cochlea, figure 3 , turn II, which I have selected as the type, as did Retzius.

The fact, demonstrated by many authors, Böttcher ('69), Retzius ('84), and others, that development progresses from the basal to the apical turn is confirmed in the albino rat.

In the albino rat the development of the cochlea, and especially of the ductus cochlearis, is somewhat retarded as compared with man, and the papilla with its elements developed in a great measure during the first ten days after birth.

As we see in figure 4, the ductus cochlearis in the new-born rat is very immature. It is remarkable that the space which lies in adult rats axialward of the papilla spiralis between the membrana tectoria and the limbus spiralis-sulcus spiralis internus (fig. 10) is not yet to be seen. Instead of the space, there is the socalled greater epithelial ridge (der grosse Epithelwulst of Böttcher) figure 4, G. consisting of pseudostratified epithelial cells. These long and narrow cells lie pressed very closely together with their large oval nuclei at various heights. The surface of the prominence sinks slightly in its center, and at the outer end of the prominence more rapidly, where it passes over into the socalled lesser epithelial ridge fig. 4, L. (der kleine Epithelwulst) at an obtuse angle.

The latter is, of course, a relatively small prominence, making up the greater part of the papilla spiralis. The pillar cells of Corti lie with their upper ends at the most inner part of the surface of the lesser ridge just in the angle with the greater ridge. 'They form two entirely separate rows of cells, the inner and the outer, but so close together that we cannot detect any space between them. Only the protoplasm of the inner pillar cell is more transparent above the nucleus, and on the inward side there is at thin rod passing from the upper end to the lower 
part near the base. This transparent area is not the locus of the future tunnel of Corti, but marks the protoplasmic change into the pillar, as the transparent substance condenses into the rod. We can see this change beginning in the basal turn before it appears in the apical turn of the cochlea. The inner and outer cells make a triangle with a narrow base, which elings to the membranea basilaris; they turn somewhat outward. ${ }^{1}$

A large oval nucleus lies in the basal part of each cell; that of the inner pillar cell is very large, about twice as large as that of the outer, and with its long axis in a radial direction. As figure 4 shows, the inner corner of the inner pillar cell does not yet reach to the habenula perforata.

The hair cells, which in the albino rat are in four rows through all the turns, are separated by the pillar cells into two groups, the inner containing one and the outer three rows of cells. They are comparatively well developed at birth (fig. 4). The inner hair cell belongs to the greater ridge, as Kölliker ('67), Gottstein ('72), Retzius ('84), Held ('09), and others have already affirmed, and contrary to the assertaion of Böttcher ('69) and others.

It is situated in the most outer part of the declivity of the greater ridge and slants away from the axis with its round lower end at about half the height of the greater thickening. It has a large round nucleus in the base and the small hairlet at the top. This hair cell is nearly twice as large as the outer hair cells. The three outer hair cells reach down to the middle of the lesser ridge, not through it, having no process at their basal end. They end with their upper parts at the surface of the prominence. They stand not straight, but turn with their long axis very slightly inward, i.e., the in direction opposite to the long axis of the inner hair cells. They are cylindrical in form with a round nucleus at their base and small hairlet on the top.

Below the outer hair cells stand the three rows of Deiters' cells, which have large oval nuclei. These rest with their wide bases on the basilar membrane and their pointed ends reach to the surface of the epithelium. They are retarded in develop-

\footnotetext{
${ }^{1}$ In the following description of the cochlea, 'outward' means away from the axis 'inward' towards the axis.
} 
ment, and at birth their cell bodies are short and undeveloped, so) that they hardly suggest the adult cells.

Hensen's supporting cells (fig. 10, at maturity) are as yet undeveloped and nearly uniform in height, their nuclei being at nearly the same level.

Outward from the Hensen's cells the height of the epithelial cells at maturity rapidly diminishes and passes over to the cylindrical cells of sulcus spiralis externus. At birth no such distinction is present. Through all the turns the surface of the lesirer epithelial ridge remains about parallel to the plane of the membrana basilaris.

The membrana basilaris, which stretches from the labium tympanicum outward to the crista basilaris of the ligamentum

Figs. 4 to 13 showing the increase in size and morphological changes in each part of the tympanic wall of ductus cochlearis of the cochlea during arowth, in the radial vertical section-albino rat. All the figures have been uniformly enlarged.

lige $f$ One day. (r, greater epitholial ridge; $L$, lesser epithelial ridge.

Fige. is 'lhree days.

Fig. 6 Six days.

Figs. 7 to 8 showing the differences in size and morphologieal changes in the tymuanic wall of ductus cochlearis between a nine-day-old rat which can already hear (figr. 8) and one that cannot (fig. 7)

Fir. 9 Twelve days.

Fig. 10 'Twenty ditys. In figure 10 we have drawn all the elements of the orgin.

\section{ABBHEVIATIONS}

M.T., mennhlonma foctorias. Corti

L. I., labium vestibulare of crista spiralis

S.S.J., suldens spiralis intermus

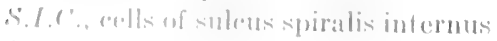

l.s. immer smpmorling rolls

I.H, inmer hair molls

(). H. moter hatir ands

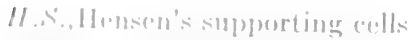

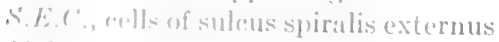

il. homembrama basilaris

l't', inuer pillar

lite. 11 ()ne hmolred days.

lin. 12 510 days.
$O . P^{\prime}$, outer pillar

B.C., basal cells

D.C., Deiters' cells

Bo.C., Boetteher's cells

L.S'., ligamentum spirale

A.F., myelinated fibers of ramus acustici

li. $F$, rudial fibers of rimus basilaris acustici in the tunnel of Corti

' $T$ '. tumnel of Corti

B., blood vessels

$O$, bone 

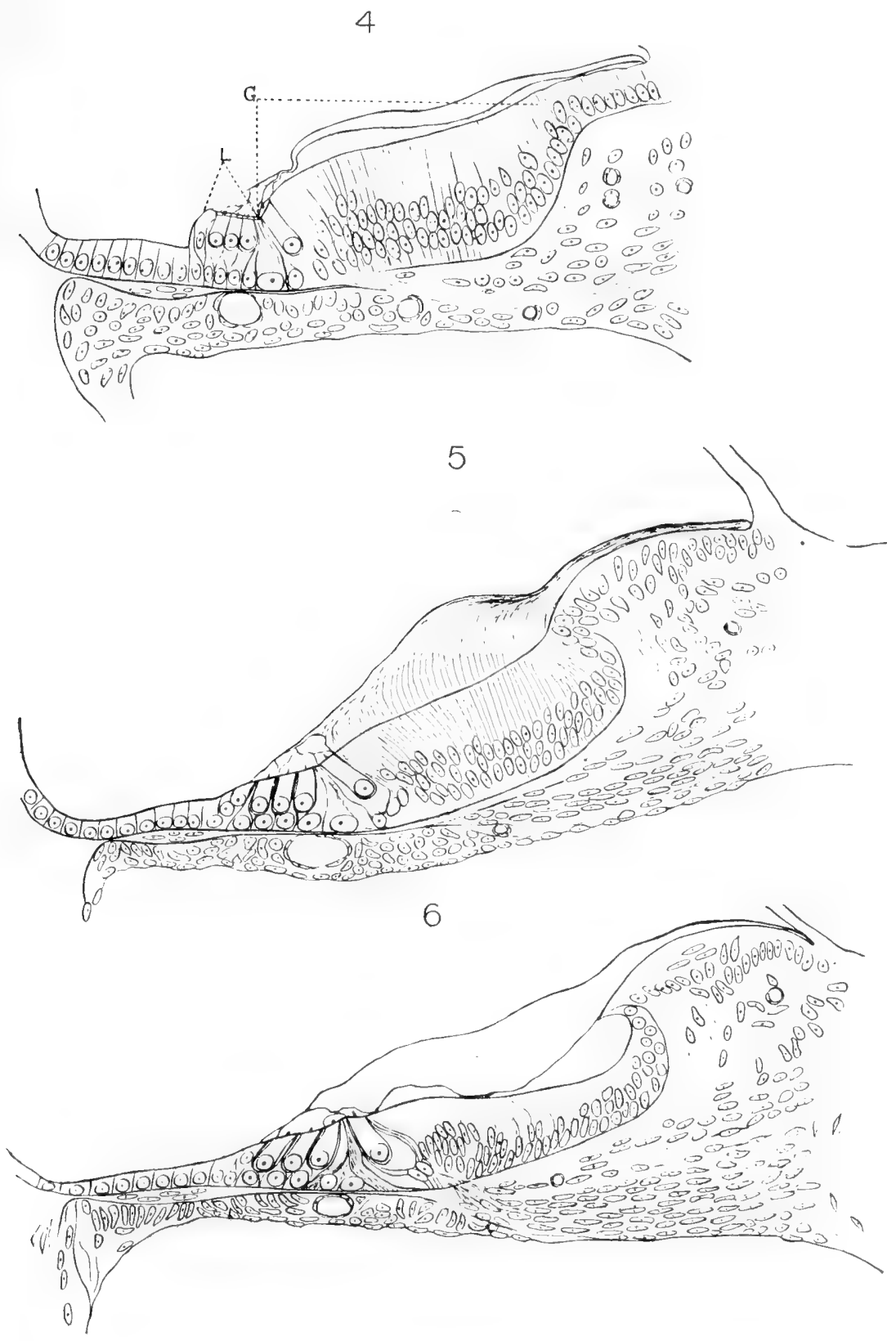

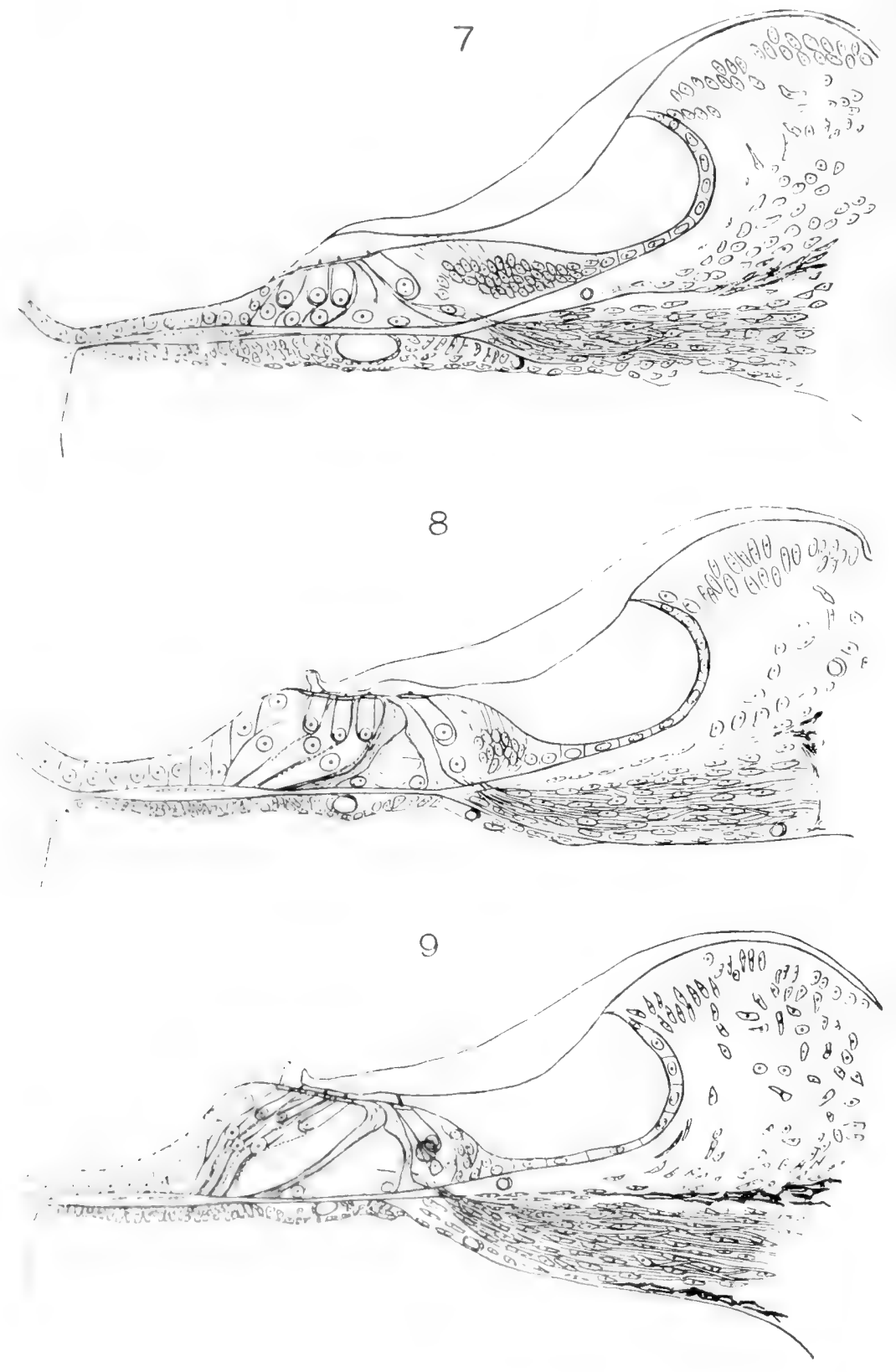

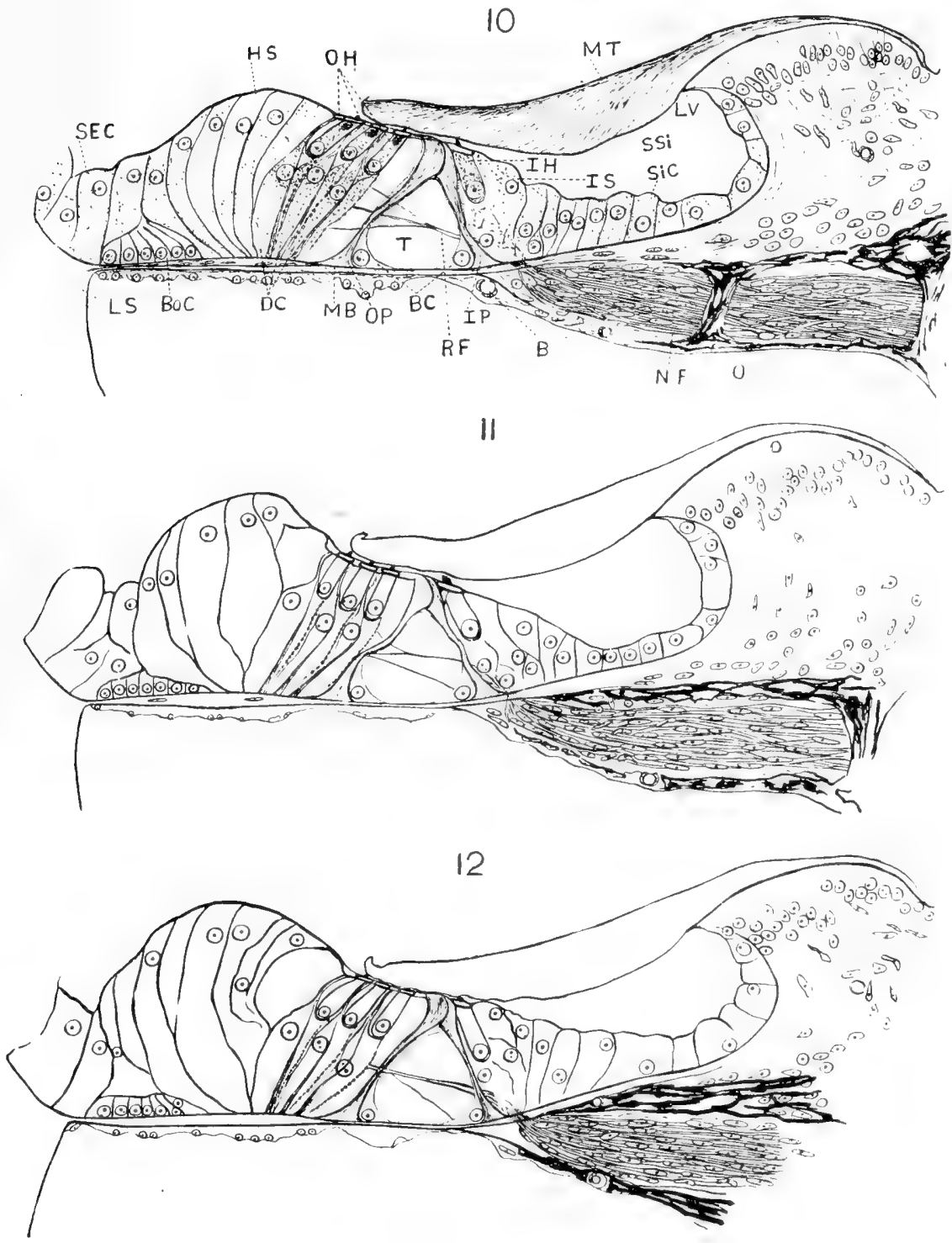
spirale, (onsists of two layers, an upper, membrana basilaris propria, and an under, tympanic investing layer (tympanale Belegschicht: Retzius). The former, of course, is divided into two portions, an inner, zona arcuata (Deiters) and an outer, zona pectinata (Todd-Bowman). While the zona arcuata is thin from the beginning of life, the zona pectinata thickens at its central part where it contains cells with oblong nuclei. On passing to the spiral ligament it again becomes thin. In the young, the under layer is not so regular in structure as in the adult. The cells close to the basilaris propria are arranged vertically.

On the contrary the cells below them, which vanish in great part with age, have an irregular arrangement; those near the rndothelial cells of scala tympani having a more radial arrangement. 'Therefore, this layer is thick, several times the thickness of the basilaris propria, and the thickness increases towards the upper turns. The ras spirale is strikingly large at this stage and lies just under the outer pillar and the Dieters' cells.

The membrana tectoria, beginning at the inner angle of the ductus cochlearis, where Reissner's membrane rises, covers the "pithelium of the limbus laminae spiralis and the greater epithelial ridge, lying close to their surfaces. At the inner part it is thin, but thickens where the greater ridge begins, and at the outer part again becomes thin. In the basal turn there is seen as a very thin strand reaching to Hensen's prominence, but in the apical turm it reaches hardly to the inner hair cell. Although it gives rise to several thread-like processes going to the surface of the papilla, these do not seem to connect with the hairs of the hair rells, but with the terminal plates of the Dieters' cells.

When we divide the tympanic wall of the ductus cochlearis at the boundary between the greater and lesser epithelial ridges, we olscrve that the inner portion-from the inner angle to the mere cond of the greater ridge - is far larger than the outer portion, which, howrer, is the more important for hearing. This mation hoomos more erident as we pass from the base to the afrex. Moreorer. the total radial length of the tympanic wall 
diminishes at this stage towards the apex, though it is larger in the beginning of the middle turn than in the middle of the basal turn. As will be shown later, these relations are entirely reversed in the adult cochlea. This fact indicates that the cochlea at this stage is very immature.

In the three-day-old rat the cochlea is much better developed (fig. 5). The radial breadth of the typmanic wall of the ductus cochlearis becomes greater in all the turns, especially in the upper turn; therefore the differences between the radial breadths in each successive turn are smaller than at the earlier stage. There is some change as we pass towards the apex in the relation of the inner and outer portion of the tympanic wall. At the basal turn and the beginning of the middle turn the radial breadth of the outer portion increases greatly, but diminishes again towards the apex. Although the radial breadth of the inner portion increases through all the turns, the proportion of this increase becomes greater towards the apex. As the inner portion is composed of the greater epithelial ridge and of the limbus laminae spiralis, and as the breadth of the latter diminishes towards the apex, the increase of the radial breadth of the inner portion is due to changes in the greater epithelial ridge.

The heights of the greater epithelial ridge, however, diminishes through the successive turns, becoming less and less from base to apex. Thus in the cochlea at this age it has a small radial breadth and vertical height in the basal turn and a larger radial breadth and height in the upper turns.

In all the turns the inner hair cell is inclined outwards and lies with its surface forming the outermost part of the greater ridge. The obtuse angle which it helps to make (fig. 5) as a boundary between the greater and lesser ridge in upper turns, vanishes in the basal turn where there is no sharp boundary between the two ridges.

The pillar cells of Corti develop more and more during this early stage; the radial breadth of their base increases, but as yet there is no space between them. They incline much more outwards than in the earlier stage. The protoplasmic change in the rod progresses, especially in the basal turn, and the head plate of the cell can be seen distinctly. 
The onter hair cells become higher and wider; they are slightly inclined inward in the upper turn. On passing towards the basal tum the inclination inward increases, and in the basal turn it is most oblique, almost at $45^{\circ}$, to the plane of the basilar membrane. In figure 4 the inclination of these cells is only slight.

Deiters' and Hensen's cells are not well developed; the conditions are as in the former stage.

The plane of the surface of the lesser epithelial ridge is intimately related to the development of the outer hair cells and Deiter's' cells, and as the latter are in an undeveloped condition, it runs nearly parallel to the plane of the membrana basilaris, sometimes dipping outward.

The membrana basilaris seems to be much longer; its composition is about the same as that in the one-day rat, only the thickness is somewhat decreased, owing to the reduction of the rows of cells in the tympanic layer.

The membrana tectoria grows in breadth and thickness, covering very closely the inner portion of the tympanic wall and connects outrards with Deiters' and Hensen's cells by slender fibrous processes - the so-called outer marginal zone. The hairs of the cells stand between these processes, but have no) commeetion with them.

The vas spirale does not suffer reduction.

At six days (fig. 6) the development of the cochlea has procrected futher. The radial breadth of the tympanic wall has increased. Thus we find the tympanic wall, especially its inner' portion, increasing towards the apex, chiefly owing to the augmentation of the radial breadth of the greater ridge. In this a remarkable change is to be seen. In the basal turn the long stender colls disappear in the inner part of the greater ridge, and insteat of them there are found cylindrical cells with oval muclei noar thejp bases.

The heright of these colls increases gradually to the level of the surfare of the inner hair eall; their upper surface is here in contact with the membrana teretoria. Thus a space appears between How cylindrical apthelium and the membrane-the sulcus 
spiralis internus - which is deep and wide in the basal turn, becomes gradually shallow and narrow as we pass upward, and in the middle part of the middle turn is to be seen as a small and flat space. In the apical turn it is not yet present. The inner side of this space is made by the labium vestibulare of the limbus laminae spiralis.

As a result of this change in the greater ridge, the obtuse angle between the greater and lesser ridge vanishes entirely, and the two surfaces come to lie in the same place. The inner hair cell becomes larger and inclines less outward.

It is to be noted that the inner hair cell is supported on both sides by long slender cells. These have been variously described by several authors, but first Hans Held ('02) and afterwards Kolmer ('07) have considered them as supporting cells, reaching from the surface of the hair cell to the plane of the basilar membrane. Held has termed the cell which lies outward the 'Phalangenzelle.'

I have paid some attention to this cell and the changes in it. It is long and slender and stands between the inner hair cell and the inner pillar cell, with the upper end reaching to the surface, and is attached at its base to the inner corner of the inner pillar. The oblong oval nucleus lies in its basal portion. On the inner side of the inner hair cell there is a group of two to three cells of the same kind. These cells, termed 'Grenzzellen' by Held, stand near the habenula perforata, reach to the height. of epithelium, and have their bases in intimate relation to the former.

These are not neuro-epithelial cells nor in intimate relation with the nerve fibers, but similar to the Deiters' cells which support the outer hair cells.

The developing pillar cells become progressively wider at their bases. The inner pillar cell sends a long foot towards the habenula perforata and in the basal turn it sometines reaches to it. The outer pillar cell increases its length very rapidly and extends its foot outward on the basilar membrane. Thus in the basal turn the triangle made by the inner and outer pillar cells and having a short base, in the upper turns changes to an equilateral 
friangle and stands upright on the basilar membrane. In the appical turn the inner pillar cell is not yet so long as in the lower, furms and is still inclined outwards. The head plates and pillars are farly prominent, but there is as yet no space between them.

'The outer hair cells have grown and are inclined inward. Deiter's' and Hensen's cells have not yet begun to develop, as have the other elements of the organ of Corti just described.

In the membrana basilaris we see the reduction of cells in the tympanic covering layer. The vas spirale shows more or less reduction. The membrana tectoria increases its radial breadth following the associated structures. The so-called marginal zone connects with Hensen's cells and the lamina reticularis by filorous processes.

Among five nine-day-old rats, as shown later, one responded to the tests for hearing. As the majority of them gave no reaction, the cochlea of the latter, non-hearing rat, may be taken as the type for this age. The differences between the cochlea of the hearing and non-hearing rats will be mentioned later.

In rats of this age (fig. 7.) the cochlea is still further advanced. 'Thesulcus spiralis internus appears through all the coils, and is deepest and broadest in the basal turn, diminishing in depth or gradually toward the apex. The cells covering the space are low and cuboid in the lower turns, but in the apical turn they are yet relatively high, cylindrical cells.

These cells probably have their origin from the long slender colls of the greater epithelial ridge, as Bötteher ('69) and others maintain, although (iottstein ( 72 ) and some others think that they come by the outward migration of the epithelium of the limbus spiralis, and Retzius ('84) regards this latter view as the more probable.

'The inner and outer hair cells become large and approach their mature form. The supporting cells of the inner hair cell are vory arident.

'The pillar colls develop more and more, their radial breadth imcrous and the pillars and headplates also become distinet. fomotimes we sures small space between the inner and outer pillirl arls in tho lower tum, but not in the upper. Nuel's space 
is not yet to be seen. Deiters' cells become longer, somewhat in the processus phalangeus but chiefly in the cell body, and the nuclei move upward. Hensen's cells also increase in height slightly.

While the membrana tectoria lies close to the surface of the outer part of the greater ridge in the upper turns of the cochlea, there arises a small space between them, which is continuous with the sulcus spiralis internus. The outer marginal zone of the membrane is still connected with Hensen's supporting cells and the lamina reticularis. The vas spirale remains as a large vessel. This is the condition of the nine-day cochlea in a rat which does not hear.

Although the detailed description of the cochlea of the nineday rat which can hear will be deferred for a time, yet to complete the series of growth changes, figure 8, representing the cochlea in such a rat, is inserted here.

In the next stage, twelve days old (fig. 9), the development of the tympanic wall is much advanced. The cells lining the sulcus spiralis internus and the inner supporting cells have nearly their mature form and arrangement in the basal and middle turns; only in the apical turn many and slender cells remain close to the inner hair cell.

The outer pillar cell shows a remarkable increase in length so that it is twice as long as in the former stage, while the growth of the inner pillar is much less marked.

Therefore the outer pillar is much longer than the inner through all the turns. From this change in the pillar cells it results that the nearly equilateral triangle formed by them becomes unequal and its summit is shifted inward. In all the turns we can see the tunnel of Corti and also the space of Nuel. The hair cells develop further and their previous inclinations are increased.

Deiters' cells show a very rapid development, especially in the cell body, which increases many times, the nucleus moving upwards. The inclination of these cells follows that of the outer hair cells. 
Hensen's supporting cells are also fully developed. Through the development of Deiters' and Hensen's cells a change is effected in the course of the lamina reticularis. It runs no longer parallel to the plane of the membrana basilaris, but dips inward.

Though the membrana basilaris remains nearly stationary in its breadth, the thickness of the tympanic covering layer is reduced and the longitudinal nuclei in the zona pectinata diminish in number.

The membrana tectoria reaches in the basal turn to the outermost row of the outer hair cells, but the apical turn only to the second row. 'The so-called 'outer marginal zone' connects with the terminal frame (Schlussrahmen) of the lamina reticularis.

In the next stage, the twenty-day-old rat (fig.10), the papilla spiralis and the tissues about it are developed almost completely; therefore, the structural relations of the cochlea accord nearly with those of the adult cochlea, as generally recognized in histology.

It is to be noted here that in the basal turn, Böttcher's cells are to be seen in sulcus spiralis externus as a cell group situated on the outer part of the vestibular surface of the membrana basilaris. This cell group consists of several granular compact and sharply bounded cells entirely covered by high swollen cells on all sides. That this cell group belongs to the epithelium of the sulcus spiralis externus can be easily demonstrated. While the cells in this group show no particular changes in structure, the neighboring cells diminish in their height and size towards the apex, and finally become similar to the former. After twenty days of age the general features of the cochlea are those of the adult and do not require general description. The finer differmeres will be discussed in subsequent chapters.

Figure 11 shows the relations at 100 days and figure 12 at Dotidets.

1. 11 mbram tectoria. Is stated above, this membrane is divided into two zones, an outer and inner, using the outer edge uf the lahium vetibulare as the point of division (fig. 1, 7-7'). liath zome was again divided into two equal parts at 6-6'and8-8'. Thus the sum of the lorealths of the two outer parts represents 
in each instance the breadth of the outer zone, and the sum of the two inner parts that of the inner zone, while the sum of all four parts gives the total radial breadth. For the purpose of the exact measurement of the growth of the membrane, I have, as noted above, projected the sections at 100 diameters and made the determinations on the outlines thus obtained.

In table 4 (charts 2 and 3 ) are given the values for the total average breadth, as well as for that of each zone, and also the thickness of the membrane, from 1 to 546 days of age. At the bottom of each column are given the ratios of the breadth at 1 to 546,12 to 546 , and 20 to 546 days. While the ratio between 1 and 546 days is 1.7 , those from 12 to 546 days and 20 to 546 days diminish to about $1: 1.0$, that is the membrane at twelve days has attained about its full breadth, and there is only a very gradual increase in its breadth with advancingage. After twelve days similar ratios are found for the separate zones as well.

From 1 to 546 days the ratios for the two zones differ considerably; that for the second zone is 1:1.2 and that for the first is $1: 3.6$. This is due to the fact that in the cochlea at birth the development of the labium vestibulare is incomplete, even in the basal turn, while at the apex we can very often hardly see the invasion of the mesenchymal tissue in the inner part of the greater epithelial ridge.

At every stage the outer zone is broader than the inner; the ratio between them at birth is $1: 3.8$. This diminishes to $1: 1.25$ at twelve days, after which age it remains practically constant. Owing to the form of the membrana tectoria and to its great sensitiveness to the method of preparation, it is difficult to obtain good values for its thickness.

Generally speaking, the membrane is thickest about midway between the outer edge of the labium vestibulare and the inner boundary of the inner hair cell, and it was here the measurements given in table 4 were made. As shown in this table, the thickness increases rather rapidly from birth to twenty days, but after that period remains approximately constant. 
Is we know, the radial breadth of the membrane increases gradually from the basal to the apical turn. Table 5 (charts 4 , 5. and (i) shows how the breadth of the total and of each part of the membrane changes in successive turns from base to apex arerorling to age. It birth it is broadest in the beginning of the middle turn (turn II) decreasing gradually towards the apex. From three to twenty days the greatest breadth is usually found

\section{TABISE 4}

Average ralial breath of the membrana tectoria and its thichness in radial-vertical section. Averages of all four turns (charts 2 and 3)

\begin{tabular}{|c|c|c|c|c|c|c|c|}
\hline$\cdots+1:$ & $\begin{array}{c}\text { Hovr } \\
\text { WHLIT }\end{array}$ & $\begin{array}{c}\text { Bony } \\
\text { Li:itu }\end{array}$ & $\begin{array}{c}\text { Outer zone } \\
\text { between free } \\
\text { end of mem- } \\
\text { brane and } \\
\text { labium }\end{array}$ & $\begin{array}{c}\text { Inner zone } \\
\text { labium } \\
\text { vestibulare } \\
\text { and inser- } \\
\text { tion of mem- } \\
\text { brane }\end{array}$ & $\begin{array}{l}\text { Total length } \\
\text { of men- } \\
\text { brane }\end{array}$ & $\begin{array}{l}\text { Ratios } \\
\text { inner and } \\
\text { outer zone }\end{array}$ & $\begin{array}{l}\text { Thickness } \\
\text { membrane }\end{array}$ \\
\hline days & grams & $\mathrm{mm}$. & $\mu$ & $\mu$ & $\mu$ & & $\mu$ \\
\hline 1 & 5 & 48 & 140 & 37 & 177 & $1: 3.78$ & 12 \\
\hline 3 & 8 & 56 & 134 & 94 & 228 & $: 1.43$ & 32 \\
\hline fi & 11 & 63 & 154 & 105 & 259 & $: 1.44$ & 32 \\
\hline 9 & 10 & 58 & $15 \mathrm{~s}$ & 123 & 281 & $: 1.28$ & 27 \\
\hline 12 & 13 & 60 & 157 & 126 & 28.3 & $: 1.25$ & 25 \\
\hline 15 & 13 & 75 & 160 & 124 & 284 & $: 1.29$ & 28 \\
\hline 20 & 29 & 95 & 162 & 129 & 291 & $: 1.26$ & 38 \\
\hline 25 & 36 & $10 \pm$ & 162 & 128 & 290 & $: 1.27$ & 34 \\
\hline 50 & 59 & 125 & 162 & 131 & 293 & $: 1.24$ & 35 \\
\hline 100 & 112 & 159 & 162 & 132 & 294 & $: 1.23$ & 36 \\
\hline 150 & 183 & 190 & 161 & 131 & 292 & $: 1.23$ & 32 \\
\hline 257 & $1: 37$ & 175 & 163 & 129 & 292 & $: 1.26$ & 38 \\
\hline 3600 & 181 & 191 & 162 & 131 & 293 & $: 1.24$ & 35 \\
\hline it 16 & . 255 & 213 & 163 & 132 & 295 & $: 1.23$ & 34 \\
\hline Ratios 1 & $1-546$ & i days & $1: 1.2$ & $1: 3.6$ & $1: 1.7$ & & $1: 2.8$ \\
\hline & $12-546$ & ; i & $: 1.0$ & $: 1.0$ & $: 1.0$ & & $: 1.4$ \\
\hline & $20-5$ & $"$ & $: 1.0$ & $: 1.0$ & $: 1.0$ & & $: 0.9$ \\
\hline
\end{tabular}

in turn III, but after this in turn IV. At the bottom of each column are given the ratios of the radial breadth in each turn betweren the several age limits.

These show that after twelve days there is but little change in the radial breadth of the entire membrane in any turn.

(1) cxamining the growth in each zone of the membrane thromph the screral turns, we find that after three days the outer zune of the membrane becomes at each age always broader from biase to apex. 


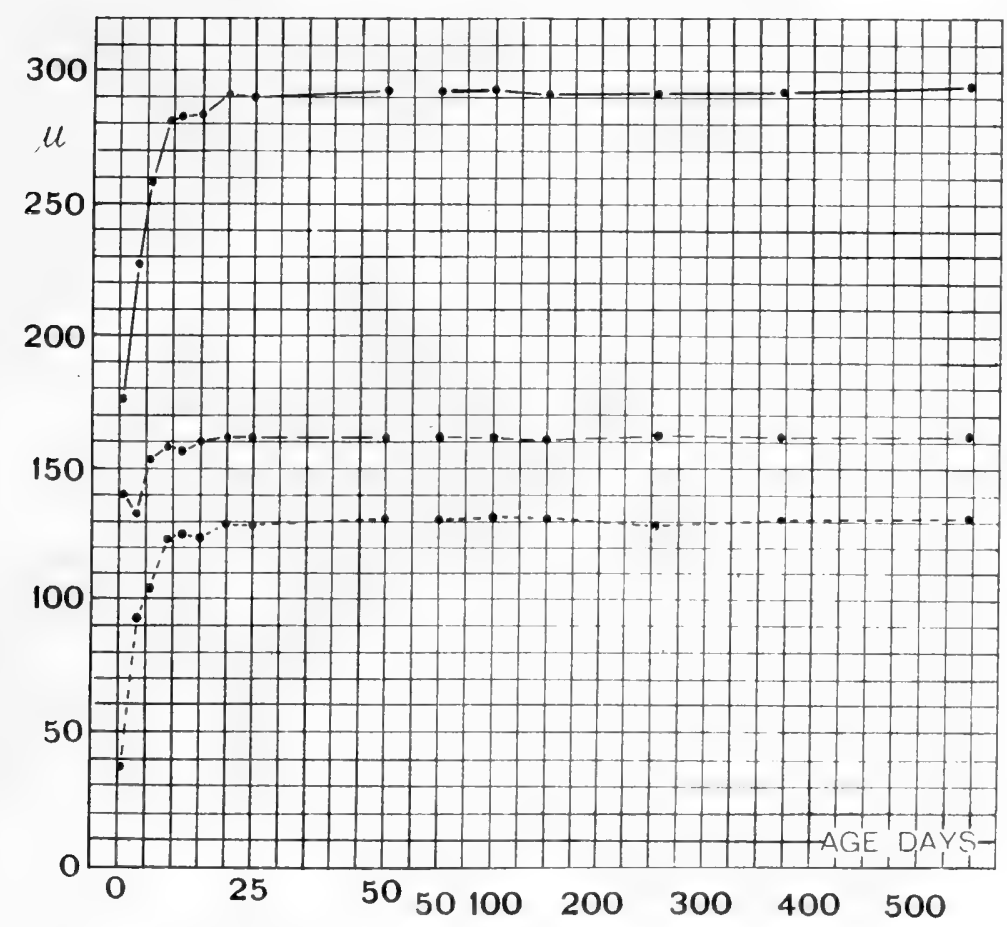

Chart 2 'The radial breadth of membrana tectoria, table 4, figure 1. Total radial breadth of the membrane.

Radial breadth of outer zone.

Radial breadth of inner zone.

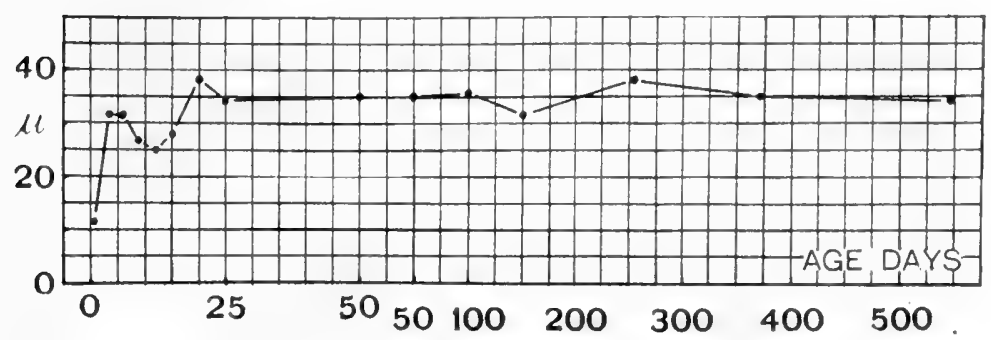

Chart 3 The thickness of membrana tectoria, table 4. 
ANATOMICA, AND PHYSIOLOGICAL STUDIES ON

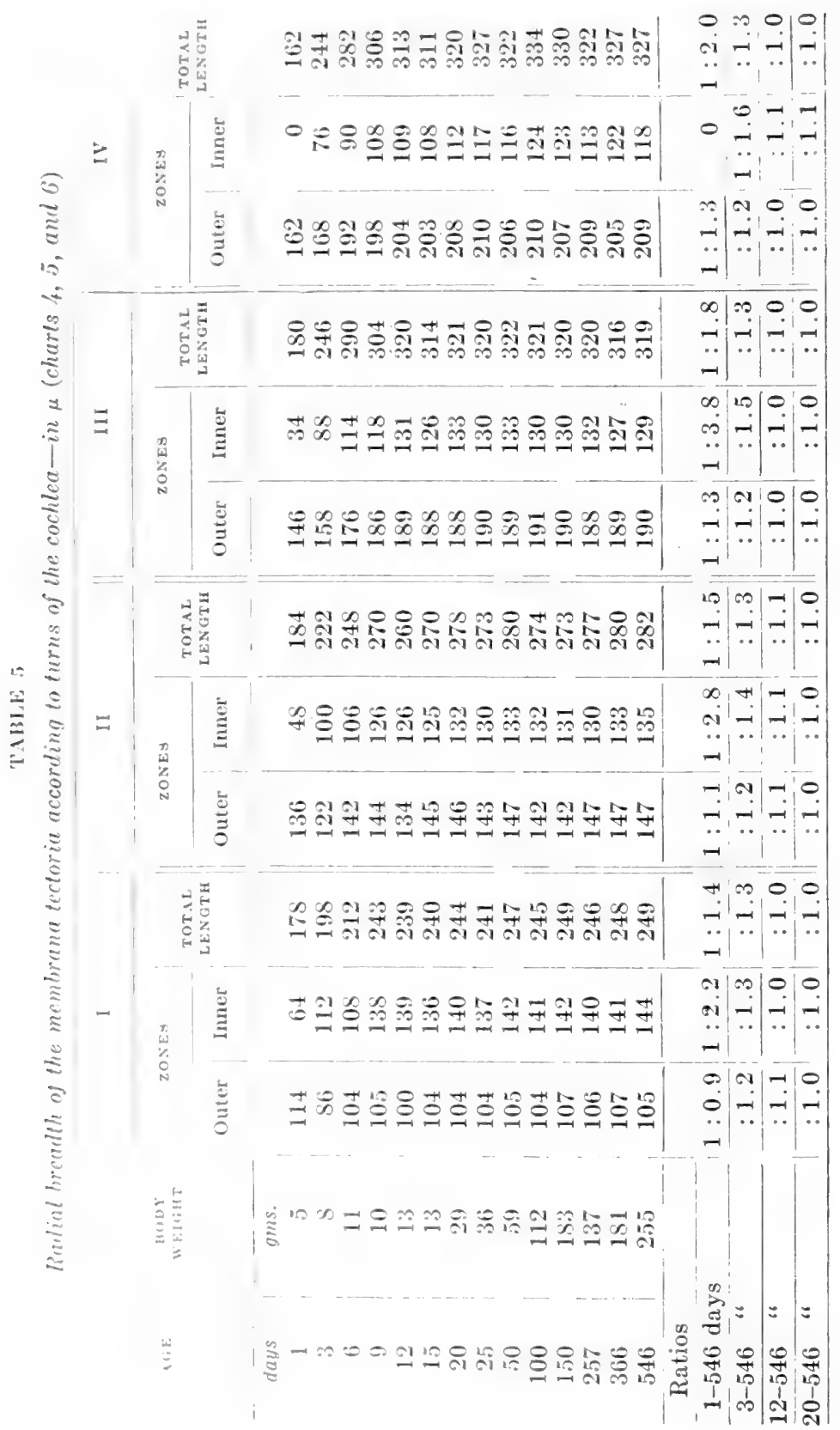


The values at birth are relatively greater than those at three days, as noted above, due to the undevelopment of the labium vestibulare. The inner zone grows in a like manner in breadth, but not so rapidly as the outer zone, and hence its relative breadth diminishes gradually from base to apex.

Table 6 shows these relations. While the ratios in the inner zone decreases from base to apex, those in the outer zone increase. Thus the ratios in the inner and outer zones according to the turns go in opposite directions. As stated above, the radial breadth is generally larger in the outer zone, but this relation is, in general, reversed in turn I, table 5 .

TABLE 6-Condensed

Ratios of the radial breadth of each zone of the membrana tectoria

\begin{tabular}{|c|c|c|c|c|c|c|c|c|c|c|c|}
\hline \multirow{4}{*}{$\mathbf{A G E}$} & \multirow{4}{*}{$\begin{array}{c}\text { BODY } \\
\text { WEIGHT }\end{array}$} & \multicolumn{10}{|c|}{ Ratios according to turns of the cochlea } \\
\hline & & \multicolumn{3}{|c|}{ INNER ZONE } & \multicolumn{3}{|c|}{ OUTER ZONE } & \multicolumn{4}{|c|}{$\begin{array}{l}\text { Ratios between inner and } \\
\text { outer zone }\end{array}$} \\
\hline & & \multicolumn{3}{|c|}{ Turns } & \multicolumn{3}{|c|}{ Turns } & \multicolumn{4}{|c|}{ Turns } \\
\hline & & I-II & I-III & I-IV & I-II & I-III & I-IV & I & II & III & IV \\
\hline days & grams & & & & & & & & & & \\
\hline 1 & 5 & $1: 0.8$ & $1: 0.5$ & $1: 0.0$ & $1: 1.2$ & $1: 1.3$ & $1: 1.4$ & $1: 1.8$ & $1: 2.8$ & $1: 4.3$ & $1: 0.0$ \\
\hline 8 & 11 & $: 0.9$ & $: 0.9$ & $: 0.8$ & $: 1.4$ & $: 1.8$ & $: 1.9$ & $: 0.8$ & $: 1.2$ & $: 1.6$ & $: 2.0$ \\
\hline 18 & 21 & $: 0.9$ & $: 0.9$ & $: 0.8$ & $: 1.4$ & $: 1.8$ & 2.0 & $: 0.8$ & $: 1.1$ & $: 1.5$ & $: 1.9$ \\
\hline 203 & 160 & $: 0.9$ & $: 0.9$ & $: 0.8$ & $: 1.4$ & $: 1.7$ & $: 2.0$ & $: 0.8$ & :1. 1 & $: 1.5$ & $: 1.8$ \\
\hline
\end{tabular}

In turn I the average ratios are, after eight days, smaller than 1.0; therefore, the inner zone is wider than the outer in turn I. It increases in all ages from turn II toward the apex.

In table 7 are given the ratios between each turn of the cochlea. The ratios after nine days of age are practically constant according to age, but those between turns I and II are always smaller than the others; the ratios for the two latter being alike. The ratio at one day is, however, an exception, as stated already.

As the measurements show, the membrana tectoria is at birth relatively undeveloped; it is thin and immature. After birth it increases rapidly during the first nine days, a statement which applies generally to the postnatal growth of the organs of the albino rat. Thus we get a ratio of the radial breadth $1: 1.7$ between 1 and 546 days, but after twelve days the ratios remain practically $1: 1.0$. (Table 4.) 
It is not my purpose to describe the fetal development of the membrana tectoria, but it is worth while to consider briefly the zones which compose the membrane; in other words, the parts of the tympanie wall from which it originated. There are chiefly

TABLE 7

liatios of the radial breadth of the membrana tectoria according to the turns of the cochlea

\begin{tabular}{|c|c|c|c|c|}
\hline \multirow{2}{*}{$\operatorname{AGE}$} & \multirow{2}{*}{ BODY WETGHT } & \multicolumn{3}{|c|}{ Ratios according to turn of the cochlea } \\
\hline & & I-II & I-III & $\mathrm{I}-\mathrm{IV}$ \\
\hline days & gms. & & & \\
\hline 1 & $\begin{array}{l}5 \\
8\end{array}$ & $1: 1.0$ & $1: 1.0$ & $1: 0.9$ \\
\hline 3 & 8 & $: 1.2$ & $: 1.2$ & $: 1.2$ \\
\hline 6 & 11 & $: 1.2$ & $: 1.4$ & $: 1.3$ \\
\hline 9 & 10 & $: 1.1$ & $: 1.3$ & $: 1.3$ \\
\hline 12 & 13 & $: 1.1$ & $: 1.3$ & $: 1.3$ \\
\hline 15 & 13 & $: 1.1$ & $: 1.3$ & $: 1.3$ \\
\hline 20 & 29 & $: 1.1$ & $: 1.3$ & $: 1.3$ \\
\hline 25 & 36 & $: 1.1$ & $: 1.3$ & $: 1.4$ \\
\hline 50 & 59 & $: 1.1$ & $: 1.3$ & $: 1.3$ \\
\hline 100 & 112 & $: 1.1$ & $: 1.3$ & $: 1.4$ \\
\hline 150 & 183 & $: 1.1$ & $: 1.3$ & $: 1.3$ \\
\hline 257 & 137 & $: 1.1$ & $: 1.3$ & $: 1.3$ \\
\hline 366 & 181 & $: 1.1$ & $: 1.3$ & $: 1.3$ \\
\hline 546 & 255 & $: 1.1$ & $: 1.3$ & $: 1.3$ \\
\hline
\end{tabular}

Chart 4 The total radial breadth of membrana tectoria arranged according to the turns of the cochlea, table 5 .

___ About middle part of the basal turn (I).

-....... About the beginning of the middle turn (II).

About the middle part of the middle turn (III).

About the beginning of the apical turn (IV). ${ }^{2}$

Chart 5) The radial breadth of the inner zone of the membrana tectoria, according to the turns of the cochlea, table 5 .

Chart $(;$ 'The radial breadth of the outer zone of the membrana tectoria, according to the turns of the cochlea, table 5.

"In most cases when the values which have been determined are analyzed :urending to the turns of the cochlea, it is found that they increase with later urowth from the basal (I) to the apical (IV) turn and in the order just given in "hart a (O) to this uniformity of behavior, some thirteen charts showing the seral values according to turn have been omitted, since the graph given b. the atrerage value is sufficiently informing in each instance.

In the mase of those charts which have been retained, and in which the manturanents are areording to the turns of the cochlea, the respective turns 1.11 are remplon by characteristic lines similar to those used for them in chant and in these citses the further designations of the turns are omitted. 

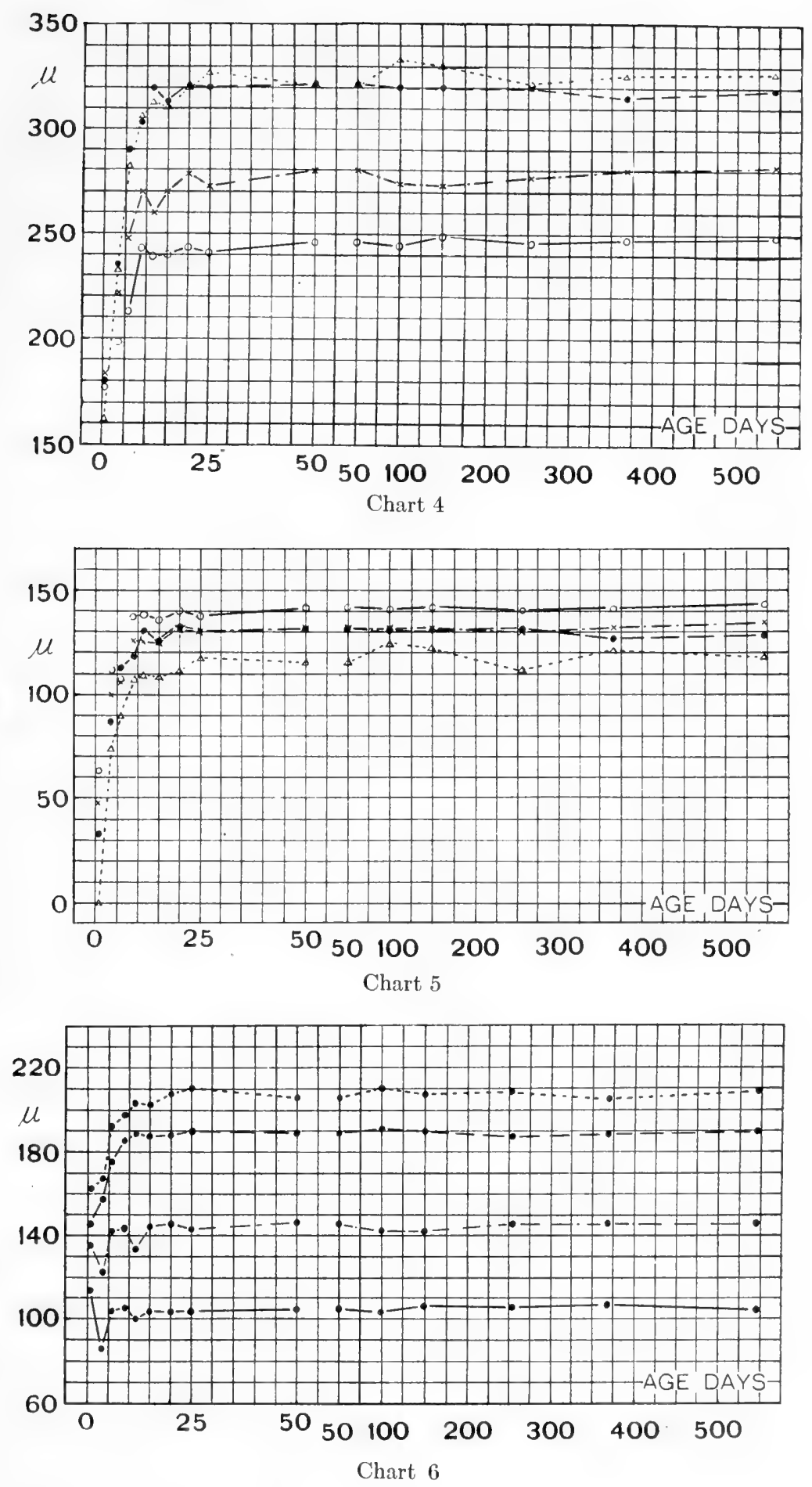
two views about this. While a few authors, Kölliker ('67), Hensen ('63), and recently Hardesty ('08, '15), and others hold that wnly the greater epithelial ridge takes part in the formation of the inembrane, most investigators (for example, Böttcher, 'b9: Retzius, 'St; Rickenbacher, '01; Held, '09; Van der Stricht, '1s) (onsider that it originates from both the greater and lesser epithelial ridge. My figure 5, supports the latter view; that is, while the main part is developed from the greater ridge, the outer narrow marginal part is secreted from the lesser ridge.

The figure in Quain's Anatomy by Schäfer ('09) (vol. 3, part 2, p. 332, 11th ed.,) is from the earlier paper of Hardesty and shows the membrane in the pig as arising from the greater epithelial ridge only.

Hardesty has corrected this figure in his paper published in 1915. Thus in the very early stage after birth in these forms we have three zones, an inner, an outer, and a marginal zone. With age, howerer, this marginal zone becomes, as Held ('09) and others agree, gradually smaller. and smaller, and finally it is difficult to differentiate it from the outer zone. Thus for convenience in measurements I have treated the membrane as consisting of two zones only.

Comparing the breadth of the inner and outer zones, it is evident that the outer is always the broader. The ratio is (table 4) at birth $1: 3.78$, at three days $1: 1.43$, and then gradually diminishes to $1: 1.23$ with age.

Now if we examine the ratios of the total breadth of the membrane according to the turns of the cochlea, we find after six days that the ratio generally increases from base to apex, and that these ratios remain nearly constant after nine days of age, as shown in table 7 .

Thus the ratio between turns I and II is $1: 1.1$; between turns I and III, 1:1.3; between turns I and IV, 1:1.3. The breadth of the membrane increases, therefore, in the albino rat gradually from the base to the middle part of the middle turn; from this point it does not increase to the apex.

since the breadth at the tip of the apex diminishes greatly, as is generally recognized, Hardesty ('08) found in the pig the following ratios (table 8): 
Comparing these ratios obtained by Hardesty in the pig with mine, there appear to be large differences between them. The reason for these I will discuss later.

When we consider the breadth in each part of the membrane according to the turn, we find that the increase of the breadth of the membrane in each turn is due to the development of the outer zone. The inner zone, which is adherent to the labium vestibulare, does not increase in the rat as Hardesty ('08,'15) found to be the case for the pig, but on the contrary decreases from base to apex - a relation found by Retzius ('84) in the rabbit, cat, and man and confirmed by Rickenbacker ('01) in the guineapig. On the contrary, the outer zone increases in breadth from

TABLE 8

Ratios of the breadth of the membrana tectoria according to turn of cochlea (Hardesty)

\begin{tabular}{|c|c|c|c|c|}
\hline Find of animal & $\begin{array}{l}\text { Preparation } \\
\text { method }\end{array}$ & $\begin{array}{l}\text { Ratios between } \\
\text { breadth in } 7 \text { and } \\
5 \text { half turn }\end{array}$ & $\begin{array}{l}\text { Ratios between } \\
7 \text { and } 3 \text { half turn }\end{array}$ & $\begin{array}{l}\text { Ratios between } \\
7 \text { and } 1 \text { half turn }\end{array}$ \\
\hline $\begin{array}{l}\text { Pigs two weeks } \\
\text { of age }\end{array}$ & $\begin{array}{l}\text { Membrane } \\
\text { teased out } \\
\text { Membrane }\end{array}$ & $1: 1.4$ & $1: 1.7$ & $1: 2.5$ \\
\hline dult & $\begin{array}{l}\text { teased out } \\
\text { Membrane in } \\
\text { section }\end{array}$ & $\begin{array}{l}1: 1.8 \\
1: 1.6\end{array}$ & $\begin{array}{l}1: 2.5 \\
1: 2.1\end{array}$ & $\begin{array}{l}1: 2.7 \\
1: 1.8\end{array}$ \\
\hline
\end{tabular}

base to apex, and in each stage the ratios between the successive turns are nearly the same. These ratios between successive turns, however, show rather large differences according to the different authors.

My results (table 5) show that the outer zone in the albino rat is nearly two times wider at the apex than at the base. This agrees with what von Ebner ('02) finds in the human cochlea.

When we consider the thickness of the membrane, we find it thin at birth, but at three days (table 4) it increases rapidly and reaches almost its greatest thickness. This increase in thickness arises through the apposition of new layers to the under surface, as Hasse ('73) and others have noted, but very large differences appear between the figures given by various authors. 
Kölliker ('67) finds the membrane $45 \mu$ thick in the ox. In the guinea-pig it is $15 \mu$ in the thickest place, according to $\therefore$ (hwallye ( 57 ). Middendorp ('67) gets in mammals generally a very thin membrane, about $1 \mu$ thick. Retzius ('84) states that in the thickest part in the rabbit it measures $27 \mu$, in the cat 32 to $50 \mu$, and in man 24 to $25 \mu$. Hardesty finds in the young pig an average thickness of the teased membrane of $50 \mu$ and in an adult $\operatorname{hog} 119.3 \mu$. I get $35 \mu$ as an average in the adult albino rat after twenty days of age, varying from 32 to $38 \mu$. Ny result is therefore closest to that for the cat as obtained by Retzius. These results are plainly influenced by the disimilar technical methods used by the several investigators.

About the outermost end of the membrane there are still two different views. One view is that the outer end of the membrane projects beyond Hensen's prominence; Kolmer ('07; pig, calf goat and horse); Hardesty ('15; pig, hog) Shambaugh ('10; pig). Others assert that the membrane terminates with its outer edge at the outer boundary of the outermost series of the outer hair cells. My preparations show that in the rat the outer end of the membrane does not reach Hensen's prominence.

Possibly this difference is due to the technique of preparation. In the figures drawn by many authors we can recognize many artifacts and postmortem changes in the cochlea. Even in the figures of Kolmer ( 07 ) we see these changes, although he injected the fixing solution through the carotid artery. Held ('09) says in his criticism of Hardesty's figures that "figures 6 and 7 wie schon Hardesty selbst vermutet hat, sicherlich auf einer Verquellung beruhen.

I myself never observed such a gigantic membrane as Hardesty ('(1), '15), shambaugh ('10), and others show in the cochlea of the pig. On the other hand, I cannot absolutely deny that there may have been shrinkage in the cochleas prepared by my methords, though I see no evidence of it.

From our present knowledge, however, the method of vital fixing is comsidered the best available, as already maintained by Fichumman and Yoshii ('0S), Metzner and Yoshii ('09), Nager and Lishii ('10), Wittmack and Laurowitsch ('12), and others. 
By using this vital-fixation method we get perfect sections which can be used to solve the problem of the shifting of the organ of Corti-an event which I will discuss later.

2. Membrana basilaris. The membrana basilaris of the cochlea stretches between the limbus laminae spiralis and the ligamentum spirale. The acoustic terminal apparatus is situated on it and according to the dominant Helmholtz-Hensen theory, this membrane is to be considered as very important in tone perception. The row of the fine holes, foramina nervina, is generally designated as the inner boundary of this membrane. Strictly speaking, however, the beginning of the membrane is at the outer edge of the labium tympanicum, which sharpens at first beyond the foramina nervina and passes over to the substance of the membrana basilaris. Practically it is almost impossible to decide exactly the point of transition. Thus I have used in the measurement of the membrane the foramina of the habenula perforata as an inner limiting line following in this Retzius, ('84) Schwalbe ('87), and others. Here it is to be mentioned that the organ of Corti lies with its inner portion not only upon the inner part of the membrane, but extends to the foramina nervina also.

The membrana basilaris is usually divided into two portions; the inner, termed the zona arcuata, and the outer, the zona pectinata. The former stretches from the habenula perforata across the base of the tunnel of Corti to the outer edge of the foot of the outer rods of Corti; the latter extends from this point to the ligamentum spirale (fig. 2), $5=$ inner zone, $10=$ outer zone.

In table 9 (chart 7 ) are given the values for the total radial breadth of the membrane, that of each zone, and the ratios between them. At the bottom of each column are given the ratios at 1 to 546,12 to 546 , and 20 to 546 days of age. In the total radial breadth of the membrane, as the table shows, there are large differences on age from birth to nine days. Between 1 day and three days the increase is $30 \mu$ and between three days and six days, $28 \mu$. After nine days the breadth increases more slowly but continuously to old age. 
In the growth of both zones we see about the same relation. These increase rapidly from birth till nine (or twelve) days and after that very slowly. These relations are shown clearly in the ratios at 1 to 546,12 to 546 , and 20 to 546 days. While after twelve days the ratios in total breadth and in each zone are the same, $1: 1.1$, that for 1 to 546 days is smaller for the outer zone than it is for the inner zone, thus the inner zone increases

TABLE 9

Radial brealth of the membrana basilaris measured between the foramina nervina and ligamentum spirale in radial sections-on age (chart 7, fig. 2)

\begin{tabular}{|c|c|c|c|c|c|}
\hline$A G E$ & BODY WEIGHT & $\begin{array}{l}\text { INNER ZONE } \\
\text { (Zona } \\
\text { arcuata) }\end{array}$ & $\begin{array}{l}\text { OUTER ZONE } \\
\text { (ZONa } \\
\text { pectinata) }\end{array}$ & $\begin{array}{c}\text { Total radial } \\
\text { breadth of } \\
\text { the mem- } \\
\text { brane }\end{array}$ & $\begin{array}{l}\text { Ratios between } \\
\text { the radial breadth } \\
\text { of the inner and } \\
\text { outer zone }\end{array}$ \\
\hline days & grams & $\mu$ & $\mu$ & $\mu$ & $\mu$ \\
\hline 1 & 5 & 49 & 75 & 124 & $1: 1.5$ \\
\hline 3 & 8 & 63 & 91 & 154 & $: 1.5$ \\
\hline 6 & 11 & 77 & 105 & 182 & $: 1.4$ \\
\hline $9^{1}$ & 10 & 79 & 111 & 190 & $: 1.4$ \\
\hline 12 & 13 & 88 & 100 & 188 & $: 1.1$ \\
\hline 15 & 13 & 87 & 102 & 189 & $: 1.2$ \\
\hline 20 & 29 & 86 & 106 & 192 & $: 1.2$ \\
\hline 25 & 36 & 87 & 108 & 195 & $: 1.2$ \\
\hline 50 & 59 & 88 & 107 & 195 & $: 1.2$ \\
\hline 100 & 112 & 92 & 106 & 198 & $: 1.2$ \\
\hline 150 & 183 & 92 & 107 & 199 & $: 1.2$ \\
\hline 257 & 137 & 92 & 107 & 199 & $: 1.2$ \\
\hline 366 & 181 & 93 & 111 & 204 & $: 1.2$ \\
\hline 546 & 255 & 94 & 113 & 207 & $: 1.2$ \\
\hline \multirow{2}{*}{\multicolumn{2}{|c|}{ Ratios $1-546$ days }} & $1: 1.9$ & $1: 1.5$ & $1: 1.7$ & \\
\hline & & $: 1.1$ & $: 1.1$ & $: 1.1$ & \\
\hline $20-$ & $546 \quad "$ & $: 1.1$ & $: 1.1$ & $: 1.1$ & \\
\hline \multicolumn{6}{|c|}{${ }^{1}$ A rat of nine days which could hear, gave the following: } \\
\hline \multirow{3}{*}{\multicolumn{2}{|c|}{ Right side }} & 94 & 103 & 197 & \\
\hline & & 91 & 104 & 195 & \\
\hline & & 93 & 104 & 196 & $1: 1.1$ \\
\hline
\end{tabular}

considerably after birth, while the outer zone does not grow, as some authors have imagined, as much as the inner zone. I will discuss this point later.

Comparing the growths of the radial breadth of the inner and outer zones, we find that the inner zone is relatively narrow at nine days; thus the ratios between them are 1:1.4; after that perind the inner zone increases rapidly, and even at twelve days the ratio becomes $1: 1.1$, which is almost the same as in the adult, $1: 1.2$. 
In table 10 the radial breadths of the whole membrane and of its zones are arranged accordingly to the turns of the cochlea on age. At the bottom of each column are given the ratios from 1 to 546, 12 to 546, and 20 to 546 days. We see at first that the total radial breadth at one day is largest in the basal turn; at three days it becomes larger on passing from the basal toward the II and III turns, but in turn IV it is again small.

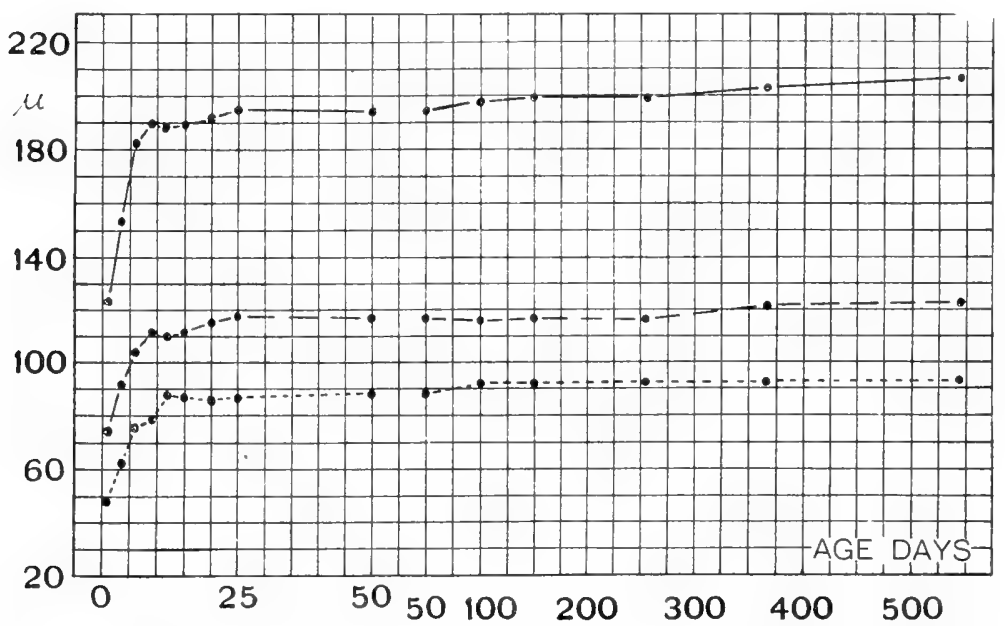

Chart 7 The radial breadth of the membrana basilaris, table 9, figure 2, distance 11.

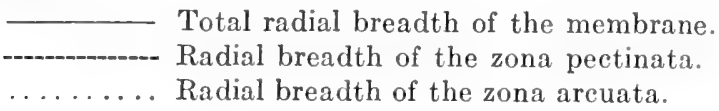

After six days it is a well-known fact that the radial breadth of the membrana basilaris is narrowest in the basal, and widest in the apical turn (not the tip of the apex, but the beginning of the apical turn). These differences are not always the same between all the turns; those between I and II, and II and III are marked; those between III and IV are small. The ratios at 1 to 546 days show those for the upper turn to be largest, while from 12 to 546 , and 20 to 546 days the ratios in all turns are about $1: 1.1$. 


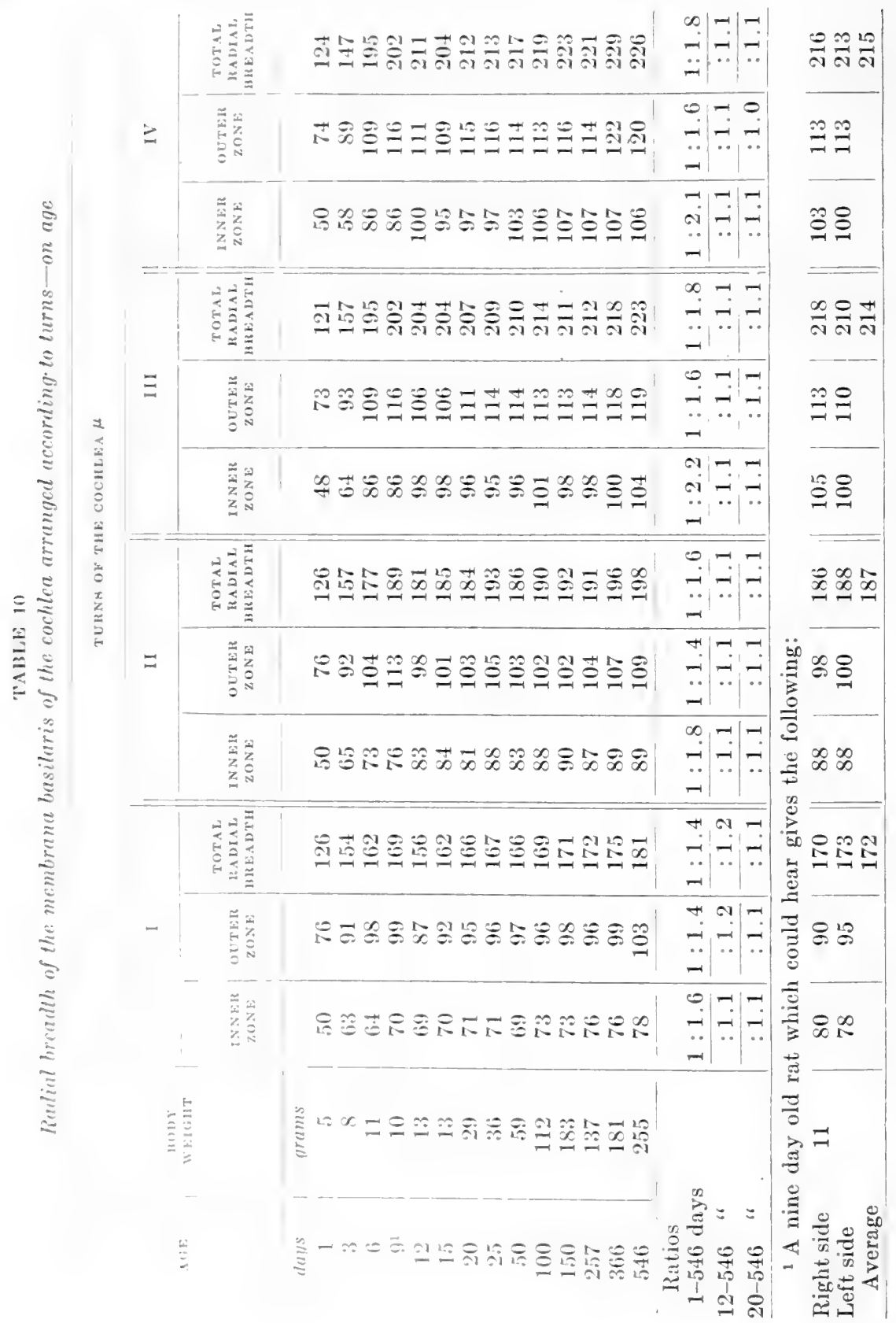


In the zona arcuata (inner zone) the same relation is to be seen in each turn; therefore, in the early period the breadth is less in turn IV than in the other turns. Very soon, however, the value in turn IV becomes the largest and diminishes toward the base. The rate of the growth of this zone, from 1 to 546 days, is also smallest in turn I, and largest in turns III or IV; the ratios being in the first $1: 1.6$, and in the last $1: 2.1$.

In the zona pectinata (outer zone) we see also similar relations.

TABLE 11

Ratios of the radial breadth of the membrana basilaris according to the turns of the cochlea-on age

\begin{tabular}{|c|c|c|c|c|}
\hline \multirow{2}{*}{$\triangle G E$} & \multirow{2}{*}{ BODY WEIGHT } & \multicolumn{3}{|c|}{ Ratios between turns } \\
\hline & & I-II & I-III & $\mathrm{I}-\mathrm{IV}$ \\
\hline days & $g m s$. & & & \\
\hline 1 & 5 & $1: 1.0$ & $1: 1.0$ & $1: 1.0$ \\
\hline 3 & 8 & $: 1.0$ & $: 1.0$ & $: 1.0$ \\
\hline 6 & 11 & $: 1.1$ & $: 1.2$ & $: 1.2$ \\
\hline 9 & 10 & $: 1.1$ & $: 1.2$ & $: 1.1$ \\
\hline 12 . & 13 & $: 1.2$ & $: 1.3$ & $: 1.3$ \\
\hline 15 & 13 & $: 1.1$ & $: 1.3$ & $: 1.3$ \\
\hline 20 & 29 & $: 1.1$ & $: 1.2$ & $: 1.3$ \\
\hline 25 & 36 & $: 1.2$ & $: 1.3$ & $: 1.3$ \\
\hline 50 & 59 & $: 1.1$ & $: 1.3$ & $: 1.3$ \\
\hline 100 & 112 & $: 1.1$ & $: 1.3$ & $: 1.3$ \\
\hline 150 & 183 & $: 1.1$ & $: 1.2$ & $: 1.3$ \\
\hline 257 & 137 & $: 1.1$ & $: 1.2$ & $: 1.3$ \\
\hline 366 & 181 & $: 1.1$ & $: 1.2$ & $: 1.3$ \\
\hline 546 & 255 & $: 1.1$ & $: 1.2$ & $: 1.3$ \\
\hline
\end{tabular}

Only slight differences in the ratios according to age are found.

In table 11 the ratios according to the turns of the cochlea are given. While from one to three days the ratios are the same in each turn, 1:1.0, yet after six days those for turns I to II are smallest, and for I to IV larger, thus showing slight differences between them.

In the literature we find only one description, that by Retzius ('84) touching the growth of the radial breadth of the membrana basilaris according to age. He measured this membrane in the rabbit and cat and got the following values in $\mu$ (table 12). 
(omparing these values with mine obtained for the albino rat, it is to be noted that those of Retzius are generally larger than those for the albino. For example, while I get at birth only $126 \mu$ in the basal turn, Retzius ('84) obtains $180 \mu$ in the rabbit and even $270 \mu$ in the cat. As stated above, the radial breadth increases in the albino rat continuously with age. It is rery peculiar to find in the Retzius table that the breadth of the membrane in the eat is decidedly larger at birth than at three and seven days. The average value for the new-born is $315 k$, which is larger than at thirty days, which is $310 \mu$.

Retzius ' data show the membrane in the rabbit and cat always wider in the apical than in the basal turn at birth and at two

TABLE 12

\begin{tabular}{|c|c|c|c|c|c|c|}
\hline \multicolumn{4}{|c|}{ FABBIT } & \multicolumn{3}{|c|}{$\mathrm{CAT}$} \\
\hline Age & Basal & Middle & Apical & Basal & Middle & Apical \\
\hline days & & & & & & \\
\hline Sew-born & 180 & 270 & - & 270 & 300 & 375 \\
\hline 2 & 220 & 272 & 280 & - & - & - \\
\hline 3 & - & - & - & 200 & 280 & - \\
\hline 7 & 270 & 306 & $\overline{-}$ & 211 & 258 & 300 \\
\hline 10 & 255 & 310 & 390 & - & -- & -- \\
\hline 11 & 二- & $\overline{-}$ & $\overline{-10}$ & 255 & 300 & 330 \\
\hline $\begin{array}{l}14 \\
30\end{array}$ & 300 & 360 & 410 & $\overline{240}$ & 300 & $\overrightarrow{390}$ \\
\hline & & & & & & \\
\hline
\end{tabular}

days. My results, given in table 10 , show the reverse at the ages of one and three days. This is an expression of greater immaturity in the case of the rat.

In comparisons like the foregoing, several conditions must be kept constantly in view.

in far as absolute values are concerned, it is to be expected that these would be unlike in the different mammals, because the cochleas differ in size. As to the relations between the values at hirth and at maturity, it is plain that these cannot be expectert to agree unless the cochleas of the animals compared are in the same phase of development at birth. In the foregoing instances if appears that the cat is relatively precocious, as compared with the rabbit, while, as might be expected, because 
of their closer zoological relationship, the rat and the rabbit are in better agreement, although the rabbit appears to be a trifle more advanced at birth than the rat.

Finally, in the comparison of different series of data, differences due to the lack of homogeneity in the series of animals used and to the various techniques employed can hardly fail to play an important part, and allowance must be made for these disturbing factors.

When we consider the rate of growth, the ratio of a one to a fourteen-day-old rabbit is $1: 1.6$, according to Retzius; therefore,

TABLE 13

\begin{tabular}{|c|c|c|c|c|c|}
\hline \multirow{2}{*}{$\begin{array}{l}\text { ANIMAL } \\
\text { AUTHOR }\end{array}$} & \multicolumn{5}{|c|}{ TURN IN WHICH MEASUREMENT WAS MADE IN $\mu$} \\
\hline & Basal & Second & Third & Fourth & Average \\
\hline Man-New-born & & & & & \\
\hline Hensen ('63) & 235 & 413 & & 495 & 381 \\
\hline Man-Mature & & & & & \\
\hline Retzius ('84) & 210 & & 340 & 360 & 303 \\
\hline Calf & & & & & \\
\hline Kolmer ('07) & 200 & 280 & & 400 & 293 \\
\hline Pig & & & & & \\
\hline Kolmer ('07) & 168 & 200 & 256 & 304 & 232 \\
\hline Goat & & & & & \\
\hline Kolmer ('07) & 124 & 384 & 432 & & 313 \\
\hline Cat & & & & & \\
\hline Böttcher ('69) & 90 & & 435 & & 263 \\
\hline $\begin{array}{l}\text { Cat } \\
\text { Middendorp ('67) }\end{array}$ & & & & & $246-275$ \\
\hline
\end{tabular}

it has very nearly the value found in the albino. In the cat, however, the ratio between one and thirty days is $1: 0.97$; therefore, it apparently decreases a bit.

This difference is most readily explained as due to the precocious development in the cat at birth.

On comparing the radial breadth of the membrane obtained from several mammals by various authors, we find the following values (table 13).

The values here given must be read in the light of the various modifying conditions to which reference has just been made. 
My average value after twenty days is $199 \mu$; therefore, it is absolutely the smallest in this series of mammals. The rat is also the smallest species examined.

Is shown in the literature quoted, and also in my own results, the membrane increases in its breadth in all the mammals examined from the base toward the apex - a relation contrary to that reported by the older authors (Corti, '51, and others). This increase is continuous, but is at first more rapid and afterwards more gradual. The ratios of this increase in the albino rat are given in table 11 .

The next question relates to the breadth of each zone of the membrane according to age. So far as I know, there is no such study in the literature, not even in Retzius. In the albino rat, as shown in table 9, each zone increases in breadth with age. The rate of growth, however, is somewhat different, and in the zona arcuata it is greater than in the zona pectinata (1:1.9 and $1: 1, \bar{n}$, respectively), although the absolute value is always greater in the latter.

As noted above, the membrane increases in its radial breadth from the basal to the apical turn. How, and in which portion of the membrane does this increase arise? Henle ('66) first regarded the breadth of the inner (zona arcuata) as approximately constant.

"Nicht nur in den verschiedenen Regionen einer Schnecke, sondern, soviel ich sehe, selbst in den Sshnecken verscheidener 'Tiere und des Menschen; sie schwankt nur wenig um $0.01 \mathrm{~mm}$. " (Eingeweidelehre des Menschen, 1866, S. 793).

In the second edition of his book ('73) he states, however, that in the increase of the breadth according to the turn, both zones seem to take part. Hensen ('63) gets in the zona arcuata of the base of the human cochlea the breadth of $19 \mu$ and in the apex $85 \%$ Middendorp ('68) gives in the cochlea of the cat a continuous increase of the breadth of the zona arcuata from 94 (1) 1 1 2:2.5) :

More detailed data are given in table 14 .

According to all these authors, the breadth of both the inner and outer zones increases from base toward apex and results 
in the increase of the total radial breadth of the membrane according to turn. My results obtained from the albino rat agree with these data.

3. Radial distance between the habenula perforata and the inner corner of the inner pillar cells at base. The measurements of the radial distance from the habenula perforata to the bases of the inner and outer pillar cells were taken to determine their postnatal growth. As already stated, the cells from which the arch of Corti arises stand at birth nearly vertically and have no space between them (fig. 4). In the adult, however (fig. 10), we see a space, the tunnel of Corti lying between them and changes in the form of the arch occur. To follow these changes

TABLE 14

Breadth of the inner zone of the membrana basilaris in $\mu$

\begin{tabular}{l|c|c|c|c}
\hline & \multicolumn{4}{|c}{ NUMBER OF TURN } \\
\cline { 1 - 3 } & First & Second & Third & Fourth \\
\hline $\begin{array}{l}\text { Cat-adult ('69) } \\
\text { Böttcher ('69) }\end{array}$ & 60 & 105 & 135 & \\
$\begin{array}{l}\text { Guinea-pig } \\
\text { Winiwarter ('70) }\end{array}$ & $45-52$ & $63-68$ & $71-80$ & $80-83$ \\
\hline
\end{tabular}

it seems at first necessary to study the growth of the pillar cells and of the other elements in the organ of Corti. At the same time we must take into consideration the inward shifting of the organ of Corti, first studied by Hensen. This shift inward of the organ is, according to Hensen, chiefly caused by the wandering of the pillar cells, especially the inner pillar cell. Therefore, it seemed necessary to determine the radial distance of the pillar cells from the habenula perforata at different ages before discussing this interesting problem.

In table 15 are given the values for the radial distances between the habenula perforata and the inner corner of the inner pillar cell at its base according to age (figs. 4 to 9 ). As we see, the average value increases till three days of age, then vanishes suddenly, though at six days we have a measurable interval in the upper turns of the cochlea. Comparing these distances according to the turn, they are smallest in turn $\mathrm{I}$ and increase 
toward the apex. In some cases, at six days, we have no interval in the basal turn, but in the higher turns an interval gradually appears and at the apical turn is largest. This table shows, therefore, that the inner corner of the base of the inner pillar cell lies at birth outward from the habenula perforata at an

TABLE 15-Condensed

Radial distance between the habenula perforata and the inner corner of the inner pillar at base-on age

\begin{tabular}{|c|c|c|c|c|c|c|}
\hline \multirow{2}{*}{$\triangle G E$} & \multirow{2}{*}{$\begin{array}{l}\text { BODY } \\
\text { WEIGHT }\end{array}$} & \multicolumn{5}{|c|}{ TURNS OF THE COCHLEA $\mu$} \\
\hline & & I & II & III & IV & Aver. \\
\hline days & 5 & 19 & 22 & 22 & 23 & 22 \\
\hline 3 & 8 & 23 & 28 & 28 & 30 & 27 \\
\hline 6 & 11 & $\begin{array}{c}\text { In one case } 5 \\
\text { In other } 3 \text { cases } 0\end{array}$ & $\begin{array}{l}\text { In } 2 \text { cases } 10 \\
\text { In other cases } 0\end{array}$ & 14 & 18 & - \\
\hline 9 & 10 & 0 & 0 & 0 & 0 & 0 \\
\hline 12 & 13 & 0 & 0 & 0 & 0 & 0 \\
\hline
\end{tabular}

average distance of $22 \mu$. At three days of age the inner corner moves farther outward with the developing membrana basilaris and the distance increases from the base to the apex. Between three to six days this outward movement not only stops, but reverses its direction, and at six days it often becomes zero in the basal turn. Böttcher ('72) finds in the cat the following values for this interval in $\mu$ (table 16 ).

TABLE 16

\begin{tabular}{|c|c|c|c|c|c|c|c|c|c|}
\hline \multicolumn{5}{|c|}{ CAT EMBRYO-11 CM. LONG } & \multicolumn{5}{|c|}{ ADULT CAT } \\
\hline 1 & II & III & IV & Average & I & II & III & IV & Average \\
\hline 15 & 39 & 30 & 30 & 29 & 3 & 3 & 3 & 3 & 3 \\
\hline
\end{tabular}

TABLE 17

\begin{tabular}{|c|c|c|c|c|c|c|c|c|}
\hline \multicolumn{5}{|c|}{ RABBIT } & \multicolumn{4}{|c|}{ CAT } \\
\hline$\triangle G E$ & $\begin{array}{c}\text { Basal } \\
\text { turn }\end{array}$ & Middle & Apical & Average & Basal & Middle & Apical & Average \\
\hline daus & & & & & & & & \\
\hline Sew-born & 300 & 300 & 300 & 300 & 5 & 40 & 45 & 30 \\
\hline 2 & 10 & 12 & 30 & 17 & - & - & - & - \\
\hline 3 & 0 & 0 & 0 & 0 & 3 & 36 & - & - \\
\hline 7 & 0 & 0 & 0 & 0 & 0 & 0 & 0 & 0 \\
\hline 11 & 0 & 0 & 0 & 0 & 0 & 0 & 18 & - \\
\hline
\end{tabular}


Retzius ('84) studied this distance in the rabbit and cat and gets the values given in Table 17 .

Comparing the values of these two authors with my own, there are of course some differences. While in the rabbit the interval is large at one day, it is greatly diminished at two days of age. At three days the inner corner of the cell reaches the habenula perforata. In the cat the values are nearer to mine. The fact that the values increase from base toward apex is to be seen here also. This peculiar phenomenon appears, therefore not only in the albino rat, but also in the rabbit and the cat during the earliest stage of postnatal life.

4. The radial distance between the habenula perforata and the outer corner of the inner pillar cell (resp. the inner corner of the outer pillar cell) at base. This measurement is difficult. As we know, the inner and outer pillar cells in the albino are from birth till nine days of age in contact with each other along their whole length, and therefore they do not yet surround the space forming the tunnel of Corti. At about nine days, however, the tunnel appears while the cells remain in contact by their bases. It is almost impossible to determine the line of contact on the basilar membrane in my preparations. To get the radial distance between the habenula perforata and the outer corner of the inner pillar cell I have proceeded therefore as follows:

First, I have measured this distance directly up to nine days of age; after that this distance consists of the sum of the radial basal breadth of the inner pillar (not pillar cell) and the breadth of the inner basal cell on the basilar membrane. Since it is impossible to get the latter value directly in my sections, I considered that half of the radial distance between the outer corner of the inner pillar and the inner corner of the outer pillar would be equivalent to it.

Of course, I do not know whether the value of the sum of these two distances is at all ages, identical with the distance between the habenula perforata and the outer corner of the inner pillar cell at its base. I believe, however, that a systematic study of the growth of this distance will be significant. 
In table 1s are given the ralues for the radial distance between the habenula perforata and the outer corner of the inner pillar at base up to nine days of age. As shown, these values, on the average, increase with age. The increase of this distance means that the base of the inner pillar cell spreads outward more and more.

When we consider this distance according to the coil of the cochlea, it is at birth about the same through all the turns (table 18; at three days it increases up to turn III, and in turn

TABLE 18

Radial distance between the habenula perforata and the outer corner of the inner pillar at base-on age

\begin{tabular}{|c|c|c|c|c|c|c|}
\hline \multirow[b]{2}{*}{$\mathrm{AGE}$} & \multirow[b]{2}{*}{ BODY WEIGHT } & \multicolumn{5}{|c|}{ TURNS OF COCHLEA $\mu$} \\
\hline & & I & II & III & VI & Average \\
\hline days & grams & & & & & \\
\hline 1 & 5 & 40 & 41 & 39 & 39 & 40 \\
\hline 3 & 8 & 48 & 49 & 50 & 48 & 48 \\
\hline 6 & 11 & 38 & 45 & 58 & 53 & 49 \\
\hline 9 & 10 & 44 & 46 & 56 & 53 & 50 \\
\hline
\end{tabular}

IV the value is the same at the apex as at the base. At six days the value in turn III is also largest, and next largest in turn IV. At nine days of age the same relations are to be seen.

In table 19 (chart 8) are given the values for the radial basal breadth of the inner pillar (not pillar cell) on age. At the bottom of the last column are the ratios from 6 to 546 , and 20 to 546 days. As above noted, the rod can be followed at birth from the upper part to near the base of the cell (fig. 4). At three days (fig. 5), its base reaches the basilar membrane as a thin and slender thread, but we cannot measure its basal breadth accurately. During the next few days it increases in radial breadth rapidly, and at six days has the average value of $29 \mu$ (table 19). After nine days it decreases distinctly till twenty days, after which the value remains nearly constant. These relations are evident in the ratios. While the breadth at six days is about twice that at 546 days, that at twenty days has the same value. 
According to the turn of the cochlea, the values from nine to fifteen days become gradually larger on passing from the base toward the apex. After twenty days, however, this relation vanishes, and the values become nearly the same through all

TABLE 19

Radial basal breadth of the inner pillar-on age (chart 8)

\begin{tabular}{|c|c|c|c|c|c|c|}
\hline \multirow{2}{*}{$A G E$} & \multirow{2}{*}{$\begin{array}{c}\text { WEIGHT } \\
\text { BODY }\end{array}$} & \multicolumn{5}{|c|}{ TURNS OF THE COCHLEA $\mu$} \\
\hline & & I & II & III & IV & Average \\
\hline days & grams & & & & & \\
\hline 1 & 5 & 0 & 0 & $\mathbf{0}$ & 0 & 0 \\
\hline 3 & 8 & 0 & 0 & 0 & 0 & 0 \\
\hline 6 & 11 & 29 & 31 & 27 & 27 & 29 \\
\hline 9 & 10 & 28 & 28 & 33 & 35 & 31 \\
\hline 12 & 13 & 18 & 19 & 22 & 25 & 21 \\
\hline 15 & 13 & 18 & 18 & 19 & 19 & 19 \\
\hline 20 & 29 & 14 & 15 & 15 & 15 & 15 \\
\hline 25 & 36 & 14 & 15 & 14 & 15 & 15 \\
\hline 50 & 59 & 14 & 14 & 14 & 13 & 14 \\
\hline 100 & 112 & 14 & 14 & 14 & 13 & 14 \\
\hline 150 & 183 & 15 & 15 & 15 & 15 & 15 \\
\hline 257 & 137 & 15 & 15 & 15 & 15 & 15 \\
\hline 366 & 181 & 16 & 17 & 15 & 15 & 16 \\
\hline 546 & 255 & 15 & 14 & 16 & 15 & 15 \\
\hline \multicolumn{2}{|c|}{ Ratios $\begin{array}{r}6-546 \text { days } \\
20-546\end{array}$} & & & & & $\begin{aligned} 1 & : 0.5 \\
& : 1.0\end{aligned}$ \\
\hline
\end{tabular}

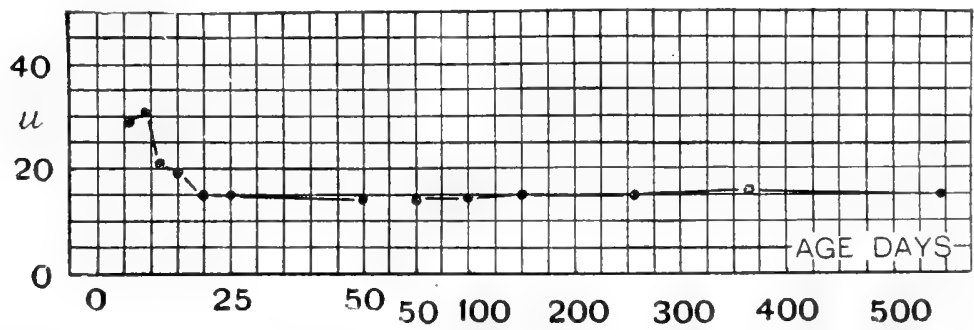

Chart 8. The radial basal breadth of the inner pillar (not pillar rell), table 19, figure "2, distance 3.

the turns. In table 20 the ratios of the turns I to II, I to III, and I to IV are given for three age groups (condensed from table 19) 
From the data given by Retzius (' 84 ) we get the values in $\mu$ of the radial basal breadth of the inner pillar in the rabbit and cat as follows (table 21).

Comparing these values with my own, it is to be ncted that Retzius' measurements in the rabbit agree perfectly at the earliest stage with those in the albino rat. Also we find in the

TABLE 20-Condensed

Ratios of the radial basal breadth of the inner pillar according to the turns of the cochlea-on age

\begin{tabular}{|c|c|c|c|c|}
\hline \multirow{2}{*}{$A G E$} & \multirow{2}{*}{ BODY WEIGHT } & \multicolumn{3}{|c|}{ RATIOS BETWEEN TURNS } \\
\hline & & I-II & I-III & $I-I V$ \\
\hline days & grams & & & \\
\hline 8 & 11 & $1: 1.0$ & $1: 1.0$ & $1: 1.1$ \\
\hline 14 & 13 & $: 1.1$ & $: 1.2$ & $: 1.3$ \\
\hline 189 & 124 & $: 1.0$ & $: 1.0$ & $: 1.0$ \\
\hline
\end{tabular}

TABLE 21

\begin{tabular}{|c|c|c|c|c|c|c|c|c|}
\hline \multicolumn{5}{|c|}{ RABBIT } & \multicolumn{4}{|c|}{ CAT } \\
\hline Age & $\begin{array}{l}\text { Basal } \\
\text { turn }\end{array}$ & Middle & Apical & Average & Basal & Middle & Apical & Average \\
\hline daus & & & & & & & & \\
\hline Sew-born & 0 & 0 & 0 & 0 & 11 & - & 一 & - \\
\hline 2 & 0 & 0 & 0 & 0 & - & - & - & - \\
\hline 3 & - & - & - & - & 12 & - & - & 一 \\
\hline 7 & 15 & 12 & 15 & 14 & 10 & 15 & - & - \\
\hline 10 & 17 & 18 & 18 & 18 & - & - & - & 一 \\
\hline 11 & - & - & - & - & 15 & 15 & - & - \\
\hline 14 & 15 & 15 & 12 & 14 & - & - & 一 & - \\
\hline 30 & - & - & 一 & - & 9 & 12 & 15 & 12 \\
\hline
\end{tabular}

rabbit at seven days values homologous with those obtained in the albino rat at fifteen days of age, only in the rat the breadth is absolutely greater. In the cat the values at seven days of ttre stre about the same, or a bit smaller, than those in the albino rat. Here again the rabbit is a trifle more precocious than the rat, and the eat much more so.

Table 22 (chart 9) shows the values for the radial distance between the outer corner of the inner pillar (not pillar cell) 
TABLE 22

Radial distance between the outer corner of the inner pillar and the inner corner of the outer pillar-at base-on age (chart 9)

\begin{tabular}{|c|c|c|c|c|c|c|}
\hline \multirow{2}{*}{$A G E$} & \multirow{2}{*}{ BODY WEIGHT } & \multicolumn{5}{|c|}{ TURNS OF THE COCHLEA $\mu$} \\
\hline & & $\mathbf{I}$ & II & III & IV & Average \\
\hline days & grams & & & & & \\
\hline 1 & 5 & 0 & 0 & 0 & 0 & 0 \\
\hline 3 & 8 & 0 & 0 & 0 & 0 & 0 \\
\hline 6 & i i & 25 & 28 & 29 & 34 & 29 \\
\hline 9 & 10 & 27 & 30 & 35 & 30 & 31 \\
\hline 12 & 13 & 37 & 41 & 51 & 53 & 46 \\
\hline 15 & 13 & 35 & 46 & 56 & 56 & 48 \\
\hline 20 & 29 & 43 & 53 & 66 & 68 & 58 \\
\hline 25 & 36 & 42 & 58 & 67 & 68 & 59 \\
\hline 50 & 59 & 41 & 54 & 68 & 74 & 59 \\
\hline 100 & 112 & 44 & 59 & 71 & 78 & 63 \\
\hline 150 & 183 & 43 & 59 & 68 & 76 & 62 \\
\hline 257 & 137 & 46 & 56 & 66 & 75 & 61 \\
\hline 366 & 181 & 45 & 57 & 68 & 74 & 61 \\
\hline 546 & 255 & 47 & 60 & 71 & 74 & 63 \\
\hline
\end{tabular}

Ratios $6-546$ days

$12-546$ "

$1: 2.2$

$20-546$ “

$: 1.4$

$: 1.1$

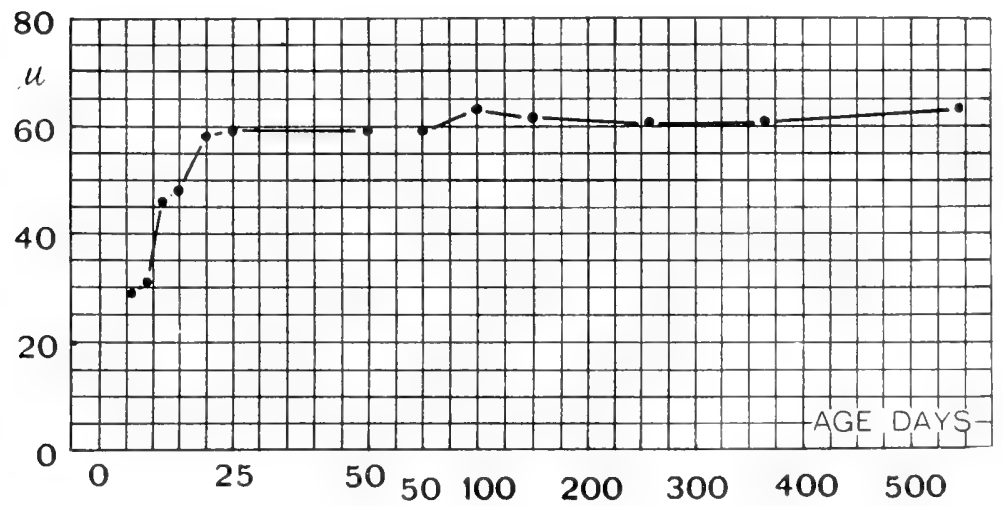

Chart 9. The radial distance between the outer corner of the inner pillar (not pillar cell) and the inner corner of the outer pillar (not pillar cell) at base, table 22 , figure 2 , distance 6 . 
and the inner corner of the pillar (not pillar cell) at the base, on age. It the bottom of the last column are given the ratios from 6 to 546, 12 to 546 , and 20 to 546 days. As just stated, the inner, and especially the outer rods, do not appear in the respective pillar cells at the earliest stage, the latter becoming evident a bit later than the former. After six days of age the distance between them can be determined.

As table 22 shows, this distance increases at first rapidly, then more slowly with age. This agrees with the growth of the membrana basilaris, as already noted. While the value at 546 days is over twice as large as at six days, it is but little larger than at twenty days, as the ratios show. Moreover, the distance increases from the base toward the apex rapidly up to turn

TABLE 23-Condensed

Ratios of the radial distance between the outer corner of the inner pillar and the inner corner of the outer pillar, at base-according to turns of the cochlea-on age

\begin{tabular}{r|r|r|r|r}
\multirow{2}{*}{ AGE } & BODY WeIGHT & \multicolumn{3}{|c}{ RATIOS BETWEEN TURN } \\
\hline days & grams & I-II & I-III & I-IV \\
\hline 8 & 11 & $1: 1.1$ & $1: 1.2$ & $1: 1.2$ \\
14 & 13 & $\vdots 1.2$ & $\vdots 1.5$ & $\vdots 1.5$ \\
189 & 124 & $: 1.3$ & $\vdots 1.5$ & $\vdots 1.7$
\end{tabular}

III and less rapidly to turn IV. This relation is more concisely presented in table 23. Retzius (' 84 ) gives the value of this distance in the rabbit and the cat as follows (table 24).

The table 24 shows that there is no measurable distance between the outer corner of the inner pillar and the inner corner of the outer pillar at the very early stage in the rabbit, and this result is like that for the albino rat. Later the distance is larger in the rabbit than in the rat. The rate of increase of the values from the base to the apex is, however, similar in both forms. In the cat, on the other hand, there is already at birth a large distance between the pillars. The cochlea of the cat is therefore at this period more advanced in this character than that of the rabbit or rat, but in the cat also the distance tends to increase from the base toward the apex. 
In table 25 (chart 10) are given the values for the radial distance between the habenula perforata and the outer corner of the inner pillar cell (resp. the inner corner of the outer pillar cell) at the base according to age. This table is derived from tables 18, 19, and 22. The values from one to nine days of age are from table 18. Those after twelve days consist of the sum of the values in table 19 plus the one-half of those given in table 22 (fig. 2 value for bracket 3 plus one-half the value for bracket $6)$.

TABLE 24

Radial disiance beween the outer corner of the inner pillar and inner corner of the outer pillar-in $\mu$ (Retzius)

\begin{tabular}{|c|c|c|c|c|c|c|c|c|}
\hline \multicolumn{5}{|c|}{ RABBIT } & \multicolumn{4}{|c|}{ CAT } \\
\hline Age & $\begin{array}{c}\text { Basal } \\
\text { turn }\end{array}$ & $\left|\begin{array}{c}\text { Middle } \\
\text { turn }\end{array}\right|$ & $\begin{array}{l}\text { Apical } \\
\text { turn }\end{array}$ & $\begin{array}{c}\text { Average } \\
\text { turn }\end{array}$ & $\underset{\text { turn }}{\text { Basal }}$ & $\begin{array}{c}\text { Middle } \\
\text { turn }\end{array}$ & $\begin{array}{c}\text { Apical } \\
\text { turn }\end{array}$ & $\begin{array}{c}\text { Average } \\
\text { turn }\end{array}$ \\
\hline days & & & & & & & & \\
\hline New-born & 0 & 0 & 0 & 0 & 64 & - & - & - \\
\hline 2 & 0 & 0 & 0 & 0 & - & - & - & - \\
\hline 3 & - & - & - & - & 45 & - & - & - \\
\hline 7 & 57 & 75 & 75 & 69 & 50 & 75 & - & - \\
\hline 10 & 52 & 72 & 74 & 66 & - & - & - & - \\
\hline 11 & - & - & - & - & 75 & 95 & - & - \\
\hline 14 & 63 & 100 & 99 & 87 & - & - & - & - \\
\hline 30 & - & - & - & - & 66 & 93 & 90 & 83 \\
\hline
\end{tabular}

The values increase gradually after birth till nine days, when they reach a maximum, and then decrease, but increase again very gradually till old age. If this method of measurement is accepted, then the inner corner of the inner pillar cell lengthens inward at the base in the earlier stages. At the time when the inner pillar reaches the habenula perforata, the outer corner of the inner pillar has not yet moved inward, and thus the breadth of the base is largest. After the inward wandering of the inner pillar cell, the base diminishes a little in its breadth; then it increases slightly with advancing age.

When considered according to the turn of the cochlea, this measurement generally increases from the base to the apex, but more rapidly from turn I to turn III, and only slightly from 
TABLE 25

Radial distance between the habenula perforata and the outer corner of the inner pillar cell (resp. the inner corner of the outer pillar cell) at base-on age. Derived from tables 18, 19 and 22 (chart 10)

\begin{tabular}{|c|c|c|c|c|c|c|}
\hline \multirow[t]{2}{*}{$A G E$} & \multirow{2}{*}{ BODY WEIGHT } & \multicolumn{5}{|c|}{ TURNS OF THE COCHLEA- $\mu$} \\
\hline & & I & II & III & IV & Average \\
\hline days & grams & & & & & \\
\hline 1 & 5 & 40 & 41 & 39 & 39 & 40 \\
\hline 3 & 8 & 46 & 49 & 49 & 49 & 48 \\
\hline 6 & 11 & 38 & 45 & 58 & 53 & 49 \\
\hline 9 & 10 & 44 & 46 & 56 & 53 & 50 \\
\hline 12 & 13 & 36 & 45 & 50 & 50 & 45 \\
\hline 15 & 13 & 36 & 41 & 47 & 47 & 43 \\
\hline 20 & 29 & 36 & 42 & 48 & 49 & 44 \\
\hline 25 & 36 & 35 & 44 & 48 & 49 & 44 \\
\hline 50 & 59 & 35 & 41 & 48 & 50 & 44 \\
\hline 100 & 112 & 36 & 44 & 50 & 52 & 46 \\
\hline 150 & 183 & 36 & 45 & 49 & 53 & 46 \\
\hline 257 & $13 \pi$ & 38 & 43 & 48 & 51 & 45 \\
\hline 366 & 181 & 39 & 45 & 49 & 52 & 46 \\
\hline 546 & 255 & 39 & 44 & 52 & 52 & 47 \\
\hline
\end{tabular}

Ratios $\begin{array}{r}1-546 \text { days } \\ 9-546 \\ 12-546 \\ 20-546\end{array}$

$1: 1.2$

$: 0.9$

$: 1.0$

$: 1.1$

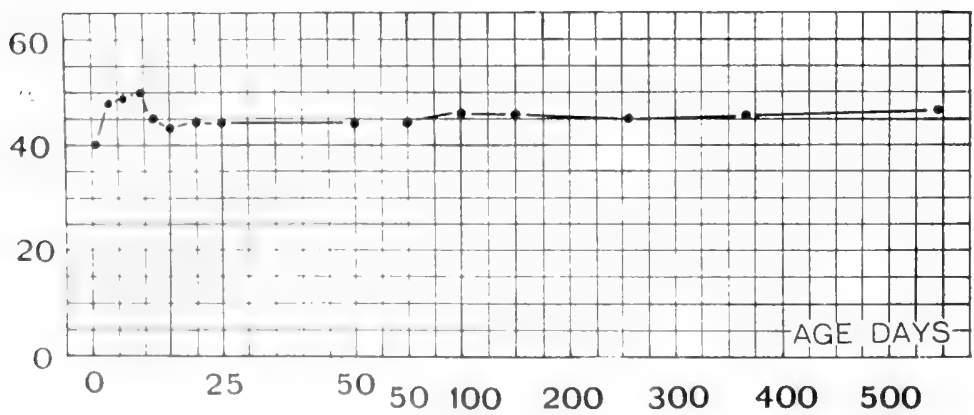

Chart 10 the radial distance between the habenula perforata and the miter corner of the inner pillar cell (resp. the inner corner of the outer pillar (will) at hase, table 25, figure 2 , distance 8. 
turn III to IV. Table 26 shows this relation. While at birth the ratio is in all turns the same, $1: 1.0$, at other ages it is always higher. Retzius ('84) gives the results obtained from the rabbit and the cat as follows (table 27).

TABLE 26-Condensed

Ratios of the radial basal distance between the habenula perforata and the ouler corner of the inner pillar cell (resp. the inner corner of the outer pillar cell) at base-on age-according to the turns of the cochlea

\begin{tabular}{|c|c|c|c|c|}
\hline \multirow{2}{*}{$\mathrm{AGE}$} & \multirow{2}{*}{ BODY WEIGHT } & \multicolumn{3}{|c|}{ RATIOS BETWEEN TURNS } \\
\hline & & I-II & I-III & I-IV \\
\hline days & grams & & & \\
\hline 1 & 5 & $1: 1.0$ & $1: 1.0$ & $1: 1.0$ \\
\hline 8 & 11 & $: 1,2$ & $: 1.4$ & $: 1.3$ \\
\hline 18 & 21 & $: 1.2$ & $: 1.3$ & $: 1.3$ \\
\hline 213 & 138 & $: 1.2$ & $: 1.3$ & $: 1.4$ \\
\hline
\end{tabular}

TABLE 27

Distance between the habenula perforata and the outer corner of the inner pillar cell in $\mu$ (Retzius)

\begin{tabular}{c|c|c|c|c||c|c|c|c}
\multicolumn{1}{c|}{ Age } & $\begin{array}{c}\text { Basal } \\
\text { turn }\end{array}$ & $\begin{array}{c}\text { Middle } \\
\text { turn }\end{array}$ & $\begin{array}{c}\text { Apical } \\
\text { turn }\end{array}$ & $\begin{array}{c}\text { Average } \\
\text { turn }\end{array}$ & $\begin{array}{c}\text { Basal } \\
\text { turn }\end{array}$ & $\begin{array}{c}\text { Middle } \\
\text { turn }\end{array}$ & $\begin{array}{c}\text { Apical } \\
\text { turn }\end{array}$ & $\begin{array}{c}\text { Average } \\
\text { turn }\end{array}$ \\
\hline $\begin{array}{c}\text { days } \\
\text { New-born }\end{array}$ & 30 & 45 & 39 & 38 & 60 & 60 & 60 & 60 \\
2 & 30 & 36 & 30 & 32 & - & - & - & - \\
3 & - & - & - & - & 44 & 60 & - & - \\
7 & 37 & 46 & 45 & 43 & 45 & $69(?)$ & 65 & 60 \\
10 & 39 & 52 & 48 & 46 & - & - & - & - \\
11 & - & - & - & - & 60 & 66 & 75 & 67 \\
14 & 40 & 54 & 51 & 48 & - & - & - & - \\
30 & - & - & - & - & - & 60 & 60 & - \\
\hline
\end{tabular}

At the earlier stage this distance in the rabbit is a little less than in the rat. Soon after, however, it becomes about the same. In the cat the values are generally larger than in the rat.

5. Radial basal breadth of the outer pillar cell (including the outer pillar). The measurement of the radial basal breadth of the outer pillar cell is difficult. At the earlier stage, in which the inner and outer pillar cells are in contact with each other along 
TABLE 28

Radial basal brcadth of the outer pillar cell (including the outer pillar) from one to nine days of age

\begin{tabular}{|c|c|c|c|c|c|c|}
\hline \multirow{2}{*}{ AGE } & \multirow{2}{*}{ DODY WEIGHT } & \multicolumn{5}{|c|}{ TURNS OF THE COCHLEA- $\mu$} \\
\hline & & I & II & III & IV & Average \\
\hline days & grams & & & & & \\
\hline 1 & 5 & 10 & 9 & 8 & 8 & 9 \\
\hline 3 & 8 & 15 & 16 & 15 & 12 & 15 \\
\hline 6 & 11 & 26 & 28 & 28 & 33 & 28 \\
\hline 9 & 10 & 26 & 30 & 30 & 35 & 30 \\
\hline
\end{tabular}

TABLE 29

Radial basal breadth of the outer pillar-on age (charl 11)

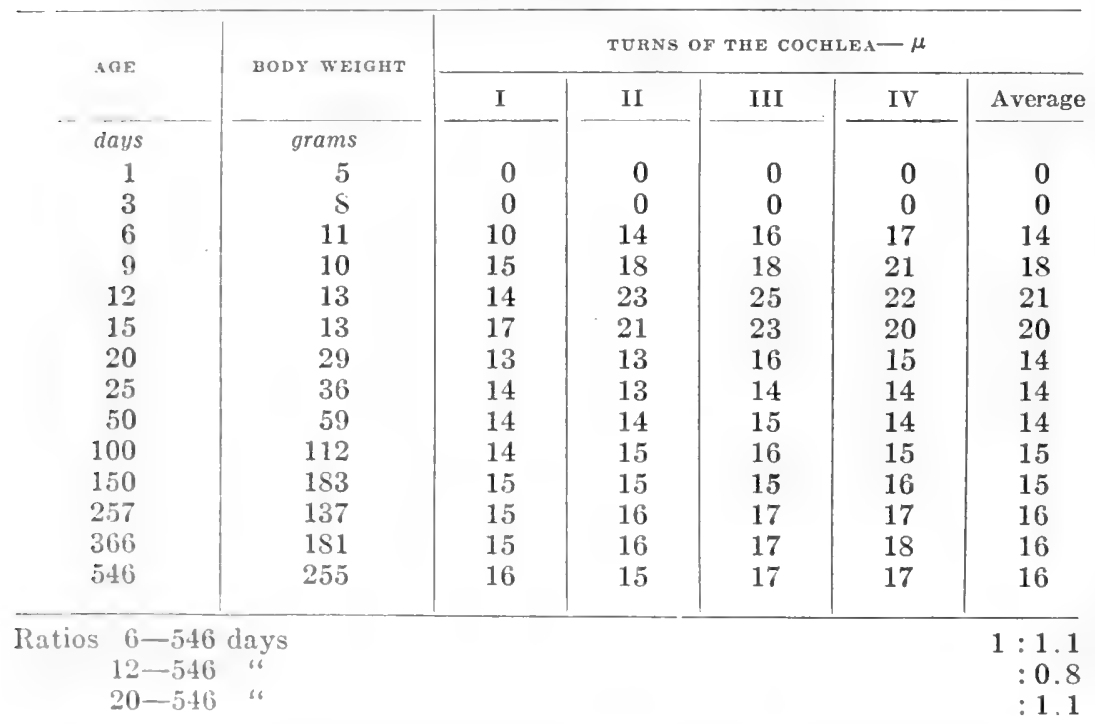

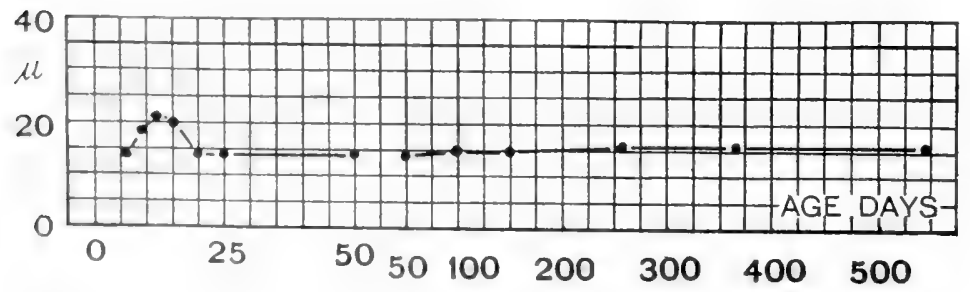

Chart 11 The radial basal breadth of the outer pillar (not pillar cell) table 29, figure 2, distance 7 . 
their whole length, we can easily measure this distance. After twelve days, however, the breadth consists of the sum of the radial breadth of the outer pillar and the half of the radial distance between the outer corner of the inner pillar and the inner corner of the outer pillar, as previously explained.

In table 28 are given the values for the radial basal breadth of the outer pillai cell (including the outer pillar) from birth to nine days of age. These values show a rapid inerease. According to the turn of the cochlea, the breadth at birth diminishes from the base to the apex. At three days it increases already in turn II, but at the later ages it increases gradually from the base to the apex.

TABLE 30-Condensed

Ratios of the radial basal breadth of the outer pillars-on age-according to the turns of the cochlea

\begin{tabular}{r|c|r|r|r}
\hline \multirow{2}{*}{ AGE } & \multirow{2}{*}{ BODY WEIGHT } & \multicolumn{3}{|c}{ RATIOS BETWEEN TURN } \\
\cline { 3 - 5 } & & I-II & I-III & I-IV \\
\hline days & grams & & & \\
8 & 11 & $1 \cdot 1.2$ & $1: 1.3$ & $1: 1.5$ \\
14 & 13 & $: 1.4$ & $: 1.5$ & $\vdots 1.3$ \\
189 & 124 & $: 1.0$ & $: 1.1$ & $\vdots 1.1$ \\
\hline
\end{tabular}

In table 29 (chart 11) are given the values for the radial basal breadth of the outer pillar (not pillar cell). As in the case of the inner pillar, here also the outer pillar first appears distinctly at six days of age. After the continuous increase of the values till twelve to fifteen days, they decrease suddenly at twenty days, and then increase again very slowly. This relation is elearly shown by the ratios at the bottom of the last column. That the values tend to increase from the base toward the apex is also shown, though there are some exceptions. Table 30 gives the condensed results.

From Retzius' work ('84) we have calculated the values for the radial basal breadth of the outer pillar in the rabbit and cat as follows (table 31).

There are large differences between my results and those of Retzius during the earlier stage, especially in the rabbit. 
At birth, the inner pillar has not yet distinctly developed at the base of the pillar cell in the rabbit and the rat, as above stated. We know that the development of the elements of the cochlea proceeds generally from the axis to the periphery, as

TABLE 31

Radial basal breadth of outer pillar measured in $\mu$ (from Retzius)

\begin{tabular}{|c|c|c|c|c|c|c|c|c|}
\hline \multicolumn{5}{|c|}{ RABBIT } & \multicolumn{4}{|c|}{ CAT } \\
\hline Alue & $\begin{array}{l}\text { Basaal } \\
\text { turn }\end{array}$ & $\begin{array}{l}\text { Mididle } \\
\text { turn }\end{array}$ & $\begin{array}{l}\text { Apical } \\
\text { turn }\end{array}$ & Average & $\begin{array}{c}\text { Basal } \\
\text { turn }\end{array}$ & $\begin{array}{c}\text { Middle } \\
\text { turn }\end{array}$ & $\begin{array}{l}\text { Apical } \\
\text { turn }\end{array}$ & Average \\
\hline days & & & & & & & & \\
\hline Jew-born & $15 ?$ & $12 ?$ & $7 ?$ & $11 ?$ & 25 & 15 & - & - \\
\hline 2 & 50 & 45 & 44 & 46 & - & 一 & - & - \\
\hline 3 & 一 & - & - & - & 20 & - & - & - \\
\hline 7 & $2 S$ & 28 & 17 & - 24 & 18 & 20 & 18 & 19 \\
\hline 10 & 31 & 30 & 37 & 33 & - & - & - & 一 \\
\hline 11 & 一 & 一 & - & - & 30 & 19 & - & - \\
\hline 14 & 28 & 25 & 18 & 24 & - & - & - & - \\
\hline 30 & - & - & - & 一 & 10 & 15 & 15 & 13 \\
\hline
\end{tabular}

TABLE 32

Radial basal breadth of the outer pillar cells-on age, based on tables 22, 28, and 29 (charts 12 and 13)

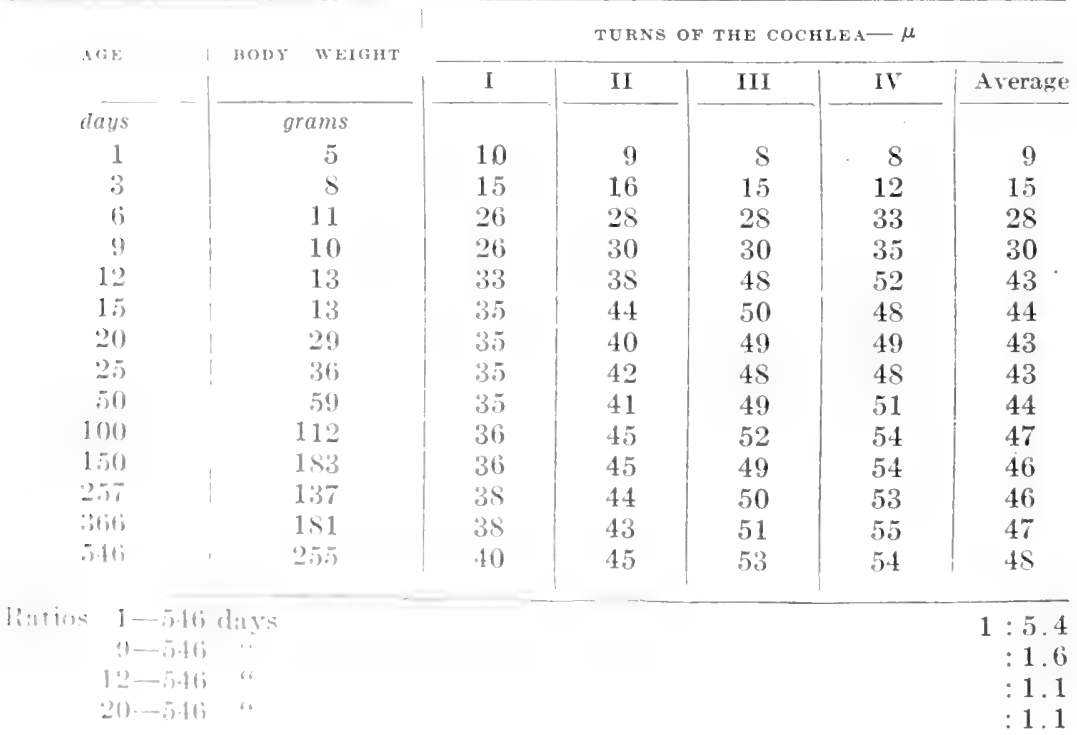


Held ('09) and others have pointed out. Yet, according to Retzius, the outer pillar develops in the rabbit earlier than does the inner pillar. This result seems to me very peculiar, but, at present, I am unable to explain it.

In table 32 (charts 12 and 13) are given the values for the radial basal breadth of the outer pillar cells. These data are

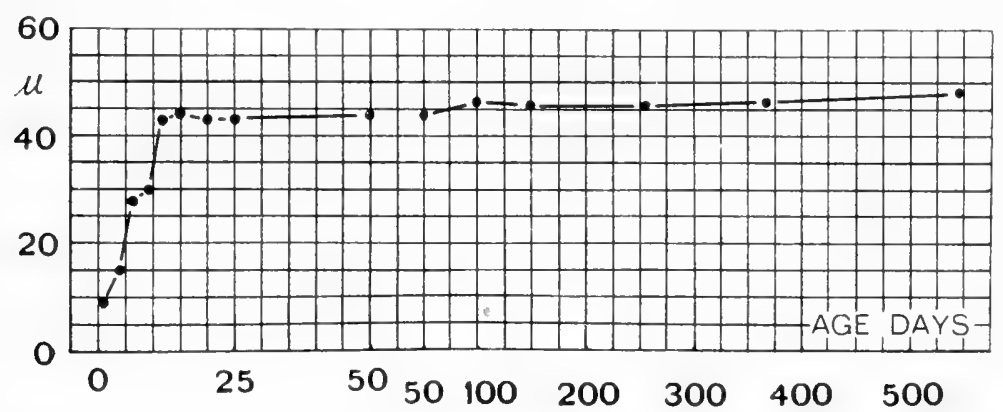

Chart 12 The radial basal breadth of the outer pillar cell, table 32, figure 2, distance 9 .

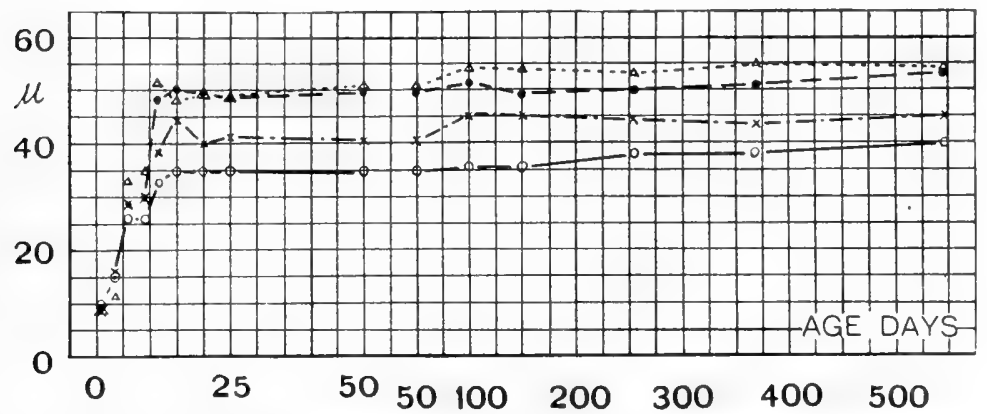

Chart 13 The radial basal breadth of the outer pillar cell, according to the turns of the cochlea, table 32 , figure 2 , distance 9 .

derived from tables 22, 28, and 29. At the foot of the last column are given the ratios from 1 to 546,9 to 546,12 to 546 , and 20 to 546 days. The values increase rapidly during the earlier stage, but after twelve days very slowly, as the ratios show.

The breadth is, at birth, largest in the basal and smallest in the apical turn. Very soon, however (six days), the reverse 
relation appears, and the breadth increases from the base to turn III relatively rapidly, but from turn III to IV slowly. In table 33 the ratios are given in a condensed form. The radial breadth of the outer pillar cells as given by Retzius ('84) are as follows (table 34.)

TABLE 33-Condensed

Ratios of the radial basal breadth of the outer pillar cells-on age-according to turns of cochlea

\begin{tabular}{r|c|c|c|c}
\hline \multirow{2}{*}{ AGE } & \multirow{2}{*}{ BODY WEIGHT } & \multicolumn{3}{|c}{ RATIOS BET WEEN TURNA } \\
\cline { 3 - 5 } & & I-II & I-III & I-IV \\
\hline days & grams & & & \\
1 & 5 & $1: 0.9$ & $1: 0.8$ & $1: 0.8$ \\
8 & 11 & $\vdots 1.1$ & $\vdots 1.2$ & $\vdots 1.3$ \\
18 & 21 & $\vdots 1.2$ & $\vdots 1.4$ & $: 1.4$ \\
213 & 138 & $: 1.2$ & $: 1.4$ & $: 1.4$ \\
\hline
\end{tabular}

TABLE 34

Radial basal breadth of the outer pillar cells in $\mu$ (Retzius)

\begin{tabular}{|c|c|c|c|c|c|c|c|c|}
\hline \multicolumn{5}{|c|}{ RABBIT } & \multicolumn{4}{|c|}{ CAT } \\
\hline$\triangle G E$ & $\begin{array}{c}\text { Basal } \\
\text { turn }\end{array}$ & $\mid \begin{array}{l}\text { Middle } \\
\text { turn }\end{array}$ & Apical & $\begin{array}{c}\text { Average } \\
\text { turn }\end{array}$ & $\begin{array}{c}\text { Basal } \\
\text { turn }\end{array}$ & $\left|\begin{array}{c}\text { Middle } \\
\text { turn }\end{array}\right|$ & \begin{tabular}{|} 
Apical \\
turn
\end{tabular} & $\begin{array}{l}\text { Average } \\
\text { turn }\end{array}$ \\
\hline days & & & & & & & & \\
\hline New-born & 21 & 22 & 23 & 22 & 36 & 30 & 30 & 32 \\
\hline 3 & 30 & 40 & 30 & 33 & - & - & - & - \\
\hline 3 & - & - & - & - & 36 & 30 & - & - \\
\hline 7 & 65 & 66 & 60 & 64 & 36 & 54 & 36 & 42 \\
\hline 10 & 52 & 60 & 69 & 60 & - & - & 一 & - \\
\hline 11 & - & - & - & - & 50 & 60 & 18 & 43 \\
\hline 14 & 57 & 80 & 80 & 72 & - & - & - & - \\
\hline 30 & - & - & - & 一 & - & 60 & 60 & - \\
\hline
\end{tabular}

This table shows that the breadth of the outer pillar cell increases in the rabbit and the cat continuously from birth to old age, as I have found in the rat. Also the value is generally smallest in the base, largest in the apex. though there are some exreptions. The main differences between the results of Retzius and mine is that the values in the rabbit are larger than in the rat. This is probably due to the differences in the size of the animals. 
6. The radial distance between the habenula perforata and the outer border of the foot of the outer pillar cell. The determination of this distance is deemed necessary not only as a datum on growth in general, but also for its bearing on the difficult question of the shifting of the outer pillar cell, to be discussed later. On the other hand, this distance is identical with the radial length of the zona arcuata of the membrana basilaris (table 7. inner zone).

In table 35 (chart 14) are given the values for the radial distance between the habenula perforata and the outer corner of the outer pillar cell at base. At the foot of each column are given the ratios at 1 to 12,1 to 20,1 to 546 , and 20 to 546 days. As table 35 shows, the distance increases continuously from birth to old age, rapidly up to twelve days, but later gradually. Up to three days the distance is slightly larger in the lower turns, but after this age the relation is reversed, and this persists through life.

The increasing ratio of the distance for each turn according to age is smallest in turn I and largest in turn IV. The ratios for the condensed data are given in table 36 . While the ratio at birth is the same in each turn, 1:1.0, that of turn I to II is smallest for every condensed age. Also it is to be seen that the increase of the ratio in turn I to II is smallest and that in turns I to IV is largest. In Retzius' work ('84) we find the following values for this distance (table 37 ).

Table 37 shows that in the rabbit the growth changes are similar to those in the rat, though the absolute values are somewhat larger. As in preceding determinations, the values for the cat do not stand in the same relation as those for the rabbit, but indicate precocity. Some corresponding observations by Hensen, Böttcher, and others will be presented later.

\%. The greatest height of the greater epithelial ridge (der grosse Epithelwulst (Bottcher) s. Organon Kollikeri) resp. of the inner supporting cells $(f i g .4, G)$. The so-called greater epithelial ridge is a prominence formed by high cylindrical pseudostratified cells. It is situated axialward on the tympanic wall and continued outward to the lesser epithelial ridge. About the fate of this ridge there were various divergent opinions among the older 
authors. Now, the view of Böttcher ('69) is generally accepted. This large prominence vanishes during development, and instead of it a deep) and wide furrow lined with low epithelium appears. These epithelial cells become peripherally higher and finally lean

TABLE 35

Radial distance between habenula perforata and the outer corner of the outer pillar cells at base-on age (chart 14 ). For the average values see the third column in table 9

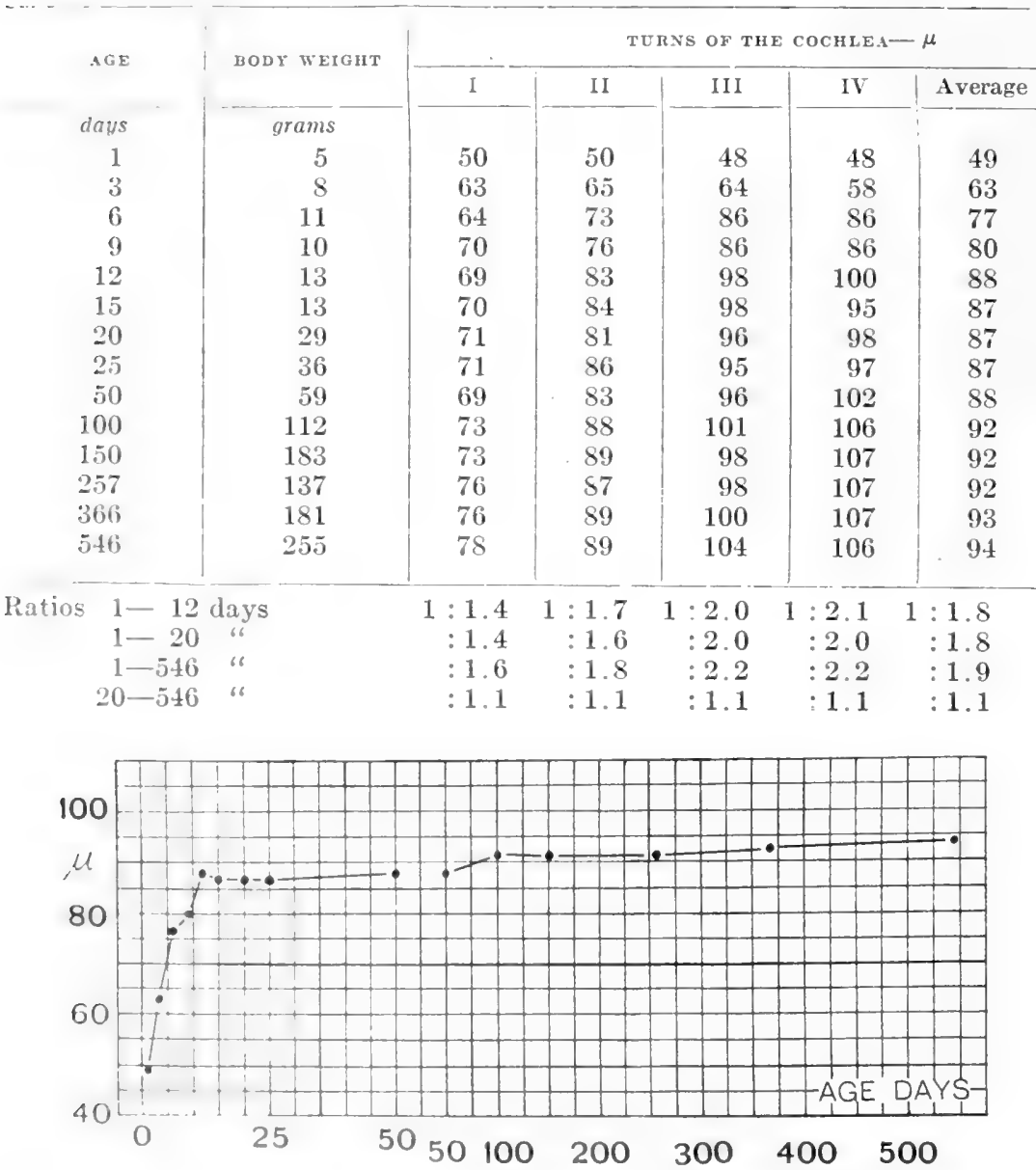

Chart it The radial distance between the habenula perforata and the outer corner of the outer pillar cell at base, table 35 , figure 2 , distance 5 . 
on the inner supporting cells, which are termed 'Grenzzellen' by Held ('02). The latter belong, of course, to this ridge, since the inner hair cell marks the outmost row in the ridge. The 'Grenzzellen' of Held, however, are different from other high cylindrical cells in the ridge, as they have a very intimate relation with the 'Phalangenzellen' of Held, stand with their bases just

TABLE 36-Condensed

Ratios of the radial distance between the habenula perforata and the outer corner of the outer pillar cells at base-on age

\begin{tabular}{|c|c|c|c|c|}
\hline \multirow{2}{*}{$A V E R A G E A G E$} & \multirow{2}{*}{$\begin{array}{c}\text { AVERAGE BODY } \\
\text { WEIGHT }\end{array}$} & \multicolumn{3}{|c|}{ RATIOS BETWEEN TURNB } \\
\hline & & I-II & I-III & $I-I V$ \\
\hline days & grams & & & \\
\hline 1 & 5 & $1: 1.0$ & $1: 1.0$ & $1: 1.0$ \\
\hline 8 & 11 & $: 1.1$ & $: 1.3$ & $: 1.2$ \\
\hline 18 & 21 & $: 1.2$ & $: 1.4$ & $: 1.4$ \\
\hline 213 & 138 & $: 1.2$ & $: 1.3$ & $: 1.4$ \\
\hline
\end{tabular}

TABLE 37

Radial distance between habenula perforata and the outer corner of the outer pillar cells at base-in $\mu$ (Retzius)

\begin{tabular}{|c|c|c|c|c|c|c|c|c|}
\hline \multicolumn{5}{|c|}{ RABBIT } & \multicolumn{4}{|c|}{ CAT } \\
\hline Age & $\begin{array}{c}\text { Basal } \\
\text { turn }\end{array}$ & $\left|\begin{array}{c}\text { Middle } \\
\text { turn }\end{array}\right|$ & $\begin{array}{c}\text { Apical } \\
\text { turn }\end{array}$ & $\begin{array}{c}\text { Average } \\
\text { turn }\end{array}$ & $\begin{array}{c}\text { Basal } \\
\text { turn }\end{array}$ & $\left|\begin{array}{c}\text { Middle } \\
\text { turn }\end{array}\right|$ & $\begin{array}{c}\text { Apical } \\
\text { turn }\end{array}$ & $\begin{array}{c}\text { Average } \\
\text { turn }\end{array}$ \\
\hline days & & & & & & & & \\
\hline New-born & 75 & 80 & 75 & 77 & 105 & 105 & 120 & 110 \\
\hline 2 & 80 & 90 & 100 & 90 & - & - & - & - \\
\hline 3 & - & - & - & - & 80 & 120 & - & - \\
\hline 7 & 100 & 115 & 107 & 107 & 78 & 110 & 120 & 103 \\
\hline 10 & 100 & 120 & 129 & 116 & - & - & - & - \\
\hline 11 & - & - & - & - & 120 & 129 & 108 & 119 \\
\hline 14 & 106 & 140 & 129 & 125 & - & - & - & - \\
\hline 30 & - & - & - & - & 85 & 120 & 120 & 108 \\
\hline
\end{tabular}

outward from the habenula perforata and serve to support the inner hair cell as Deiters' cells support the outer hair cells.

Thus the greater ridge includes in its prominence three kinds of cells, the high cylindrical cells, the 'Grenzzellen' of Held and the inner hair cell.

The greatest height of this ridge is not situated at a fixed point, but first lies somewhat outward from the middle part and 
after the furrow appears, passes outward towards the inner supporting cells. Thus the greater ridge decreases in thickness from birth to nine days of age, then increases gradually to twenty days. Ifter twenty-five days the values diminish again very slowly but continuously.

In table 38 (charts 15 and 16) are given the values of the greatest height of the greater epithelial ridge from the basilar membrane

TABLE 38

Greatest height of the greater epithelial ridge (resp. of the inner supporting cells) on age (charts 15 and 16)

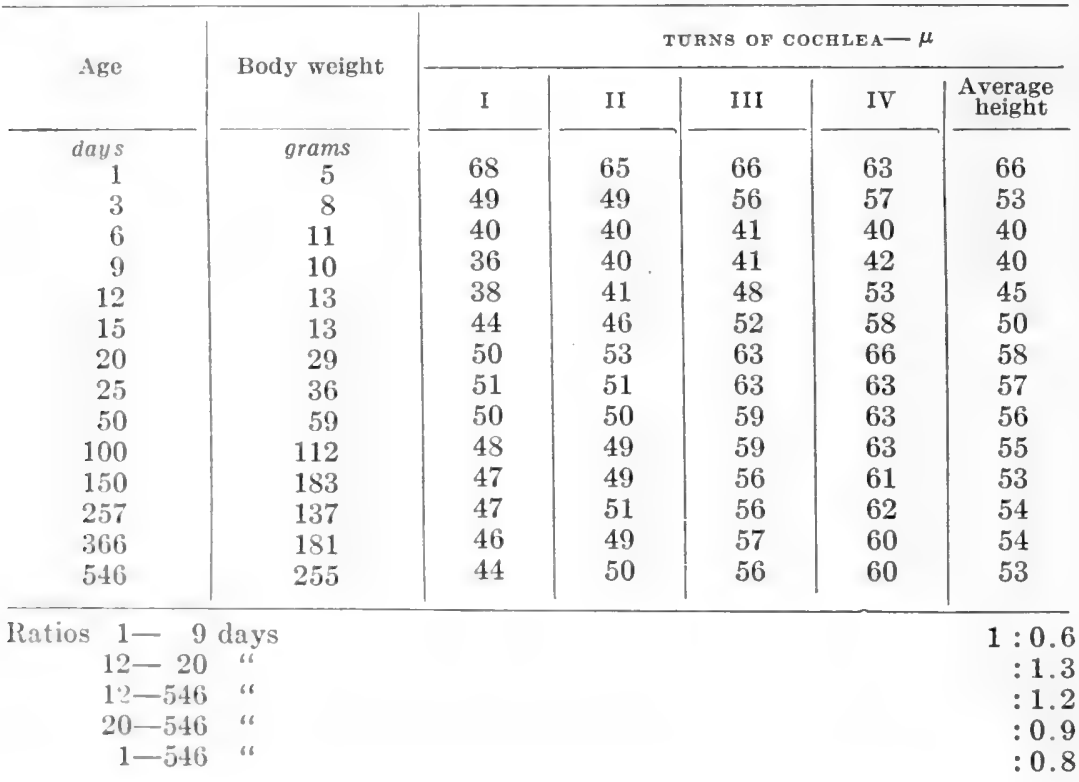

through the summit of the supporting cells, according to age. At the bottom of the last column is given the ratio at 1 to 9 , 1 to 546,12 to 20,12 to 546 , and 20 to 546 days of age.

The values in turn I are at birth the largest, but at three days the relation is reversed and remains so in the later age (moup). Tablo 39 show this relation from the condensed data.

Retzins ( $S 4$ ) gives in the rabbit and eat the following values (table 40). 
In the rabbit the values decrease from birth till ten days, then increase; therefore, they agree in general with my results

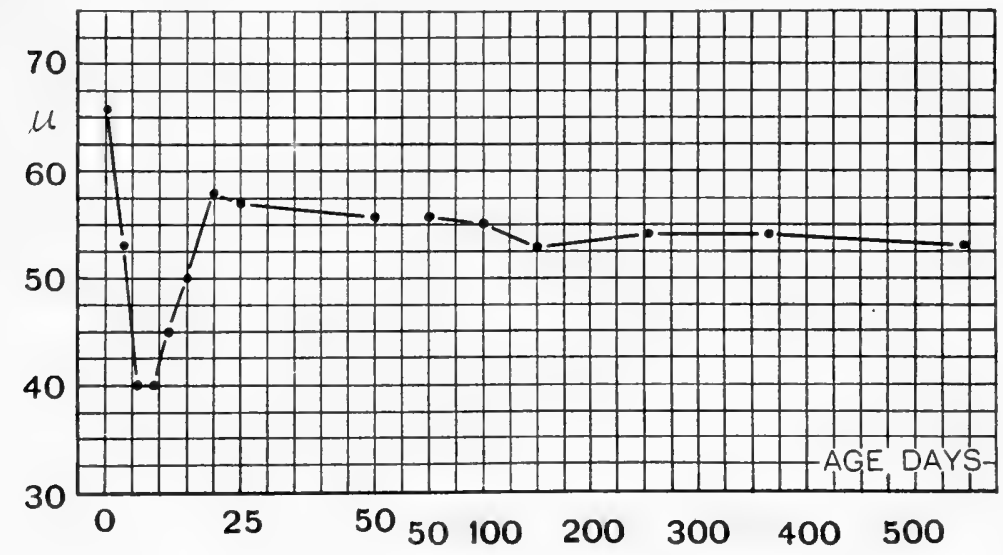

Chart 15 The greatest height of the greater epithelial ridge (resp. of the inner supporting cells) table 38 , figures 4 to 12 .

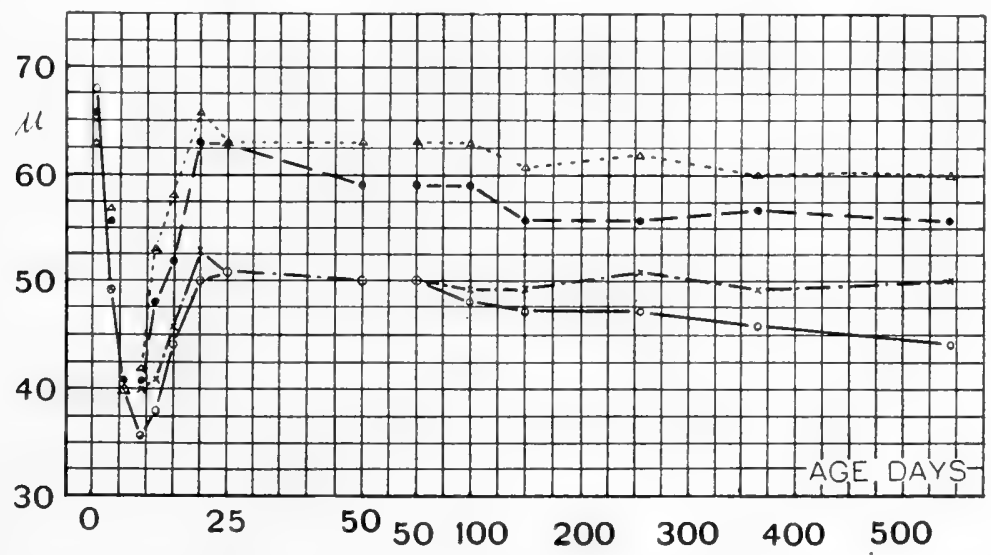

Chart 16 The greatest height of the greater epithelial ridge (resp. of the inner supporting cells) arranged according to the turns of the cochlea, table 38 , figures 4 to 12 .

on the rat, while in the cat they diminish from birth till thirty days though irregularly.

The absolute values are greater for the rabbit than for the rat during the earlier stage, but afterwards they arc similar. 
In the cat the early data give values similar to those for the rat, but the later values are lower.

Böttcher's observations ('69) on the cat, calf, and sheep also give larger values than mine. In the cat the greater ridge has an arerage height of $75 \mu$ and in both the others of $90 \mu$. Therefore, even in the same animal (cat) there are large differences in the data presented by different authors.

TABLE 39-Condensed

Ratois of the greatest height of the grealer epithelial ridge (resp. of the inner supporting cells) according to the turns of the cochlea-on age

\begin{tabular}{|c|c|c|c|c|}
\hline \multirow{2}{*}{ Average age } & \multirow{2}{*}{$\begin{array}{c}\text { Average body } \\
\text { weight }\end{array}$} & \multicolumn{3}{|c|}{ RATIOS BETWEEB TURNS } \\
\hline & & I-II & I-III & I-IV \\
\hline days & grams & & & \\
\hline 1 & 5 & $1: 1.0$ & $1: 1.0$ & $1: 0.9$ \\
\hline $\mathrm{s}$ & 11 & $: 1.0$ & $: 1.1$ & $: 1.2$ \\
\hline 18 & 21 & $: 1.1$ & $: 1.2$ & $: 1.3$ \\
\hline 213 & 138 & $: 1.0$ & $: 1.2$ & $: 1.3$ \\
\hline
\end{tabular}

TABLE 40

Greulest height of the greater epithelial ridge measured through the inner supporting cells, in $\mu$ (Retzius)

\begin{tabular}{|c|c|c|c|c|c|c|c|c|}
\hline \multicolumn{5}{|c|}{ RABBIT } & \multicolumn{4}{|c|}{ CAT } \\
\hline $\begin{array}{l}\text { Age } \\
\text { days }\end{array}$ & $\begin{array}{c}\text { Basal } \\
\text { turn }\end{array}$ & $\begin{array}{c}\text { Middle } \\
\text { turn }\end{array}$ & $\begin{array}{c}\text { Apical } \\
\text { turn }\end{array}$ & $\begin{array}{l}\text { Average } \\
\text { turn }\end{array}$ & $\begin{array}{l}\text { Basal } \\
\text { turn }\end{array}$ & $\begin{array}{c}\text { Middle } \\
\text { turn }\end{array}$ & $\begin{array}{c}\text { Apical } \\
\text { turn? }\end{array}$ & $\begin{array}{c}\text { Average } \\
\text { turn }\end{array}$ \\
\hline New-born & 78 & 99 & 90 & 89 & 45 & 75 & 68 & 63 \\
\hline 2 & 60 & 90 & 90 & 80 & - & - & - & - \\
\hline 3 & - & - & - & - & 40 & 84 & - & - \\
\hline 7 & 51 & 68 & 63 & 61 & 40 & 54 & 63 & 52 \\
\hline 10 & 36 & 54 & 56 & 49 & - & - & - & - \\
\hline 11 & - & - & - & - & 50 & 58 & 66 & 58 \\
\hline 14 & 51 & 51 & 51 & 51 & - & - & - & - \\
\hline 30 & 一 & - & - & - & 30 & 45 & 45 & 40 \\
\hline
\end{tabular}

Gottstein ('72) thinks that the greater epithelial ridge does not diminish its height for some time after birth, but through the outward development of the labium tympanicum, and in addition to this through the growth of the labium vestibulare, the sulcus spiralis internus arises. He does not give measurements. 
His idea was strongly opposed by Böttcher ('72) and my results are also opposed to Gottstein's view.

8. The radial distance between the labium vestibulare and the habenula perforata. The purpose of this measurement is to determine how the habenula perforata stands in relation to its surroundings during the development of the cochlea. The measurements of this distance is difficult. During the earlier stages, the labium vestibulare is quite undeveloped, especially in the upper turns. At birth we see on the inner surface of the greater epithelial ridge a small prominence under which the epithelial cells are short and pressed together so that the nuclei seem to be arranged in several rows (fig. 4). This appearance is due to the invasion of the subjacent connective tissue into the epithelium.

Thus the vestibular lip arises. We do not see a furrow at this time and cannot use the top of the furrow as a point for measuring as did Hensen ('63) in the ox and Böttcher ('69); in the embryo cat). To the measure the distance between the insertion of Reissner's membrane and the habenula perforata has no meaning for my purpose, because the length of the limbus laminae spiralis changes with age.

Thus I have measured the distance between the small epithelial prominence on the axial side of the greater ridge, corresponding to the edge of the labium vestibulare, and the habenula perforata.

In table 41 (charts 17 and 18) are given the values of the radial distance between the labium vestibulare and the habenula perforata. At the foot of the last column are given the ratios from 1 to 546, 9 to 546, and 20 to 546 days. As we see, the values are a little bit smaller at the earlier stage. After nine days they are almost the same in every stage. The small differences at the earlier and later stages are probably due to the retarded development of the labium vestibulare.

When we consider the values for this distance in each turn, it is evident that these increase from base to apex. In the condensed table 42 this relation is shown.

Hensen ('63) finds that the distance from the top of the furrow to the habenula perforata is in the fetal calf and in the ox the 
-imle, 2,5) . He considers the holes of the habenula as a "punctum fixum.' Böttcher ('69, '72) agrees with Hensen and gets in the cat embryo and the adult cat the following values (table 43).

TABLE 41

Radial distance between the labium vestibulare and the habenula perforata-on age (charts 17 and 18)

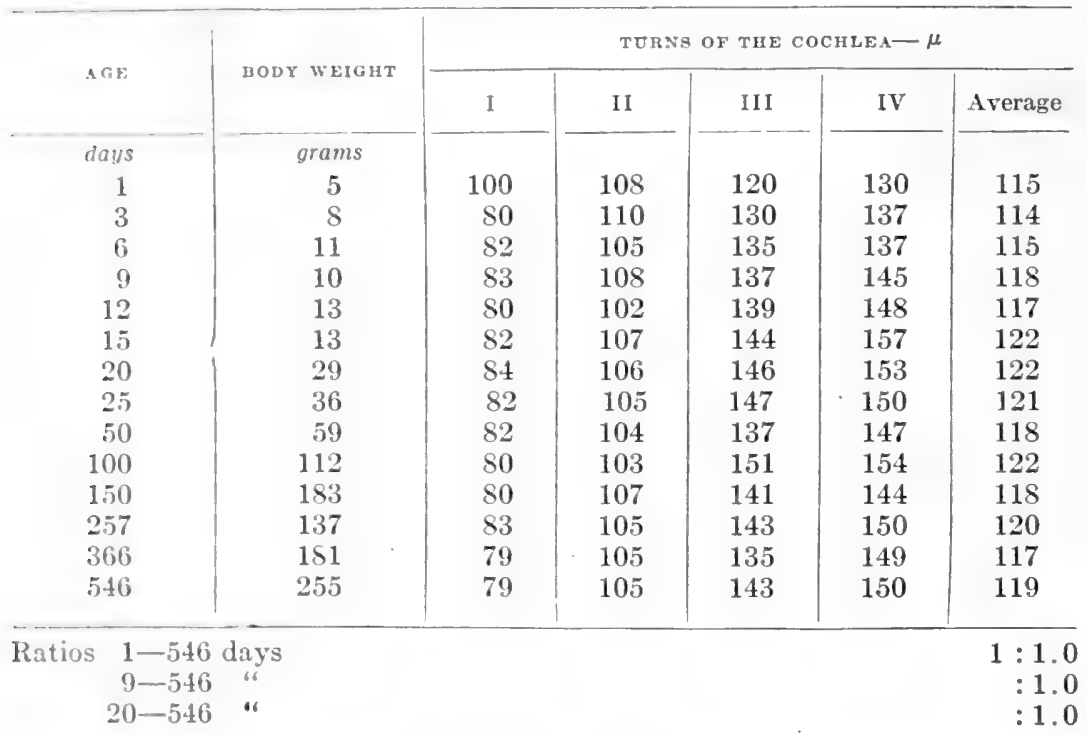

TABLE 42-Condensed

Ratios of the radial distance between the labium vestibulare and the habenula perforata according to turns of the cochlea

\begin{tabular}{|c|c|c|c|c|}
\hline \multirow{2}{*}{ AVERAGF AGE } & \multirow{2}{*}{$\begin{array}{l}\text { AVERAGE BODY } \\
\text { WEICBHT }\end{array}$} & \multicolumn{3}{|c|}{ RATIOS BETWEEN TURNS } \\
\hline & & I-II & I-II I & I-IV \\
\hline dalss & grams & & & \\
\hline $\begin{array}{r}1 \\
5 \\
141\end{array}$ & $\begin{array}{r}5 \\
10 \\
93\end{array}$ & $\begin{aligned} 1 & : 1.1 \\
& : 1.3 \\
& : 1.3\end{aligned}$ & $\begin{aligned} 1 & : 1.2 \\
& : 1.6 \\
& : 1.7\end{aligned}$ & $\begin{aligned} 1 & : 1.3 \\
& : 1.8 \\
& : 1.8\end{aligned}$ \\
\hline
\end{tabular}

Comparing the results of both Hensen and Böttcher with my own, the ralues obtained by Hensen are large, as would be expected in the larger animal. The eat and rat however, give similar values. We conclude, therefore, that broadly speak- 
ing, the habenula perforata is to be considered as a 'punctum fixum,' at least after birth.

9. The radial distance be'ween the labium vestibulare and the inner edge of the head of the inner pillar cell. To measure the

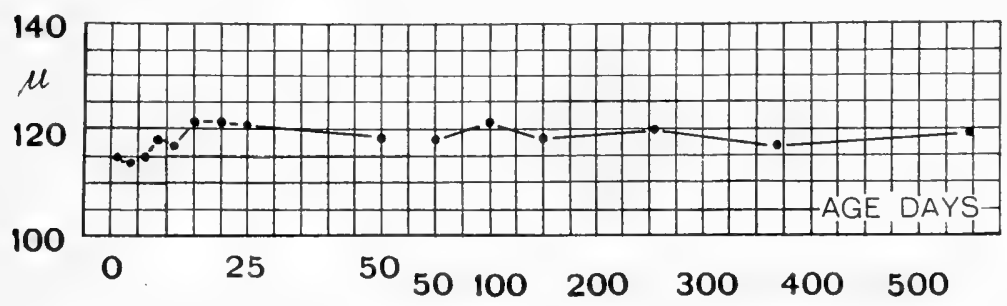

Chart 17 The radial distance between labium vestibulare and the habenula perforata, table 41, figure 10 .

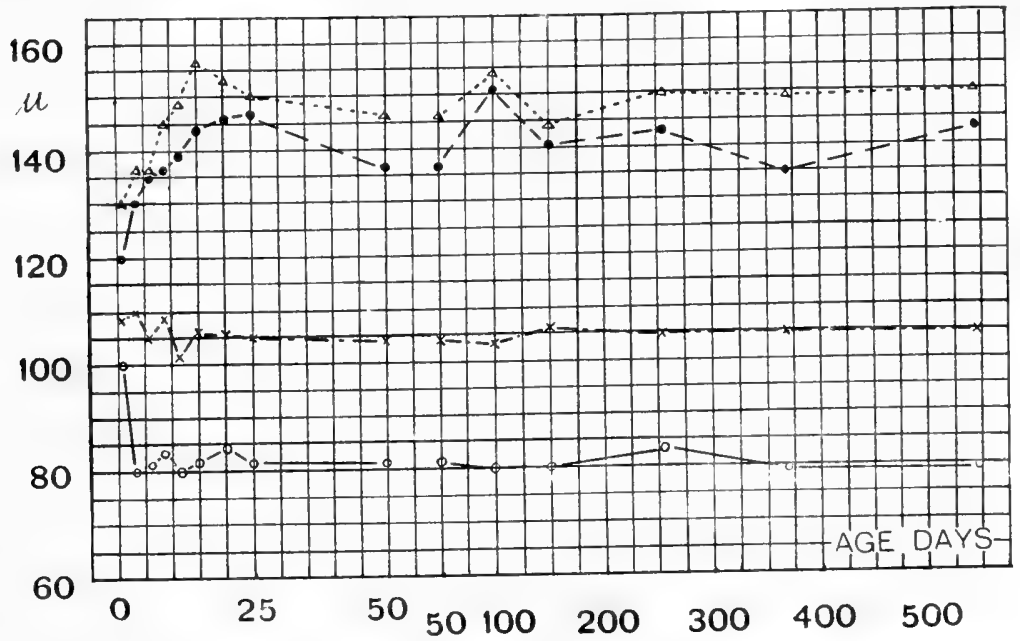

Chart 18 The radial distance between labium vestibulare and the habenula perforata according to the turns of the cochlea, table 41 .

radial breadth from the labium vestibulare to the inner edge of the head of the inner pillar cell, I have used, at earlier stages, as in the preceding chapter, the same small prominence as an inner fixed point (fig. 4). In table 44 (chart 19) are given the values for this radial distance according to age. At the bottom of the last column are given the ratios from 1 to 9,1 to 546 
TABLE 43

Dislance between labium vestibulare and habenula perforata in $\mu$ (Böttcher)

\begin{tabular}{|c|c|c|c|c|c|}
\hline $\begin{array}{l}\text { TLACE OF } \\
\text { MVAUREMENT }\end{array}$ & $\mid \begin{array}{c}\text { CAT EMBRYO } 9 \text { CM. } \\
\text { LONG }\end{array}$ & $\begin{array}{l}\text { CAT EMBRYO } 11.5 \\
\text { CM. LONG }\end{array}$ & $\operatorname{cAT}$ & $\begin{array}{c}\text { THREE DAXS } \\
\text { OLD }\end{array}$ & ADULT CAT \\
\hline I turn & 120 & 120 & & 120 & 100 \\
\hline II turn & 130 & 130 & & 130 & 110 \\
\hline III turn & 150 & 140 & & 140 & 130 \\
\hline
\end{tabular}

TABLE 44

Rutial distance between the labium vestibulare and the inner edge of the head of the inner pillar cell-on age (chart 19)

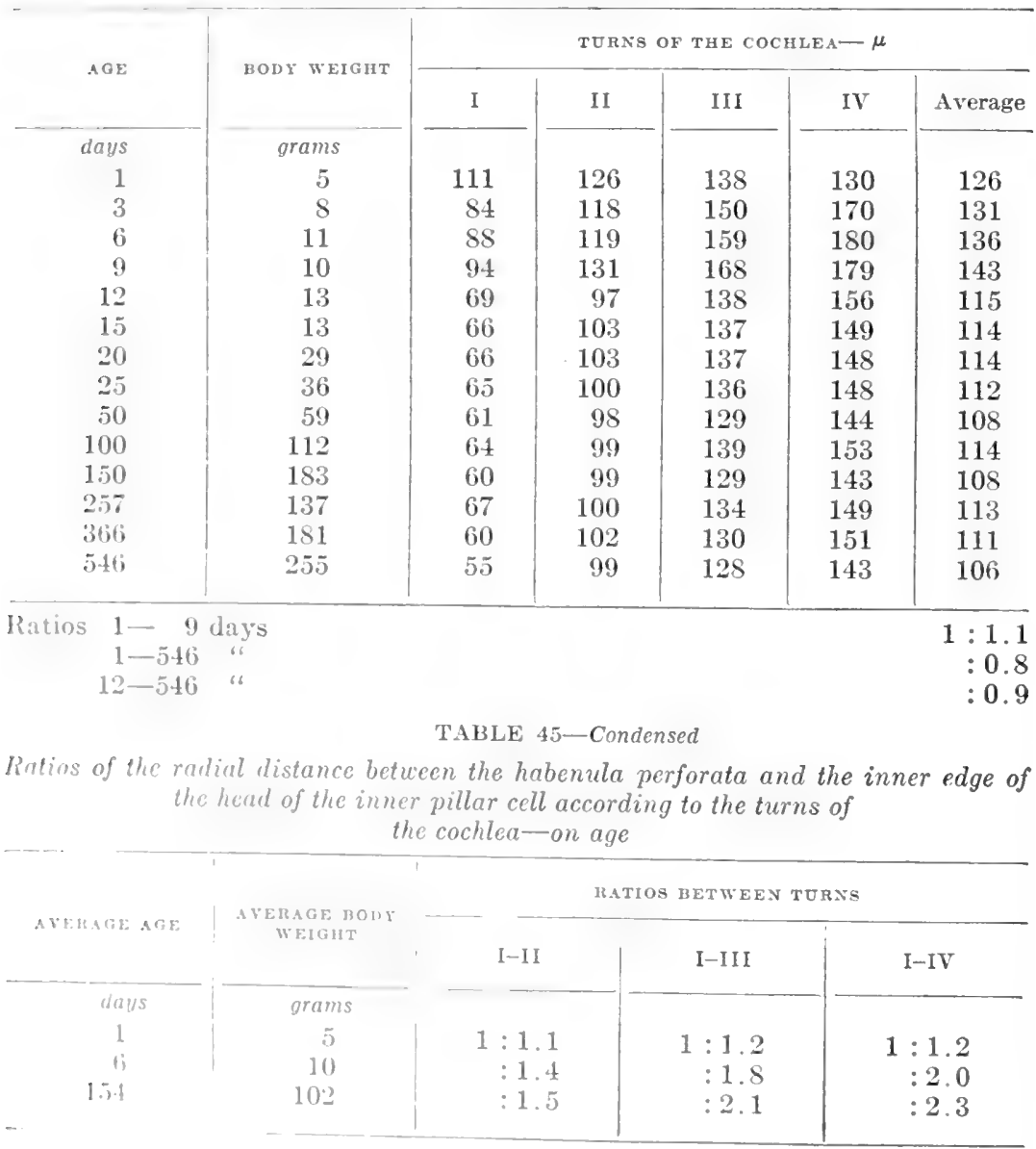


and 12 to 546 days of age. As the table shows, the values increase in general from birth to nine days; therefore, the surface of the greater epithelial thickening from the labium vestibulare to its outer boundary becomes, during the earlier stage, wider and wider, then decreases sharply, and after that continuously but slowly. This sudden diminishing of the distance has a very intimate relation with the change in the form of the papilla spiralis at this stage of development.

This point I will discuss later.

That the values increase from the base to the apex first rapidly and later less rapidly, is also to be seen here. Table 45 shows this relation clearly. It is remarkable, however, that the ratio becomes

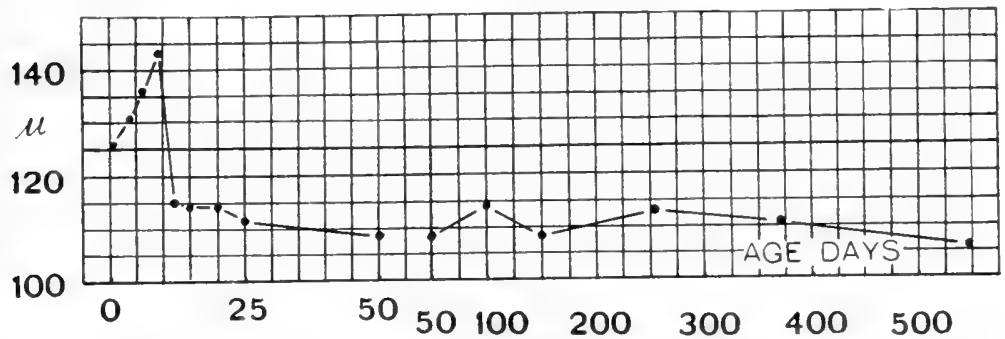

Chart 19 The radial distance between the labium vestibulare and the inner edge of the head of the inner pillar cell, table 44 .

at each turn larger with age, although the absolute value is after nine days generally smaller than at the preceding age. Therefore, we see that the diminution of the distance after nine days is largest in the basal turn and smallest in the apical.

Hensen ('63) asserts that there is a movement axialward of the organ of Corti (resp. the head of the pillar cell), but gives no measurements. Neither Böttcher nor Retzius measured this distance. Prentiss ('13, page 445) states that "the distance between the inner angle of the cochlea and the pillar cells, two definite points, may be measured with considerable accuracy and shows no important change in the position of the spiral organ from the $13 \mathrm{~cm}$. to the $18.5 \mathrm{~cm}$. stage, nor later in the new born animal" (pig). But he also does not record his measurements. 
Irardesty ('15, p. 54) says "that the space occupied by the wilth of the greater epithelial ridge increases throughout the coils of the cochlea up to pigs of 15 to $16 \mathrm{~cm}$., and thereafter it begins to decrease very perceptibly." He measured the width "from the membrana propria of the epithelium of the greater ridge, at its most axial extension under Huschke's teeth, to the apical end of the inner hair cell of the spiral organ." The

TABLE 46

Vertical distance from the membrana basilaris to the surface of the pillar cells-on age (chart 20)

\begin{tabular}{|c|c|c|c|c|c|c|}
\hline \multirow{2}{*}{$A G B$} & \multirow{2}{*}{ BODY WEIGHT } & \multicolumn{5}{|c|}{ TURNA OF THE COCHLEA $-\mu$} \\
\hline & & I & II & III & IV & Average \\
\hline days & grams & & & & & \\
\hline 1 & 5 & 35 & 36 & 39 & 36 & 37 \\
\hline 3 & 8 & 30 & 29 & 29 & 29 & 29 \\
\hline 6 & 11 & 29 & 32 & 31 & 29 & 30 \\
\hline 9 & 10 & 32 & 33 & 35 & 36 & 34 \\
\hline 12 & 13 & 41 & 45 & 50 & 52 & 47 \\
\hline 15 & 13 & 44 & 48 & 53 & 57 & 51 \\
\hline 20 & 29 & 53 & 57 & 67 & 71 & 62 \\
\hline 25 & 36 & 55 & 56 & 66 & 68 & 61 \\
\hline 50 & 59 & 53 & 55 & 67 & 68 & 61 \\
\hline 100 & 112 & 53 & 54 & 64 & 67 & 60 \\
\hline 150 & 183 & 52 & 54 & 63 & 66 & 59 \\
\hline 257 & 137 & 53 & 56 & 63 & 69 & 60 \\
\hline 366 & 181 & 51 & 56 & 66 & 67 & 60 \\
\hline 546 & 255 & 52 & 55 & 62 & 66 & 59 \\
\hline Ratios & $\begin{array}{l}\text { lays } \\
\text { " } \\
\text { " } \\
\text { " }\end{array}$ & & & & & $\begin{array}{r}1.1 .3 \\
: 1.7 \\
: 1.6 \\
\vdots 13 \\
: 1.0\end{array}$ \\
\hline
\end{tabular}

mothol of medsurement differs from mine, so the results cannot be compared directly. While the distance in the rat increases to nine days of age, that in the pig decreases perceptibly in fetuses more than $16 \mathrm{~cm}$. long.

Acording to Hardesty ('15, p. 55). "the decrease in the I and III half turns may be as much as one-third of the width of the greater ridge when at its maximum size and activity." Int "after the tectorial membrane is about completely produced, 
and while the spiral organ is enlarging, the inner hair cells, and therefore the organ, may be moved in the apical coil of the cochlea axialward a distance of about half the maximum width of the greater epithelial ridge,......."

The differences of the values in the rat at 9 and 546 days are in the basal and apical turn about the same, 39 and $36 \mu$, respectively (table 44). Thus while the inner edge of the inner pillar cell approaches at 546 days in the basal turn by as much as 41 per cent of the distance present at nine days, that in the

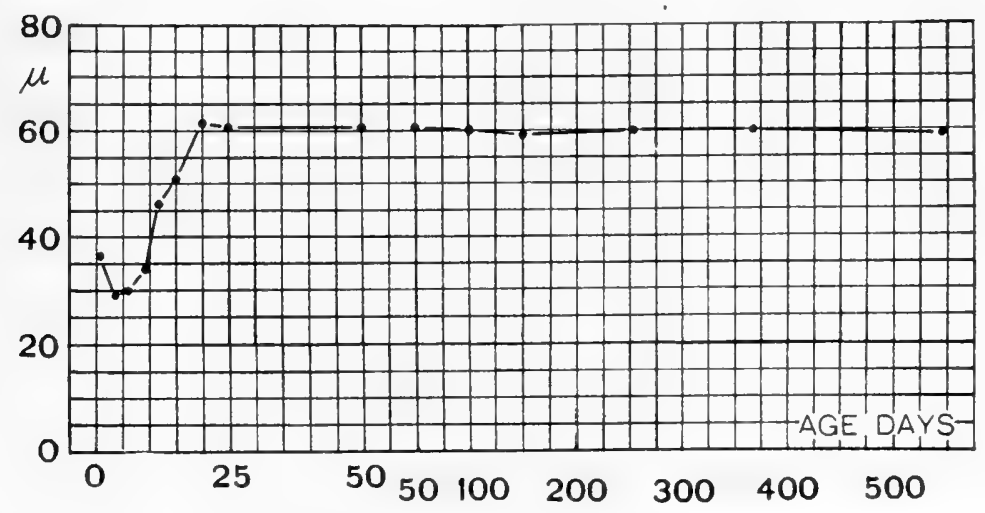

Chart 20 The vertical distance from the membrana basilaris to the surface of the pillar cells, table 46, figure 1, 1-1.

apex moves only 20 per cent inward in old age. This result is the reverse of that obtained in the pig by Hardesty. The reason for this contradiction I will discuss later.

10. The vertical distance from the membrane basilaris to the summit of the pillar cells. The method of getting the vertical distance from the membrana basilaris to the surface of the pillar cells is shown in figure 1, line 1-1. In table 46 (chart 20) are given the values thus obtained. At the foot of the last column are given the ratios of this distance at 1 to 12,1 to 20 , 1 to 546,12 to 546 , and 20 to 546 days. The average value is relatively large at birth, it diminishes at three days, then increases more rapidly to twenty days. After this it decreases very slowly. The maximum height of the arch of Corti is at twenty days of 
age. Comparing the values for the height in each turn, we find that from nine days they increase from the basal to the apical turn. This relation can be easily seen in table 47 .

Retzius ('St) gives in the rabbit and cat the following values (table 48).

TABLE 47-Condensed

Ratios of the tertical distance from the membrana basilaris to the surface of the

\begin{tabular}{|c|c|c|c|c|}
\hline \multirow{2}{*}{ AVERAGEAGE } & \multirow{2}{*}{$\begin{array}{c}\text { AVERAGE BODY } \\
\text { WEIGHT }\end{array}$} & \multicolumn{3}{|c|}{ RATIOS BETWEEN TURNS } \\
\hline & & I-II & I-III & $\mathrm{I}-\mathrm{IV}$ \\
\hline days & grams & & & \\
\hline 1 & 5 & $1: 1.0$ & $1: 1.1$ & $1: 1.0$ \\
\hline 1 & 11 & $: 1.1$ & $: 1.1$ & $: 1.1$ \\
\hline $1 S$ & 21 & $: 1.1$ & $: 1.2$ & $: 1.3$ \\
\hline 213 & 138 & $: 1.0$ & $: 1.2$ & $: 1.3$ \\
\hline
\end{tabular}

TABLE 48 .

I'ertical distance from the membrana basilaris to the summit of the pillar cells

\begin{tabular}{|c|c|c|c|c|c|c|c|c|}
\hline \multirow[b]{2}{*}{ Age } & \multicolumn{4}{|c|}{ RABBIT } & \multicolumn{4}{|c|}{$\mathrm{CAT}$} \\
\hline & $\begin{array}{c}\text { Basal } \\
\text { turn }\end{array}$ & $\left|\begin{array}{c}\text { Middle } \\
\text { turn }\end{array}\right|$ & $\left|\begin{array}{c}\text { Apical } \\
\text { turn }\end{array}\right|$ & Average " & $\begin{array}{c}\text { Basal } \\
\text { turn }\end{array}$ & $\begin{array}{c}\text { Middle } \\
\text { turn }\end{array}$ & $\begin{array}{c}\text { Apical } \\
\text { turn }\end{array}$ & Average \\
\hline dnys & & & & & & & & \\
\hline Sew-born & $4 i$ & 70 & 61 & 5̃? & 45 & 60 & 48 & 51 \\
\hline 2 & 45 & 69 & 40 & 51 & 一 & - & 一 & 一 \\
\hline$: 3$ & - & - & - & 一 & 39 & 60 & - & - \\
\hline 7 & 46 & 60 & 60 & 55 & 4.5 & 47 & 50 & 44 \\
\hline 10 & 45 & 69 & 69 & 61 & 一 & - & 一 & 一 \\
\hline 11 & 一 & - & - & - & 50 & 60 & 42 & 51 \\
\hline 14 & 45 & 57 & 60 & 56 & - & 一 & 一 & - \\
\hline$: 30$ & 一 & 一 & - & 一 & 33 & 51 & 57 & 47 \\
\hline
\end{tabular}

Table 4 s shows that the height of the arch of Corti in the rabbit approximates that in the rat, though there are considerable differences in the earlier stages. In the former the arch of Corti dremopis after birth only a little, and is therefore more prerocious than in the rat. In the cat the same relation is to be soen, hut the absolute values in the latter animal are smaller than in cither the rabbit or the rat. 
11. The greatest height of the tunnel of Corti. Some authors have reported in several animals the appearance of the tunnel of Corti just after birth, or even in later intrauterine life. In the rat, however, it first appears through all the turns after the ninth day. Sometimes we see it at nine days in the lower turn, though not yet in the upper. The method of measuring the height is shown in figure 1 , line $1-1^{\prime}$. Table 49 (charts 21 and 22) gives the values for the greatest height of the tunnel of Corti. At the foot of the last column are given the ratios from 12 to 25,12 to 546 , and 25 to 546 days.

As the table shows, the space appears in all the turns at twelve days and has considerable height. This increases to twenty-five days, than decreases very slowly. This increase and decrease correspond to the changes in the distance of the summit of the pillar cells from the basilar membrane.

When we consider the height in each coil of the cochlea, we find the value increases from the base to the apex, first rapidly then slowly. In table 50 this relation is clearly shown.

Retzius ('84) gives the values for the adult rabbit, man and cat (one month) as follows (table 51).

According to this table, the average height is in the adult man, cat, and rabbit somewhat less than in the rat.

12. The height of the papilla spiralis at the third series of the outer hair cells. The measurements were taken along the line $2-2$ shown in figure 1 . The growth of this vertical height depends not only upon the increase of the length of the corresponding outer hair cell, but chiefly upon the development of the Deiters' cells, especially of the outermost row, and of the sustentacular cells of Hensen.

In table 52 (charts 23 and 24), are given the values for this vertical height of the papilla spiralis at the third series of the outer hair cells according to age. At the bottom of the last column are the ratios at 1 to 12,1 to 20,1 to 546 , and 20 to 546 days. The heights decrease at three days, but increase from nine to twelve days very rapidly, nearly doubling their minimal values, and reach a maximum at tiventy days. After that time they decrease very gradually to the end of the record. There- 
TABLE 49

Greatcst height of the tunnel of Corti-on age (charts 21 and 22)

\begin{tabular}{|c|c|c|c|c|c|c|}
\hline \multirow{2}{*}{$\operatorname{sGE}$} & \multirow{2}{*}{ BODY WEIGHT } & \multicolumn{5}{|c|}{ TURNS OF THE COCHLEA- $\mu$} \\
\hline & & I & II & III & IV & Average \\
\hline days & grams & & & & & \\
\hline 1 & 5 & - & - & - & - & - \\
\hline 3 & 8 & - & - & - & - & 一 \\
\hline 6 & 11 & - & - & - & - & - \\
\hline $9^{1}$ & 10 & - & - & - & - & - \\
\hline 12 & 13 & 29 & 33 & 39 & 37 & 35 \\
\hline 15 & 13 & 31 & 34 & 42 & 46 & 38 \\
\hline 20 & 29 & 37 & 42 & 52 & 56 & 47 \\
\hline 25 & 36 & 39 & 41 & 54 & 56 & 48 \\
\hline 50 & 59 & 38 & 41 & 53 & 57 & 47 \\
\hline 100 & 112 & 38 & 43 & 51 & 56 & 47 \\
\hline 150 & 183 & 37 & 41 & 49 & 54 & 45 \\
\hline 257 & 137 & 38 & 43 & 51 & 56 & 47 \\
\hline 366 & 181 & 37 & 41 & 52 & 53 & 46 \\
\hline 546 & 255 & 36 & 39 & 48 & 53 & 44 \\
\hline $\begin{array}{l}512- \\
12- \\
25-\end{array}$ & $\begin{array}{l}\text { days } \\
\text { " }\end{array}$ & & & & & $\begin{aligned} 1 & : 1.4 \\
& : 1.3 \\
& : 0.9\end{aligned}$ \\
\hline
\end{tabular}

1 In one case-nine days old-which could hear the space was found through all the turns of the cochlea.

TABLE 50-Condensed

Ratios of the greatest height of the tunnel of Corti-according to the turns of the

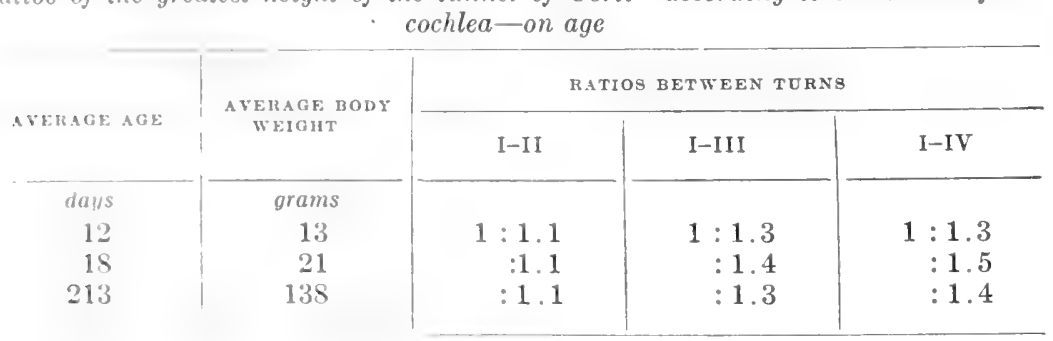

TABLE 51

The greatest height of the tunnel of Corti-in $\mu$ (Retzius)

\begin{tabular}{|c|c|c|c|c|c|c|c|c|c|c|c|}
\hline \multirow[b]{2}{*}{ |B:Leal } & \multicolumn{3}{|c|}{ HAnHT } & \multicolumn{4}{|c|}{ CAT (one month) } & \multicolumn{4}{|c|}{ MAN } \\
\hline & Mirlole & Apical & $\begin{array}{l}\text { Aver- } \\
\text { atgo }\end{array}$ & I3asal & Middle & Apical & $\begin{array}{l}\text { Aver- } \\
\text { age }\end{array}$ & Basal & Middle & Apical & $\begin{array}{c}\text { Aver- } \\
\text { age }\end{array}$ \\
\hline 30 & $3 !)$ & 36 & 35 & 18 & 37 & 36 & 30 & 28 & 45 & 49 & 41 \\
\hline
\end{tabular}


fore, the difference between the ratios at 1 to 20 and 1 to 546 days is very small.

At twelve days and after, the values for the height increase in passing from the base to the apex, at first rapidly, then more slowly. In the earlier stages this relation is obscure or reversed.

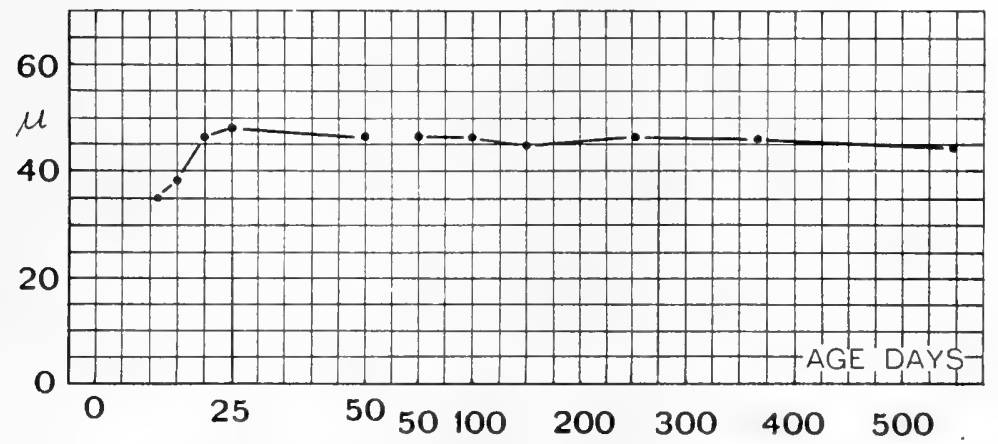

Chart 21 The greatest height of the tunnel of Corti, table 49 , figure $1,1-1$.

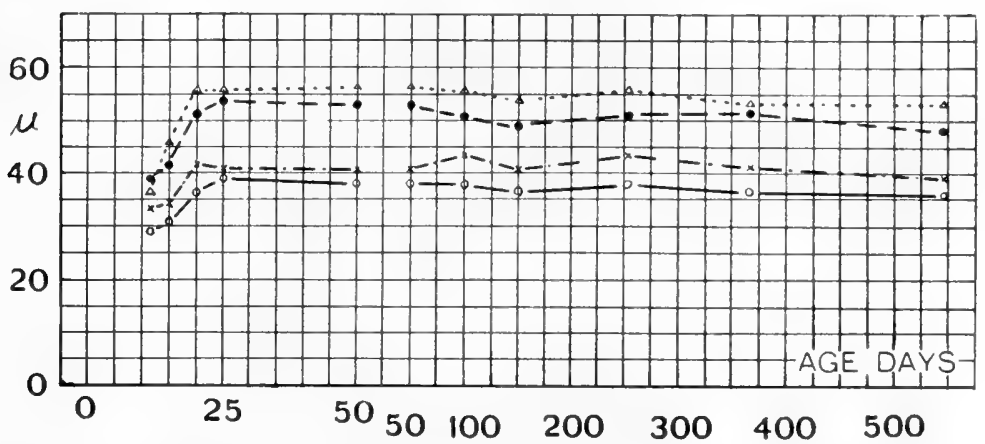

Chart 22 The greatest height of the tunnel of Corti, according to the turns of the cochlea, table 49 .

In the condensed table 53 are given the ratios in each turn. While the ratio of each turn before eight days is about 1:1.1, and between turns I and II remains constant in the later age, that for I to III and I to IV is at 18 and 213 days decidedly larger. Therefore, the increase of the height is most marked in the III and IV turn, as shown in chart 24. 
TABLE 52

Ileight of the papilla spiralis at the third series of outer hair cells-on age (charts 23 and 24)

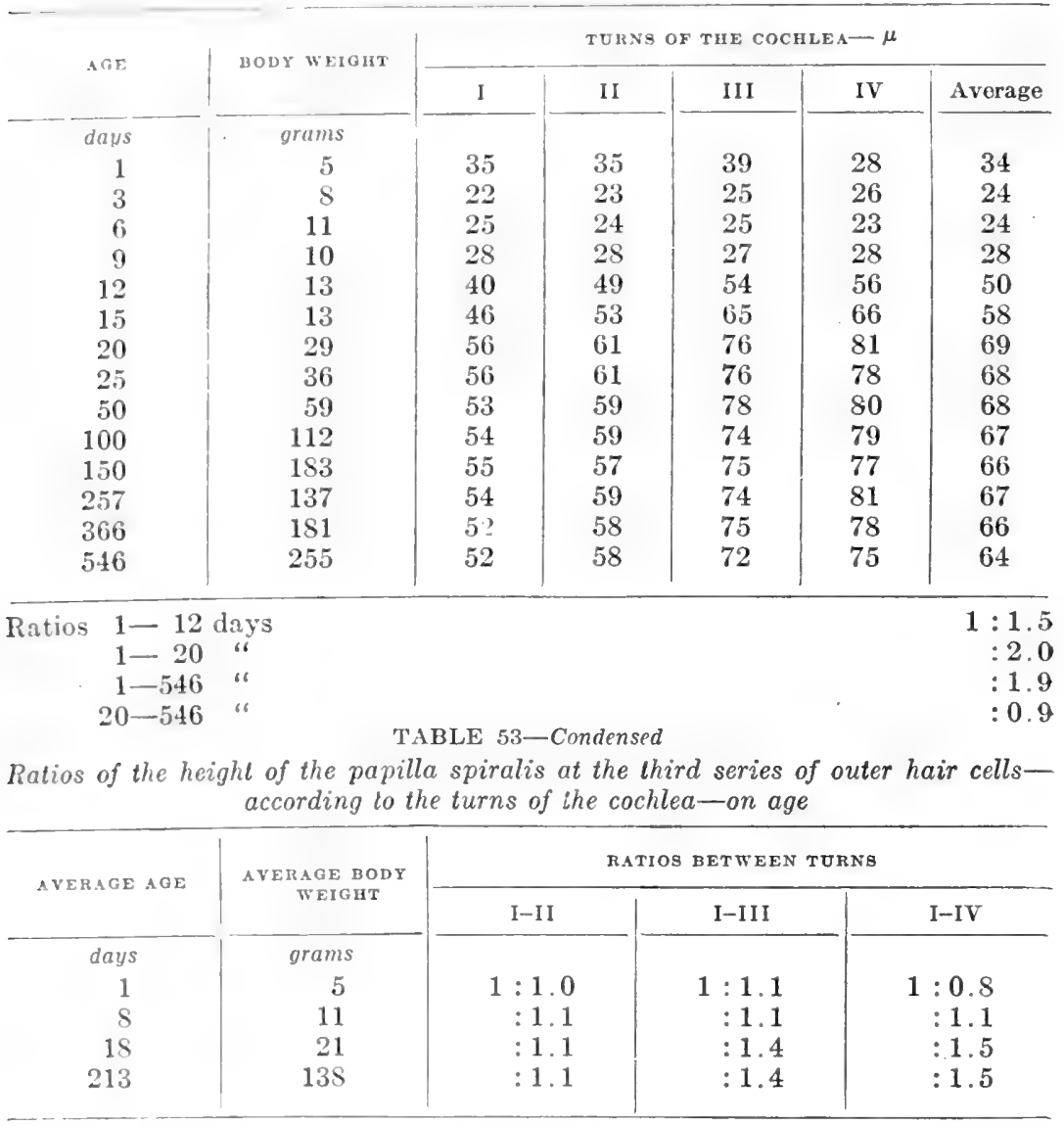

TABLE 54

Height of the papilla spiralis at the third sories of outer hair cells in $\mu$ (Retzius)

\begin{tabular}{|c|c|c|c|c|c|c|c|c|}
\hline \multicolumn{5}{|c|}{ RABBIT } & \multicolumn{4}{|c|}{ CAT } \\
\hline$A+E$ & $\begin{array}{l}\text { Jaisal } \\
\text { turtu }\end{array}$ & $\begin{array}{c}\text { Midalle } \\
\text { turn }\end{array}$ & $\begin{array}{c}\text { Apical } \\
\text { turn }\end{array}$ & Average & $\begin{array}{c}\text { Basal } \\
\text { turn }\end{array}$ & $\underset{\text { turn }}{\text { Middle }}$ & $\begin{array}{c}\text { Apical } \\
\text { turn }\end{array}$ & Average \\
\hline daus & & & & & & & & \\
\hline New-horn & 48 & 70 & 60 & 59 & 45 & 60 & 45 & 50 \\
\hline 2 & 45 & 70 & 54 & 56 & - & - & - & - \\
\hline 3 & - & - & - & - & 40 & 58 & - & - \\
\hline 7 & 54 & 69 & $66^{\circ}$ & 63 & 42 & $5 i$ & 48 & 49 \\
\hline 10 & 42 & Sti & 8.4 & 71 & - & - & - & - \\
\hline 11 & - & - & - & - & 60 & 72 & 42 & 58 \\
\hline 14 & 60 & 87 & 90 & 79 & - & - & - & - \\
\hline 30 & - & - & - & - & $3 i$ & 57 & 70 & 54 \\
\hline
\end{tabular}


Retzius ('84) finds in the rabbit and cat the values for this height given in (table 54).

Comparing these average numbers with mine, it appears that the height in the rabbit is greater, and in the cat smaller than

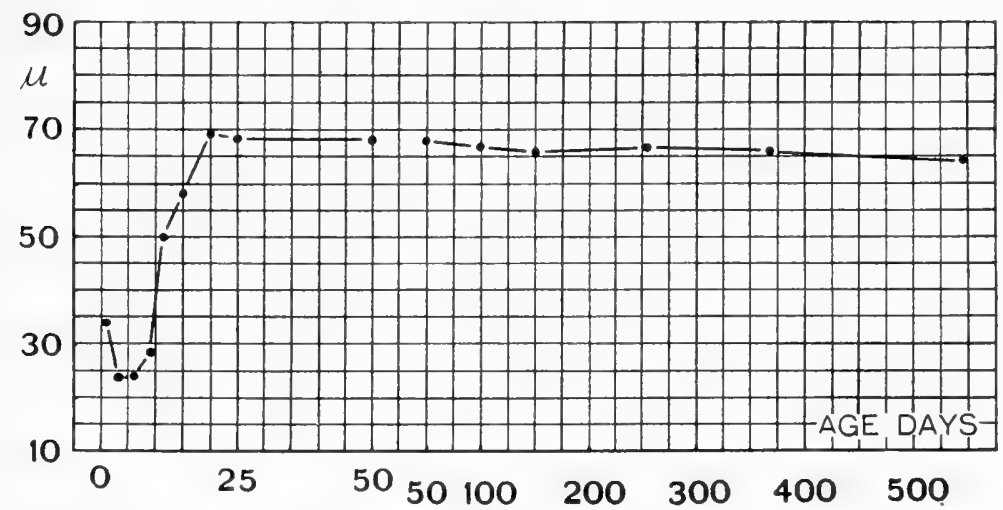

Chart 23 The height of the papilla spiralis at the third series of the outer hair cells, table 52, figure 1, 2-2.

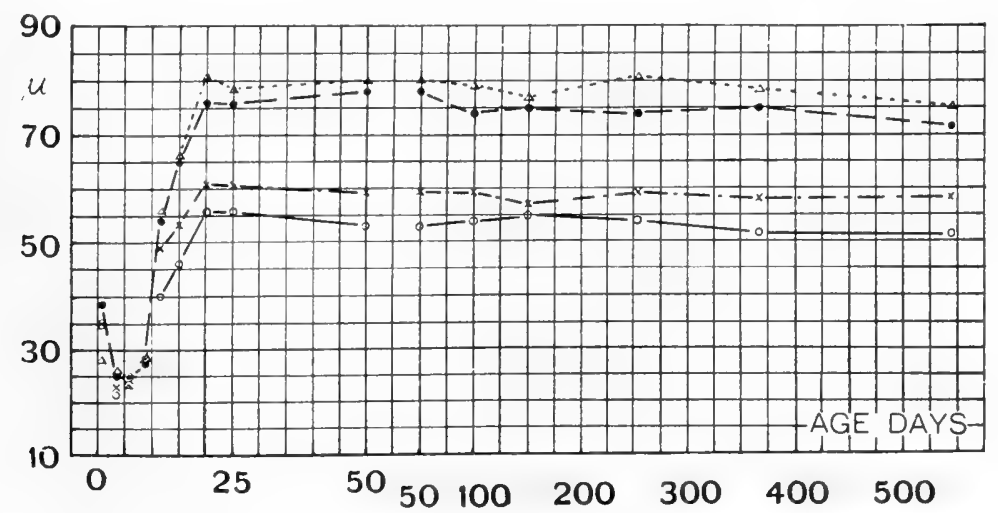

Chart 24 The height of the papilla spiralis at the third series of the outer hair cells, according to the turns of the cochlea, table 52 .

in the rat. In both animals the values increase rapidly at ten to eleven days of age, as in the albino rat, but the height in these animals is at the earlier stage almost twice as large as in the rat. Hardesty ('15) measured the thickness of the organ of Corti in 
the pig in a somewhat different way, using the vertical line from the hasilar membrane proper through the middle of the outer hair cell to the surface of the organ, and found the increase in thickness to take place most rapidly at the stages before full term, though it seems to continue after birth. I have not made cor-

TABLE 55

Greatest height of Hensen's supporting cells--on age (chart 25)

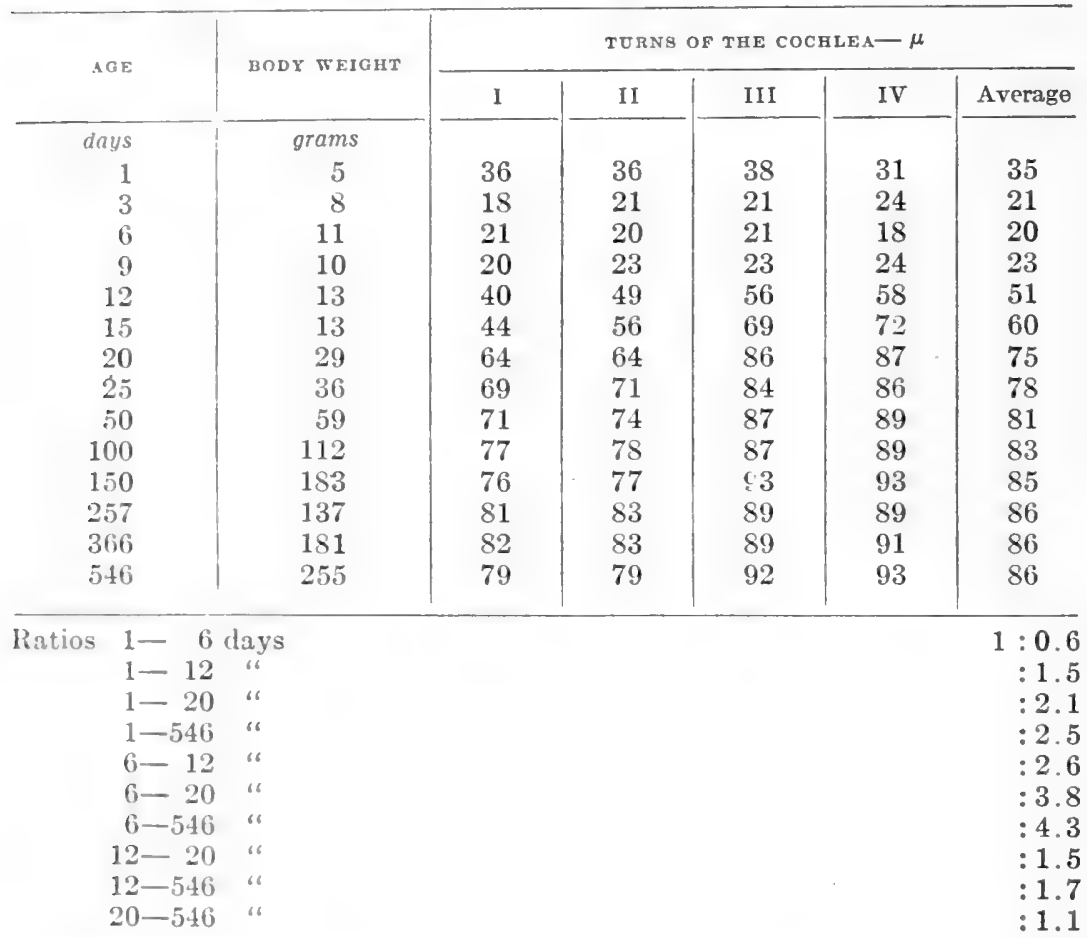

responding studies on the rat. In the latter animal, however, the rapid increase usually appears at twelve days of age, when the animal as a rule first responds to auditory stimuli, and thus we have a correlation between the development of the organ and the beginning of the function, which will be discussed later. In the case of one rat that could hear at nine days this change had already oceurred. 
13. The greatest height of Hensen's supporting cells. The older authors (Kölliker and others) thought that the arch of Corti marks the highest point of the papilla which slopes from this point gradually outward to the cells of the zona pectinata. Against this erroneous idea Hensen ('63) first published observations showing that the highest point is in the papilla which ascends laterally from the outer hair cells, and then slopes abruptly and passes over to the cells of the sulcus spiralis externus. We term this prominence Hensen's prominence and the cells, Hensen's supporting cells. The measurements of the height of

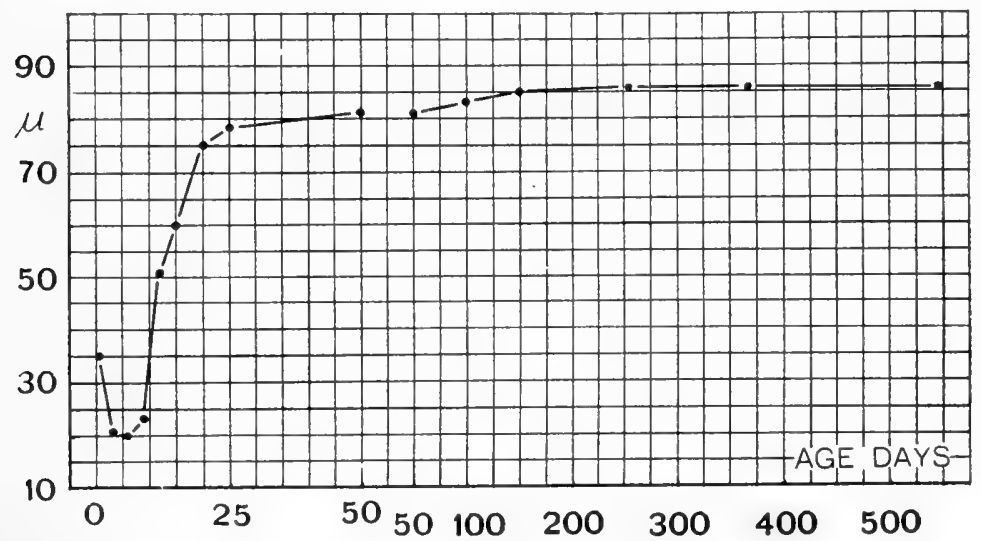

Chart 25 The greatest height of Hensen's supporting cells, table 55.

these cells were made along $3-3$ in figure 1 . Table 55 (chart 25) shows the values for the greatest vertical height of these supporting cells according to age. At the foot of the last column are given the ratios from 1 to 6,1 to 12,1 to 20,1 to 546,6 to 12 , 6 to 20,6 to 546,12 to 20,12 to 546 , and 20 to 546 days. The values diminish at the earlier stage from birth to six or nine days.

At twelve days they increase suddenly, more than doubling. After that they increase to old age, rapidly up to twenty days and then slowly. Here also the height increases from the base to the apex, the most marked increase occurring between turns II and III. In table 56 this relation is clearly shown. Retzius ('84) gets values of this height in the rabbit and cat as follows (table 57). 
In both the rabbit and the cat the height increases at ten to eleven days very considerably, as it does in the rat. Only there is a large difference in the absolute values for the three animals, these being largest in the rabbit and smallest in the cat. The final average values in the cat are nearly the same as those in the rat at the same age.

Kolmer $\left({ }^{\prime} 07\right)$ finds in the calf the value in the highest point of the organ of Corti in the region of the innermost Hensen's rells as follows:

In the basal turn, $\quad 84 \mu$
In the second turn, $\quad 90 \mu$
In the third turn, $\quad 105 \mu$
$\quad$ Average,

Hensen ('63) gives in man the average height of the papilla as $90 \mu$ in the hamulus and $60 \mu$ in the radix. Thus the height of Hensen's cells is different in different animals.

When we consider the growth in the height of Hensen's cells we can picture the change of the form in the papilla spiralis. As shown already, the height of the pillar cells is largest at the earlier stage, when the papilla has its highest point at the summit of the arch of Corti, and slopes downward to the Hensen's cells. But at twelve days the form is reversed, and the highest point is in Hensen's prominence from which the surface slopes inward more or less steeply to the surface of the pillar cells and the inner supporting cells. Thus the surface of the papilla does not run parallel to the basilar membrane, but makes with it a sharp angle opening outward. This angle has been measured.

14. The angle subtended by the extension of the surface of the lamina reticularis with the extended plane of the membrana basilaris. As just stated, the 'amina reticularis after the earlier stages is not parallel to the membrana basilaris, but forms an angle with it. The measurements of this angle $\Theta$, were taken as shown in lines $4-4^{\prime}$ in figure 1 . In table 58 (chart 26) are given the values for the angle in degrees. Before nine days there is no appreciable angle. From twelve to twenty days the angle increases rather rapidly, and after twenty days continuously but slowly. The ratio at the bottom of the last column shows this clearly. 
Comparing the values of the angle in each turn according to age, there is no clear evidence that it increases from base to apex, though it tends to be largest in turn III and next largest in turn II. The condensed table 59 shows these relations. Retzius ('84) finds this angle in the rabbit and cat to be as in table 60 .

TABLE 56-Condensed

Ratios of the greatest height of Hensen's supporting cells according to the turns of the cochlea

\begin{tabular}{|c|c|c|c|c|}
\hline \multirow{2}{*}{ AVERAGE AGE } & \multirow{2}{*}{$\begin{array}{l}\text { AVERAGE BODY } \\
\text { WEIGHT }\end{array}$} & \multicolumn{3}{|c|}{ RATIOS BETWEEN SUCCLSSIVE TURNG } \\
\hline & & I-II & I-I I I & I-IV \\
\hline days & grams & & & \\
\hline 1 & 5 & $1: 1.0$ & $1: 1.1$ & $1: 0.9$ \\
\hline 8 & 11 & $: 1.1$ & $: 1.2$ & $: 1.2$ \\
\hline 18 & 21 & $: 1.1$ & $: 1.4$ & $: 1.5$ \\
\hline 213 & 138 & $: 1.0$ & $: 1.2$ & $: 1.2$ \\
\hline
\end{tabular}

TABLE 57

Greatest height of Hensen's supporting cells in $\mu$ (Retzius)

\begin{tabular}{|c|c|c|c|c|c|c|c|c|}
\hline \multicolumn{5}{|c|}{ RABbit } & \multicolumn{4}{|c|}{$\mathrm{C}_{\mathrm{AT}}$} \\
\hline$\underset{\text { Days }}{\text { Age }}$ & $\underset{\text { turn }}{\text { Basal }}$ & Middle & Apical & Average & Basal & Middle & Apical & $\begin{array}{c}\text { Aver- } \\
\text { age }\end{array}$ \\
\hline New-born & $38 ?$ & $60 ?$ & $50 ?$ & $49 ?$ & 45 & 50 & 39 & 45 \\
\hline 2 & $55 ?$ & $60 ?$ & - & - & - & - & - & - \\
\hline 3 & - & - & - & - & 39 & 54 & - & - \\
\hline 7 & 48 & 81 & 67 & 65 & 57 & 50 & 40 & 49 \\
\hline 10 & 105 & 125 & 105 & 112 & - & - & - & - \\
\hline 11 & - & - & - & - & 75 & 78 & 45 & 66 \\
\hline 14 & - & 150 & 120 & - & - & - & - & - \\
\hline 30 & - & 一 & - & 一 & 50 & 69 & 95 & 71 \\
\hline
\end{tabular}

Retzius also finds in man in the basal turn $25^{\circ}$, in the middle $35^{\circ}$, and in the apical $23^{\circ}$. Thus the angle always increases with age, but has different absolute values in different mammals and always tends to be greater in the middle turns.

15. Lengths of the inner and outer pillar cells. The measurements of length were taken as shown by lines $1-1$, and $2-2$ as in figure 2. This does not give the total length, but the length from the base to the point, just below the joint. As is well 
TABLE 58

Angle of the lamina reticularis with the plane of the membrana basilaris-in degrees, $\theta$ (chart 26)

\begin{tabular}{|c|c|c|c|c|c|c|}
\hline \multirow{2}{*}{$A G E$} & \multirow{2}{*}{ BODY WEIGHT } & \multirow[b]{2}{*}{ I } & \multicolumn{4}{|c|}{ TURNB OF THE COCHLEA-DEGREE } \\
\hline & & & II & III & Iv & Average \\
\hline doys & $\begin{array}{l}\text { grams } \\
5\end{array}$ & - & - & - & - & - \\
\hline 1 & $\begin{array}{l}5 \\
\mathrm{~s}\end{array}$ & - & - & - & - & - \\
\hline $\begin{array}{l}3 \\
6\end{array}$ & 11 & - & - & - & - & - \\
\hline $\begin{array}{l}6 \\
9\end{array}$ & 10 & - & - & - & - & - \\
\hline $\begin{array}{r}9 \\
12\end{array}$ & 13 & 7 & 12 & 13 & 9 & 10 \\
\hline $\begin{array}{l}12 \\
15\end{array}$ & 13 & 11 & 14 & 13 & 13 & 13 \\
\hline $\begin{array}{l}15 \\
20\end{array}$ & 29 & 15 & 13 & 11 & 11 & 13 \\
\hline 25 & 36 & 14 & 14 & 13 & 13 & 14 \\
\hline 50 & 59 & 15 & 15 & 17 & 11 & 15 \\
\hline 100 & 112 & 15 & 14 & 16 & 14 & 15 \\
\hline 150 & 183 & 15 & 15 & 19 & 17 & 17 \\
\hline 257 & 137 & 13 & 15 & 18 & 17 & 16 \\
\hline 366 & 181 & 16 & 15 & 16 & 16 & 16 \\
\hline 546 & 255 & 16 & 16 & 17 & 17 & 17 \\
\hline \multicolumn{2}{|c|}{ Vertical a verages } & 13.7 & 14.3 & 15.3 & 13.8 & \\
\hline \multicolumn{2}{|c|}{$\begin{array}{r}\text { Ratios } 12-20 \text { days } \\
12-346\end{array}$} & & & & & $1: 1.3$ \\
\hline
\end{tabular}

Ratios of the angle of the lamina reticularis with the plane of the membrana basilaris according to the turns of the cochlea

\begin{tabular}{|c|c|c|c|c|}
\hline \multirow{2}{*}{ AVERAGE AGE } & \multirow{2}{*}{$\begin{array}{c}\text { AVERAGE BODY } \\
\text { WEIGHT }\end{array}$} & \multirow[b]{2}{*}{ I-II } & \multicolumn{2}{|c|}{ RATIOS BETWEEN TURNS } \\
\hline & & & I-III & I-IV \\
\hline $\begin{array}{c}\text { days } \\
12\end{array}$ & $\begin{array}{l}\text { grams } \\
13\end{array}$ & $1: 1.7$ & $1: 1.9$ & $1: 1.3$ \\
\hline 18 & 21 & $: 1.0$ & $: 0.9$ & $: 0.9$ \\
\hline 213 & 138 & $: 1.0$ & $: 1.2$ & $: 1.0$ \\
\hline
\end{tabular}

TABLE 60

Angle of the lamina reticutaris with the plane of the membranabasilaris in degrees (Relzius)

\begin{tabular}{|c|c|c|c|c|c|c|c|c|}
\hline & & IRABВT & & & & & $A T$ & \\
\hline Age & $\begin{array}{l}\text { Insal } \\
\text { turn }\end{array}$ & $\begin{array}{c}\text { Middide } \\
\text { turn } \\
\end{array}$ & $\left|\begin{array}{c}\text { Anical } \\
\text { turn }\end{array}\right|$ & Average & $\begin{array}{l}\text { Basal } \\
\text { turn }\end{array}$ & $\begin{array}{c}\text { Middle } \\
\text { turn }\end{array}$ & $\begin{array}{l}\text { Apical } \\
\text { turn }\end{array}$ & Average \\
\hline $\begin{array}{c}d a y s \\
\text { Sew-burn }\end{array}$ & 0 & $-5 ?$ & $-8 ?$ & - & 0 & - & $-5 ?-8 ?$ & - \\
\hline 2 & 0 & 0 & -1 & - & - & - & - & - \\
\hline 3 & - & - & - & - & 0 & $-5 ?-8 ?$ & - & - \\
\hline$\tau$ & 17 & 19 & -11 & - & 5 & 5 & -10 & - \\
\hline 10 & 20 & 30 & 23 & 24 & - & - & - & - \\
\hline 11 & - & - & - & - & 20 & $10-20$ & 0 & - \\
\hline 1.1 & $2 \bar{j}$ & 50 & 4.5 & 40 & - & - & - & - \\
\hline 30 & - & - & - & - & 18 & 23 & 20 & 20 \\
\hline
\end{tabular}


known, the inner and outer pillar cells when mature show a more or less S-shaped curvature, though they are straighter in the earlier stages. Thus the length as measured in the adult cochlea is somewhat smaller than the natural lengths.

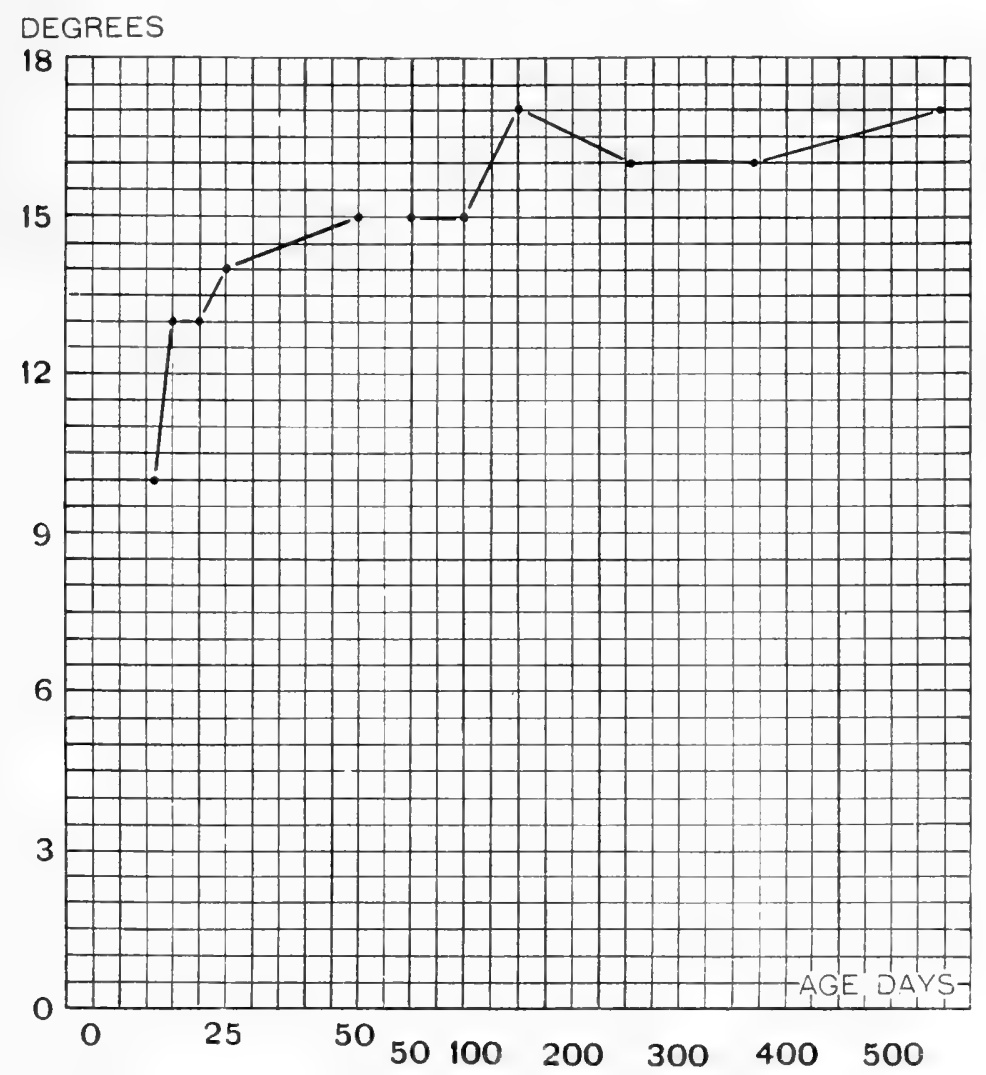

Chart 26 The angle subtended by the extension of the lamina reticularis with the extended plane of the membrana basilaris, in degrees, table 58, figure 1 , $4-4^{\prime}, 0$.

In table 61 (charts 27 to 32 ) is given the values for the lengths of the inner and outer pillar cells according to age. At first we shall consider the average values for the length of the inner and outer pillar cells taken together. This length diminishes at three days. From three to twelve days it increases rapidly, 
and from twelve to twenty days more slowly. After twenty days it decreases a little. The ratios at the bottom of the last column show these relations. The familiar fact, that the length increases from the base to the apex is clearly shown in chart 28 .

TABLE 61

Lenglhs of the inner and outer pillar cells (without head) measured from the fostplate on the membrana basilaris to the point directly below the junction

(charts 27 to 32 )

\begin{tabular}{|c|c|c|c|c|c|c|c|c|c|c|c|c|}
\hline \multirow{3}{*}{$A G E$} & \multirow{3}{*}{$\begin{array}{c}\text { BODY } \\
\text { WEIGHT }\end{array}$} & \multicolumn{5}{|c|}{ INNER PILLAR } & \multicolumn{5}{|c|}{ OUTER PILLAR } & \multirow{3}{*}{$\begin{array}{c}\text { Com- } \\
\text { bined } \\
\text { Average }\end{array}$} \\
\hline & & \multicolumn{5}{|c|}{ Turns of the cochlea $\mu$} & \multicolumn{5}{|c|}{ Turns of the cochlea $\mu$} & \\
\hline & & $\mathrm{I}$ & II & III & IV & Average & I & II & III & IV & Average & \\
\hline days $\left.\right|^{-}$ & $g m s$ & & & & & & & & & & & \\
\hline 1 & 5 & 28 & 29 & 29 & 29 & 29 & 24 & 27 & 27 & 26 & 26 & 28 \\
\hline 3 & 8 & 26 & 23 & 26 & 23 & 25 & 19 & 20 & 20 & 21 & 20 & 23 \\
\hline 6 & 11 & 35 & 36 & 36 & 37 & 36 & 21 & 26 & 27 & 26 & 25 & 31 \\
\hline 9 & 10 & 35 & 34 & 41 & 40 & 39 & 26 & 26 & 29 & 29 & 28 & 34 \\
\hline 12 & 13 & 33 & 38 & 44 & 44 & 40 & 46 & 59 & 72 & 72 & 62 & 51 \\
\hline 15 & 18 & $3 t$ & 38 & 48 & 51 & 43 & 44 & 59 & 74 & 78 & 64 & 54 \\
\hline 20 & 29 & 43 & 47 & 56 & 60 & 52 & 56 & 65 & 79 & 83 & 71 & 62 \\
\hline 25 & 36 & 43 & 47 & 56 & 60 & 52 & 53 & 64 & 80 & 84 & 70 & 61 \\
\hline 50 & 59 & 42 & 44 & 55 & 61 & 51 & 52 & 64 & 79 & 84 & 70 & 61 \\
\hline 100 & 112 & 42 & 44 & 53 & 58 & 49 & 52 & 62 & 79 & 84 & 69 & 59 \\
\hline 150 & 183 & 41 & 43 & 54 & 59 & 49 & 51 & 64 & 76 & 85 & 69 & 59 \\
\hline 257 & 137 & 40 & 44 & 53 & 60 & 49 & 53 & 64 & 75 & 85 & 69 & 59 \\
\hline 366 & 181 & 39 & 45 & 53 & 59 & 48 & 50 & 64 & 78 & 83 & 69 & 59 \\
\hline 546 & 255 & 41 & 44 & 53 & 58 & 49 & 49 & 64 & 78 & 83 & 69 & 59 \\
\hline Ratios & $81-12$ & day & & & & $1: 1.4$ & & & & & $1: 2.4$ & $1: 1.8$ \\
\hline & $1-20$ & & & & & : 1.8 & & & & & $: 2.7$ & $: 2.2$ \\
\hline & $1-546$ & " & & & & $: 1.7$ & & & & & $: 2.7$ & $: 2.1$ \\
\hline & $20-5.46$ & “" & & & & $: 0.9$ & & & & & $: 1.0$ & $: 1.0$ \\
\hline
\end{tabular}

When we calculate the average values of the inner and outer pillar cells from Retzius table ('84), we get the following (table (62).

'TABLE 62

Combined lengthis of the inner and outer pillars from the foot plate to a poin: direclly belou the junction-in $\mu$ (Retzius)

\begin{tabular}{|c|c|c|c|c|c|c|c|c|c|c|c|}
\hline \multirow[b]{2}{*}{$\begin{array}{l}\text { Bacal } \\
: \text { : } 1111\end{array}$} & \multicolumn{3}{|c|}{ HA ИВІт (aclult) } & \multicolumn{4}{|c|}{ Cat (adult) } & \multicolumn{4}{|c|}{ MAN (adult) } \\
\hline & $\begin{array}{l}\text { Micille? } \\
\text { Turn }\end{array}$ & $\begin{array}{l}\text { Apical } \\
\text { luint }\end{array}$ & $\begin{array}{l}\text { Aver- } \\
\text { age } \\
\text { turn }\end{array}$ & $\begin{array}{r}\text { Bataal } \\
\text { turn }\end{array}$ & $\begin{array}{l}\text { Wirldile } \\
\text { turn }\end{array}$ & $\begin{array}{c}\text { Apical } \\
\text { turn }\end{array}$ & $\begin{array}{l}\text { Aver- } \\
\text { age }\end{array}$ & $\begin{array}{c}\text { Basal } \\
\text { turn }\end{array}$ & $\begin{array}{l}\text { Middde } \\
\text { turn }\end{array}$ & $\begin{array}{c}\text { Apical } \\
\text { turn }\end{array}$ & $\begin{array}{l}\text { Aver- } \\
\text { age }\end{array}$ \\
\hline litj & $\left(\mathrm{Si}^{\prime}\right.$ & 78 & 76 & 5.7 & 75 & 73 & 67 & 55 & 84 & 87 & 75 \\
\hline
\end{tabular}




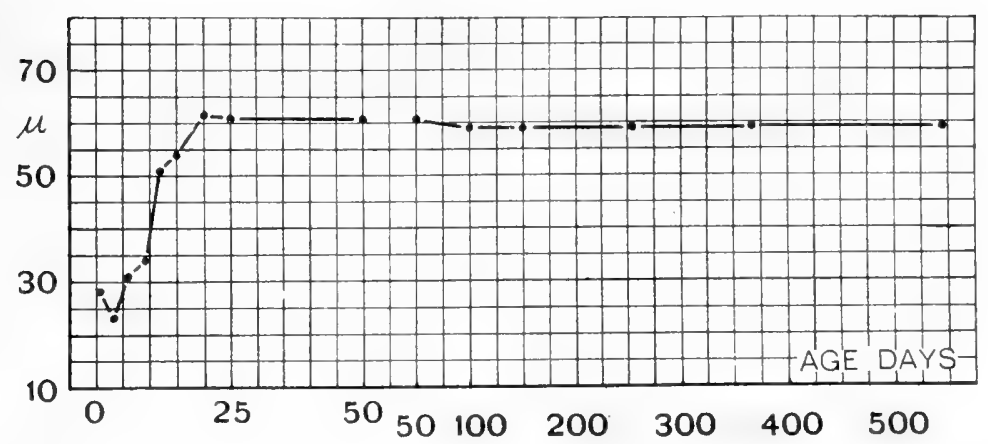

Chart 27 The length of inner and outer pillar cells combined, without head, measured from the foot plate on the membrana basilaris to the point directly below the junction, table 61 , figure $2,1-1,2-2$.

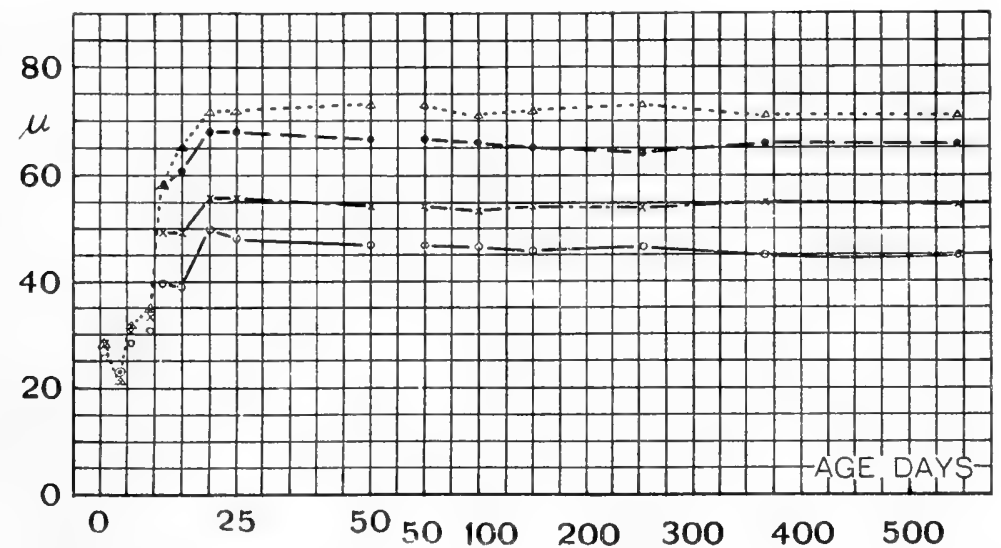

Chart 28 The length of inner and outer pillar cells combined, without head, measured from the foot plate on the membrana basilaris to the point directly below the junction, according to the turns of the cochlea, table 61 .

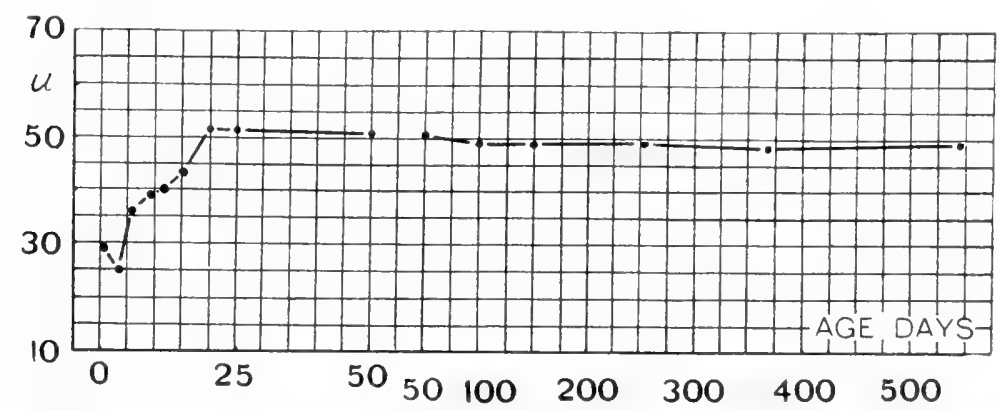

Chart 29 The length of inner pillar cell without head, table 61, figure 2, 1-1. 
As table 62 shows, the values in these mammals are larger than those in the albino rat - a result which fits with our previous observations.

When we consider the length of the inner pillar cells alone, we see that the values (chart 29) here also increases from three dars to twenty days, but not so largely as in the combined values of the inner and outer pillar cells. After twenty days the values for the inner pillar cells decrease slightly. This relation is shown by the ratios at the bottom of the corresponding column. That the increase progresses from the base to the apex, being most marked in turn III, is illustrated in chart 30 . The condensed table 63 shows those relations also. The one-day-old rat is an exception.

We turn now to the growth in the length of the outer pillar cells. As we see in table 61 (chart 31), the length of the outer pillar cell does not increase so much from one to nine days as the inner pillar cell did. At twelve days, however, the increase in length is very marked, that is, 2.2 times as much as at nine days.

After the outer pillar cell reaches its maximum at twenty days, it decreases only slightly with advancing age. The ratios at the bottom of the corresponding column show this relation clearly. The length increases from base to apex, though this relation is not well established until twelve days, as shown in table 61 and chart 32 . The ratios of the outer pillar cells according to the turns of the cochlea are shown in table 64 .

The inner and outer pillar cells show marked differences in their growth. While at the earlier ages the length of the inner is greater than that of the outer, yet after twelve days this relation is reversed. Moreover, from nine to twelve days the growth is gradual in the inner pillar cells, but rapid in the outer. The condensed table 65 shows the values for the length of the inner and outer pillar cells separately. In the last column are given the ratios between them.

In the accompanying table 66 I have compared the values obtained in the rat with those given by other authors.

As table 66 shows, the absolute values differ in various animals. However, the ratios between the values for the inner and outer 


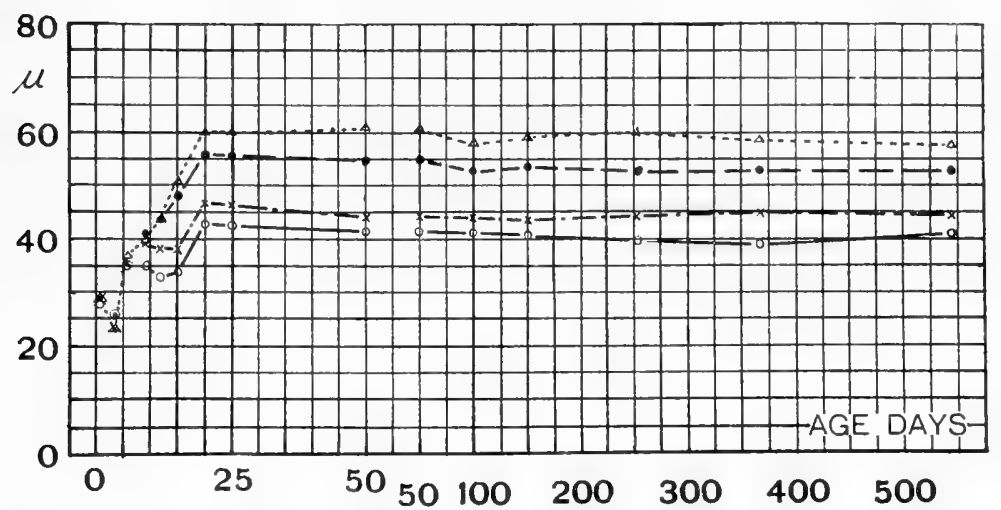

Chart 30 The length of the inner pillar cell without head, according to the turns of the cochlea, table 61.

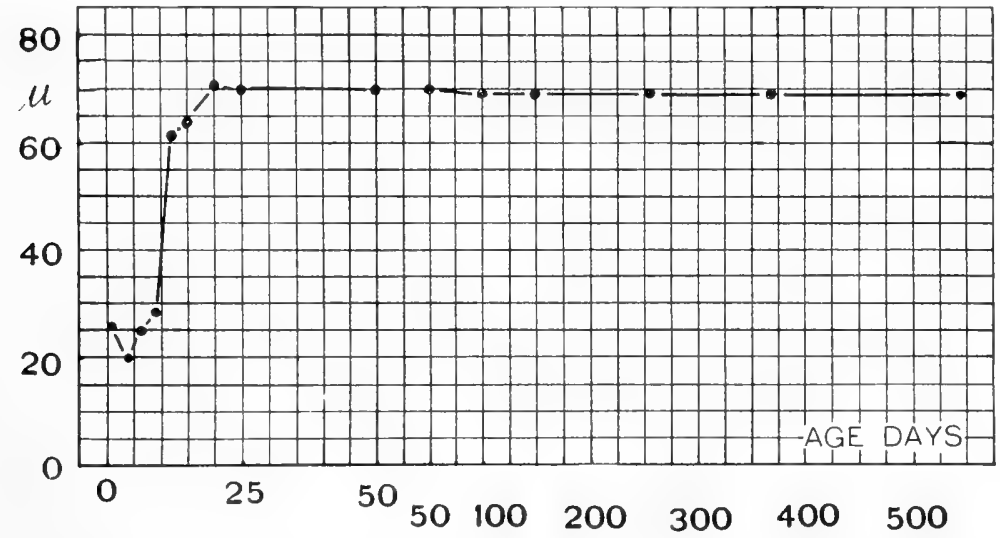
2-2.

Chart 31 The length of outer pillar cells without head, table 61, figure 2,

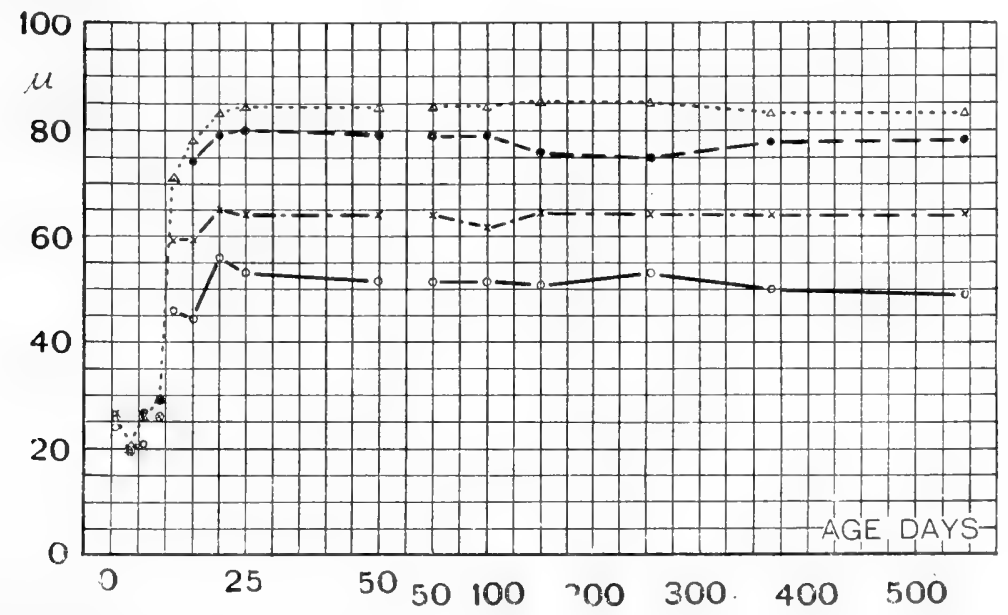

Chart 32 The length of outer pillar cells without head, according to the turns of the cochlea, table 61 . 
TABLE 63-Condensed

Ratios of the length of the inner pillar cells-according to the turns of the cochlea

\begin{tabular}{|c|c|c|c|c|}
\hline \multirow{2}{*}{ AVERAGE AGE } & \multirow{2}{*}{$\begin{array}{l}\text { AVERAGE HODY } \\
\text { WEIGHT }\end{array}$} & \multicolumn{3}{|c|}{ RATIOS BETWEEN TURNS } \\
\hline & & I-II & I-II I & $\mathrm{I}-\mathrm{IV}$ \\
\hline days & - grams & & & \\
\hline 1 & 5 & $1: 1.0$ & $1: 1.0$ & $1: 1.0$ \\
\hline \& & 11 & $: 1.1$ & $: 1.2$ & $: 1.1$ \\
\hline 18 & 21 & $: 1.1$ & $: 1.3$ & $: 1.4$ \\
\hline 213 & 138 & $: 1.1$ & $: 1.3$ & $: 1.4$ \\
\hline
\end{tabular}

TABLE 64-Condensed

Rutios of the length of the outer pillar cells according to the turns of the cochlea

\begin{tabular}{|c|c|c|c|c|}
\hline \multirow{2}{*}{$A V E M A E A G E$} & \multirow{2}{*}{$\begin{array}{c}\text { AVERAGE BODY } \\
\text { WEIGHT }\end{array}$} & \multicolumn{3}{|c|}{ RATIOS BETWEEN TURNS } \\
\hline & & I-I I & I-III & $\mathrm{I}-\mathrm{IV}$ \\
\hline days & grams & & & \\
\hline 1 & 5 & $1: 1.1$ & $1: 1.1$ & $1: 1.0$ \\
\hline$\hat{s}$ & 11 & $: 1.2$ & $: 1.3$ & $: 1.3$ \\
\hline 18 & 21 & $: 1.2$ & $: 1.5$ & $: 1.6$ \\
\hline 213 & 138 & $: 1.3$ & $: 1.5$ & $: 1.6$ \\
\hline
\end{tabular}

TABLE 65-Condensed

Comparison of the awerage length of the inner and outer pillar-cells-without head.

\begin{tabular}{|c|c|c|c|c|}
\hline \multirow[t]{2}{*}{ AVERAGE AGE } & \multirow{2}{*}{$\begin{array}{l}\text { AVERAGE BODY } \\
\text { WEIGHT }\end{array}$} & \multicolumn{2}{|c|}{$\begin{array}{l}\text { AVERAGE LENGTH OF PILLAR CELLS } \\
\text { WITHOUT HEAD }\end{array}$} & \multirow{2}{*}{$\begin{array}{l}\text { RATIOS OF INNER } \\
\text { TO OCTER }\end{array}$} \\
\hline & & Inner & Outer & \\
\hline days & grams & & & \\
\hline 1 & 5 & 29 & 26 & $1: 1.0$ \\
\hline 8 & 11 & 35 & 34 & $: 1.0$ \\
\hline 18 & 21 & 48 & 68 & $: 1.4$ \\
\hline 213 & 135 & 50 & 69 & $: 1.4$ \\
\hline
\end{tabular}

pillar cells are smallest in man and in the rat and alike in the other two forms, Retzius ('84). Hensen ('63) states that in the base of the human cochlea both pillar cells are equally long. Later, Pritchard ('78) supported this observation. In the literature, however, no one except these two authors report the inner and outer pillar cells in the base of the adult cochlea as equal in length, but the inner is always stated to be shorter than the outer. We may therefore say that most authors agree that the inner pillar cells are at earlier stages longer than the outer, then they become equal, and finally the outer surpass the inner. 
TABLE 66

Lengths of inner and outer pillars in several mammals according to different authors.

Measurements in $\mu$

\begin{tabular}{|c|c|c|c|c|c|c|c|c|c|c|c|c|}
\hline \multicolumn{7}{|c|}{ INNER PILLAR } & \multicolumn{6}{|c|}{ OUTER PILLAR } \\
\hline Authors & Animals & $\begin{array}{l}\text { Basal } \\
\text { turn }\end{array}$ & $\begin{array}{c}\text { Mid- } \\
\text { dle }\end{array}$ & Apical & & Av. & B. & $M$. & A. & & Av. & Ratio \\
\hline Corti & $\begin{array}{c}\text { Mam- } \\
\text { mals }\end{array}$ & 30 & 30 & 34 & & 31 & $\begin{array}{l}45- \\
49\end{array}$ & $\begin{array}{l}54- \\
58\end{array}$ & 69 & & 57 & $1: 1.8$ \\
\hline $\begin{array}{l}\text { Hen- } \\
\text { sen }\end{array}$ & Man & 48 & - & $\begin{array}{c}86 \\
\text { (Hamul- } \\
\text { us) }\end{array}$ & & 48 & - & & $\begin{array}{c}98 \\
\text { (Hamul- } \\
\text { us) }\end{array}$ & & & \\
\hline \multirow{3}{*}{$\begin{array}{l}\text { Ret- } \\
\text { zius }\end{array}$} & Rabbit & 56 & 60 & 60 & & 59 & 75 & 110 & 95 & & 93 & $: 1.6$ \\
\hline & Cat & 41 & 54 & 57 & & 51 & 68 & 95 & 89 & & 84 & $: 1.6$ \\
\hline & Man & 48 & 68 & 70 & & 62 & 62 & 100 & 103 & & 88 & $: 1.4$ \\
\hline \multirow[t]{2}{*}{ Wada } & $\begin{array}{c}\text { Albino } \\
\text { rat }\end{array}$ & I & II & III & IV & & I & II & III & IV & & \\
\hline & $\begin{array}{c}\text { after } 20 \\
\text { days }\end{array}$ & 41 & 45 & 54 & 59 & 50 & 52 & 64 & 78 & 84 & 70 & $: 1.4$ \\
\hline
\end{tabular}

16. Inner and outer hair cells. For a long time the inner and the outer hair cells have been regarded as the most important elements in the papilla spiralis. As these sense cells have a delicate histological structure which is readily altered, the systematic study of their growth, especially after the appearance of hearing, is a difficult matter. Though there are some observations on the length of these cells, detailed studies on their growth have not been made heretofore. I have therefore endeavored to follow the changes of their size during the postnatal period. It is first necessary to determine the form of these cells. They are generally described as cylindrical, but this description is inexact. Moreover, the inner and outer hair cells are somewhat different in shape. The former has on the surface a large oval terminal disk, which is wide in the spiral and narrow in the radial direction. This narrows downwards to a thinner neck which expands into the broader body and terminates in a more or less round but somewhat pointed irregular end. 


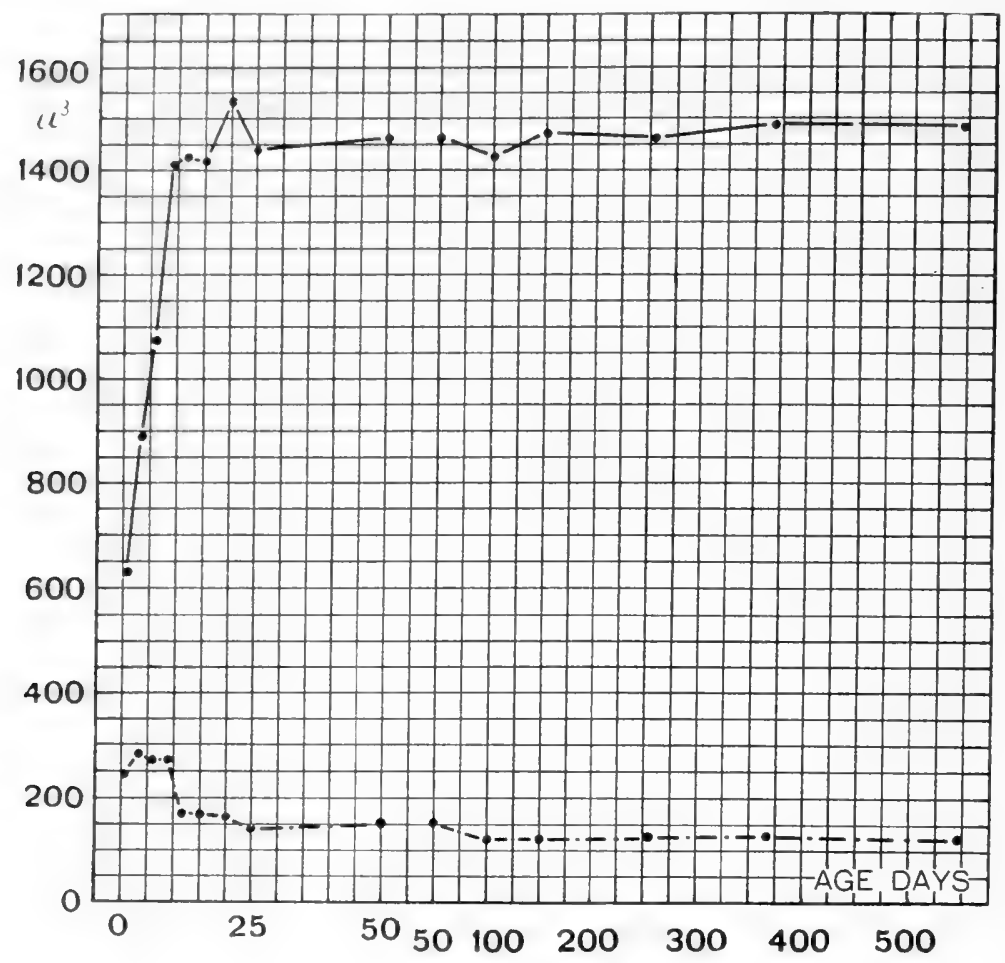

Chart 33 The weighted volume of inner and outer hair cells combined, and of their nuclei in cubic micra, tables 67 and 69.

Weighted volume of inner and outer hair cells combined.

-........ Weighted volume of nuclei of inner and outer hair cells combined.

The outer hair cells have a much more cylindrical form, their upper terminal disk is not so wide and not round, but hexagonal. They become a bit thin in the neck, then wide in the body. Their lower end is rounded. In order, however, to determine the cell volume, the cell form has been taken as that of a cylinder. For computation, the average of the diameters measured in three places, the end disk, neck, and cell body, was taken as the liameter and the length of the cell as the length of the cylinder. From these data the volume of the cylinder was computed. 
In table 67 are given the values for the volume of the cell bodies in the (1) inner and (3) outer hair cells separately and the weighted volume of both cells (in the radial section of the rat cochlea we see one row of inner and three rows of outer hair cells), according to age.

TABLE 67

Average volumes of the inner and outer hair cells-in cubic micra (charts 33 to 37 )

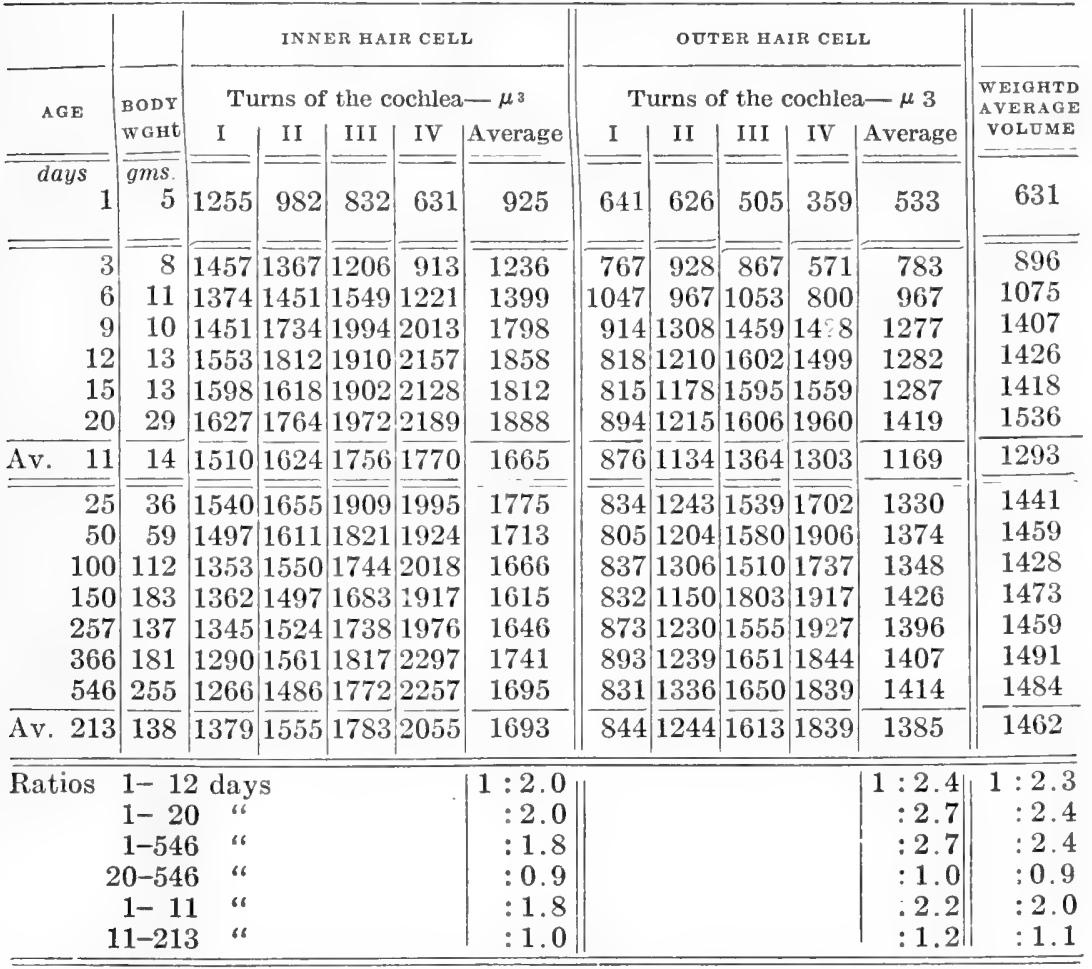

At first we shall consider the weighted volume for the cell bodies of the inner and outer hair cells combined (chart 33). As table 67 shows, the volume increases continuously to the full size at twenty days. From one to twelve days the increase is rapid, and after that the volumes are about the same, though somewhat fluctuating. The ratios show this relation clearly. 
('ondensing all age groups into three (averages in table 67), then the relation changes somewhat. From one to eleven days the volume increases more than 100 per cent, while from eleven to 213 days it increases only 13 per cent.

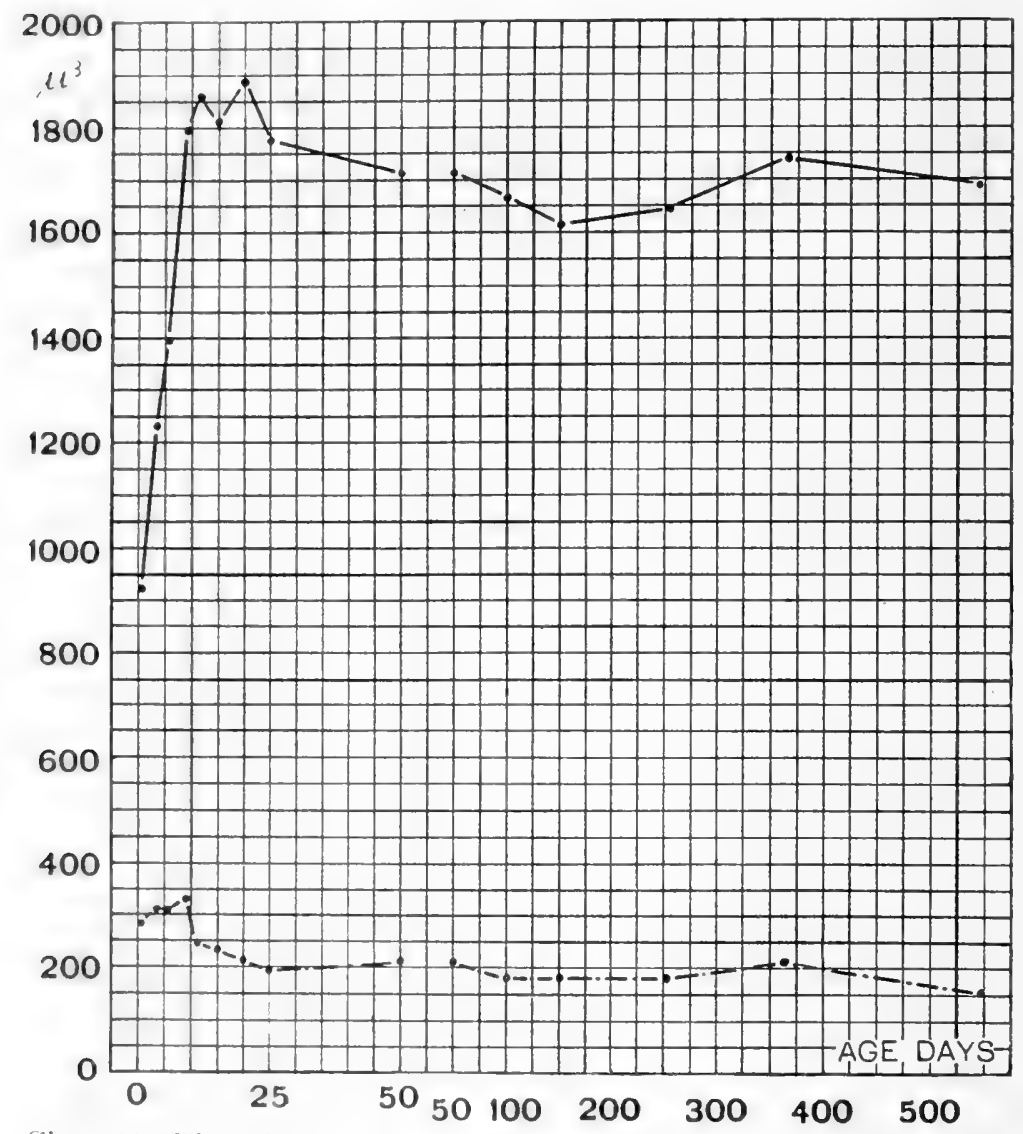

Chart 34 The volume of inner hair cells and of their nuclei, tables 67 and 69.

- Volume of inner hair cells.

-....... Volume of nuclei of inner hair cells.

The data for the growth of the nuclei of the inner and outer hair cells are presented in tables 68 and 69 . The weighted values for the diameters of the nuclei (table 68) are large at the rarlier stages, but from twelve days decrease gradually till 
old age. In the three condensed age groups (averages) we see the decrease of the values from birth till old age. In table 69 are given the values for the volumes of the nuclei, calculated as spheres (chart 33).

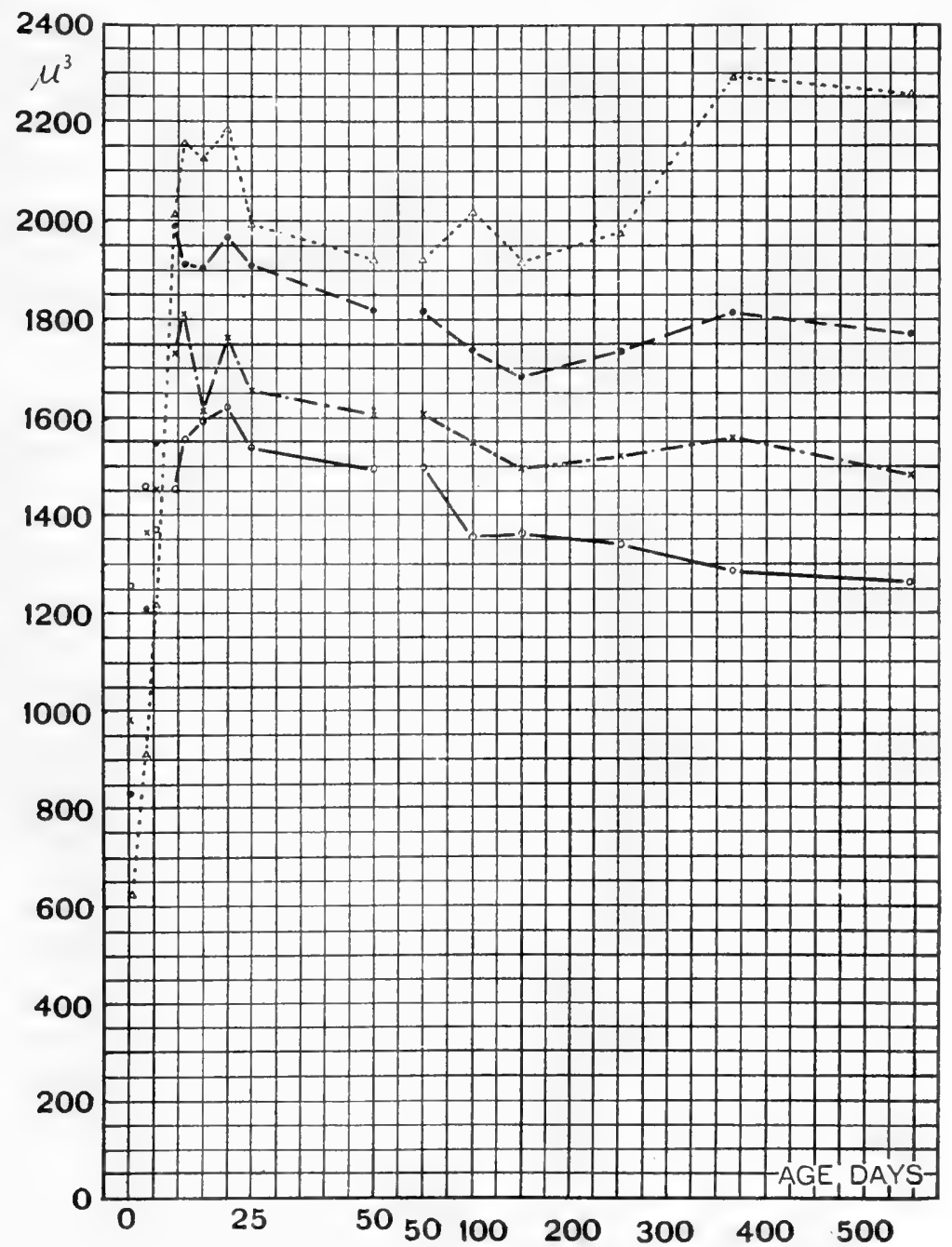

Chart 35 The volume of inner hair cells, according to the turns of the cochlea, table 67. 
The weighted values for the volumes of the inner and outer hair cells in each turn are given in $\mu^{3}$ table 70 . At the bottom of each column is given the ratio from 1 to 12,1 to 20,1 to 546 , and 20 to $5+6$ days of age. While the volume at birth is largest in turn I and smallest in turn IV, that in turn III is largest at

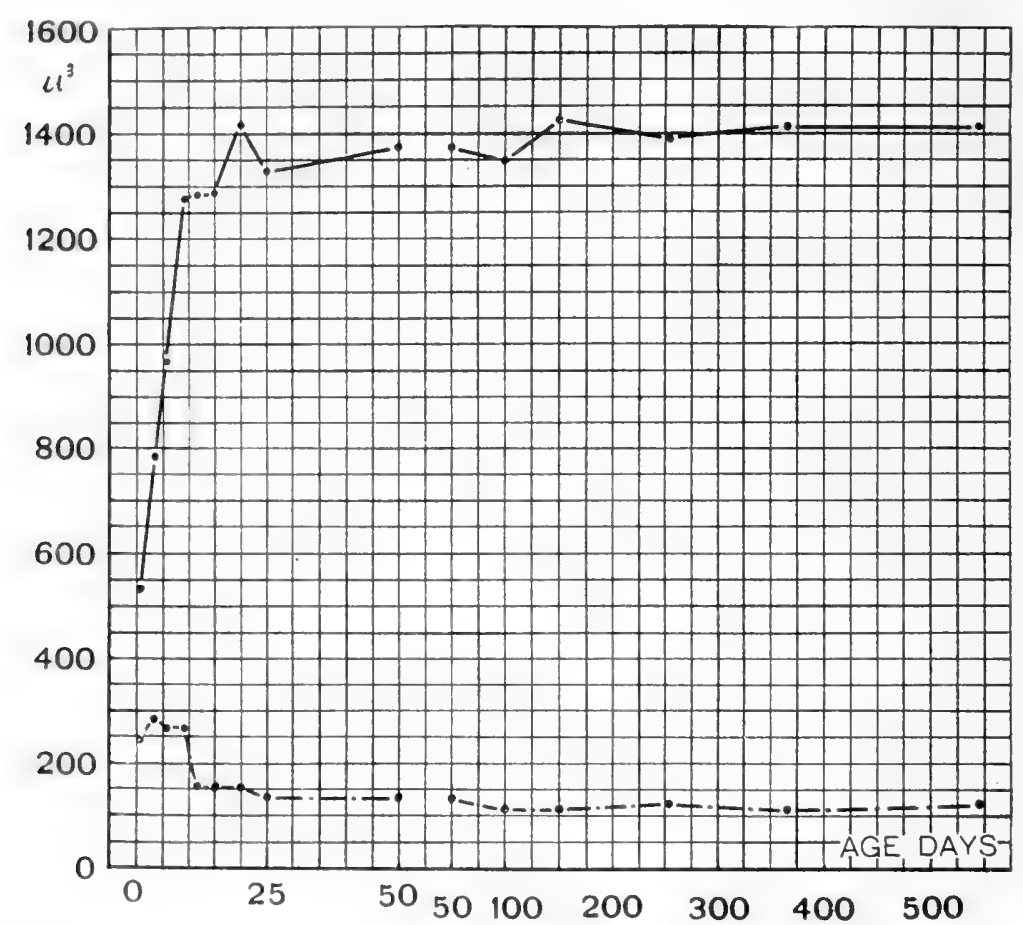

Chart 36 The volume of outer hair cells and of their nuclei, in cubic micra, tables 67 and 69 .

_ Volume of outer hair cells.

-...-.... Volume of nuelej of outer hair cells.

six days. Lfter nine days the volume increases always from base to apex.

Comparing the weighted vo ume in each turn according to age, we find that the rate of increase in volume is smallest in turn I (1.3 to 1.2) and largest in turn IV (3.9 to 4.6) (table 70).

In table 72 are given the weighted values for the diameters of the nuclei of the inner and outer hair cells in each turn. They 
increase and then decrease during the first twelve days. The rate of decrease is largest in turn I, and smallest in turn IV, as the ratios at the bottom of each column show. That the diameters at

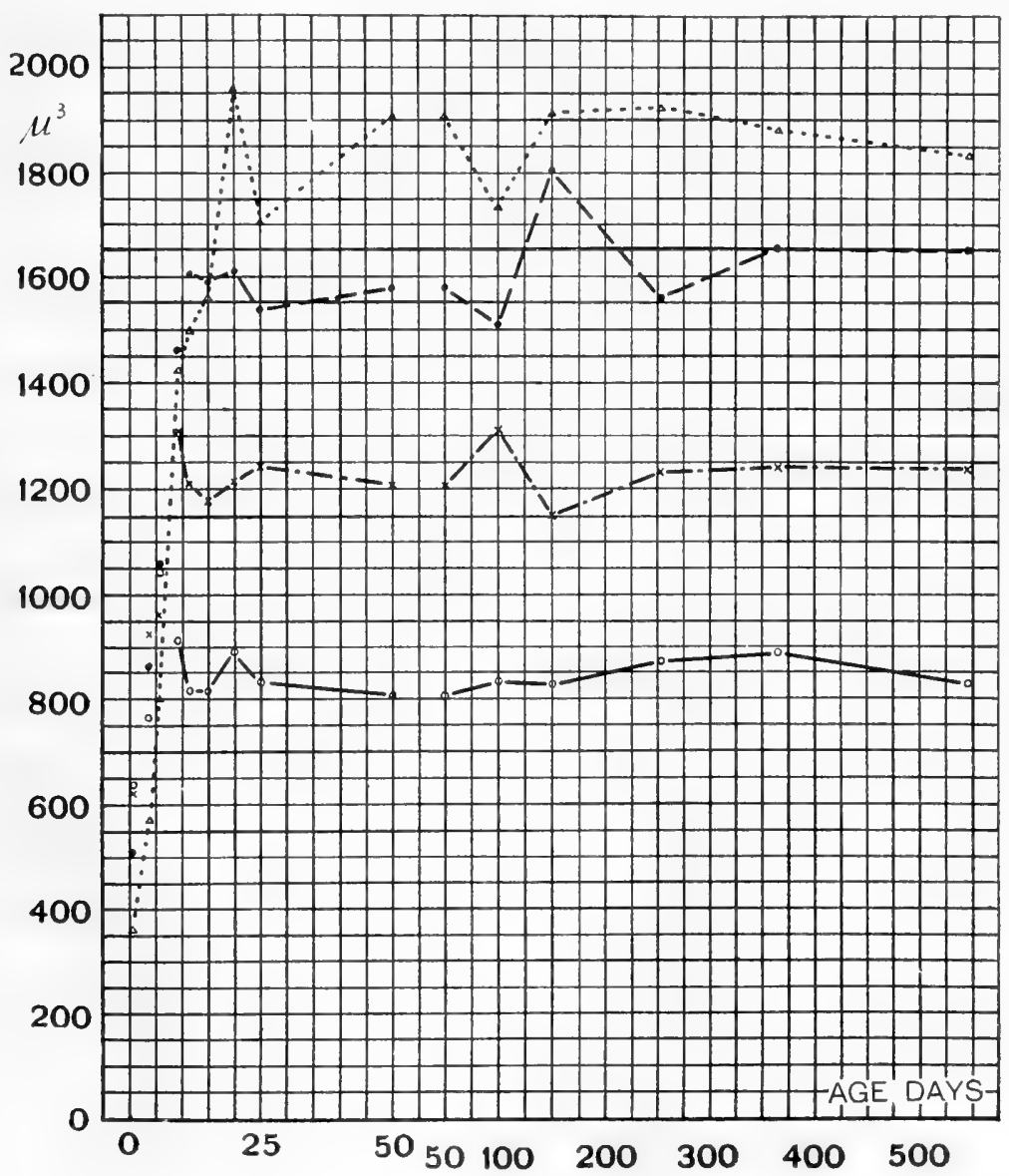

Chart 37 The volume of outer hair cells, according to the turns of the cochlea, table 67.

the later ages have about the same value in each turn, or are a little larger in the upper than in the lower turn, is to be seen in table 73 . 
TABLE 68

Mcan diameters of the nuclei of the inner and outer hair cells-in $\mu$

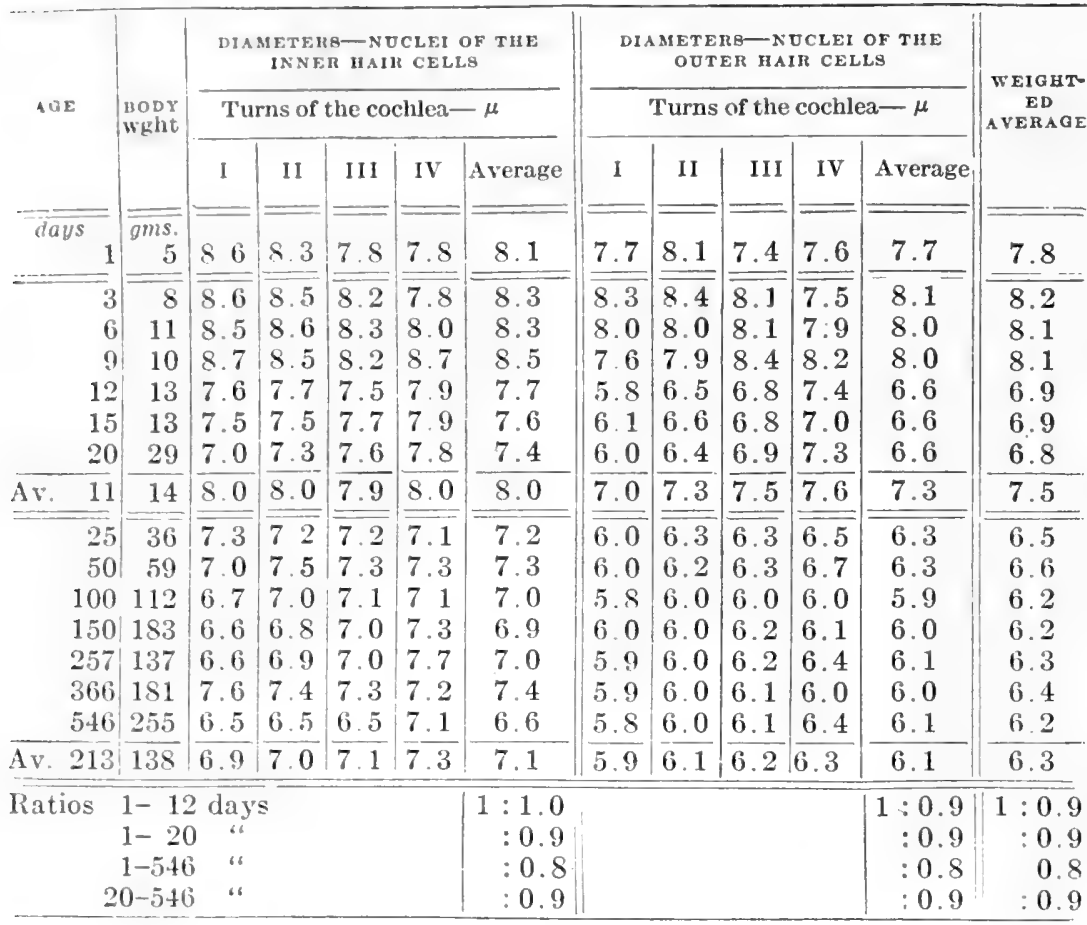

TABLE 69

Average volumes of the nuclei of the inner and outer hair cells (charts 33, 84 and 36)

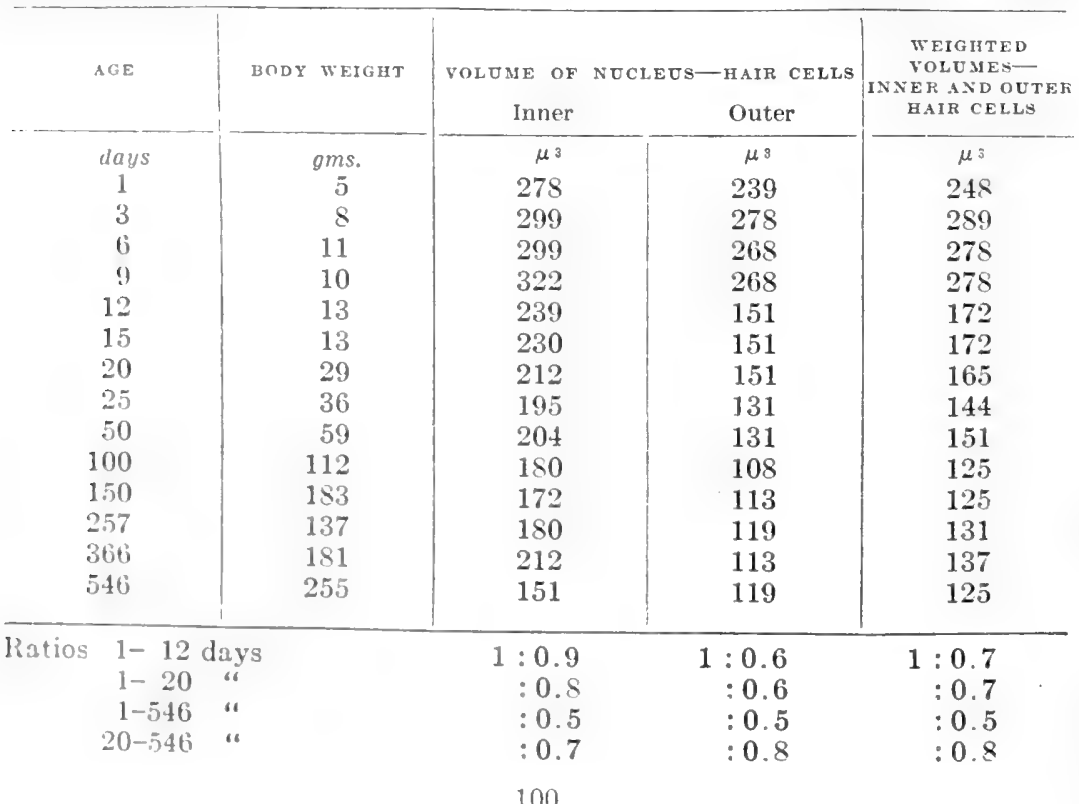


The growth of the inner hair cell. The volume of the inner hair cell table 67 (chart 34) increases with age up to twenty

TABLE 70

Weighted volumes of the inner and outer hair cells according to the turns of the cochlea

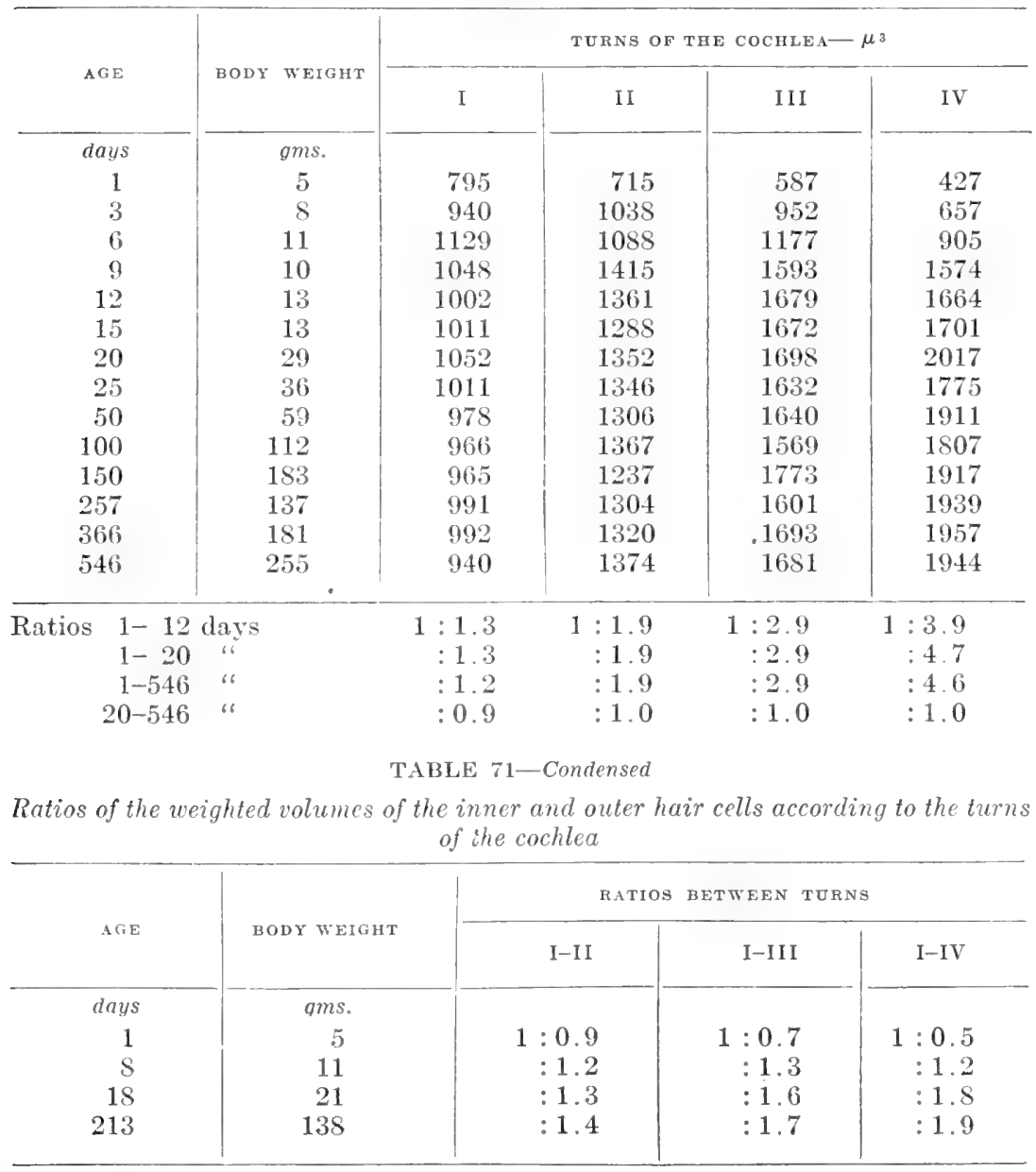

days; to nine days rapidly, then slowly. After twenty days it decreases slowly, as do the weighted volumes of the inner and outer hair cells, and with fluctuations, is nearly the same after 
100 days. The three condensed age groups show that from 1 to 11 days it has increased 80 per cent, while from 11 to 213 days it has gained less than 2 per cent.

TABLE 72

Weighted diameters of the nuclei of the inner and outer hair cells according to the turns of the cochlea

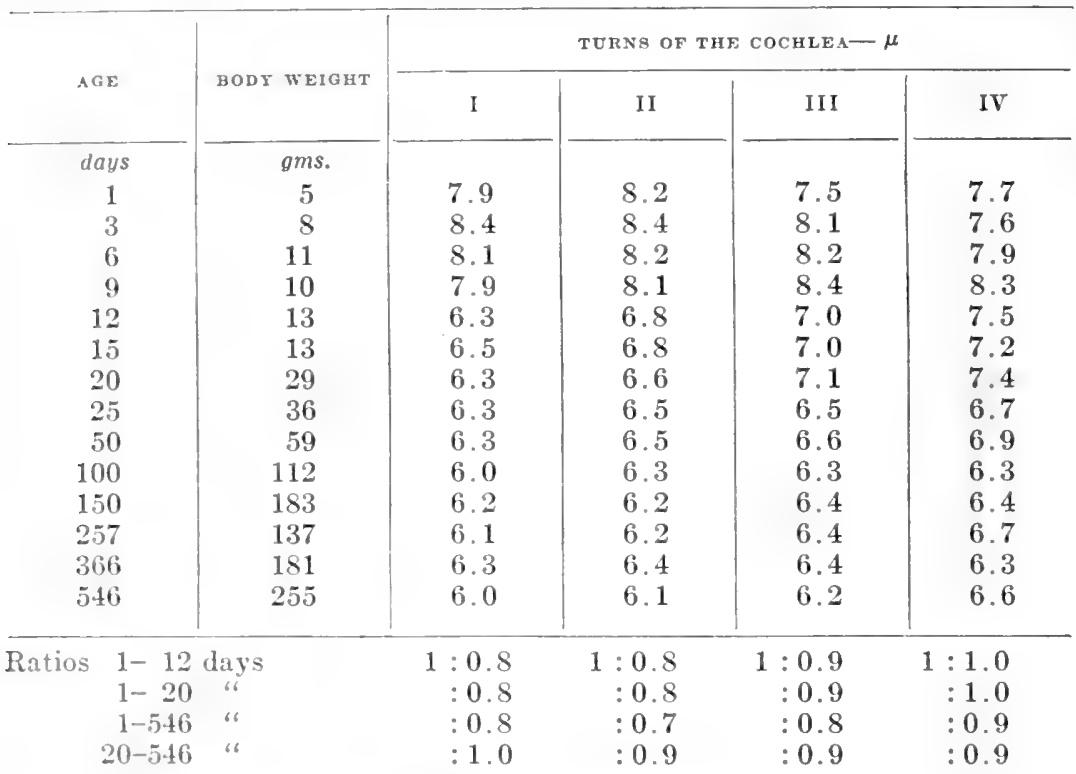

TABLE 73-Condensed

Ratios of the weighted diameters of the nuclei of the inner and outer hair cellsaccording to the turns of the cochlea

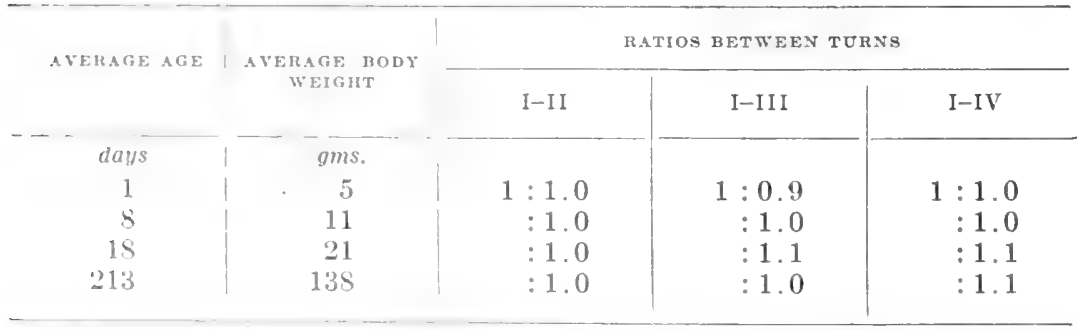

From nine days on the rolume of the inner hair cell increases in passing from the base to the apex. During the earlier stages 
there are some fluctuations (table 67 , chart 35 ). In the condensed table 74 the general relations are shown. The growth of the nuclei of the inner hair cells in diameter is given in table 68 .

As we see, the diameters increase from birth to nine days, then decrease slowly but steadily. In the three average age groups, however, the values decrease continuously with age. .In table 69 are given the values for the volumes of the nuclei of the inner hair cell (chart 34).

TABLE 74-Condensed

Ratios of the volume of the inner hair cells according to the turns of the cochlea

\begin{tabular}{c|c|c|c|c}
\hline \multirow{2}{*}{ AVERAGE AGE } & \multicolumn{3}{|c}{ RATIOS BETWEEN TURNB } \\
& $\begin{array}{c}\text { AVERAGE BODY } \\
\text { WEIGHT }\end{array}$ & I-II & I-III & I-IV \\
\cline { 2 - 4 } & & & & \\
\hline days & grams & $1: 0.8$ & $1: 0.7$ & $1: 0.5$ \\
1 & 14 & $\vdots 1.1$ & $\vdots 1.2$ & $: 1.2$ \\
213 & 138 & $: 1.1$ & $: 1.3$ & $: 1.5$ \\
\hline
\end{tabular}

TABLE 75-Condensed

Ratios of the diamelers of the nuclei of the inner hair cells according to the turns of the cochlea

\begin{tabular}{|c|c|c|c|c|}
\hline \multirow{2}{*}{$\triangle V E R A G E \quad A G E$} & \multirow{2}{*}{$\begin{array}{l}\text { AVERAGE BODY } \\
\text { WEIGHT }\end{array}$} & \multicolumn{3}{|c|}{ RATIOS BETWEEN TURNG } \\
\hline & & I-II & I-III & $\mathrm{I}-\mathrm{IV}$ \\
\hline days & grams & & & \\
\hline 1 & 5 & $1: 1.0$ & $1: 0.9$ & $1: 0.9$ \\
\hline 11 & 14 & $: 1.0$ & $: 1.0$ & $: 1.0$ \\
\hline 213 & 138 & $: 1.0$ & $: 1.0$ & $\therefore 1.1$ \\
\hline
\end{tabular}

The ratios of the diameters of the nuclei of the inner hair cells decrease at the earlier ages in each turn from the base to the apex. After nine days they are nearly the same in all the turns (tables 68 and 75), though their absolute values decrease in all the turns after nine days.

The growth of the outer hair cells. In general, the changes in the volume of the outer hair cells are like those in the inner hair cells. Therefore, the volume increases strikingly up to nine days of age, then gradually to twenty days. The main dif- 
ferenee is that the volume in the outer hair cells does not diminish so much after twenty-five days, but holds nearly the same value (table 67, chart 36). In condensed age groups, therefore, we see a large increase in the size of the cells with age.

To determine the growth of the outer hair cells in each turn of the cochlea, table 67 is used (chart 37 ). From twenty days on the values increase from the basal to the apical turn. Before twenty days the relations are irregular or reversed. In table 76 this relation is clearly brought out.

Comparing the changes of the volume of the outer hair cells in three age groups (table 67), we find that the average volume increases throughout each turn with age, except in turn I, where

TABLE 76-Condensed

Ratios of the volumes of the outer hair cells according to the turns of the cochlea

\begin{tabular}{r|r|r|r|r}
\hline AVERAGE AGE & $\begin{array}{r}\mid c \\
\text { AVERAGE BODT } \\
\text { WEIGHT }\end{array}$ & I-II & I-III & I-IV \\
\hline days & grams & & & \\
1 & 5 & $1: 1.0$ & $1: 0.8$ & $1: 0.6$ \\
11 & 14 & $: 1.3$ & $: 1.6$ & $: 1.5$ \\
213 & 138 & $: 1.5$ & $: 1.9$ & $: 2.2$ \\
\hline
\end{tabular}

that at eleven days is largest. In the inner hair cells, however, values at eleven days are largest in both turn I and II.

For the nuclei of the outer hair cells, the diameters are given in table 68). Here the dameters tend to increase from one to nine days. At twelve days they decrease strikingly, and after that very slowly. In table 69 are given the values for the volumes of the nuclei of the outer hair cells.

In table 68 are given also the measurements for the nuclei of the outer hair cells according to the turn of the cochlea. At nine days and after, the diameters become larger in passing from base to apex, while in the earlier stages this relation is irregular or reversed. The decrease of the measurements in, each turn with age is clearly shown in the three age groups. 
In table 77 are given the average ratios of turn $\mathrm{I}$ to the three other turns.

The comparison of the growth of the inner and outer hair cells. As already stated, the growth of the inner and outer hair cells in volume proceeds in about the same way till they reach their full size at twenty days. After that we note a difference between them. While the outer hair cells maintain a nearly constant volume, the volume of the inner hair cells diminishes

TABLE 77-Condensed

Ratios of the diamelers of the nuclei of the outer hair cells according to the turns of the cochlea

\begin{tabular}{|c|c|c|c|c|}
\hline \multirow{2}{*}{ AVERAGE AGE } & \multirow{2}{*}{$\begin{array}{c}\text { AVERAGE BODY } \\
\text { WEIGHT }\end{array}$} & \multicolumn{3}{|c|}{ RATIOS BETWEEN TURNS } \\
\hline & & $\mathrm{I}-\mathrm{II}$ & I-III & $\mathrm{I}-\mathrm{IV}$ \\
\hline days & grams & & & \\
\hline 1 & 5 & $1: 1.1$ & $1: 1.0$ & $1: 1.0$ \\
\hline 11 & 14 & $: 1.0$ & $: 1.1$ & $: 1.1$ \\
\hline 213 & 138 & $: 1.0$ & $: 1.1$ & $: 1.1$ \\
\hline
\end{tabular}

TABIE 78-Condensed

Comparison of the volumes of the inner and the outer hair cells

\begin{tabular}{|c|c|c|c|c|}
\hline \multirow{2}{*}{ AVERAGE AGE } & \multirow{2}{*}{$\begin{array}{l}\text { AVERAGE BODY } \\
\text { WEIGHT }\end{array}$} & \multicolumn{2}{|c|}{ AVERAGE VOLUMES-HAIR CELLS } & \multirow{2}{*}{$\begin{array}{l}\text { RATIOS OF INNER } \\
\text { TO OUTER }\end{array}$} \\
\hline & & Inner & Outer & \\
\hline days & grams & $\mu^{3}$ & $\mu^{3}$ & \\
\hline 1 & 5 & 925 & 533 & $1: 0.6$ \\
\hline 11 & 14 & 1665 & 1169 & $: 0.7$ \\
\hline 213 & 138 & 1693 & 1385 & $: 0.8$ \\
\hline
\end{tabular}

somewhat with age. When we consider the volume according to the three age groups, it increases in both groups throughout life (table 78). There are, however, large differences in the rate of increase. The inner hair cell increases its volume at 11 days by 80 per cent and between 11 and 213 days by less than 2 per cent. For the outer hair cells the increase by 11 days is 120 per cent and from 11 to 213 days, 19 per cent. At the same time the inner are always larger than the outer hair cells, as the ratios in table 78 show. 
The diameters of the nuclei in both the inner and outer hair cells diminish in value after nine days of age. This decrease is larger in the outer than in the inner cells. In table 79 are given the values for the diameters of the nuclei in both inner and outer hair cells. In the last column are the ratios between them.

Thus, while the volumes of the outer hair cells, as compared with the inner hair cells, become relatively larger with age (table 78), the diameters of their nuclei become relatively smaller (table 79).

TABLE 79-Condensed

Comparison of the diameters of the nuclei of the inner and outer hair cells

\begin{tabular}{|c|c|c|c|c|}
\hline \multirow{2}{*}{ AVERAGEAGE } & \multirow{2}{*}{$\begin{array}{c}\text { AVERAGE } \\
\text { BODY } \\
\text { WEIGHT }\end{array}$} & \multicolumn{2}{|c|}{$\begin{array}{l}\text { AVERAGE DIAMETERS OF THE } \\
\text { NUCLEI OF THE HATR CELLS }\end{array}$} & \multirow{2}{*}{$\begin{array}{c}\text { RATIOS OF THE AVERAGE } \\
\text { DIAMETERS OFTHE NUCLEIOF } \\
\text { THE INNER AND OUTER HATR } \\
\text { CELLS }\end{array}$} \\
\hline & & Inner & Outer & \\
\hline days & grams & $\mu$ & $\mu$ & \\
\hline 1 & 5 & 8.1 & 7.7 & $1: 1.0$ \\
\hline 11 & 14 & 8.0 & 7.3 & $: 0.9$ \\
\hline 213 & 138 & 7.1 & 6.1 & $: 0.9$ \\
\hline
\end{tabular}

Comparison of the growth of the inner and outer hair cells according to sex. A careful and elaborate comparison has been made to determine whether there are differences in the growth of the hair cells according to sex.

In table 80 are given the average values for the volumes of the rell borlies and their respective nuclei. No significant differences according to sex were found.

Comparison of the growth of the inner and outer hair cells according to side. The same treatment of the data was followed as in the determination for the influence of sex. In table 81 are given the average values for the volumes of the inner and outer hair cells and their respective nuclei. Again no significant differences according to side were found.

On the mucleus-plasma ratios of the inner and outer hair cells. For the inner and outer hair cells here measured the weighted volumes of the cell bodies and of their nuclei are entered in the rondensed table 82 , and the ratios of the volume of the nucleus. 
to that of the cytoplasm (=cell volume less nucleus volume) are given in the last column. This ratio increases with age, as table 82 shows. While the ratio is 1.5 in the youngest and smallest group, it is 9.9 in the largest. This means that as a group these cells are continually growing in volume. This result may be analysed for the two groups of cells involved.

TABLE 80

Average volumes of inner and ouler hair cells and of their respective nucleiin $\mu^{3}$ according to sex

\begin{tabular}{|c|c|c|c|c|c|c|c|c|c|}
\hline \multirow{3}{*}{$\mathcal{A Q E}$} & \multirow{3}{*}{ BODY } & \multirow{3}{*}{$\begin{array}{c}\text { NO. OF } \\
\text { RATS }\end{array}$} & \multirow{3}{*}{ SEX } & \multirow{2}{*}{\multicolumn{2}{|c|}{$\begin{array}{c}\text { INNER HAIR CELLS } \\
\text { Average volume }\end{array}$}} & \multirow{2}{*}{\multicolumn{2}{|c|}{ OUTER HAIR CELLS }} & \multirow{2}{*}{\multicolumn{2}{|c|}{$\begin{array}{l}\text { WEIGHTED AVERAGE } \\
\text { VOLUME }\end{array}$}} \\
\hline & & & & & & & & & \\
\hline & & & & Cell & Nucleus & Cell & Nucleus & CELLS & NUCLEI \\
\hline days & grams & & & & & & & & \\
\hline \multirow[t]{2}{*}{3} & 7 & 1 & $\sigma^{7}$ & 1213 & 310 & 815 & 268 & 915 & 278 \\
\hline & 8 & 1 & 우 & 1319 & 310 & 888 & 322 & 996 & 319 \\
\hline \multirow[t]{2}{*}{6} & 11 & 2 & $\sigma^{7}$ & 1426 & 289 & 955 & 278 & 1073 & 281 \\
\hline & 10 & 2 & & 1372 & 310 & 979 & 268 & 1077 & 278 \\
\hline \multirow[t]{2}{*}{9} & 10 & 2 & $\sigma^{x}$ & 1701 & 310 & 1351 & 258 & 1439 & 271 \\
\hline & 9 & 2 & 우 & 1895 & 345 & 1203 & 278 & 1376 & 295 \\
\hline \multirow[t]{2}{*}{12} & 14 & 2 & $\sigma^{x}$ & 1830 & 258 & 1344 & 157 & 1466 & 182 \\
\hline & 12 & 2 & ๆ & 1886 & 221 & 1221 & 151 & 1387 & 168 \\
\hline \multirow[t]{2}{*}{100} & 146 & 1 & $\sigma^{7}$ & 1687 & 180 & 1342 & 113 & 1428 & 129 \\
\hline & 103 & 1 & q & 1779 & 212 & 1319 & 108 & 1434 & 184 \\
\hline \multirow[t]{2}{*}{150} & 189 & 1 & $\sigma^{7}$ & 1679 & 165 & 1382 & 119 & 1456 & 131 \\
\hline & 154 & 1 & 우 & 1639 & 212 & 1611 & 119 & 1618 & 142 \\
\hline \multirow[t]{2}{*}{365} & 205 & 1 & $\sigma^{7}$ & 1739 & 258 & 1389 & 119 & 1477 & 154 \\
\hline & 170 & 1 & q & 1659 & 221 & 1486 & 113 & 1529 & 140 \\
\hline \multirow{3}{*}{\multicolumn{4}{|c|}{$\begin{array}{l}\text { Volume greater in male } \\
\text { Volume greater in female } \\
\text { Equal }\end{array}$}} & 3 & 2 & 3 & 4 & 5 & 3 \\
\hline & & & & 4 & 4 & 4 & 2 & 2 & 4 \\
\hline & & & & 0 & 1 & 0 & 1 & 0 & 0 \\
\hline
\end{tabular}

The nucleus-plasma ratio of the inner and outer hair cells considered separately. This is shown for the inner hair cells in table 83. The ratios are also progressive, but somewhat larger for the earlier age groups and smaller for the oldest, than in the previous instance.

The ratios for the outer hair cells are also progressive, and the range is greater than for the inner hair cells as table 84 shows. Here the ratio is 1.2 for the youngest group and 10.6 for the 
oldest. This indieates that at one day and eleven days the relative rolume is less in the outer than in the inner hair cells, but at the later age the outer hairs cells grow more.

TABLE 81

Tolumes of the inner and outer hair cells and of their respective nuclei according to side in $\mu^{3}$

\begin{tabular}{|c|c|c|c|c|c|c|c|c|c|}
\hline \multirow{3}{*}{$A G E$} & \multirow{3}{*}{$\begin{array}{c}\text { BODY } \\
\text { WEIGHT }\end{array}$} & \multirow{3}{*}{$\left|\begin{array}{cc}\text { No. } & \text { OF } \\
\text { RATS }\end{array}\right|$} & \multirow{3}{*}{$\mid$} & \multicolumn{4}{|c|}{ INNER GATR CELLS | OOTER HAIR CELLS' } & \multirow{2}{*}{\multicolumn{2}{|c|}{$\begin{array}{l}\text { WEIGHTED AVERAGE } \\
\text { VOLUME }\end{array}$}} \\
\hline & & & & \multicolumn{2}{|c|}{ Average volume } & \multicolumn{2}{|c|}{ Average rolume } & & \\
\hline & & & & Cell & Nucleus & Cell & Nucleus & CELLS & NUCLEI \\
\hline \multirow[t]{2}{*}{1} & 5 & 2 & $\mathrm{R}$. & 895 & 299 & 555 & 248 & 640 & 261 \\
\hline & & & L. & $9 \tilde{5}$ & 268 & 511 & 230 & 622 & 239 \\
\hline \multirow[t]{2}{*}{3} & 7 & 1 & $\mathrm{R}$. & 1213 & 310 & 815 & 268 & 915 & 278 \\
\hline & & & L. & 1395 & 299 & 920 & 299 & 1039 & 299 \\
\hline \multirow[t]{2}{*}{6} & 11 & 2 & R. & 1381 & 322 & 1010 & 278 & 1103 & 289 \\
\hline & & & L. & 1416 & 289 & 923 & 258 & 1046 & 268 \\
\hline \multirow[t]{2}{*}{9} & 9 & 2 & $\mathrm{R}$. & 1782 & 310 & 1177 & 268 & 1328 & 278 \\
\hline & & & L. & 1815 & 333 & 1378 & 268 & 1487 & 284 \\
\hline \multirow[t]{2}{*}{12} & 12 & 1 & R. & 1887 & 212 & 1310 & 151 & 1454 & 166 \\
\hline & & & L. & 1885 & 221 & 1132 & 151 & 1320 & 168 \\
\hline \multirow[t]{2}{*}{15} & 13 & 1 & IR. & 1895 & 230 & 1522 & 144 & 1615 & 165 \\
\hline & & & L. & 1848 & 239 & 1419 & 151 & 1526 & 172 \\
\hline \multirow[t]{2}{*}{20} & 29 & 2 & $R$. & 1914 & 212 & 1365 & 144 & 1502 & 161 \\
\hline & & & L. & 1862 & 221 & 1472 & 165 & 1570 & 179 \\
\hline \multirow[t]{2}{*}{25} & 36 & 2 & $R$. & $175 \mathrm{~s}$ & 204 & 1307 & 131 & 1420 & 149 \\
\hline & & & L. & 1732 & 195 & 1351 & 131 & 1461 & 147 \\
\hline \multirow[t]{2}{*}{50} & 59 & 2 & R. & $17+1$ & 201 & 1443 & 125 & 1518 & 145 \\
\hline & & & L. & 1687 & 204 & 1305 & 137 & 1401 & 154 \\
\hline \multirow[t]{2}{*}{100} & . 102 & 2 & $\mathrm{R}$. & 1675 & 187 & 1355 & 113 & 1440 & 131 \\
\hline & 123 & 2 & L. & 1658 & 172 & 1339 & 113 & 1419 & 128 \\
\hline \multirow[t]{2}{*}{150} & 189 & 1 & $R$. & 1565 & 172 & 1420 & 113 & 1456 & 128 \\
\hline & & & L. & 1679 & 165 & 1382 & 119 & 1456 & 131 \\
\hline \multirow[t]{2}{*}{257} & 137 & 2 & $\mathrm{R}$. & 1685 & 187 & 1377 & 125 & 1454 & 140 \\
\hline & & & L. & 1607 & 180 & 1416 & 119 & 1464 & 134 \\
\hline 367 & 175 & 2 & R. & 1634 & 195 & 1436 & 113 & 1486 & 134 \\
\hline 36.5 & $18 \mathrm{~s}$ & 2 & L. & 1848 & 230 & 1374 & 113 & 1493 & 142 \\
\hline \multirow[t]{2}{*}{546} & 2.55 & 2 & $\mathrm{R}$. & 1831 & 157 & 1474 & 119 & 1563 & 128 \\
\hline & & & L. & 1559 & 151 & 1353 & 119 & 1405 & 127 \\
\hline \multirow{3}{*}{\multicolumn{4}{|c|}{$\begin{array}{l}\text { Volume greater on right sid } \\
\text { Volump greater on left side } \\
\text { Equal }\end{array}$}} & side 7 & 8 & 9 & 3 & 7 & 6 \\
\hline & & & & ide 7 & 5 & 5 & 5 & 6 & 8 \\
\hline & & & & 0 & 1 & 0 & 6 & 1 & 0 \\
\hline
\end{tabular}


This seems to be important and to illustrate the fact that in the papilla spiralis the growth of the elements lying nearer the axis occurs earlier than that of the elements nearer the periphery.

TABLE 82-Condensed

Nucleus-plasma ratios of the inner and outer hair cells- $\mu^{3}$

\begin{tabular}{|c|c|c|c|c|c|}
\hline \multirow{2}{*}{$\begin{array}{l}\text { AVERAGE } \\
\text { AGE }\end{array}$} & \multirow{2}{*}{$\begin{array}{c}\text { A VERAGE } \\
\text { BODY } \\
\text { WEIGHT }\end{array}$} & \multicolumn{2}{|c|}{$\begin{array}{c}\text { AVERAGE VOLUME OF } \\
\text { INNERANDOUTER HATR CELLS }\end{array}$} & \multirow{2}{*}{$\begin{array}{l}\text { VOLUME OF } \\
\text { CYTOPLASM }\end{array}$} & \multirow{2}{*}{$\begin{array}{l}\text { NUCLEUS- } \\
\text { PLASMA RATIOS }\end{array}$} \\
\hline & & Cell & Nucleus & & \\
\hline days & grams & & & & \\
\hline 1 & 5 & 631 & 248 & 383 & $1: 1.5$ \\
\hline 11 & 14 & 1293 & 226 & 1067 & $: 4.7$ \\
\hline 213 & 138 & 1462 & 134 & 1328 & $: 9.9$ \\
\hline
\end{tabular}

TABLE 83-Condensed

Nucleus-plasma ratios of the inner hair colls- $\mu^{3}$

\begin{tabular}{|c|c|c|c|c|c|}
\hline \multirow{2}{*}{$\begin{array}{c}\text { AVERAGE } \\
\text { AGE }\end{array}$} & \multirow{2}{*}{$\begin{array}{l}\text { AVERAGE } \\
\text { BODY } \\
\text { WEIGHT }\end{array}$} & \multicolumn{2}{|c|}{$\begin{array}{c}\text { AVFRAGE VOLUME OF INNER } \\
\text { HAIK CELLS }\end{array}$} & \multirow{2}{*}{$\begin{array}{c}\text { VOLUME } \\
\text { OF } \\
\text { CYTOPLASM }\end{array}$} & \multirow{2}{*}{$\begin{array}{c}\text { NUCLEUS- } \\
\text { PLASMA RATIOS }\end{array}$} \\
\hline & & Cell & Nucleus & & \\
\hline days & gms. & & & & \\
\hline 1 & 5 & 925 & 278 & 647 & $1: 2.3$ \\
\hline 11 & 14 & 1665 & 268 & 1397 & $: 5.2$ \\
\hline 213 & 138 & 1693 & 187 & 1506 & $: 8.1$ \\
\hline
\end{tabular}

TABLE 84-Condensed

$N$ ucleus-plasma ratios of the outer hair cells

\begin{tabular}{|c|c|c|c|c|c|}
\hline \multirow{2}{*}{$\begin{array}{l}\text { AVERAGE } \\
\text { AGE }\end{array}$} & \multirow{2}{*}{$\begin{array}{c}\text { AVERAGE } \\
\text { BODY } \\
\text { WEIGHT }\end{array}$} & \multicolumn{2}{|c|}{$\begin{array}{c}\text { AVERAGE VOLUME OF OUTER } \\
\text { HAJR CELLS }\end{array}$} & \multirow{2}{*}{$\begin{array}{l}\text { YOLUME OF } \\
\text { CYTOPLASM }\end{array}$} & \multirow{2}{*}{$\begin{array}{l}\text { NUCLEUS- } \\
\text { PLASMA } \\
\text { RATIOS }\end{array}$} \\
\hline & & Cell & Nucleus & & \\
\hline days & grams & & & & \\
\hline 1 & 5 & 533 & 239 & 294 & $1: 1.2$ \\
\hline 11 & 14 & 1169 & 204 & 965 & $: 4.7$ \\
\hline 213 & 138 & 1385 & 119 & 1266 & $: 10.6$ \\
\hline
\end{tabular}

17. Deiters' cells. The Deiters' cells are most delicate elements. In the literature, so far as I know, there are no exact observations touching the growth of these cells in the papilla spiralis, except a few data for their length. They have an 
irregular form and consist of three parts, the phalangeal process, cell body, and foot. The phalangeal process is thin, somewhat crooked in the adult though it runs straight at an earlier stage. As the boundary between this process and the cell body, we take a line running through the supporting cup ('Stutzkelch' of Held) parallel to the plane of the basilar membrane (fig. 10). The cell body in its upper part is wide, including here a round nucleus. It then becomes thin and passes over to the foot. Thus it is almost impossible to get the true volume of the cells. Therefore, we have determined the volume of the cell body only, excluding that of the phalangeal process.

We think of the cell body as a cylinder having an average diameter, which is calculated from four diameters measured at four levels. The first level is just below the upper boundary of the cell body, the second in the widest part, the third below at about the middle of the cell body, and the last is at the narrowest part near the foot.

The height of the cylinder is the length of the cell body within the limits just noted. Thus the volume obtained approximates the value for the natural size of the cell body without the process.

In table 85 (chart 38) are given the values for the volumes of the Deiters' cells thus computed and the diameters and volumes of the nuclei according to age. As there are in the radial section three rows of cells, the values given are, of course, the average of these. At the bottom of the last column appear the ratios at 1 to 12,1 to 20,1 to 546 , and 12 to 546 days. As we see, the volume of the cell body increases throughout life, slowly during the first nine lays, but from twelve to twenty days very rapidly, and then less rapidly to old age.

While the ratio from one to twelve days is $1: 5.4$, that from 1 to 546 days is $1: 29.1$, or more than five times as large.

When we consider the volumes of the cells in each turn of the cochlea, we see that it is smallest in turn I and largest in turn IV, though there are some exceptions before nine days of age. Table 86 shows these relations.

The diameters of the nuclei of the cells grow, after some fluctuations in the values at earlier stages, very slowly to old 
age, as indicated in table 85 and chart 38 . The ratios at the bottom of the corresponding column show these relations. The values for the volumes of the nuclei of the cells are given in the last column. Here, also, the diameters in the upper turns tend to be larger than in the basal turn. In table 87 are given the ratios of the diameters of turn I to the three other turns. We see in all the turns about the same ratios, 1:1.0.

In the literature we find but two observations on the diameters of the nuclei of the Dieters' cells. Kolmer ('07) reports in the pig $5 \mu$, and von Ebner ('02) gives in man $7 \mu$ for. the diameter of the round nucleus of the cells.

In the rat, therefore, the diameter is larger than in these two forms, but no significance can be attached to this difference until correction has been made for the several techniques employed. This I am unable at present to do.

On the nucleus-plasma ratio in Deiters' cells. In the condensed table 88 are given the volumes of the cell bodies and of their nuclei together with the respective nucleus-plasma ratios. This shows that the ratio is progressive with age. While the ratio is at birth only 0.05 , that in the oldest group is 28.3 . The absolute increase is not great at earlier stages, but by eighteen days it is marked

The rapid change in the ratio is very interesting. Before eight days of age the cells are still immature. Some time after eight days they develop rapidly, seeming to play some important part in the special functions of the cochlea.

On the length of Deiters' cells. To measure the length of Deiters' cells we divide them into two parts, the upper and the lower, by the boundary line between the cell body and the phalangeal process. The sum of these two lengths makes the total length of the cells.

In table 89 are given the values for the total length and for each part separately (chart 39). As in the volume of the cells, we see an astonishing change in the development of the length. The length of the cells increases through life, at earlier stages a little, but at twelve days it becomes nearly twice as long as at nine days. The ratios at the bottom of the last column show the course of growth. 
TABLE 85

The volume of Deiters' cells and the mean diamelers and volumes of their respective nuclei (chart 38)

\begin{tabular}{|c|c|c|c|c|c|c|c|c|c|c|c|c|}
\hline \multirow{2}{*}{$\operatorname{AGE}$} & \multirow{2}{*}{$\begin{array}{c}\text { BODY } \\
\text { WEIGHT }\end{array}$} & \multicolumn{5}{|c|}{ VOLOME OF THF DEEITERE' CELLS } & \multicolumn{5}{|c|}{$\begin{array}{l}\text { NOCLEI } \\
\text { Diameters }\end{array}$} & \multirow{2}{*}{$\begin{array}{l}\text { VOLUAES } \\
-\begin{array}{c}\text { Average } \\
\text { volumes } \\
\mu^{2}\end{array}\end{array}$} \\
\hline & & I & II & III & IV & $\left|\begin{array}{l}\text { A verage } \\
\text { volume }\end{array}\right|$ & I & II & III & IV & $\begin{array}{c}\text { A verage } \\
\text { diam- } \\
\text { eters } \\
\mu\end{array}$ & \\
\hline days & grams & & & & & & & & & & & \\
\hline 1 & 5 & 278 & 232 & 237 & 256 & 251 & 7.6 & 7.5 & 7.5 & 8.1 & 7.7 & 239 \\
\hline 3 & 8 & 290 & 309 & 349 & 352 & 325 & 7.0 & 7.0 & 6.9 & 7.0 & 7.0 & 180 \\
\hline 6 & 11 & 425 & 395 & 495 & 364 & 420 & 7.0 & 6.5 & 6.7 & 6.6 & 6.7 & 165 \\
\hline 9 & 10 & 635 & 461 & 554 & 423 & 518 & 6.9 & 7.0 & 7.1 & 7.1 & 7.0 & 180 \\
\hline 12 & 13 & 1122 & 1369 & 13951 & 1569 & 1364 & 6.5 & 7.0 & 6.9 & 7.1 & 6.9 & 180 \\
\hline 15 & 13 & 1466 & 2187 & 26593 & 3127 & 2359 & 7.0 & 7.2 & 7.2 & 7.3 & 7.2 & 195 \\
\hline 20 & 29 & 3576 & 4271 & 57406 & 6171 & 4939 & 7.6 & 7.8 & 7.9 & 7.9 & 7.8 & 248 . \\
\hline 25 & 36 & 4088 & 4467. & 54705 & 5757 & 4695 & 7.3 & 7.2 & 7.3 & 7.4 & 7.3 & 212 \\
\hline 50 & 59 & 4839 & 5970 & 62586 & 6816 & 5971 & 7.3 & 7.5 & 7.5 & 7.4 & 7.4 & 212 \\
\hline 100 & 112 & 5011 & 6083 & 71376 & 6607 & 6210 & 6.9 & 7.6 & 7.5 & 7.4 & 7.3 & 212 \\
\hline 150 & 183 & 5755 & 6291 & 76576 & 3750 & 6613 & 7.5 & 7.6 & 7.5 & 7.1 & 7.4 & 212 \\
\hline 257 & 137 & 5776 & 6540 & 88418 & 8544 & 7425 & 7.4 & 7.8 & 7.9 & 8.0 & 7.8 & 248 \\
\hline 366 & 181 & 6163 & 6908 ? & 77017 & 7895 & 7167 & 7.4 & 7.7 & 7.9 & 7.9 & 7.7 & 248 \\
\hline 546 & 255 & $6092^{\prime}$ & 6919 & 80288 & 8152 & 7298 & 7.4 & 7.9 & 8.0 & 7.7 & 7.7 & 248 \\
\hline Ratios & $1-1$ & 12 day & & & & $1: 5.4$ & & & & & $1: 0.9$ & \\
\hline & 1 - & 20 " & & & & $: 19.7$ & & & & & $: 1.0$ & \\
\hline & $1-5$ & $46 "$ & & & & $: 29.1$ & & & & & $: 1.0$ & \\
\hline & $12-5$ & $46 "$ & & & & $\{5.4$ & & & & & $: 1.1$ & \\
\hline
\end{tabular}

TABLE 86-Condensed

Ratios of volumes of the Deiter's cells according to turns of the cochlea

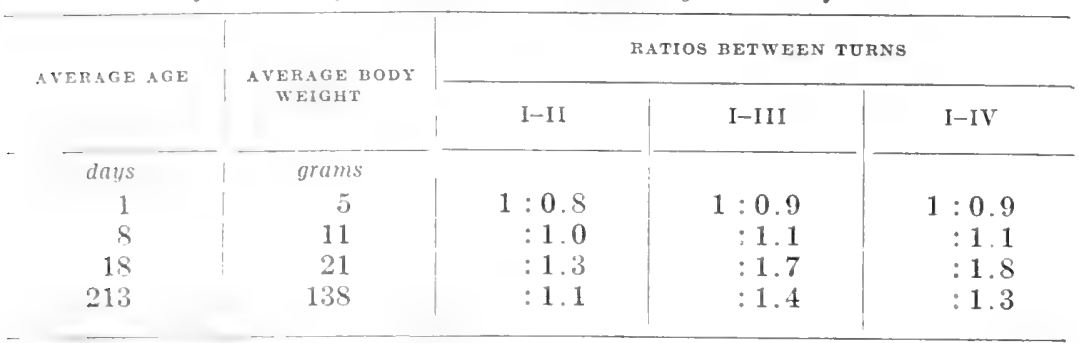

TABLE 87 -Condensed

Ratios of the dinmeters of the nuclei of Deiters' cells according to turns of the cochlea

\begin{tabular}{|c|c|c|c|c|}
\hline \multirow{2}{*}{ AVERACE ACIE } & \multirow{2}{*}{$\begin{array}{l}\text { I AVERAGE HODY } \\
\text { WEIGHT }\end{array}$} & \multicolumn{3}{|c|}{ RATIOS BETWEEN TURNS } \\
\hline & & $\mathrm{I}-\mathrm{II}$ & $I-I I I$ & I-IV \\
\hline$d a \| / s$ & rorams & & & \\
\hline 1 & 5 & $1: 1.0$ & $1: 1.0$ & $1: 1.1$ \\
\hline 8 & 11 & $: 1.0$ & $: 1.0$ & $: 1.0$ \\
\hline 18 & 21 & $: 1.0$ & $: 1.0$ & $: 1.0$ \\
\hline 213 & 138 & $: 1.0$ & $: 1.1$ & $: 1.0$ \\
\hline
\end{tabular}




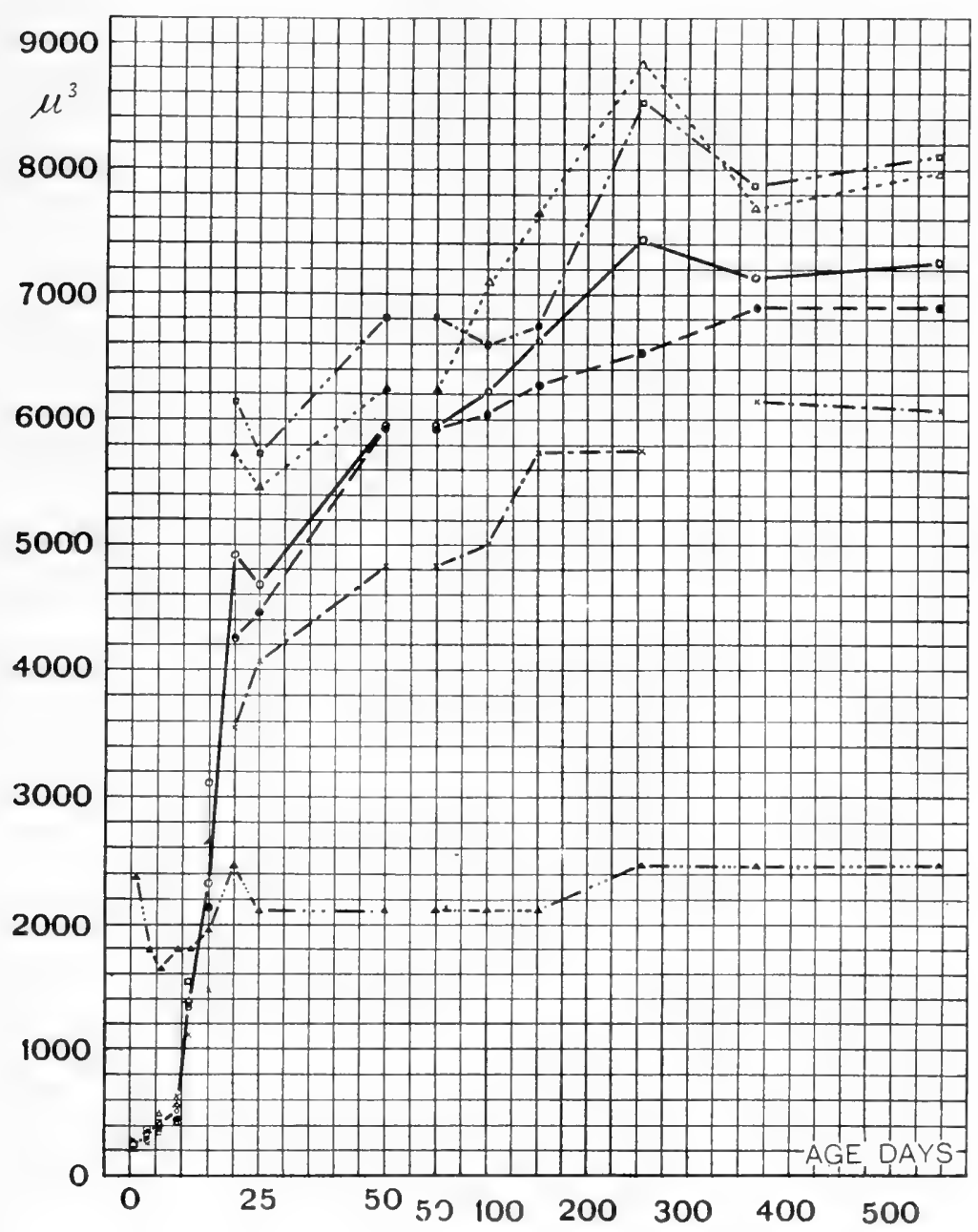

Chart 38 Showing the volume of Deiters' cells and their nuclei, on the average and according to the turns of the cochlea, table 85 .

___ _ Average volume of Deiters' cells.

-........ Volume of the cells in about the middle of the basal turn.

-.-.-.- Volume of the cells in about the beginning of the middle turn.

Volume of the cells in about the middle of the middle turn.

-...... Volume of the cells in about the beginning of the apical turn.

$\ldots \ldots$ Average volume of nuclei of Deiters' cells, $\times 10$. 
Comparing the length of the cells according to the turn of the cochlea, we find that after twelve days the length increases from the base to the apex, in turn III very rapidly, in turn IV gradually (table 90). At earlier stages the relations are irregular.

TABLE 88-Condensed

Nucleus-plasma ratios of the Deiters' cells

\begin{tabular}{|c|c|c|c|c|c|}
\hline \multirow{2}{*}{ AVERAGE AGE } & \multirow{2}{*}{$\begin{array}{c}\text { AVERAGE BODY } \\
\text { WEIGHT }\end{array}$} & \multicolumn{2}{|c|}{$\triangle V E R A G E$ VOLUMES } & \multirow{2}{*}{$\begin{array}{c}\text { VOLUME OF } \\
\text { CYTOPLAEM } \\
\mu^{3}\end{array}$} & \multirow{2}{*}{$\begin{array}{l}\text { NUCLEUS- } \\
\text { PLASMA RATIOS }\end{array}$} \\
\hline & & $\underset{\mu^{3}}{\text { Cell }}$ & $\underset{\mu^{3}}{\text { Nucleus }}$ & & \\
\hline days & grams & & & & \\
\hline 1 & 5 & 251 & 239 & 12 & $1: 0.05$ \\
\hline 8 & 11 & 657 & 172 & 485 & $: 2.8$ \\
\hline 18 & 21 & 3649 & 221 & 3428 & $: 15.5$ \\
\hline 213 & 138 & 6483 & 221 & 6262 & $: 28.3$ \\
\hline
\end{tabular}

TABLE 89

Length of cell body and of processus phalangeus of Deiters' cells $\mu$ (chart 39)

\begin{tabular}{|c|c|c|c|c|c|c|c|c|c|c|c|c|}
\hline \multirow{3}{*}{$A G E$} & \multirow{3}{*}{$\begin{array}{l}\text { BODY } \\
\text { WEIGHT }\end{array}$} & \multicolumn{5}{|c|}{ LENGTH OF THE CELL BODY } & \multicolumn{5}{|c|}{$\begin{array}{c}\text { LENGTH OF THE PROCESSUS } \\
\text { PHALANGEOS }\end{array}$} & \multirow{3}{*}{$\begin{array}{l}\text { TOTAL } \\
\text { LENGTH } \\
\text { OF THE } \\
\text { CELLS }\end{array}$} \\
\hline & & \multicolumn{5}{|c|}{ Turns of cochlea } & \multicolumn{5}{|c|}{ Turns of cochlea } & \\
\hline & & I & II & III & IV & Average & I & II & III & IV & Average & \\
\hline days & $g m s$ & & & & & & & & & & & \\
\hline 1 & 5 & 8 & 8 & 8 & 9 & 8 & 20 & 19 & 20 & 15 & 19 & 27 \\
\hline 3 & 8 & 8 & 9 & 9 & 10 & 9 & 16 & 17 & 18 & 18 & 17 & 26 \\
\hline 6 & 11 & 9 & 9 & 11 & 10 & 10 & 19 & 22 & 23 & 22 & 22 & 32 \\
\hline 9 & 10 & 18 & 12 & 13 & 11 & 14 & 18 & 21 & 26 & 24 & 22 & 36 \\
\hline 12 & 13 & 31 & 35 & 40 & 43 & 37 & 18 & 22 & 29 & 25 & 24 & 61 \\
\hline 15 & 13 & 34 & 37 & 40 & 43 & 39 & 21 & 25 & 32 & 31 & 27 & 66 \\
\hline 20 & 29 & 39 & 41 & 49 & 49 & 45 & 19 & 23 & 30 & 34 & 27 & 72 \\
\hline 25 & 36 & 42 & 43 & 51 & 51 & 47 & 17 & 21 & 30 & 32 & 25 & 72 \\
\hline 50 & 59 & 41 & 45 & 53 & 53 & 48 & 16 & 22 & 30 & 34 & 26 & 74 \\
\hline 100 & 112 & 43 & 45 & 54 & 53 & 49 & 17 & 25 & 29 & 31 & 26 & 75 \\
\hline 150 & 183 & 45 & 46 & 53 & 52 & 49 & 17 & 22 & 32 & 34 & 26 & 75 \\
\hline 257 & 137 & 43 & 46 & 56 & 58 & 51 & 18 & 24 & 28 & 31 & 25 & 76 \\
\hline 366 & 181 & 43 & $4 S$ & 55 & 55 & 50 & 17 & 23 & 29 & 32 & 25 & 75 \\
\hline 546 & 255 & 46 & 49 & 56 & 56 & 52 & 16 & 23 & 30 & 33 & 26 & 78 \\
\hline Ratic & s $1-$ & $2 \mathrm{~d}$ & ys & & & $1: 4.6$ & & & & & $1: 1.3$ & $1: 2.3$ \\
\hline & $1-$ & & & & & $: 5.6$ & & & & & $: 1.4$ & $: 2.7$ \\
\hline & $1-5$ & & & & & $: 6.5$ & & & & & $: 1.4$ & $: 2.9$ \\
\hline & $12-5$ & & & & & $: 1.4$ & & & & & $: 1.1$ & $: 1.3$ \\
\hline
\end{tabular}


When we consider the length of the cell body, it is remarkable that the increase takes place so rapidly. While at 1 day it measures only $8 \mu$ and at nine days only $14 \mu$, it increases very suddenly at twelve days of age, and after that slowly but continuously (table 89).

TABLE 90

Total length of Deiters' cells according to turns of the cochlea- $\mu$ (chart 39)

\begin{tabular}{|c|c|c|c|c|c|}
\hline \multirow{2}{*}{$A G B$} & \multirow{2}{*}{ BODY WEIGHT } & \multicolumn{4}{|c|}{ TURNS OF THE COCHLEA } \\
\hline & & I & II & III & IV \\
\hline days & grams & & & & \\
\hline 1 & 5 & 28 & 27 & 28 & 24 \\
\hline 3 & 8 & 24 & 26 & 27 & 28 \\
\hline 6 & 11 & 28 & 31 & 34 & 32 \\
\hline 9 & 10 & 36 & 33 & 39 & 35 \\
\hline 12 & 13 & 49 & 57 & 69 & 68 \\
\hline 15 & 13 & 55 & 62 & 72 & 74 \\
\hline 20 & 29 & 58 & 64 & 79 & 83 \\
\hline 25 & 36 & 59 & 64 & 81 & 83 \\
\hline 50 & 59 & 57 & 67 & 83 & 87 \\
\hline 100 & 112 & 60 & 70 & 83 & 84 \\
\hline 150 & 183 & 62 & 68 & 85 & 86 \\
\hline 257 & 137 & 61 & 70 & 84 & 89 \\
\hline 366 & 181 & 60 & 71 & 84 & 87 \\
\hline 546 & 255 & 62 & 72 & 86 & 89 \\
\hline
\end{tabular}

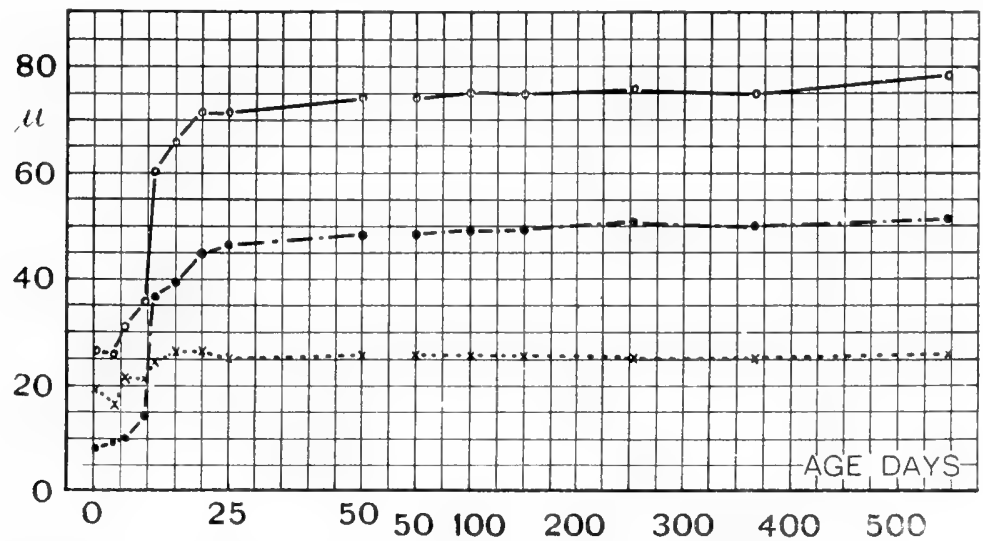

Chart 39 The length of Deiters' cells, tables 89 and 90.

- Total length of the cells.

-.......-. Length of the cell bodies.

......... Length of processus phalangeus. 
In the ratios at the bottom of table 89 this is shown very evidently and in each turn this relation is to be seen.

For the length of the phalangeal process the story is quite different. It increases from birth to twelve days a little; at fifteen days it reaches full size, and then holds its value (table 89). After three days the length is smallest in turn I and largest in turn IV. This relation lasts to old age.

Comparing the growth of the length of the cell body and phalangeal process, there is a large difference between them. While the length in the phalangeal process is at birth over twice that of the cell body, at 546 days it is only half that of the cell

TABLE 91

Total length of Deilers' cells-in $\mu$ (Retzius)

\begin{tabular}{|c|c|c|c|c|c|c|c|c|}
\hline \multirow[t]{2}{*}{$A G E$} & \multirow[b]{2}{*}{$\begin{array}{c}\text { Basal } \\
\text { turn }\end{array}$} & \multicolumn{3}{|c|}{ RABBIT } & \multicolumn{4}{|c|}{ CAT } \\
\hline & & Middle & Apical & Average & Basal & Middle & Apical & Average \\
\hline $\begin{array}{c}\text { days } \\
\text { New-born }\end{array}$ & 48 & 70 & 60 & 59 & 45 & 65 & 48 & 53 \\
\hline 2 & 45 & 66 & 54 & 55 & - & - & - & - \\
\hline 3 & - & - & - & - & 45 & 60 & - & - \\
\hline 7 & 80 & 90 & 75 & 82 & 49 & 69 & 63 & 60 \\
\hline 10 & 98 & 100 & 114 & 104 & - & - & - & - \\
\hline 11 & - & - & - & - & 75 & 90 & 45 & 70 \\
\hline 14 & 84 & זี & 112 & 100 & - & - & - & - \\
\hline 30 & - & - & - & - & 54 & 75 & 70 & 66 \\
\hline
\end{tabular}

body. Thus the increase of the total length of Deiters' cells is due chiefly to the increase in the length of the cell body.

Retzius ('84) gives the length of Deiters' cells in the rabbit and cat as in table 91.

Table 91 shows that in both the rabbit and the cat the length at all ages is greater, and especially at the earlier stage is twice as great, as in the rat. In the rabbit there is a rapid increase in length between seven and ten days. For the cat the values are smaller, nearer those of the rat, and show less change between birth and thirty days.

18. Summary and discussion. Using the foregoing data on the form and measurements of the elements of the cochlear duct, I desire here to summarize the results and to discuss the consequent changes in the form of the organ of Corti (table 92). 
We have already noted that at birth the greater epithelial ridge constitutes the main part of the tympanic wall, and the lesser epithelial ridge, from which arises later the most important organ, is represented by a small and undeveloped prominence. With age this greater ridge disappears gradually and is transformed into a furrow lined with low epithelial cells, the sulcus spiralis internus (Waldeyer). These changes appear first at the base and then pass gradually to the upper turns. In the lesser ridge also there are important developmental changes. At first the hair cells and pillar cells grow, and just before the special function appears, striking changes are seen in Deiters' and Hensen's cells. These increase, especially in their length, very rapidly.

Thus the papilla spiralis, which hitherto had its highest point at the summit of the arch of Corti, shows a remarkable change of form, as the outer part of the papilla increases its height, so that finally Hensen's cells mark the highest point in the papilla. The surface then ceases to be parallel to the basilar membrane, and slopes inward, making with the basilar membrane an acute angle opening outward. At the same time the papilla spiralis appears to be shifted inward-i.e., towards the axis.

Kölliker has described how the cells, from which the pillars or rods of Corti arise, at first stand nearly parallel, but later separate at their base. He thought that this "von einem Längenwachstum (?) der Zellen selbst oder ihrer Grundlage, der Membrana basilaris, abhängen kann."

Hensen ('63) first studied this interesting problem in the ox and found it to depend on a peculiar process. He regarded the inward migration as taking place chiefly in the inner pillar cell. The outer pillar cell in the upper turn moves somewhat outward; in the base, however, inward. Moreover, the outer pillar cell increases its length during the development of the papilla much more than the inner does. Thus the summit of the arch of Corti and therefore the papilla spiralis shifts inward on the basilar membrane. 


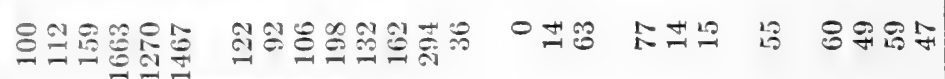

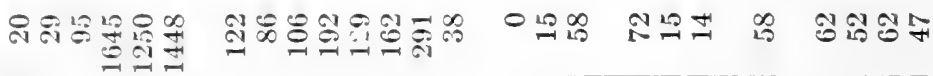

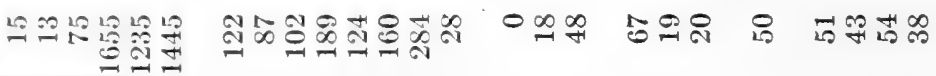

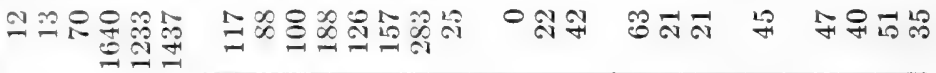

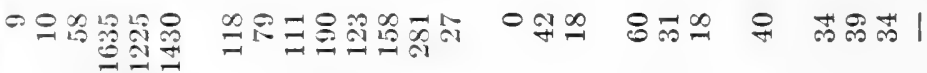

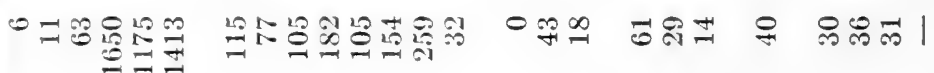

๑)

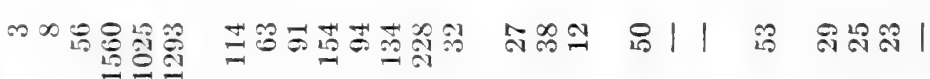

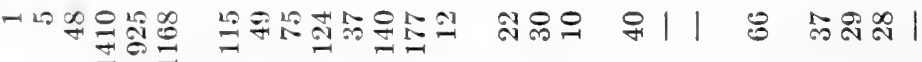

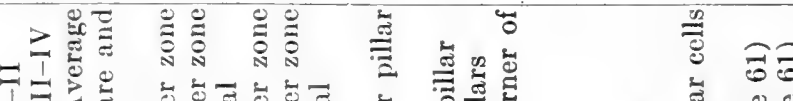

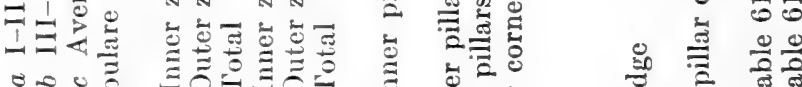

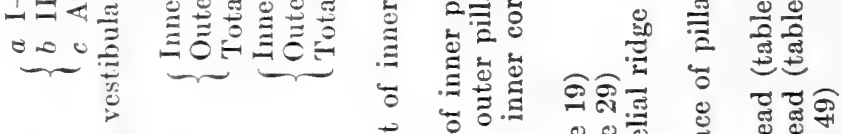

(ี)

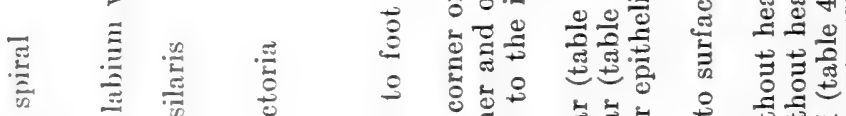

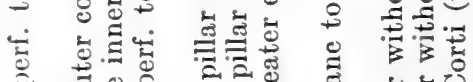

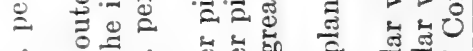

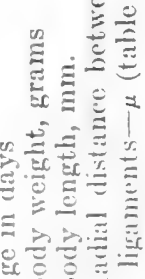

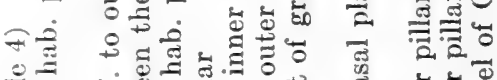

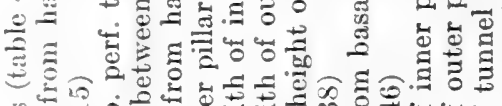

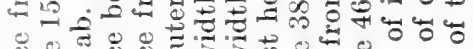

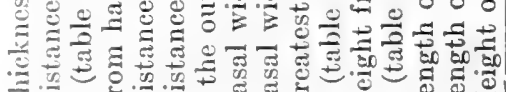
$\therefore \approx$ 


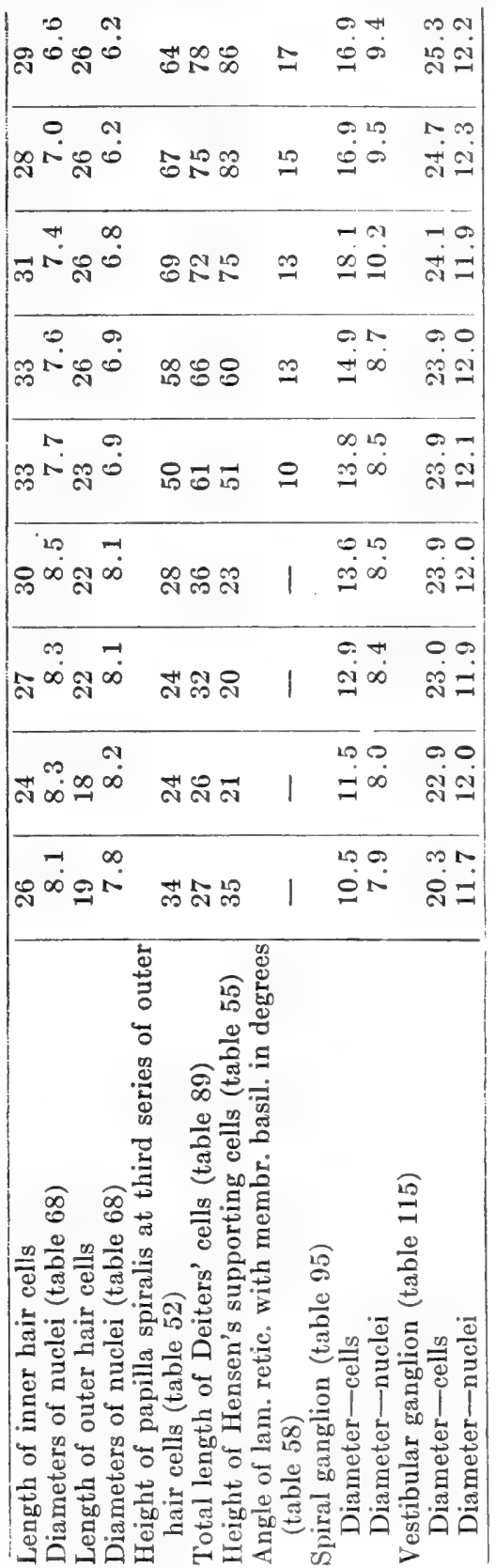


Boittrher ('69, '72) disagreed with Hensen, though he has confirmed, as did Middendorp ('67), the striking inward spreading of the base of the inner pillar cell.

(iottstein! (72) held that the inner pillar cell does not move inward, but that the increase in the length of the labium tympanicum may explain the peculiar approach of the habenula perforata to the arch of Corti.

Retzius ('84) agreed in general with Hensen's assertion that in the course of development the surface of the sense organ comes to lie under the basal surface of the membrana tectoria. He thought that this change of position is brought about "weniger in dem Verhalten der Pfeilerzellen, sondern vor allem in dem starken Wachstum der Deitersschen Zellen und der von aussen andrückenden Hensenschen Stützzellen,' and that, further, "vielleicht die Membrana tectoria selbst durch eigenes Wachstum und durch Vergrösserung des Limbus mit seinem Vorsprüngen" contributes to this.

Held ('09) agrees with Hensen on the whole.

Prentiss ('13, p. 450) denies the wandering of the spiral organ as follows: "There is no necessity for, and my preparations afford no proof of, an inward shifting of the spiral organ and a consequent displacement of the membrana tectoria."

Hardesty ('15, pp. 60 and 61) discussed the relative position of the spiral organ with reference to the basal surface of the tectorial membrane and says "the developed spiral organ acquires its position well under the basal surface of the tectorial membrane almost entirely by being carried axisward during the completion of the membrane." "In the apical turn, where these changes are greatest, the hair cells of the organ may be carried axisward a distance nearly half the width of the membrane. The upgrowth of the outer supporting cells also forces axisward the apical ends of the elements of the spiral organ and in this way contributes a small part to the shift in the relative position of the hair cells. A slight increase in width of the vestibular lip of the spiral limbus may contribute a still smaller part by extending the membrane outward.' 
I obtained from the measurements given in the tables the following results concerning the position of the papilla spiralis under the basal surface of the tectorial membrane.

As already stated, since the habenula perforata may be considered after birth as a punctum fixum (Hensen), it is found that the inner pillar cell shifts inward at its inner basal corner during the earlier stage of life. At six days of age it almost always reaches the habenula perforata in the basal turn, though not yet in the apical. At nine days there is no distance between the habenula perforata and the inner corner of the inner pillar cell.

Gottstein's assumption (no measurements) that the labium tympanicum grows outward and approaches to the arch of Corti is not applicable to the rat, as shown by my tables.

The outer pillar cell also moves outward in all the turns through life, but only slightly after nine days. This result does not agree with that of Hensen ('63), who found in the ox the outer pillar cell to move inward a little at the base, not at all in the middle turn and outward at the apex. Böttcher's outward movement of the outer pillar cell at the hamulus in the cat is $90 \mu$ and much larger than in the rat.

Contrary to Hensen, Retzius ('84) also finds in the rabbit an outward movement of the base of the outer pillar cell throughout all the turns. On the other hand, during the earlier stages of development, the top of the arch of Corti moves outward from the labium vestibulare through the outward pressure of the greater epithelial ridge. At this stage the main part of the membrana tectoria does not yet reach to the sense cells, though the part produced from the lesser epithelial ridge spans the spiral organ and connects with the outer part of the papilla.

After nine days of age the condition of the organ is quite different. The most remarkable anatomical changes from the earlier condition are the rapid increase in the length of the outer pillar cells, in the height of the pillar cells above the basilar membrane, in the height of the papilla spiralis at the third series of the outer hair cells, in the height of Deiters' cells, and in the height of Hensen's supporting cells. Also the tunnel of Corti appears. 
The greater epithelial ridge has already disappeared in large part and been replaced by a furrow. Pressure displacement of tissue in the direction of the least resistance is common in organogenesis. Thus the inner pillar cell is subject to pressure by the rapid growth of the outward lying and greater part of the papilla spiralis and moves in the direction of the least resistance, therefore inward; the head most and the base not at all. As shown in table 44, the rapid decrease in the radial distance between the labium vestibulare and the head of the inner pillar cell is very evident. The arch of Corti changes its form, now inclining inward, instead of outward as heretofore. The lamina reticularis runs not parallel to the basilar membrane, but ascends outward. The tunnel of Corti also changes more or less its form. Nuel's space now appears possibly as a result of this displacement of the papilla spiralis. Thus we see a change in the position of the sense organ with reference to the membrana tectoria.

With the inward shifting of the papilla, the hair cells come under the basal surface of the membrana tectoria. It is probable that the increase of the relative length of the membrane also takes part in this, since the increase in the breadth of the inner zone of the membrana tectoria from one to twelve days is as 1:3.4 (table 4), while the increase in the breadth of the basilar membrane is as 1:0.5 during the same interval (table 7).

Prentiss' ('13) statement that an inward shifting of the papilla spiralis and a consequent displacement of the membrana tectoria does not take place (in the pig) is not applicable to the rat.

In the rat the labium vestibulare and the inner edge of the head of the inner pillar cell are also two definite points in the same sense, and using them we see an inward shifting of the organ of Corti. I imagine that his observation may have misled him, since the tectorial membrane arises in his preparations from both greater and lesser epithelial ridges, and from the earlier stages covers with its outer part the papilla spiralis. Thus the shifting of the organ inward does not necessitate a rhange in the position of the papilla with reference to the membrane. In his study of the tectorial membrane in the same animal (pig), Hardesty ('13) describes a large displacement of the papilla spiralis inward. 
According to him, the shifting of the organ consists of, 1, the moving axisward of the organ itself, and this constitutes the main shift; 2 , the upgrowth of the outer supporting cells, and this contributes a small part to the shift, and, 3, a slight increase of the vestibular lip of the spiral limbus which may contribute a still smaller part. The relation in the rat, however, is different. The moving inward of the papilla itself is not seen in the rat. In the earlier stages the inner basal corner of the inner pillar cell alone shifts inward and reaches the habenula perforata. On the other hand, the outer pillar cell moves outward and the head of the inner pillar cell also, at earlier stages, towards the cells of Hensen. Therefore, during the earlier stages the arch of Corti moves rather outward, owing to the pressure of the growth of the greater epithelial ridge. Since the habenula perforata is to be regarded as a fixed point, the inward displacement of the head of the arch of Corti and of the papilla spiralis is not due to the active shifting inward of the organ itself, as Hardesty ('15) thinks, but to the disappearance of the greater ridge and the passive pressure exerted by the upgrowth of the outer pillar cells and Deiters' and Hensen's cells. The vestibular lip of the spiral lamina and the tectorial membrane itself both increase in their length a little, and these increases play some part in the change of the position of the papilla spiralis with reference to the basal surface of the tectorial membrane.

The membrana basilaris is not concerned with the moving inward of the organ. It increases its length with age in all the turns, but we do not find the change in the position of the feet of the pillar cells on the membrane in such a sense that the feet move inward on it.

Thus the shifting of the papilla spiralis inward in the rat during the development takes place rather in the manner described by Retzius.

Hardesty ('15) states that in the apical turn of the cochlea the organ may be moved axisward a distance equal to about half the maximum width of the greater epithelial ridge, the maximum width of the ridge representing approximately the width of the outspanning zone of the membrane produced upon it. 
No other author reports such a high degree of the inward shifting of the organ. I have not studied the pig, but in the rat I get the average distance between the labium vestibulare and the inner edge of the head of the inner pillar cell as follows (table 93).

TABLE 93

Average distance between the labium vestibulare and the inner edge of the inner pillar cell-in $\mu$ (albino rat)

\begin{tabular}{|c|c|c|c|c|c|c|c|}
\hline \multirow{2}{*}{\multicolumn{2}{|c|}{$A G E$}} & \multirow{2}{*}{ BODY WEIGHT } & \multicolumn{5}{|c|}{ TURNS OF COCHLEA } \\
\hline & & & I & II & III & IV & Average \\
\hline & days & grams & & & & & \\
\hline (1) & 5 & 9 & 94 & 124 & 1,54 & 165 & \\
\hline (2) & 154 & 102 & 63 & 100 & 134 & 148 & \\
\hline \multicolumn{3}{|c|}{$\begin{array}{l}\text { Difference between age groups } \\
1 \text { and } 2\end{array}$} & 31 & 24 & 20 & 17 & 23 \\
\hline
\end{tabular}

Therefore, in the rat the organ moves inward on the average of $23 \mu$; that is, in the ratio of $1: 0.16$ of the maximum distance between these two points. It may be noted that the difference in this table is not the same in the several turns, but diminishes from base to apex-a relation which is the reverse of that reported by Hardesty ('15) in the pig. I have no explanation for these differences except their possible dependence on the different animals used.

C. On the growth of the largest nerve cells in the ganglion spirale.

Observations. For the present studies the fourteen age groups used in the previous observations on the growth of the tympanic wall of the cochlear duct were employed. In order to see the relation between the growth of the papilla spiralis and the cells of the ganglion spirale, both studies were made on the same sections. In addition, however, I made cross-sections of the cochlea (i.e., at right angles to the axis) in several age groups to follow the growth and the changes in the form of the nerve cells as they appear in this plane. The data for the animals thus used are given in table 94 . 
For the measurement of the nerve cells a Zeiss system was used with a micrometer eyepiece, having each division equal to $2 \%$. Since we have in the radial vertical section of the cochlea of the rat at least four turns, there are four cell groups available in each section (fig. 3). The ten largest cells in each ganglion were measured, and thus a total of forty cells in a section were taken for the measurement of the nucleus and the cell.

We used, as stated, four cochleas in each age group, so that 160 cells were measured for each age. Also in the cross-sections the four nearly corresponding turns were used for the measurements, selecting the ten largest cells in each turn.

TABLE 94

Data on rats used for cross-sections of the cochlea-ganglion spirale

\begin{tabular}{|c|c|c|c|c|c|}
\hline $\mathrm{AGE}$ & BODY WEIGHT & BODY LENGTH & SEX & SIDE & HEARTNG \\
\hline days & grams & & & & \\
\hline 15 & 20 & 84 & $0^{7}$ & L. & Prompt response \\
\hline 20 & 27 & 93 & $0^{\pi}$ & $\mathrm{L}$. & " " \\
\hline 25 & 39 & 114 & $0^{7}$ & L. & " \\
\hline 100 & 95 & 152 & $0^{7}$ & $\mathrm{R}$. & “ \\
\hline 150 & 169 & 192 & $q$ & L. & “ \\
\hline 371 & 220 & 206 & $0^{x}$ & L. & “" \\
\hline
\end{tabular}

In the measurement of the cell bodies the two maximum diameters at right angles to each other were determined, and also the two corresponding diameters for the nuclei.

Here it is to be noted that the expressions turn I, II, III, and IV are used in the same sense as in the earlier chapters.

In table 95 (chart 40) are given the values for the average diameters of the cell bodies and their nuclei in the ganglion spirale in the radial vertical section according to fourteen age groups. Under 'cell body, diameter,' the first column gives the long, the second the short, and the third the computed diameter; i.e., the square root of their products. These last values approximate the mean diameters of the nerve cells. At the foot of the third column are given the ratios from 1 to 20,1 to 546 , and 20 to 546 days. The values for the diameters of the nuclei are similarly given and also the ratios. 
Is the tables and charts show, the diameters of the cell bodies and also of their nuclei are largest at twenty days of age. After that age they diminish gradually. While the ratio for one to twenty days is $1: 1.7$ in the cell bodies and $1: 1.3$ in the nuclei, that for 1 to 546 days is $1: 1.6$ and $1: 1.2$, respectively.

TABLE 95

Diamelers of the cell bodies and their nuclei in the ganglion spirale (radial-vertical section) (chart 40)

\begin{tabular}{|c|c|c|c|c|c|c|c|c|}
\hline \multirow{3}{*}{$A G E$} & \multirow{3}{*}{$\begin{array}{c}\text { BODY } \\
\text { WEIGHT }\end{array}$} & \multirow{3}{*}{$\begin{array}{c}\text { BODY } \\
\text { LENGTH }\end{array}$} & \multicolumn{6}{|c|}{ Diameters in $\mu$} \\
\hline & & & \multicolumn{3}{|c|}{ Cell body } & \multicolumn{3}{|c|}{ Nucleus } \\
\hline & & & Long & Short & Computed & Long & Short & Computed \\
\hline days & grams & $\mathrm{mm}$. & & & & & & \\
\hline 1 & 5 & 48 & 11.0 & 10.0 & 10.5 & 8.2 & 7.6 & 7.9 \\
\hline 3 & 8 & 56 & 12.0 & 11.1 & 11.5 & 8.2 & 7.8 & 8.0 \\
\hline 6 & 11 & 63 & 13.6 & 12.3 & 12.9 & 8.8 & 8.1 & 8.4 \\
\hline 9 & 10 & 58 & 14.3 & 12.8 & 13.6 & 8.9 & 8.2 & 8.5 \\
\hline 12 & 13 & 70 & 14.6 & 13.1 & 13.8 & 8.7 & 8.2 & 8.5 \\
\hline 15 & 13 & 75 & 15.7 & 14.1 & 14.9 & 9.1 & 8.4 & 8.7 \\
\hline 20 & 29 & 95 & 19.0 & 17.3 & 18.1 & 10.3 & 10.0 & 10.2 \\
\hline 25 & 36 & 104 & 18.5 & 16.9 & 17.7 & 10.2 & 9.9 & 10.1 \\
\hline 50 & 59 & 125 & 18.5 & 16.6 & 17.5 & 10.3 & 9.7 & 10.0 \\
\hline 100 & 112 & 159 & 18.1 & 15.7 & 16.9 & 9.8 & 9.2 & 9.5 \\
\hline 150 & 183 & 190 & 18.2 & 15.3 & 16.7 & 9.6 & 8.8 & 9.2 \\
\hline 257 & 137 & 175 & 18.5 & 15.3 & 16.8 & 9.9 & 9.4 & 9.6 \\
\hline 366 & 181 & 191 & 18.6 & 15.3 & 16.9 & 9.8 & 9.0 & 9.4 \\
\hline 546 & 255 & 213 & 18.6 & 15.3 & 16.9 & 9.7 & 9.0 & 9.4 \\
\hline \multirow{4}{*}{\multicolumn{2}{|c|}{$\begin{array}{l}1-20 \text { days } \\
1-546 \text { " } \\
20-546\end{array}$}} & & & & & & & \\
\hline & & & & & $1: 1.7$ & & & $1: 1.3$ \\
\hline & & & & & $: 1.6$ & & & :1.2 \\
\hline & & & & & $: 0.9$ & & & $: 0.9$ \\
\hline
\end{tabular}

In table 96 (chart 41) are a series of computed diameters of the cell bodies and of their nuclei according to the turns of the cochlea. At the bottom of each column are given the ratios from 1 to 20,1 to 546 , and 20 to 546 days. Determining the ratios for each column, it appears that in general the diameters of the cell bodies and their nuclei are largest at twenty days throughout all the turns. This increase is very considerable from fifteen to twenty days. Then they decrease very slowly till 546 days. 
Table 97 enables us to compare the ratios in the diameters of the cell bodies and their nuclei in turns I, II, III, and IV in the condensed age groups. In both the cell bodies and their nuclei the ratios become slightly larger in passing from the basal toward the apical turn, except in the one day group, which it reversed.

On the comparison of the diameters of the nerve cell bodies and their nuclei in the ganglion spirale according to sex. For this comparison seven age groups were used. In each age group we have sometimes one, sometimes two cochleas of the same sex.

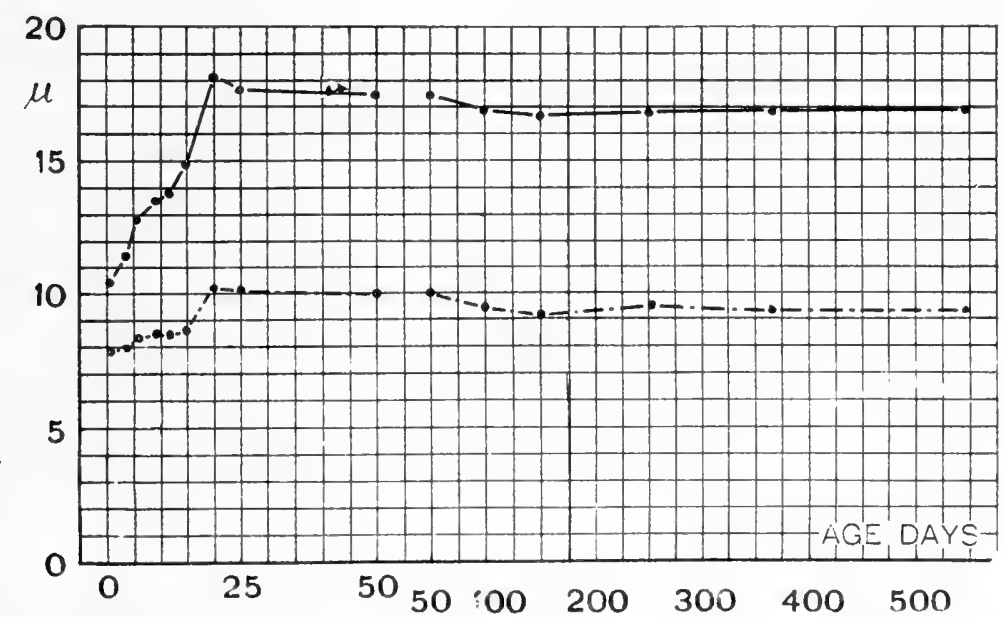

Chart 40 Showing the computed diameter of the largest cell bodies and their nuclei from the ganglion spirale, table 95 .

___ Diameters of the cell bodies.

-......... Diameters of the nuclei.

In the latter case the average value is recorded. In table 98 are given the values for these diameters, and it is plain that there is no significant difference in these values according to sex.

On the comparison of the diameters of the nerve cell bodies and their nuclei in the ganglion spirale according to side. For this purpose fourteen age groups were employed. In most cases two cochleas from the same side were used in each age group. In these cases the average value is recorded. Table 99 shows the values for the diameters of the cell bodies and their nuclei according to side, but reveals no evident difference in this character. 
On the morphological changes in the ganglion cells during growth. As my sections could not be stained with thionine, my observations on the Nissl bodies are incomplete, yet the slides stained with Heidenhain's iron haematoxylin and van Gieson's stain, as well as by haematoxylin and eosin, were helpful here.

TABLE 96

Compuled diameters of the cell bodies and their nuclei in the ganglion spirale according to the turns of the cochlea (chart 41)

\begin{tabular}{|c|c|c|c|c|c|c|c|c|c|}
\hline \multirow{4}{*}{$\begin{array}{l}\mathrm{AGE} \\
\text { days }\end{array}$} & \multirow{4}{*}{$\begin{array}{c}\text { BODY } \\
\text { WEIGHT } \\
\text { gms }\end{array}$} & \multicolumn{8}{|c|}{ TURNS OF THE COCHLEA } \\
\hline & & \multicolumn{8}{|c|}{ Computed diameters $-\mu$} \\
\hline & & \multicolumn{2}{|r|}{ I } & \multicolumn{2}{|c|}{ II } & \multicolumn{2}{|c|}{ III } & \multicolumn{2}{|c|}{ IV } \\
\hline & & $\begin{array}{c}\text { Cell } \\
\text { rody }\end{array}$ & Nucleus & $\begin{array}{c}\text { Cell } \\
\text { body }\end{array}$ & Nucleus & $\begin{array}{c}\text { Cell } \\
\text { body }\end{array}$ & Nucleus & $\begin{array}{c}\text { Cell } \\
\text { body }\end{array}$ & Nucleus \\
\hline 1 & 5 & $11 . \overline{0}$ & 8.0 & 10.8 & 8.2 & 10.4 & 8.0 & 9.6 & 7.4 \\
\hline 3 & 8 & 11.5 & 7.9 & 11.5 & 7.9 & 11.7 & 8.0 & 11.3 & 8.1 \\
\hline 6 & 11 & 12.9 & 8.4 & 12.6 & 8.2 & 13.0 & 8.5 & 13.3 & 8.6 \\
\hline 9 & 10 & 13.4 & 8.4 & 13.4 & 8.5 & 13.6 & 8.6 & 13.7 & 8.6 \\
\hline 12 & 13 & 13.6 & 8.1 & 13.5 & 8.1 & 13.8 & 8.6 & 14.7 & 9.0 \\
\hline 15 & 13 & 14.8 & 8.6 & 15.0 & 8.6 & 14.6 & 8.6 & 15.0 & 9.2 \\
\hline 20 & 29 & 17.6 & 10.0 & 17.6 & 9.9 & 18.1 & 10.2 & 19.0 & 10.4 \\
\hline 25 & 36 & 16.9 & 9.9 & 17.6 & 10.0 & 17.6 & 10.1 & 18.4 & 10.3 \\
\hline 50 & 59 & 17.2 & 9.7 & 17.2 & 9.7 & 17.6 & 10.0 & 17.9 & 10.1 \\
\hline 100 & 112 & 16.9 & 9.6 & 16.9 & 9.4 & 16.3 & 9.3 & 16.9 & 9.6 \\
\hline 150 & 183 & 16.9 & 9.3 & 16.3 & 9.0 & 16.6 & 9.1 & 17.0 & 9.1 \\
\hline 257 & 137 & 16.7 & 9.6 & 16.7 & 9.4 & 16.9 & 9.7 & 17.0 & 9.7 \\
\hline 366 & 181 & 16.7 & 9.3 & 16.4 & 9.2 & 16.7 & 9.1 & 17.7 & 9.7 \\
\hline 516 & 255 & 15.8 & 9.2 & 16.3 & 9.4 & 16.9 & 9.4 & 17.4 & 9.5 \\
\hline \multirow[t]{3}{*}{ Ratios } & 20 day: & $1: 1.6$ & $1: 1.3$ & $1: 1.6$ & $1: 1.2$ & $1: 1,7$ & $1: 1.3$ & $1: 2.0$ & $1: 1.4$ \\
\hline & $5+6 \quad 6$ & $: 1 \ldots$ & $: 1.2$ & $: 1.5$ & $: 1.2$ & $: 1.7$ & $: 1.2$ & $: 1.8$ & $: 1.3$ \\
\hline & 546 & $: 1.0$ & $: 0.9$ & $: 0.0$ & $: 1.0$ & $: 0.9$ & $: 0.9$ & $: 0 . \mathrm{S}$ & $: 0.9$ \\
\hline
\end{tabular}

TABLE 97-Condensed

Ratios of the diameters of the cells and nuclei of the ganglion spirale

\begin{tabular}{|c|c|c|c|c|c|c|c|}
\hline \multirow[b]{3}{*}{$\begin{array}{c}\text { AVERAGE } \\
\text { AGE }\end{array}$} & \multirow[b]{3}{*}{$\begin{array}{c}\text { AVERAGE } \\
\text { BODY } \\
\text { WFIGUT }\end{array}$} & \multicolumn{6}{|c|}{ RATIOS BETWEEN TURNS } \\
\hline & & \multicolumn{2}{|c|}{ I-II } & \multicolumn{2}{|c|}{ I-III } & \multicolumn{2}{|c|}{$\mathrm{I}-\mathrm{IV}$} \\
\hline & & Cell body & Nucleus & 1/ Cell body & Nucleus & Cell body & Nucleus \\
\hline days & grams & & & & & & \\
\hline 1 & 5 & $1: 0.98$ & $1: 1.25$ & $1: 0.95$ & $1: 1.00$ & $1: 0.87$ & $1: 0.93$ \\
\hline$s$ & 11 & $: 0.99$ & $: 1.00$ & $: 1.01$ & $: 1.02$ & $: 1.03$ & $: 1.05$ \\
\hline 1s & 21 & $: 1.01$ & $: 1.00$ & $: 1.01$ & $: 1.01$ & .1 .04 & $: 1.05$ \\
\hline .13 & 138 & $: 0.99$ & $: 0.99$ & $: 1.01$ & $: 1.00$ & $: 1.04$ & $: 1.02$ \\
\hline
\end{tabular}




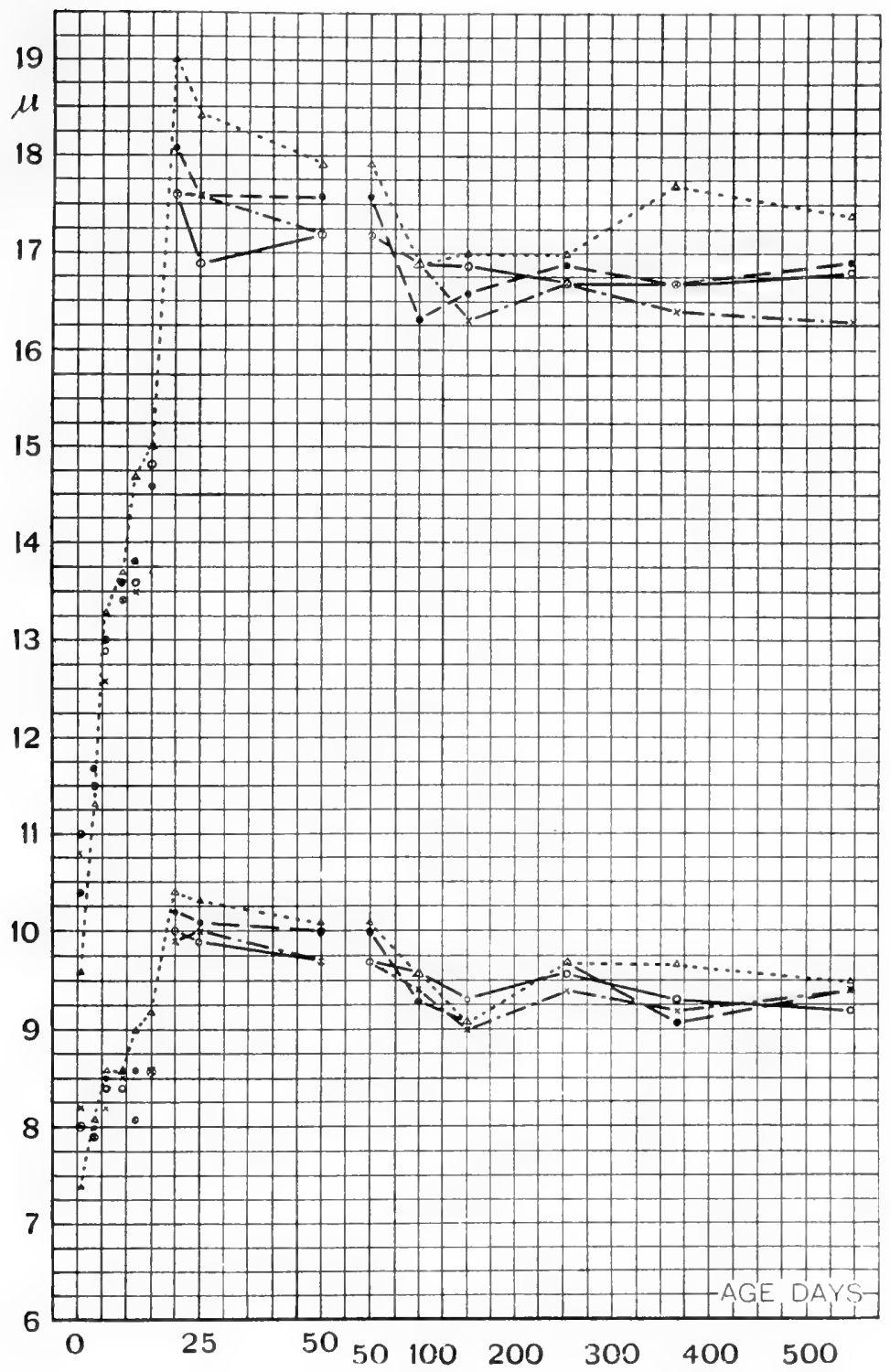

Chart 41 The computed diameter of the largest cell bodies and of their nuclei from the ganglion spirale, according to the turns of the cochlea, table 96. Upper graphs: diameters of the cell bodies. Lower graphs: diameters of the nuclei of the cells. 
Figure 13 illustrates semidiagrammatically the nerve cells in the spiral ganglion of the albino rat at 1 day and at 20 and 366 days.

The body of the ganglion cells at birth is small and has the characteristic fetal form. The cytoplasm is homogeneous and scanty and the Nissl bodies are not yet seen. The nucleus forms

TABLE 98

Comparison according to sex of the diameters of the cell bodies and the nuclei in the ganglion spirale

\begin{tabular}{|c|c|c|c|c|c|}
\hline \multirow{2}{*}{$A G E$} & \multirow{2}{*}{ BODY WEIGHT } & \multirow{2}{*}{ NO. OF RATS } & \multirow{2}{*}{$\operatorname{sex}$} & \multicolumn{2}{|c|}{ COMPUTED DIAMETERS- $\mu$} \\
\hline & & & & Cell & Nucleus \\
\hline days & grams & & & & \\
\hline \multirow[t]{2}{*}{3} & 7 & 1 & $\sigma^{\top}$ & 11.4 & 8.0 \\
\hline & 8 & 1 & $\%$ & 11.4 & 8.0 \\
\hline \multirow[t]{2}{*}{6} & 11 & 2 & $\sigma^{7}$ & 13.1 & 8.5 \\
\hline & 10 & 2 & \% & 12.8 & 8.4 \\
\hline \multirow[t]{2}{*}{9} & 10 & 2 & $\sigma^{7}$ & 13.6 & 8.5 \\
\hline & 9 & 2 & & 13.5 & 8.6 \\
\hline \multirow[t]{2}{*}{12} & 14 & 2 & $\sigma^{7}$ & 13.7 & 8.5 \\
\hline & 12 & 2 & $q$ & 13.9 & 8.4 \\
\hline \multirow[t]{2}{*}{100} & 146 & 1 & $\sigma^{7}$ & 17.2 & 9.6 \\
\hline & 103 & 1 & १ & 16.9 & 9.4 \\
\hline \multirow[t]{2}{*}{150} & 189 & 1 & $0^{7}$ & 16.5 & 9.1 \\
\hline & 154 & 1 & ㅇ & 17.1 & 9.1 \\
\hline \multirow[t]{2}{*}{365} & 205 & 1 & $\sigma^{7}$ & 16.3 & 9.0 \\
\hline & 170 & 1 & ф & 16.7 & 9.1 \\
\hline \multirow{2}{*}{\multicolumn{4}{|c|}{$\begin{array}{l}\text { Average-male } \\
\text { Average-female }\end{array}$}} & 14.5 & 8.7 \\
\hline & & & & 14.6 & 8.7 \\
\hline \multicolumn{4}{|c|}{ Male larger than female } & 3 & 3 \\
\hline \multicolumn{4}{|c|}{ Female larger than male } & 3 & 2 \\
\hline \multicolumn{4}{|c|}{ Male and female equal } & 1 & 2 \\
\hline
\end{tabular}

the greater part of the cell. The chromatin is not yet well differentiated, and the so-called 'Kernfaden' are not visible.

The sharply marked nucleolus is in most cases in the central position, but sometimes located peripherally.

The cytoplasm matures rapidly. At six days the Nissl bodies appear, though they are of course, less abundant and smaller than in the later stages. The nucleus develops also and the chrmmatin is well differentiated. Thus the development in both the cell body and the nucleus proceeds rapidly in the earlier stage, 


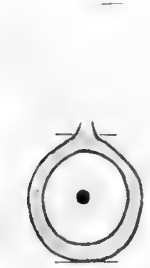

I Day

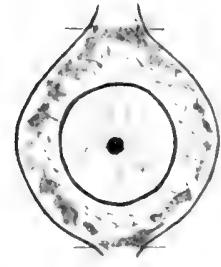

20 Days

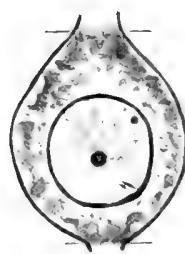

366 Days

Fig. 13 Showing semi-diagrammatically the size and the morphologicul changes in the ganglion cells in the ganglion spirale of the albino rat at the age of 1, 20 and 366 days. All cell figures have been uniformly magnified 1000 diameters. 
At twenty days the cell body reaches its maximum size. The Nissl bodies are large and abundant. The nucleus also attain.

TABLE 99

Comparison according to side of the cell bodies and their nuclei in the ganglion spirale

\begin{tabular}{|c|c|c|c|c|c|}
\hline \multirow{2}{*}{$\triangle G E$} & \multirow{2}{*}{ BODY WHIGHT } & \multirow{2}{*}{ NO. OF RATS } & \multirow{2}{*}{ SIDE } & \multicolumn{2}{|c|}{ COMPUTED DIAMETEKS- $\mu$} \\
\hline & & & & Cell & Nucleus \\
\hline days & grams & & & & \\
\hline \multirow[t]{2}{*}{1} & 5 & 2 & $\mathrm{R}$. & 10.6 & 8.0 \\
\hline & & & L. & 10.4 & 7.8 \\
\hline \multirow[t]{2}{*}{3} & 7 & 1 & $R$. & 11.4 & 8.0 \\
\hline & & & L. & 11.5 & 8.0 \\
\hline \multirow[t]{2}{*}{6} & 11 & 2 & $\mathrm{R}$ & 13.0 & 8.5 \\
\hline & & & Ls. & 12.9 & 8.4 \\
\hline \multirow[t]{2}{*}{9} & 9 & 2 & $R$. & 13.4 & 8.5 \\
\hline & & & L. & 13.7 & 8.6 \\
\hline \multirow[t]{2}{*}{12} & 12 & 1 & $\mathrm{R}$. & 13.9 & 8.4 \\
\hline & & & L. & 14.0 & 8.4 \\
\hline \multirow[t]{2}{*}{15} & 13 & 1 & $\mathrm{R}$. & 14.7 & 8.6 \\
\hline & & & L. & 14.8 & 8.5 \\
\hline \multirow[t]{2}{*}{20} & 29 & 2 & R. & 18.0 & 10.1 \\
\hline & & & L. & 18.5 & 10.2 \\
\hline \multirow[t]{2}{*}{25} & 36 & 2 & R. & 17.6 & 10.1 \\
\hline & & & $\mathrm{L}$. & 17.7 & 10.1 \\
\hline \multirow[t]{2}{*}{50} & 59 & 2 & $\mathrm{R}$. & 17.5 & 9.9 \\
\hline & & & $\mathrm{L}$. & 17.5 & 9.8 \\
\hline \multirow[t]{2}{*}{100} & 102 & 2 & R. & 16.8 & 9.5 \\
\hline & 123 & & L. & 17.0 & 9.5 \\
\hline \multirow{2}{*}{150} & 189 & 1 & $R$. & 16.4 & 9.2 \\
\hline & & & L. & 16.5 & 9.1 \\
\hline \multirow[t]{2}{*}{257} & 137 & 2 & $\mathrm{R}$. & 17.1 & 9.7 \\
\hline & & & L. & 16.6 & 9.5 \\
\hline 367 & 175 & 2 & $\mathrm{R}$. & 17.3 & 9.7 \\
\hline 365 & 188 & & L. & 16.5 & 9.1 \\
\hline \multirow[t]{2}{*}{546} & 255 & 2 & $\mathrm{R}$. & 16.9 & 9.3 \\
\hline & & & L. & 16.9 & 9.3 \\
\hline \multicolumn{2}{|c|}{ Average right side } & & & 15.3 & 9.1 \\
\hline \multirow{2}{*}{\multicolumn{2}{|c|}{$\begin{array}{l}\text { Average left side } \\
\text { Right larger than left }\end{array}$}} & & & 15.3 & 9.0 \\
\hline & & & & 4 & 7 \\
\hline \multicolumn{2}{|c|}{ Left larger than right } & & & 8 & 2 \\
\hline \multicolumn{2}{|c|}{ Right and left equal } & & & 2 & 5 \\
\hline
\end{tabular}

its maximum size at this age, though the rate of increase is slower than that for the cell body. With this increase of size the histological structure becomes that of the adult rat. Then, as the 
age advances, the size of both the cell body and of the nucleus slowly diminishes, while within the eytoplasm the differentiation of the Nissl bodies progresses. This relation is seen in the figure of the cell at 366 days, which shows that the absolute volume of the cell body and also of the nucleus is smaller than at twenty days.

From twenty to 366 days, gradual and progressive changes in all histological structures can be seen, though there are no sudden changes.

'TABLE 100

Diameters of the cell bolies and their nuclei in the ganglion spirale-in cross scctions of the cochlea (chart 42)

\begin{tabular}{|c|c|c|c|c|c|c|c|}
\hline \multirow{3}{*}{$\triangle G E$} & \multirow{3}{*}{$\begin{array}{c}\text { RODY } \\
\text { WEIGHT }\end{array}$} & \multicolumn{6}{|c|}{ DIAMETERS IN $\mu$} \\
\hline & & \multicolumn{3}{|c|}{ Cell body } & \multicolumn{3}{|c|}{ Nucleus } \\
\hline & & Long & Short & Computed & Long & short & Computed \\
\hline days & grams & & & & & & \\
\hline 15 & 20 & 15.7 & 14.3 & 15.0 & 9.3 & S. 4 & 8.8 \\
\hline 20 & 27 & 18.3 & 16.6 & 17.4 & 10.3 & 10.0 & 10.1 \\
\hline 25 & 39 & 18.0 & 16.6 & 17.3 & 10.1 & 9.8 & 9.9 \\
\hline 100 & 95 & 17.6 & 16.2 & 16.9 & 9.9 & 9.5 & 9.7 \\
\hline 150 & 169 & 17.4 & 16.0 & 16.7 & 9.8 & 9.1 & 9.4 \\
\hline 371 & 220 & 16.5 & 15.8 & 16.2 & 9.5 & 8.6 & 9.0 \\
\hline \multirow[t]{3}{*}{ Ratios } & $-25 \mathrm{da}$ & & & $1: 1.1$ & & & $1: 1.1$ \\
\hline & -371 & & & $: 1.1$ & & & $: 1.0$ \\
\hline & -371 & & & 10 & & & $: 0.9$ \\
\hline
\end{tabular}

The question here arose whether this change in volume was in any way related to a shift in the long axis of the cell at the later ages. To answer this difficult question it was deemed desirable to compare the form of the ganglion cells obtained in the cross-section with that found in the radial section of the cochtea. In table 100 (chart 42) are given the values for the diameters of the cell bodies and their nuclei in the ganglion spirale in the cross-section. Below are given the respective ratios from 15 to 25,15 to 371 , and 25 to 371 days. Both cell body and nucleus increase in size up to twenty days and then diminish very slowly, as the age advances. These are similar to the relations found in the radial sections. 
Looking at the diameters of the cell bodies and their nuclei in each turn (table 101), we do not find in the later age groups a regular increase in passing from the base toward the apex, as in the cells on the radial section. The differences are generally TABLE 101

Diameter of the cell bodies and their nuclei in the ganglion spirale according to the turns of the cochlea (cross section)

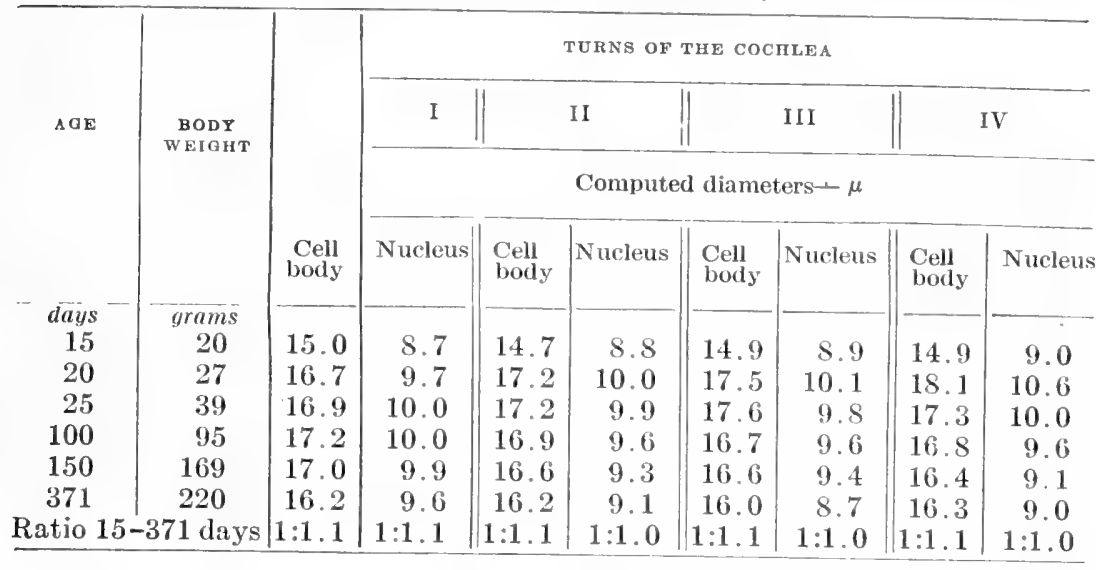

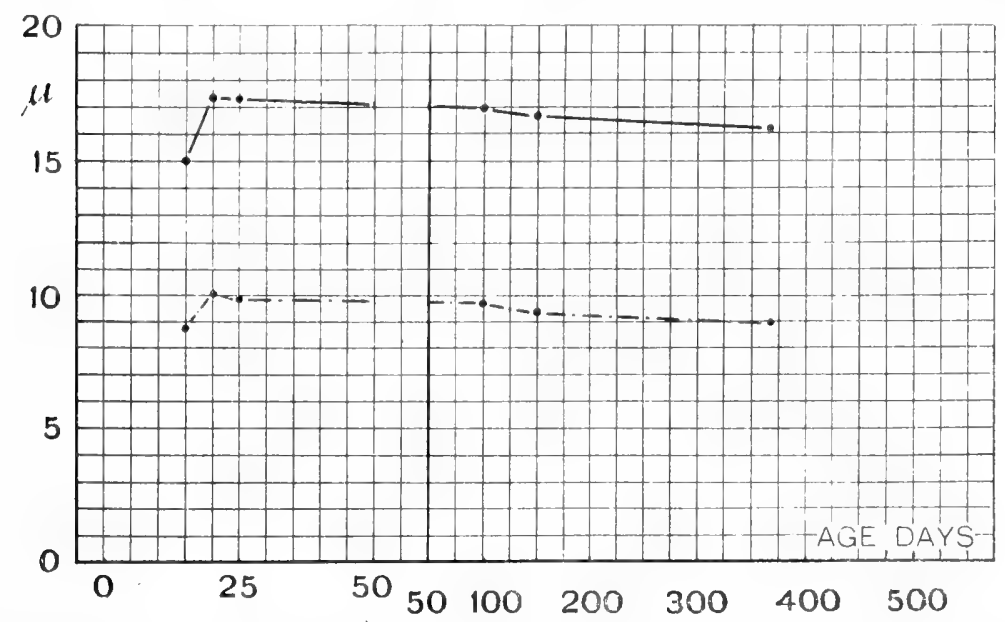

Chart 42 The average diameter of the largest cell bodies and of their nuelei of the nerve cells from the ganglion spirale, after 15 days (cross-section), table 100. 
far smaller than on the radial section. This result seems to have some comnection with the position of the long axis of the ganglion cells in relation to the axis of the cochlea.

Comparing the diameters of the cell bodies and their nuclei in nearly corresponding places in the radial and cross-section, the long diameters of the cells are in each age group almost always larger in the radial than on the cross-section. Therefore the cells are somewhat ovoid. The short diameters, however, are at the same age sometimes longer, sometimes shorter on the radial than on the cross-section. This is probably due to the fact that in the upper turns the cells stand with their long diameter more nearly parallel to the axis of the modiolus, and therefore, on passing from the upper to the lower turn, the long axes of the cells become more inclined to the modiolus.

In order to show that the cell form is ovoid, I reconstructed the cells at 15, 100, and 365 days of age by the usual method, and obtained models which agreed in form with that determined by the microscope.

It appears, therefore, that while there is some difference in the diameters of these cells according to the plane of the section, neverthless, the change in volume after twenty days is similar in both cases, and so this change does not depend on the plane in which the sections were made.

On the nucleus-plasma relations of the cells in the ganglion. spirale. The computed diameters of the cell bodies and their nuclei, measured on radial sections, are given in table 102 and the nucleus-plasma ratios have been entered in the last column. The ratio is at one day only 1:1.3 and increases rapidly and regularly till twenty days; after that period there are slight fluctuations. Generally speaking, the ratios increase with the advancing age of the rat, but after twenty days only very slightly. Thus we see that the nucleus-plasma relation nearly reaches an equilibrium at twenty days, though the cells mature slowly even after that time.

When we consider this relation according to the turns of the cochlea, we find that this ratio increases in all the turns regularly and definitely till twenty days, after. which there are some 
fluctuations (table 103). Thus we see here also the same relation as before.

TABLE 102

Nucleus-plasma ratios of cells in the ganglion spirale (radial-vertical section)

\begin{tabular}{|c|c|c|c|c|c|}
\hline \multirow[b]{2}{*}{$A G E$} & \multirow{2}{*}{$\begin{array}{c}\text { BODY } \\
\text { WEIGHT }\end{array}$} & \multirow{2}{*}{$\begin{array}{l}\text { BODY } \\
\text { LENGTH }\end{array}$} & \multicolumn{3}{|c|}{ COMPUTED DIAMETERS- $\mu$} \\
\hline & & & Cell body & Nucleus & $\begin{array}{l}\text { Nucleus-plasma } \\
\text { ratios }\end{array}$ \\
\hline days & grams & $m m$. & & & \\
\hline 1 & 5 & 48 & 10.5 & 7.9 & $1: 1.3$ \\
\hline 3 & 8 & 56 & 11.5 & 8.0 & $: 2.0$ \\
\hline 6 & 11 & 63 & 12.9 & 8.4 & $: 2.6$ \\
\hline 9 & 10 & 58 & 13.6 & 8.5 & $: 3.1$ \\
\hline 12 & 13 & 60 & 13.8 & 8.5 & $: 3.3$ \\
\hline 15 & 13 & 75 & 14.9 & 8.7 & $: 4.0$ \\
\hline 20 & 29 & 95 & 18.1 & 10.2 & $: 4.6$ \\
\hline 25 & 36 & 104 & 17.7 & 10.1 & $: 4.4$ \\
\hline 50 & 59 & 125 & 17.5 & 10.0 & $: 4.4$ \\
\hline 100 & 112 & 159 & 16.9 & 9.5 & $: 4.6$ \\
\hline 150 & 183 & 190 & 16.7 & 9.2 & $: 5.0$ \\
\hline 257 & 137 & 175 & 16.8 & 9.6 & $: 4.4$ \\
\hline 366 & 181 & 191 & 16.9 & 9.4 & $: 4.8$ \\
\hline 546 & 255 & 213 & 16.9 & 9.4 & $: 4.8$ \\
\hline
\end{tabular}

TABLE 103

Nucleus-plasma ratios of cells in the ganglion spirale according to the turns of the cochlea. Based on table 96

\begin{tabular}{|c|c|c|c|c|c|}
\hline \multirow{2}{*}{$\mathbf{A G E}$} & \multirow{2}{*}{ ВОDY WEIGHT } & \multicolumn{4}{|c|}{ TURNS OF THE COCHLEA } \\
\hline & & I & II & III & IV \\
\hline days & grams & & & & \\
\hline 1 & 5 & $1: 1.6$ & $1: 1.5$ & $1: 1.2$ & $1: 1.2$ \\
\hline 3 & 8 & $: 2.1$ & $: 2.1$ & $: 2.1$ & $: 1.7$ \\
\hline 6 & 11 & $: 2.6$ & $: 2.6$ & $: 2.6$ & $: 2.7$ \\
\hline 9 & 10 & $: 3.1$ & $: 2.9$ & $: 3.0$ & $: 3.0$ \\
\hline 12 & 13 & $: 3.7$ & $: 3.6$ & $: 3.1$ & $: 3.4$ \\
\hline 15 & 13 & $: 4.1$ & $: 4.3$ & $: 3.9$ & $: 3.2$ \\
\hline 20 & 29 & $: 4.5$ & $: 4.6$ & $: 4.6$ & $: 5.1$ \\
\hline 25 & 36 & $: 4.0$ & $: 4.5$ & $: 4.3$ & $: 4.7$ \\
\hline 50 & 59 & $: 4.6$ & $: 4.6$ & $: 4.5$ & $: 4.6$ \\
\hline 100 & 112 & $: 4.5$ & $: 4.8$ & $: 4.4$ & $: 4.5$ \\
\hline 150 & 183 & $: 5.0$ & $: 4.9$ & $: 5.1$ & $: 5.5$ \\
\hline 257 & 137 & $: 4.3$ & $: 4.6$ & $: 4.3$ & $: 4.4$ \\
\hline 366 & 181 & $: 4.8$ & $: 4.7$ & $: 5.2$ & $: 5.1$ \\
\hline 546 & 255 & $: 5.1$ & $: 4.2$ & $: 4.8$ & $: 5.1$ \\
\hline
\end{tabular}


In the nucleus-plasma ratio of the cells on the cross-section, as shown in table 104, the increase with age is very regular. As the diameters of the cell bodies and their nuclei decrease slowly after twenty days, this increase of the ratio means that the nuclei are diminishing relatively more rapidly than the cytoplasm.

Comparing these ratios from the radial and cross sections, we find that they agree (table 105).

TABLE 104

Nucleus-plasma ratios of the cells in the ganglion spirale (cross-sections)

\begin{tabular}{|c|c|c|c|c|c|}
\hline \multirow[b]{2}{*}{$A \in \mathbb{E}$} & \multirow[b]{2}{*}{ BODY WEICHT } & \multirow{2}{*}{ BODY LENGTH } & \multicolumn{3}{|c|}{ COMPUTED DIAMETERS- $\mu$} \\
\hline & & & Cell body & Nucleus & $\begin{array}{l}\text { Nucleus-plasma } \\
\text { ratios }\end{array}$ \\
\hline days & gramis & $m m$. & & & \\
\hline 15 & 20 & 84 & 15.0 & 8.8 & $1: 4.0$ \\
\hline 20 & 27 & 93 & 17.4 & 10.1 & $: 4.1$ \\
\hline 25 & 39 & 114 & 17.3 & 9.9 & $: 4.3$ \\
\hline 100 & 95 & 152 & 16.9 & 9.7 & $: 4.5$ \\
\hline 150 & 169 & 192 & 16.7 & 9.4 & $: 4.6$ \\
\hline 371 & 220 & 206 & 16.2 & 9.0 & $: 4.8$ \\
\hline
\end{tabular}

TABLE 105

The nucleus-plasma ratios according to the plane of the section at two age periodsalbino rat

\begin{tabular}{|c|c|c|c|}
\hline$A B F$ & $\begin{array}{l}\text { NUCLEUS-PLASMA RATIO } \\
\text { ON THE KADIAL AECTION }\end{array}$ & $\begin{array}{l}\text { NUCLEUS-PLASMA RATIO } \\
\text { ON THE CROSS SECTION }\end{array}$ & $\mathrm{AGE}$ \\
\hline $\begin{array}{c}\text { lays } \\
15 \\
366\end{array}$ & $\begin{array}{l}1: 4.0 \\
1: 4.8\end{array}$ & $\begin{array}{l}1: 4.0 \\
1: 4.8\end{array}$ & $\begin{array}{c}\text { days } \\
15 \\
371\end{array}$ \\
\hline
\end{tabular}

Discussion. According to the foregoing data, the maximum size of the cells in the ganglion spirale, at twenty days, is in cross-sections about $18.7 \times 16.9 \mu$ for the cell body and $10.3 \times$ $10.0 \mathrm{i}$ for the nucleus. Both the long and short diameter of the cell body thus obtained is therefore a little less than that obtained in the radial section, while the diameters for the nucleus are the same.

In the literature we have not found any data for the Norway rat, but there are a few observations on the size of these cells in other mammals by Kölliker ('67) and von Ebner ('02). 
Schwalbe ('87) and Alagna ('09) find these ganglion cells 25 to $30 \mu$ in diameter in the guniea-pig and cat.

Alexander ('99) has also reported measurements on a series of mammals, but as the size of such cells is greatly influenced by the method of preparation, and as our averages are based on the largest cells while those of other authors have been obtained in a different manner, it seems best not to report the other values in the literature, as they are sure to be misleading.

TABLE 106

Showing the changes with age in the diameters of the cells and the nuclei of the spiral ganglion and the lamina pyrmidalis of the cerebral

cortex, respectively

\begin{tabular}{|c|c|c|c|c|c|}
\hline$A \in F$ & \begin{tabular}{|} 
CELL BODY IN \\
THE GANGL. \\
SPRALE COMPUT- \\
ED DIAM. $\mu$
\end{tabular} & $\begin{array}{l}\text { CELL BODY IN } \\
\text { THE LAMINA } \\
\text { PYRAMID COM- } \\
\text { PUTED DIAM. }\end{array}$ & $\begin{array}{l}\text { NUCLEUS IN } \\
\text { GANGL. SPIR. } \\
\text { COAP. DIAM. }\end{array}$ & $\begin{array}{l}\text { NUCLEUS IN } \\
\text { THE LAMINA } \\
\text { PYRAM. COMB. } \\
\text { DIAM. }\end{array}$ & $A \cap E$ \\
\hline days & & & & & days \\
\hline 1 & 10.5 & 11.4 & 7.9 & 9.4 & 1 \\
\hline 20 & 18.1 & 18.7 & 10.2 & 15.7 & 20 \\
\hline 546 & 16.9 & 17.0 & 9.4 & 13.8 & 730 \\
\hline Ratio be- & & & & & ratio \\
\hline $\begin{array}{c}\text { tween } 1 \text { and } \\
20 \text { days }\end{array}$ & $1: 1.7$ & $1: 1.6$ & $1: 1.3$ & $1: 1.3$ & $\begin{array}{c}\text { of } 1 \text { to } \\
20\end{array}$ \\
\hline $\begin{array}{l}\text { Ratio be- } \\
\text { tween } 1 \text { and } \\
546 \text { days }\end{array}$ & $1: 1,6$ & $1: 1.5$ & $1: 1.2$ & $1: 1.2$ & $\begin{array}{l}\text { days } \\
\text { ratio } \\
\text { of } 1 \text { to } \\
730 \\
\text { days }\end{array}$ \\
\hline
\end{tabular}

Considering the course of growth in these cells, we find it to be similar in both the spiral ganglion and the lamina pyramidalis of the cerebral cortex (rat) as reported by Sugita ('18). In the former the cells attain at twenty days of age, the time of weaning, their maximum size, and then diminish slowly with advancing age. The cells of the lamina pyramidalis also reach their full size at twenty days, and then diminish in the same way. Therefore, the course of the growth of both of these groups of nerve cells coincides. However, I do not know of other instances of the phenomenon. When tabulated, the relations here noted appear as in table 106.

The difference between them is only in the absolute values of the diameters of the cell bodies and especially of the nuclei, 
the nuclei in the cells of the lamina pyramidalis being decidedly larger than in those of the spiral ganglion. The ratios of increase are, however, similar.

When we consider the increasing ratios of the diameters of the ganglion cells, we see a close similarity in the maximum values between the cells in the spiral and gasserian ganglion (Nittono, '20). Nevertheless while in the former the ratios from 1 to 20 and 1 to 366 days are in the cell bodies $1: 1.7$ and $1: 1.6$, respectively, in the latter the ratios for the corresponding intervals are 1: 1.43 and 1: 1.69, respectively (Nittono, '20, p. 235). In the nucleus also similar relations are to be seen in both ganglia.

Is these ratios show, there is in the gasserian ganglion a definite increase in the diameters of cells and nuclei after 20 days of age; the time when the maximum is reached by the cells of the spiral ganglion. Thus the former continue to grow after growth in the latter has ceased. These results suggest that the neurons in the more specialized ganglia, like the spiral ganglion, may mature earlier than do those in the less specialized.

On the correlation between the growth of the hair cells of the papilla spiralis and of the nerve cells of the ganglion spiraie. When we compare the growth changes in the hair cells with those in the ganglion cells, we find that the course of the development is similar. Both classes increase in volume from one to twenty days of age, then tend to diminish slowly - the hair cells more slowly than the ganglion eells. In the ratios of increase, however, there are marked differences. Thus in table 67 (bottom of last column) the volume ratios from 1 to 20 and 20 to 546 days are $1: 2.4$ and $1: 0.9$, respectively in the hair cells, and in the ganglion cells, table 108, the ratios of the volumes in the fourth column work out for the corresponding ages as 1:5.1 and 1:0.8, respectively. In the case of the nuclei the growth changes are somewhat different. In the hair cells the nucleus grows in diameter more rapidly, and therefore reaches at nine days its maximum value and then diminishes at succeeding ages.

I have sought to determine whether there was any correlation in grow th between either the entire eylindrical surface or the area of the cross-section of the hair cells, on the one hand and the volume 
of the cells of the ganglion spirale on the other. The reason for making this comparison was the fact that Levi ('08), Busacca ('16), and Donaldson and Nagasaka ('18) have noted in the cells of the spinal ganglia of several mammals that the postnatal growth in volume was correlated with the increase in the area of the body surface, and recently Nittono ('20) has found in the rat a similar relation between the growth of the cells of the gasserian ganglion and the area of the skin of the head. On examining this problem, it is evident that the correlations thus far reported

TABLE 107

Comparison of ratios between the volumes of the cells of the ganglion spirale and the ratios of the area of the cylindrical surface of the hair cells of the organ of Corti-on the maximum values

\begin{tabular}{|c|c|c|c|c|c|}
\hline$A G F$ & $\begin{array}{c}\text { BODY } \\
\text { WEIGHT }\end{array}$ & $\begin{array}{l}\text { VOLUME OF THE } \\
\text { GANGLION CELI, } \\
\mu^{3}\end{array}$ & $\begin{array}{l}\text { RATIOS ON } \\
\text { THF } \\
\text { MAXIMUM } \\
\text { VALUE }\end{array}$ & \begin{tabular}{|c} 
AREA OF \\
CYLINURICAL \\
NURFACE OF THE \\
HAIR CELIS- $\mu 2$
\end{tabular} & $\begin{array}{l}\text { RATIOS ONTHE } \\
\text { MAXIMUM } \\
\text { VALUE }\end{array}$ \\
\hline days & $g m s$. & & & - & $-\cdots \cdots$ \\
\hline 1 & 5 & $606: 3105$ & $:: 1: 5.12$ & $395: 723$ & $:: 1: 1.83$ \\
\hline 3 & 8 & $796:$ : & $: 3.90$ & $463: " 6$ & $:: \quad: 1.56$ \\
\hline 6 & 11 & $1124: "$ & $: 2.76$ & $582: " 6$ & $:: \quad: 1.24$ \\
\hline 9 & 10 & $1317: "$ & $: 2.36$ & $648: " 6$ & $:: \quad: 1.12$ \\
\hline 12 & 13 & 1376 : " & $: 2.26$ & $681: " 6$ & $:: \quad: 1.03$ \\
\hline 15 & 13 & $1732:$ & $: 1.79$ & $729: " 6$ & $:: \quad: 0.99$ \\
\hline 20 & 29 & $3105:$ & $: 1.00$ & $723:$ " & $: 1.00$ \\
\hline 25 & 36 & $2903:$ & $: 1.07$ & $691:$ : & $: 1.05$ \\
\hline 50 & 59 & $2806: "$ & $: 1.11$ & $697:$ : & $: 1.04$ \\
\hline 100 & 112 & $2527:$ : & $: 1.23$ & $678: " 6$ & $: 1.07$ \\
\hline 150 & 183 & $2439: " 6$ & $: 1.28$ & $691:$ & $: 1.05$ \\
\hline 257 & 137 & 2483 : " & $: 1.25$ & $689:$ " & $: 1.05$ \\
\hline 366 & 181 & 2527 : " & $: 1.23$ & $683: "$ & $: 1.06$ \\
\hline 546 & 255 & $2527:$ " & $: 1.23$ & $699:$ " & $::: 1.03$ \\
\hline
\end{tabular}

apply to the postnatal growth period, and that we must consider that the functional relations of the skin are well established, even at the earliest age. The data with which we have worked in the case of the cochlea are presented in several tables (107 to 110 ).

In tables 107 and 108 are given the volumes of the cells of the ganglion spirale and the areas of the cylindrical surface of the hair cells. In table 107 the ratios are computed by dividing the maximum value by the values at each age, and in table 108 by dividing the values at each age by the initial value. 
'TABISE $10 \mathrm{~S}$

Comparison of the ratios of the volume of the cells of the ganglion spirale with the ratios of the area of the cylindrical surface of the hair cells of the organ of

Corti-on the initial values

\begin{tabular}{|c|c|c|c|c|c|}
\hline$A G E$ & $\begin{array}{c}\text { BODY } \\
\text { WFI(iHT }\end{array}$ & $\begin{array}{c}\text { VOLUME OF THE } \\
\text { GANGLION } \\
\text { CELLS- } \mu^{3}\end{array}$ & $\mid \begin{array}{c}\text { IATIOS ON } \\
\text { INITIAL } \\
\text { VALUE }\end{array}$ & $\begin{array}{l}\text { AREA OF THE } \\
\text { CYLINDRICAL } \\
\text { SURFACE OF THE } \\
\text { HAIR CELLS - } \mu 2\end{array}$ & $\begin{array}{r}\text { RATIOS ON } \\
\text { THE INITIAE } \\
\text { VALUE }\end{array}$ \\
\hline days & grams & & & & \\
\hline 1 & 5 & $606: 606::$ & $: 1: 1.00$ & $395: 395::$ & $1: 1.00$ \\
\hline 3 & 8 & : $796::$ & $: 1.31$ & $: 463::$ & $: 1.17$ \\
\hline 6 & 11 & $: 1124::$ & $\therefore \quad: 1.85$ & $: 582::$ & $: 1.47$ \\
\hline 9 & 10 & $: 1317::$ & $: \quad: 2.17$ & $: 648::$ & $: 1.64$ \\
\hline 12 & 13 & $: 1376::$ & $: \quad: 2.27$ & : $681::$ & $: 1.72$ \\
\hline 15 & 13 & $: 1732::$ & $: 2.86$ & : $729::$ & $: 1.85$ \\
\hline 20 & 29 & : $3105::$ & $: 5.12$ & : $723::$ & $: 1.83$ \\
\hline 25 & 36 & $: 2903::$ & $: 4.79$ & : $691::$ & $: 1.75$ \\
\hline 50 & 59 & $: 2806::$ & $: 4.63$ & : $697::$ & $: 1.76$ \\
\hline 100 & 112 & : $2527::$ & $: 4.17$ & : $678::$ & $: 1.72$ \\
\hline 150 & 183 & $: 2439::$ & $: 4.02$ & : $691::$ & $: 1.75$ \\
\hline 257 & 137 & $: 2483::$ & $: 4.10$ & : $689::$ & $: 1.74$ \\
\hline 366 & 181 & $: 2527::$ & $: 4.17$ & : $683::$ & $: 1.73$ \\
\hline 546 & 255 & $: 2527::$ & $: 4.17$ & : $699::$ & $: 1.77$ \\
\hline
\end{tabular}

TABLE 109

Area of the cross-section of the inner and outer hair cells

\begin{tabular}{|c|c|c|c|c|c|}
\hline AOE & $\begin{array}{c}\text { BODY } \\
\text { WEIGHT }\end{array}$ & $\begin{array}{l}\text { DIAMETER OF } \\
\text { ONE INNER } \\
\text { HAIR CELI } \\
\mu\end{array}$ & $\begin{array}{c}\text { AVERAGE } \\
\text { DAMETER OF } \\
\text { THREE OUTER } \\
\text { HAIR CELLS } \\
\mu\end{array}$ & $\begin{array}{c}\text { WEIGHTED } \\
\text { DIAMETER OF } \\
\text { INNER AND } \\
\text { OUTER HAIR } \\
\text { CELLS } \\
\mu\end{array}$ & $\begin{array}{c}\text { WEIGHTED } \\
\text { AREAS OF CROSS } \\
\text { SECTION OF } \\
\text { HAIR CELLS } \\
\mu^{2}\end{array}$ \\
\hline days & grams & 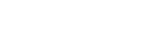 & & & \\
\hline 1 & 5 & 6.6 & 6.0 & 6.2 & 30 \\
\hline 3 & 8 & 8.0 & 7.4 & 7.6 & 45 \\
\hline 6 & 11 & 8.1 & 7.6 & 7.7 & 48 \\
\hline 9 & 10 & 8.8 & 8.5 & 8.6 & 59 \\
\hline 12 & 13 & 8.5 & 8.3 & 8.4 & 5.5 \\
\hline 15 & 13 & 8.4 & 7.7 & 7.9 & 50 \\
\hline 20 & 29 & 8.8 & 8.2 & 8.4 & 55 \\
\hline 25 & $36^{\circ}$ & 8.8 & 8. 1 & 8.3 & 55 \\
\hline 50 & 59 & 8.8 & 8.2 & 8.4 & 55 \\
\hline 100 & 112 & 8.6 & 8.1 & 8.2 & 53 \\
\hline 150 & 18.3 & 8.5 & 8.3 & 8.4 & 55 \\
\hline 257 & $1: 37$ & 8.5 & 8. 3 & 8.4 & 55 \\
\hline ititi & 151 & S. S & 8.4 & 8.5 & $5 \mathrm{~S}$ \\
\hline 546 & 25.5 & 8.6 & S. 2 & 8.3 & 55 \\
\hline
\end{tabular}


I have calculated the cylindrical surface of the hair cells according to the formula for the lateral surface of a cylinder; therefore, this area equals $2 \pi r a$ ( $r=$ radius, $a=$ height of the cylinder). As the hair cells are more or less pointed at their lower end, the surface obtained by this formula has nearly the value of the total surface of the hair cells less that for the upper end disk.

As has been already shown, both classes of cells grow rapidly from birth to twenty days, and after that both tend to decrease slightly in volume. It is evident that during the growing period,

T'ABLE 110

Comparison of the ratios of the volume of the cells of the ganglion spirale with the ratios of the areas of the cross-section of the inner and outer hair cells of the organ of Corti

\begin{tabular}{|c|c|c|c|c|c|}
\hline $\begin{array}{l}\mathrm{AGE} \\
\text { days }\end{array}$ & $\begin{array}{c}\text { BODY } \\
\text { WEIGHT } \\
\text { gms }\end{array}$ & $\begin{array}{l}\text { VOLUME OF THE } \\
\text { GANGLION } \\
\text { CELLS- }{ }^{3}\end{array}$ & $\mid \begin{array}{c}\text { RATIOS ON THE } \\
\text { INITIAI } \\
\text { VALUE }\end{array}$ & $\begin{array}{c}\text { AREA OF THE } \\
\text { CROSS-SECTION } \\
\text { OF THE HAIR } \\
\text { CELLS }\end{array}$ & $\begin{array}{c}\text { RATIOS ON THE } \\
\text { INITIAL } \\
\text { VAIUEE }\end{array}$ \\
\hline 1 & 5 & $606: 606:$ & $: 1: 1.00$ & $30: 30::$ & $1: 1.00$ \\
\hline 3 & 8 & : 796: & $: 1.31$ & $: 45::$ & $: 1.50$ \\
\hline 6 & 11 & $: 1124:$ & $: 1.85$ & $: 48::$ & $: 1.60$ \\
\hline 9 & 10 & $: 1317:$ & $: 2.17$ & $: 58::$ & $: 1.93$ \\
\hline 12 & 13 & $: 1376:$ & $: 2.27$ & $: 55::$ & $: 1.83$ \\
\hline 15 & 13 & : 1732 : & $: 2.86$ & $: 50::$ & $: 1.67$ \\
\hline 20 & 29 & $: 3105:$ & $: 5.12$ & $: 55::$ & $: 1.83$ \\
\hline 25 & 36 & : 2903 & $: 4.79$ & $: 55::$ & $: 1.83$ \\
\hline 50 & 59 & $: 2806:$ & $: 4.6: 3$ & $: 53::$ & $: 1.77$ \\
\hline 100 & 112 & $: 2527:$ & $: 4.17$ & $: 53::$ & $: 1.77$ \\
\hline 150 & 183 & : 2439 : & $: 4.02$ & $: 55::$ & $: 1.83$ \\
\hline 257 & 137 & $: 2483:$ & $: 4.10$ & $: 55::$ & $: 1.83$ \\
\hline 366 & 181 & $: 2527:$ & $: 4.17$ & $: 58::$ & $: 1.93$ \\
\hline 546 & 25.5 & $: 2527:$ & $: 4.17$ & $: 55::$ & $: 1.83$ \\
\hline
\end{tabular}

from one day to the end of the record, the volumes of the ganglion cells increase more rapidly than do the cylindrical areas of the hair cells (table 108). If we seek a numerical expression of these relations, it seems best to start not with the values at birth, but with those at nine days of age when the cochlea is just beginning to function, and to extend the comparison only up to twenty days when both groups of cells have reached their maximum size.

Thus at nine days (table 108) the volume of the ganglion cells is $1317 \mu^{3}$, while at twenty days it is $3105 \mu^{3}$, or as $1: 2.3$, while the area of the cylindrical surfaces of the hair cells at the respective 
ages is $648 \mu^{3}$ and $723 \mu^{3}$, or as $1: 1.1$, thus showing a rapid growth of the ganglion cell bodies accompanied by but slight enlargement of the hair cells.

It is evident from these ratios that the ganglion cells are increasing in volume more rapidly than the hair cells in area. It is possible that the nervus cochlearis innervates the other cells of the cochlea as well, but even if this is taken into consideration the general relations remain the same.

It follows from this that during the period between the earliest appearance of the functional response (nine days) and the attainment of the maximum size of the cells, the innervation of the hair cells is steadily improving, if we may infer such an improvement from the increase in the volume of the ganglion cells. After the close of this early growing period the relations are approximately fixed through the remainder of life. We do not find, therefore, in the cochlea any relation which corresponds to those found between the spinal ganglion cells or those of the gasserian ganglion and the associated areas of the skin during postnatal growth. This seems to indicate that in the cochlea growth is fixed or limited, while in the body as a whole it is more or less continuous, and the ganglion cells behave differently in the two cases.

In table 109 are shown the diameters of the inner and outer hair cells and their weighted diameters. In the last column is given the area of the cross-section of the hair cells.

The ratios of these areas on the initial area are shown in table 110 in comparison with the volumes of the ganglion cells on the initial volume, and indicate that from three days of age the values for the ganglion cells are increasing more rapidly than those for the area of the cross-section of the hair cells, and at twenty days the increase in the case of both elements has reached a maximum. Here, as in the case of the cylindrical surface, both elements show like phases of growth, but the increase in the volumes of the ganglion cells is much greater than the increase in the cylindrical area or cross-section of the hair cells.

As it may be desirable to use for comparison the measurements on the cells of the ganglion spirale as here reported, the 
constants for the determinations based on 160 cells in each age group are given in table 111 for the radial vertical sections and in table 112 for the cross-sections.

TABLE 111

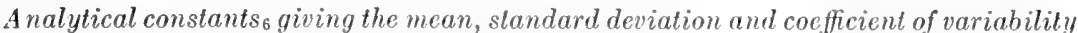
with their respective probable errors for the diameters of the cells and their nuclei of the ganglion spirale in radial vertical section

\begin{tabular}{|c|c|c|c|c|}
\hline \multirow[b]{2}{*}{$\begin{array}{l}\text { AGE } \\
\text { days }\end{array}$} & \multicolumn{4}{|c|}{ FOR TOTAL NUMBER OF CELLS } \\
\hline & $\begin{array}{l}\text { Cell } \\
\text { Nucleus }\end{array}$ & Mean & $\begin{array}{l}\text { Standard } \\
\text { deviation }\end{array}$ & $\begin{array}{l}\text { Coeflicient of } \\
\text { variability }\end{array}$ \\
\hline \multirow[t]{2}{*}{1} & Cell & $10.2 \pm 0.05$ & $0.90 \pm 0.03$ & $8.9 \pm 0.33$ \\
\hline & Nucleus & $7.8 \pm 0.02$ & $0.46 \pm 0.01$ & $5.9 \pm 0.2 \%$ \\
\hline \multirow[t]{2}{*}{3} & Cell & $11.3 \pm 0.03$ & $0.50 \pm 0.02$ & $4.4 \pm 0.17$ \\
\hline & Nucleus & $7.9 \pm 0.02$ & $0.32 \pm 0.01$ & $4.1 \pm 0.15$ \\
\hline \multirow[t]{2}{*}{6} & Cell & $12.6 \pm 0.04$ & $0.68 \pm 0.03$ & $5.4 \pm 0.20$ \\
\hline & Nucleus & $8.4 \pm 0.03$ & $0.48 \pm 0.02$ & $5.7 \pm 0.22$ \\
\hline \multirow[t]{2}{*}{9} & Cell & $13.1 \pm 0.03$ & $0.61 \pm 0.02$ & $4.7 \pm 0.18$ \\
\hline & Nucleus & $8.5 \pm 0.03$ & $0.52 \pm 0.02$ & $6.1 \pm 0.23$ \\
\hline \multirow[t]{2}{*}{12} & Cell & $13.4 \pm 0.05$ & $0.86 \pm 0.03$ & $6.4 \pm 0.24$ \\
\hline & Nucleus & $8.4 \pm 0.03$ & $0.61 \pm 0.02$ & $7.3 \pm 0.28$ \\
\hline \multirow[t]{2}{*}{15} & Cell & $14.6 \pm 0.04$ & $0.73 \pm 0.03$ & $5.0 \pm 0.13$ \\
\hline & Nucleus & $8.7 \pm 0.03$ & $0.58 \pm 0.02$ & $6.7 \pm 0.25$ \\
\hline \multirow[t]{2}{*}{20} & Cell & $17.8 \pm 0.06$ & $1.17 \pm 0.04$ & $6.6 \pm 0.25$ \\
\hline & Nucleus & $10.0 \pm 0.02$ & $0.40 \pm 0.02$ & $4.1 \pm 0.15$ \\
\hline \multirow[t]{2}{*}{25} & Cell & $17.3 \pm 0.05$ & $0.88 \pm 0.03$ & $5.1 \pm 0.19$ \\
\hline & Nucleus & $9.9 \pm 0.02$ & $0.36 \pm 0.01$ & $3.6 \pm 0.14$ \\
\hline \multirow[t]{2}{*}{50} & Cell & $17.2 \pm 0.04$ & $0.78 \pm 0.03$ & $4.5 \pm 0.17$ \\
\hline & Nucleus & $9.7 \pm 0.02$ & $0.34 \pm 0.01$ & $3.6 \pm 0.14$ \\
\hline \multirow[t]{2}{*}{100} & Cell & $16.5 \pm 0.03$ & $0.65 \pm 0.02$ & $3.9 \pm 0.15$ \\
\hline & Nucleus & $9.4 \pm 0.02$ & $0.38 \pm 0.01$ & $4.0 \pm 0.15$ \\
\hline \multirow[t]{2}{*}{150} & Cell & $16.4 \pm 0.03$ & $0.79 \pm 0.02$ & $4.8 \pm 0.18$ \\
\hline & Nucleus & $9.1 \pm 0.02$ & $0.42 \pm 0.02$ & $4.6 \pm 0.17$ \\
\hline \multirow[t]{2}{*}{257} & Cell & $16.6 \pm 0.06$ & $1.09 \pm 0.04$ & $6.6 \pm 0.25$ \\
\hline & Nucleus & $9.5 \pm 0.02$ & $0.39 \pm 0.01$ & $4.1 \pm 0.15$ \\
\hline \multirow[t]{2}{*}{366} & Cell & $16.7 \pm 0.05$ & $1.02 \pm 0.01$ & $6.1 \pm 0.22$ \\
\hline & Nucleus & $9.3 \pm 0.03$ & $0.52 \pm 0.02$ & $5.6 \pm 0.21$ \\
\hline \multirow[t]{2}{*}{546} & Cell & $16.7 \pm 0.06$ & $1.06 \pm 0.04$ & $6.4 \pm 0.24$ \\
\hline & Nucleus & $9.3 \pm 0.02$ & $0.45 \pm 0.02$ & $4.9 \pm 0.18$ \\
\hline
\end{tabular}

Conclusion. For the study of the growth of the nerve cells in the ganglion spirale fourteen age groups were taken and the data obtained from the 160 largest cells in each age group. Besides these, six age groups, representing six cochleas, were examined in cross-sections to determine the form of the ganglion 
cells and the relation of their long axes to the axis of the cochlea. Here also the ten largest cells in each of four, nearly corresponding turns, were measured. We obtained the following results:

1. As thus prepared, the ganglion cells at birth have a maximum size of $11 \times 10 \mu$ in cell body and $8.2 \times 7.6 \mu$ in nucleus. At twenty days the diameters are the largest, $18.7 \times 16.9 \mu$ in cell body and $10.3 \times 10.0 \mu$ in nucleus.

TABLE 112

Analylical constanls giving the mean, standard deviation and cocfficient of variability with their respective probable errors for the diameters of the cells and their nuclei of the ganglion spirale, in cross-section

\begin{tabular}{|c|c|c|c|c|}
\hline \multirow{2}{*}{ AGE } & \multirow[b]{2}{*}{$\begin{array}{l}\text { Cell } \\
\text { Nucleus }\end{array}$} & \multicolumn{3}{|c|}{ FOR TOTAL NUMBER OF CELLS } \\
\hline & & Mean & $\begin{array}{l}\text { Standard } \\
\text { deviation }\end{array}$ & $\begin{array}{c}\text { Coefficient of } \\
\text { variability }\end{array}$ \\
\hline \multirow[t]{2}{*}{$\begin{array}{l}\text { dayss } \\
15\end{array}$} & Cell & $14.7 \pm 0.04$ & $0.40 \pm 0.03$ & $2.7 \pm 0.21$ \\
\hline & Nucleus & $8.9 \pm 0.04$ & $0.34 \pm 0.03$ & $3.8 \pm 0.29$ \\
\hline \multirow[t]{2}{*}{20} & Cell & $17.1 \pm 0.09$ & $0.83 \pm 0.06$ & $4.9 \pm 0.37$ \\
\hline & Nucleus & $10.0 \pm 0.06$ & $0.58 \pm 0.04$ & $5.8 \pm 0.44$ \\
\hline \multirow[t]{2}{*}{25} & Cell & $17.1 \pm 0.07$ & $0.63 \pm 0.05$ & $3.7 \pm 0.28$ \\
\hline & Nucleus & $9.8 \pm 0.03$ & $0.30 \pm 0.02$ & $3.1 \pm 0.23$ \\
\hline \multirow[t]{2}{*}{100} & Cell & $16.7 \pm 0.05$ & $0.44 \pm 0.03$ & $2.6 \pm 0.20$ \\
\hline & Nucleus & $9.6 \pm 0.04$ & $0.36 \pm 0.03$ & $3.7 \pm 0.25$ \\
\hline \multirow[t]{2}{*}{150} & Cell & $16.4 \pm 0.07$ & $0.69 \pm 0.05$ & $4.2 \pm 0.32$ \\
\hline & Nucleus & $9.4 \pm 0.05$ & $0.46 \pm 0.03$ & $4.9 \pm 0.37$ \\
\hline \multirow[t]{2}{*}{371} & Cell & $16.0 \pm 0.06$ & $0.55 \pm 0.04$ & $3.5 \pm 0.24$ \\
\hline & Nucleus & $9.1 \pm 0.05$ & $0.43 \pm 0.03$ & $4.7 \pm 0.36$ \\
\hline
\end{tabular}

2. The ganglion cells grow relatively rapidly after birth and reach at twenty days of age their maximum size. After having passed the maximum at twenty days, they diminish in size very slowly, but the internal structure matures more and more with successive age.

3. The nuclei are relatively large at birth but increase more slowly than the cell bodies do; nevertheless, they follow the same course of development as the latter. This peculiar course in the growth of the ganglion cells is similar to that followed by the cells of the lamina pyramidalis of the cerebral cortex of the rat as found by Sugita ('18) 
4. Within the cochlea the cell bodies and nuclei increase their diameters from the base toward the apex, except in the earlier stages.

5. There are no evident differences in the diameters of the cell bodies and the nuclei of the ganglion cells either according to sex or side.

6. Both the cell bodies and the nuclei are immature at birth, but differentiate rapidly, and even at six days the Nissl bodies are visible. The differentiation proceeds with advancing age.

7. The ganglion cells are bipolar and oval in shape. The direction of the long axis of the cells differs according to the turn of the cochlea and in the upper turn it runs almost parallel to the axis of the modiolus but inclines more and more to the horizontal position on passing to the base.

8. The nucleus-plasma ratios of the ganglion cells increase with age in both the radial and cross-sections.

9. The increase in the volume of the ganglion cells and the area of the cross-section of the hair cells is approximately similar during the first nine days of life, but after that the ganglion cells increase relatively very rapidly. These relations are very different from those found for the spinal ganglion cells by Donaldson and Nagasaka ('18) and for the cells of the gasserian ganglion by Nittono ('20).

The nervus cochlearis innervates not only the hair cells, but all the elements of the cochlea, and this may have some influence upon this relation. It is interesting to note that the rate of increase in the cylindrical surface of the hair cells is similar to that in the area of the cross-sections of these same cells.

\section{CORRELATION BETWEEN THE INCEPTION OF HEARING AND THE GROWTH OF THE COCHLEA}

The present study aims merely to compare in the rat the size of each element of the cochlea just before and just after the appearance of hearing and to ascertain the changes in the cochlea which take place during this phase. The rats which have sense of hearing show the so-called 'Ohrmuschelreflex' 
of Preyer and other responses to auditory tests. Both the guineapig and rat react most evidently to sounds. The former animal responds usually five to six hours after birth. In the rat, however, the development of the function is, as already stated, relatively retarded and usually first appears at about ten days of age.

To test the presence of hearing there are several methods, as for example, Preyer's' Ohrmuschelreflex' and the reflex closure of the eyelid, and these I used in making my observations. As the source of the sound I selected the hand clap, a whistle (Triller-pfeife, about $\mathrm{c}^{4}$ ) and a low sound made by drawing in the breadth with nearly closed lips (about $\mathrm{c}^{1}$ ).

Since it is my purpose merely to determine the first appearance of a response to sound, it is not nescessary to carry out such refined examinations as did Hunter ('14, '15, '18) Watson ('07), and others on white rats, and Marx ('09) on the guineapig, nor was it necessary to use the tuning-fork which by the way is not so good for tests on animals as for those on man. Since sometimes we may have a defect of hearing in animals, as shown by many investigators, it was deemed necessary to use several sources of sound and to take care not to produce air currents striking the test animal or to touch it in any way. For this purpose a large sheet of glass was placed between the source of sound and the rats to be tested. While the rat was resting I suddenly produced the sound and noted whether the rat responded. When the animals already had their eyes open the test was made from behind to avoid visual reflexes.

\section{Observations}

Rats at birth show no response to auditory stimuli. Most of them respond at twelve days of age very clearly, sometimes at ten to eleven days Under certain circumstances, the time of the reflex can be rather accurately noted. For example, while in the morning at ten days no reflex was noted it was present in the evening of the same day. Fortunately, I obtained five nine-day-old rats belonging to one litter and in nearly the same condition of nourishment and developnent. One of these 
responded to the test very evidently at noon on the ninth day, but the others did not. The sound which was effective was fairly intense, but to a faint and low-pitched sound this rat did not respond. In this case the external auditory canal was open. In the others there was in some a small open canal, but more or less closed by a cellular plug. In the latter cases I removed this obstruction without much difficulty or damage by washing, yet no reaction could be obtained to the stimuli. As it was to be expected, that also in the latter the reflexes would very shortly appear, all the cochleas of these young rats, both the not-hearing and hearing, were fixed by the method previously described and later examined.

In chapter 1, in which I followed the growth changes in the constituents of the membranous cochlea and in its ganglion cells from birth to maturity, including 'not hearing' and 'hearing' rats, very evident differences were observed in rats between nine and twelve days of age. In view of this, it will be of interest to compare the measurements obtained from the 'not hearing' and 'hearing' rats nine days old and members of the same litter. From the differences thus obtained we can conclude concerning the developmental changes in the cochlea requisite for the first appearance of hearing, provided there are no obstacles in the sound-conducting apparatus or deficiencies in the central organ.

In table 113 are given the values for the size of the several constituents of the cochlea from a rat which did not hear and one which did, at nine days. The former data are the averages from four cochleas, while the latter are from two. The table shows in a striking way that where there is a significant difference. The values obtained from the rat which could hear are usually larger than those of the rat which could not hear.

Among these measurements we see sometimes very marked and sometimes only slight differences. Only the radial distance between the labium vestibulare and the inner edge of the head of the inner pillar cell in the first two turns and the diameter of the nuclei of the inner and outer hair cells are in the former smaller than in the latter. In both instances, however, these smaller 
TABLE 113

Comparison of the dimensions of the constituents of the cochlea in a hearing rat $(H$. wilh those in a rat nol hearing $\left(N_{.}\right)$at nine days of age-measurements in micra

\begin{tabular}{c|r|r}
\hline RAT & AGE & $\begin{array}{c}\text { BODY } \\
\text { WEIGHT }\end{array}$ \\
\cline { 3 - 3 }$(\mathrm{N})$. & days & grams \\
(H.) & 9 & 10 \\
& 9 & 11 \\
\hline & & Average distance between two spiral ligaments \\
(N.) & 1430 & \\
(H.) & 1434 & \\
\hline
\end{tabular}

Breadth of membrana tectoria

\begin{tabular}{|c|c|c|c|c|c|c|}
\hline & TCRN I & II & III & IV & Average & T h ickness \\
\hline$\left(\mathrm{N}_{0}\right)$ & 243 & 270 & 304 & 306 & 281 & 27 \\
\hline (H.) & 242 & 268 & 308 & 314 & 283 & 27 \\
\hline
\end{tabular}

Breadth of membrana basilaris

\begin{tabular}{c|c|c|c|c|c|c|c}
\hline & IURN I & II & III & IV & AVERAGE & $\begin{array}{c}\text { ZONA } \\
\text { ARCOATA }\end{array}$ & $\begin{array}{c}\text { ZONA } \\
\text { PECTINATA }\end{array}$ \\
\cline { 1 - 3 } (N.) & 169 & 189 & 202 & 201 & $\mathbf{1 9 1}$ & 79 & 112 \\
(H.) & 171 & 186 & 214 & 204 & 196 & 93 & 103
\end{tabular}

Distance between the habenula perforata and the outer corner of the inner hair cell

\begin{tabular}{c|c|c|c|c|c|c}
\hline & TURN I & II & III & IV & AVERAGE & \\
\hline (N.) & 38 & 38 & 44 & 49 & 42 & \\
(H.) & 40 & 42 & 58 & 60 & 50 & \\
\hline
\end{tabular}

Distance between habenula perforata and the outer corner of the outer pillar cell at foot

\begin{tabular}{|c|c|c|c|c|c|c|}
\hline & TURN I & II & III & IV & Average & \\
\hline (N.) & 70 & 76 & 86 & 86 & 79 & \\
\hline (H.) & 79 & 88 & 103 & 102 & 93 & \\
\hline
\end{tabular}

Height of greater epithelial ridge

\begin{tabular}{c|c|c|c|c|c|}
\hline & TURN I & II & III & IV & AVERAGE \\
\cline { 1 - 3 }$(\mathrm{N})$. & 36 & 40 & 41 & 42 & 40 \\
(H.) & 42 & 43 & 48 & 50 & 46 \\
\hline
\end{tabular}

Distance between the labium vestibulare and the habenula perforata.

\begin{tabular}{c|c|c|c|c|c|}
\hline IV.) & IORN 1 & II & III & IV & Average \\
\hline (H.) & 83 & 108 & 137 & 145 & 118 \\
85 & 104 & 140 & 150 & 120 \\
\hline
\end{tabular}


TABLE 113-Continued.

Distance between the labium vestibulare and the inner edge of the head of the inner pillar cell

\begin{tabular}{|c|c|c|c|c|c|}
\hline & TURN I & II & III & IV & Average \\
\hline$(\mathrm{N})$. & 94 & 131 & 168 & 179 & 143 \\
\hline (H.) & 78 & 108 & 170 & 210 & 142 \\
\hline
\end{tabular}

Height from basal plane to surface of pillar cells

\begin{tabular}{c|c|c|c|c|c|c}
\hline & TURN I & II & I I I & IV & AVERAGE \\
\hline (N.) & 32 & 33 & 35 & 36 & 34 \\
(H.) & 40 & 42 & 45 & 45 & 43 & \\
\hline
\end{tabular}

Height of tunnel of Corti

\begin{tabular}{l|r|r|r|r|r|}
\hline & TURN I & \multicolumn{1}{|c|}{ II } & III & IV & AVERAGE \\
\cline { 1 - 3 } (N.) & 0 & 0 & 0 & 0 & 0 \\
(H.) & 20 & 18 & 14 & 11 & 16 \\
\hline
\end{tabular}

Height of papilla spiralis at the third series of outer hair cells

\begin{tabular}{c|c|c|c|c|c|c}
\hline & TURN I & II & II I & IV & AVERAGE \\
\cline { 1 - 4 } (N.) & 28 & 28 & 27 & 28 & 28 \\
(H.) & 42 & 43 & 39 & 36 & 40 & \\
\hline
\end{tabular}

Height of Hensen's cells

\begin{tabular}{c|c|c|c|c|c|}
\hline & TURN I & II & III & IV & AVERAGE \\
\cline { 1 - 4 } (N.) & 20 & 23 & 23 & 24 & 23 \\
(H.) & 42 & 45 & 38 & 30 & 39
\end{tabular}

Angle of lamina basilaris with plane of membrana basilaris-degrees

\begin{tabular}{c|r|r|r|r|r|}
\hline & TURN I & \multicolumn{1}{|c|}{ II } & III & IV & IVERAGE \\
\cline { 1 - 3 }$(\mathrm{N})$. & 0 & 0 & 0 & 0 & 0 \\
(H.) & +7 & +4 & -8 & -7 & -
\end{tabular}

Length of the inner and outer pillar cells

\begin{tabular}{|c|c|c|c|c|c|c|}
\hline & $\begin{array}{l}\text { INNER } \\
\text { TURN I }\end{array}$ & II & III & IV & $A V E R A G E$ & \\
\hline$(\bar{N})$. & 35 & 39 & 41 & 40 & 39 & \\
\hline \multirow[t]{2}{*}{ (H.) } & 36 & 39 & 42 & 45 & 41 & \\
\hline & $\begin{array}{l}\text { OUTER } \\
\text { TURN I }\end{array}$ & I I & II I & IV & AVERAGE & $\begin{array}{l}\text { WEIGHTED } \\
\text { AVERAGE }\end{array}$ \\
\hline (N.) & 26 & 26 & 29 & 29 & 28 & 30 \\
\hline (H.) & 45 & 54 & 50 & 40 & 47 & 46 \\
\hline
\end{tabular}

Volume of inner and outer hair cells $-\mu^{3}$

\begin{tabular}{c|c|c|c} 
& INNER: AVERAGE & OUTER: AVERAGE & WEIGHTED AVERAGE \\
\cline { 1 - 2 }$(\mathrm{N})$. & 1798 & 1277 & 1407 \\
(H.) & 1815 & 1279 & 1428 \\
\hline
\end{tabular}


TABLE 113-Concluded

Diameter of nuclei of the inner and outer hair cells

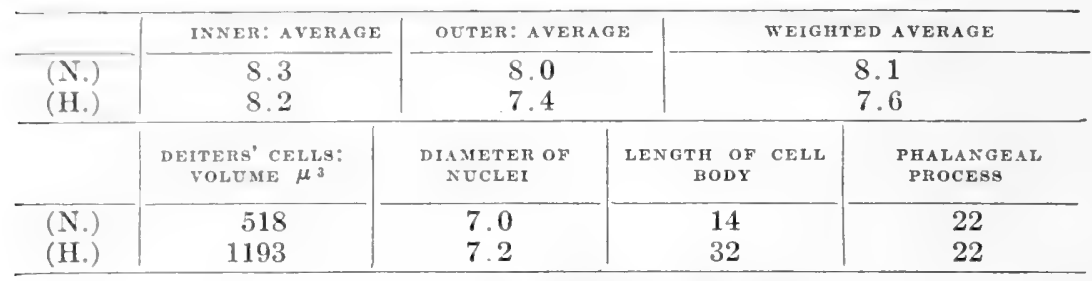

Ganglion spirale: diameters computed

\begin{tabular}{l|c|c}
\hline & CELLS & NUCLEI \\
\cline { 2 - 3 }$(\mathrm{N})$. & 13.6 & 8.5 \\
$(\mathrm{H})$. & 13.7 & 8.6 \\
\hline
\end{tabular}

values are marks of maturity. These changes in size accord with the results given in chapter 1 at twelve days of age, though there are some differences between them in the absolute values.

Figures 7 and 8 illustrate the outlines of the tympanic wall of the membranous cochlea in nine-day-old rats which could not and could hear, respectively. These figures have been drawn from the corresponding sections at the beginning of the middle turn of the cochlea and are comparable with figures 3 to 6 and 9 to 12 . On comparing figures 7 and 8 , the more noticeable differences appear to be the following.

The membrana tectoria is a bit.longer in the hearing rat. The appearance and the position of it with reference to the surface of the papilla spiralis is also different. In the not-hearing cochlea it has an infantile look.

The outer end of the main part does not yet reach the second row of the outer hair cells and connects with the Hensen's prominence by a thick thread. There are also many fine fibers to be seen between the basal surface of the membrane and the papilla. In the hearing rat the fine fibers are absent. The membrane reaches already the row of the outer hair cells and there is a strong connection between this part and the terminal ame (Schlussrahmen) of the lamina reticularis by a thick read as shown in figure 8 . Thus the position of the membrane 
above the papilla depends a little bit upon the increase of the length of the membrane itself, but chiefly upon other factors such as the inward shifting of the papilla. The membrana basilaris as a whole shows a small increase o? breadth in the hearing rat. The zona arcuate, however, increases much in its breadth, while the zona pectinata rather decreases. This is due to the development of the pillar cells. The base of the inner and outer pillar cell spread much on the membrane. At the same time the length of the cells, especially of the outer, increases nearly twice as much as in the not-hearing rat.

Thus the foot of the outer pillar cell moves outward, as Böttcher ('69, '72) stated, while the inner corner of the inner pillar cell does not move in any way, as the habenula perforata stands at a fixed point. This results in a change in the form of the arch of Corti. The hitherto outward inclined arch tends to bend inward and between both inner and outer cells arises a space, the tunnel of Corti. The appearance of the tunnel seems to have some relation to hearing. The tunnel is always present in the cochleas of hearing rats. Sometimes the tunnel is present in the lower turns, but not in the upper turns in the not-hearing rats. We can say, therefore, that it probably appears through all the turns before the special function of the cochlea begins. In this way the zona arcuata of the membrana basilaris increases its breadth.

The next striking change is the rapid increase in the size of the Deiters' cells, Hensen's cells, and the resultant change of the form, with an inward shifting, of the papilla spiralis.

The Deiters' cells increase their height very rapidly; the length of the cell body becomes over twice that in the not-hearing rat, but the processus phalangeus changes only slightly. Hensen's cells develop also, but not so much as Deiters' cells. The papilla spiralis thus increases in height. On the other hand, the greater epithelial ridge vanishes inwards from the inner supporting cells and appears as a furrow-the sulcus spiralis internus. Through the pressure of these outward-lying cells the papilla spiralis swings inward as a whole, without really moving on the membrana basilaris. The lamina reticularis 
becomes inclined inward instead of outward and subtends a slight angle with the plane of the membrana basilaris. The distance from the labium restibulare to the inner edge of the head of the inner pillar cell becomes smaller through the inward shifting of the papilla.

In the hair cells and the cells of the ganglion spirale we see a smaller difference between the hearing and not-hearing rats. Only the diameter of the nuclei of the hair cells in the hearing rat diminishes a little, as it continues to do in the adult cochlea.

All the changes just enumerated begin at the base of the cochlea and progress to the apex. Therefore we see the high and outward ascending papilla spiralis in turn I, while in the upper turns the papilla is not yet so developed, is smaller in all the constituents, and shows in general the characters of a younger and less mature cochlea-conditions which disappear with age. This upper and immature part seems not to respond to the test for hearing. Indeed, my testing result is positive for sounds of high pitch, but not for low pitch. Therefore we conclude that the papilla spiralis develops functionally from base to apex and that when the papilla spiralis has developed in the basal turns, but not in the upper turns, it responds to sounds of high pitch alone.

\section{Discussion}

If we assume that our tests for hearing are trustworthy, then the differences between the size of the constituents of the cochlea in nine-day-old rats which could and could not hear will indicate what developmental changes in the cochlea of the albino rat are necessary for the appearance of the hearing reflex. Whether all the differences found by us are necessary is difficult to determine, and the problem is open for further study; but as the matter stancls, our results give the closest correlation between structural changes and the appearance of function which has as yet been reported.

Kreidl and Yanase ('07) studied the differences between the not-hearing and hearing rat and summarized their results on page 509: "Kurz vor Eintritt des Hörreflexes ist das Cortische 
Organ im wesentlichen fertig ausgebildet." They publish no measurements nor data. The condition of the development of the organ of Corti described as 'fertig ausgebildet' is not sufficiently precise.

Further, on the same page they say, "Der auffäligste und, soweit die Untersuchungen bis jetzt eregben haben, einzige Unterchied, der zwischen dem anatomischen Bild des Labyrinthes eines neugeborenen Tieres, das den Reflex eben noch nicht aufweist, und dem eines solchen, das denselben zum ersten Male eben erkennan lässt, ist der, dass beim ersteren noch ein Zusammenhang zwischen Cortischem Organ und Cortischer Membran besteht, beim letzteren dagegen dieser Zusammenhang bereits gelöst oder gelockert ist." Their observation is quite different from mine. In my case the papilla spiralis shows in the development of its constituent elements pretty large differences between the not-hearing and hearing rats. Therefore it seems probable that the changes in the growth and form of the papilla just before the first appearance of the special function, take place very quickly. Also we cannot agree to their statement concerning the relation of the membrana tectoria to the papilla spiralis. In our preparations there is still a connection of the membrane with the terminal frame of the lamina reticularis through a thick thread in the cochlea of the rat which could hear (fig. 8) and also in that of the rat which could not hear (fig. 7).

This is a point on which opinions differ. While one opinion, represented by Kishi ('07) and others, is to the effect that this connection remains through life, the other, represented by Kölliker ('67) and others, asserts the membrane projects free in the endolymph. I have never seen this connection in the adult cochlea, nor have I found such a connection of the membrane with the hairs of the hair cells, as Shambaugh ('10) described in the pig. In the young rats, at fifteen days for example, we very often see upon the terminal frame the broken remainder of this connecting thread. Whether this break arises through natural development or is the result of artificial manipulation it is hard to say. At any rate, Held's assertion ('90), that in an animal capable of hearing the membrana tectoria is never connected 
with the papilla spiralis, is not supported by my observation. That the freeing of the outer zone of the membrane is not absolutely necessary for the mediation of auditory impulses is demonstrated in the cochlea of birds, as shown by Hasse ('66), Retzius ('S4), Sato ('17), and others. In these forms the membrane remains through life attached to the epithelial ridge.

My results agree with those of Hardesty ('15) on this point, though he obtained a tectorial membrane which floats free in the endolymph with its outer zone. Lane ('17) studied the correlation between the structure of the papilla spiralis and the appearance of hearing in the albino rat, but his description is brief and does not touch on this relation of the papilla to the tectorial membrane.

Thus the inception of hearing does not coincide with the detachment of the tectorial membrane from the papilla spiralis, but with the development of each constituent of the papilla spiralis and the membrane tectoria, as has been described. As these changes occur first at the base and then pass to the apex; the animal can perceive at first only the sounds of high pitch. One or two days later development is complete in all the turns, and then the rat can hear the sounds of lower pitch also. Thus the process of the development of the cochlea does not support the 'telephone theory' of audition, but on the contrary agrees with the conclusion that the papilla in different locations in the turns of the cochlea responds to sounds of a definite pitch, as Wittmaack ('07), Yoshii ('09), Hoessli ('12), and others have shown by experimental studies on the mammals.

Concerning the exact age of the first appearance of the function in the rat, there are several different statements. Lane ('17) found no response to sound before the twelfth day after birth, and on the sixteenth day he reports hearing well established. Freill and Yanase ('07) state that hearing begins in the rat at from twelve to fourteen days. My rats responded usually at ten to twelve days, but one at nine days. These differences depend in all probability on the vigor of the young during the first days of postnatal life, and it seems probable that exceptionally well-nourished young might develop precociously in this 
respect. The intensity of the stimulus is important in determining the hearing reflex, as Small ('99) has stated. In my cases the young rats responded very evidently to intense sounds, while they reacted weakly or not at all to those which were faint. Thus only the intense sounds were perceived by the rat of nine days.

\section{Conclusions}

1. The hearing reflex was never obtained in rats less than nine days of age.

2. At nine days a single rat, one of five in a litter, responded to a sharp sound like clapping the hands and to a whistle of high pitch; the other four did not respond. At the tenth day some of the four reacted, and at the twelfth day all could hear.

3 . The hearing reflex probably occurs early in young rats that are vigorous and well nourished.

4. To obtain the first hearing reflexes it is necessary to have rather strong sounds of high pitch.

5. A comparison of the histological structure of the cochlea in rats of nine days, one of which could hear and the other could not, shows clear differences in its development of the cochlea. These consist not in the detachment of the tectorial membrane from the papilla spiralis, but in the degree of differentiation of the constituents of the papilla. The tectorial membrane is connected in both cases at its outer end with the terminal frame of the lamina reticularis by a thick thread. The papilla is more differentiated in the hearing rat in several characters. The tectorial membrane has reached with its outer end the outermost row of the outer hair cells, but in the not-hearing rat it has not yet reached the second row of the cells.

6 . The form of the papilla and its relation to the surrounding structures, especially to the tectorial membrane, are in the hearing rat at nine days very similar to those in the rat at twelve days of age, though there are some differences between them in absolute size.

7. The freeing of the tectorial membrane from the papilla spiralis is not necessary to the appearance of the hearing reflex, 
but the differentiation of the papilla, its shifting inward, its change in form and position under the membrana tectoria, appear to be important.

S. since the papilla develops from the base toward the apex, it first reaches in the lower turn a high degree of differentiation, and this part first begins to function. Therefore the rat can hear only sounds of high pitch when it first responds.

9. This result accords with that well-known fact that the papilla in the lower turn responds to sounds of a high pitch, while in the upper turn it responds to sounds of low pitch.

\section{ON THE GROWTH OF THE LARGEST NERVE CELLS IN THE GANGLION VESTIBULARE}

\section{Material and technique}

The material used for the present study was in a great part the same that was employed for the studies reported in chapter 1 , with the addition of some new specimens as shown in table 114 and table 94 . In the slides obtained in the radial vertical section we see the vestibular ganglion cells situated in a single group at the radix of the cochlea (Fig. 3 G. V.). As four ears were used in each age group, four cell groups were examined at each age. Besides these fourteen age groups, six rats used for cross-sections, in chapter 1 , were also included.

The measurements were made in the same way and under the same conditions as those described earlier for the cells of the spiral ganglion. Since the ganglion vestibulare consists of two parts, the ganglion vestibulare superius and inferius, the ten largest cells were taken from each part and the results averaged.

\section{Observations}

By way of introduction I wish to say a word about equilibration in the young rat. The young just born crawl over on each other and seem to attempt to find the mothers nipples. They turn the head to and fro and roll over on the flanks, belly, or back. While resting they take their normal position or lie on the side. When turned on their backs they endearor to regain the normal 
position. The fore legs are of more use than the hind in making readjustments. The tails hang down between the hind legs. TABLE 114

Data on rats used for the study of the cells of the ganglion vestibulare (radial section). See also table 94

\begin{tabular}{|c|c|c|c|c|c|}
\hline$A G E$ & $\begin{array}{c}\text { BODY } \\
\text { WEIGHT }\end{array}$ & $\begin{array}{c}\text { BODY } \\
\text { LENGTH }\end{array}$ & $\operatorname{SEX}$ & SIDE & $\begin{array}{l}\text { AODITORY } \\
\text { RESPONSE }\end{array}$ \\
\hline days & grams & $\mathrm{mm}$. & & & \\
\hline \multirow[t]{3}{*}{1} & 5 & 44 & 우 & R. & - \\
\hline & 4 & 44 & 우 & R. & - \\
\hline & 5 & 48 & $\sigma^{7}$ & R. L. & - \\
\hline \multirow[t]{2}{*}{3} & 9 & 60 & $0^{x}$ & R. L. & - \\
\hline & 8 & 56 & ㅇ & R. L. & - \\
\hline \multirow[t]{3}{*}{6} & 10 & 64 & $0^{7}$ & R. & - \\
\hline & 10 & 64 & q & R. L. & - \\
\hline & 11 & 62 & $\sigma^{7}$ & $\mathrm{R}$ & - \\
\hline \multirow[t]{3}{*}{9} & 11 & 67 & $\sigma^{\pi}$ & R. L. & + \\
\hline & 9 & 58 & 우 & $\mathrm{R}$ & - \\
\hline & 10 & 57 & $0^{7}$ & $\mathrm{R}$ & \pm \\
\hline \multirow[t]{3}{*}{12} & 13 & 70 & $0^{2}$ & R. L. & + \\
\hline & 12 & 68 & q & R. & + \\
\hline & 15 & 72 & $0^{x}$ & R. & + \\
\hline \multirow{2}{*}{15} & 13 & 74 & $\sigma^{7}$ & R. L。 & + \\
\hline & 14 & 75 & q & R. L. & + \\
\hline \multirow[t]{2}{*}{20} & 30 & 96 & $0^{x}$ & R. L. & + \\
\hline & 28 & 94 & $0^{7}$ & R. L. & + \\
\hline \multirow[t]{2}{*}{25} & 34 & 101 & 우 & R. L. & + \\
\hline & 34 & 100 & $0^{7}$ & R. L. & + \\
\hline \multirow[t]{2}{*}{50} & 58 & 121 & ○ & R. L. & + \\
\hline & 43 & 104 & $0^{7}$ & R. L. & + \\
\hline \multirow[t]{3}{*}{100} & 146 & 176 & $\sigma^{7}$ & L. & + \\
\hline & 103 & 154 & $q$ & L. & + \\
\hline & 101 & 152 & 우 & R. L. & + \\
\hline \multirow[t]{3}{*}{150} & 154 & 184 & q & R. L. & + \\
\hline & 189 & 191 & $\sigma^{7}$ & $\mathrm{R}$. & + \\
\hline & 199 & 192 & $0^{7}$ & $\mathrm{R}$. & + \\
\hline \multirow[t]{3}{*}{260} & 137 & 162 & 우 & R. & + \\
\hline & 140 & 171 & $q$ & R. L. & + \\
\hline & 134 & 178 & q & $\mathrm{R}$. & + \\
\hline \multirow[t]{3}{*}{367} & 205 & 202 & $0^{7}$ & L. & + \\
\hline & 170 & 182 & ㅇ & L. & + \\
\hline & 179 & 196 & 우 & R. L. & + \\
\hline \multirow[t]{2}{*}{546} & 282 & 222 & $\sigma^{7}$ & R. L. & + \\
\hline & 227 & 204 & $\sigma^{7}$ & R. L. & + \\
\hline
\end{tabular}

At three days they move and crawl very actively. They tend to assume the normal position. When rolled over on the back or side they succeed in regaining the normal position in 
a few seconds. When six days old the rats have fairly well coordinated movements. They use their fore and hind legs effectively and in the same way. When the mother's body touches them they respond quickly by searching for the nipples.

It nine days they move much more quickly and the movements are well coordinated. Though the eyes are still closed, they

TABLE 115

Diameters of the cells and their nuclei in the ganglion restibulare in radial vertical section (Chart 48)

\begin{tabular}{|c|c|c|c|c|c|c|c|}
\hline \multirow{3}{*}{$\triangle G E$} & \multirow{3}{*}{$\begin{array}{c}\text { BODY } \\
\text { WEIGHT }\end{array}$} & \multicolumn{6}{|c|}{ DIAMETERS IN $\mu$} \\
\hline & & \multicolumn{3}{|c|}{ CELL BODY } & \multicolumn{3}{|c|}{ NUCLEUS } \\
\hline & & Long & Short & Computed & Long & Short & Computed \\
\hline days & grams & & & & & & \\
\hline 1 & 5 & 21.2 & 19.5 & 20.3 & 12.4 & 11.1 & 11.7 \\
\hline 3 & 9 & 23.7 & 22.2 & 22.9 & 12.5 & 11.6 & 12.0 \\
\hline 6 & 11 & 24.0 & 22.1 & 23.0 & 12.3 & 11.9 & 11.9 \\
\hline 9 & 10 & 24.8 & 23.0 & 23.9 & 12.5 & 11.6 & 12.0 \\
\hline 12 & 1,3 & 24.9 & 23.0 & 23.9 & 12.5 & 11.7 & 12.1 \\
\hline 15 & 13 & 24.8 & 23.0 & 23.9 & 12.5 & 11.6 & 12.0 \\
\hline 20 & 27 & 25.0 & 23.3 & 24.1 & 12.3 & 11.6 & 11.9 \\
\hline 25 & 34 & 25.2 & 23.6 & 24.4 & 12.5 & 11.8 & 12.1 \\
\hline 50 & 50 & 25.6 & 23.6 & 24.5 & 12.5 & 11.6 & 12.0 \\
\hline 100 & 112 & 25.5 & 23.9 & 24.7 & 12.8 & 11.9 & 12.3 \\
\hline 150 & 174 & 25.4 & 23.5 & 24.4 & 12.8 & 11.6 & 12.2 \\
\hline 260 & 138 & 25.8 & 23.4 & 24.6 & 12.4 & 11.7 & 12.0 \\
\hline 367 & 184 & 26.2 & 24.9 & 25.5 & 12.9 & 11.8 & 12.3 \\
\hline 546 & 255 & 26.5 & 24.2 & 25.3 & 12.8 & 11.8 & 12.2 \\
\hline \multirow[t]{3}{*}{ Ratios } & 367 days & & & $1: 1.3$ & & & $1: 1.1$ \\
\hline & 5.46 "6 & & & $: 1.2$ & & & $: 1.0$ \\
\hline & 367 & & & $: 1.1$ & & & $: 1.0$ \\
\hline
\end{tabular}

crawl toward the object sought. When turned over on the back they regain the normal position immediately. While resting they lie on their bellies with all the legs spread well apart.

Twelve-day-old rats, though the eyes are still closed, go to and fro actively with good coordination, but are somewhat slower than the adults. The body loses its fetal red color through the development of the first hairs. After this period the rats do not differ greatly from the adult in their general behavior. 
The growth changes in the ganglion cells of the ganglion vestibulare. In table 115 (chart 43) are given the values for the diameters of the cell bodies and their nuclei in the largest cells of the ganglion vestibulare. At the bottom of the last column for the cell body and for the nucleus, respectively, are recorded the ratios at 1 to 367,1 to 546 , and 15 to 367 days. The last ratio was taken

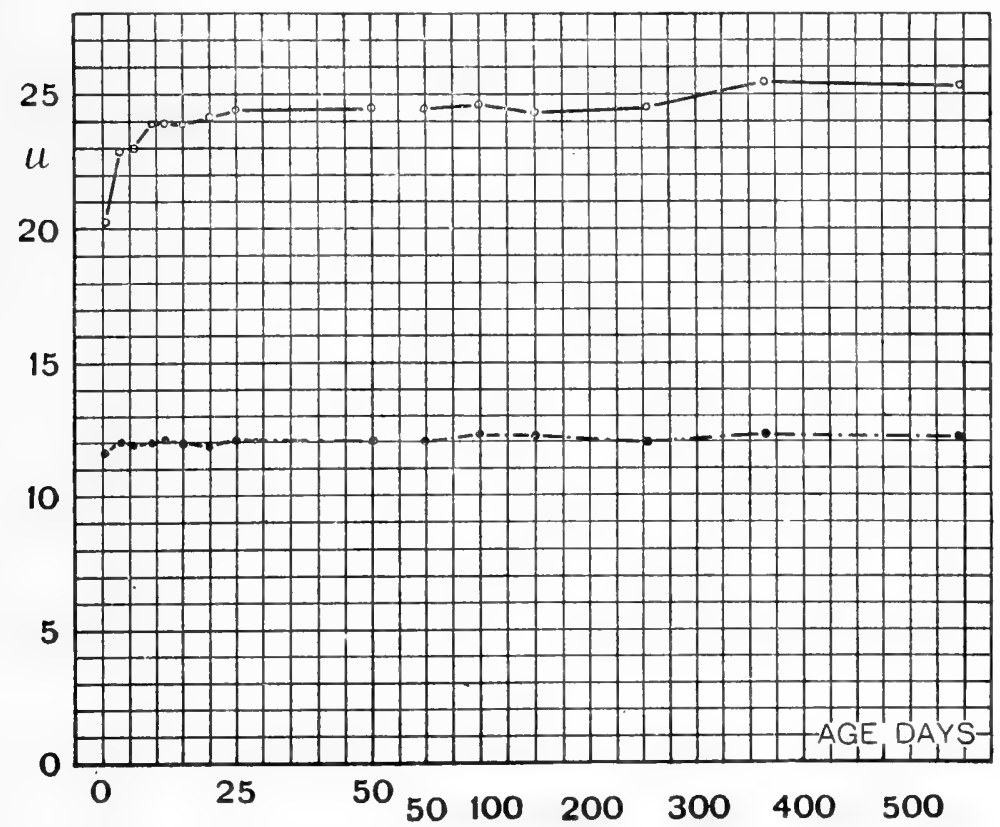

Chart 43 The diameter of the largest cell bodies and of the nuclei from the ganglion vestibulare, table 115 .

Cell bodies. -......... Nuclei.

to facilitate a comparison with the data in table 118 which begin at 15 days.

Looking at the ratios of the cell bodies and of their nuclei from 1 to 546 days, it appears that the ganglion cells increase 1.2 in diameter, while their nuclei have only a very slight increase, and therefore the ratio is $1: 1.0$. This increase in the cell bodies is continuous from birth to old age, but after fifteen days is very slow. In the nucleus we see a slight increase at the earlier 
ages, after which the values are nearly constant. This means that after birth the size of the cell bodies and their nuclei does not increase so much as do those of the spiral ganglion cells, or, expressed in another way, the cells in the vestibular ganglion have developed earlier than those of the spiral ganglia and at birth have already attained nearly their full size.

On the comparison of the diameter of the cel! bodies and their nuc ei in the nerve cells of he ganglion vestibulare according to sex. For this purpose twelve age groups of albino rats were used. In seven cases we have two cochlea in each group in the same sex, in which the average value is recorded. In table 116 are entered the values for these diameters and at the foot of the table the data are analysed. They reveal no evidence of a significant difference in the diameters according to sex.

On the comparison of the diameters in the cell bodies and nuclei of the nerve cells in the ganglion ves ibulare according to side. For the present study fourteen age groups were employed. As indicated in table 117, the data in five instances are based on the average of two cochleas of the same side. Table 117 enables us to make the comparison of the diameters of the cell bodies and their nuclei on both sides, and the analysis of the data given at the bottom of the table shows that there is no difference in these characters according to side.

On the morphological changes in the cells of the vestibular ganglion. Figure 14 illustrates semi-diagrammatically the ganglion cells in the vestibular ganglion of the albino at birth, 20 and 367 days of age. These figures, as in the ganglion spirale, have been magnified 1000 times and the absolute values of the diameters are given in table 115 .

As seen in figure 14 , both the cell body and the nucleus are at birth already well developed and more precocious in their development than the cells in any of the other cerebrospinal ganglia thus far examined. The cytoplasm is relatively abundant and the Nisi bodies are present, though both of these characters become more marked later.

The nucleus is also large, the chromatin somewhat differentiated and the so-called 'Kernfaden' often occur. Generally speaking, 

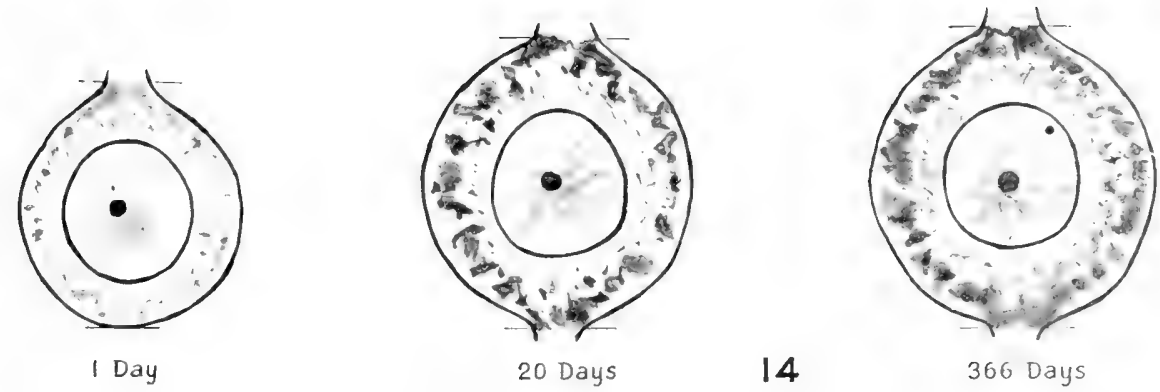

fig. 14 Showing semi-diagrammatically the size and the morphological changes in the ganglion cells in the ganglion vestibulare of the albino rat at the age of 1,20 and 366 days. All cell figures have been magnified 1000 diameters. 

therefore, the cells have the characteristics of the mature elements though they stain less deeply than in the adult. At twenty days of age the cell body is enlarged and fully mature. The Nissl

TABLE 116

Comparison of the diameters of the cells and their nuclei in the ganglion vestibulare -according to sex

\begin{tabular}{|c|c|c|c|c|c|}
\hline \multirow{2}{*}{$\triangle G E$} & \multirow{2}{*}{$\begin{array}{c}\text { BODY } \\
\text { WEIGHT }\end{array}$} & \multirow{2}{*}{$\underset{\substack{\text { NUMBRS } \\
\text { RATS }}}{\text { OF }}$} & \multirow{2}{*}{$\operatorname{SEX}$} & \multicolumn{2}{|c|}{ COMPUTED DIAMETERS } \\
\hline & & & & Cell body & Nucleus \\
\hline days & grams & & & & \\
\hline \multirow[t]{2}{*}{1} & 5 & 2 & $0^{7}$ & 20.8 & 11.9 \\
\hline & & & \& & 19.9 & 11.5 \\
\hline \multirow[t]{2}{*}{3} & 9 & 2 & $\sigma^{7}$ & 21.7 & 11.8 \\
\hline & 8 & 2 & \% & 23.8 & 12.2 \\
\hline \multirow[t]{2}{*}{6} & 11 & 2 & $0^{7}$ & 22.7 & 11.9 \\
\hline & 10 & 2 & & 23.1 & 12.1 \\
\hline \multirow[t]{2}{*}{9} & 11 & 1 & $0^{7}$ & 23.8 & 12.5 \\
\hline & 9 & 1 & \% & 23.8 & 12.1 \\
\hline \multirow[t]{2}{*}{12} & 15 & 1 & $\sigma^{7}$ & 24.4 & 12.2 \\
\hline & 12 & 1 & q & 23.1 & 11.9 \\
\hline \multirow[t]{2}{*}{15} & 13 & 2 & $0^{7}$ & 24.3 & 12.2 \\
\hline & 13 & 2 & \& & 23.4 & 11.9 \\
\hline \multirow[t]{2}{*}{20} & 30 & 1 & $0^{7}$ & 24.7 & 11.9 \\
\hline & 19 & 1 & q & 24.6 & 12.6 \\
\hline \multirow[t]{2}{*}{25} & 34 & 2 & $0^{7}$ & 24.4 & 11.9 \\
\hline & 34 & 2 & 우 & 24.4 & 12.4 \\
\hline \multirow[t]{2}{*}{50} & 43 & 2 & $0^{7}$ & 26.1 & 12.4 \\
\hline & 58 & 2 & 우 & 22.6 & 11.4 \\
\hline \multirow[t]{2}{*}{100} & 146 & 1 & $\sigma^{7}$ & 26.3 & 12.8 \\
\hline & 103 & 1 & ㅇ & 23.4 & 12.6 \\
\hline \multirow[t]{2}{*}{150} & 194 & 2 & $\sigma^{7}$ & 24.4 & 12.5 \\
\hline & 154 & 2 & 우 & 24.4 & 12.0 \\
\hline \multirow[t]{2}{*}{365} & 205 & 1 & $\sigma^{7}$ & 24.2 & 11.7 \\
\hline & 170 & 1 & 웅 & 24.6 & 12.1 \\
\hline \multicolumn{4}{|c|}{ Average for male } & 24.0 & 12.1 \\
\hline \multicolumn{4}{|c|}{ Average for female } & 23.4 & 12.1 \\
\hline \multicolumn{4}{|c|}{ Males larger } & 6 & 7 \\
\hline \multicolumn{4}{|c|}{ Females larger } & 3 & 5 \\
\hline \multicolumn{4}{|c|}{ Males and females equal } & 3 & 0 \\
\hline
\end{tabular}

bodies are more differentiated and the nucleus is mature, though it shows only a slight increase in size.

At 367 days the histological structures appear much as at twenty days, but the diameters of both the cell body and the nucleus have very slightly increased. This is in contrast to the change which occurs in the cells of the spiral ganglion. 
In order to study the form of the cells of the ganglion vestibulare the measurements also were made on the cross-sections. Table

TABLE 117

Comparison of the diameters of the cells and their nuclei in the ganglion vestibulareaccording to side

\begin{tabular}{|c|c|c|c|c|c|}
\hline \multirow{2}{*}{$A G E$} & \multirow{2}{*}{$\begin{array}{l}\text { BODY } \\
\text { WEIGHT }\end{array}$} & \multirow{2}{*}{$\begin{array}{l}\text { NUMBER } \\
\text { OF RATS }\end{array}$} & \multirow{2}{*}{$\operatorname{SIDE}$} & \multicolumn{2}{|c|}{ COMPUTED DIAMETERS } \\
\hline & & & & Cell body & Nucleus \\
\hline days & grams & & & & \\
\hline \multirow[t]{2}{*}{1} & 4 & 1 & $\mathrm{R}$. & 20.1 & 12.0 \\
\hline & 5 & 1 & L. & 22.0 & 12.5 \\
\hline \multirow[t]{2}{*}{3} & 9 & 2 & $\mathrm{R}$. & 23.0 & 11.8 \\
\hline & & & L. & 22.6 & 12.3 \\
\hline \multirow[t]{2}{*}{6} & 10 & 1 & $\mathrm{R}$. & 23.2 & 12.1 \\
\hline & & & $\mathrm{L}$. & 23.5 & 12.0 \\
\hline \multirow[t]{2}{*}{9} & 11 & 1 & R. & 25.1 & 12.3 \\
\hline & & & L. & 23.8 & 12.5 \\
\hline \multirow[t]{2}{*}{12} & 15 & 1 & $\mathrm{R}$ & 24.4 & 12.2 \\
\hline & 13 & 1 & L. & 25.1 & 12.5 \\
\hline \multirow[t]{2}{*}{15} & 13 & 2 & $\mathrm{R}$. & 24.2 & 12.2 \\
\hline & & & L. & 23.6 & 11.9 \\
\hline \multirow[t]{2}{*}{20} & 30 & 1 & $\mathrm{R}$ & 24.7 & 11.9 \\
\hline & & & L. & 23.5 & 11.4 \\
\hline \multirow[t]{2}{*}{25} & 34 & 2 & R. & 23.9 & 12.1 \\
\hline & & & L. & 24.9 & 12.2 \\
\hline \multirow[t]{2}{*}{50} & 50 & 2 & $\mathrm{R}$. & 23.1 & 11.6 \\
\hline & & & L. & 25.6 & 12.3 \\
\hline \multirow[t]{2}{*}{100} & 101 & 1 & $\mathrm{R}$ & 25.0 & 12.0 \\
\hline & & & L. & 24.8 & 11.7 \\
\hline \multirow[t]{2}{*}{150} & 199 & 1 & $\mathrm{R}$. & 25.1 & 12.8 \\
\hline & 154 & 1 & L. & 25.4 & 12.5 \\
\hline \multirow[t]{2}{*}{263} & 140 & 1 & $\mathrm{R}$ & 26.5 & 12.3 \\
\hline & & & L. & 25.1 & 12.4 \\
\hline \multirow[t]{2}{*}{368} & 179 & 1 & R. & 27.2 & 12.6 \\
\hline & & & L. & 26.2 & 13.0 \\
\hline \multirow[t]{6}{*}{546} & 255 & 2 & $\mathrm{R}$. & 26.0 & 12.4 \\
\hline & & & L. & 24.6 & 12.0 \\
\hline & \multirow{2}{*}{\multicolumn{3}{|c|}{$\begin{array}{l}\text { Average right side } \\
\text { Average left side }\end{array}$}} & 24.4 & 12.2 \\
\hline & & & & 24.3 & 12.2 \\
\hline & \multicolumn{3}{|c|}{ Right larger } & 8 & 6 \\
\hline & \multicolumn{3}{|c|}{ Left larger } & 6 & 8 \\
\hline
\end{tabular}

118 (chart 44) shows the results. Looking at the ratios of 15 to 371 days, we see the same rate of increase in the cell bodies and the nuclei as that in the radial section; i.e., in the cell bodies 1: 1.1 and in the nuclei $1: 1.0$. Comparing the diameters at each 
TABLE 118

Diameters of the cell bodies and their nuclei in the ganglion vestibulare, on crosssection (chart 44)

\begin{tabular}{|c|c|c|c|c|c|c|c|}
\hline \multirow{3}{*}{$\triangle G E$} & \multirow{3}{*}{$\begin{array}{c}\text { BODY } \\
\text { WEIGHT }\end{array}$} & \multicolumn{6}{|c|}{ DIAMETERS- $\mu$} \\
\hline & & \multicolumn{3}{|c|}{ CELL BODY } & \multicolumn{3}{|c|}{ NUCLEUS } \\
\hline & & Long & Short & Computed & Long & Short & Computed \\
\hline days & grams & & & & & & \\
\hline 15 & 20 & 25.1 & 22.8 & 23.9 & 12.4 & 11.6 & 12.0 \\
\hline 20 & 27 & 25.2 & 23.4 & 24.3 & 12.5 & 11.7 & 12.1 \\
\hline 25 & 39 & 25.2 & 24.0 & 24.6 & 12.3 & 12.0 & 12.1 \\
\hline 100 & 95 & 26.6 & 24.7 & 25.6 & 12.8 & 11.8 & 12.3 \\
\hline 150 & 169 & 26.7 & 24.7 & 25.7 & 13.0 & 11.7 & 12.3 \\
\hline 371 & 220 & 26.8 & 25.3 & 26.0 & 12.8 & 11.8 & 12.3 \\
\hline \multicolumn{2}{|c|}{ Ratio $15-371$ days } & & & $1: 1.1$ & & & $1: 1.0$ \\
\hline
\end{tabular}

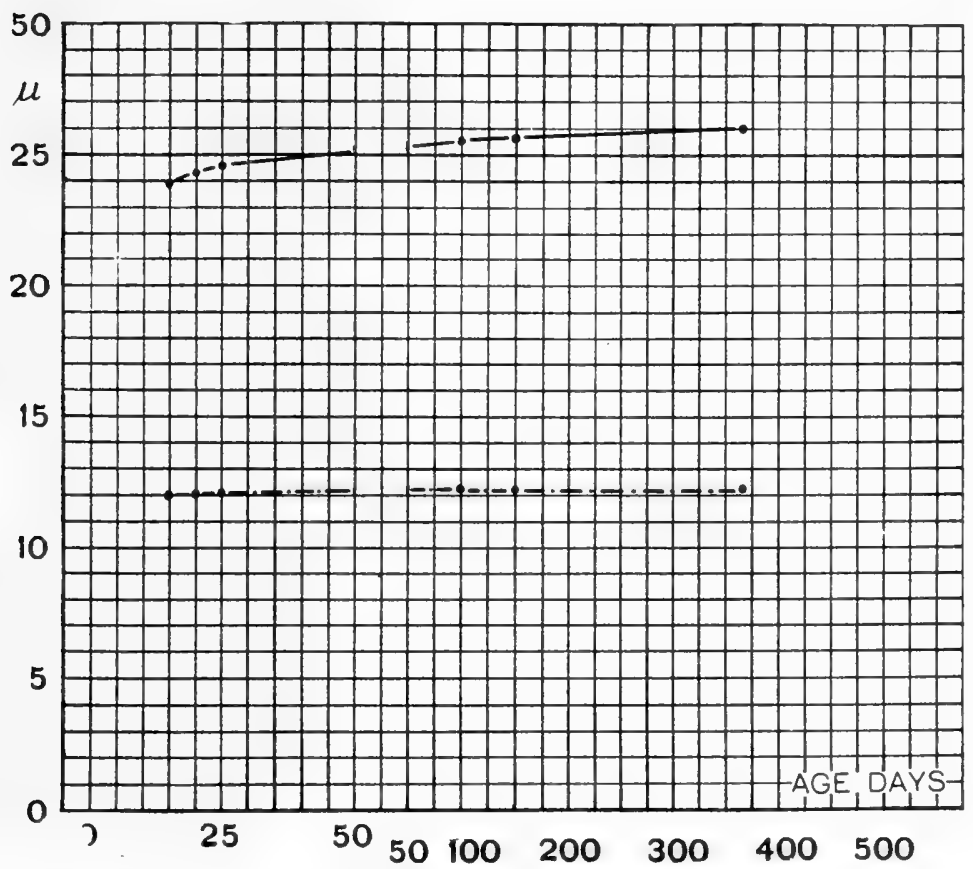

Chart 44 The diameters of the cell bodies and of their nuclei from the ganglion vestibulare, after fifteen days (cross-section), table 118.

Cell bodies. -......... Nuclei. 
ane in both the radial and cross-sections, they are almost the same, with a slight tendency for the cells in the cross-section to give higher values, which suggests that the long axes of these cells tend to lie in the plane of the section.

On the mucleus-plasma relations of the ganglion cells in the ganlion vestibulare. In table 119 are entered the computed diameters of the cell bodies and their nuclei in the radial section, and in the last column the ratios of the volume of the nucleus to that of the cytoplasm obtained by the method previously given. As

TABLE 119

Tucleus-plasma ratios of the cells in the ganglion vestibulare-radial vertical section

\begin{tabular}{|c|c|c|c|c|}
\hline \multirow[b]{2}{*}{$A G E$} & \multirow[b]{2}{*}{ BODY WEIGHT } & \multicolumn{3}{|c|}{ COMPUTED DIAMETERS- $\mu$} \\
\hline & & Cell body & Nucleus & $\begin{array}{l}\text { Nucleus-plasma } \\
\text { ratios }\end{array}$ \\
\hline days & grams & & & \\
\hline 1 & 5 & 20.3 & 11.7 & $1: 4.2$ \\
\hline 3 & 9 & 22.9 & 12.0 & $: 5.9$ \\
\hline 6 & 11 & 23.0 & 11.9 & $: 6.2$ \\
\hline 9 & 10 & 23.9 & 12.0 & $: 6.9$ \\
\hline 12 & 13 & 23.9 & 12.1 & $: 6.7$ \\
\hline 15 & 13 & 23.9 & 12.0 & $: 6.9$ \\
\hline 20 & 27 & 24.1 & 11.9 & $: 7.3$ \\
\hline 25 & 34 & 24.4 & 12.1 & $: 7.2$ \\
\hline 50 & 50 & 24.5 & 12.0 & $: 7.5$ \\
\hline 100 & 112 & 24.7 & 12.3 & $: 7.1$ \\
\hline 150 & 174 & 24.4 & 12.2 & $: 7.0$ \\
\hline 260 & 138 & 24.6 & 12.0 & $: 7.6$ \\
\hline 367 & 184 & 25.5 & 12.3 & $: 7.9$ \\
\hline 546 & 255 & 25.3 & 12.2 & $: 7.9$ \\
\hline
\end{tabular}

seen, the ratio is at birth relatively large, $1: 4.2$, and this increases with age, in the earlier stages considerably, but in the later, less rapidly. In the oldest age group it is largest, 1: 7.9.

On the crosi-section the nucleus-plasma ratio is also progressive and the increase is very regular (table 120). Comparing the ratios in the radial with those in the cross-sections, they are found to be nearly the same at fifteen twenty and twenty-five days, but at the later ages those in the cross-sections are somewhat larger than in the radial. It is difficult to determine whether the ratios on the cross-section are really larger or whether the 
result depends on the fact that the number of the cells here measured is only one-fourth of that measured in the radial section, and hence fewer cells of smaller size were included. At any rate, these ganglion cells in both the radial and crosssections of the cochlea appear to grow at about the same rate.

The statistical constants for these cells and their nuclei are given in tables 121 and 122 .

\section{Discussion}

The nerve cells in the ganglion vestibulare are, as seen from the above description, already well developed at birth both in size and histological structure. After that time they grow con-

TABLE 120

Nucleus-plasma ratios of cells of the ganglion vestibulare, in cross-section

\begin{tabular}{|c|c|c|c|c|}
\hline \multirow{2}{*}{$A G E$} & \multirow{2}{*}{$\begin{array}{l}\text { BODY } \\
\text { WEIGHT }\end{array}$} & \multicolumn{3}{|c|}{ DIAMETERS COMPUTED $\mu$} \\
\hline & & Cell body & Nucleus & $\begin{array}{c}\text { Nucleus-plasma } \\
\text { ratios }\end{array}$ \\
\hline days & grams & & & \\
\hline 15 & 20 & 23.9 & 12.0 & $1: 6.9$ \\
\hline 20 & 27 & 24.3 & 12.1 & $: 7.1$ \\
\hline 25 & 39 & 24.6 & 12.1 & $: 7.4$ \\
\hline 100 & 95 & 25.6 & 12.3 & $: 8.0$ \\
\hline 150 & 169 & 25.7 & 12.3 & $: 8.1$ \\
\hline 371 & 220 & 26.0 & 12.3 & $: 8.4$ \\
\hline
\end{tabular}

tinuously but slowly so long as followed. The increase from 1 to 546 days in the ratios of the diameters is in the cell body $1: 1.3$, in the nucleus $1: 1.1$, and is therefore very small. In the cerebrospinal ganglion cells and in the cells of the cerebral cortex, studied in the albino rat, there is no case which shows such a small rate of increase between birth and maturity. The following table 123 shows the ratios of increase which have been found.

It is to be noted that for the cells of the seventh spinal ganglion and the spinal cord, the ratios were taken from 17 to 360 days. If we had the ratios from 1 to 360 days, they would be without question much larger.

There are a few measurements on the size of the ganglion cells in the vestibular ganglion of various animals in the liter- 
ature. Schwalbe ('87) and Alexander ('99) report measurements on these cells in several animals, but for the reasons already given when considering the diameters of the cells in the ganglion spirale, the values obtained by the authors are not repeated here.

TABLE 121

Giving the mean, standard deviation and coefficient of variability, with their respective probable errors, for the diameters of the cells in the ganglion vestibulare, in radial-vertical section

\begin{tabular}{|c|c|c|c|c|}
\hline$\triangle G E$ & $\begin{array}{c}\text { CELL } \\
\text { NUCLEUS }\end{array}$ & MEAN & $\begin{array}{l}\text { STANDARD } \\
\text { DEVIATION }\end{array}$ & $\begin{array}{l}\text { COEFFICIENT OF } \\
\text { VARIABILITY }\end{array}$ \\
\hline \multirow[t]{2}{*}{$\begin{array}{c}\text { days } \\
1\end{array}$} & Cell & $20.1 \pm 0.16$ & $1.46 \pm 0.11$ & $7.3 \pm 0.55$ \\
\hline & Nucleus & $11.7 \pm 0.11$ & $0.99 \pm 0.07$ & $8.5 \pm 0.64$ \\
\hline \multirow[t]{2}{*}{3} & Cell & $22.6 \pm 0.14$ & $1.33 \pm 0.10$ & $5.9 \pm 0.44$ \\
\hline & Nucleus & $11.9 \neq 0.07$ & $0.63 \pm 0.05$ & $5.3 \pm 0.40$ \\
\hline \multirow[t]{2}{*}{6} & Cell & $22.8 \pm 0.13$ & $1.23 \pm 0.09$ & $5.4 \pm 0.41$ \\
\hline & Nucleus & $11.9 \pm 0.05$ & $0.43 \pm 0.03$ & $3.6 \pm 0.27$ \\
\hline \multirow[t]{2}{*}{9} & Cell & $23.6 \pm 0.16$ & $1.48 \pm 0.11$ & $6.3 \pm 0.48$ \\
\hline & Nucleus & $12.0 \pm 0.09$ & $0.82 \pm 0.06$ & $6.8 \pm 0.52$ \\
\hline \multirow[t]{2}{*}{12} & Cell & $23.6 \pm 0.14$ & $1.28 \pm 0.10$ & $5.4 \pm 0.41$ \\
\hline & Nucleus & $12.0 \pm 0.06$ & $0.59 \pm 0.04$ & $4.9 \pm 0.37$ \\
\hline \multirow[t]{2}{*}{15} & Cell & $23.6 \pm 0.13$ & $1.21 \pm 0.09$ & $5.1 \pm 0.39$ \\
\hline & Nucleus & $12.1 \pm 0.06$ & $0.60 \pm 0.05$ & $5.0 \pm 0.38$ \\
\hline \multirow[t]{2}{*}{20} & Cell & $23.9 \pm 0.16$ & $1.54 \pm 0.11$ & $6.5 \pm 0.49$ \\
\hline & Nucleus & $11.9 \pm 0.10$ & $0.90 \pm 0.07$ & $7.6 \pm 0.55$ \\
\hline \multirow[t]{2}{*}{25} & Cell & $24.2 \pm 0.16$ & $1.48 \pm 0.11$ & $6.1 \pm 0.46$ \\
\hline & Nucleus & $12.1 \pm 0.08$ & $0.74 \pm 0.06$ & $6.1 \pm 0.46$ \\
\hline \multirow[t]{2}{*}{50} & Cell & $24.1 \pm 0.30$ & $2.80 \pm 0.21$ & $11.6 \pm 0.88$ \\
\hline & Nucleus & $11.8 \pm 0.09$ & $0.86 \pm 0.06$ & $7.3 \pm 0.55$ \\
\hline \multirow[t]{2}{*}{100} & Cell & $24.3 \pm 0.20$ & $1.86 \pm 0.14$ & $7.7 \pm 0.58$ \\
\hline & Nucleus & $12.2 \pm 0.09$ & $0.86 \pm 0.06$ & $7.0 \pm 0.53$ \\
\hline \multirow[t]{2}{*}{150} & Cell & $24.1 \pm 0.18$ & $1.70 \pm 0.13$ & $7.1 \pm 0.53$ \\
\hline & Nucleus & $12.2 \pm 0.09$ & $0.83 \pm 0.06$ & $6.8 \pm 0.52$ \\
\hline \multirow[t]{2}{*}{260} & Cell & $24.3 \pm 0.26$ & $2.45 \pm 0.18$ & $10.1 \pm 0.76$ \\
\hline & Nucleus & $11.9 \pm 0.07$ & $0.67 \pm 0.05$ & $5.6 \pm 0.42$ \\
\hline \multirow[t]{2}{*}{367} & Cell & $25.2 \pm 0.22$ & $2.07 \pm 0.16$ & $8.2 \pm 0.62$ \\
\hline & Nucleus & $12.3 \pm 0.09$ & $0.88 \pm 0.07$ & $7.2 \pm 0.54$ \\
\hline \multirow[t]{2}{*}{546} & Cell & $25.0 \pm 0.19$ & $1.80 \pm 0.14$ & $7.2 \pm 0.54$ \\
\hline & Nucleus & $12.1 \pm 0.09$ & $0.81 \pm 0.06$ & $6.7 \pm 0.50$ \\
\hline
\end{tabular}

On the differences between the growth of the cells in the ganglion spirale and ganglion vestibulare. The foregoing discussion has made plain that the vestibular ganglion cells grow not only in size, but also in histological structure very much before birth, while after birth they grow slowly though continuously. On the other hand, the spiral ganglion cells are relatively immature at 
birth, but in the earlier stages after birth grow very rapidly, reach at twenty days their maximum size, and then diminish slowly. This great difference in the course of growth is probably related to the maturity of the functions of the animal.

TABLE 122

Giving the mean, standard deviation and coefficient of variability with their respective probable errors for the diameters of the cells in the ganglion vestibulare on cross-section

\begin{tabular}{|c|c|c|c|c|}
\hline $\begin{array}{l}\mathrm{AGE} \\
\text { days }\end{array}$ & $\begin{array}{l}\text { CELL } \\
\text { NUCLEUS }\end{array}$ & MEAN & $\begin{array}{l}\text { STANDARD } \\
\text { DEVIATION }\end{array}$ & $\begin{array}{l}\text { COEFFICIENT OF } \\
\text { VARIABILITY }\end{array}$ \\
\hline \multirow[t]{2}{*}{15} & Cell & $23.8 \pm 0.21$ & $1.00 \pm 0.15$ & $4.2 \pm 0.58$ \\
\hline & Nucleus & $12.0 \pm 0.12$ & $0.55 \pm 0.08$ & $4.6 \pm 0.69$ \\
\hline \multirow[t]{2}{*}{20} & Cell & $23.9 \pm 0.20$ & $0.92 \pm 0.14$ & $3.9 \pm 0.58$ \\
\hline & Nucleus & $12.1 \pm 0.06$ & $0.30 \pm 0.05$ & $2.5 \pm 0.37$ \\
\hline \multirow[t]{2}{*}{25} & Cell & $24.4 \pm 0.20$ & $0.94 \pm 0.14$ & $3.9 \pm 0.58$ \\
\hline & Nucleus & $12.1 \pm 0.03$ & $0.16 \pm 0.02$ & $1.3 \pm 0.20$ \\
\hline \multirow[t]{2}{*}{100} & Cell & $25.4 \pm 0.32$ & $1.51 \pm 0.23$ & $5.9 \pm 0.90$ \\
\hline & Nucleus & $12.3 \pm 0.15$ & $0.72 \pm 0.11$ & $5.9 \pm 0.88$ \\
\hline \multirow[t]{2}{*}{150} & Cell & $25.6 \pm 0.20$ & $0.94 \pm 0.14$ & $3.7 \pm 0.55$ \\
\hline & Nucleus & $12.4 \pm 0.09$ & $0.42 \pm 0.06$ & $3.4 \pm 0.51$ \\
\hline \multirow[t]{2}{*}{371} & Cell & $25.9 \pm 0.41$ & $1.91 \pm 0.29$ & $7.4 \pm 1.11$ \\
\hline & Nucleus & $12.3 \pm 0.06$ & $0.26 \pm 0.04$ & $2.1 \pm 0.32$ \\
\hline
\end{tabular}

TABLE 123

Ratios of diameters between the ages given.

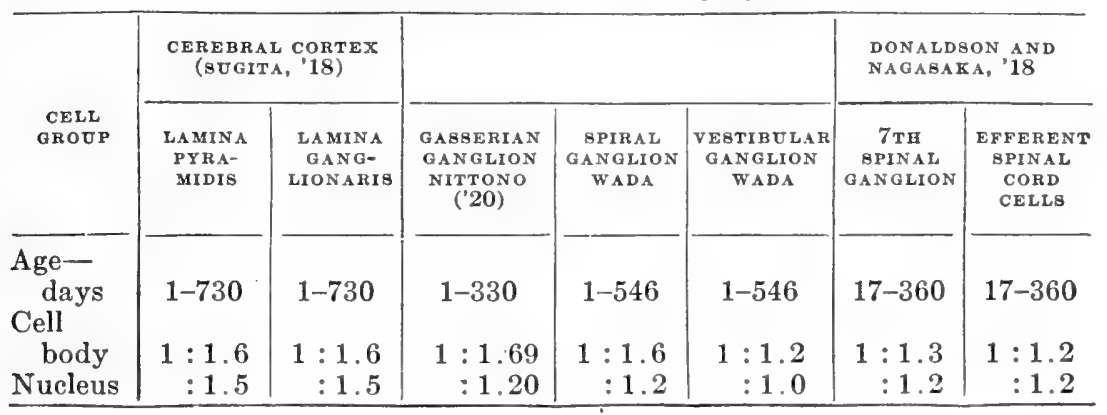

As a consequence, in the nucleus-plasma ratio there is also a large difference between the cells in the two ganglia. Table 124 shows this.

The ratio at birth in the ganglion vestibulare is large as compared with that in the ganglion spirale, but the increase in this ratio 
at 546 days is relatively slight as compared with what takes place in the cells of the ganglion spirale. It appears, therefore, that the cells in the vestibular ganglion are at birth in a more mature condition.

As to the correlation between the development of the ganglion cells and the equilibrium function, we have noted that the albino rats, even just after birth, show some sense of equilibrium, though the movements are lacking in coordination. With adrancing age the balance of the body is held much better and all the movements gradually become coordinated. The histological structure and the size of the cells at birth suggest that they are functional at that time, and the later increase in the volume and maturity of the cells is accompanied by a corresponding

TABLE 124

\begin{tabular}{|c|c|c|}
\hline & $\begin{array}{l}\text { GANGLION } \\
\text { VESTIBULARE }\end{array}$ & $\begin{array}{l}\text { GANGLION } \\
\text { SPIRALE }\end{array}$ \\
\hline $\begin{array}{l}\text { Nucleus-plasma ratio at one day } \\
\text { Nucleus-plasma ratio at } 546 \text { days }\end{array}$ & $\begin{aligned} & 1: 4.8 \\
&: 7.9 \\
&\end{aligned}$ & $\begin{aligned} & 1: 1.3 \\
&: 4.2 \\
&\end{aligned}$ \\
\hline
\end{tabular}

increase in the functional development. When the tactile sense is well developed and the eyes open equilibrium is almost perfected.

It is a well-known fact that these two senses have very intimate relations to the maintenance of equilibrium. In this case, as we might expect, the early development of a function is accompanied by an early maturing of the neural mechanism on which it depends.

\section{Conclusions (for the ganglion vestibulare)}

1. The measurements were taken on the largest nerve cells of the ganglion vestibulare in the radial section of the cochlea, and the developmental changes during portnatal growth studied in fourteen age groups, comprising four ears in each group. Further, in six age groups the cell size was determined in crosssections. The results have been given $\mathrm{n}$ tables 115 and 118 and charts 43 and 44 . 
2. The computed diameter at birth is $20.3 \mu$ for the cell body and $11.7 \mu$ for the nucleus, and at 546 days, 25.3 and $12.2 \mu$, respectively. Therefore the cells at birth are comparatively large and increase in size very slowly, but the increase is continuous.

3. The increase in the ratio of the cell body is as $1: 1.3$, of the nucleus as $1: 1.1$. We have between the same age limits no such small rate of increase in any other cerebrospinal ganglion studied in the albino rat. This small ratio indicates that the cells in the vestibular ganglion are well developed at birth.

4. We find no appreciable difference in the diameters of the cell bodies or the nuclei according either to sex or side.

5. Morphologically, the cells at birth are well differentiated. The form of the cells is ovoid.

6. The nucleus-plasma ratios are large at birth and increase regularly with age.

7. Comparing the development of the function of equilibrium with the growth of the cells, we see that these are correlated.

\section{Fina! summary}

This study is concerned with the age changes in the organ of Corti and the associated structures. The changes in the largest nerve cells which constitute the spiral ganglion and the vestibular ganglion, respectively, have also been followed from birth to maturity. On pages 116 to 124 are given the summary and discussion of the observations on the growth of the tympanic wall of the ductus cochlearis.

The conclusions reached from the study of the largest nerve cells in the ganglion spirale appear on pages 143 to 145 . On pages 155 and 156 are presented the results of the study on the correlation between the response to sound and to the conditions of the cochlea.

Finally, the observations on the growth of the largest cells in the ganglion vestibu'are are summarized on pages 168 and 169.

It is not necessary to again state in detail the conclusions reached in the various parts of this study.

At the same time, if we endeavor to obtain a very general picture of the events and changes thus described, this may be sketched as follows: 
Within the membranous cochlea there occurs a wave of growth passing from the axis to the periphery as shown in figures 4 to 13 . The crest or highest point of the tissue mass appears at birth near the axis, in the greater epithelial ridge, and then progressively shifts toward the periphery, so that at maturity it is in the region of the Hensen cells. With advancing age the hair cells come to lie more and more under the tectorial membrane and the pillar cells seem to shift toward the axis.

At from 9 to 12 days the tunnel of Corti appears and the rat can hear.

All of these changes occur first in the basal turn and progress toward the apex. The mature relations are established at about twenty days. There are thus two waves of change in the membranous cochlea, from the axis to the periphery and the other from the base to the apex. The rat can usually hear at twelve days of age or about three days before the eyes open.

The largest cells in the ganglion spirale are very immature at birth, reach their maximum at twenty days, and after that diminish in size, slightly but steadily. The rat hears, therefore, before these cells have reached their full size.

The largest cells in the vestibular ganglion are precocious and remarkably developed, even at birth. They cease their rapid growth at about fifteen days of age, but increase very slightly though steadily throughout life. 


\section{LITERATURE CITED}

Alagna, G. 1909 Beitrag zur normalen und pathologischen Histologie der Ganglien des Akustikus. Ztseher. f. Ohrenh., Bd. 59.

Alexander, G. 1899 Zur Anatomie des Ganglion vestibulare der Säugethiere. Sitz.-Ber. Akad. Wiss. math. nat. Cl., Wien, Bd. 108, Abt. 3.

Ayers, H. 1890 On the origin of the internal ear and the functions of the semi-circular canals and cochlea. Milwaukee.

1891 Die Membrana tectoria-was sie ist, und die Membrana basilaris-was sie verrichet. Anat. Anz., Bd. 6 .

1889 On the membrana basilaris, the membrana tectoria and the nerve endings in the human ear. Zool. Bull., vol. 1.

Barth 1889 Beitrag zur Anatomie der Schnecke. Anat. Anz., Bd. 4.

BötтснER, A. 1869 Ueber Entwickelung und Bau des Gehörlabyrinthes nach Untersuchungen an Säugethieren. F. Blockmann u. Sohn, Dresden.

1872 Kritische Bemerkungen und neue Beiträge zur Literatur des Gehörlabyrinths. Dorpat.

BusacCA, A. 1916 Studi sulla curva di accrescimento delle cellule nervose dei gangli spinali nei mammiferi. Areh. ital. di anat. e di embriologia, T. 15 .

Conti, A. 1851 Recherches sur l'organe de l'ouie des mammifères. Ztschr. f. wiss. Zool., Bd. 3.

Czinner, H. I., und Hammerschlag, V. 1897 Beitrag zur Entwicklungsgeschichte der Corti'schen Membran. Archiv f. Ohrenh., Bd. 44.

Donaldson, H. H. 1915 The rat. Reference tables and data for the albino rat (Mus norvegicus albinus) and the Norway rat (Mus norvegicus). Memoirs of the Wister Institute of Anatomy and Biology, no. 6.

Donaldson, H. H., and Nagasaka, G. 1918 On the increase in the diameters of nerve cell bodies and of the fibers arising from them, during the later phases of growth (albiao rat). Jour. Comp. Neur., vol. 29.

Dupuis, A. 1894 Die Cortische Membran. Anat. Hefte, Bd. 3.

von EBNER, V. 1902 In A. Kölliker's Hanbd. d. Gewebelehre des Menschen, Bd. 3, 2 Hälfte, S. 899-959.

Ewald, J. R. 1899 Zur Physiologie des Labyrinthes. VI. Mitteil. Eine neue Hörtheorie. Arch. ges. Physiol., Bd. 76.

Ewald, J. R. UND JäDERholm, G. A. 1906 Auch alle Geräusche geben, wenn sie intermittiert werden, Intermittenztöne. Arch. ges. Physiol, Bd. 115.

Gottstein, J. 1872 Ueber den feineren Bau und die Entwickelung der Gehörschnecke der Säugethiere und des Menschen. Arch. f. mikr. Anat., Bd. 8.

HARDESTY, I. 1908 The nature of the tectorial membrane and its probable rôle in the anatomy of hearing. Am. Jour. Anat., vol. 8.

1915 On the proportions, development and attachment of the tectorial membrane. Am. Jour. Anat., vol. 18. 
Hasse, C. 1866 Die Schnecke der Vögel. Ztscher. f. wiss. Zool., Bd. 17. 1873 Die vergleìchende Morphologie und Histologie des häutigen Gehörorganes der Wirbeltiere. Suppl. zu dem anatom. Studien von C. Hasse, Bd. 1, Leipzig.

HeLD, H. 1902 Untersuchungen über den feineren Bau des Ohrlabyrinths der Wirbeltiere. I. Zur Kenntnis des Corti'schen Organs u. der übrigen Sinnesapparate des Labyrinths bei Säugetieren. Abhandl. d. k. Sächs. Ges. d. Wiss., Math.-phys. Kl., Bd. 28.

1909 Untersuchungen über den feineren Bau des Ohrlabyrinths der Wirbeltiere. II. Zur Entwicklungsgeschichte des Corti'schen Organs und der Macula acustica bei Säugetieren und Vögeln. Abhandl. d. k. Sächs. Ges. d. Wiss., Math-phys. Kl., Bd. 31.

Hexie, J. 1866 Handbuch d. systemat. Anatomie des Menschen. II. Bd. Eingeweidelehre des Menschen. Braunschweig.

1873 Handbuch d. systemat. Anatomie des Menschen. II. Bd. Eingeweidelehre des Menschen. 2. Aufl. Braunschweig.

v. Hexsex, 1863 Zur Morphologie der Schnecke, des Menschen und der Säugetiere. Ztscher. f. wiss. Zool., Bd. 13.

1873 Dr. A. Böttcher: Ueber Entwicklung und Bau des Gehörlabyrinths nach untersuchungen an Säugetieren. Arch. f. Ohrenh., Bd. 6.

Hoessli, H. 1912 Weitere experimentelle Studien über die akustische Schädigung des Säugetierlabyrinths. Ztschr. f. Ohrenh., Bd. 64.

Huxter, W. S. 1914 The auditory sensitivity of the white rat. Jour. Animal Behavoir, vol. 4.

1915 The auditory sensitivity of the white rat. Jour. Animal Behavoir, vol. 5.

1918 Some notes on the auditory sensitivity of the white rat. Psychobiology, vol. 1.

Kato, T. 1913 Zur Physiologie der Binnenmuskeln des Ohres. Arch. f. d. ges. Physiol., Bd. 150.

IIIsiI, J. 1902 Über den Verlauf und die periphere Endigung des Nervus cochleae. Arch. f. mikr, Anat., Bd. 59.

Kishi, K. 1907 Cortische Membran und Tonempfindungstheorie. Arch. f. d. ges. Physiol., Bd. 116.

v. Köldiker, A. 1867 Handbuch der Gewebelehre des Menschen. 5. Aufl. Leipzig.

Kolmer, W. 1907 Beiträge zur Kenntnis des feiıeren Baues des Gehörorgans mit besonderer Berücksichtigung der Haussäugetiere. Arch. §. mikr. Anat., Bd. 70.

Krause, F. 1906 Entwicklungsgeschichte des Gehörorgans. Handb. d. Entwicklungslehre der Wirbeltiere, Bb. 2, Teil 2. Jena.

Irreide, A., und Yanase, J. 1907 Zur Physiologie der Cortischen Membran. Zentralbl. f. Physiol., Bd. 21.

LANE, H. H, 1917 The correlation between structure and function in the development of the special senses of the white rat. . Diss. presented to Princeton Univ. University of Oklahoma, Norman. 
Levi, G. 1908 I gangli cerebrospinali. Studi di istologia comparata e di istogenesi. Arch. Ital. Anat. Embr., T. 7, Suppl.

MARx, H. 1909 Untersuchungen über experimentelle Schädigungen des Gehörorgans. Ztschr. f. Ohrenh., Bd. 59.

Metzner and Yoshi 1909 Experimentelle Schädigungen des Gehörorgans durch Schalleinwirkungen. Verh. d. Ges. deutsch Nat. Aerzte Vers., 2. Teil. 2. Hälfte.

Middendorp, H. W. 1867 Het vliezig slakkenhuis in zijne wording en in den ontwikkelden toestand. Groningen.

1868 Zur Histologie und Entwickelung der Schnecke. Monatschr. f. Ohrenh., nos. 11 and 12 .

NAGER, F. R. 1905 Uber postmortale histologische Artefakte am Nervus acusticus und ihre Erklärung, ein Beitrag zur Lehre der Corpora amylacea. Ztschr. f. Ohrenh., Bd. 51.

Nager, F. R., UND Yoshir, U. 1910 Zur Kenntnis der cadaverösen Veränderungen des inneren Ohres. Zeitsehr. f. Ohrenh., Bd. 60.

Na zamURA, Y. 1914 Experimentelle Untersuchungen über die Einwirkung des Aethyl und Methylalkols auf dem Gehörorgan. Beitr, z. Anat., Physiol.. Path. u. Therap. d. Ohres, Bd. 8.

Nittono, KenJi 1920 On the growth of the neurons composing the gasserian ganglion of the albino rat, between birth and maturity. Jour. Comp. Neur., vol. 32.

Prentiss, C. W. 1913 On the development of the membrana tectoria with reference to its structure and attachments. Am. Jour. Anat., vol. 14.

Pritchard, U. 1878 The development of the organ of Corti. Jour. Anat. and Physiol., vol. 13.

Retzius, G. 1884 Das Gehörorgan der Wirbeltiere. 11. Stockholm.

Rickenbacher, O. 1901 Untersuchungen über die embryonale Membrana tectoria des Meerschweinchens. Anat. Hefte, Bd. 16.

Sato, N. 1917 Der histologische Bau der Vogelschnecke und ihre Schädigung durch akustische Reize und durch Detonation. Basel.

SCHÄFER, E. A. 1909 Quain's elements of anatomy, vol. 3, part 2, 11th ed., London.

Scrwalbe, G. 1887 Lehrbuch der Anatomie der Sinnesorgane. Erlangen.

Scott, Sydney 1909 A contribution to the histology of the human osseous and membranous labyrinth. J. of Anat. Physiol., vol. 43, pp. 329-345.

Shambaugh, G. E. 1910 Das Verhältniss zwischen der Membrana tectoria und dem Cortischen Organ. Ztschr. f. Ohrenh., Bd. 62.

$1910 \mathrm{~A}$ The physiology of the cochlea. Ann. Otol. Rhinol. and Laryngol., vol. 19.

$1910 \mathrm{~B}$ The physiology of tone perception. Ann. Otol. Rhinol. and Laryngol., vol. 19.

Siebenmann UNd Yoshir 1908 Präparate von zirkumskripter Labyrinthitis. Verhandl. der Deutsch. otolog. Gesellsch.

Sirall, W. S. 1899 Notes on the psychic development of the young white rat. Am. Jour. Psychol, vol. II. 
Sugits, N. 1918 Comparative studies on the growth of the cerebral cortex. VI. On the increase in size and on the developmental changes of some nerve cells in the cerebral cortex of the albino rat during the growth of the brain. Jour. Comp. Neur., vol. 29.

TADOKORO, K., AND WATANABE, T. 1920 Experimental studies on the vital fixations of the cochlea. Ikaijiho (Medical Review, Japan), no. 1345 , p. 552.

VAN DER STRICHT, O. 1918 The genesis and structure of the membrana tectoria and the crista spiralis of the cochlea. Con. to Embryology (Carnegie Inst. of Wash.), no. 227.

Watson, J. B. 1907 Kinaesthetic and organic sensations: their rôle in the reactions of the white rat to the maze. Psychol. Review, Monograph Suppl., vol. 8.

Winiwarter, A. v. 1870 Untersuchungen über die Gehörschnecke der Säugetiere. Sitz. d. k. Akad. d. Wiss. in Wein, Bd. 61.

WitmuaAck, K. 1904 Ueber Markscheidendarstellung und den Nachweis von Markhüllen der Ganglienzellen im Akustikus. Arch. f. Ohrenh., Bd. 61 .

1906 Zur histo-pathologischen Untersuchung des Gehörorgans mit besonderer Berücksichtigung der Darstellung der Fett. und MyelinSubstanzen. Ztschr. f. Ohrenh., Bd. 51.

1907 Ueber Schädigungen des Gehörs durch Schalleinwirkungen. Verhandl. d. deutsch, otol. Gesellsch., Jena.

WittmaAck, K., und LaUrowitsch, Z. 1912 Ueber artefizielle, postmortale und agonale Beeinflussung der histologischen Befunde im membranös -en Labyrinthe. Ztschr. f. Ohrenh., Bd. 65.

Yosnir, U. 1909 Experimentelle Untersuchungen über die Schädigung des Gehörorgans durch Schalleinwirkung. Ztschr. f Ohrenh., Bd. 58. 
193

$$
\text { - }
$$





\title{
THE AMERICAN ANATOMICAL MEMOIRS
}

NuMBERS I TO 7 INCLUSIVE APPEARED AS MEMOIRS OF
THE WISTAR INSTITUTE OF ANATOMY AND BIOLOGY

EDITED BY

GEORGE S. HUNTINGTON

Columbia University

WITH THE COLLABORATION OF

CHARLES R. STOCKARD

AND

Cornell University Medical. School
HERBERT M. EVANS

University of CALifornia, Berkeley

\section{THE PIGMENTARY, GROWTH AND ENDOCRINE} DISTURBANCES INDUCED IN THE ANURAN

TADPOLE BY THE EARLY ABLATION

OF THE PARS BUCCALIS OF THE HYPOPHYSIS

\author{
P. E. SMITH
}

ANATOMICAL LABORATORY OF THE UNIVERSITY OF CALIFORNIA

\section{PUBLISHED BY}

THE WISTAR INSTITUTE OF ANATOMY AND BIOLOGY

PHILADELPHIA, PA., U. S. A.

Price: $\$ 3.00$ post paid 


\section{BIBLIOGRAPHIC SERVICE}

for the

JOURNAL OF MORPIIOLOGY

THE ANATOMICAL RECORD

THE JOURNAL OF COMPARATIVE NEUROLOGY

THE JOURNAL OF EXPERIMENTAL ZOOLOGY

THE AMERICAN JOURNAL OF ANATOMY

THE AMERICAN ANATOMICAL MEMOIRS

BIOLOGICAL BULLETIN

ENDOCRINOLOGY

AMERICAN JOURNAL OF PHYSICAL ANTHROPOLOGY

Eacl per accented for publication in one of the above periodicals is accompanied by the nuthor's it)stract (not exceeding 250 words) and a list of subject headings under which the various sections of the work are treated.

Upon receipt at The Wistar Institute, the abstract is printed immediately on one side of a standard library card. On the reverse side of the card is given the complete bibliographic reference to the paper as it will appear eventually, the various subject headings following the main title. Copies of this abstract bibliographic card are distributed at once to the anatomists, zoologists, university and college libraries, research institutes, public libraries, academies and scientific societies of the world.

This instant publication of results precedes the appearance of the full text of the paper in a journal by some weeks and in some instances by months. The abstracts are translated into the spanish, Japanese and Chinese languages and are printed in these languages together witb the full Fuglish text, in the Spanish, Japanese and Chinese editions of the several journals published by The Wistar Institute.

For the Author: The Bibliographic Service gives immediate publicity to his investigations, 1) litwe the reference to his work on file in the important public and private libraries and makes his writings easily available to all groups of readers.

For the Investigator: The Biblingraphic Service brings the essential features of the latest researches promptly to his attention with the least expenditure of time and makes it pcssible for him to select quickly the papers which he wishes to read in detail.

For the Teacher: The abstract reference cards make it easy for him to keep informed upon the progress of his science from day to day without the necessity of an orgy of reading at more or less long intervals at the university library.

For the Student: No better stimulus to activity is offered than a glimpse at the progress being made in anatomy and zoology.

For the Librarian: This servire makes it possible to classify and eatalogue technical papers in

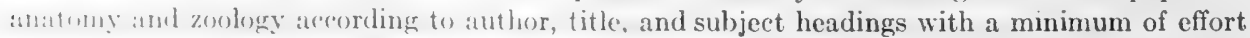
and without the necessity of reading the complete papers.

Subseribers to this service receive two cards for cach publication; one bearing the abstract on one side with the reference on the reverse side (main entry card to be filed alphabetically acrorcling to author), the other bearing the reference only and intended to be used as a subject indrx card. Extra cards may be secured.

The subscription price is $\$ 5.00$, for the year ending June 1, 1921. Cards already issued will he supplied. 
THE AMERICAN ANATOMICAL MENOIRS

10.11

THE PIGMENTARY, GROWTH AND ENDOCRINE DISTURBANCES INDUCED IN THE ANURAN TADPOLE BY THE EARLY ABLATION OF THE PARS BUCCALIS OF THE HYPOPHYSIS

PHILIP E. SMITH

ANATONICAL LABORATORY OF THE UNIVERSTTY OF CALIFORNIA

1920

PUBLISHED BY

THE WISTAR INSTITUTE OF ANATOMY AND BIOLOGY

PHILADELPHIA 

. 


\section{CONTENTS}

1. Introduction. . . . . . . . . . . . . . . . .

The conditions of the experiment.................... 7

2. Alterations in the pigmentary system. . . . . . . . . . . . . . 10

The chromatophores of the albinous larvac................ 14

The epidermal melanophores. . . . . . . . . . . . . . . . . . . . . . . 14

The deep melanophores........................ 18

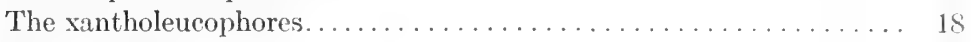

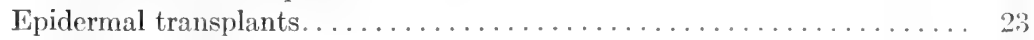

The effect of various diets upon the pigment cells............. 27

The responses of the chromatophores to various physiological and pharmacological agents. . . . . . . . . . . . . . . . . . . . . . 30

3. Growth disturbances. . . . . . . . . . . . . . . . . . . . . . . 41

The growth rate of the albino; the effect of the administration of various physiological substances upon this growth rate............. 4

The growth rate of thyroidectomized larvae ..............67

4. Modifications in the size and structure of the endocrine organs........ 6 s

The hypophysial components. . . . . . . . . . . . . . . . . . 69

The thyroid. . . . . . . . . . . . . . . . . . . . . . . . . . . . .

The adrenal cortex and medulla ....................... 90

The epithelial bodies. . . . . . . . . . . . . . . . . . . . . 97

The fat-organ ............................... 99

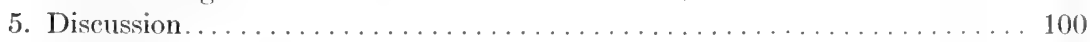

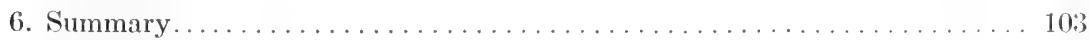

Bibliography ................................. 109 


\section{THE PIGMENTARY, GROWTH AND ENDOCRINE DISTURBANCES INDUCED IN THE ANURAN TADPOLE BY THE EARLY ABLATION OF THE PARS BUCCALIS OF THE HYPOPHYSIS ${ }^{1}$}

\section{INTRODUCTION}

Only within the brief period of four years has the favorable character of the early amphibian tadpole for analyzing the functional nature and the reactions of the members of the endocrine system been recognized. This may indeed seem strange, since the value of this material, to which attention was called by Born and which has been used so advantageously by Harrison, in the solution of those problems requiring experimental procedure upon the early embryo has long been appreciated. The early amphibian tadpole is peculiarly useful in experimental biological investigations, since in its earliest stages it is available for operation and has the inherent capacity to survive the most severe mutilations. These characteristics make a special appeal in studies upon the functional interrelationships obtaining in the endocrine system, for derangements in this system can be induced by the ablation of certain of its members in their early embryonal and non-functional stages by a simple operation, in itself not harmful. The early removal of a gland will afford then knowledge not only of the essentiality of this gland per se, but also concerning the dependence of the other endocrine organs upon this gland for their full development. This interdependence may be productive of even greater structural changes in the other glands than a later operation would produce, because of the lability inherent in embryonal structures. Further, the utilization of embryonal material would appear

${ }^{1}$ Aided by a grant from the Research Board of the University of California. 
to be neessary in studies upon hypophysial extirpation if the prolonged survival of the animals is desired, since the complete extirpation of the epithelial hypophysis' in the adult invariably proves fatal within a brief period. And it would appear that only by the prolonged survival of the animal can the maximal alterations in the other members of this correlative system fully express themselves, as is shown by the structural picture presented by the endocrine organs of the 'hypophysectomized' tadpole. These organs exhibit structural changes exceeding in magnitude those obtaining in the hypophysectomized mammal. Indeed, it is possible to look upon these structural alterations as the expression of a restored functional balance in the endocrine system which has permitted the survival of the animal. One further advantage is bestowed by the use of embryonic material, for we may discover a more general influence of the endocrine organ in question on the manner or rate of development of all of the tissues and organs of the body-namely, on growth-and, as we shall see further on, growth effects are among the most prominent ones manifested by these disturbances.

In 1912 Gudernatsch reported that frog larvae could be metamorphosed by thyroid feeding. This remarkable result stimulated Adler in the same year to utilize the tadpole for the ablation of members of the endocrine system. By what now appears to be a crude method, Adler, in 1912, burned out the pituitary from half-grown frog larvae. Although the failures were numerous, the death rate high, and in the surviving successful cases the injury to the neighboring structures severe, nevertheless, Adler was able to show that the destruction of the pituitary impaired the thyroid gland and prevented metamorphosis. Subsequent and far more successful ablations of the hypophysis have amply confirmed Adler's findings.

In 1914 the author attempted to remove the epithelial anlage of the hypophysis in the early larvae of the newt-D. torosus. As had been the experience of other investigators, this urodele material proved unfavorable for early operation. The follow-

\footnotetext{
2'That portion of the hypophysis arising from the oral ectoderm.
} 
ing season unsuccessful attempts to transport living frog eggs from the Middle West were made. Finally favorable material was secured from the rather scanty local anuran fauna by collecting the adult pairs of the frog, Rana boylei, at the time of laying. The larvae of this form proved ideal, wounds healed rapidly, feeding was vigorous, and growth uniform.

An astonishing result of this early removal of the epithelial hypophysis was now revealed. Characteristic, silvery-colored larvae-albinos - in great contrast to their darkly pigmented normal mates, resulted. Similar results were obtained simultaneously by B. M. Allen. In a series of papers the writer, B. M. Allen, E. R. and M. M. Hoskins, and W. C. Atwell have further confirmed and sought to analyze this discovery. Allen has subsequently studied in more detail the changes induced by an equally early ablation of the thyroid gland. No one, it would appear, has endeavored to confine his attention to the altered anatomy and physiology displayed by these pituitaryfree 'albinos.' The present monograph aims to do this. While brief statements of some of its material have appeared from time to time, there has been collected here for the first time as complete an account as is now possible of the pigmentary upset and other correlated bodily changes, especially endocrine alterations called forth by this procedure.

\section{The conditions of the experiment}

All amphibian material is not equally favorable for work of this nature. In order to assure prompt healing, the yolk must be moderate in amount and of a cohesive nature. Thus operative work upon the larvae of the common newt, D. torosus, is precluded, due to its large, abundant, and non-cohesive yolk granules, which extrude for hours through the wound, even final healing being prevented. The unfavorable character of the Amblystoma punctatum for work of this nature has previously been commented upon by Harrison. For studies on growth it is further essential that the animals be vigorous feeder's and develop at a rather uniform rate. This desideratum would 
apparently rule out one of the common California frogs, $R$. aurora dratonyii, as well as the newt. The frog, Rana boylei Baird, and to a limited extent the toad, Bufo boreas, were utilized in this work and have proved very satisfactory, since they recover quickly from the operation, are vigorous feeders, and exhibit a rather uniform rate of growth.

The anlage of the epithelial hypophysis can be more easily ablated than any of the other glands of internal secretion save the thyroid. As is well known, this ectodermal invagination, lying between the brain and the pharynx, is connected with the surface epithelium in very young frog larvae, ${ }^{3}$ and is consequently readily accessible (fig. 12). If a transverse cut with finely ground needles be made through the surface ectoderm between the forebrain protuberance and the pharynx ${ }^{4}$ (figs. 11, 12) and these two structures gently separated, the hypophysial ingrowth is readily distinguished lying on the ventral surface of the brain, from which it can be separated without serious injury to the latter. The stage selected for the operation should neither be too young, in which case the structures are undifferentiated and serious injury may be done to the mouth, nor too old, in which case the hypophysis will have migrated to its deeper position, thus making its removal extremely difficult. Larrae of $3 \frac{1}{2}$ to $4 \mathrm{~mm}$. in length, at which time the tail bud is well formed and the nasal placodes distinct, appear to be in the most favorable stage for epithelial hypophysectomy (fig. 11). Since reflex movement has not yet appeared, no anaesthetic is necessary.

It is essential to furnish a continuously renewed supply of well-aerated water to the larvae. In this locality the added necessity of 'sterilizing' the water by heat at $60^{\circ} \mathrm{C}$. for at least an hour, followed by cooling and reaeration, has been forced upon us (Smith, '18), because of the pathogenic organisms which

\footnotetext{
${ }^{3}$ Excellent descriptions of the development of this structure in Amphibia have been given by Orr ('89), Corning ('99), Kingsley and Thyng ('04), Atwell ('18), and others.

4 depression at the point of invagination of the hypophysis plainly marks its position (figs. 11, 12, IIyp. p.). With later develomment this pit gradually disappears or merges into the stomodacum.
} 
apparently gain ingress through the city water supply. Experience during the past three seasons has abundantly justified this 'sterilization,' since infection has been inversely proportional to the extent to which this treated water was utilized. Such treatment of the water appears to impair in no way the normality of the animals raised therein.

With the daily feeding of special or check food substances, as has been done in this study, the necessity of removing the uneaten particles which would otherwise putrify has forced us to have special containers manufactured. Our needs were met by having vessels of two sizes cast. One size, made of a gray glazed earthenware, is 12 inches square by 6 inches deep; the other size, made of a gray porcelain, is 6 inches square by 4 inches deep. The water level in either type can be readily changed by an L-tube draining through a hole near the bottom of the container. It was found that from fifty to seventy-five specimens could be reared in each of the larger containers without overcrowding and from ten to twenty specimens in each of the smaller ones. The daily cleaning of such containers proved not to be an onerous task when done with a syphon cleaning tube fitted with an appropriately shaped inlet.

Various check and special food substances have been fed: liver, muscle, ${ }^{5}$ anterior lobe, posterior lobe of the hypophysis, adrenal cortex, adrenal medulla, as well as various extractives and residues of the anterior lobe of the hypophysis. As a check diet, finely ground fresh liver has proved more satisfactory than muscle, since the connective tissue of even finely ground muscle often unites fragments and thus prevents complete deglutition of partly swallowed series of food particles, resulting in the death of the animals. In all cases an abundant supply of boiled lettuce has been furnished. Although liver has proved satisfactory for the normal tadpole, yet by far the most adequate food substance for raising a vigorous, healthy albino is the fresh anterior lobe of the beef hypophysis. With this diet, which

\footnotetext{
${ }^{5}$ Mendel and Osborne ('18) report that the proteins in both muscle and liver are adequate for the needs of nutrition in growth.
} 
as will be shown replaces the growth substance lost by hypophysectomy, the albinos thrived and were much more healthy, vigorous, and enjoyed a greater longevity than with any other diet. This gland proved to be a very desirable food substance for the normal tadpole as well.

The alterations referable to hypophyscetomy in frog or toad larvae express themselves in several ways. There early appears a pigmentary disturbance productive of a silvery tadpole-the albino. This system then exhibits profound structural and functional modifications. An early retardation in growth is apparent which progressively becomes more marked with development. The growth curves of these animals differ not only in their magnitude, but in their character when compared to the normal. And finally, most of the other members of the internal secretory system present a structural picture differing greatly from the normal.

It is thus convenient to present the matter under three headings:

Disturbances in the pigmentary system.

Alterations in the growth rate.

Alterations in the other glands of internal secretion.

\section{ALTERATIONS IN THE PIGMENTARY SYSTEM}

The striking color changes which many of the lower vertebrates exhibit under changed environmental conditions has long been known and early attracted attention to the mutual interplay of the various components of the chromatophore groups by which this chromatic 'adaptability' was effected. In addition to these environmental color changes, it has also been shown that pronounced changes in certain of the chromatophore groups can be experimentally induced: by the injection of adrenalin into the frog, Lieben ('06); by the immersion of the entire animal or portions of it in certain endocrine extracts, McCord and Allen ('17), Lowe ('17), Spacth ('13 and '18, with fish scales); by experimental operative procedures, Lister ('58), Bimmerman 
('78), Biedermann ('92), Hooker ('12), Redfield ('16); by electrical stimulation, Hermann ('86), Winkler ('10), Spaeth ('16, with fish scales); by pharmacological reagents, Lowe ('17); as well as by producing numerical and physiological modifications in the pigment cells by rearing the larvae in different backgrounds, Babák ('13). ${ }^{6}$ It is not surprising that a mechanism exhibiting such a functional lability would be modified by disturbances in the endocrine system; indeed, that this piginentary mechanism is influenced by the internal secretory system has been suggested by Fuchs ('14) and Redfield ('16, '18). It was not known, however, until the reports of the writer and of B. M. Allen appeared in 1916 that the ablation of one of the endocrine glands would in itself profoundly and permanently modify the pigmentary system. It was then shown that the early ablation ${ }^{7}$ of the pars buccalis of the hypophysis induced pigmentary changes leading to the formation of a 'silvery' tadpole the albino - the most striking pigmentary alteration as yet effected in the tadpole. In this pigmentary disturbance all components of the chromatophore system have been pictured as playing a significant rôle by various writers.

The epidermal melanophores have been shown to be diminished in number (Smith, Allen), in pigment content (Smith), and to display a persistent contraction (Allen), all of which has been substantiated in the recent article by Atwell and by the author. It has further been shown that the free melanin which lies near the outer border of the peripheral layer of epidermal cells suffers a pronounced diminution (Smith).

By this diminution in the melanin content of the epidermis, a modification which lends greater transpareney to this epithelial covering, the iridescent quality of the subjacent chromatophore group - the xantholeucophores - which in the albino display a

${ }^{6}$ The literature on the pigment cells is stupendous, only a glimpse of it being given here. A complete bibliography on this subject will be found in the comprehensive article of Fuchs in Wintersteins' Handb. d. vergl. Physiol., Bd. 3, 1 Hälfte, 2 Teil.

${ }^{7}$ An early operation appears to be essential for the production of a pigmentary effect, since Adler reports no striking pigmentary disturbance subsequent to hypophysectomy in the midlarval stages. 
broad and persistent expansion, is permitted full effect. This striking and persistent expansion in the xantholeucophores or 'interference' cells appears to have heretofore escaped attention, yet in this phenomenon of albinism they play no secondary rôle, since to them is referable the silvery and iridescent quality of the albino. ${ }^{8}$

The contraction of the deep melanophores, first described by Allen and later confirmed by Atwell, who indeed refers the picture of albinism primarily to the altered physiological state of these cells, the author can corroborate for the young albinous tadpole, but repeated examinations have failed to reveal a definite contraction in the older albinous larvae of $\mathrm{R}$. boylei. As will be subsequently pointed out, the physiological condition of these cells could make no significant contribution to the picture of albinism.

To anticipate, then, what will be more fully shown in this section, the essential pigmentary changes ${ }^{9}$ contributing to the picture of albinism in this form are three in number:

1. A diminution in the epidermal free pigment.

2. A diminution in the number and melanin content of the epidermal melanophores (because of their paucity in number and pigment content, the contraction of these cells plays no important rôle in the formation of this picture).

3. A great and persistent expansion in the xantholeucophores.

It is most essential in a study of this nature that the environmental condition be well known on account of the adaptability of the pigment system to such external factors. The standard environmental condition, which we believe closely approximates that obtaining in nature, was furnished by a diffuse light, a gray background and room temperature $\left(18^{\circ}\right.$ to $25^{\circ} \mathrm{C}$.). The ex-

${ }^{8}$ I have recently called attention to the significant contribution which these cells make to the picture of albinism (Proc. Soc. Exp. Biol. and Med., 43-1418, 1919).

"Although the pigmentary system of a hypophysectomized tadpole $12 \mathrm{~mm}$. or even less in length shows variations from the normal, nevertheless, an animal two, or better, three or more times this size has these modifications more clearly differentiated. The descriptions, except when otherwise stated, were made upon animals raised upon an anterior-lobe diet and which have attained a size in excess of $45 \mathrm{~mm}$. and were not less than 31 , 3 months old. 
treme variations from this 'indifferent' condition have been assumed to be a) a white background with direct sunlight; b) a black background and the absence of light, temperature in all cases being noted and regulated to suit the experimental desiderata.

The observations upon the pigment cells have been made both upon the well-illuminated living animal with the binocular microscope (a Zeiss instrument fitted with a water-immersion objective and no. 2 oculars; magnification, 42 diameters) and by examination of cutaneous whole mounts. By the first method the progressive changes in the pigment cells under altered environmental conditions can be noted, the observations in most cases of necessity being rapidly taken so as to exclude possible alterations resulting from the rather brilliant illumination necessary for binocular observation (as, for instance, in observing a dark-adapted animal). These observations have been checked and supplemented by skin whole mounts of the fixed animal, the fixation being so rapidly effected as to preclude any physiological alterations which might take place. Observations have been largely limited to the dorsal and neighboring lateral portions of the body, save in certain cases where the pigment cells lining the body cavity were noted in fixed specimens. Although observation of the deep melanophores of the dorsal region involves some difficulty more especially in the albino, in which they are largely masked by the expanded xantholeucophores, yet the observations herein reported were restricted to this region, since repeated observations have revealed the fact that the pigment cells exhibit regional variations both in the time and the magnitude of their response.

In this section of the paper there will be presented:

1. The anatomical and physiological characteristics of the pigment cells of the albino as compared with those of the unoperated tadpole and some remarks on the development of this condition.

2. The responsibility of the endocrine system for this pigment fault as shown by- 
a. Epidermal transplants.

b. The effect of various pabula upon the pigment cells.

c. The response of the chromatophores to various physiological and pharmacological agents.

\section{The chromatophores of albinous larvae}

As is well known, the melanophores of the tadpole are of two types. One type - the epidermal melanophore - is found in the cpithelial covering of the body; the other type - the deep melanophore-lies in or around the deeper structures. These two types, then, of necessity, will be treated independently.

The epidermal melanophores. The epidermal melanophore, when in an expanded condition, presents an irregularly shaped body from which branched, slender processes radiate for relatively long distances (fig. 13). When in a greatly contracted condition, these processes are not evident and the cell body then is of a spherical or slightly irregular shape (figs. 19 and 21). All intermediate conditions between these two extremes can be seen with proper light and temperature conditions.

The melanophores of the epidermis are greatly reduced in number in the albino (figs. 13 and 14), many counts showing an average reduction of two-thirds from the normal number. Even in a greatly expanded condition these cells are usually separated by wide intervals, a condition which contrasts sharply with that obtaining in the normal animal where the expanded processes unite with, or even overlap, each other. Thirty-one counts from five specimens gave an average of 38 epidermal melanophores in a unit area of 0.36 of a sq.mm. Similar counts from normal animals reveal 119 to this unit area, thus exceeding by over three times the number present in the albino (table 1 ). It is emphasized, however, that the distribution of these cells in neither type of animal is uniform. Yet their number in the normal even in the areas where they are most thinly distributed exceeds very considerably their number in the albino where they are most thickly placed. Further, the actual melanin content of these cells is diminished in the albino (figs. 13 and 20). Their processes, slender and of light color, present a very differ- 
ent appearance from that furnished by the course black processes of the normal melanophore. ${ }^{10}$

Not only do these superficial melanin-bearing cells exhibit differences of a quantitative nature in these two types of animals, but constant physiological dissimilarity is also encountered. It may be urged that the functional states of these cells in the normal usually exhibit such wide variation not only between two or more individuals, but also in the cells of a single individual, that the determination of a normal physiological condition is precluded. Certain it is that not only do we find differences between the condition of the individual cells of a specimen, but under identical environmental conditions these cells in one animal may be expanded while those of its mates are partly contracted.11 Yet this variability is not so great as to preclude our defining the condition of these cells in a normal animal in an 'indifferent' environment as one of complete or nearly complete expansion (fig. 13).

With the albino, as with the normal, but to a lesser extent, the same variability in the superficial melanophores of various individuals is exhibited. The individual cells of any one specimen, however, usually exhibit a greater dissimilarity than in the normal animal. A very few of these cells are almost invariably broadly expanded, a few are half expanded, while the majority are completely contracted or but slightly expanded (fig. 14). It is apparent, then, that the usual physiological

${ }^{10}$ The evidence on this point is quite clear; corroborative evidence has also recently been furnished by Atwell, although Allen is apparently not in agreement with these findings, for he says: "These observations and a careful study of the pigment cells convince me that there is no disappearance and bleaching of the pigment cells as asserted by Smith." It is worthy of mention here that the author has never mentioned a "disappearance and bleaching of the pigment cells," stating, "Counts of the epidermal melanophores-in the albinos and checks show that the number of these cells in the epidermis is reduced in the former" and- "the melanophores of the albino specimens contain fewer pigment granules than do those of the checks and thus have a distinctly lighter appearance." The process leading to this condition was not then discussed by the author.

${ }^{11}$ This variability has led certain investigators to confine their obscrvations in various physiological experiments to the more uniformly reacting deep melanophores-for example, Laurens. 


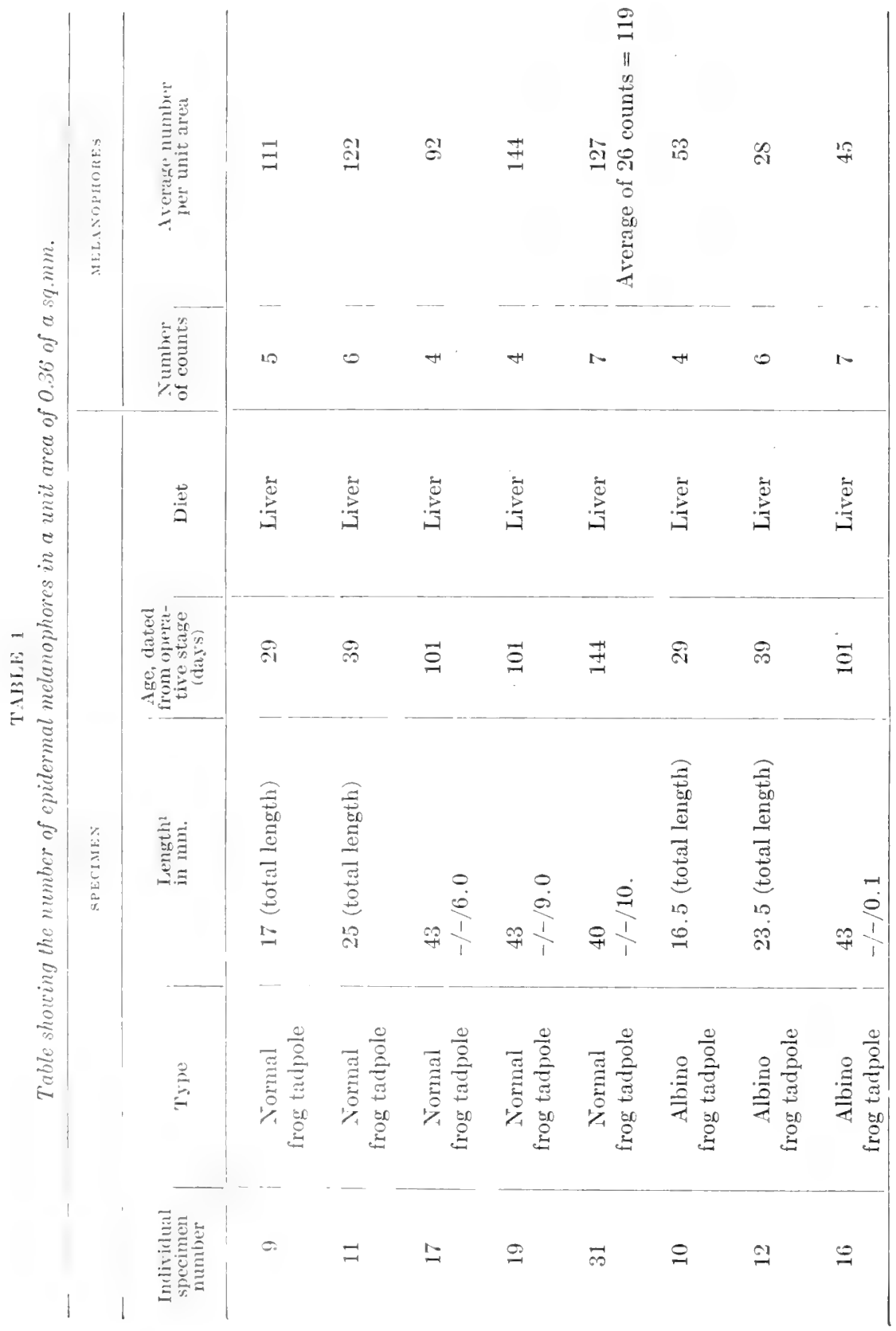


THE PARS BUCCALIS OF THE HYPOPHYSIS

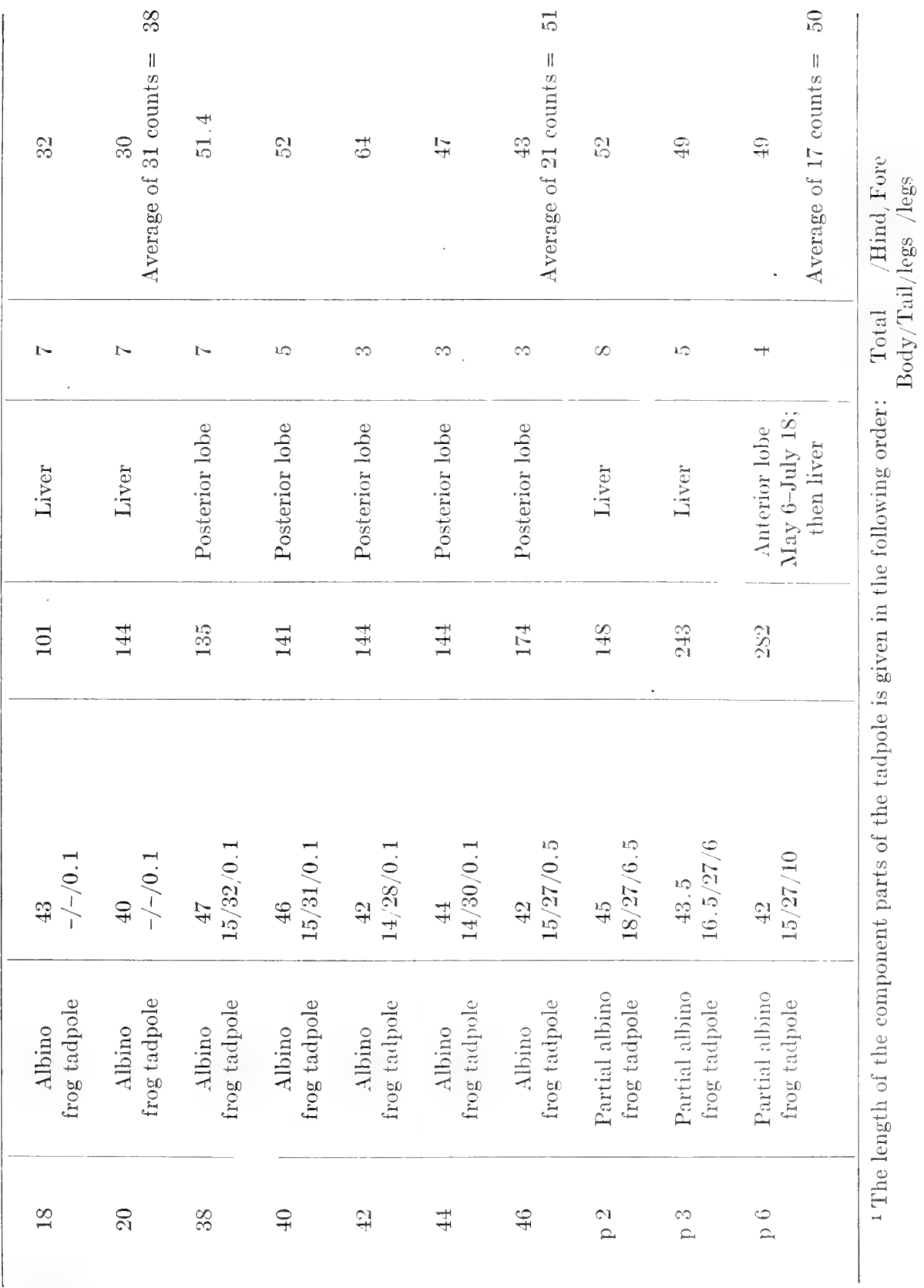

MEMOIR No. 11. 
condition obtaining in these cells in the albino is one of complete, or nearly complete, contraction.

The free pigment which forms a definite, though imperfect, layer in the normal animal is much diminished in amount and is irregularly distributed in the albinous larvae (figs. 13, 14). In the skin whole mounts of the albino, it indeed forms but a scanty and irregular sheet which stands in contrast to the very distinct layer present in the normal animal.

The decp melanophores. The number and melanin content of the deep melanophores apparently are not altered by the ablation of the hypophysis. This structural independence appears not to lend support to those investigators who assert that both groups of melanophores, epidermal and corial, arise from a common source. ${ }^{12}$

That the deep melanophores exhibit a contracted condition has been noted by Allen and Atwell, the latter, indeed, referring the phenomenon of albinism primarily to their contracted condition. Many examinations of larvae in excess of $45 \mathrm{~mm}$. in length, made both on the living animal and after rapid fixation, convince the author beyond question that in the body and head regions these cells, whether occurring in the corium, in muscle sheaths, or in the fascia of the viscera and body cavities, exhibit nearly the same physiological state in the fully developed albino of $\mathrm{R}$. boylei as in the normal (figs. 13, 14); in the young albino, however, certain of these cells appear to be in various stages of contraction (fig. 16).

The xantholeucophores. We have noted significant and constant changes in the superficial layer of the first group of pigment cells- the bearers of melanin. Changes no less significant in the phenomenon of albinism are encountered in the second group of chromatophores, the bearers of guanine and xanthine. Indeed, since the silvery and iridescent characteristics of many fishes are referable to these cells, it would seem to make them of paramount importance in the phenomenon of albinism. When viewed by transmitted light, these cells are of a grayish or brown-

12 Ehrmann (' 96 and carlicr) refers the common origin of the melanophores to the mesoblast of the dorsal cephalie region of the body. 
ish color. It is, however, with reflected light that their great beauty and their contribution to the color of the animal becomes apparent. For one constituent, the guanine, distributed in minute crystals reflects the light and lends to it the iridescent qualities; the other constituent, the xanthine, small in amount in the tadpole, contributes to this color effect.

Delicate in structure and apparently exhibiting no resistant cell membrane, these cells are prone to disintegrate, consequently appropriate and rapid fixation is essential for their preservation. This delicacy is well shown in the epidermal transplants where although but a few seconds may lapse before the graft 'takes,' yet these cells in any region where an intimate union between host and graft does not obtain, change their character and ultimately disintegrate. Or, indeed, even when not subject to mechanical disturbances, as following the natural death of their host, they are wont to lose quickly their cellular integrity, forming a diffuse layer of fine crystals, which exhibit a vigorous Brownian movement - a most striking picture with the polariscope. Not only is early and rapid fixation essential, but appropriate fixers must be employed. This is well shown if a specimen be dropped into formol. Such an animal after a few weeks, or even days, loses its silvery appearance and assumes a gray tone. Microscopic examination reveals the fact that the xantholeucophores are no longer visible.

Over the dorsal body areas the xantholeucophores form two well-defined layers, each layer being composed of discrete independent cells. The peripheral layer, lying just beneath the epidermal basement membrane, is usually separated by a considerable interval from the deeper layer which lies adjacent to but external to the corial melanophores. In those areas where the epidermis closely approximates the underlying firm body structures, these two layers of xantholeucophores, except under high magnification, may appear as a common layer. We thus see that the iridescent cells lie between the two types of melanophores, an arrangement the recognition of which is of no little moment in evaluating the rôle of the various groups of pigment cells in albinism. 
Both layers of corial xantholeucophores are broadly expanded in the albino (figs. 14, 16, 18, 20 to 23,55 to 58), an expansion which is singularly unamenable, more especially in the older albinos, to altered environmental conditions. To the broad expanse of the refractive cells the albino owes its metallic tone, as can be clearly shown by all procedures which contract these cells.

We have thus far confined our attention to two types of tadpoles, that type in which the tadpoles have suffered the entire loss of the buccal component of the pituitary, the albino, and that type whose nembers have suffered no operative interference, the normal. It is now desirable to consider a third type-those in which the epithelial hypophysis was incompletely ablated, the 'partial' albino (figs. 52 to 54). This type of tadpole usually suffers a serious pigmentary disturbance, its pigmentary system simulating that of the albino more than that of the normal. In fact, its almost typical albinism frequently makes this animal difficult and often impossible to distinguish during early development from its completely hypophysectomized brothers. Later in life it is readily distinguishable, since legs develop in the partially but not in the completely hypophysectomized tadpole. In the albinous type of partially hypophysectomized tadpole as in the typical albino the free pigment is greatly diminished in amount and the epidermal melanophores are scanty in number. That the epidermal melanophores are slightly greater in number than in the complete albino, however, is apparent from counts. It will be recalled that thirty-one counts from five albinos gave an average of thirty-eight epidermal melanophores to a unit area 0.36 of a sq.mm. Seventeen similar counts from three 'partial' albinos gave an average of fifty to this unit area (table 1). The xantholeucophores appear' to be no way different from those of the typical albino. They cxhibit a broad and persistent expansion. Although the pigment system of this animal elosely resembles that of the albino, yet, in contrast to the albino, it does not suffer serious structural defects in any of its endocrine organs save one, the neural component of the pituitary. Exhibiting, then, characteristies of both the albino and the normal, this 'hybrid' tadpole has been 
of especial value in freeing any of the other endocrine glands which have been studied from responsibility for the pigmentary disturbance, as will be later shown.

An examination of the pigmentary system of the albino has revealed that one group of chromatophores, the xantholeucophores, exhibits a great expansion; another group, the epidermal melanophores, is diminished both in number and pigment content and displays an unusual contraction. It is necessary, then, to examine the developmental stages leading to the production of the characteristic albino if we wish to determine whether this is a progressive phenomenon; whether from the beginning the formation of the epidermal melanophores, for example, is inhibited by the endocrine fault, or whether on the other hand they form only to partially disappear later. The three groups of pigment-bearing cells make their appearance in the following sequence: deep melanophores, xantholeucophores, epidermal melanophores. A period of several days intervenes between the appearance of each of these groups, and so they may well be treated independently in a developmental study.

The time of appearance of the deep melanophores apparently is identical in both the normal and hypophysectomized tadpole. In a 6 to $7 \mathrm{~mm}$. stage for the normal, they have already made their appearance in the dorsal regions of the head and body. A few show the typical shape of the deep melanophore. A majority, however, have longer and more delicate processes than the typical corial melanophore. They either lie well separated from the epidermis or, especially where the epithelium elosely approximates the underlying firm structures, may be in contact with the epithelial covering. From this stage they progressively increase in number and gradually become organized until they attain the typical arrangement as a corial sheet at a 10 to $12 \mathrm{~mm}$. stage (fourteen to twenty days after the operative stage).

The xantholeucophores make their appearance in larvae of 10 to $11 \mathrm{~mm}$. (fourteen to sixteen days after the operative stage), appearing concomitantly both in time and number in the normal and hypophysectomized larvae. Slightly more numerous, pos- 
sibly, in the hypophysis-free specimens, this numerical difference is so slight as to be well within the limits of variability. From their earliest appearance they are expanded in the operated tadpole (fig. 16) in contrast to their punctate character in the normal (fig. 15). The early, almost imperceptible albinous appearance which denotes a successful hypophysis extirpation is due largely to the expanded condition of these cells, since in these early stages the free epidermal pigment in both albinous and normal larvae is identical and the epidermal melanophores have not as yet formed in either type of specimen. Scarcely perceptible at first, this whiteness of the hypophysectomized tadpoles progressively increases with the increase in the number of the xantholeucophores, and is further emphasized by the reorganization and diminution in the early embryonic pigment which takes place, as will be described later.

In the diminution in the epidermal melanin we find the first structural pigmentary alteration referable to hypophysectomy. Here we have to deal with the double expression of the melanin, that existing as free granules and that included in the chromatophores. In the earliest stages free pigment is found diffusely scattered throughout the two cell layers of the epidermis, although occurring more plentifully in the outer of these layers and in certain cells of this outer layer. At a $10 \mathrm{~mm}$. stage it has become localized in the superficial layer of the epithelium, and by the time the larvae have reached approximately a 20 to $25 \mathrm{~mm}$. stage it is found only in the peripheral zone of this cell layer. ${ }^{13}$ Identical in amount in the earlier larval stage of the operated and normal larvae (figs. 15, 16), it gradually becomes diminished in the albino (figs. 17, 18), a diminution which aids in permitting the iridescent qualities of the xantholeucophores to be fully expressed and which is shown by the rapid development of the albinous picture at this time (figs. 42 to 45 ).

The first typical epidermal melanophores make their appearance in about a $10 \mathrm{~mm}$. normal (twenty-two days after the operative stage, fig. 15). At first seatteringly distributed and

\footnotetext{
${ }^{13}$ 'The changes here described are nearly identical with those deseribed by Maurer (9i)
} 
light in color, these cells rapidly increase in number and melanin content; by a $15 \mathrm{~mm}$. stage they have numerically and structurally attained the mature larval condition (fig. 17, table 1). Their appearance in the albino is more tardy. They do not appear as early and are always diminished in number and melanin content as shown by figures 16 and 18, which were drawn from albinos of the same age and size as the normals from which figures 15 and 17 , respectively, were drawn. A partly contracted condition is also evident from their earliest appearance.

No evidence has accrued from these studies which suggests that the diminution in the number of epidermal melanophores suffered by the albino is affected by a migration of the epidermal melanophores into the corium as suggested by Allen. On the other hand, the evidence all points to the developmental and functional independence of the two systems of melanophores. The first melanophores to appear are those in the corium, and there is at no time any evidence that their number is augmented by a migratory process from the epidermis. The formation of the epidermal melanophores from the beginning is apparently partially inhibited in the albino, an inhibition which is expressed not only in the diminished number of cells, but in their melanin content as well.

One of the remarkable features in this pigmentary disturbance is its early appearance. Whether referable to some missing hormone of the anterior lobe or to other hormonal disturbances provoked by the operation, it appears clear that hormones are already produced by the small groups of embryonic cells constituting the endocrine glands at a time when the latter exhibit but little if any of the structural differentiations which characterize the adult internal secretory organs.

\section{Epidermal transplants}

We have detailed at some length the pigmentary disturbances which result from the early loss of the epithelial hypophysis in the tadpole. It is now of interest to inquire whether this functional upset is due directly to an alteration in the quality of 
the fluids bathing these cells or, on the other hand, to alterations in their nervous mechanism.

Unimpeachable evidence has been secured on this point by reciprocal skin transplants. In a very considerable number of (atses skin interchanges have been successfully effected between a normal tadpole and its albinous mate. Invariably, and in a period not exceeding four hours for the xantholeucophores and a somewhat longer period for the epidermal melanophores, ${ }^{14}$ these cells of the transplant assume the state characteristic for the corresponding cells of the host.

The technical manipulations involved in performing these skin exchanges even in larvae exceeding $40 \mathrm{~mm}$. in length are not difficult. A narcosis sufficiently deep for operative work has not readily been effected at room temperature, although serving well for ordinary examinations in which no trauma was inflicted. Of the several anaesthetics employed, ethyl eurethane (Merk) in a strength of 0.5 per cent has proved the most efficacious, especially when used at a low temperature $\left(1^{\circ}\right.$ to $\left.3^{\circ}\right)$. The lighter narcosis effective at this low temperature is of no little significance, since not only is recovery more certain, but also functional changes in the pigment cells inherent in a profound anaesthesia are avoided.

After a sufficiently deep insensibility had been produced, the specimens were placed closely together in depressions in the wax plate lining the dish. Incisions on the dorsal epidermis mapping out an area approximately $4 \times 6 \mathrm{~mm}$. were then made on the dorsum of each specimen with the aid of the binocular. Following this the skin was rapidly freed and the interchange effected, the grafts being gently pressed down and not infrequently tucked under the edge of the host's skin. These grafts quickly adhered, and in a short time no movement of the host could dislodge them.

\footnotetext{
${ }_{14}$ This reation of the epidemal melanophores of the albinous graft to the normal host-one of expansion-applies only to the colls originally belonging to the graft. Epidermat melanophores from the surrounding normally pigmented epithelium of the host quickly invade the albinous graft. These cells display a state of great contraction for at least a considerable interval.
} 
There now was exhibited one of the most striking phenomena presented in this work. The heretofore broadly expanded xantholeucophores of the albinous graft gradually contracted under the influence of its normal host. In half an hour they were much reduced; in two hours they were punctate, even exceeding in minuteness under this new stimulus the diminutive size of the host's 'interference' cells (figs. 57 and 58). Likewise the epidermal melanophores of the albinous graft gradually expanded. This change from the altered physiological state of these cells in the albino to the state characteristic of the normal animal then persisted for the life of the host.

A change as striking was exhibited by the heretofore contracted xantholeucophores and expanded epidermal melanophores of the normal graft. In about the same interval the xantholeucophores of the normal graft became broadly expanded (figs. 57, 58), and after a somewhat longer interval the epidermal melanophores assumed a punctate condition. These cells, then, in this brief interval had changed from the functional state they had so long experienced to the opposite condition exhibited by them in the new host.

There is, however, the possibility that this remarkable transformation was due to the mechanical manipulation and not to the influence of the host. This possibility can definitely be excluded by the simple test involved in an autoplastic skin graft. Identical incisions were made, the freed epidermis, however, instead of being transferred to a new host, was returned to the position from which it for a brief interval had been removed. In neither the normal nor albinous larvae did these cells suffer any permanent change, but remained in the same condition as the cells which had not been removed.

Definite evidence has thus been secured which shows that the altered state of these cells in the albino has been brought about by the action of some substance present in the tissue fluids and not by alterations in the nervous mechanism, since we can conceive of no reestablishment of nervous connection in such a brief interval. Further, it would seem probable that this substance acts directly upon the pigment cell itself and not upon 
the severed nerve termination. This would appear to be the case, since if this atypical condition exhibited by the cells of the normal graft to the albinous host was due to the action of the tissue fluids upon the severed motor connections, we would expect a change in the size of these cells in that interval which must occur between the degeneration of this nerve ending and the reestablishment of a new nervous connection, a change which apparently does not occur. Because of the known potency of minute amounts of endocrine secretions, the most natural assumption is that this alteration has been effected through some 'hormonal' component of the plasma or lymph.

Rather interesting results have been secured by submitting these operated animals to adrenalin and to 'light and heat' stimuli. These experiments, although not as complete as could be wished, have been carried out on some half-dozen albinous and normal tadpoles into which grafts from the opposite type of animal had been made. The response or failure to respond in the case of host and transplant cells has been nearly identical. The tests were carried out from twelve hours to three days subsequent to the operation and supply additional evidence that the effective force causing a response of these cells to stimuli is the direct application of the internal secretory substance to the cell bodies and is not effected through the motor sympathetic endings, since it is probable that any nerve ending severed as it is from the nerve fiber would have degenerated in this interval, and even after this lapse of time new connections could hardly have been established.

Some rather significant evidence has been secured on the formation and migration of the epidermal melanophores in the transplants. There invariably occurred an early migration of the epidermal melanophores from the normal host into or over the albinous transplant. In a period of a few hours the sulcus intervening between the two types of skin would become filled with a dense mass of melanin-rich cells in which the pigmented epidermal cells could not readily be distinguished from the true melanophores. In twelve hours, or even less, growing points would appear from this confused sear tissue which invaded or 
became incorporated gradually into the albinous graft. In this invading tissue, and indeed in those parts of the albinous graft which clearly had not suffered an invasion by the epidermis of the host, epidermal melanophores could readily be distinguished which curiously displayed, for a considerable interval, a state of great contraction. In the end the albinous transplant was as abundantly supplied with melanophores as was the normal epidermis. Although the free pigment of the albinous graft increased more slowly than did the epidermal melanophores, yet this too ultimately exhibited a normal condition. Thus, after an interval not exceeding two months, both the free pigment and the epidermal melanophores of the albinous transplant had assumed the characteristics typical of the epithelium of the normal host.

The sequence of changes in a dark graft to an albinous host is of a quite different nature from the alternate just described. Although there appeared to be a slight reduction in both the amount of the free pigment and the number of the melanophores of the epidermis, yet these changes were of a minor nature. No extensive migration of the melanophores from the normal transplant where they were thickly congregated into the sparsely supplied surrounding albinous epithelium occurred, nor by any other process did any great reduction in the number or pigment content of the transplanted melanophores take place during the interval that the animals were under observation (two months). These cells, once formed, appear to retain their integrity. This would appear to be the correct interpretation of the non-effect upon the pigment cells of hypophysectomy in the midlarval stages (Adler).

\section{The effect of various diets upon the pigment cells}

We have just shown by the skin exchanges that the atypical physiological state of the xantholeucophores and epidermal melanophores of the albino is directly referable to an alteration in the tissue juices which in turn is probably of an 'hormonal' nature. If, then, this endocrine disturbance which is inaugu- 
rated by an hypophysial deficiency leads to an upset in the pigmentary system, will it not be possible with the proper endorrine diets to abort or ameliorate this derangement? The possibility appears the more probable since the general growth effects inherent in the loss of the buccal hypophysis can be prevented by the administration of the beef glandular lobe, as will be shown later.

Of the endocrine substances which have been fed, glandular lohe and neural lobe (with the pars intermedia) of the hypophysis, adrenal cortex, adrenal medulla, and liver, one only - the neural, or posterior lobe has caused a formation of epidermal melanin approaching the normal, while none have reduced the xantholeucophores to a normal state of contraction.

It was early seen that those specimens receiving the posterior lobe of the pituitary exhibited a darker appearance than the albinous larvae fed upon the other fresh glands (figs. 46 to 51). Although expressed feebly at first, this depth of color became more pronounced as the feeding and growth progressed. So pronounced did it become after five months of this diet that there would have been some uncertainty in identifying these as hypophysectomized specimens save for the fact that legs did not develop. An examination of the living animal with the binocular reveals that although the xantholeucophores are typical of albinos, i.e., are fully expanded, there has been a great replacement of the epidermal melanin. This replacement was readily confirmed by a study of whole mounts of the epidermis which reveal that both components of the epidermal melanin have been increased (compare figs. 21 to 23 with figs. 14, 20). The free pigment is not, as in the typical albino, distributed in diffuse aggregations, but is found in considerable amounts in all of the superficial cpidermal cells. The epidermal melanophores also show a depth of color never attained in the typical albino, as is most clearly shown if the processes of the broadly expanded melanophores (a condition readily obtained by the death of the animal) of the posterior-lobe-fed albino be compared with those of the albinos on any other diet. 
Not only are the melanophores darker in the albinos receiving posterior lobe, but the number of these cells is also increased (table 1). Instead of averaging but thirty-eight to the unit area, they average in excess of fifty to this unit area $(0.36$ of a sq.mm.). Thus both in number and pigment content the epidermal melanophores of these animals are intermediate between those of the normal specimens and the typical albinos. ${ }^{15}$

It is not on the structural side alone that we find changes with a posterior lobe diet. The epidermal melanophores of these posterior-lobe-fed specimens uniformly exhibit a great and persistent contraction; they are uniformly either rounded or, at most, slightly irregular in shape, appearing as intense dark dots in all areas of the dorsal epidermis (fig. 21). Moreover, this contraction is persistent. After days of the substitution of another diet, it still persists; indeed, under the most potent stimulus-light and heat-for causing an expansion of the epidermal melanophores of the albino, a considerable interval must intervene in which neural lobe is not fed in order to obtain a decisive expansion of these cells.

It is curious that no increment in the epidermal melanin was produced in the unoperated tadpoles with a diet of fresh posterior lobe. Not only did no pigmentary increment result, but the contraction of the epidermal melanophores so typical of albinos on this diet did not regularly occur, or at most was but transitory.

Of the other substances which have been fed, none have appreciably affected the epidermal melanophores. One, namely, liver, has produced unmistakable differences, however, in the appearance of the xantholeucophores as contrasted to the albinos upon other diets. This effect is not expressed in any alteration in the usual extreme expansion of these cells, but rather in their color. These specimens do not show the golden sheen of the anterior or posterior lobe or adrenal cortex fed animals, but exhibit a chalky whiteness especially noticeable in the gill regions (figs. 46,48 ), an appearance probably due to a reduction in the lipochrome content of the cells.

\footnotetext{
15 The author has not supplied albinous larvae with posterior-lobe extracts. It is apparent from Allen's work, however, that if they are potent in eausing a melanin increase, they must be fed for a considerable interval of time.
} 


\section{The responses of the chromatophores to various physiological and pharmacological agents}

It has been shown that the pigment cells of both the normal and the albinous tadpole are influenced by the internal secretory system. Since the endocrine system is abnormal in the albino, it is logical to inquire whether the atypical pigmentary system of these specimens will react to various stimuli as does this system in the normal animal.

Although we can largely confirm Laurens' observations (made on Amblystoma) upon the irregular reactions of the epidermal melanophores, it will be recalled that in the unoperated tadpole the usual state of these cells under indifferent environmental conditions-diffuse light and a gray background-is one of two-thirds to full expansion. The xantholeucophores, on the contrary, are punctate or slightly expanded, while the deep melanophores are fully expanded.

The usual condition of the epidermal melanophores of an albino in our so-called 'indifferent' environment was one of complete, or nearly complete, contraction. The xantholeucophores, on the contrary, are broadly expanded.

If we now place a large albinous and a large normal ${ }^{16}$ specimen in the dark for a period of one to two hours at room temperature, we find certain well-marked changes take place. The epidermal molanophores of the normal, if not completely expanded, become so, but those of the albino being previously greatly contracted are unaffected. The xantholeucophores of the normal become punctate; these cells in the albino remain fully expanded. The decp melanophores of both animals become greatly contracted, the animals then displaying a 'transpareney' typical of the contracted condition of these cells. A low temperature $\left(0^{\circ}\right.$ to $\left.15^{\circ}\right)$ apparently does not increase the reaction to any extent, the epidermal melanophores of the albino surely not being affected.

${ }^{16} \mathrm{As}$ complete an analysis of the reactions of the epidermal melanophores in the young normal tadpole as could be desired has not been made. The reactions here deseribed unless otherwise stated apply only to large larvae at a time shortly precerling metamorphosis (in the normal). 
If we now subject these large animals to the opposite environmental conditions (direct sunlight, a white background, and a high temperature $-33^{\circ}$ to $35^{\circ}$ ), we see a striking change take place. The epidermal melanophores of the normal frequently gradually contract and may ultimately after an hour or even less at times assume only a slightly expanded condition (fig. 19). These cells in the albino, on the contrary, invariably expand, ultimately exhibiting a fully expanded condition (fig. 20). There is thus frequently exhibited a reversal in the reaction of these cells in the large specimens of these two types of animals, ${ }^{17}$ a reversal not evineed to its fullest extent with any stimulus tried by the author save that of heat combined with direct sunlight. Either extreme heat or light evokes this reaction to some extent, the relative importance of each factor, however, being difficult to determine. A normal specimen, if placed in the dark at $30^{\circ}$ to $35^{\circ}$, may exhibit after two to three hours partly contracted superficial melanophores. If the temperature becomes normal, these cells expand; if the temperature is maintained and sunlight used, further contraction not infrequently takes place. An albino, if placed in the dark at $30^{\circ}$ to $35^{\circ}$, exhibits in two

${ }^{17}$ One of the most striking features of the experimental work upon the epidermal pigment cells of the albinous and normal larvae has been the invariable response of these cells in the former as contrasted to their uncertain response in the latter. Of the very considerable number of albinous larvae which have been subjected to the stimulus of 'light and heat' a response, one of expansion, has invariably been exhibited by the epidermal melanophores. In contrast to this stands the variable response of these cells in the normal larvae. Because of the influence which the internal secretory glands have upon these pigment cells, this invariable response in the albino would appear to be of considerable significance, since certain of the endocrine glands in this type are structurally and also presumably functionally deficient. Consequently, we could expect that the response of these cells in this form would be more eertain than in the normal where these cells are under the variable influence of the internal secretory products.

In 1919 (Proc. Soc. Exp. Biol. and Med., 44-1419) I called attention to the opposed reaction of the epidermal melanophores in the albinous and normal larvae. The experimental work upon which this description was based was carried out upon the older albinous and normal larvae and should have been so stated. These normal larvae very uniformly exhibited a contraction of their epidermal melanophores when subjected to 'heat and light' as contrasted to the expansion of these cells in the albino under identical conditions. Subsequent work has revealed a more variable response of these cells in the normal, but not in the albino. 
hours partly expanded epidermal melanophores; if the temperature becomes normal, they contract to the usual condition; if the temperature is maintained and sunlight used in addition, they expand to the maximum. Thus we see that, although high temperature alone evokes the reaction, it is incomplete and slowly expressed, double the time being necessary. The same condition prevails if light alone is used. The reactions are evoked slowly and incompletely. Thus a combination of both light and heat is necessary to evoke the maximal response in the shortest time.

It has been mentioned that the xantholeucophores of the normal are uniformly nearly punctate in a dark-adapted animal. If the large normal animal be subjected to high temperature and direct sunlight, these cells become broadly expanded (fig. 19), never exhibiting, however, as great an expansion as invariably is presented by these cells in the albino. Thus we see that in the large normal animal there is frequently a reversal in the reaction between the 'interference' cells and the epidermal melanophores-one expands and the other contracts. Such a correlated opposite reaction of the pigment-cell groups no longer holds in the case of the albino, inasmuch as the xantholeucophores are always maximally expanded there. However, since under the usual environment the epidermal melanophores of the albino are almost maximally contracted, these two groups of cells are consequently usually in an opposite physiological condition, as is the case in the large normal larvae. We have already given evidence for our belief that the failure of albino xantholeucophores to react to stimuli is due to a tonic hormonal disturbance present in the tissue juices.

The deep melanophores with a white background and light expand; in darkness they contract; thus, in both types of animals their reaction is identical under all the environmental conditions employed by the author.

Specimens that have been thyroidectomized at an early stage, as is well known, exhibit no pigment deficiencies. Under the conditions of light and heat or of darkness, they react as do their unoperated brothers, with this difference: the reaction, 
although of an identical nature, is more slowly evoked. In determining the possible cause for this tardy response, the work of Levy is particularly suggestive. This investigator has shown that the reponses to adrenalin are more rapid if the thyroid has been stimulated or its extract injected. Although it has not been shown to what extent these responses of the pigment cells are referable either to the adrenal or directly to the sympathetic nervous system, still the slower responses of thyroidless larvae may well be of considerable significance in view of Levy's work. Furthermore, since pigment cells are formed and react in the thyroidless specimens in an identical manner with those of the normal, it is apparent that neither their atypical formation nor reaction in the albino can be referred to the atrophy of the thyroid effected by the hypophysectomy.

It has been shown that the epidermal melanophores of the posterior-lobe-fed hypophysectomized specimens exhibit a uniform state of great contraction, a contraction that persists for an extended period after the substitution of some other diet. Will these cells then respond to light and heat as do those of the typical albino?

It will be recalled that in the typical albino these cells, unlike the xantholeucophores, are sensitive to brilliant illumination coincident with increased temperature, undergoing an expansion. But the epidermal melanophores of the posterior-lobe-fed albinos stubbornly maintain their contracted condition with this stimulus and appear incapable of responding. Lest it be supposed that the reaction of these cells has approached that frequently exhibited by normal larvae, one need only to try their response to complete darkness where normal behavior would give us full expansion. Under all circumstances, their contracted condition is maintained just as is the corresponding persistent expansion of the xantholeucophores in these hypophysectomized larvae.

It was highly interesting to note that an abrupt change in the diet of the posterior-lobe-fed albinos, a substitution of a liver diet, led gradually to a resumption of the response characteristic of the typical albino. After an interval of one week in which they havereceived no nervous hypophysis they become MEMOIR No. 11. 
definitely expanded (fig. 22) when subjected to heat and direct sunlight. This response becomes more and more marked, until after five weeks we have an almost typical response (fig. 23). The xantholeucophores in these animals as in the typical albino remain broadly expanded under all environmental conditions. Posterior lobe feeding, then, which gives us an epidermal melanophore system which approaches the normal in melanin content, does not permit these cells to exhibit normal responses to light and heat. It merely maintains them in a refractory and contracted state, and when the feeding is stopped they exhibit the typical physiology of the albino.

The stimuli to which the two types of larvae have thus far been subjected are such as they might meet in the extremes of their normal environment. There is yet another class of stimuli which may be employed, namely, pharmacological agents, in which the larvae may be directly immersed. By this means we may be able to secure further evidence in regard to the endocrine locus responsible for the peculiar functional state of the chromatophore groups in the albino. Of the substances employed (pars intermedia emulsion, pituitrin, adrenalin, pineal gland emulsion), the first--pars intermedia emulsion ${ }^{18}$-from the profound pigmentary changes which it induces in the albino, especially merits attention. Atwell has called attention to the darkening of albinous larvae when placed in emulsions or extracts of this substance and has noted the response-one of expansion - of the deep melanophores to this treatment, a response which led him to refer the usual picture of albinism to a contraction of this melanophore group, and conversely the darkening of these treated albinous larvae to the expansion of these cells. We can fully confirm Atwell's observations as pertains both to the darkening of these larvae and the complete expansion of the corial melanophores when placed in the pars

18 'The pars intermedia substance was secured by carefully clipping off pieces of this glindular substance from the subjacent neural lobe, as described by Herring ('14) and Atwell ('18). After drying on a warm plate the powdered substance was triturated with the desired amount of tap)-water. 
intermedia solution. ${ }^{19}$ Such a darkening clearly occurs, but an attendant color change was unnoted by Atwell. These larvae not only become darker, but they almost completely lose their metallic iridescent appearance so characteristic of the picture of albinism. As has been previously stated, this metallic effect is due to the broad expansion of the xantholeucophores, an effect which is displayed in its full beauty only because of the deficiency in the epidermal melanin which characterizes albinos. As might be surmised, then, these 'interference' cells have suffered a great contraction, causing an almost entire loss of the metallic-like albinous picture. Still another pigment change is wrought by the pars intermedia solution. The epidermal melanophores undergo expansion, ultimately assuming the expanded condition typical of the normal animal under 'indifferent' environmental conditions. It is thus seen that the pars intermedia emulsion can be described as bringing about a normal physiological state in this atypical pigment system of the albino and, as will be later pointed out, aids us in determining the endocrine locus responsible for this pigmentary disturbance. ${ }^{20}$

When large albinous or normal specimens are placed in an adrenalin ${ }^{21}$ solution, serious respiratory and cardiovascular symptoms develop. The respiration becomes labored and slowed and the heart beat decreases in rate. Although more active for a few minutes, they soon become sluggish and rest in any position. Gradually the gills become flushed and it is noted that

${ }_{19}$ Two strengths of pars intermedia solutions have been used. One made by triturating $10 \mathrm{mg}$. of the dried substance in $100 \mathrm{ce}$. of water, the other by triturating $10 \mathrm{mg}$. in $300 \mathrm{cc}$. of water. Both solutions produced identical effects, but at a different rate. The larvae would later succumb when left in the stronger solution for a period of one and a half hours or longer.

${ }^{23}$ The immersion of larvae in Pituitrin (Parke, Davis \& Co.) has produced neither constant nor pronounced changes in the pigmentary system even when used in strengths sufficient to cause the serious distress or death of the animals. An emulsion of the posterior lobe (less the pars intermedia), even when used in strengths greatly in excess of that employed with the pars intermedia, appears not to evoke this reaction. Solutions of hypophysial colloid cause no pigmentary response.

${ }^{21}$ Adrenalin (Parke, Davis \& Co.) has been employed in strengths of 1 to 20,000 to 1 to 80,000 . The stronger solutions ( 1 to 20,000 and 1 to 40,000 in amounts of 10 to 40 ce. per animal) have been of more value, and attention is called only to the responses evoked by these strengths. 
the entire animal appears somewhat translucent. While evoked to an extent by the lower dilutions, these effects are much more clearly expressed with the stronger dosages. If the animals be examined with the binocular at five-minute intervals, the progressive alterations in the pigment cells can be followed. Especially uniform and particularly well pronounced is the contraction of the deep chromatophores. This contraction is the most important factor in the translucent appearance which follows the administration of adrenalin.

In adrenalin treatment the superficial melanophores are also affected, those of the albino more uniformly than those of the normal. In the albino these cells gradually expand and after an average period of forty to forty-five minutes a very changed state is evident. The picture presented is the reverse of that which obtains normally. Instead of these cells for the most part being in a contracted condition, they now show a state of expansion. Although only a part of this cell type is completely expanded, the percentage of completely expanded cells has definitely increased and all exhibit a more expanded state than before treatment. In the large normal animal the response of these cells when a considerable amount of fluid is used (40 ec. per specimen) is one of expansion. If only partly expanded, the processes soon present their maximum size; if already completely expanded, this condition persists. With a small amount of fluid (10 ce. per animal) these effects are not so pronounced and, curiously, are not infrequently reversed.

The third group of pigment cells, the xantholeucophores, also respond to adrenalin. In the albino the surface layer of these cells is the first to withdraw its processes, a response which may or may not extend to their more deeply placed brothers. Indeed, not all of these cells of the superficial stratum are affected, for here and there are interpolated areas of uncontracted cells, and a maximum contraction of all these cells has not been secured in the large albino, save with a lethal dose. In the normal, these cells react in a most varied manner, their reaction, at with the epidermal melanophores, apparently depending upon the amount of fluid used. With the larger amount there 
is usually a contraction, although sometimes preceded by a preliminary expansion. With the smaller amounts these cells usually expand, there then being presented in the more favorable cases xantholeucophores of approximately the same size, both in the albino and in the normal.

The deep melanophores of both albinous and normal larvae contracted by a solution of pineal glands (two beef glands in 150 cc. water), the same transparency being exhibited as after adrenalin. ${ }^{22}$ This contraction of the deep melanophores, which, as pointed out, can be produced by darkness as well, somewhat intensifies the albinous appearance of true albinos, but its extreme effect in no case renders normal larvae albinous in appearance. These facts are of service in the evaluation of the relative significance of the various groups of pigment cells in producing the picture of albinism.

The anatomical and physiological findings which have been detailed may now be reexamined in order that we may be able to evaluate the relative importance which the various components of the pigmentary system have in creating the picture of albinism. Any explanation of structural or functional causes for the albinous appearance must keep clearly in mind the arrangement of these pigment cell types. It will be recalled that the deepest group of pigment cells-the corial melanophoresare overlaid by double strata (in most regions of the body) of xantholeucophores, which in turn lie beneath the epidermal pigment formed by the double component of free melanin and epidermal melanophores. With this arrangement in strata it is obvious, then, that a decrease in the color depth of an overlying stratum will exaggerate the effect of the subjacent one, or conversely an increase in the color depth of a stratum will proportionately decrease the color effect of those lying beneath. The decrease in pigment which obtains in the superficial pigment layer (epidermal) of the albino then exaggerates the chromatic effect of the abnormally expanded subjacent strata of the

\footnotetext{
${ }^{22}$ With neither of these agents was the extreme transparency gained which McCord and Allen describe. Indeed, it is difficult to conceive how such an extreme effect could be produced with the very considerable amount of melanin which the epidermis of these specimens contains.
} 
xantholeucophores, whose abnormal expansion in turn masks or minimizes the effect of the underlying layer, the deep melanophores. The mere arrangement which obtains, together with the physiological and structural modifications met in the albino, tends to exaggerate the effect of the 'interference' cell layers, and to minimize the rôle of the melanin-containing cells (the cpidermal melanin being structurally deficient, the deep melanophores being masked by the overlying, broadly expanded layers of xantholeucophores), hence the color of the albino is characterized by its iridescent metallic nature. This effect is different from the transparency displayed by dark adapted normal larvae or those under pineal or adrenalin treatment, procedures which contract the deep melanophores and, since the xantholeucophores are unexpanded, enable this effect to be seen in a general lightening of tone (transluceney) of the larvae.

It is possible to still further test the validity of this reasoning by examining the results of our experiments in which larvae were submitted to various stimuli (environmental and pharmacological) which brought about changes in the components of one or more of these pigment cell layers. A pronounced darkening of the albino was caused by immersion in pars intermedia solution. This change, however, does not permit us to analyze the rôle played by the various pigment strata, since all are affected (it will be reealled that the deep and superficial melanophores expand and the xantholeucophores contract, the epidermal free pigment of necessity not being changed). Yet by applying a test by which the pigment cells, save for the xantholeucophores, undergo the same change as with pars intermedia emulsion, we can determine whether the expansion of the deep and superficial melanophores has materially contributed to this darkening and loss of the metallic tone. ${ }^{23}$ Such a test is afforded by placing albinous larvae in intense light when it is seen that they do not materially darken in color, although the deep melanophores may have been previously contracted. The translucency resulting from a maximal contraction of these cells has pre-

: The epidemal melanophores are so scanty in number and pigment content that their expansion a priori could have little effect. 
viously been noted. It thus appears evident that the rôle of the deep melanophores in the formation of this picture of albinism is of no great importance. In fact, they are so completely masked in the body region in the albino by the overlying, broadly expanded xantholeucophores that from the anatomical arrangement alone it would be apparent that in R. boylei they could play no significant rôle in the formation of this picture, and most certainly not the primary rôle as maintained by Atwell in $R$. sylvatica.

It is also possible to test the relative significance of the diminished pigment content of the epidermis in the formation of this albinous picture. Attention has been called to the partial replacement of the pigment deficiency which takes place with a posterior lobe diet, and it was seen that these larvae became distinctly darker in color than the albinos not supplied with this gland. Or again, in the skin exchanges, the normal graft, whose xantholeucophores become broadly expanded, nevertheless is decidedly darker than the albinous host. This color depth can be referred in both cases in part to the color directly contributed by this epidermal melanin and in part to the masking of the underlying xantholeucophores by this pigment. It thus seems clear that the anatomical factors chiefly involved in the picture of albinism are, first, the broad expansion of the xantholeucophores; second, the diminution in the epidermal melanin which permits full display of the refractive xantholeucophores.

The greatest interest attaches to the determination of the endocrine locus responsible for the altered structural and physiological state of the pigment cells. Attention was called to the fact that the feeding of neither anterior lobe, adrenal cortex, adrenal medulla, nor liver deepened the color of the albino. On the other hand, a diet of posterior lobe (and associated pars intermedia) materially darkened the albino-an effect immediately referable to a partial replacement of the epidermal melanin. Also the immersion of the larvae in a solution of pars intermedia alone, of all the endocrine extracts employed, produced a normal physiological condition of the chromatophore system. It would 
thus appear from these responses that the extracts or diets of the intermediate and posterior lobes of the pituitary were intimately concerned in this pigmentary fault. Corroborative evidence is supplied by a study of the structural malformations occurring in the endocrine glands of the albinous and the partially hypophysectomized larvae. For, as will be detailed in a subsequent section (4), the neural hypophysis, thyroid, epithelial bodies, adrenal cortex, and adrenal medulla suffer definite and often profound structural and size alterations in the albino. In the partially hypophysectomized tadpole, however, whose pigment system may suffer a profound disturbance (indeed, the picture of albinism approaching that of the true albino), none of these internal secretory organs save the posterior lobe and the associated pars intermedia exhibit significant structural defects. ${ }^{24}$ The evidence thus points to a deficiency in the secretion formed by either the posterior or intermediate lobes of the pituitary or by the 'interaction' of these two intimately associated components of the pituitary as being responsible for the pigmentary upset in the larvae. ${ }^{25}$

${ }^{24}$ Further evidence freeing the thyroid from responsibility for this pigmentary disturbance comes from the thyroidectomized specimens whose pigmentary system is not at fault.

${ }_{25}^{5}$ Indeed, the pigmentary system in the frog, at least, appears to be very sensitive (1) hypophysial disturbance. This is shown in a striking way by one specimen of a considerable number (seventy) of tadpoles which suffered the extirpation of their pineal glands in an early larval stage. In this operation the aqueduct of Sylvius of one specimen was inadvertently injured, an injury leading to its complete oeclusion. This apparently induced an internal hydrocephalus of the III and lateral ventricles with the consequent inevitable pressure upon the pituitary, sections revealing at flattened gland slightly reduced in size. The specimen exhibited unmistakable albinism, a condition unguestionably referable to the compression of the pituitary gland, since it is certain that this pigmentary disturbance was not due to the loss of the pineal body, for, ats has been shown by Laurens ('13), the loss of this gland produces no fault in the pigmentary system, ample confirmation of which has been made in this laboratory. 


\section{GROWTH DISTURBANCES}

Little doubt can be entertained but that the pituitary gland plays a significant rôle in the regulation of growth. Observations on clinical material which have been elucidated and extended by experimental operative work, more particularly by that of Paulesco and Cushing, have shown rather clearly that a hypersecretion of this gland results in an overgrowth of the skeletal system (giantism and acromegaly), the opposite picture of a pituitary deficiency being seen in dystrophea adiposogenitalis.

Clear as such findings appear to be, it seems the more enigmatical that the administration of this gland has failed to elicit a definite growth accelerative response, indeed the response most uniformly evoked being one of retardation. The evidence so far presented is in many cases at least of such an equivocal and uncertain nature as to come well within the limits of experimental error and to even be subjected to an opposite interpretation. This can be said not only of the feeding experiments of different investigators, but of single investigators as well, and only to the latter do we need to address our attention for a moment. Aldrich ('12), from the administration of anterior lobe to pups, concluded that growth was not stimulated nor retarded, but later concluded from work on white rats that growth retardation occurred (Aldrich, '12). Robertson, in the most elaborate work which has yet appeared upon this subject and who has not only used large numbers of animals of the same species (white mice), but who has also applied the valuable adjuvant of refined statistical methods to his data, at first concluded (Robertson, '16), "The administration of $0.125 \mathrm{gms}$. per day per animal of fresh anterior lobe pituitary tissue to mice, beginning at 4 weeks after birth (conclusion of the second growth cycle), leads to retardation of growth during the earlier portion of the third growth cycle, between the 6th and 20 th weeks. In the latter part of the third growth cycle, however, from the 20 th to the 60 th weeks after birth, the growth of the pituitary-fed animals is markedly accelerated, so that they 
not only catch up to the normals, but actually, at about one year of age, come to surpass the normals in weight." Later he says (Robertson, '19): "The computation of the deviations in terms of probable error units shows that the effect of the dosage of pituitary tissue administered upon the growth of the male animals was of uncertain significance, since the observed deviations were only from one to two times the probable error. That the deviations from the normal nevertheless were real and due to the administration of the pituitary tissue is evidenced by the much greater effect of the same character upon the female, consisting of a retardation during the earlier stages of growth. In both males and females the deviations from the normal after the 30 th week are of indeterminate significance; that is, the growth curves of the normal and of the pituitary-fed animals are, so far as our estimates reveal, identical after seven months of age. Hence the preliminary retardation of growth has clearly, prior to the 30th week, been succeeded by acceleration." That a transient growth retardation in the young animal results from pituitary administration seems evident not only from the work of Robertson ('16, '19), but from that of Cerletti ('07), Sandri ('09), Aldrich ('12), Wulzen ('14). But that any subsequent acceleration which may be exhibited is due to anterior lobe administration is not clear. Indeed, it seems not improbable that such an acceleration is compensatory, such as Osborne and Mendel have shown to oceur with an adequate diet after an animal has been stunted by undernutrition. This seems the more probable in view of Robertson's feeding experiments with Tethelin in which he was forced to abandon the view which he had previously strongly urged - that his alcoholic anterior lobe extract (Tethelin) supplied a growth-accelerating principle. These animals, indeed, exhibited a more pronounced secondary acceleration when the Tethelin diet was withdrawn than when it was continued.

The principle has been formulated by Halsted that a 'physiological deficit' is essential for successful organ transplantation. From analogy it seems not improbable that if a physiological deficit could be created in experimental animals, they would 
be able to 'utilize' the growth-maintaining ('accelerating') principle of the administered anterior-lobe substance as they could not do were this deficit not existent. If, then, the animals suffering from such a deficit exhibited a pronounced retardation in growth and if in other animals this retardation could be prevented by pituitary administration, we would obtain a combination of conditions giving a pronounced effect from such a dietary régime. Such indeed is the case in the hypophysectomized (albinous) frog tadpole, as has previously been pointed out by the author (Smith, '18). The growth response to anterior lobe administration in such animals, as compared to the normal, is greatly magnified, since, 1) the hypophysectomized frog tadpole grows at a slower rate than the normal (Smith, Allen) and never attains, or attains only after an extended period, the size of the normal tadpole (Smith) and, 2) the operated tadpole supplied with bovine anterior lobe not only exhibits a normal growth rate, but, due to the persistence of the larval condition and the consequent extension of the larval growth span, ultimately attains a size notably in excess of the normal. By this sensitiveness of the albinous frog tadpole a clear response to the growth-maintaining principle of the pituitary has been secured. ${ }^{26}$

The ease of securing such operated material, its prolonged survival after buccal hypophysectomy, and the magnified response of the albinous frog tadpole to anterior-lobe administrations all combine to make this material of singular value in testing various hypophysial extracts and residues for the presence or absence of the growth-maintaining ('accelerating') principle. Such material alone affords an ideal way to analyze physiologically the various hypophysial substances which have been administered in order to determine the rôle of this gland

${ }^{26}$ It will be quite evident why the term growth-'maintaining' substance is used in comparing the growth rate of the albinous larvae with the growth rate of the normal. The growth rate of the albino is not accelerated by the administration of anterior lobe as compared to the normal; their growth rate is maintained. Such a diet, however, clearly accelerates the growth of the albinous tadpole as compared to their albinous fellows on liver diet. 
in growth. ${ }^{27}$ It is obvious that a determination of the presence or absence of a growth-'accelerating' principle in an extract or fraction of this gland can hardly be made with the normal animal when the administration of the fresh gland does not call forth such a response.

The growth rate of the albino; the effect of the administration of various hypophysial substances upon this growth rate

In order to discuss the deviations from normality of the growth rate of the hypophysectomized tadpole and the effect of the administration of fresh bovine anterior lobe and its extractives and residues upon these deviations, it will first be necessary to examine the growth rate of the normal unoperated tadpole. The growth curve of a normal tadpole with a liver-lettuce diet consists of three phases, the first two indistinctly separable, the third more pronounced. An early transient and not clearly marked period of slow growth, which perhaps should receive even less emphasis than has been accorded it (Smith, '18), shades insensibly into a protracted second phase of rapid growth during which the tadpole attains nearly its maximum size, and which is in turn terminated rather abruptly by the advent of metamorphosis (fig. 1). The administration of bovine anterior lobe neither alters the nature of this curve nor produces quantitative results of unquestionable significance, although there appears to result in most cases from this diet a small increment in size and a somewhat earlier completion of metamorphosis.

The growth curve of albinous frog larvae with a liver-lettuce diet differs in character and in magnitude from that of the normals (fig. 1). I have described these changes previously (Smith, '18), and later work has amply confirmed them. A retardation in growth following the appearance of albinism is unquestioned and becomes progressively greater until approximately a $30-$ to

\footnotetext{
${ }_{2 i}$ Caselli ('00), whole-gland gylycerin extracts; Cerletti ('01), a centrifugalized arqueous-glyeerin emulsion; Aldrich ('12), fresh desiccated non-defatted anteriorInbe substance; Aldrich ('12), fresh defatted anterior-lobe substance; Robertson ('16), fresh anterior lobe and his alcoholic extract, Tethelin, of the desiccated anterior lobe.
} 
THE PARS BUCCALIS OF THE HYPOPHYSIS

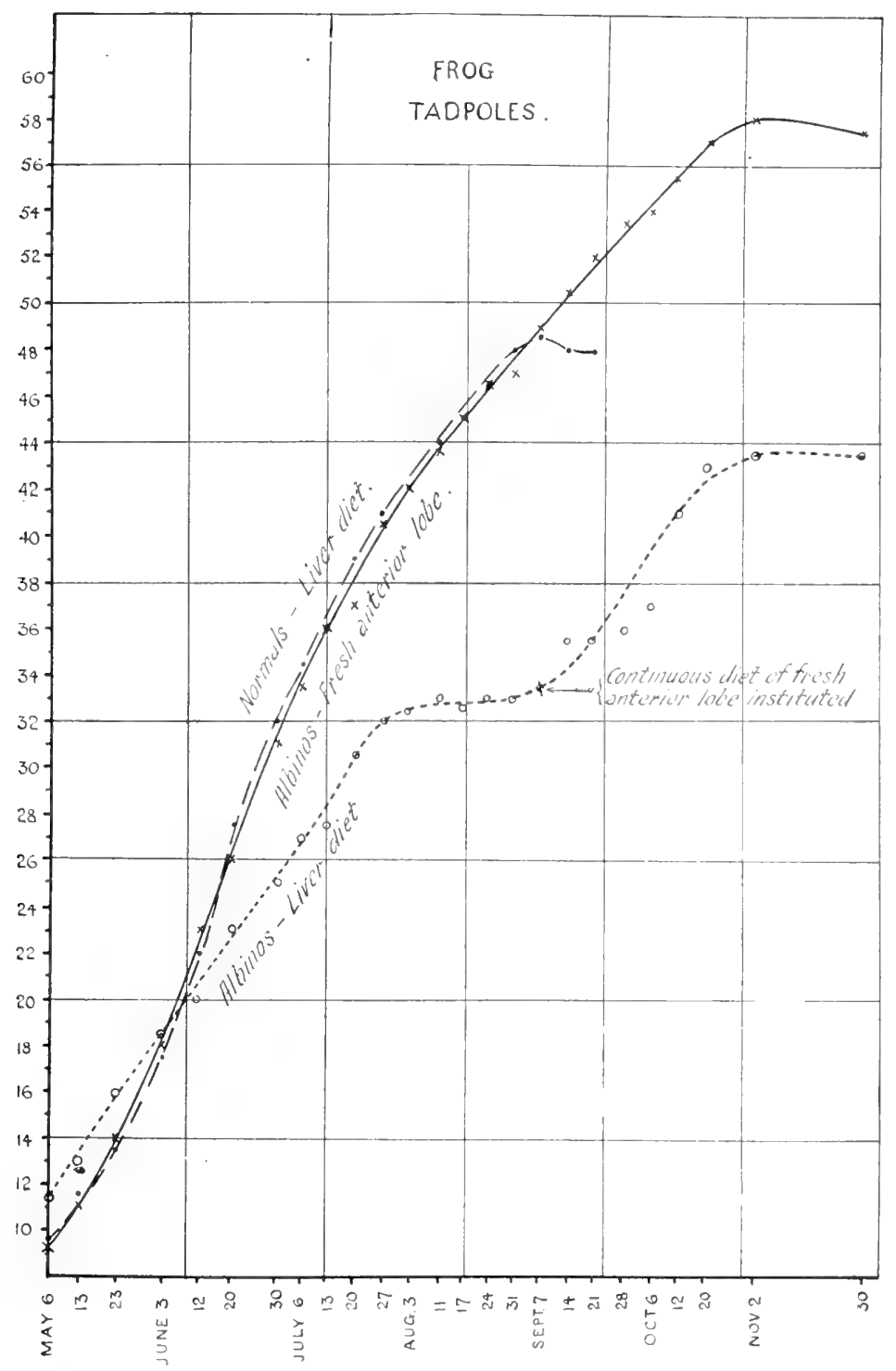

Fig. 1 Growth curves of normal frog larvae supplied with a liver diet, hypophysectomized frog larvae supplied with liver and with fresh anterior-lobe substance. The ordinates represent the total length of the larvae expressed in millimeters. 
32-1mm. stage (midlarval period) is reached. At this stage the retardation beemes extremely pronounced and an abrupt change in the direction of the growth curve ensues. So definite and so characteristic is this point that it appears to indicate a significant period in the development of these albinous larvae and hereafter will be designated as the 'critical point.' Both in time and stage of development this point has been coincident in the curves plotted from data secured in 1918 and 1919. From this 'critical point' the divergence between the curves of the normal and albinous larvae increases for a time, the curves later approaching each other again due to the onset of metamorphosis in the former and the continued growth of the latter. ${ }^{28}$

It is now possible to inquire whether the administration of a 'substitution' or 'replacement' diet of fresh bovine anterior lobe will effect a normal rate of growth in these animals suffering from hypophysial deprivation. This can be answered for the frog tadpole in the affirmative. The albinous frog tadpoles supplied throughout their growing period with a continuous diet of fresh anterior-lobe substance exhibit no significant growth deviation from the liver-fed normals (fig. 1, table 2). Since metamorphosis does not supervene, however, their growth extends beyond the normal larval period, and they consequently attain a size notably in excess of their unoperated normal fellows. ${ }^{29}$ The alimentary régime of fresh bovine anterior lobe has then clearly supplied the morphogenic principle lost by buccal hypophysectomy.

It is conceivable that pituitary substance greatly in excess of the amount actually requisite to replace the growth principle

${ }^{28}$ It will be noted from the tables that after September 7th a continuous diet of fresh bovine anterior lobe was supplied the albinos whose curve of growth is here plotted. This apparently eaused an abrupt rise in their growth curve. The growth curves of a group of albinos supplied throughout their life-span with a liver diet are shown on page 18 (Smith, '18).

${ }_{22}$ The final and rather abrupt termination in growth exhibited by the albinous squecimens might conceivably be due to one of at least two factors: 1) a self-limiting growth factor inherent in every organism; or, 2) a seasonal growth rhythm. That this is not attributable to the latter is shown by a group of albinous frog larvae which survived for seventeen months. No resumption of growth occurred in the second season; rather, they beeame progressively more lethargic, the anorexia increased, and death finally supervened. 
THE PARS BUCCALIS OF THE HYPOPHYSIS

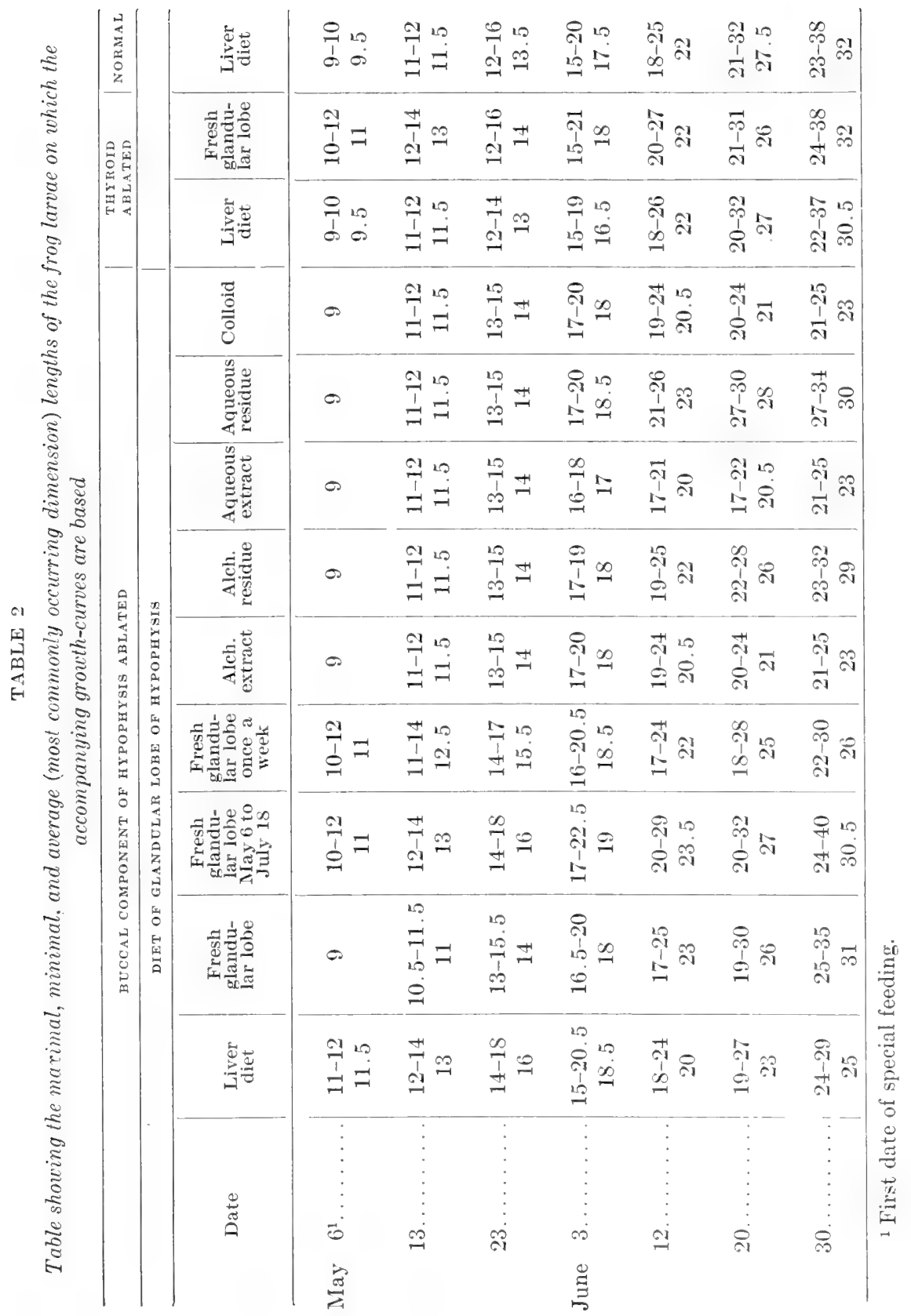




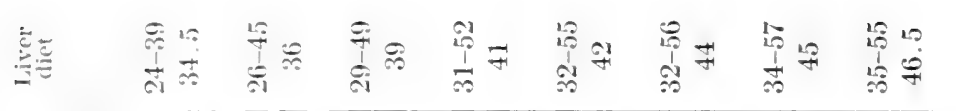

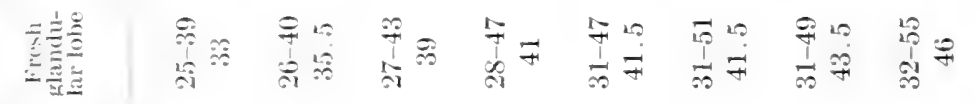

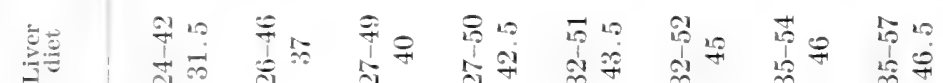

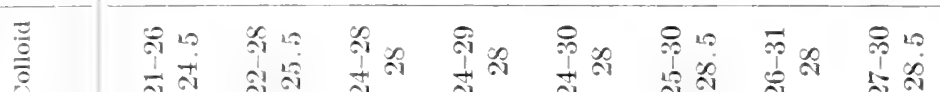

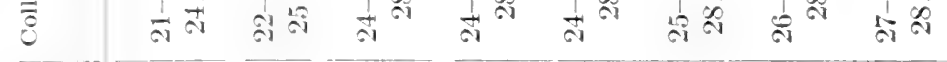

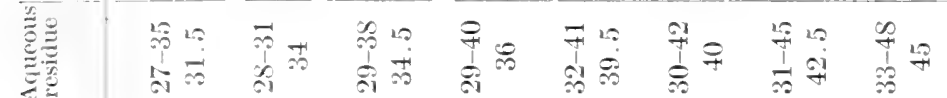

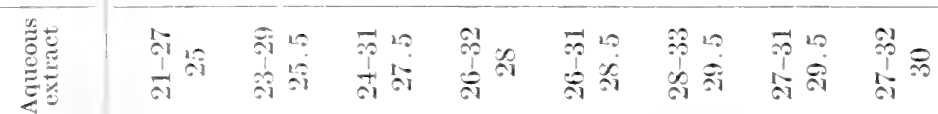

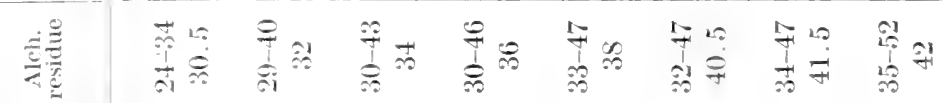

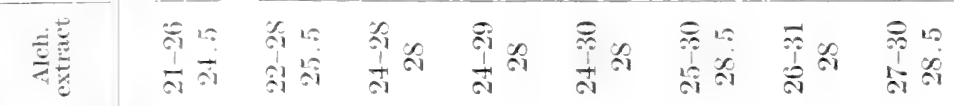

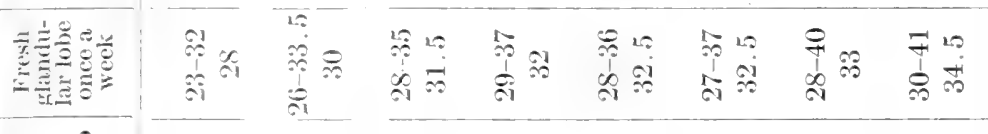

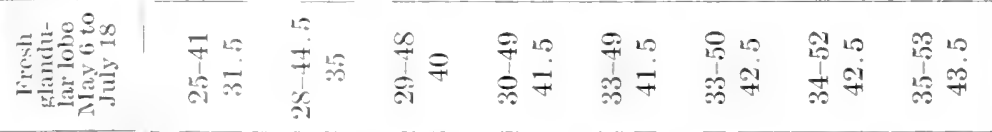

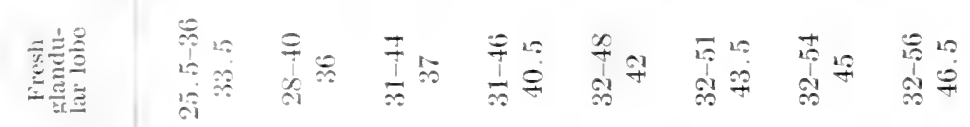

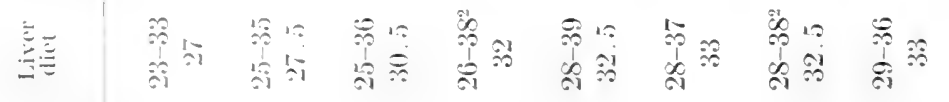

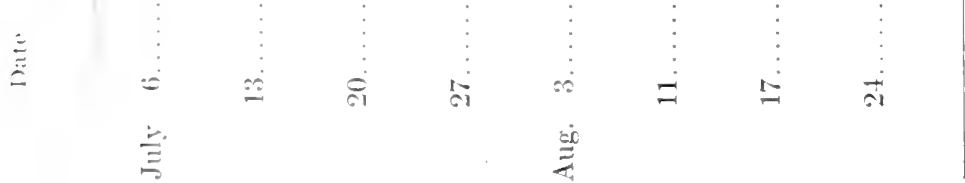


THE PARS BUCCALIS OF THE HYPOPHYSIS

49

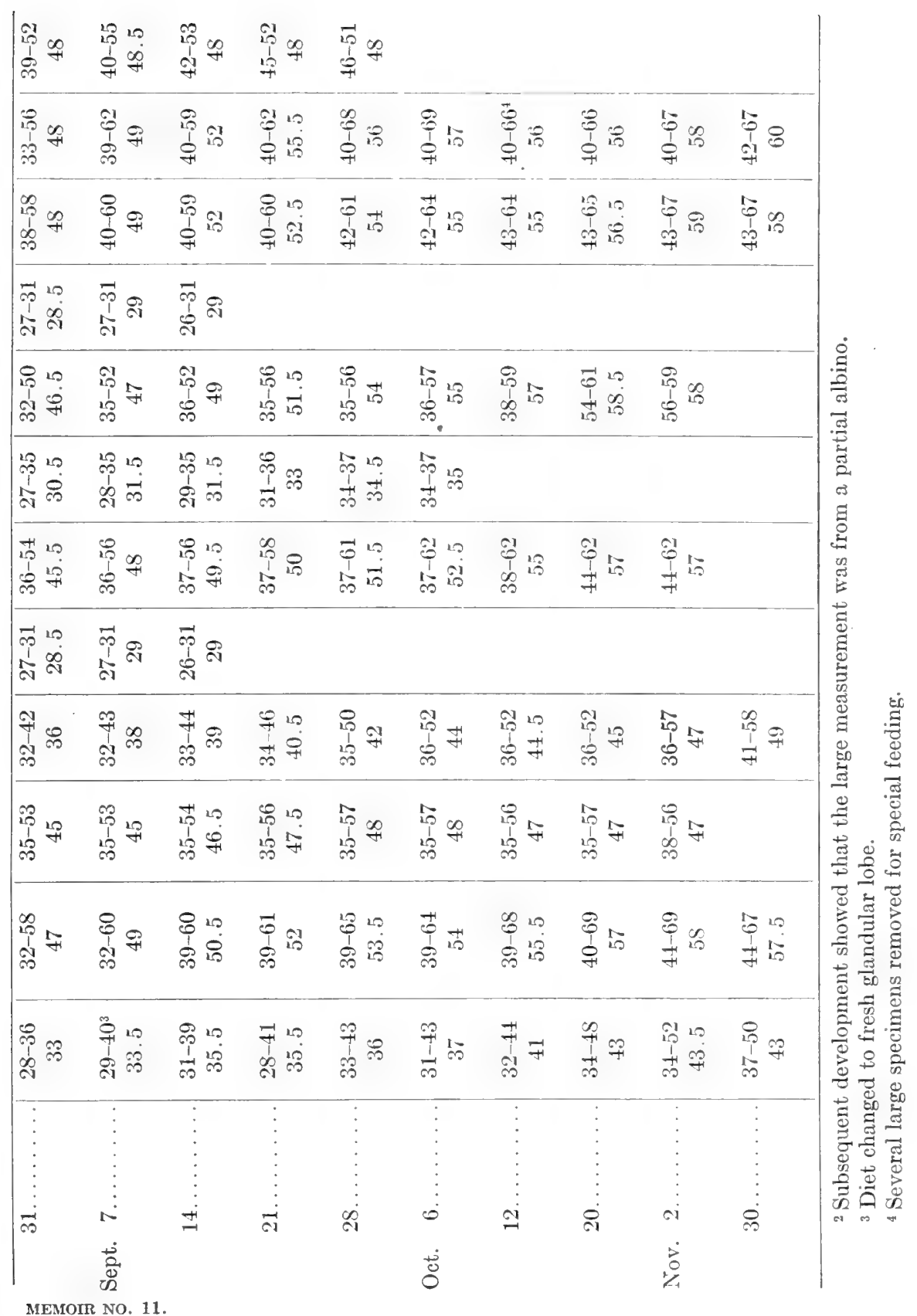


lost hy hypophysectomy has been supplied these albinous larvae exhibiting a normal growth rate, since it will be noted that this anterior-lobe substance was fed daily and formed their entire food supply aside from a small component of lettuce. This seems the more probable if the conception usually held in regard to 'hormonal' substances be correct, namely, that minute amounts are effective. But that this substance must be supplied continuously is clearly shown by three groups of albinos: 1) a group receiving anterior-lobe substance once each week, liver being fed on the other days; 2 ) a group receiving anterior lobe until an average length of $36 \mathrm{~mm}$. (on July 18th) had been attained, a liver diet then being instituted; 3) a group (the converse of group 2) reared on a liver diet until they had attained an average length of $33 \mathrm{~mm}$. (on September $7 \mathrm{th}$ ), the liver diet then being replaced by anterior lobe.

The growth curve of the first group, those receiving anterior lobe once a week, although considerably modified, resembles that of the liver- rather than that of the hypophysis-fed group (fig. 2). Though the incidence of the early retardation is slightly deferred, nevertheless the 'critical point' appears in the usual position, though in a less pronounced manner. After a brief pcriod of depression, the curve rises in a regular manner until the level of the normal is attained. Their curve thus resembles that of the liver-fed albinos, and the ultimate size attained by these specimens is intermediate between that of the anteriorlobe- and that of liver-fed specimens.

The second group, those receiving anterior lobe until July 18th, grew at a normal rate up to and for approximately two and one-half weeks past the time when the liver régime was instituted (fig. 2). A definite growth retardation then appeared, the specimens eventually attaining the size of their unoperated companions, but failing by some $10 \mathrm{~mm}$. to reach the size of their operated mates supplied throughout their growing period with glandular hypophysis.

The specimens of the third group, those supplied with liver until they had attained a size of $33 \mathrm{~mm}$., had suffered the usual carly growth retardation and the pronounced midlarval slowing 


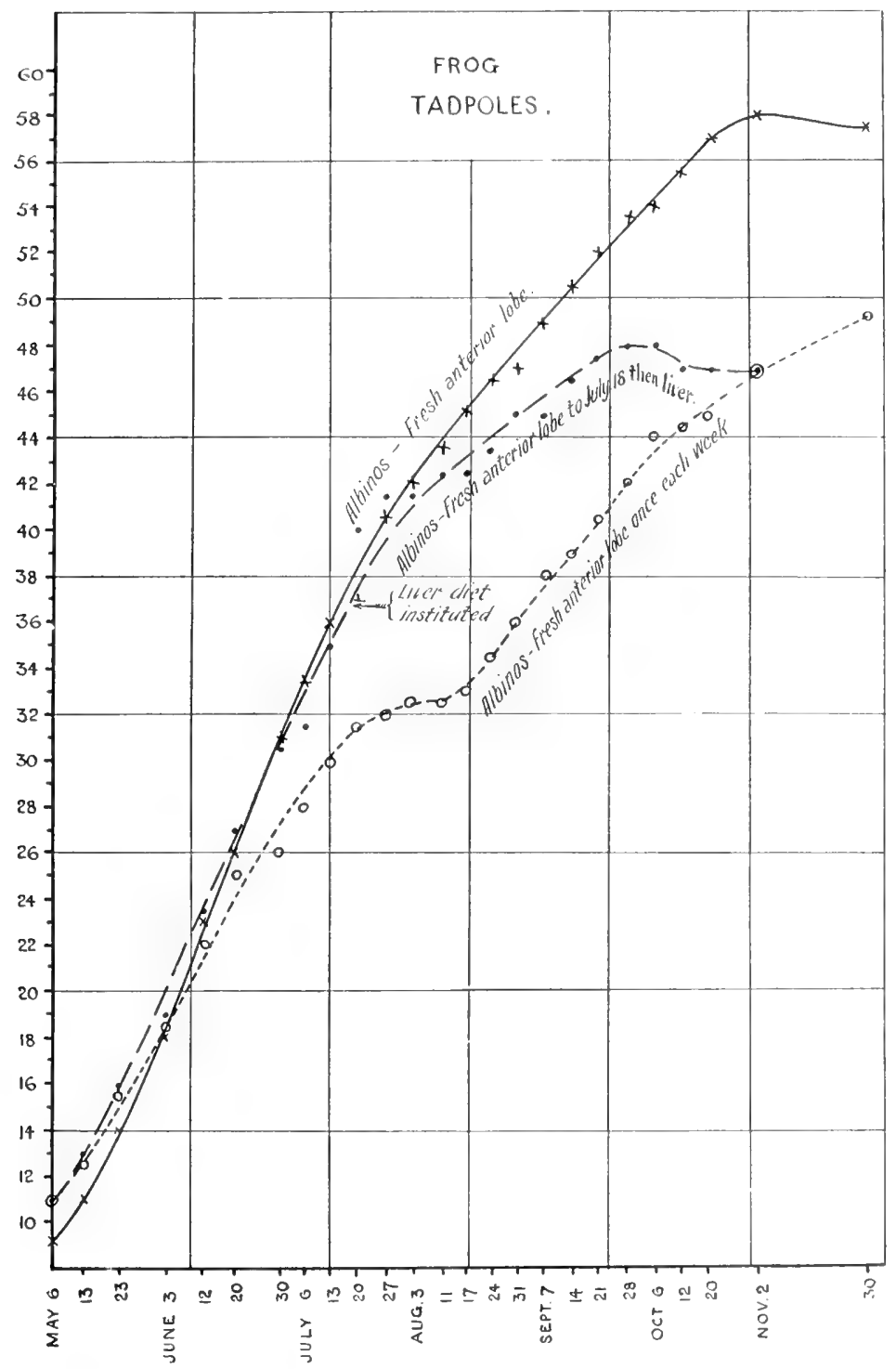

Fig. 2 Growth curves of hypophysectomized frog larvae supplied with a continuous diet of fresh anterior-lobe substance, anterior lobe once a week and anterior lobe from May 6th to July 18th, then liver. The ordinates represent the total length of the larvae expressed in millimeters. 
invariahly exhibited by albinos supplied with this diet. Following the substitution of a hypophysial for a liver diet, a normal growth rate is exhibited for a time, the albinos, however, not attaining the large size induced by continuous anterior-lobe feeding (fig. 1).

It seems clear from these three groups that neither an interrupted diet of anterior-lobe substance nor a full diet of this substance during merely the early or the late portions of the growing period will bring about a normal growth of the albinous larvae. It is indeed remarkable that albinous larvae, growing at a normal rate in response to anterior-lobe administration, will exhibit a growth retardation so quickly on the withdrawal of this 'substitution' diet.

It may then be regarded as demonstrated that the retardation in growth, resulting from the early removal of the epithelial hypophysis, can be ameliorated by a continuous diet of bovine anterior lobe, the growth curves of the albinous larvae thus treated showing no deviation from normality save by its continuance beyond the normal growing period. It will likewise be granted by the reader that such material is of peculiar value for determining the presence of the growth-maintaining principle in any hypophysial extractire or its residue. The experimental utilization of this material should show us whether the extraction of the fresh anterior lobe with boiling alcohol or boiling water removes or destroys this growth-maintaining principle-a test which can be provided with a double check, since both the extract and its residue can be fed to similar groups of albinos. To the group of four substances (aqueous extract and its residue, alcoholic extract and its residue) which were submitted to this test was added the hypophysial colloid occurring in the intraglandular (vestigial cleft) of this gland. ${ }^{30}$

\footnotetext{
${ }^{30}$ In the preparation of the aqueous extract and its residue, the ground fresh anterior-lobe substance was extracted in a modified Bailey-Walker apparatus (Robertson) over boiling aq. dest. for forty-eight hours, five bovine anterior lobes being placed in each alundum thimble. After this prolonged extraction the substance was dried, powdered, and placed in vials tightly corked. Each group of specimens (20) to 24) received the dried residue from one and a half glands at a feeding. The clear, yellowish extract on evaporation yielded a dark, readily soluble amorphous
} 
Obviously, since the aqueous and alcoholic extracts and the colloid were of slight or no nutritive value, additional food substance had to be furnished, but such food substances were only supplied after obtaining a maximum intake of the special glandular substance. After turning off the flowing water, the special substance was fed, one half-hour later the nutritional substances, liver and lettuce, being supplied. Twenty-four hours later, after removing all food particles, the process was repeated.

In the accompanying table (table 3 ) is shown the number of frog larvae at the commencement of the special feeding and at three subsequent periods. Although the number is relatively small, yet they were average-sized, carefully selected, healthy tadpoles free from injury or malformation. Work with a larger number was precluded, due to the difficulty of securing a sufficient amount of the special substances, 90 to 100 bovine hypophyses being used daily with even this number of specimens.

substance giving a lipoid-like odor on burning. The extract from five glands was supplied each group of tadpoles (20 to 24 ) at a feeding. The feeding was done with sufficient rapidity to insure against an extensive solution of the solid substance, and from the rapidly initiated movements of the tadpoles it was certain that they were feeding directly upon this substance.

The alcoholic extract (Tethelin) was supplied by H. K. Mulford Company. In the feeding of this substance even greater care was exercised than with the aqueous extract, to guard against solution. After a period of a few seconds subsequent to the breaking of the vacuum-sealed tube, the tadpoles would be feeding upon the substance. Fifty milligrams (the extract from five glands) was given each group at feeding.

In the preparation of the alcoholic residue the method elaborated by Robertson for the extraction of Tethelin was slightly modified. Dehydration was carried out with 95 per cent alcohol instead of anhydrous sodium and calcium sulphates, since the addition of the salts would render the residue useless. Following dehydration, the tissue was thoroughly dried over an electric stove, then extracted in a BaileyWalker apparatus with boiling absolute alcohol for forty-eight hours. The residue, freed from alcohol, and preserved in tightly corked vials, was supplied in amounts equal to one and a half of the fresh glands at a feeding.

The colloid was secured from the vestigial eleft, between the glandular and intermediate lobes. The amount obtained from the forty-five glands and administered to the twelve to fifteen tadpoles at each feeding varied considerably, but averaged 0.5 gram. Occasional very large pieces $(0.675 \mathrm{gram})$ were found, many other glands revealing none. Usually it occurred as a firm, amorphous mass, molded by the shape of the cleft, now and then, however, gels of differing viscosity or even an aqueous-like substance was obtained. Before feeding, the amorphous masses were crushed and mixed with the more fluid portions. 


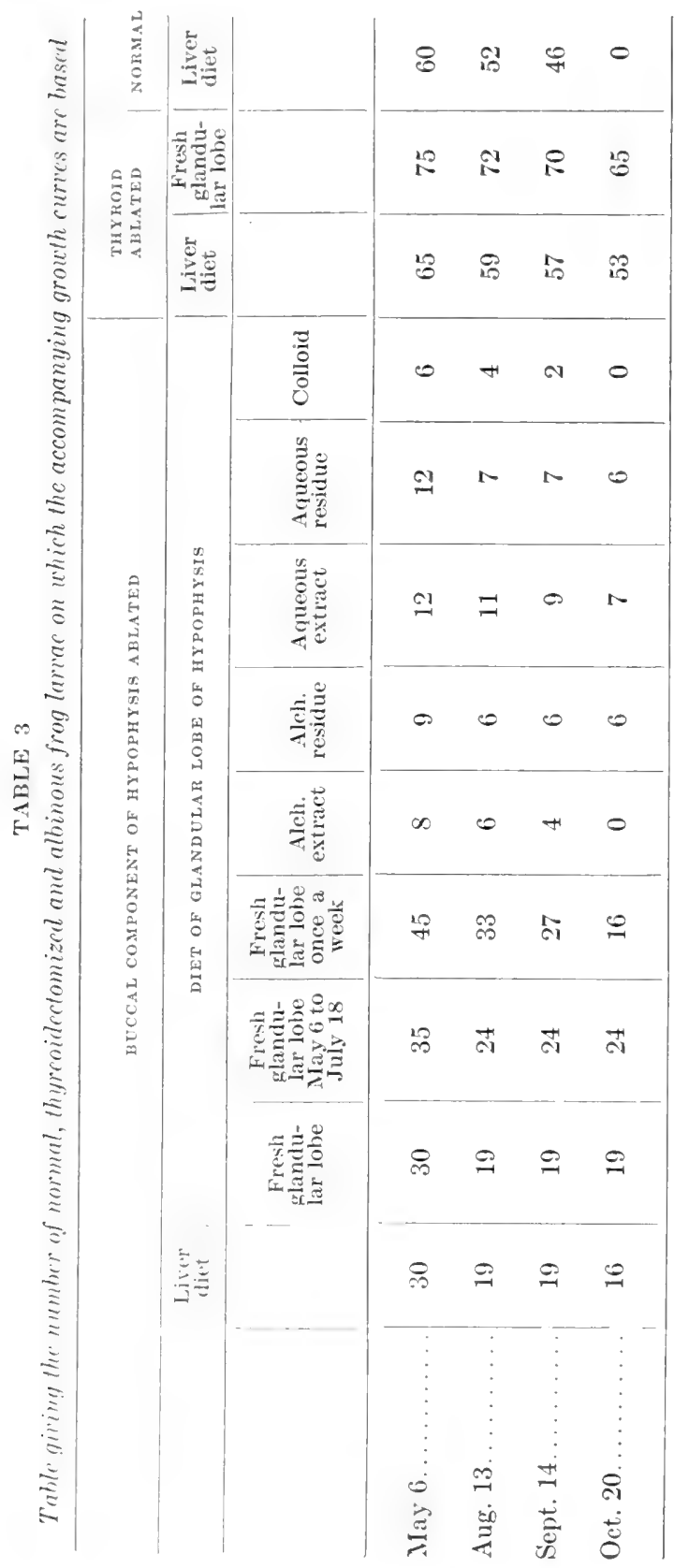


Further, it was believed that if this number of animals should show an unequivocal response to hypophysial administration, it would furnish convincing evidence of either the presence or the absence of the growth-maintaining principle in these special substances-a belief which we feel has been amply sustained.

The growth curves of the albinous frog tadpoles supplied with either alcoholic or aqueous residues show the same maintenance of growth as is exhibited by their fellows fed with the fresh anterior lobe (figs. 3, 4). No 'critical point' appears; the three curves are coincident.

This is not the case with frog albinos receiving aqueous extract, Tethelin, or colloid (figs. 3, 4, 5). Their curves are quite similar to that of the liver-fed albinous larvae. The same early retardation is noted, the 'critical point' is well marked, but appears at a somewhat earlier period (twelve days) and at a somewhat smaller average stage $(6 \mathrm{~mm}$.) than their liver-fed companions. Following the critical point, some divergence appears in the three curves. The specimens supplied with aqueous extract exhibit a slight secondary acceleration in growth, but they do not attain quite the average length of their liver-fed mates. The 'Tethelin' group does not, exhibit any secondary acceleration subsequent to the 'critical point,' while the colloid group exhibits an even greater retardation than its fellows supplied with Tethelin.

In order to further test the growth effects of hypophysectomy and its response to an anterior-lobe diet, a series of experiments similar in every way to those just reported upon were carried out with toad larvae. These larvae respond in general in the same way as the similarly treated frog tadpoles. The early retardation, the usual midlarval slowing ('critical point'), followed by slow growth, appears as in the frog tadpole (fig. 6). In this, my observations are somewhat at variance with those of Allen, who reports no retardation in the velocity of growth in hypophysectomized toads. Fuller reports may explain this essential difference in our results. I wish to emphasize, however, that the early retardation, the 'critical point,' and the later period of slow growth are not so distinctly shown in the 


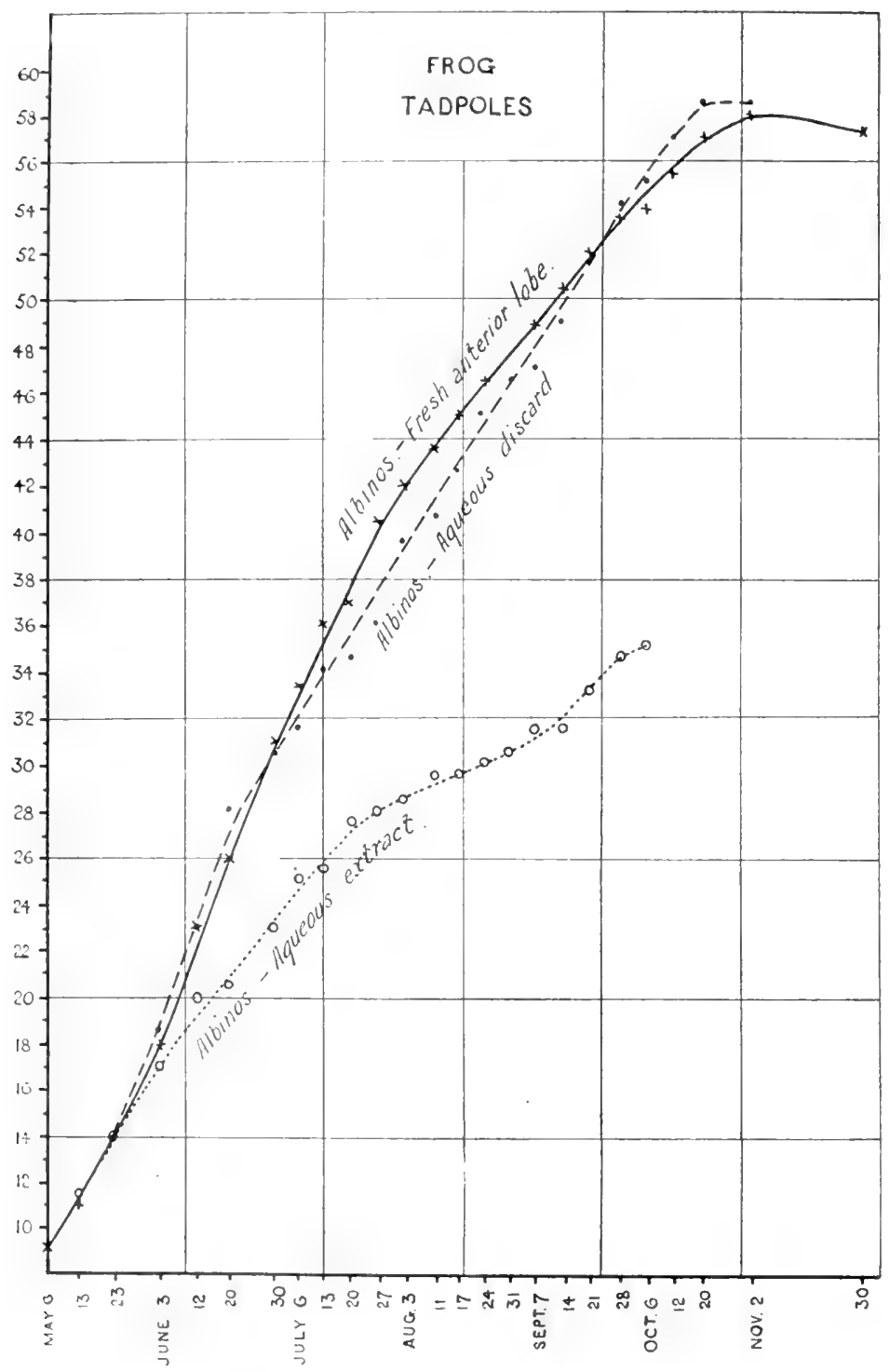

Fig. 3 Growth curves of hypophysectomized frog larvac supplied with fresh anterior-lobe substance, with aqueous extract, and with aqueous residue of the anterior lobe. The ordinates represent the total length of the larvae expressed in millimeters. 


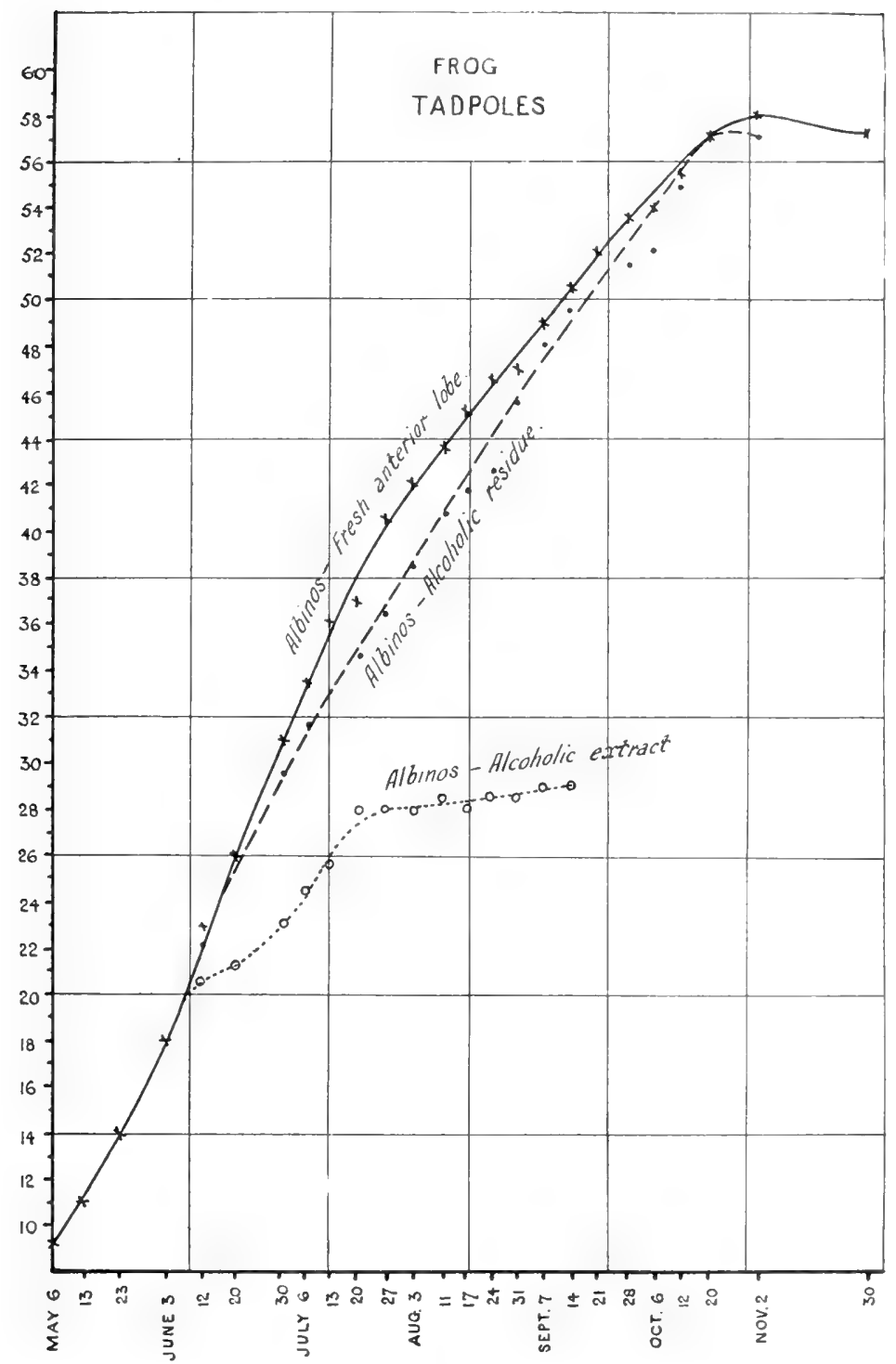

Fig. 4. Growth curves of hypophysectomized frog larvae supplied with fresh anterior-lobe substance, with alcoholic extract and with alcoholic residue of the anterior lobe. The ordinates represent the total length of the larvae expressed in millimeters. 


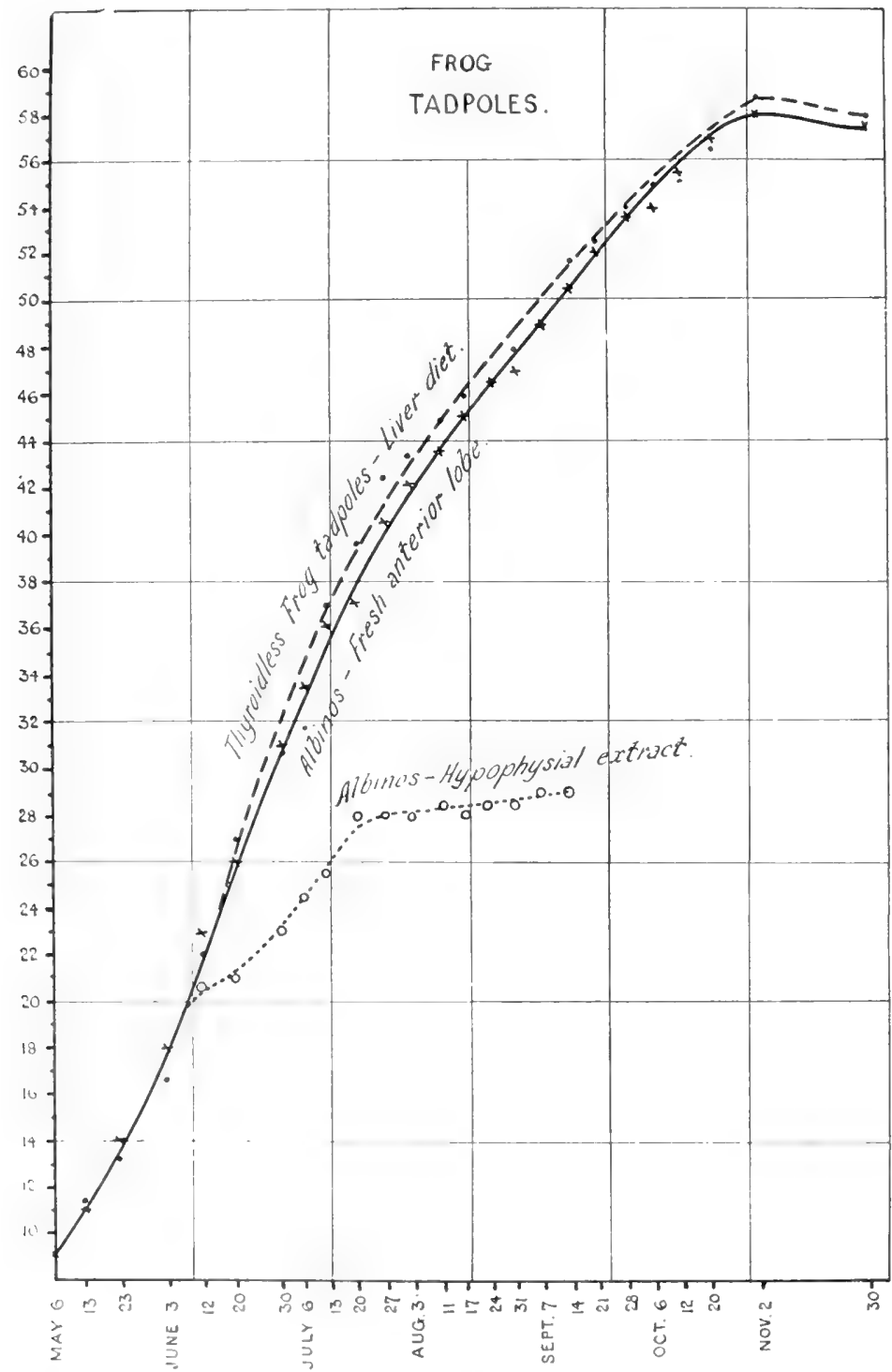

Fig. 5 Growth eurves of thyroidectomized frog larvae supplied with liver diet, hypophysectomized frog larvae supplied with fresh anterior-lobe substance, and with hypophysial colloid. The ordinates represent the total length of the larvae cxpresserd in millimeters. 


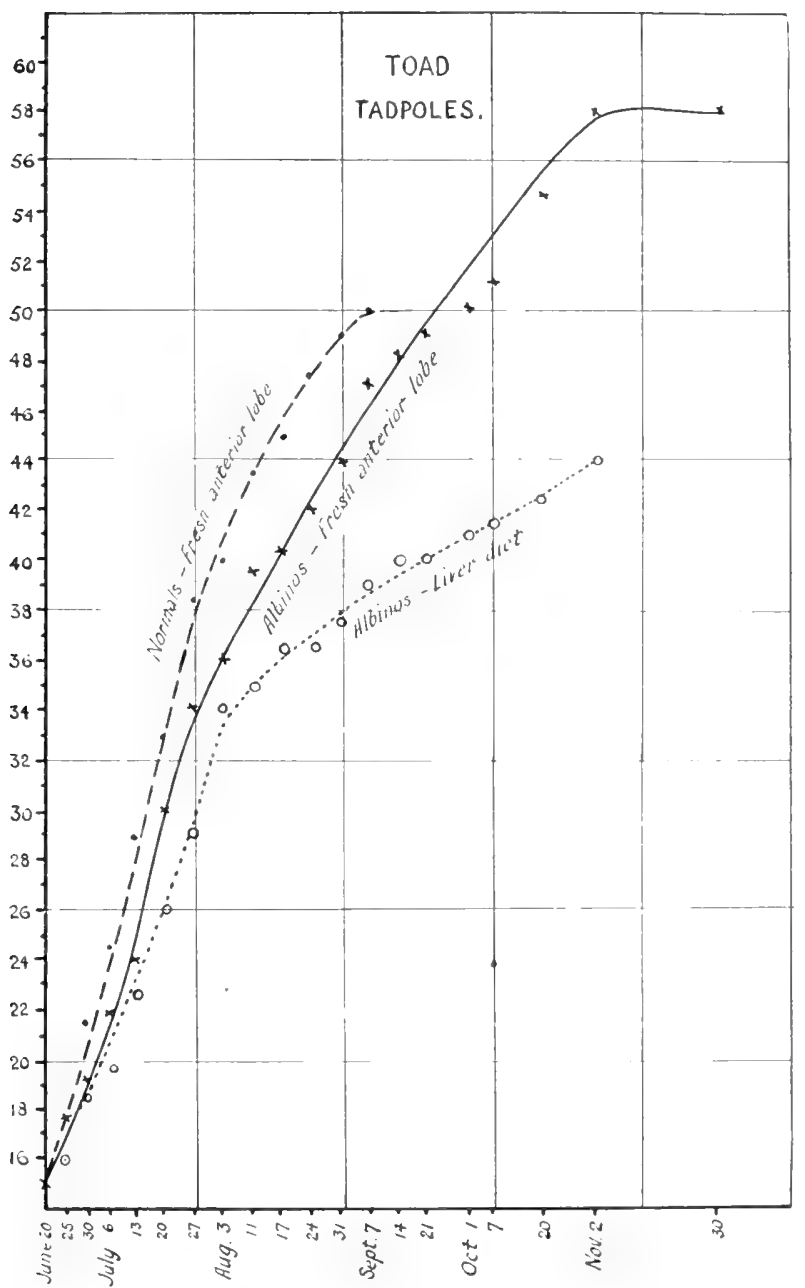

Fig. 6 Growth curves of normal toad larvae supplied with fresh anterior-lobe substance, hypophysectomized toad larvae supplied with fresh anterior-lobe substance and with liver. The ordinates represent the total length of the larvae expressed in millimeters. 
toad as in the albinous frog larvae. This is also true of their response to a 'substitution' diet of anterior-lobe substance. The growth rate of those toad albinos supplied with an hypophysial diet does not quite equal that of their normal brothers. ${ }^{31}$ Neither has the administration of hypophysial extracts, residues, and colloid given as clear results as in the frog tadpole (figs. 7 , 8, 9). However, an unmistakable growth retardation is shown by the albinous toad larvae supplied with the extracts and colloid, and the administration of the residues has caused a distinct acceleration in growth rate as compared to their liverfed albinous mates. Table 4 gives the measurements upon which the growth curves of the toad tadpole are based, and table 5, the number of specimens used in the study.

From a survey of these groups receiving the various hypophysial substances and liver it is evident that they are separable, whether frog or toad larvae be used, into two distinct categories, both by the size attained and by the nature of their growth curves. On the one hand is the group formed by those larvae supplied with either the alcoholic or aqueous residues; their growth curves are identical with that of the fresh anteriorlobe-fed group; on the other hand is the group formed by the larvae receiving Tethelin, aqueous extract and colloid; these exhibit some variation in size, but their curves are similar in nature to that of the liver-fed albinos.

To what factor or factors is due, 1) the normal growth rate of the albinous larvae supplied with fresh anterior lobe and the hypophysial residues, and, 2) the retardation of specimens fed with liver, hypophysial extractives, and colloid? The normality of the growth rate exhibited by the specimens of the first division might conceivably be due to the superior nutritive value of the anterior lobe rather than to a morphogenic agent. If this was the responsible factor, however, we should expect as great a deviation in both the magnitude and the nature of the growth curves of normal tadpoles fed in this way. No such

${ }^{31}$ It is to be noted, however, that the normal specimens received a diet of fresh anterior lobe, not of liver. A slight acceleration in the normal produced by this diet may account for the divergence in the two curves. 


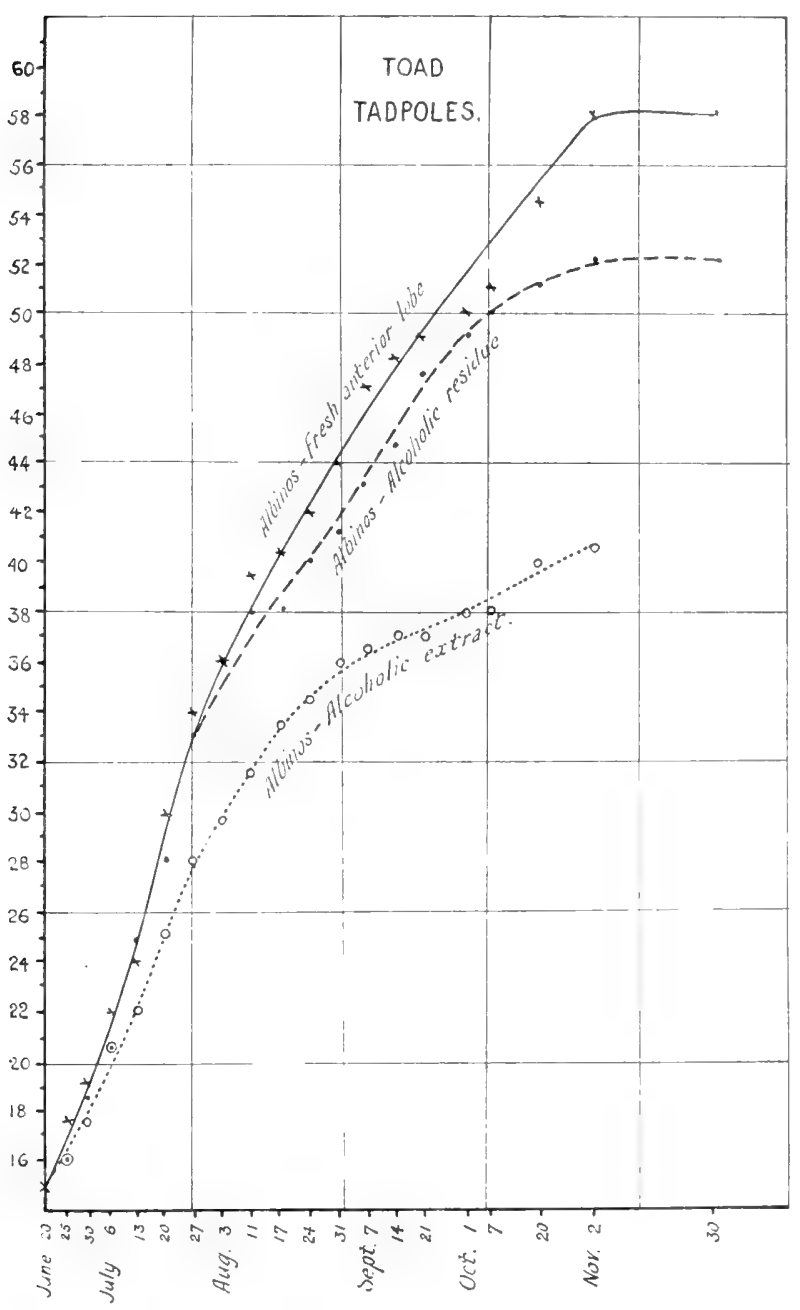

Fig. 7 Growth curves of hypophysectomized toad larvae supplied with fresh anterior-lobe substance, with alcoholic extract, and with alcoholic residue of the anterior lobe. The ordinates represent the total length of the larvae expressed in millimeters. 


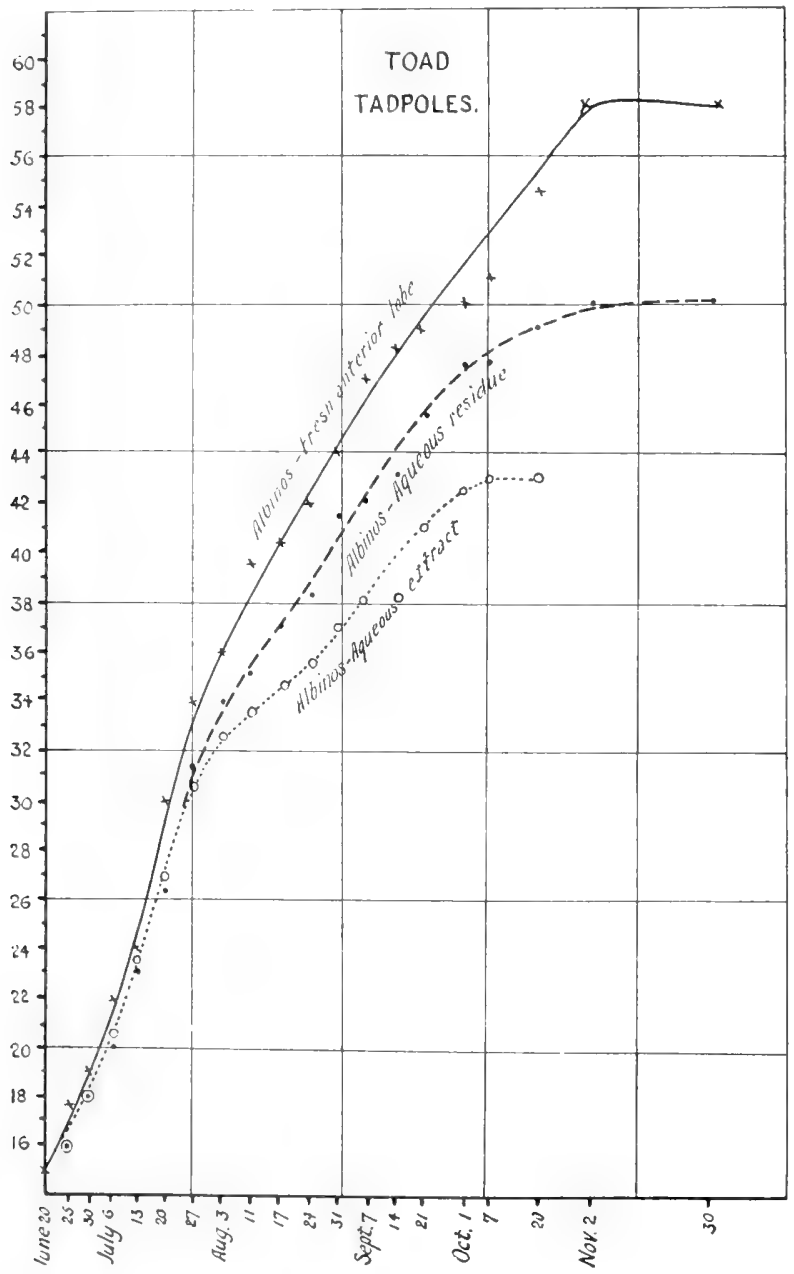

liig. 8 Growth eurves of hypophysectomized toad larvae supplied with fresh anterior-lobe substance, with aqueous extract, and aqueous residue of the anterior lobe. The ordinates represent the total length of the larvae expressed in millimeters. 


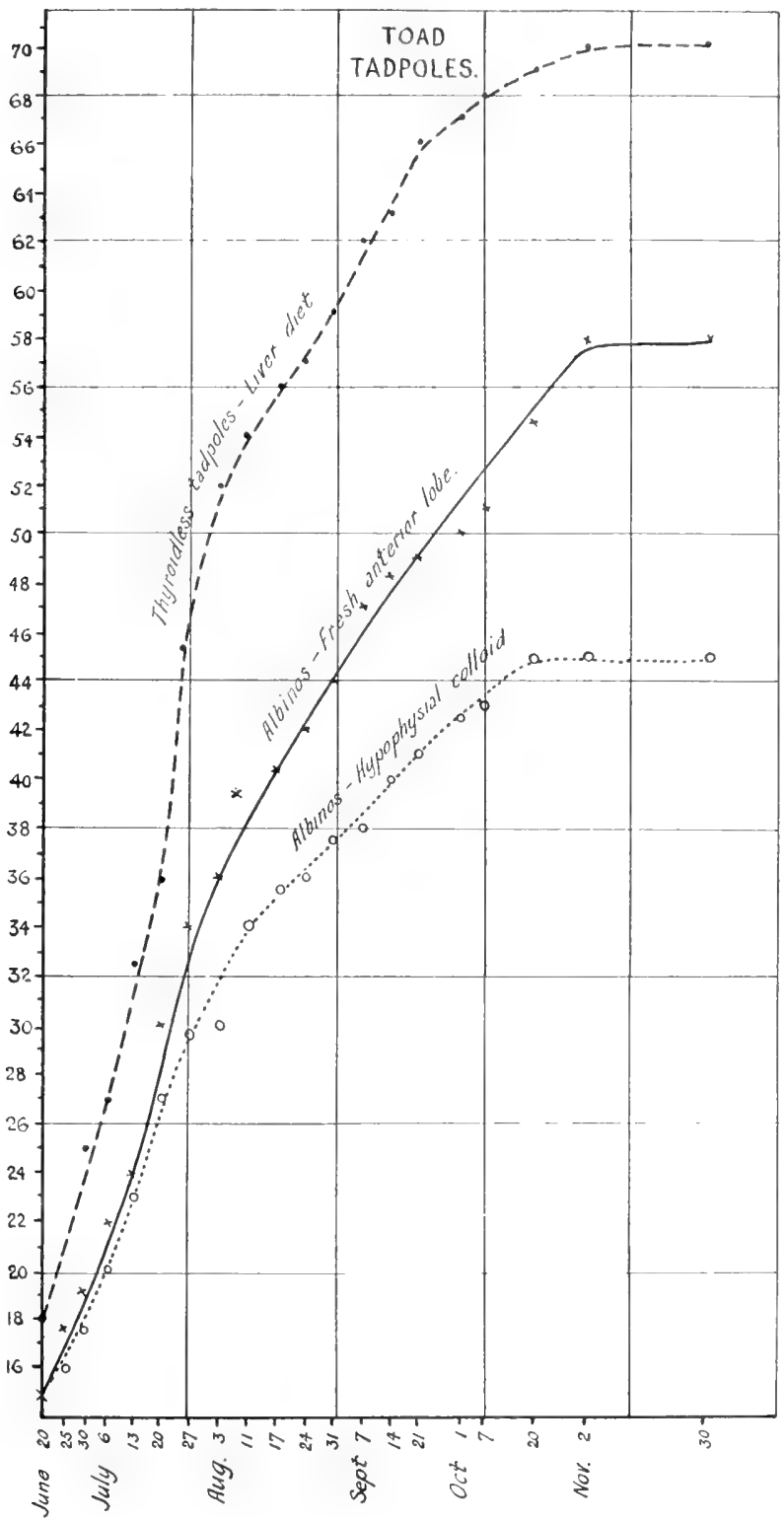

Fig. 9 Growth eurves of thyroidectomized toad larvae supplied with liver, hypophysectomized toad larvae supplied with fresh anterior-lobe substance and with hypophysial colloid. The ordinates represent the total length of the larvae expressed in millimeters. 


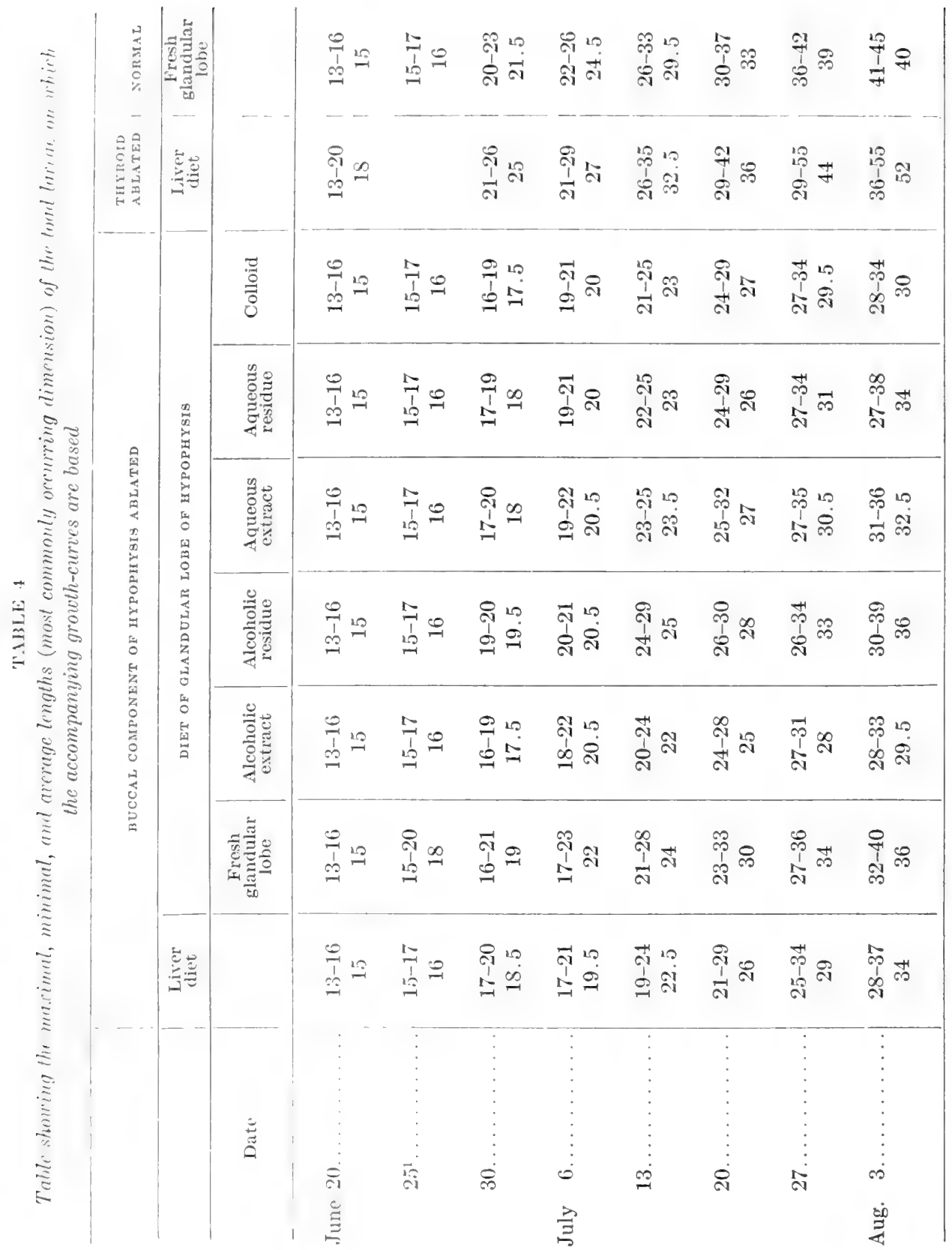




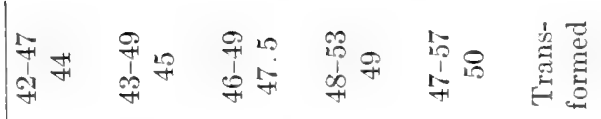

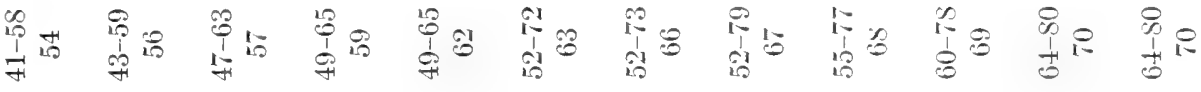

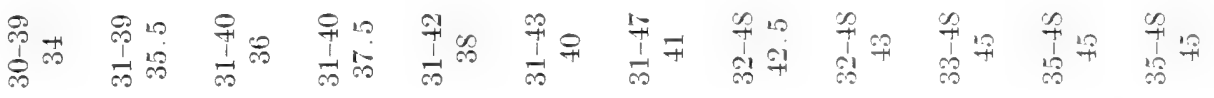

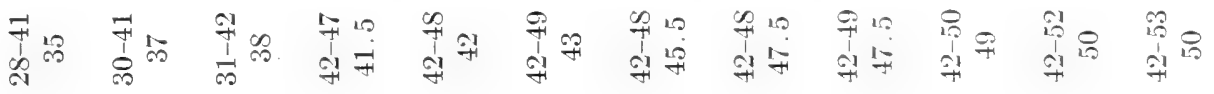

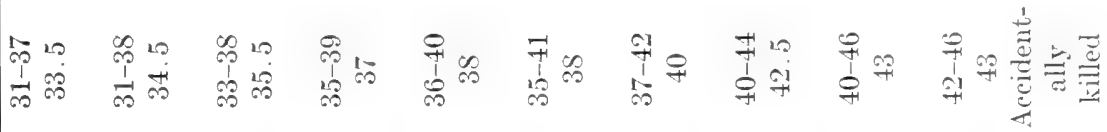

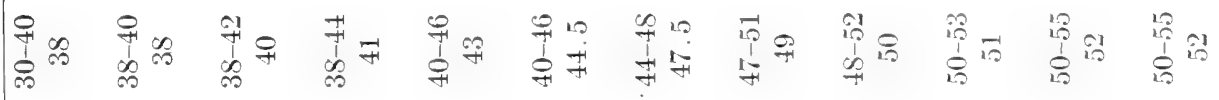

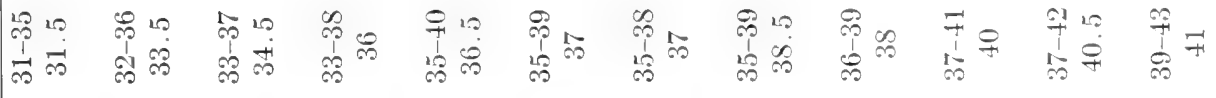

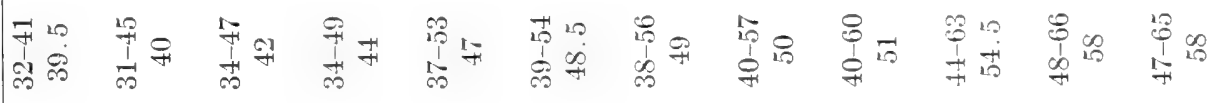

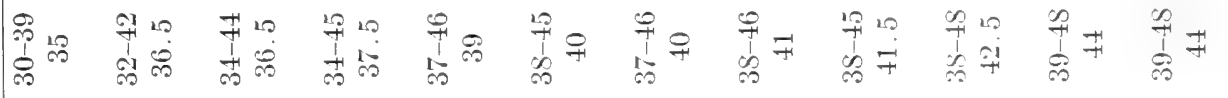

MEMOIR NO. 11. 
effect has been produced in normal larvae by such alimentary régimes.

One article of diet, liver-the chief nutritive substance supplied - is common to the specimens of the second division. That the retardation in the growth rate of these specimens is not due to a growth-retarding substance in the liver, but to the absence of the hypophysial growth-maintaining substance, is clearly indicated by three lines of evidence: 1) we should have

TABLE 5

Thale giving the number of normal, thyroidectomized, and albinous toad larvae on which the accompanying growth-curves are based

\begin{tabular}{|c|c|c|c|c|c|c|c|c|c|}
\hline \multicolumn{8}{|c|}{ BUCCAL COMPONENT OF HXPOPHYSIS ABLATED } & \multirow{3}{*}{\begin{tabular}{|}
$\mid \begin{array}{c}\text { THYROID } \\
\text { ABLATED }\end{array}$ \\
$\begin{array}{c}\text { Liver } \\
\text { diet }\end{array}$
\end{tabular}} & \multirow{3}{*}{\begin{tabular}{|c} 
NormaL \\
$\begin{array}{c}\text { Glandu- } \\
\text { lar lobe } \\
\text { dict }\end{array}$
\end{tabular}} \\
\hline & $\begin{array}{l}\text { Liver } \\
\text { diet }\end{array}$ & \multicolumn{6}{|c|}{ DIET OF GLANDULAR LOBE OF HYPOPHYSIS } & & \\
\hline & & $\begin{array}{l}\text { Fresh } \\
\text { mlandin- } \\
\text { lar lobe }\end{array}$ & $\begin{array}{l}\text { Alco- } \\
\text { lolic } \\
\text { extract }\end{array}$ & $\begin{array}{l}\text { Alco- } \\
\text {, holic } \\
\text { residue }\end{array}$ & $\begin{array}{l}\text { Aqueous } \\
\text { extract }\end{array}$ & $\begin{array}{l}\text { Aqueous } \\
\text { residue }\end{array}$ & Colloid & & \\
\hline June 25 & 8 & 30 & s & 8 & $s$ & 8 & 8 & 14 & 18 \\
\hline Aur. 13 & 7 & 23 & 7 & 8 & 6 & 8 & 8 & 13 & 18 \\
\hline Sept. 14 & 7 & 21 & 7 & 6 & 6 & 8 & 7 & 13 & 0 \\
\hline Oct. 20 & 6 & 20 & 4 & 6 & $0^{1}$ & 6 & 7 & 8 & 0 \\
\hline
\end{tabular}

${ }_{1}^{1}$ Filled aceidentally.

to likewise assume that such growth-retarding substances were in adrenal cortex, adrenal medulla, and posterior lobe, for the same growth delay exists when albinous larvae are fed with any of these substances; 2) Mendel and Osborne ('18) have shown that the proteins of liver are adequate for the needs of nutrition in mammalian growth; 3 ) normal frog larvae supplied with a liver diet exhibit an entirely normal rate of growth.

It seems clear, then, that the normal growth rate of the albinous specimens receiving fresh anterior lobe or its residues is due to an alimentary replacement of the growth-maintaining 
substance normally furnished by the tadpole's own gland. It is significant of the stability of this substance that its efficacy or physiological nature has not been seriously impaired by the severe treatment accorded it in the prolonged extraction with boiling water or absolute alcohol. It would seem certain that the retardation in the growth rate of the albinos receiving liver, hypophysial extracts, and colloid is due to the absence of the morphogenic principle normally furnished by the anterior lobe of the pituitary.

\section{The growth rate of thyroidectomized larvae}

It has been noted by previous workers (Allen, Hoskins) that thyroidectomized larvae attained a size much in excess of the normal and that the pituitary glands of these specimens were relatively increased in size. Since the larval condition persists in the thyroidless larvae and since the hypophysis is hypertrophied, it might be expected that these specimens would exhibit a more prolonged, and a more rapid rate of growth than even the anterior-lobe-fed albinous tadpole. By thyroidectomy, then, there would be obtained tadpoles which would simulate the rapid growth exhibited at times by the acromegalous human subject.

Observations, however, made on two groups of thyroidectomized frog larvae, one group (seventy-two specimens) fed on anterior lobe, the other (fifty-nine specimens) fed on liver, show that their growth is identical in rate with that of their normal brothers or with the albinos supplied with a continuous diet of the fresh anterior lobe (fig. 5). Their large size is never attained by a more rapid growth rate, but rather, as in the anterior-lobe-fed albinos, by a prolongation of the growth period. No variation in growth rate was caused by feeding the fresh anterior lobe of the pituitary, a non-effect already reported upon by Allen ('18). The enlarged pituitary which these animals possess does not appear to have supplied any growth stimulus in excess of the normal.

Nevertheless, a different condition obtains with the thyroidectomized toad larvae, at least when supplied with a liver diet. 
This is well shown by the members of one group (fourteen specimens) whose growth rate was more rapid than that of their normal fellows supplied with anterior lobe substance (fig. 9). Moreover, they attained a size notably in excess of that reached by their hypophysis-fed albinous mates.

Evidently, then, in the case of the frog larvae the enlarged hypophysis, which Allen and Hoskins have shown to result from thyroidectomy, has not supplied any growth stimulus in excess of the normal. To what the acceleration in the toad larvae is due has as yet been undetermined, but that an increased secretion from the hypertrophied pituitary may be an important factor, as suggested by Hoskins, seems not improbable.

\section{MODIFICATIONS IN THE SIZE AND STRUCTURE OF THE ENDOCRINE ORGANS}

It seems probable that a tissue, whether its distribution be diffuse or localized, is more labile and 'adaptive' in its early formative stage than in its mature condition. An example of this is seen in the nervous system, which in its mature, highly differentiated condition loses its capacity for regeneration and 'adaptation,' a capacity which it exhibits to a surprising degree, however, in its early formative stages (Lewis), more especially when associated tissues can elicit a developmental response (Burr). It is likely, then, that if a disturbance be experienced by the endocrine system in its early and embryonic stages, greater alterations in its members will result than if this upset had been suffered later in the life of the individual. As has been previously suggested, the more extensive structural changes which are manifested by the internal secretory organs of the hypophysisfree tadpole as compared to the hypophysectomized mammal are probably referable to the earlier institution of this disturbance. Extensive structural modifications, as we will show, are invariably manifested in the thyroid, the neural portion of the hypophysis, and the interrenal and chromaffin components of the adrenal gland subsequent to the early loss of the epithelial hypophysis, while lesser though distinct changes are shown by the epithelial bodies. The behavior of the fat-organ in hypophysial deficiency is also described in this section. 


\section{The hypophysial components}

The endocrine disturbance leading to the abnormal condition of the epithelial bodies, the thyroid and adrenal glands, subsequently to be described, has of necessity been mediated to these distant organs by the blood stream. The neural hypophysis, while subjected as are these other glands to this general endocrine disturbance, has, in addition, been subjected to the loss of its intimate anatomical associate, the epithelial hypophysis, a loss which in itself might conceivably greatly modify the neural lobe entirely apart from the general disturbance introduced into this correlative system of organs by buccal hypophysectomy. That the intimate anatomical association existing between the neural and epithelial components, to which attention has been called by many observers, ${ }^{32}$ is fundamental for the elaboration of the secretion of at least the posterior lobe, finds support not only in the anatomical evidence afforded by this relationship, but also in the recent work of Schmidt and May from the chemical side. ${ }^{33}$ As will be pointed out, corroborative evidence bearing upon the significance of this coalescence will accrue from this study. It must be kept in mind that in this experimental work the buccal constituent of this gland has been removed prior to the umion with its neural associate, which consequently remains undisturbed, and that the infundibular process at this time gives no indication of the structural differentiation which it is to later undergo, so that any modifications exhibited by the neural lobe (or the infundibular process) are not referable to any direct operative injury inflicted upon this member. As will be subsequently pointed out more in detail, sections and models of these albinos reveal a profound reduction in size, as well as an atypical shape and

${ }^{32}$ Herring, Trautmann, Stumpf, Kohn, Erdheim and Stumme, Vogel, Stendel, and others.

${ }^{33}$ Schmidt and May, by appropriate chemical treatment of the alcoholic hypophysial extract, Tethelin, have secured a substance whose action simulates the active principle of the posterior lobe, i.e., causes a contraction of the isolated uterus and produces a vasoconstriction. 
abnormal position of the neural lobe. ${ }^{34}$ Indeed, this malformation is not limited to the neural lobe, but is participated in also by the floor of the infundibular process. This floor, normally of considerable thickness, is membranous and folded in the albinous larvae. ${ }^{35}$

It is of considerable importance, in view of the conditions obtaining in the albino, to have clearly in mind the parts of the infundibular process together with their structure in the normal animal, and more especially that of the apical and ventral portions. The walls of this process have three divisions: ${ }^{36}$ 1) a ventromedial portion in contact with the pituitary gland, the 'pituitary' wall or floor; 2) a dorsal portion, the 'saccular' wall; and, 3) the lateral extensions of both these walls which form the shallow lateral concavities, the 'lateral processes.' The neural lobe in its early stage develops near the apex of the infundibular process, and in its fully formed condition is readily identified as a distinct element attached by a broad surface to the dorsal wall of the infundibular process, near its ventral border (fig. 25). An examination of the three portions of the infundibular process of the normal animal reveals the fact that these regions are of two structural types. One type, that exhibited by the lateral processes and saccular wall, is membranous and composed of a squamous ependyma with little or no ectally placed neuropilem. The other type, that forming the pituitary wall, is thickened and composed of a high columnar

${ }^{34}$ The reduction in the size of the neural lobe in the albino was reported in The Anatomical Record. In the present paper more comprehensive data have been given.

${ }^{35}$ 'The hypophysis of an anuran larva, in common with other vertebrates, consists of four components, three arising from oral ectoderm, one from the infundibular process. The development of those lobes derived from the buccal rudiment (the pars intermedia, the pars glandularis and its paired cephalic processes, the pars tuberalis) conforms in general to that recently described by Atwell for R. pipiens. Wax models, $\times 133$, of the pituitaries of nine normal larvae, from $17 \mathrm{~mm}$. in length to the young adult stage have been made (table 6 ). In addition to these, the neural lobes of ten albinos, ranging in size from 16 to $51 \mathrm{~mm}$., and the neural and buceal lobes of nine partial albinos were modeled. The lobes of the pituitary are readily identified and their relationship to each other is constant (fig. 25, a, b,c), compare to Atwell's figure 13 , page 81 , but considerable variation in their relative size is shown.

${ }^{36}$ The terminology is essentially that of Tilney ('15). 
ependyma with an ectally placed prominent stratum of neuropilem (fig. 28). In the albino the saccular wall and lateral processes and pituitary wall all exhibit the membranous type of structure (fig. 29). The pituitary floor, which is normally in contact with the epithelial hypophysis and which has been deprived of such contact by the epithelial hypophysectomy, thus exhibits the same type of structure as those portions not normally in contact with this epithelial component of the hypophysis. Directly attributable to the membranous character of this pituitary floor are invariably seen certain pronounced but irregular folds which appear in this structure in the albino (fig. 26), but not in the normal animal (fig. 25). Although such foldings are undoubtedly due to the technical procedure incident to the preparation of this material, yet the membranous nature of the infundibular floor of the albino is directly conducive to them, while the firmer structure of the normal infundibulum prevents them.

The abnormality in the infundibular process in the albino is not limited to the pituitary floor, for it is very evident that the neural lobe in the albino as compared to the normal animal of corresponding dimensions (table 6 ) is also diminished in size, a diminution which varies from 40 per cent to 80 per cent and which transcends very distinctly the considerable variability which this lobe exhibits in both types of specimens. ${ }^{37}$ Associated with this diminution in size is a profound alteration in the shape and position of this lobe. Instead of the symmetrical, transversely placed, dumb-bell-shaped lobe of the normal (fig. $25)$, this dwarfed lobe is oval, asymmetrical in shape and position, and has no great transverse extent (fig. 26). Normally attached somewhat dorsally to the apex of the intundibular process and thus abutting and being attached to its dorsal surface, in the albino it is constantly found grasping the apex of this process and extends invariably slightly onto the pituitary

${ }^{37}$ It does not appear from figures 28 and 29 that the neural lobe of the albino is smaller than in the normal. It must be kept in mind, however, that due to the difference in the shape of this lobe in the two types that a median sagittal section passes through its smallest dimension in the normal animal, and through its maximum sagittal diameter in the albino (figs. 25, 26). 
surface (figs. 26, 29). This lobe is thus profoundly modified by the loss of its associate. It attains normal development neither as regards size, form, nor position. ${ }^{38}$ In its response to buccal hypophysectomy the reduction of this gland thus aligns it with the thyroid and the adrenal cortex reduction. Indeed, in those animals suffering only a partial loss of the epithelial hypophysis, the thyroid and adrenal glands are usually not altered in development, but the neural hypophysis is invariably atypical.

In an earlier section of the paper we have referred to the type of tadpole in which the removal of the epithelial hypophysis was incomplete. Since these animals usually manifest definite pigmentary alterations, we have designated them 'partial albinos. ${ }^{3} 9$ Especial interest attaches to the examination of the endocrine system, more particularly its hypophysial components in this type, since we have here an intermediate condition between a complete deficiency of the epithelial hypophysis and a normal structure. A study of this form throws much additional light upon the interesting relationship obtaining between the neural and epithelial components of the pituitary as well as supplying evidence bearing upon the endocrine locus responsible for the pigmentary deficiency.

In the partial albinos no uniformity in shape is displayed by the vestige of the epithelial hypophysis. It is usually oval in outline and of a variable thickness (figs. 27, 30). Only occasionally do we find it displaying the normal division into glandu-

${ }^{38}$ 'The findings of Allen (Abstracts, Am. Assoc. Anatomists, 1917) are distinctly at variance with those reported here. This author states, "The pars nervosa of the hypophysis forms normally in tadpoles, both Rana and Bufo, from which the anlage of the anterior lobe has been removed." As I have previously pointed out, a median sagittal section of the infundibulum usually shows a neural hypophysis of normal or even enlarged proportions. By modeling this component, unmistakable evidence concerning its diminution in size and atypical form is secured, however.

${ }^{39}$ I called attention in 1916 (Proc. Am. Assoc. Anat.) to an albinous tadpole in which a leg development took place. At that time the minute buccal fragment displayed by this animal had not been noted. Allen, in 1918, called attention to the complete metamorphosis of certain toad and frog tadpoles with an imperfect hypopliysis and displaying a definite pigmentary deficiency. 
lar and intermediate components. The $\operatorname{size}^{40}$ of this vestigial gland is always considerably less than that obtaining in the normal tadpole of corresponding dimensions (table 6). As would be anticipated, this epithelial gland, subjected as it was to a varying surgical interference, leaves a vestige which shows great diversity in its position as well as in shape and size. That the position which this lobe assumes is of paramount importance in the influence it may exert upon the other glands and upon metamorphosis, is evident from a correlation of the structural changes enjoyed by the partial albino with the position which the buccal fragment has assumed. In the specimens thus far studied, three positions have been assumed by this fragment: 1) In the first case, this fragment, not separable into glandular and intermediate components, does not reach the caudal extremity of the infundibular process, nor does it touch at any point the true neural lobe (figs. 27,30). The members of this group, which includes the partial albinos ( $1, \mathrm{p} 2, \mathrm{p} 3, \mathrm{p} 4$, p 5), all displayed a pronounced albinism. It is to be noted that none of these animals complete metamorphosis, though, as in the other groups, their thyroid glands are not atrophic. 2) In the second case, the fragment, not separable into glandular and intermediate components, does not reach its usual caudal position, but nevertheless attains a definite though small contact with the true neural lobe. This class includes a smaller number of specimens ( $\mathrm{p} 7, \mathrm{p} 9, \mathrm{p}$ 10), the members of which display a variable pigmentary disturbance. They complete metamorphosis, though tardily, and the thyroid glands exhibit a pronounced colloidal hypertrophy (colloid goiter). 3) In the third case, the epithelial fragment, which is separable into intermediate and glandular components, assumes the position typical of the normal animal. One specimen only fell in this class (p 8); it did not exhibit a pronounced pigmentary upset; it completed metamorphosis and had a normal thyroid gland. A study of a

\footnotetext{
${ }^{40}$ The metamorphic changes in all the partial albinos, except $p 1$, which died from infection, whose hypophyses were modeled (table 6), had ceased for some time prior to the fixation of the animal. It is certain that the metamorphosis would never have been completed nor even materially advanced had the specimens survived longer.
} 
74 PIGMENTARY GROWTH AFTER ABLATION OF

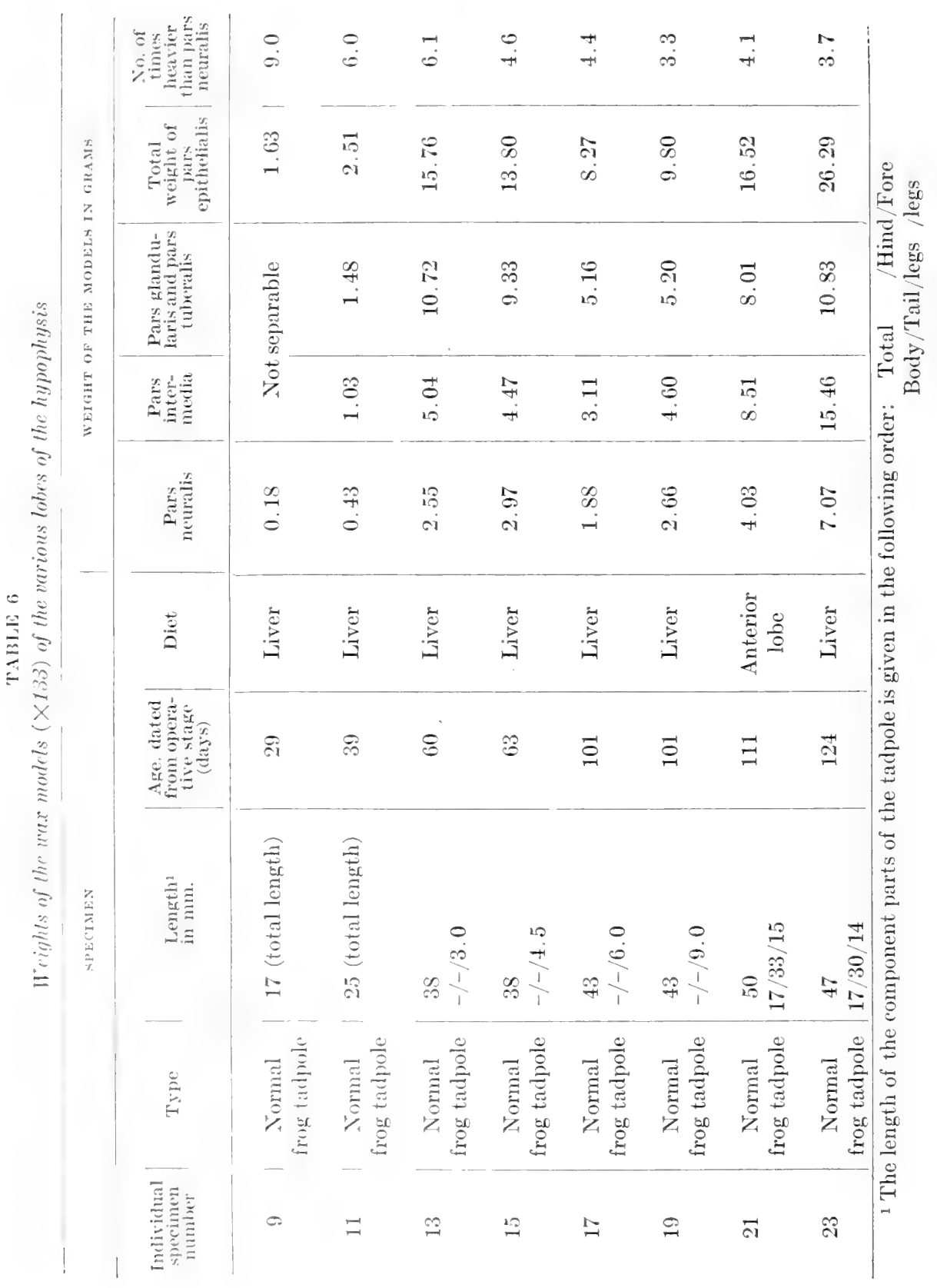




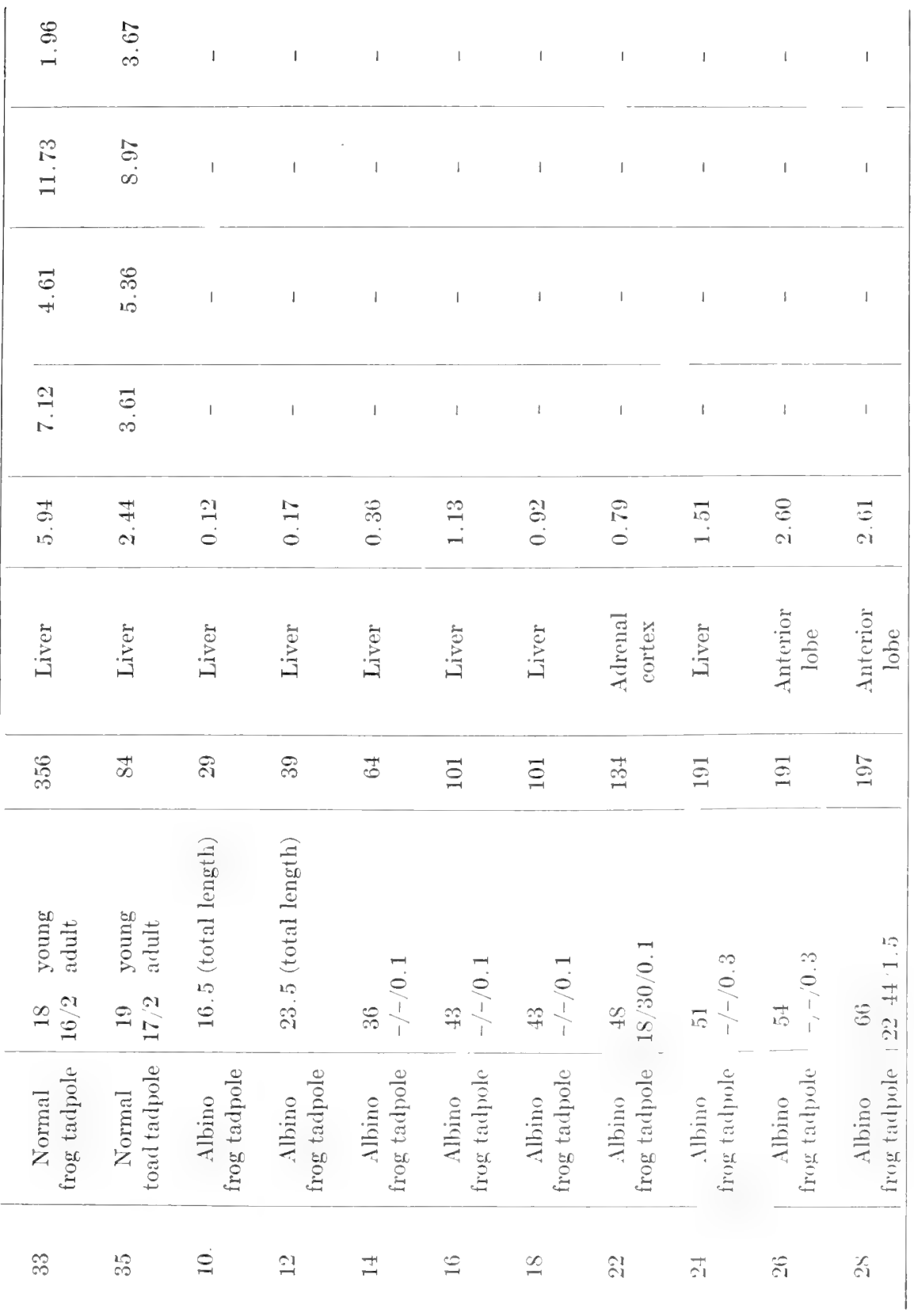




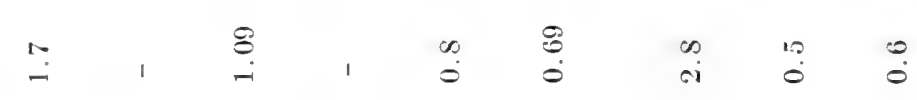

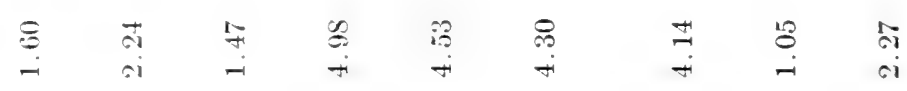

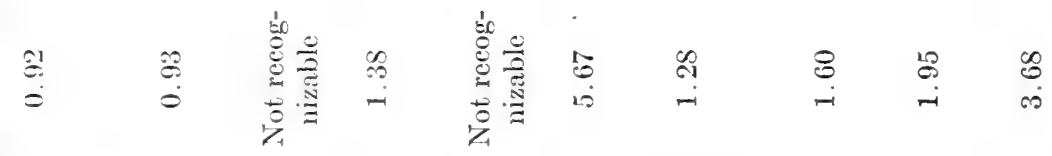

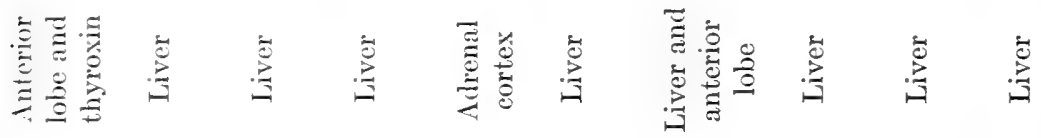

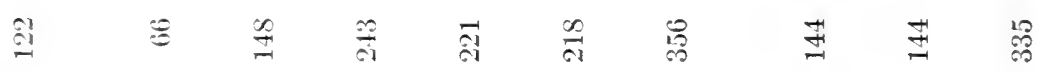

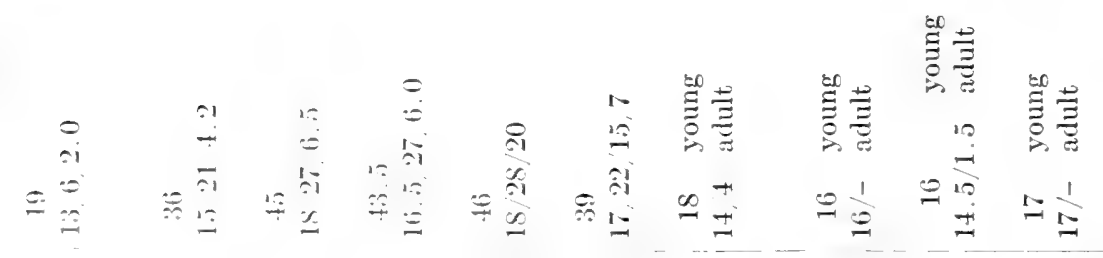

美竞

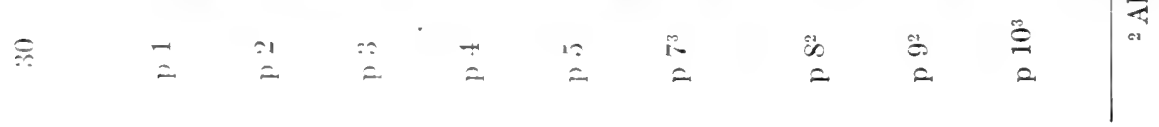


greater number of 'partial' albinos, it is anticipated, will reveal an overlapping of these classes, but because of the apparent association between the progress of metamorphosis, the reaction of the thyroid gland and the position of this epithelial fragment, such a tentative classification appears justifiable and will be discussed further when the thyroid glands of these specimens are more specifically considered.

The description of the picture presented by the epithelial hypophysis of the partial albino would be incomplete unless wo added a word in regard to the structural characteristic of this vestige. Its structure (in the first and second classes mentioned above) is characteristic neither of the glandular nor the intermediate components of the pituitary. Certain portions are composed of acidophilic cells, other portions of cells similar to those normally found in the pars intermedia. The organization of those cells, however, is typical of the pars intermedia, since the component cells are neither arranged in definite cords nor separated by numerous nor large sinusoids (fig. 30 ).

The response of the neural lobe to partial hypophysectomy is of even greater value in analyzing the interrelationship existing between the neural and epithelial components of the pituitary than was the reaction of this lobe to the complete loss of the buccal component, as obtains in the albino. In size it is usually diminished as compared to the normal animal of corresponding dimensions and stage of advancement (table 6) and at times the lobe as such is not even recognizable (specimens $p 2, p 4$ ). When present it is asymmetrical in shape and position and frequently encroaches upon the pituitary floor. Of great interest are the conditions obtaining immediately about the epithelial fragment. About this fragment there is formed a thickening of the neural tissue which we might designate as a 'novel' neural lobe. This partially surrounds and grasps the buceal fragment (fig. 30), an appearance which in part may be explained by the indentation which this lobe makes in the brain substance. When the usual neural lobe is absent or greatly diminished in size (specimens p 2, p 4), there is evident in those specimens that have been thus far examined a thickening of the pituitary floor 
(fig. 30), a condition which strongly suggests that the neural lobe had migrated cephalically and was attempting to assume a juxtaposition with the unusually placed epithelial fragment. This seems the more probable, sinee in the specimens which have suffered a complete loss of the epithelial hypophysis there is always a readily distinguishable neural lobe. That the epithelial hypophysis apparently exhibits not only this 'attractive' force upon the neural lobe, but definitely stimulates the growth of adjacent neural tissue, is shown both by the thickening of the neural tissue about the epithelial hypophysial vestige ${ }^{41}$ in the partial albinos and by the negative evidence supplied by the absence of the usual thickening of the pituitary floor and diminished size of the neural lobe in the albino which displays no epithelial hypophysis whatever. It thus seems clear that in the absence of a nearly normal epithelial component the neural hypophysis cannot undergo its normal development nor attain its typical shape or size. ${ }^{42}$ That the neural lobe can and does form even in the absence of its associate, however, is clear, and it seems equally clear that in those specimens in which a sufficient metamorphic stimulus is supplied, whether by the thyroid or the hypophysis or jointly, that this lobe can attain a very considerable size. ${ }^{43}$

1 Although this neural lobe simulates in structure the typical lobe, nevertheless, it scems doubtful whether it is able to assume the functions of that lobe. That it can assume this function appears improbable both from the failure of such specimens to metamorphose as well as from the serious pigmentary disturbance which they display.

${ }^{42}$ To what an extent the general disturbance in this correlative system of organs plays a part is problematical. It is difficult to determine, save by grafts of the buecal component with the hypophysectomized larvae, an undertaking which has not been fruitful in the hands of the author. A similar failure to secure significant effects has recently been reported by the Hoskinses. Likewise, efforts to secure an apposition of the buccal component and the lateral or dorsal walls of the infundibular process have so far failed. The author hoped to determine by such misplacement of the buccal component whether these walls would undergo the hypertrophy normally exhibited by the pituitary wall.

${ }^{43}$ No clear evidence is at hand showing whether the buceal lobe would undergo a normal development in the absence of its neural associate. Suggestive evidence, however, that it can develop independently is furnished by the work of Haberfeldt ('09). According to this author, the pharyngeal hypophysis, although far remote from any neural associate, parallels in development and differentiation the pars glandularis of the hypophysis. 
A study of the older albinous and partially hypophysectomized larvae does not throw light upon the developmental process which has led to the thinning of the pituitary floor and the diminution in the size of the neural lobe in these specimens. From such a study we can conceive that one of two developmental processes lead to this anatomical condition. In the first place, it is possible that a normal differentiation and development of these parts may have taken place, so that at some not very early period they were structurally identical in both the albinous and normal larvae. Later, due to the absence of the association with the epithelial hypophysis, these normally developed parts underwent an atrophy which led to the conditions just described. Or, in the second place, it is possible that, due to the absence of the 'stimulatory' force normally supplied by the epithelial hypophysis, the neural lobe and pituitary floor even from their earliest stages did not undergo the normal increase in size. A developmental study of the albino, the normal, and the partially hypophysectomized tadpole affords clear evidence that the second hypothesis is correct. An examination of the divisions (lateral, saccular, and pituitary) of the infundibular process in an early stage $(5$ to $10 \mathrm{~mm}$.) reveals the fact that these parts are nearly identical in structure and that no differences exist between a normal larva and a larva which has suffered the loss of its epithelial hypophysis. This infundibular pocket, slightly thinner at its apex where it is formed of a cuboidal epithelium, thickens near its attachment to the firmer walls of the brain where it is formed of columnar epithelium. As development proceeds, the dorsal and lateral walls of this pouch become progressively thinner in both the albino and normal animal, and at a 14- to $16-\mathrm{mm}$. stage their epithelium is of the squamous type and remains so through their larval life span (fig. 10). Thus the development of the dorsal and lateral walls (save the small portion giving rise to the neural lobe) is identical in the two types of animals. It is in the development of the pituitary wall, however, that the differences between the albinous and normal larvae make their appearance. This portion, both in the albino and the normal, undergoes for 


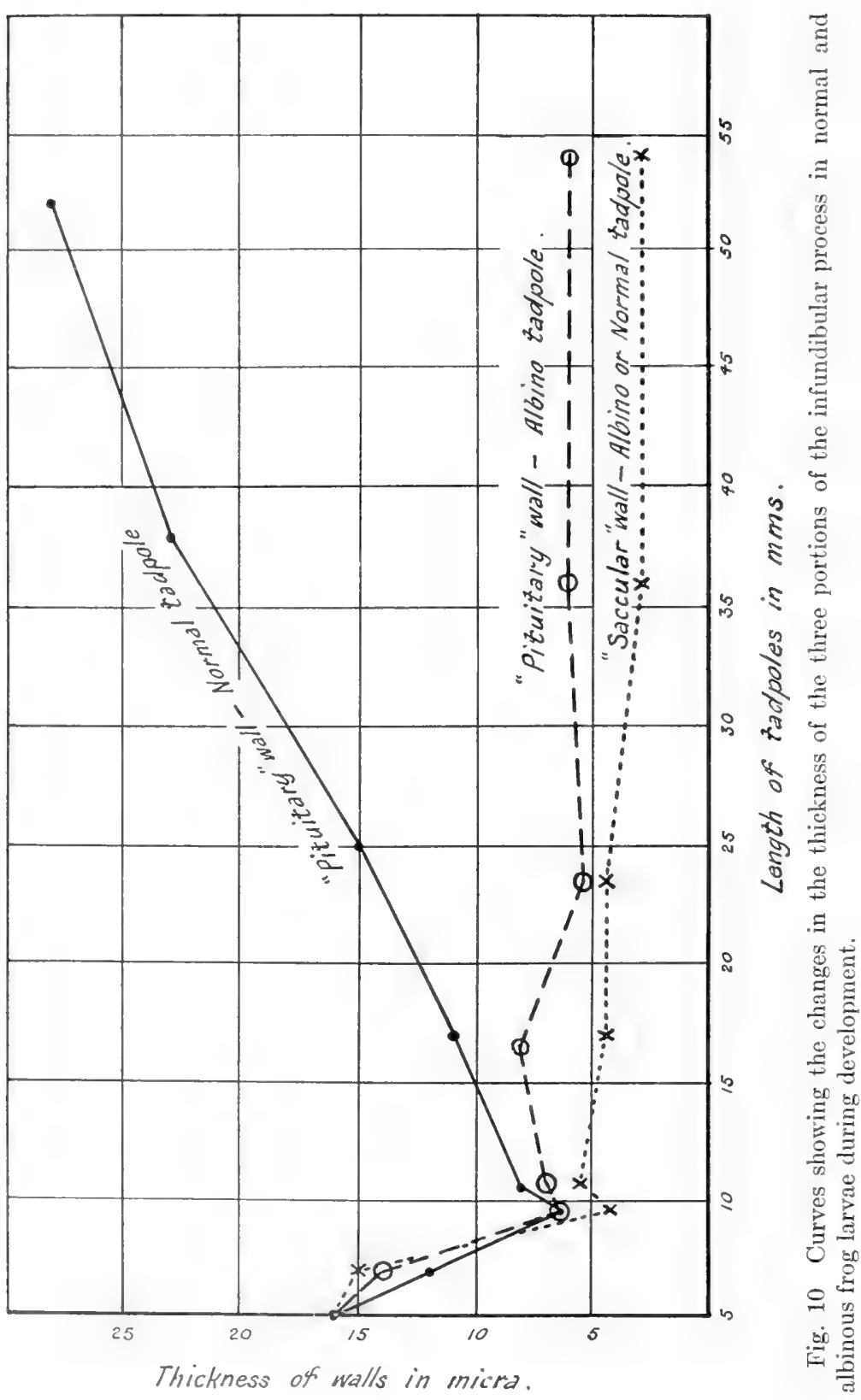


a time the same thinning as do the dorsal and lateral walls. By a 9.5-mm. stage the pituitary wall has become much thinned, and consequently the various portions of the infundibular process are approximately of the same thickness (fig. 10) and nearly structurally identical. From this point a series of changes take place leading to a very different condition in the pituitary wall of the two types. In the albino the membranous wall persists. In the normal this becomes progressively thicker and finally attains a thickness many times that obtaining in the $9.5-\mathrm{mm}$. stage. It is significant that the epithelial hypophysis, although previously in contact with a small portion of the infundibular floor prior to a $10-\mathrm{mm}$. stage, institutes an intimate juxtaposition with the pituitary wall of the infundibular process at the time when the latter loses its membranous character and begins to thicken.

Differences between the neural lobe of the albino and the normal appear at a later stage than they do in the pituitary wall. The thickening near the apex of the infundibular process indicating the first formation of the neural lobe makes its appearance at approximately a $14-\mathrm{mm}$. stage in both the normal and albinous tadpole, ${ }^{44}$ and is nearly identical in position and size in both types at a $16-$ to $17-\mathrm{mm}$. stage. From this stage the neural lobe in the normal increases concomitantly with the growth and lateral extensions of the developing pars intermedia. In the albino, on the contrary, a slower growth (table 6) and relatively slight lateral extension take place a process leading to the small, malformed neural lobe of the albino.

The small neural lobe and the membranous pituitary wall of the albino are thus clearly referable to a non-development rather than to an atrophy of a normally sized structure. The walls of the early infundibular process have apparently two inherent possibilities after having undergone the primary thinning: one, to retain this membranous characteristic as do both the dorsal and lateral walls of the normal or albinous larvae and the pituitary wall of the albino; the other, to develop into

${ }^{44}$ According to Atwell, this lobe becomes recognizable in an 18 to $20 \mathrm{~mm}$. stage in $R$. pipiens.

Memorr No. 11, 
the thickened wall characteristic of the pituitary floor of the normal specimens. If freed from the influence of its buccal associate and left to its own independent development, the membranous structure persists; under the stimulatory influence of its buccal associate, a thickening results, leading to the solid, firm structure of the normal tadpole. Curiously, in the absence of the buceal hypophysis, the inherent capacity for growth expresses itself in the neural lobe as if an hereditary influence here exerts itself and leads to the formation of a 'vestigial' structure. That the epithelial hypophysis does exert a stimulatory effect upon the adjacent neural tissue seems clear, as has been pointed out, not only from the evidence accruing from a study of the albino in its different stages, but from the 'partial' albino as well. The diminutive and misplaced fragment of the buccal hypophysis in these specimens has invariably formed about itself a brain lobe, identical in structure, so far as can be determined, with the normally placed pars nervosa of the pituitary. Moreover, the 'influence' of this vestigial epithelial gland appears to be effective at some distance, as indicated by certain specimens which, in sharp contrast to the albino, have no apically placed neural lobe. This condition suggests that this lobe has either been inhibited and a new atypically placed lobe formed de novo or it has been attracted to a new position by this misplaced epithelial fragment.

The inherent capacity for growth existing in the three portions of the infundibular process and the response of these portions to the presence or absence of the buccal component of the hypophysis can perhaps best be shown by schematic curves illustrating the reaction of the pituitary floor and one of the other portions of the infundibular process under the two conditions of normality and buccal hypophysectomy (fig. 10). These curves show the development of the pituitary wall in a normal tadpole and its albinous mate, together with a third curve showing the development of the dorsal and lateral walls of the infundibular process in either normal or albinous tadpoles. 
Early in this section of the paper we stated that two lines of evidence indicated that the neural lobe is dependent upon its epithelial companion for its complete development. These briefly are: 1) certain cellular elements from the pars epithelialis (pars intermedia) apparently migrate into the neural component of the hypophysis and contribute to its secretion; 2) by appropriate chemical treatment a substance can be secured from the anterior lobe which displays certain of the physiological characteristics typical of extracts of the posterior lobe of thepituitary. From this study a third line of evidence from the experimental and developmental work herein detailed has been secured; 3) the neural lobe and pituitary floor are dependent upon the association with the epithelial hypophysis for their full development. The epithelial hypophysis then appears to exert a stimulating effect upon these structures and even upon any adjacent neural tissue, as is shown by the hypertrophy of the neural tissue about the atypically placed epithelial lobe.

\section{The thyroid}

Sections of the larger albinous larvae show that the thyroid glands of these specimens have suffered a profound atrophy, an atrophy so intense that the remaining vestige could hardly be suspected of playing any important physiological rôle. That, in fact, this is the case has recently been shown by Allen, whose experimental animals, suffering a double extirpation of the thyroid and buccal portion of the hypophysis, do not differ from those deprived only of the epithelial hypophysis. Indeed, the interrelationship obtaining between the hypophysis and thyroid appears to be of such an intimate nature that the ablation of the former, even in the midlarval stages, effects an atrophy of the latter (Adler, '14).

The thyroid gland, then, is greatly diminished in size (table 7 , figs. 31 to 34 ) and modified in structure in those tadpoles suffering from an early and complete loss of the epithelial hypophysis. By this atrophy the thyroid is diminished, in tadpoles in excess of $36 \mathrm{~mm}$. total length, to one-sixth or less of its normal size. 


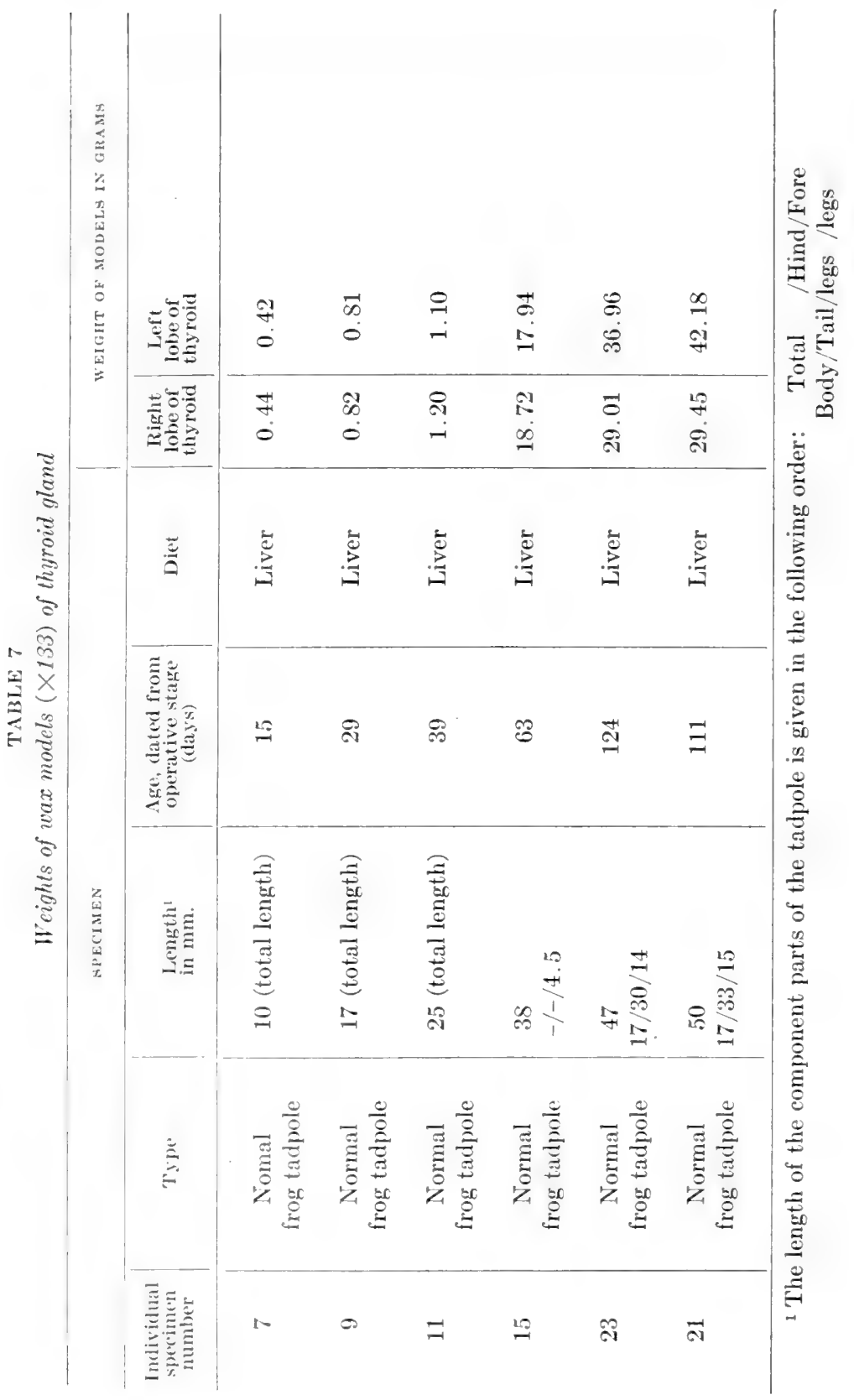


THE PARS BUCCALIS OF THE HYPOPHYSIS

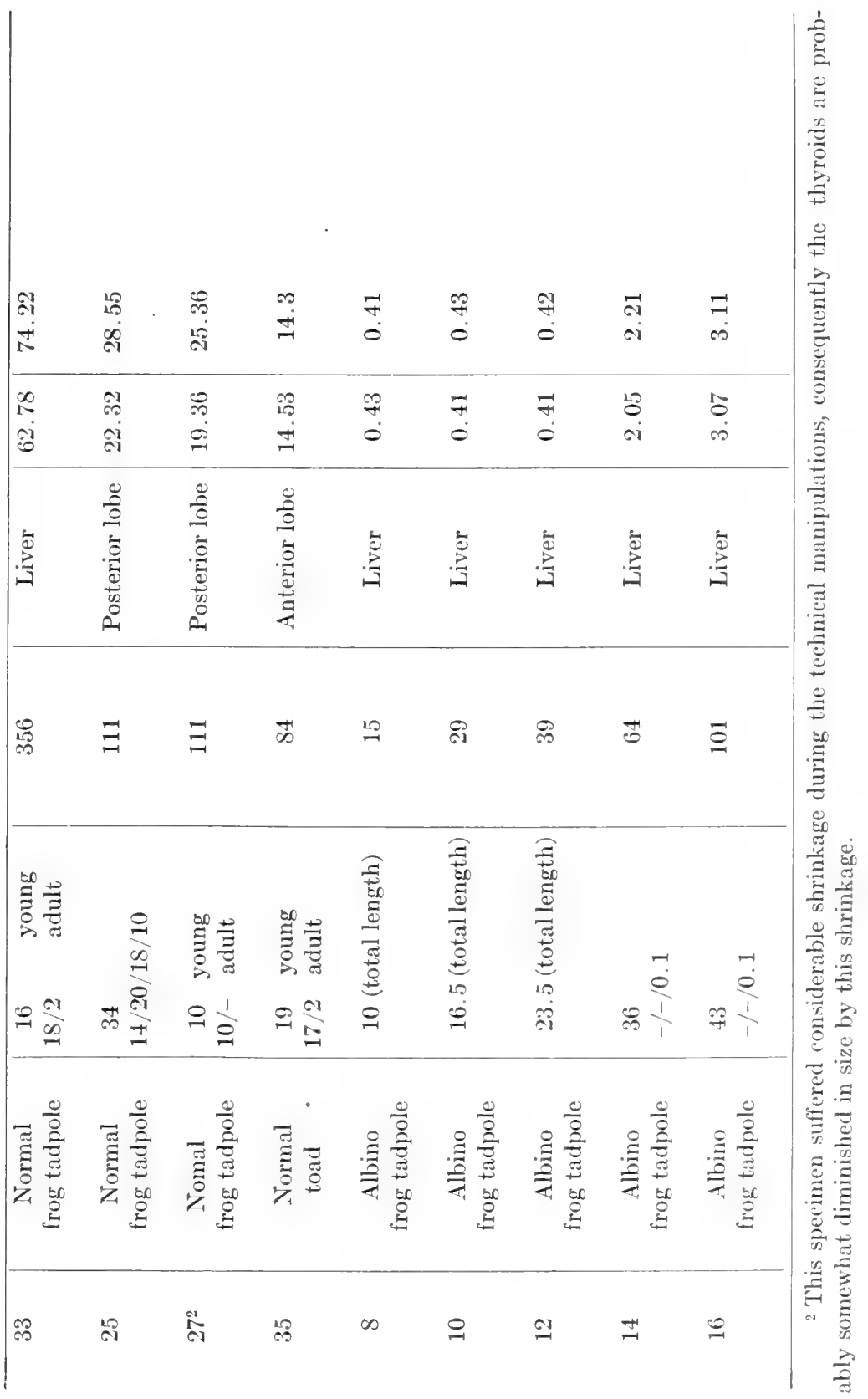




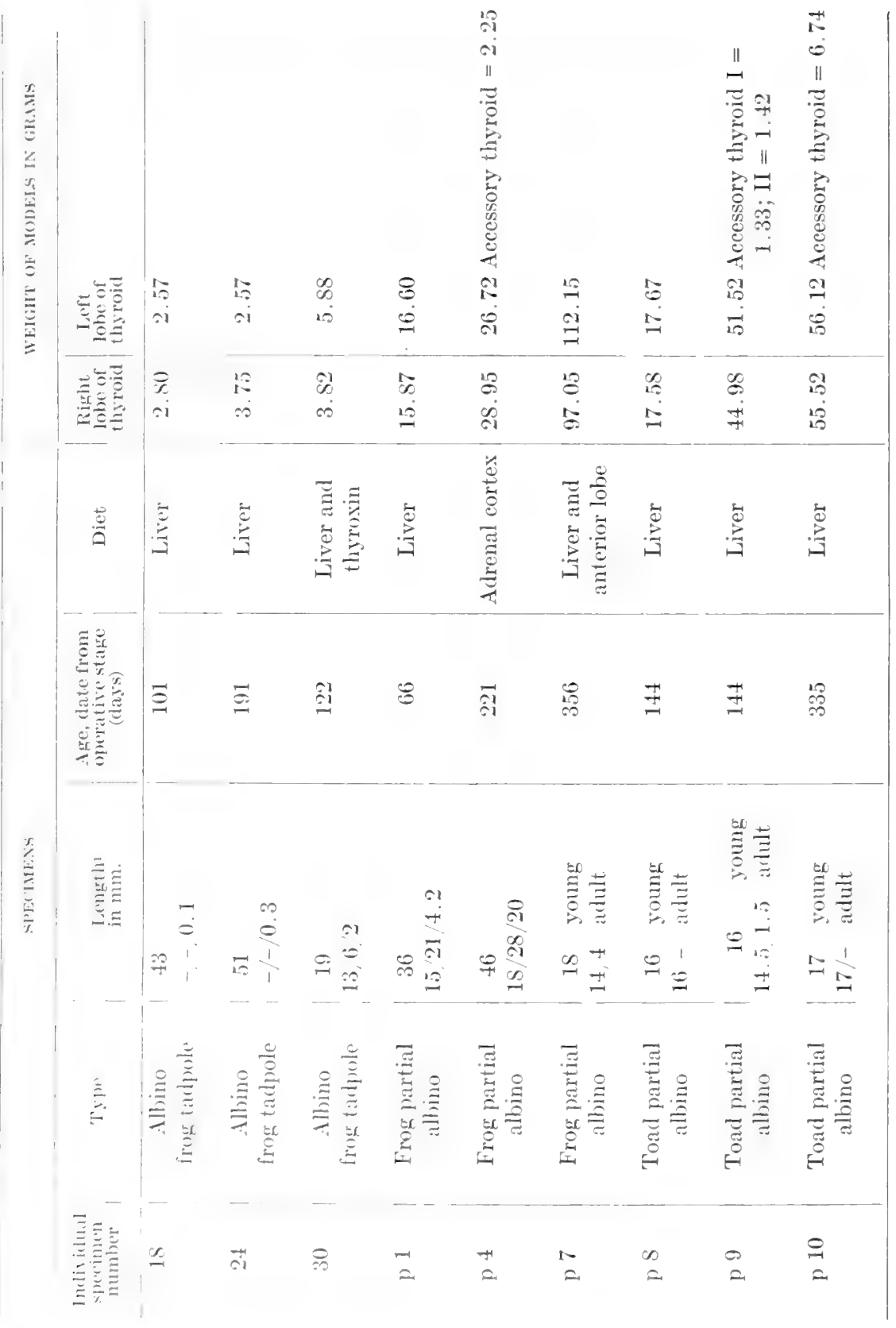


Structurally, this atrophy is expressed by a reduction in the size of the follicles and in their colloid content (figs. 33 to 36). Indeed, certain cell clusters would not be recognizable as a follicular remnant, save for their location, so atypical are they. Other follicles exhibit the characteristic organization and may even contain an insignificant amount of poorly staining colloid. In no case do we see the large-sized, colloid-filled follicle of the normal animal. The component cells of the follicles appear also to have suffered from the hypophysial deprivation. Their cytoplasmic content is very noticeably diminished. This reduction in the size of the component follicles, together with an apparent disappearance of some of them, results in a loose organization of the gland, the majority of the follicles being separated by wide intervals. Had these interfollicular spaces been excluded in the models, an even greater discrepancy between the size of the thyroids of the albino as compared to the normal would have been shown.

Although not evident in specimens of $10 \mathrm{~mm}$. total length (eighteen days after the operative stage), by the time larvae have reached a length of 17 to $18 \mathrm{~mm}$. (twenty-nine days after the operative stage) the thyroid of the albinos is slightly but invariably smaller than that of the controls. This discrepancy progressively increases and is strikingly expressed in a 24- $\mathrm{mm}$. (thirty-nine days after the operative stage) albino as shown in table 7. The pronounced atrophy of this gland in the albino is not due, then, to a regressive process in the normal gland; it is a phenomenon of retarded and atypical development.

It will be recalled that the 'partial' albinos, because of the position assumed by the atypical epithelial fragment of the hypophysis, were grouped into three classes: 1) those in which there was no contact between the true neural lobe and the epithelial fragment; 2) those in which there was a definite but slight juxtaposition between these two components; and, 3) those in which the epithelial fragment though diminished in size nevertheless displayed its usual division into glandular and intermediate lobes, which in turn displayed the usual relation with the infundibular derivatives. Curiously, the thyroid glands of 
none of the animals included in these three classes are atrophic, though the epithelial hypophysis be but one-sixth of its normal size; indeed, those included in the second class exhibit greatly hypertrophied thyroids with the frequent formation of accessory glands (table 7, p $7, p 9, p$ 10). It will further be recalled that only the specimens of the second and third classes completed metamorphosis, while those of the first class underwent an abrupt and persistent metamorphic stasis at some stage in this process. It would thus appear that by the slight reaction between the true neural and the buccal components of the hypophysis, a sufficient 'hormonal' substance was supplied to cause an hypertrophic response of the thyroid gland.45 These tadpoles metamorphosed (class 2, specimens p 7, p 9, p 10). On the other hand, if a larger amount of secretion was supplied by the pituitary (class 3 , specimen p 8), no hypertrophy of the thyroid then resulted. A tentative explanation of the correlations obtaining between the epithelial and neural lobes of the hypophysis and the thyroid in the first class of animals, those in which no contact is made between the true neural lobe and the epithelial fragment, is more difficult. Since the thyroid is of normal size in these animals, it is evident that no compensatory response of this gland was evoked, although there would seem to be a need for such a response, since these animals did not complete metamorphosis. It would appear that some interaction between the true neural lobe and the epithelial lobe is necessary in order to evoke a hypertrophic response of the thyroid. Thus a functional specificity attends this union of true neural lobe tissue with the reduced epithelial component of the gland. The thyroid does not hypertrophy and metamorphosis appears never to be completed when the epithelial hypophysis comes in contact with only an atypical or a new neural lobe.

${ }^{45}$ It is of interest to note in this connection that the thyroids, which were subjected to microscopic examination, in Cushing's canine hypophysectomies, exhibited an excess of colloid. Further, that partial hypophysial extirpations in two human patients resulted in thyroid enlargement (Exner, cit. after Cushing). 
The conditions then obtaining in these three classes of tadpoles seem to indicate that the epithelial fragment where separated from the true neural lobe, either in itself or through its reaction with brain tissue, other than the true neural lobe, is able to stimulate the thyroid to normal development, but that under these conditions metamorphosis cannot be completed; that when this fragment is in very slight contact with the neural lobe an hypertrophied thyroid results and complete metamorphosis is effected, and that when the usual relations of a completer contact between the two parts of the hypophysis obtain no hypertrophy of the thyroid occurs and we have the completion of the metamorphic processes. It might thus appear that the activity of the thyroid is thus the sole or determining factor on which the metamorphic processes are dependent. That such may not be the case seems clear from evidence gained by thyroid feeding. In thyroid and thyroxin feeding extending for periods in excess of six weeks and during which time daily minute doses of thyroid or thyroxin were administered, I have not been able to bring to complete metamorphosis a typical hypophysis-free albinous tadpole. The early stages in this process were passed through (leg growth, partial tail absorption), but the tadpole could not be carried past a certain stage, death invariably supervening. This appears to be the case also with the 'partial' albinos of class 1 , whose metamorphic processes could not be carried to completion nor materially advanced after the onset of the metamorphic stasis by instituting a carefully controlled thyroid dosage. The results secured from the feeding of thyroid to completely and partially hypophysectomized tadpoles stand in sharp contrast to similar feeding experiments with the thyroidectomized tadpoles, which were readily completely metamorphosed by this treatment. It is not to be. denied that a more carefully regulated or a different dosage of thyroid might bring about complete metamorphosis in the albino, but that it would do so appears improbable from the evidence at hand. The evidence thus indicates that metamorphosis is dependent upon the active principle of at least two glands; in the absence of either, the larval condition persists. One gland, the thyroid, 
can apparently initiate the process, but unless there be some hypophysial secretion (and it would appear that this must be formed at least in part by the interaction of the true neural lobe with the epithelial component) the process apparently cannot be completed.

\section{The adrenal cortex and medulla}

If the abdomen of a normal tadpole in the later larval stages be opened and the ventral surface of the mesonephros be examined under the binocular, there will be seen a longitudinally placed whitish-appearing cord. This cord, irregular in outline, extends from a point somewhat cephalad to the kidney, over the anterior four-fifths of this organ (fig. 37). This is the adrenal gland.

When such a specimen is dropped into an alcoholic solution of sudan III or scarlet R, this cord takes on a reddish hue. Subsequent treatment with potassium bichromate reveals, however, that not all the cells of this column are tinted with the fat dye, for with chromation, groups of browned cells surrounded by the lipoid-containing cords are revealed. Similar differential staining of the cortex is shown by osmium vapor or when an osmicbichromate solution is used (figs. 38 to 41). If potassium bichromate alone is used, however, it can be readily seen that only the centrally placed cells of this strand give the chromaffin reaction, a reaction participated in also by certain groups of cells surrounding the central intestinal artery and neighboring parts of the aorta. By these staining methods we may thus clearly show the two components of the adrenal gland, the medulla exhibiting the chromaffin reaction and the cortex, or interrenal component, characterized by its lipoid content. The arrangement of these two components resembles with surprising accuracy that of the adult as described by Stilling ('98) and (irynfeltt ('04).

The adrenal components of a thyroidectomized tadpole do not differ in any marked degree from those of the normal animal, yet there appears to be an increase in the cortical or interrenal tissue not entirely explained by the larger size reached by these animals (table 9). 
Albinous tadpoles, on the contrary, reveal notable variations even on surface view from the picture presented by the two normally pigmented types (fig. 39). Although the kidney is of normal size, the adrenal column appears much more slender and more mesially placed than in a normal or thyroidectomized specimen of corresponding or even of inferior size. Not only is the column more delicate, but its caudal extent is somewhat less, its cephalic extent, however, corresponding to the normal. Sudan III does not color the column deeply, while the osmicbichromate solution produces only a grayish coloration in contrast to the dark brown of the normal gland. Treatment with potassium bichromate gives an effect nearly identical with that of the normal. We thus have evidence, from surface views alone, which leads us to suspect that the adrenal cortex of the albino is diminished.

A section study of the three above-described types of animals lends corroborative evidence of an unquestioned nature to that furnished by the surface examination. For such a study it is essential that the technique employed not only preserve the lipoid content of the cortical or interrenal cells, but that the medulla be clearly, although not necessarily differentially, stained. The most satisfactory fixing fluid has proved to be an osmicbichromate mixture (Flemming's fluid less the acetic acid) which, although blackening the lipoids, does not interfere with the subsequent staining of the other tissues. Curiously, the chromaffin reaction is not shown when the osmium and bichromate, either mixed together or subsequent to each other, are used. Following fixation, immersion in 50 per cent. alcohol for twentyfour hours deepens the color of the lipoid granules and appears to render them less soluble in the higher alcohols and the clearing agents. The sections ( 5 to $8 \mu$ ) are rapidly run down to 60 per cent. alcohol and then stained for two to three hours in Babes' safranin at $36^{\circ}$. After rinsing in alcohol, rapidly dehydrating and mounting, there is presented a preparation in which the lipoid granules, a few of which have apparently been partially dissolved, are distinctly shown and in which the chromaffin cells can be unmistakably identified by their red tinge. 
Further evidence that this identification is not incorrect was secured by fixation in Müller's fluid followed by a prolonged mordantage in potassium bichromate, the sections then showing the reticular fat-free cortical cells and the browned medulla.

By the employment of these two methods it can be readily determined that this longitudinal cell mass, aside from bloodvessels, connective tissue, and an occasional readily identified nephric tubule, is composed entirely of adrenal cortex and medulla.

The cortical cords, varying somewhat in width, are usually formed of three or four cell columns. They measure in the normal animal from 30 to $48 \mu$ in diameter, an average of $36.6 \mu$. In the thyroidectomized specimens they are from 24 to $56 \mu$ in diameter, an average of $36.5 \mu$ (table 8 ). The individual cells composing these cords are of approximately the same size in the two animals, in the normal averaging $15.1 \mu$ in diameter, in the thyroidectomized specimens $16.5 \mu$. These cells are composed of a mass of lipoid granules imbedded in a cytoreticulum and surrounding a nucleus approximately centrally placed. This structure, then, after the osmic-bichromate solution gives a coarse, dark granular appearance, or after ordinary fixation and treatment with fat solvents reveals a delicate reticular cell.

If we compare these cortical cords, or cells, of the albino with those of the unoperated tadpole (figs. 38 to 41), we find that they are decreased in size in the former. The cords (in a 55-mm. albino) vary from 24 to $32 \mu$ in diameter, an average of $23.7 \mu$, a reduction of approximately 33 per cent. from the normal. The cells vary from 12 to $16 \mu$ in diameter and average $12.7 \mu$ (table 8), a reduction of approximately 25 per cent. from the normal. It is difficult to determine, because of their profuse branching, whether the cords are actually reduced in number in the albino, but apparently this is the case.

The interrenal cells of the normal or thyroidless animal are browned by osmic; those of the albino assume a gray tone (figs. $38,39)$. This would appear to be due to a different reaction of these granules and not to their volume, since the granules of both types of specimen are blackened by subsequent treatment with a low grade of alcohol. 
THE PARS BUCCALIS OF THE HYPOPHYSIS

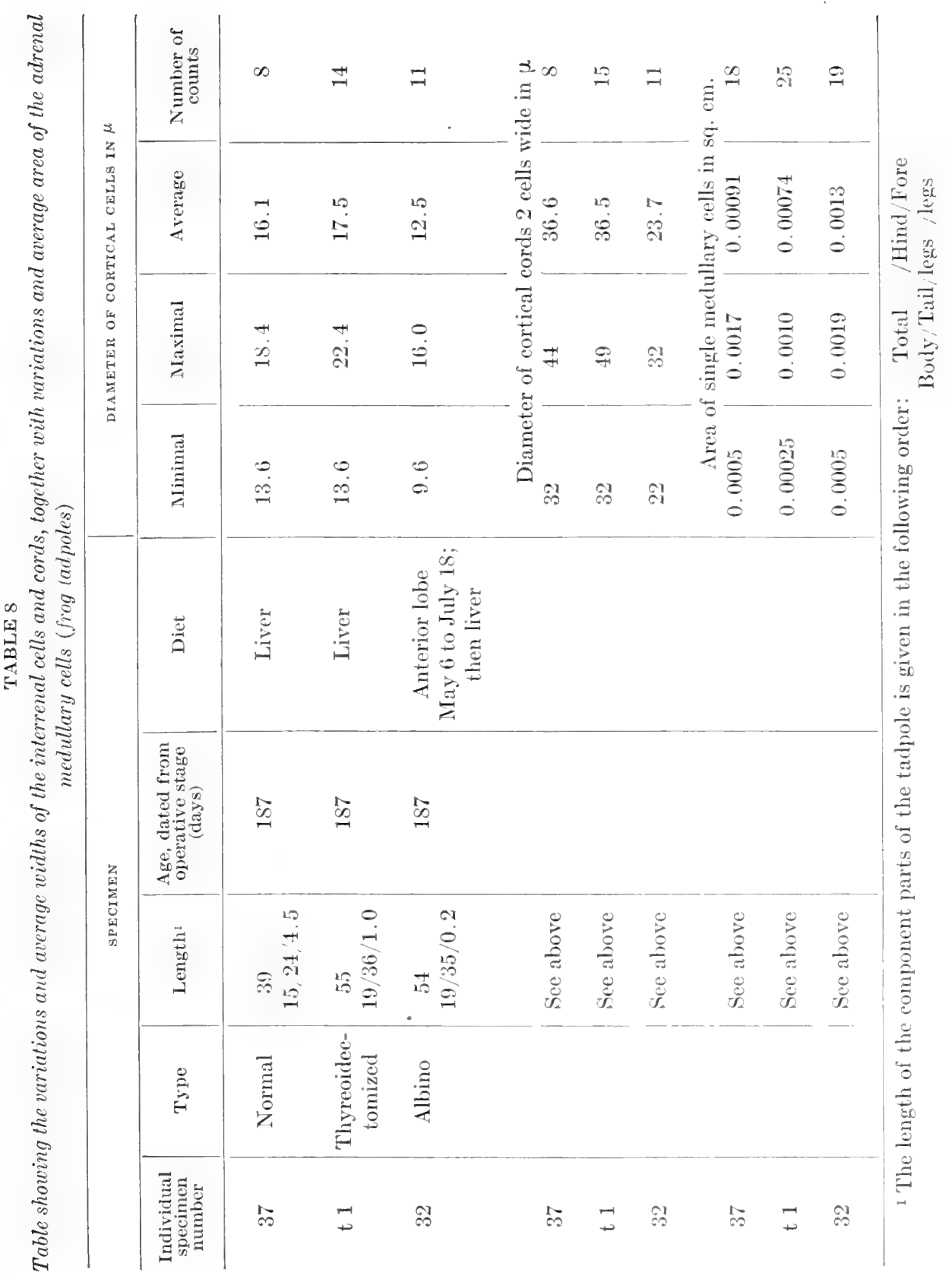


In order to determine accurately the diminution in the adrenal cortex in the albino and its inerease in the thyroidectomized tadpole, this substance was accurately drawn with the camera at a magnification of 300 diameters in three specimens, a $67-\mathrm{mm}$. albino, a 56-mm. thyroidless tadpole, and a 42-mm. normal animal. The drawings were transferred to a wax plate of proportionate thickness and the weight of the models of the cortex

TABLE 9

Table giving the weight of wax models (X300) of cortex of left adrenal (fiog tadpoles)

\begin{tabular}{|c|c|c|c|c|c|}
\hline \multicolumn{5}{|c|}{ SPECIMEN } & \multirow[t]{2}{*}{$\begin{array}{l}\text { Weight of } \\
\text { model in } \\
\text { grams }\end{array}$} \\
\hline $\begin{array}{c}\text { Individual } \\
\text { specimen } \\
\text { number }\end{array}$ & Type & Length ${ }^{1}$ & $\begin{array}{l}\text { Age, dated } \\
\text { from oopera- } \\
\text { tive stage } \\
\text { (days) }\end{array}$ & Diet & \\
\hline 36 & Albino & $\begin{array}{l}67 \\
-/-/ 0.2\end{array}$ & 228 & $\begin{array}{l}\text { Anterior lobe } \\
\text { May } 6 \text { to July } 18 \text {; } \\
\text { then liver }\end{array}$ & 144.43 \\
\hline 41 & Normal & $\begin{array}{l}42 \\
-/-/ 12\end{array}$ & 228 & Liver & 382.75 \\
\hline t 2 & $\begin{array}{c}\text { Thyroidec- } \\
\text { tomized }\end{array}$ & $\begin{array}{l}56 \\
-/-/ 2.0\end{array}$ & 228 & Anterior lobe & 759.60 \\
\hline p 11 & $\begin{array}{l}\text { Partial } \\
\text { albino }\end{array}$ & $\begin{array}{l}41 \\
-/-/ 16\end{array}$ & 286 & Same as spec. 36 & 360.15 \\
\hline
\end{tabular}

${ }^{1}$ The length of the component parts of the tadpole is given in the following order: Total/Hind/Fore

Body/Tail/legs/legs

thus secured for these three specimens (table 9). The cortical substance of one adrenal - the left in each case - was treated in this way The albino, although $11 \mathrm{~mm}$. longer than the thyroidectomized tadpole, and $25 \mathrm{~mm}$. longer than the normal specimen, had but 38 per cent. of the cortical tissue presented by the normal and 19 per cent. of that of the thyroidectomized specimen. It would thus appear to be established that the cortical tissue is greatly diminished in the albino as compared with 
the normal or thyroidectomized tadpole. On the other hand, the cortical adrenal tissue of the thyroidectomized tadpole exceeded by twice that of the normal. Although the thyroidless animal is somewhat larger than the normal $(11 \mathrm{~mm}$.), yet the discrepancy in the size of the adrenals is out of proportion to the difference in the size of the specimens, and it thus seems certain that the cortical tissue is hypertrophied in the thyroidless larva as compared to the normal.

Changes as striking but of a different nature are evident between the adrenal medulla of a normal or thyroidectomized tadpole and a hypophysectomized tadpole. In the normally pigmented larva the medullary cells present a diverse appearance, since certain cells are deeply stained and the cytoplasm limited by a definite cell membrane, while the opposite extreme is seen in certain other cells whose cytoplasm is reticular or even vacuolated and but slightly tinged by the dye, the cell membrane not being distinguishable (fig. 40). Between these two extremes all gradations can be found, a condition suggestive of the various secretory states exhibited by the mammalian chromaffin tissue. In the albino, on the other hand, the cells are of one type; their cell boundaries are distinct and their cytoplasm moderately and uniformly stained (fig. 41). Moreover, the cells are uniformly larger than those either of the normal or thyroidectomized tadpole as shown by table 8 .

Not only are the chromaffin cells larger in the albino, but their relation to each other and to the surrounding tissue is peculiar to these animals. They closely approximate each other and the adjacent cortical tissue, spaces between or around them being seldom evident. In the normal or thyroidectomized tadpole, on the other hand, an interval frequently separates these cells from each other and from the cortical tissue. This condition, which simulates shrinkage, was at first believed to be an artifact. Its constant occurrence in the normal and absence in the albino with identical technique suggests two possible causative factors. Either these spaces exist during life or the physical constitution of the cells of the normal and thyroidless larvae is such that shrinkage inevitably occurs during the manipu- 
lations involved in the technical treatment. Be the explanation as it may, it is certain that in the preparations the chromaffin tissue of the normal animal almost invariably does not fill the intracortical space accorded it.

A duplication in wax of the volume of the medulla $(\times 187.5)$ has been made for each of the three types of animal. In the normal and thyroidectomized animals the total intracortical medullary space has been included. It is evident, then, that if

TABLE 10

Table giving the weight of wax models (X187.5) of adrenal medulla (froy tadpoles)

\begin{tabular}{|c|c|c|c|c|c|}
\hline \multicolumn{5}{|c|}{ SPECIMEN } & \multirow[t]{2}{*}{$\begin{array}{l}\text { Weight o } \\
\text { model in } \\
\text { grams }\end{array}$} \\
\hline $\begin{array}{l}\text { Inditidual } \\
\text { specimen } \\
\text { number }\end{array}$ & Type & Length1 & $\begin{array}{l}\text { Age, dated } \\
\text { from opera- } \\
\text { tive stage } \\
\text { (days) }\end{array}$ & Diet & \\
\hline 34 & Albino & $\begin{array}{l}51 \\
19 / 35 / 0.2\end{array}$ & 217 & $\begin{array}{l}\text { Anterior lobe } \\
\text { May } 6 \text { to July } 18 \text {; } \\
\text { then liver }\end{array}$ & 27.32 \\
\hline 39 & Normal & $\begin{array}{l}39 \\
15 / 24 / 4.5\end{array}$ & 217 & Liver & 14.93 \\
\hline t 3 & $\begin{array}{c}\text { Thyroidec- } \\
\text { tomized }\end{array}$ & $\begin{array}{l}55 \\
19 / 36 / 1.0\end{array}$ & 217 & Anterior lobe & 24.46 \\
\hline
\end{tabular}

${ }^{1}$ The length of the component parts of the tadpole is given in the following order:

Total/Hind/Fore

Body/Tail/legs /legs

only the actual chromaffin tissue exclusive of the surrounding spaces had been drawn, an undertaking too laborious and uncertain to be considered, the mass of the model in the normal and thyroidless larvae would have been considerably reduced. From the included table it will be seen that the volume of the medulla while not seriously out of proportion to the size of the specimens would appear to be increased in both the albino and the thyroidless larvae (table 10).

Attention has already been repeatedly called to the incombetely hypongrectomized tadpole, the so-called 'partial' albino, 
and their characteristics described. Especial interest is associated with these specimens in the study of the adrenal, since the pigmentation in Addison's disease is usually referred to a derangement of the adrenal. Both whole mounts and sections, however, reveal the fact that neither the adrenal cortex nor medulla suffers a serious disturbance in the 'partial' albino as compared with the normal animal. To test more exactly the amount of cortex in one such specimen, it was reproduced in wax $(\times 300)$, as has been previously explained. These findings show that the cortical tissue is present in relatively as great an amount as in the normal tadpole (table 9). Apparently, then, as in the case of the thyroid, a relatively small amount of hypophysial tissue is sufficient to give rise to a normal adrenal.

\section{The epithelial bodies}

The epithelial bodies (Maurer) might be suspected of participating in the general endocrine upset experienced by the tadpole suffering from pituitary deficiency. Such, indeed, appears to be the case, although these bodies do not suffer as do the thyroids, adrenal cortex, or neural hypophysis. Models of these glands made from four normal and four albinous tadpoles reveal in many cases a profound diminution in the albino, although in other cases this decrease does not transcend the limits of variation of the individual bodies in the normal. When we take cognizance of the total amount of tissue, however, there can be no question but that it is profoundly diminished in the albino (table 11). There appears to be no serious structural abnormalities in these bodies. Thus in their reaction to epithelial hypophysectomy these bodies align themselves with all the other endocrine organs thus far examined (thyroids, adrenal cortex, neural hypophysis) save one, the adrenal medulla. An opposite response one of increasing size-is evoked in the epithelial bodies (Allen) by thyroidectomy. In this opposed response in thyroidectomy they thus align themselves with the enlargement which the pituitary (Allen, Hoskins) and adrenal cortex (Smith) enjoy.

MEMOIR NO. 11 . 


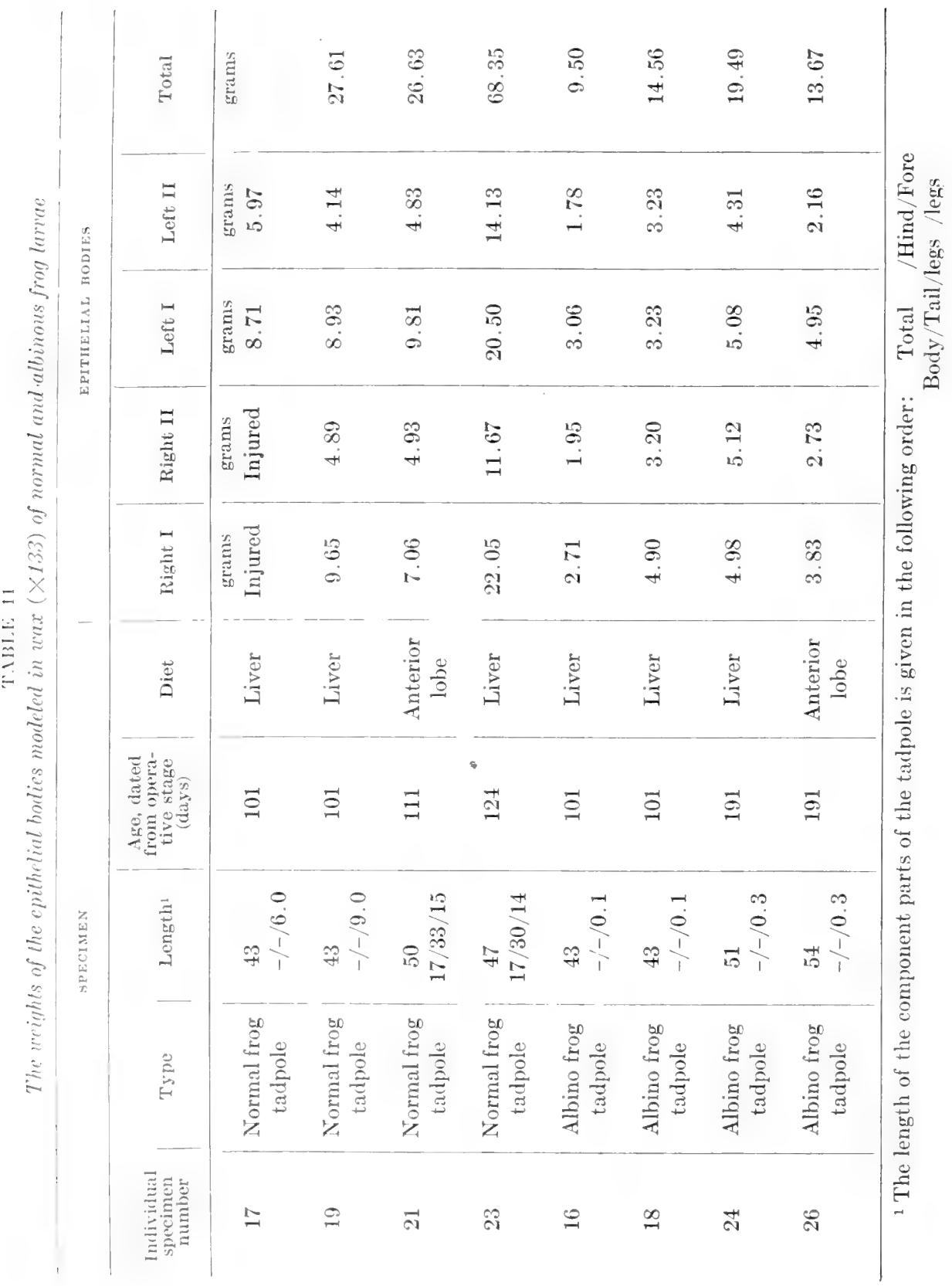




\section{The fat-organ}

Attention is called to the fat-organ, a structure which serves as a fat storehouse and as such is subject in the adult frog to seasonal and nutritional variations (Gaupp), since the behavior of this 'organ' in the tadpole suffering from hypophysial deficiency strongly simulates the behavior of the adipose tissue in the mammal suffering from hypopituitarism. The normal tadpole completing metamorphosis retains but a vestige of the former robust organ. Similarly, the fat-organ of a thyroidectomized tadpole subjected to inanition, or metamorphosed by thyroid administration, is greatly decreased in size. This is not the case with the albino (fig. 60). After prolonged starvation no decrease in the large size attained by this organ in these specimens is evident. In the 'partial' albino, too, although the animal undergoes a prolonged metamorphic period, this organ appears not to be reduced in size, though the nutritional needs of such an animal must be extreme. This was well shown by the two specimens of figure 53 . The partial albino, the most emaciated of the two, had an immense fat-organ; indeed, the fat-organ and the kidneys were the major abdominal structures. This 'organ' in the other specimen, however, a normal, was scarcely recognizable. The large size and persistency of this structure in the tadpoles suffering from a complete or partial ablation of the epithelial component of the pituitary, appears not to be unlike the adiposity exhibited by the mammal after partial hypophysectomy (adipositas universalis, Cushing) or in the human subject suffering from hypopituitarism. These animals thus furnish abundant testimony of the disturbance in fat metabolism brought about by these conditions and indicate that even under the extreme exigencies of inanition the utilization of the fat is impossible. 


\section{DISCUSSION}

It has been possible to determine the contribution which each group of pigment cells makes to the striking picture of 'albinism' produced by the operation of epithelial hypophysectomy in the early larvae of the toad and frog. Evidence from at least two sources (feeding experiments and epithelial ex(hanges) points to the importance of the paucity of the epidermal melanin in the formation of this picture. By this paucity and the consequent greater transparency of the epidermis the double sheet of broadly expanded xantholeucophores are permitted to display their full iridescent and metallic effect. The expansion of the xantholeucophore group of cells is essential to this picture, since with their contraction the albinous picture lost its characteristic metallic appearance and the larvae became notably darkened in color. Moreover, that the participation of the deep melanophores in this picture was of no great significance was evident not only from the masking which these cells suffer due to the expanded 'interference' cells, but from a variety of experimental procedures.

The atypical physiological condition of the pigment cells contributing to this picture of albinism is unquestionably referable to a fault in the endocrine system and not to an altered nervous mechanism. Not only is evidence of an unequivocal nature presented on this point as regards the altered physiological state of the xantholeucophores and epidermal melanophores by the skin exchanges, but the effect of endocrine extracts and diets on the atypical pigmentary system lends adjuvant evidence.

With the complex interrelationships obtaining in the internal secretory system, however, some difficulty has been encountered in referring the pigmentary disturbance exhibited by the tadpoles suffering from hypophysial deficiency to a definite locus in this system. Yet by the correlation of the evidence accruing both from the structural pictures presented by the members of this system together with the alterations in the pigmentary system produced by various dietary régimes and by immersion 
of the albino in endocrine extracts, the specific endocrine deficiency would appear to be disclosed. In this we have been greatly aided by the different endocrine pictures obtaining in completely and partially hypophysectomized larvae, for it will be recalled that both of these types of animals exhibit a pigmentary fault. Since all the endocrine glands save the pituitary are of normal structure in the partially hypophysectomized (but albinous) larvae, it would appear that neither the adrenal components, the epithelial bodies, nor the thyroid are at fault. The thyroid can further be freed from participation in this disturbance since the pigmentary system of the thyroidectomized tadpole is normal. Further, it will be recalled that the feeding of posterior-lobe tissue (including the pars intermedia), alone, of all the administered glandular substances (thyroid, adrenal cortex, adrenal medulla, and anterior lobe), effected a partial replacement of the epidermal melanin, although, curiously, at the same time, increasing the abnormal contraction of the epidermal melanophores. It was further shown that the immersion of these larvae in pars intermedia emulsion alone of the internal secretory extracts produced a normal functional state in the chromatophore system. Thus, the evidence derived from these three lines of investigation all points to a fault in the posteriorintermediate lobe secretory mechanism as being responsible for the pigmentary disturbance obtaining in the larvae suffering from either a partial or total loss of their epithelial hypophysis.

The alimentary assimilation of the fresh glandular lobe of the pituitary has supplied the growth-maintaining principle to the animals exhibiting a retarded growth rate induced by buccal hypophysectomy. ${ }^{46}$ Unequivocal proof of this is furnished by

${ }^{46}$ What element of this structurally diverse gland contributes this growth principle is obscure. Histological examination of frozen sections (15 to $20 \mu$ ) reveals that extraction with boiling absolute alcohol does not appreciably diminish either the number or size of the most characteristic element of this gland, the acidophilic granulations. Evidence determinative of the dissolving action of boiling distilled water is more uncertain because of the macerating action upon the connective tissues and the consequent difficulty in the examination of this material. Yet it is certain that a considerable number of these granules survive such treatment. That the tissue thus extracted exhibits the characteristic growth effects of the fresh gland, while the extracts do not exhibit such effects, supplies evidence against these granu- 
the frog, supportive evidence by the toad tadpole. Extraction of this anterior-lobe substance with either boiling absolute alcohol or boiling water appears not to remove this principle, since the albinous tadpoles supplied with such extracts exhibit the retarded growth rate typical of the liver-fed albino, while those larvae supplied with the residues remaining after extraction grow at a normal rate.

We have pointed out the structural modifications in the various organs of the internal secretory system resulting from the early ablation of the pars epithelialis of the hypophysis. By these alterations eloquent testimony as to the interdependence of the various widely separated members of this correlative system has been secured. It will be recalled that the response of these organs to the complete loss of the epithelial hypophysis led to a diminution in their size, save in one gland, namely, the adrenal medulla. It was also pointed out that the opposite response is evoked by the early removal of the thyroids, the members of this system undergoing an increase in size, save again the adrenal medulla, which appears not to be seriously altered. It is thus seen that the response of the organs of internal secretion (save the adrenal medulla) to epithelial hypophysectomy is in the reverse direction to that resulting from thyroidectomy, the loss of the hypophysis causing a diminution, the loss of the thyroid an increase in their size.

It was further pointed out that the presence of a relatively minute remnant of the epithelial pituitary was sufficient to abort the structural anomalies in these organs arising from the complete loss of the epithelial hypophysis, save the case of the derivatives of the infundibular process. These derivatives, of which the major member is the neural lobe, are always affected in any partial epithelial hypophysectomy. This we were inclined to refer to the close anatomical relationship obtaining between these two components of the pituitary. For it was shown that

lations being merely a by-product or a refuse accumulated during the secretory process. It must be admitted that such evidence is inconclusive, however, since the part played by the other cells, the basophiles and chromophobes, whose cytoplasm appears to be more labile than that of the acidophiles, has not been excluded. 
in the case of the complete absence of the epithelial hypophysis the neural lobe underwent an abortive development, while the other portion of the infundibular process, the pituitary floor, normally in contact with the epithelial component, retained its membranous character in sharp contrast to the thickened wall normally displayed. Further studies of the 'partial' albino indicated that the atypically placed epithelial fragment apparently is able to 'stimulate' the adjacent neural tissue to form a structure, simulating histologically the typical neural lobe. Doubt, however, was cast upon the functional sufficiency of this 'novel' neural lobe, since the animals displaying this anatomical arrangement failed to metamorphose in contrast to those in which this epithelial fragment attained contact, though but slight, with the true neural lobe, a failure not entirely attributable to the smaller size of this epithelial remnant. From this it would appear that the neural tissue comprising the pars nervosa of the pituitary enjoys the same functional specificity as do the other glandular tissues of the body.

It is a pleasure to acknowledge the aid which I have received throughout this work from Doctor Evans. The many helpful suggestions and the encouragement which he has given during the progress of the work and in the preparation of the manuscript have been invaluable. To Mrs. Smith and Mr. Lee for their aid in the preparation of many of the models I am much indebted. Acknowledgment is made for the services rendered by our photographer, Mr. Matthews, and by our artist, Mr. Sweet.

\section{SUMMARY}

1. The frog and the toad tadpole, because of the accessibility of the epithelial hypophysis in the early larval stages and the prolonged survival of the animals suffering the loss of this gland, has proved of great value in the institution of hypophysial disturbances and in the subsequent analysis thereof. 
2. The early removal of the epithelial hypophysis induces a striking disturbance, 1) in the pigmentary system, 2) in the growth rate, and, 3) in the structural characteristics of most of the other glands of internal secretion.

3. The pigmentary alterations resulting from early hypophysectomy are expressed by, 1) a diminution in the epidermal free pigment; 2) a diminution in the number and melanin content of the epidermal melanophores, together with an abnormal state of contraction; 3) a maximal expansion of the xantholeucophores; 4) a partial contraction of the deep melanophores in the younger larvae.

4. The first three above-mentioned alterations in this system result in and are essential to the complete formation of the picture of albinism; the fourth does not materially contribute to this picture. This would be suspected from the anatomical arrangement obtaining in these cell layers and can further be proved by various experimental procedures by which each of these factors can be modified: 1) the partial replacement of the (pidermal melanin (effected by posterior-lobe feeding) is seen to blanket partially the underlying, broadly expanded xantholeucophores, the larvac being notably darker than their brothers supplied with other diets;2) the complete expansion or contraction of the deep melanophores of the albino effected by altering the conditions of light and background does not materially change the color of the albinous larvae, and conversely the contraction of these cells in the normal by the absence of light, while productive of a translucency, does not produce an albino; 3 ) a contraction of the xantholeucophores of the albino as exhibited by an albinous graft to a normal host or by the use of a strong anaesthetic not only results in their darkening, but in the loss of the metallic silvery tone characteristic of the picture of albinism.

5. A developmental study of the pigmentary system of the allino reveals the fact that the epidermal melanophores appear at a later date and in diminished numbers as compared to the normal; that the free epidermal melanin suffers a relatively greater diminution than in the normal, and that the xantho- 
leucophores appear at the same time and in approximately the same numbers as in the normal, but exhibit from their earliest appearance a broad expansion as compared to the punctate character of these cells in the unoperated tadpole.

6. The broad expansion of the xantholeucophores and contraction of the epidermal melanophores of the albino is not due to an alteration in their nervous mechanism, but to the modified tissue fluids which bathe them. This is proved by the reciprocal skin exchanges. That this alteration in the tissue fluids is of a hormonal nature appears probable not only from the known potency of these substances, but also because of the extensive modifications suffered by the elaborators of these substances in the albino. There appears to be no ground for referring the deficiency in the epidermal melanin to other than an internal secretory origin.

7. Various physiological and pharmacological experiments on the pigmentary system of older albinous and normal larvae reveal the fact that, 1) the deep melanophores of the albino and the normal tadpole react identically under all tests tried by the author; 2) the xantholeucophores of the normal animal respond to changes in environmental conditions, those of the albino, on the other hand, maintain a refractory expansion under all sublethal stimuli tried by the author, save that afforded by the pars intermedia emulsion; 3) the epidermal melanophores of the albino invariably expand when subjected to the condition of 'light and heat.' Those of the normal tadpole react in a more variable manner, not infrequently exhibiting the opposite reaction, contracting instead of expanding.

8. The thyroid and the adrenal cortex are strikingly diminished in size in the albino; the epithelial bodies suffer a lesser though definite diminution; the adrenal medulla suffers no unquestionable quantitative changes, but it appears not improbable that it is slightly hypertrophied. Structurally, the adrenal medulla is clearly altered in the albino, since its cells are all of a uniformly staining large type, as compared to the variability in size and the diversity in appearance exhibited by the adrenal chromaffin cells of the normal. 
9. The posterior lobe is invariably diminished in size, asymmetrical in shape, and atypical in position in the albino. Moreorer, in the albino the floor of the infundibular process-pituitary floor-normally in contact with the epithelial hypophysis, does not undergo the secondary thickening which takes place in the normal subsequent to the juxtaposition of the epithelial hypophysis with this structure, but retains its membranous structure.

10. Attempts to remove the buccal hypophysis occasionally leare a sufficiently large fragment of the epithelial hypophysis in place for complete regeneration to occur. Other instances of incomplete removal of the epithelial part of the gland produce animals which are altered in a characteristic way. We have termed these 'partial' albinos. As far as their appearance is concerned, in most instances these animals are typical albinos and the incomplete nature of the operation is only disclosed later when a development of the limbs appears. Indeed, some of these 'partial' albinos furnished the only instances of the complete metamorphosis of albinous larvae. Our present knowledge of the intimate relationship of the thyroid to metamorphosis would lead us to predict that the thyroid gland at least, was not interfered with. As a matter of fact, anatomical study of all of the 'partial' albinos showed that not only the thyroid, but that all of the internal secretory glands, with one exception, were undiminished in size or degree of development. Indeed, in a limited number of those 'partial' albinos which completed metamorphosis the thyroid was greatly hypertrophied (colloid goiter) and frequently accessory thyroids were formed.

11. The neural lobe of the 'partial' albino is usually diminished in size and is invariably atypical in shape and position.

12. About the atypically placed epithelial fragment of the hypophysis of the 'partial' albino there is formed a 'novel' neural lobe, a structure apparently formed not only by the indentation of this epithelial fragment in the brain tissue, but by an actual hypertrophy of the adjacent parts. Not infrequently in these specimens there is no recognizable neural lobe such as invariably is exhibited by the typical albino. 
13. The evidence thus indicates that the neural lobe and pituitary floor are dependent upon the epithelial hypophysis for their complete development, and further that an atypically placed epithelial hypophysis has the power to cause an hypertrophy of the adjacent neural tissue.

14. Since 'partial' albinos may be secured in which the pigmentary upset or albinism is nearly as profound as in those larvae which have suffered a complete epithelial ablation, and since in these instances none of the endocrine glands are gravely impaired in development save the hypophysis, and since the feeding of posterior lobe (plus pars intermedia), alone, of the major internal secretory glands effects a partial replacement of the epidermal melanin in the albino, and further since no extract save that of the pars intermedia induces a normal physiological state in the pigmentary system of this animal, it seems justifiable to refer the endocrine fault responsible for the pigmentary disturbance to the posterior lobe or the posteriorintermediate lobe secretory mechanism and to free the other glands from responsibility.

15. The frog tadpole suffering from complete or incomplete hypophysial deficiency exhibits even after a long period of inanition or after a prolonged metamorphosis a fat-organ undiminished in size, in contrast to the small size of this organ in similarly treated thyroidless tadpoles or in normal tadpoles near the end of metamorphosis. The persistence of the fatorgan in these tadpoles appears to simulate the adiposity exhibited by the mammal suffering from hypophysial deficiency.

16. The frog tadpole which has suffered the early loss of its epithelial hypophysis exhibits a retardation in growth when supplied with a continuous diet of liver, posterior lobe, adrenal cortex, or adrenal medulla. This growth retardation is feebly expressed at first, but becomes very pronounced at about the midlarval period.

17. A continuous diet of the fresh anterior lobe of the beef replaces the growth-'maintaining' substance lost by buccal hypophysectomy and so effects a nearly normal rate of growth in the albinous frog tadpole. Since these animals do not meta- 
morphose, their growth extends beyond the normal larval period. Consequently they attain a size in excess of the normal.

18. The sensitiveness of the hypophysectomized frog tadpole to the growth-'maintaining' substance of the anterior lobe makes it possible by feeding experiments to test in a particularly efficacious manner any hypophysial substance for the presence or absence of this principle.

20. Neither aqueous nor alcoholic extracts of the anterior lobe of the pituitary nor the intraglandular colloid of the hypophysis contain the growth-'maintaining' substance of this gland. Conversely, the residues formed by extracting the hypophysis with boiling water or boiling absolute alcohol contain this growth substance. 


\section{BIBLIOGRAPHY}

Abderhalden, A. 1919 Weitere Studien über die von einzelnen Organen hervorgebrachten Substanzen mit spezifischer Wirkung. Pflügers Arch., Bd. 176, S. 236-262.

Adeer, L. 1914 Metamorphosestudien an Betrachierlarven. I. Extirpation endokriner Drüsen. A. Extirpation der Hypophyse. Arch. f. Entw.mech. d. Organ., Bd. 39, S. 21-45.

Aldrich, T. B. 1912 On feeding young white rats the posterior and anterior parts of the pituitary gland. Am. Jour. Physiol., vol. 31, pp. 94-101. 1912. On feeding young pups the anterior lobe of the pituitary gland. Am. Jour. Physiol., vol. 30, pp. 352-357.

Allen, B. M. 1916 Extirpation experiments in Rana pipiens larvae. Science, vol. 44 , pp. $755-757$.

1916 Extirpation of the hypophysis and thyroid glands of Rana pipiens. Am. Soc. Zool, Abstracts, p. 14.

1917 Effects of the extirpation of the anterior lobe of the hypophysis of Rana pipiens. Biol. Bull., vol. 32, pp. 117-130.

1917 Further studies upon amphibian larvae from which the anterior lobe of the hypophysis had been removed. Am. Assoc. Anat., Abstracts, pp. 4-5.

1917 The influence of thyroid and hypophysis removal upon general body growth and upon the development of the limbs of Rana and Bufo. Am. Soc. Zool., Abstracts, pp. 4-5.

1917 The relation of normal thyroid-gland development to bodily growth and differentiation in Rana, Bufo, and Amblystoma. Am. Assoc. Anat., Abstracts, p. 4.

1918 Results of extirpation of both thyroid and pituitary glands in tadpoles of Bufo and Rana. Am. Soc. Zool., Abstracts, pp. 20-21.

1918 Miscellaneous notes regarding experimental studies upon the endocrine glands of Rana and Bufo. Am. Soc. Zool., Abstracts, p. 21.

Atwell, W. J. 1918 The development of the hypophysis of the Anura. Anat. Rec., vol. 15, pp. 73-92.

1919 On the nature of the pigmentation changes following hypophysectomy in the frog larva. Science, N. S., vol. 49, pp. 4S-50.

Atriell, W. J., And Marinus, C. J. 1918 A comparison of the activity of extracts of the pars tuberalis with extracts of the other regions of the ox pituitary. Am. Jour. Physiol., vol. 47, pp. 76-91.

BABÁK, E. 1913 Ueber den Einflusz des Lichtes auf die Vermehrung der Hautchromatophoren. Pflügers Arch. f. d. ges. Physiol., Bd. 149, S. 462470 .

Burr, H. S. 1916 Regeneration in the brain of Amblystoma. Jour. Comp. Neur., vol. 26, pp. 203-211.

CAselli, A. 1900 Influenza della funziono dell' ipofisi sulla sviluppo dell' organisimo; nota preventiva sulla fisiopatologia della ghiandola pituitaria. Riv. sper. di freniat., Reggio-Emilia, T. 26, pp. 176, 486 (cit. after Cushing). 
Centritri, U, 1907 Effets des injections de sue d'hypophyse sur l'accroissement somatique. Arch. ital. de biol., T. 47, pp. 123-134.

Crow r, S. J., Cushing, II., And Homans, J. 1910 Experimental hypophysectomy. Bull. J. H. Hosp., vol, 21, pp. 127-169.

Cusmixci, H. 1912 The pituitary body and its disorders. Philadelphia.

Linmaxx, S. 1892 Zur Kenntnis von der Entwicklung und Wanderung des Pigmentes bei den Amphibien. Arch. f. Dermatol. u. Syphilis, Bd. 24, s. $195-223$.

Erminim, J., und Stumne, E. 1909 Über die Schwangerschaftsveränderung der Hypophyse. Beitr. path. Anat. allg. Path., Bd. 46, S. 1-132.

Fucus, R. F. 1914 Der Farbenwechsel und die chromatische Hautfunktion der Tiere. Winterstein's Handb. d. vergl. Physiol., Bd. 3, Hälfte 1, 'Teil 2, S. 1189-1657.

Gaupp, E. 1904 Anatomie des Frosehes. Bd. 3. Braunschweig.

Grinfeltr, Ed. 1904 Notes histologiques sur la capsule surrénale des amphibiens. Jour. d. I'Anat. et d. la Physiol. Ann. 40, pp. 180-220.

HAberfeLd, W. 1909 Die Rachendachhypophyse, andere Hypophysengangreste und deren Bedeutung für die Pathologie. Beitr. path. Anat. u. allg. Path., Bd. 46, S. 133-232.

HALSTED, W. S. 1909 Auto- and isotransplantation, in dogs, of the parathyroid glandules. Jour. Exp. Med., vol. 11, pp. 175-199.

HARRISON, R. G. $189 S$ 'The growth and regeneration of the tail of the frog larvae. Arch. Entw.-mech., d. Organ., Bd. 7, S. 430-485.

Herring, P. T. 1914 The origin of the active material of the posterior lobe of the pituitary body. Quart. Jour. Exp. Physiol., vol. 8, pp. 245-265.

Hooker, D. 1914 The reactions to light and darkness of the melanophores of frog tadpoles. Science, N. S., vol. 39, p. 473.

Hoskins, E. R. And M. M. 1916 On thyroidectomy in amphibia. Am. Assoc. Anat, Abstracts, p. 47.

1917 On thyroidectomy in amphibia. Proc. Soc. Exp. Biol. and Med., vol. 14, pp. 74-75.

1918 Further experiments with thyroidectomy in amphibia. Proc. Soc. Exp. Biol. and Med., vol. 15, pp. 102-104.

1919 Experiments with the thyroid, hypophysis and pineal glands of Rana sylvatica. Am. Assoc. Anat, Abstracts, p. 17.

JArtsen 1891 Ueber die Anatomie und Entwickelung des Oberhautpigmentes beim Frosche, Arch. f. Dermatol. u. Syphilis, Bd. 23, S. 559-590.

Jonvon, M. H. 1913 The control of pigment formation in amphibian larvac. Univ. Calif. P'ub, in Zool., vol. 11, pp. 53-88.

Komx, A. 1910 Uber das Pigment in der Neurohypophyse des Menschen. Arch.f. mikr. Anat., Bd. 75, s., 337-374.

Laurexs, II. 1914 the reations of normal and eyeless amphibian larvae to light. Jour. Exp. Zoöl., vol. 16, pp. 195-210.

1916 The reactions of the melanophores of Amblystoma larvae. The supposed influence of the pineal organ. Jour. Exp. Zoöl., vol. 20, pp. $237-261$. 
LAURENS, H. 1917 The reactions of the melanophores of Amblystoma tigrinum larvae to light and darkness. Jour. Exp. Zoöl., vol. 23, pp. 195-205.

Levy, R. L. 1916 Studies on the conditions of activity in endocrine glands. IV. The effect of the thyroid secretion on the pressor action of adrenalin. Am. Jour. Physiol., vol. 41, pp. 492-512.

Lewis, WARREN H. 1910 Localization and regeneration in the neural plate of amphibian embryos. Anat. Rec., vol. 4, pp. 191-198.

Leydig, Fr. 1876 Ueber die allgemeinen Bedeckungen der Amphibien. Arch.f. mikr. Anat., Bd. 12, S. 119-241.

Lieben, S, 1906 Über die Wirkung von Extrakten chromaffinen Gewebes (Adrenalin) auf die Pigmentzellen. Centralbl. f. Physiol., Bd. 20, S. 108-117.

Lowe, J. N. 1917 The action of various pharmacological and other chemical agents on the chromatophores of the brook trout, Salvelinus fontinalis Mitchell. Jour. Exp., Zoöl., vol. 23, pp. 147-193.

Maurer, F. 1888 Schilddrüse, Thymus und Kiemenreste der Amphibien. Morph. Jahrb., Bd. 13, S. 296-382.

McCord, C. P., ANd Allen, F. P. 1917 Evidences associating pineal gland function with alterations in pigmentation. Jour. Exp. Zoöl., vol. 23, pp. 207-224.

Mendel, L. B., And Osborne, T. B. 1918 Further observations on the nutritive factors in animal tissues. Proc. Soc. Exp. Biol. and Med., vol. 15, pp. 71-72.

Osborne, T. B., And Mendel, L. B. 1916 Acceleration of growth after retardation. Am. Jour. Physiol., vol. 40, pp. 16-20.

Redfield, A. C. 1916 The coördination of chromatophores by hormones. Science, N. S., vol. 43 , pp. $580-581$.

1918 The physiology of the melanophores of the horned toad Phrynosoma. Jour. Exp. Zoöl., vol. 26, pp. 275-333.

Robertson, T. B. 1916 Experimental studies on growth. III. The influence of the anterior lobe of the pituitary body upon the growth of the white mouse. Jour. Biol. Chem., vol. 24, pp. 385-396.

Robertson, T. B., And Ray, L. A. 1919 Experimental studies on growth. XI. The growth and senesence of white mice fed upon pituitary (anterior lobe) tissue, tethelin, egg lecithin, or cholesterol. Jour. Biol. Chem., vol. 37 , pp. $393-426$.

Rogers, J. B. 1918 The effect of the extirpation of the thyroid upon the thymus and pituitary glands of Rana pipiens. Jour. Exp. Zoöl., vol. 24, pp. $589-605$.

Smith, P. E. 1916 Experimental ablation of the hypophysis in the frog embryo. Science, N. S., vol. 44, pp. 280-282.

1916 The effect of hypophysectomy in the early embryo upon the growth and development of the frog. Anat. Rec., vol. 11, pp. 57-64. 
Sмiтн, P. IE. 1916 The effect of hypophysectomy upon the subsequent growth and development of the frog (Rana boylei). Am. Assoc. Anat., Abstracts, p. 94 .

1918 The growth of normal and hypophysectomized tadpoles as influenced by endocrine diets. Univ. Cal. Pub. in Physiol., vol. 5, p). $11-22$.

1919 The pigment changes in frog larvae deprived of the epithelial hypophysis. Proc. Soc. Exp. Biol. and Med., vol. 16, pp. 74-78.

1919 On the reaction of the pigment cells in normal and albinous frog larvae. Ibid., pp. $7 S-80$.

1919 Upon the experimental exchange of skin transplants between normal and albinous larvae. Ibid., vol. 16, pp. 80-81.

1919 On the effects of ablation of the epithelial hypophysis on the other endocrine glands. Ibid., vol. 16, pp. 81-82.

SPAETI, R. A. 1913 Evidence proving the melanophore to be a disguised type of smooth muscle cell. Jour. Exp. Zoöl., vol. 20, pp. 193-215.

1916 The responses of single melanophores to electrical stimulation. Am. Jour. Physiol., vol. 41, pp. 577-596.

1918 Concerning a new method of biological standardization of pituitary extract and other drugs. Jour. Phar. and Exp. Ther., vol. 11, pp. 209-219.

Srdinko, O. V. 1900 Bau und Entwickelung der Nebenniere bei Anuren. Anat. Anz., Bd. 18, S. 500-508.

Stendelu, W. 1913 Zur vergleichenden Anatomie und Histologie der Hypophysis cerebri. Arch. f. mikr. Anat., Bd. 82, S. 289-332.

Strulling, H. 1898 Zur Anatomie der Nebennieren. Arch. f. mikr. Anat., Bd. 52, S. $176-195$.

S'Tump 1911 Zur Histologie der Neurohypophyse. Virchows Arch., Bd. 206, S. $70-79$.

Terry, G. S. 1918 Effects of the extirpation of the thyroid gland upon ossification in Rana pipiens. Jour. Exp. Zoöl., vol. 24, pp. 567-587.

Tiluex, F. 1913 An analysis of the juxta-neural epithelial portion of the hypophysis cerebri, with an embryological and histological account of a hitherto undeseribed part of the organ. Intern. Monat. f. Anat. u. Physiol., Bd. 30, S. 258-293.

T'ruvmann, A. 1909 Anatomie und Histologie der Hypophysis cerebri einiger Sïuger. Arch. f. mikr. Anat., Bd. 74, S. 311-367.

Vogki, M. 1912 Das l'igment des Hinterlappens der menschlichen Hypophyse. Frankfurt. Zeitschr. f. Pathol., Bd. 11, S. 166-191.

Weigi, R. 1913 Uber homöoplastische und heteroplastische Hauttransplantation bei Amphibien mit besonderer Berücksichtigung der Metamorphose. Arch.f. Entw.-mech. d. Organ., Bd. 36, S. 595-625.

Winkleir, F. 1910 Beobachtungen über die Bewegungen der Pigmentzellen. Arch. f. Dermat. u. Syphilis, Bd. 100, S. 255-260. 
PIATES 


\section{ABBREVIATIONS}

"1.0., athesive organ

hyp., hypophysis

hyp.p., hypophysial pit

inf.. infundibulum

"1.p.ep., vestigial (2pithelial lobe (pars epithelialis)

m.p.n., new nemaral lobe

o.p., olfactory placode op.r', optic vesicle

ot.r., otic vesicle

p.f., pituitary floor

p.o., pars glandularis of the hypophysis

p.i., pars intermedia of the hypophysis

$p . n$., pars neuralis of the hypophysis

l.p.f. thickened portion of pituitary foor

$I, I I, I I I$, branchial arches

\section{PIATE 1}

\section{EXPLANATION OF FIGURES}

11 I t-mm. frog larva (R. boylei) showing the surface characteristics at a favorable stage for epithelial hypophysectomy. (a) Ventrolateral, (b) ventrocephalic view.

12. I median sagital secotion of a frog larva of aporoximately the same age and size as shown in figure 11. 
PLA'T I

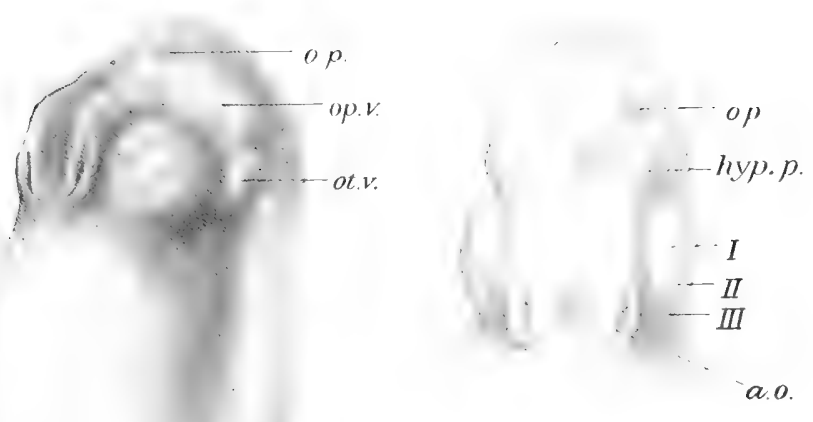

b)

$a$

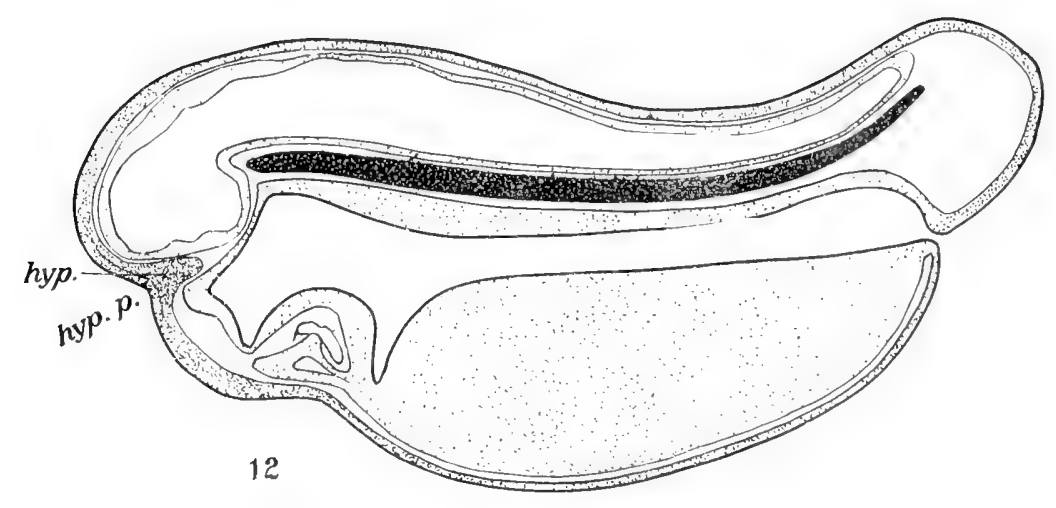


PLATE ?

\section{EXPLANATION OF FIGURES}

I:3 The pigmentary system ti of a normal 43, $9.0^{\text {ts }}$ frog tadpole, 'standard' environment, showing the suceesive layers of free pigment and chromatophores. ${ }^{2}$ the animal was fixed by dropping into Helly's fluid 101 days after the operative stage. Liver diet. X296.

14 The pigmentary system of a 43. 0.1 albino frog tadpole, 'standard' environment. Fixed by dropping into Helly's fluid 101 days after epithelial hypophysectomy. Liver diet. $\times 226$.

15) The pigmentary system of a 10 -mm. (total length) normal frog tadpole, standard enviromment. Dropped into Helly's fluid 22 days after the operative stage. Liver diet. The epidermal melanophores are just appearing. X226.

17. 11 the drawings of the pigment cells (figs. 13 to 23 ) were made from skin whole mounts taken from the dorsal region of the body.

th The total length of the specimen is shown by the first figure, the hind-leg length by the reeond.

19 In the pigment cell drawings the most superficial layer is shown on the left, the deepest on the right. Irom left to right they are in order, (a) the layer of free cpilcmal pigment, (b) the layer of epidermal melanophores, (b) the xantholeucophores, (d) the dece melanophores. 

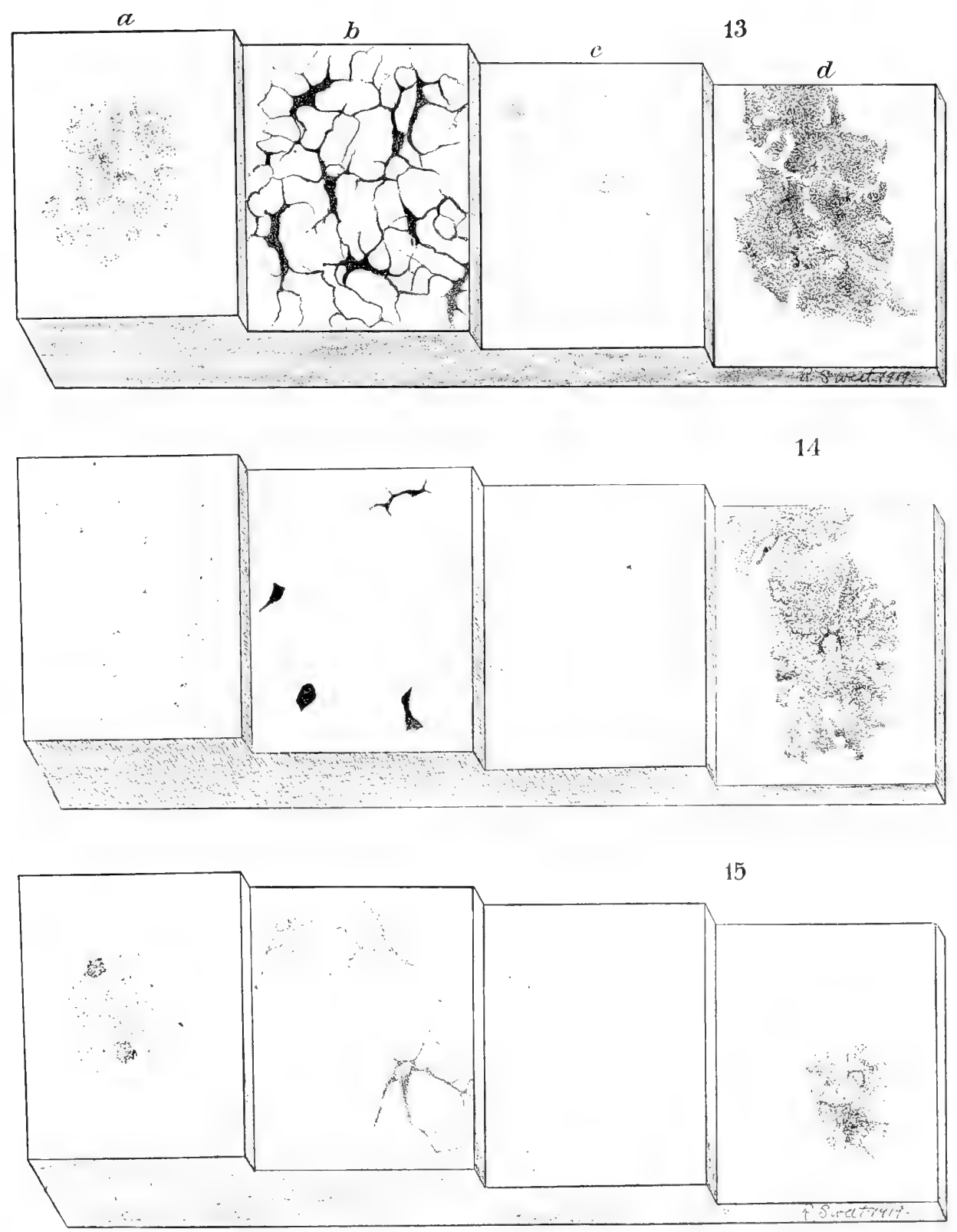
PIATE:

\section{EXPLANATION OF FIGTRES}

16 The pigmentary ststem of a 10-mm. (total length) albino frog tadpole, 'standand' enviromment. Dropped into Helly's fluid 22 days after the operative stage. Liver liet. The epidemal melanophores have not yet formed. X226.

17 The pigmentary system of a 14.5 -mm. (total length) normal frog tadpole, 'standard' enviromment. Fixed by dropping into Helly's fluid to days after the operative stage. Liver diet. $\times 226$.

Is The pigmentary system of a 14.5-mm. (total length) albino frog tadpole, standard onviromment. Fixed by dropping into Helly's fluid 47 days after the

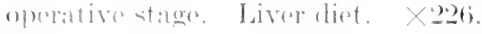



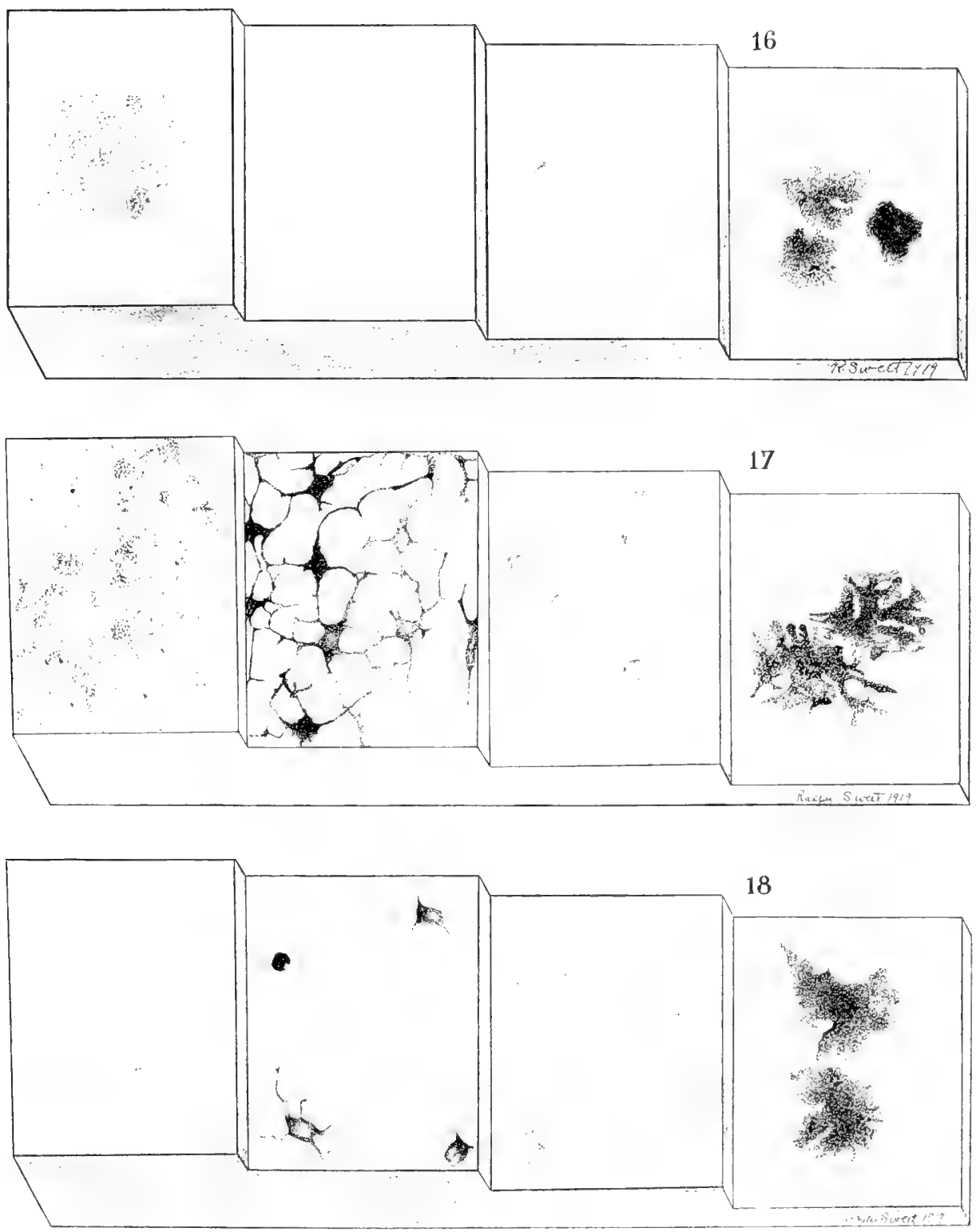
PLATE +

BXPLANATION OF FIGURES

19 The pigmentary system of a 'light and heat' adapted $38 / 6.0$ normal frog tadpole which exhibited a contraction of the epidermal melanophores under the influence of this stimulus. Fixed $5, \frac{1}{2}$ months after the operative stage by dropping into Helly's fluj(d. Liver diet. $\times 226$.

20 The pigmentary system of a 'light and heat' adapted $46 / 0.5$ albino frog tadpole. Fixed $5 \frac{1}{2}$ months after epithelial hypophysectomy by dropping into Itelly's fluid. Liver diet. $\times 226$.

21 The pigmentary system of a $46 / 0.1$ albino frog tadpole, supplied with a continuous diet of posterior lobe, 'standard' environment. Fized by dropping into Holly's ftuid, t'a monthis after epithelial hypophysertomy. $\times 226$. 
I'I A'T'
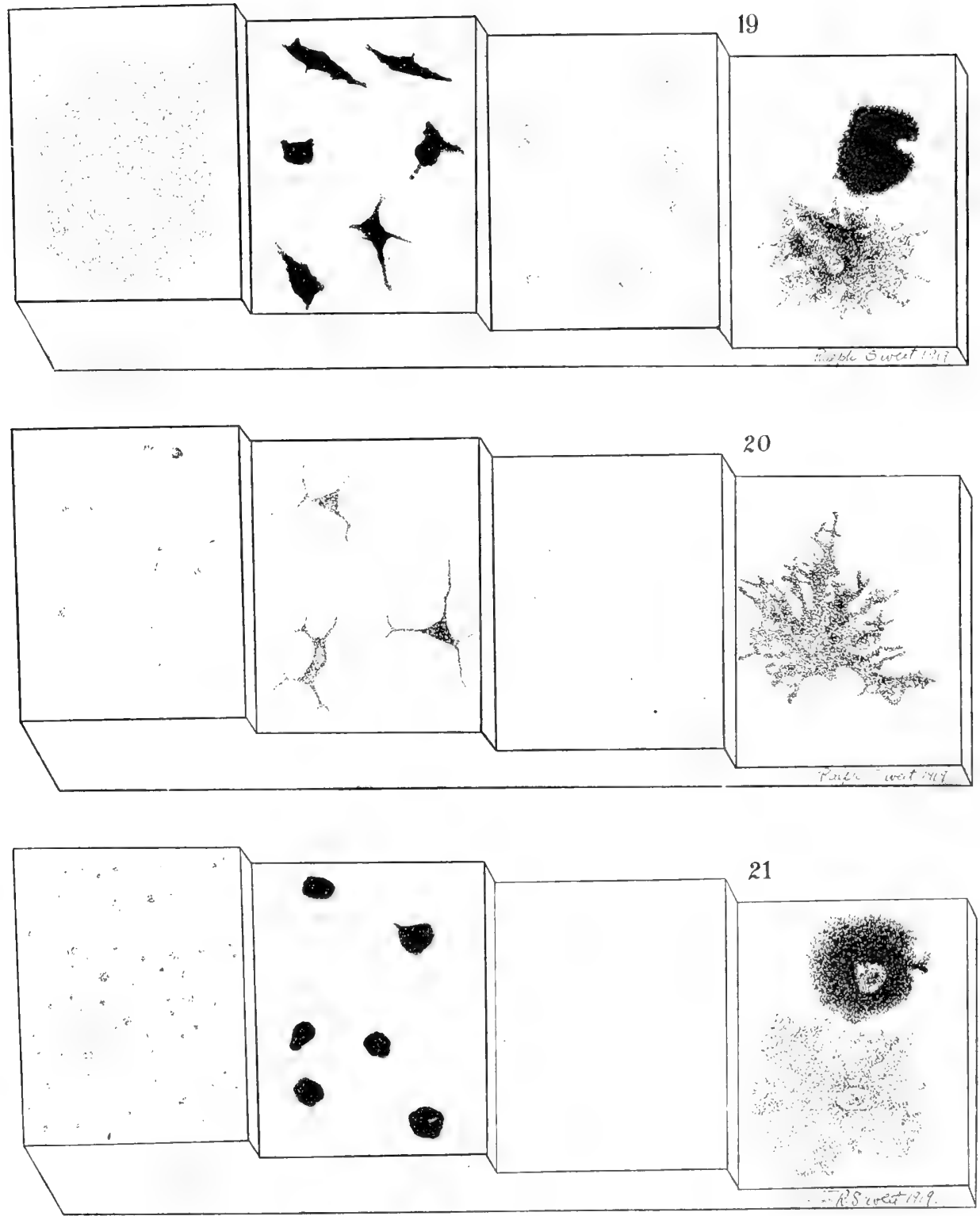
PIATE: i)

EXIRANATION (OF FIGURES

2.2 'The pigmentary system of a 46.0 .1 albino frog tadpole, "light and heat' adapted. This tadpole was supplied with a posterior-lobe diet for $41 / 4$ months. Prior to fixation it had been on a liver diet for one week. Fixed $4^{1 / 2}$ months after epithelial hypophysectomy. $\times 226$.

2:3 The pigmentary system of a 4:30.1 albino frog tadpole, 'light and heat' udapted. This tadpole was supplied with a posterior-lobe diet for $31 / 4$ months. It hat been on a liver diet for 5 weeks prior to fixation. Fixed by dropping into Holly's fluid 4 ? 2 monthes after epithelial hypophysectony: $\quad \times 226$. 
PLATE 5
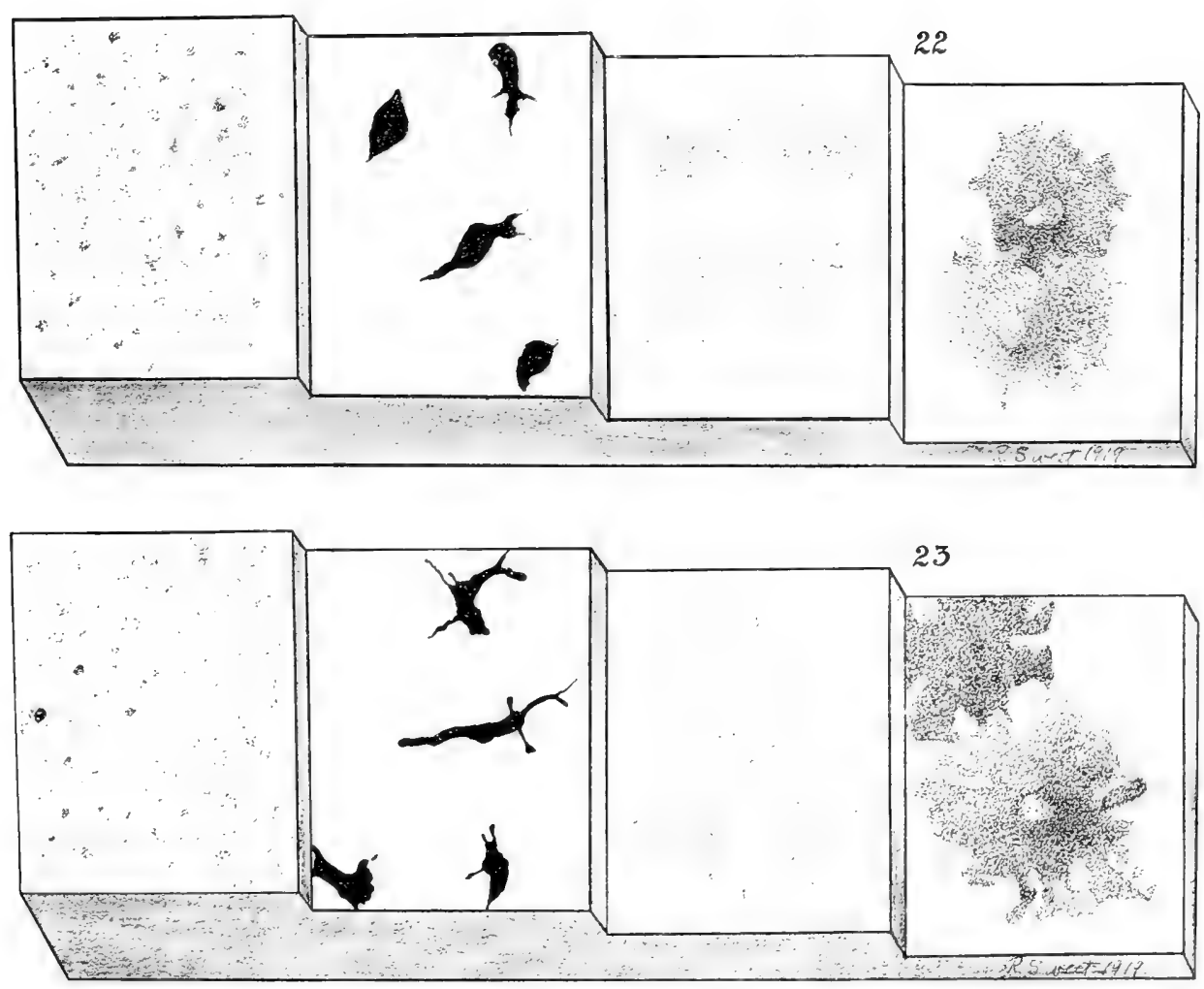
PIATE 6

EXPLANATION OF FIGURES

24 A diagram of the ventral view of the brain of a $45,6.0$ frog tadpole to show the position of the hypophysis.

25) A model of the infundibular process and hypophysial components of a :38,3.5 normal frog tadpole (specimen 15), fixed 63 days after the operative stage. Liver diet. The caudal end of the infundibular process faces the top of the page. $a$, dorsal, b, ventral, $c$, median singittal, views. $\times 89$. 
PLATE 6

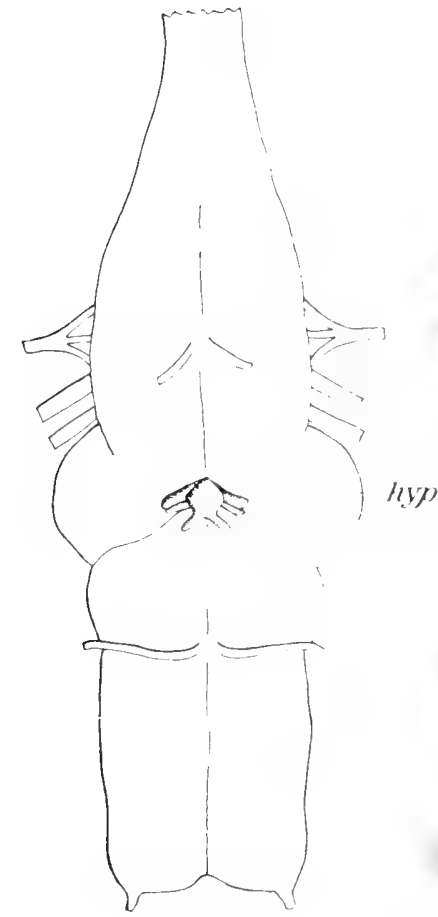

24

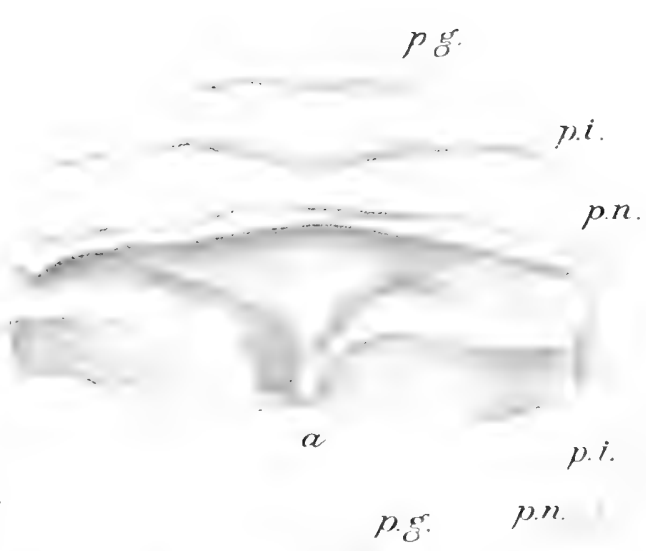

p.i.

p.n.

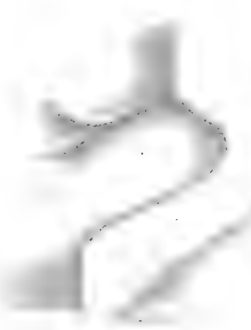

b

25 
PLATE 7

\section{WXPLANATION OF FIGURES}

26) A model of the infundibular process and hypophysial components of at $43,0.1$ albino frog tadpole (specimen 18), fixed 101 days after epithelial hypophysectomy. Liver diet. The caudal end of the infundibular process faces the top of the page. ", dor:al, b, rentral, $e$, median sagital, views. $\times 89$.

27 A model of the infundibular process and hypophysial components of a $36 / 4.2$ 'partial' althino frog tadpole (specimen, p 1), fixed 66 days after the operative stage. Liver diet. The catutal end of the infundibular process faces the top of the page. 12, dorsal, b, ventral, $c$, median sagittal, views. $\times 89$. 
LLATE 7

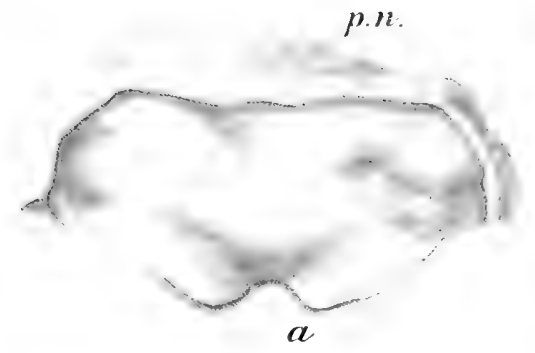

$$
\text { p.rl. }
$$$$
\text { p.f. }
$$

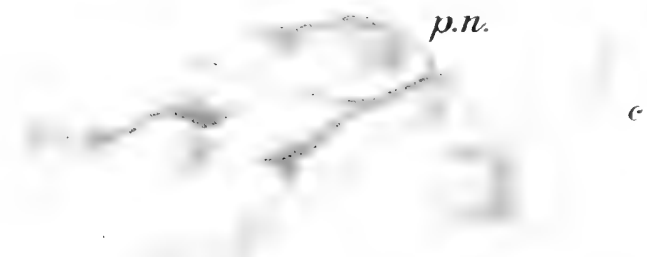

$b$
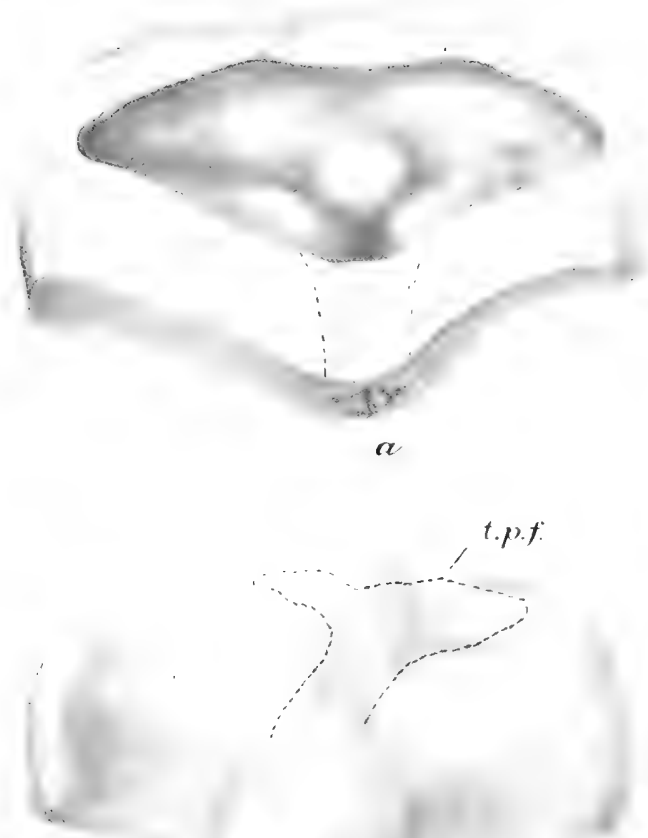
PLATES

\section{EXPLANATION OF FIGURES}

24 I median sagital section through the infundibular process and the hypophysial components of a 35.35 normal frog tadpole. Liver diet. Fixed 63 days after the operative stage. $\times 227$.

29) I median sagittal section through the infundibular process and the hypothysial components of a 4:30.1 alhino frog tadpole (specimen 16). Liver diet. Fixed 101 days after epithelial hypophysectomy. $\times 227$.

30) I median sagittal section through the infundibular process and the hypophysial components of a 36 4.2 'partial' albino frog tadpole (specimen p 1 ). Liver diet. Fixed 66 days after the attempted epithelial hypophysectomy. X227. 


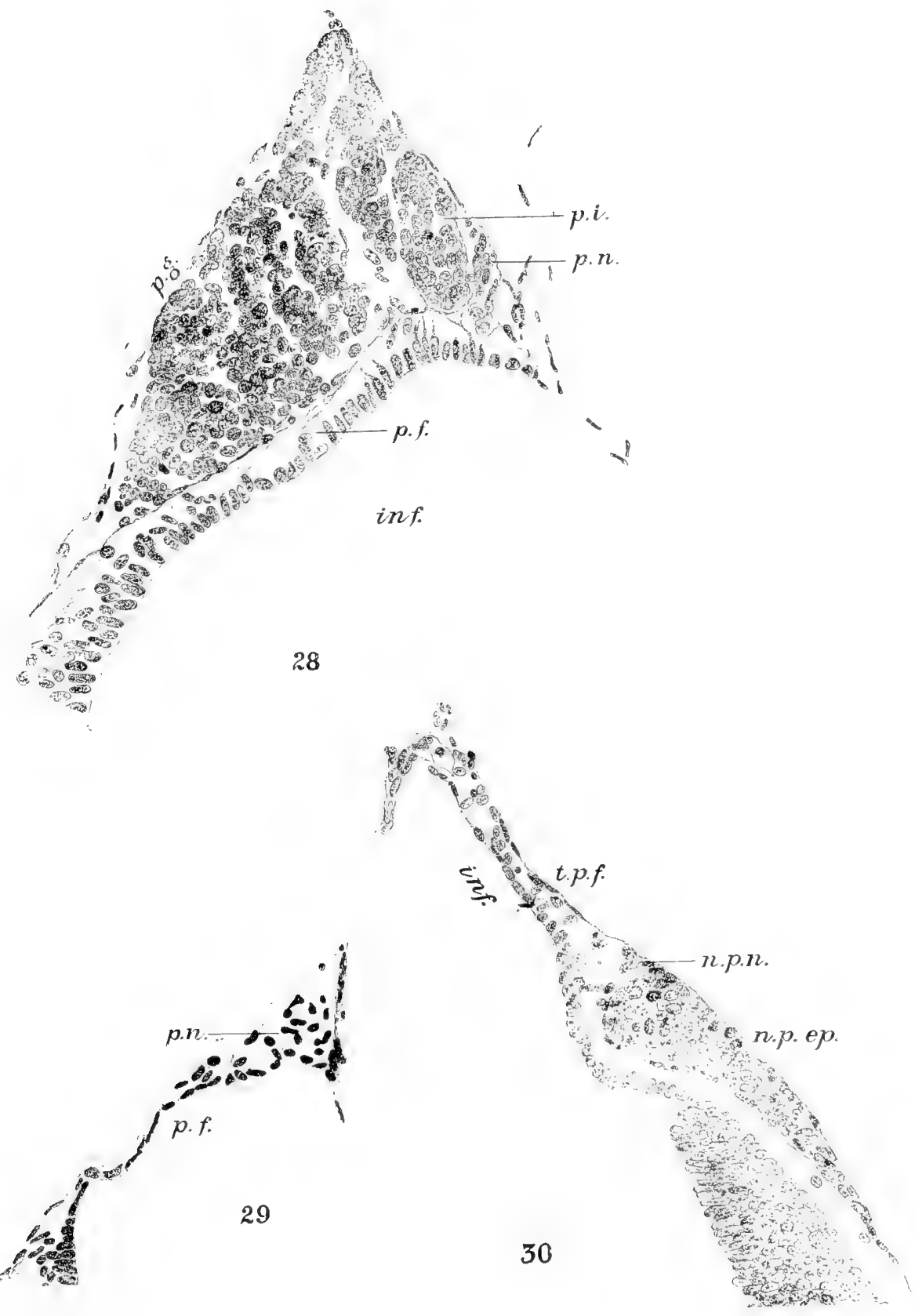

MeNotr xo. 11.

129 
PIATE: 9

\section{FXPLANATION OF FIGURE}

31 (a) Ventral and (b) median views of a model of the left thyroid of a 38.3 .5 normal frog tadpole (specimen 15). Liver diet. Fixed 63 days after the operative stage. $\times 89$.

32 (a) Ventral and (b) median views of a model of the left thyroid of a $13,0.1$ atbino frog tadpole (specimen 18). Liver diet. Fixed 101 days after epithelial hypophysectomy. $\times 89$. 
PLATE!)
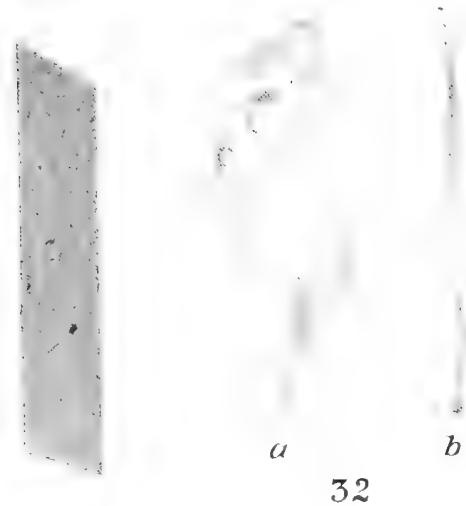

32 
PIATI 10

EXPTANATION OF FIGURES

33 A rross-sertion through the largest portion of the left thyroid of a $40 / 5.0$ normal frog tadpole. Liver diet. Fixed 64 days after the operative stage, $\times 227$.

if $A$ rross-section through the largest portion of the left thyroid of a $40 / 1.5$ albino frog tadpole. Liver diet. Fixed 64 days after epithelial hypophysectomy. $\times 227$.

3.5 The follicele, shown by an arrow, in figure $33 . \times 765$.

30 The follicle, shown by an arrow, in figure $34 . \quad \times 765$. 

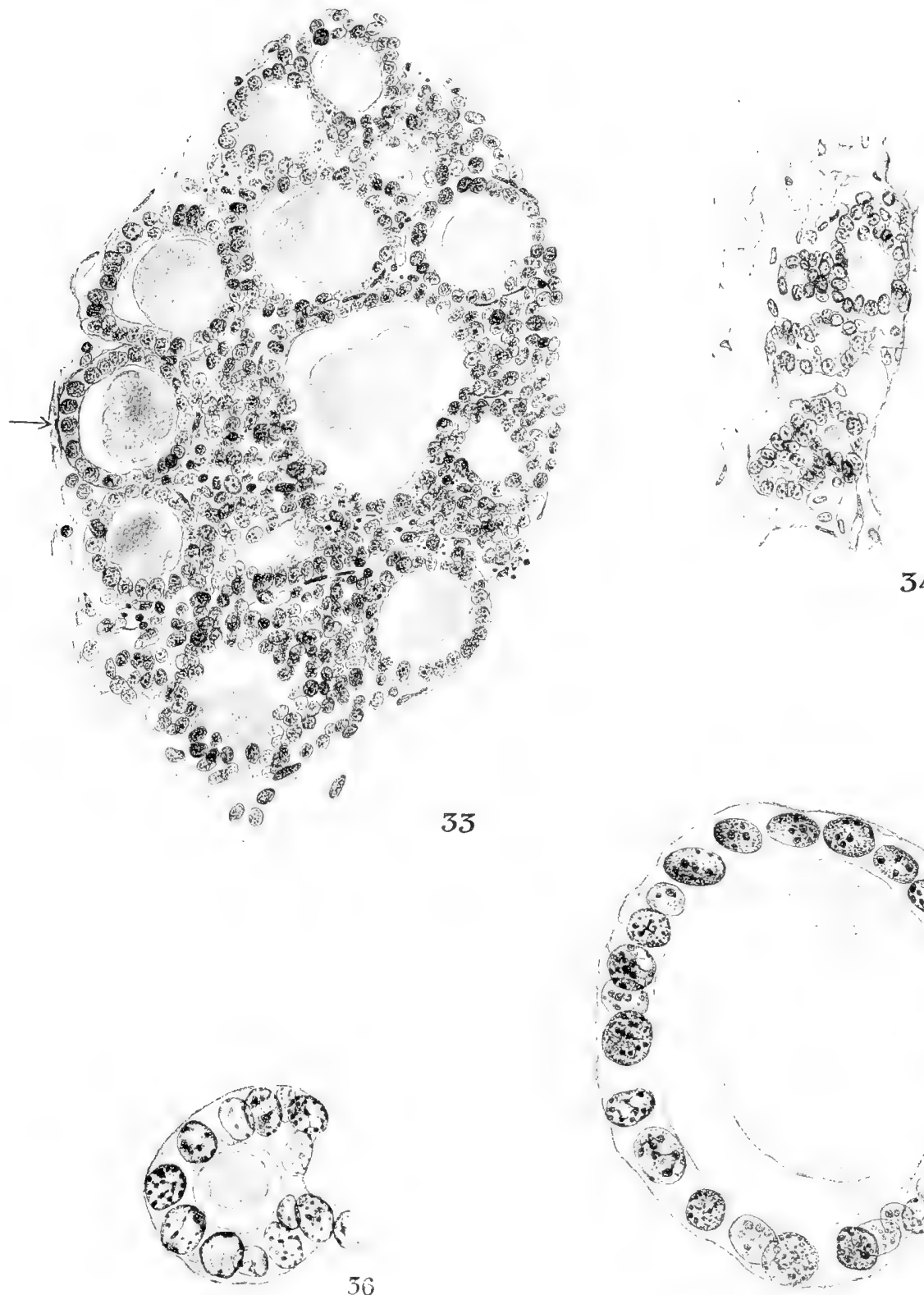

34

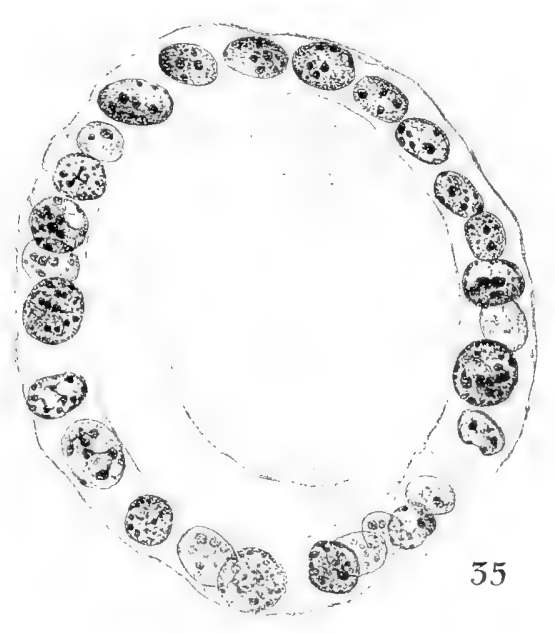


P'LA'T'L 11

\section{EXPLANATION OF FIGURE}

37 The ventral surface of the dorsal abdominal wall of a $44 / 9.0$ frog tadpole to show the position of the ardrenals.

3. The adrenal cortex of a $43,8.0$ normal frog tadpole. Drawn from a whole mount. Osmium-bicromate fixation. The specimen was killed 221 datys after the operative stage. Liver diet. $\times 24$.

39) The adrenal rortex of a $55,0.2$ albinous frog tadpole. Same fixation, age, and liet as above. $\times 24$. 
PLAT'E 11
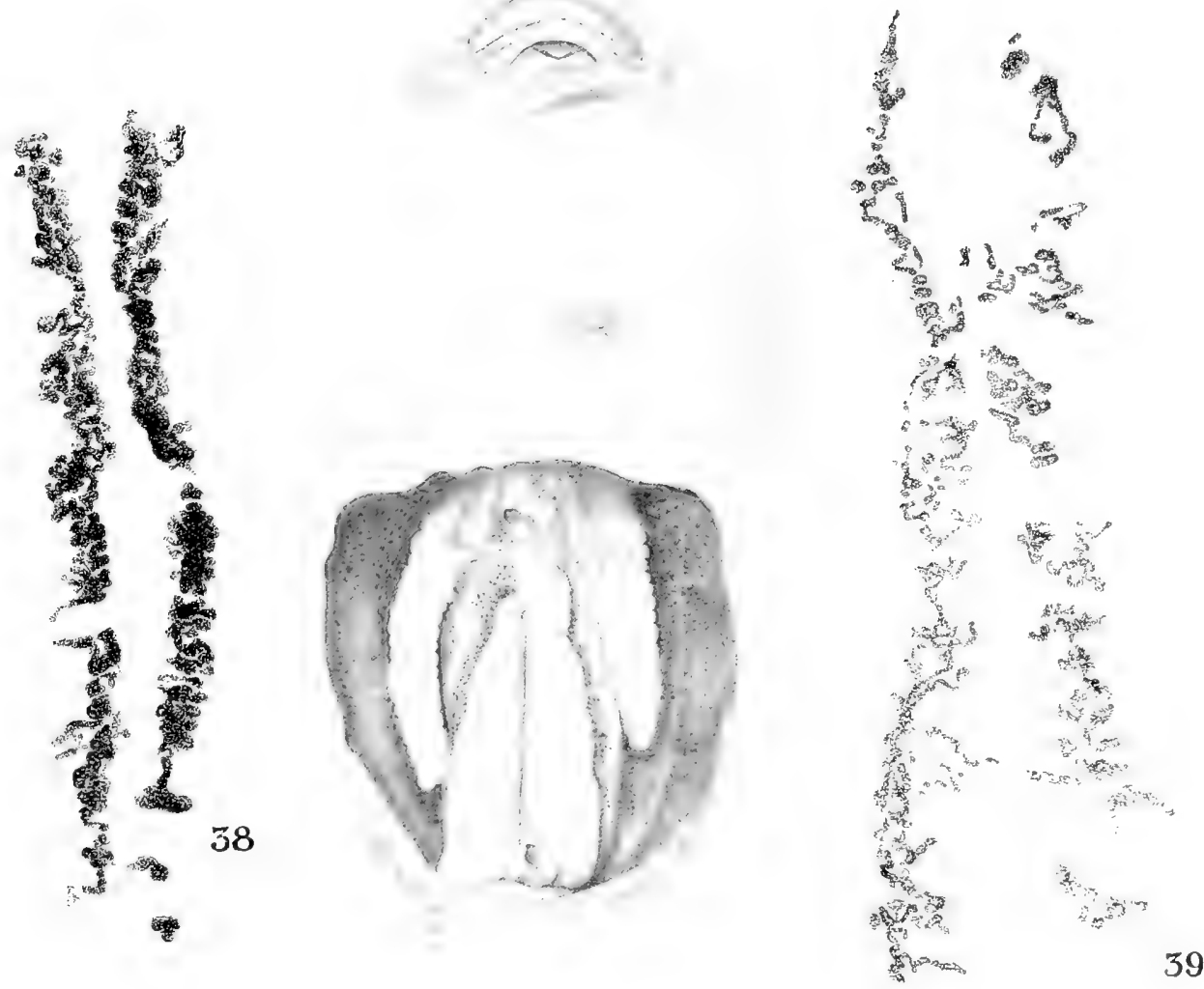
PIATE 12

\section{FXPLANATION OF FIRTREA}

4!) I small portion of the adrenal of a 489.0 normal frog tadpole. Liver diet. Fixed in asmium-bichromate 195, days after the operative stage. Babes' safranin stain. ('ortex black, medulla and muclei red. $\times 733$.

th A small portion of the adremal of a it 0.2 albino frow tadpole. Same age. diet, fixation, and stain ats above. $\times 73$ :? 


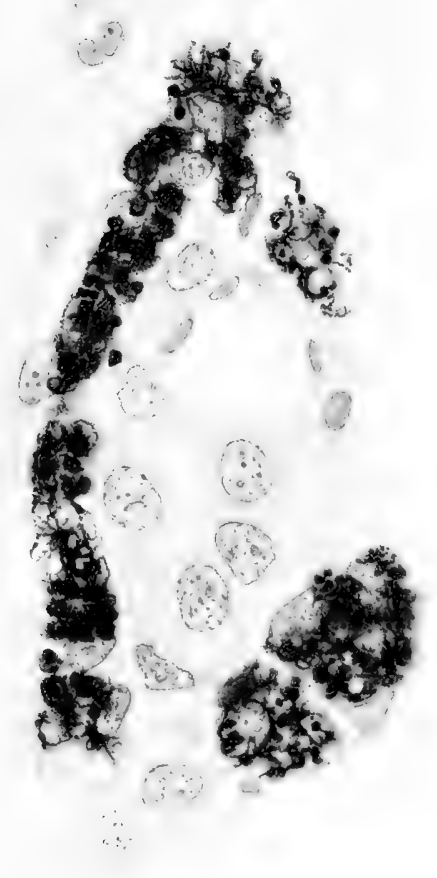

40

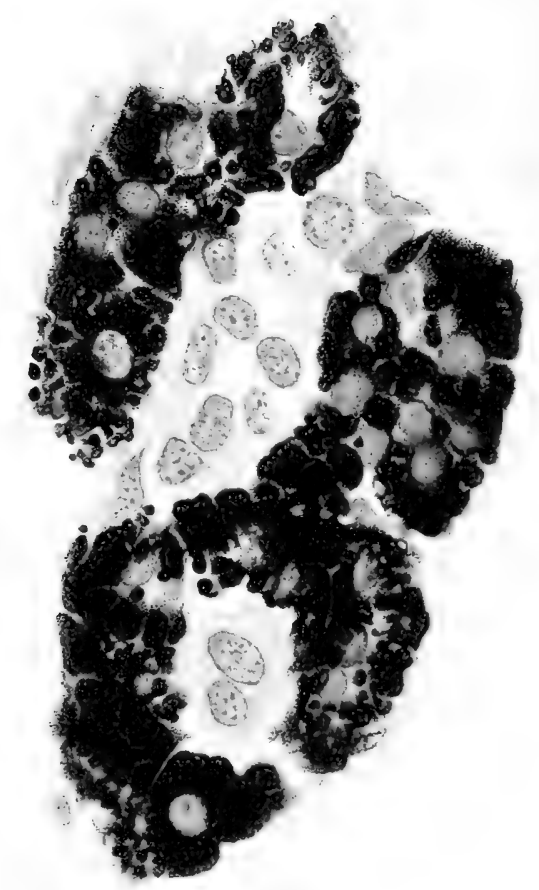

41 


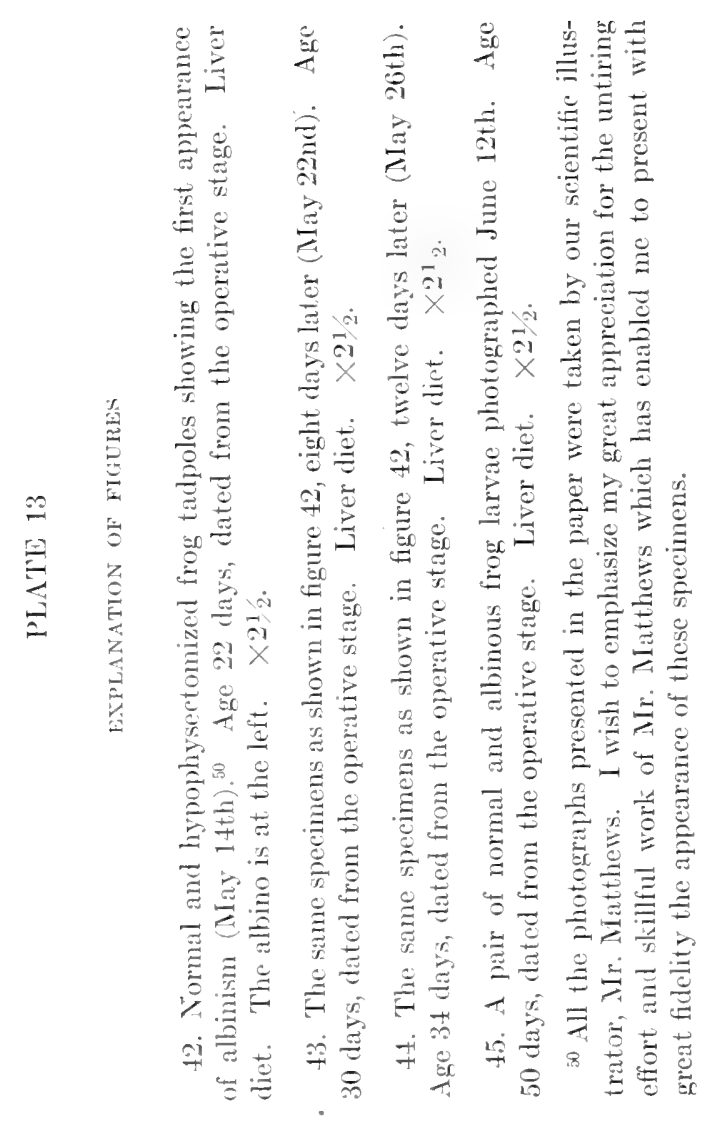





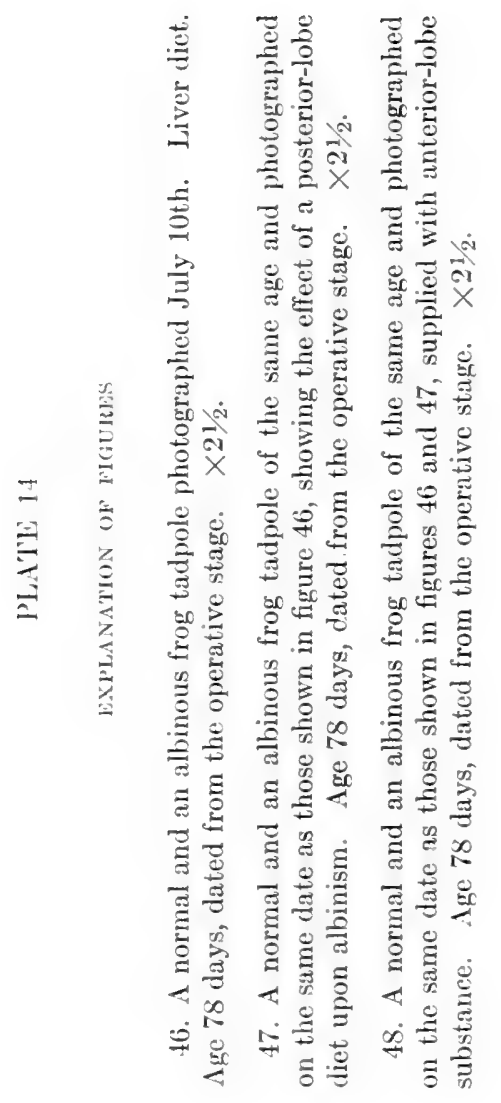




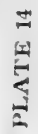
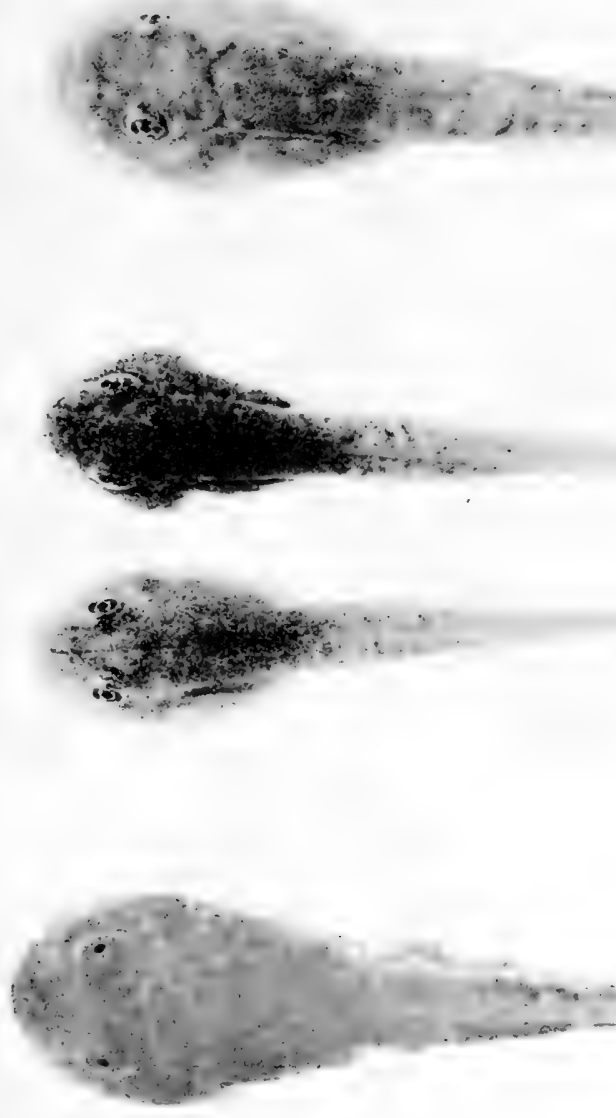


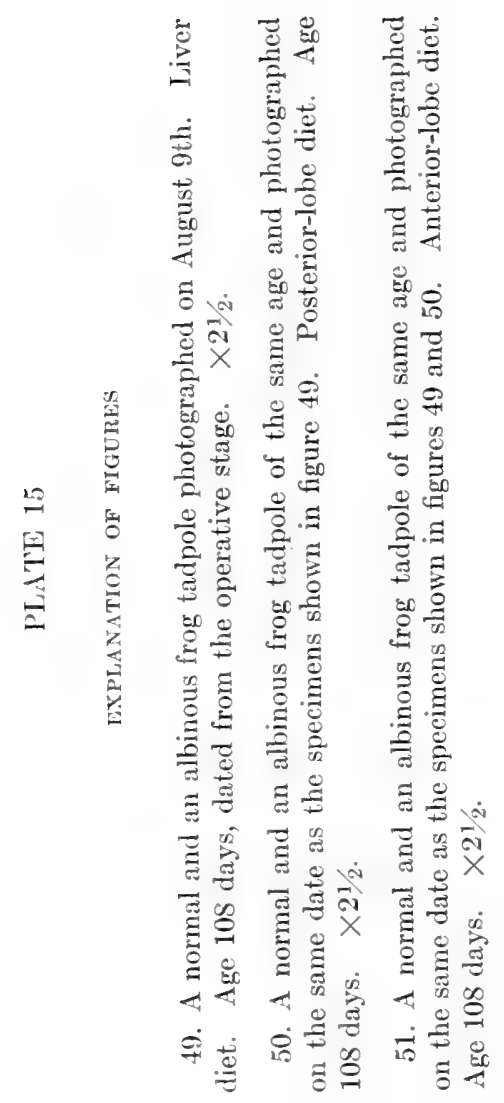


约

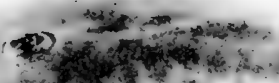

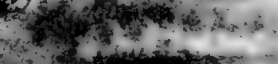

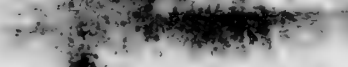

+4.
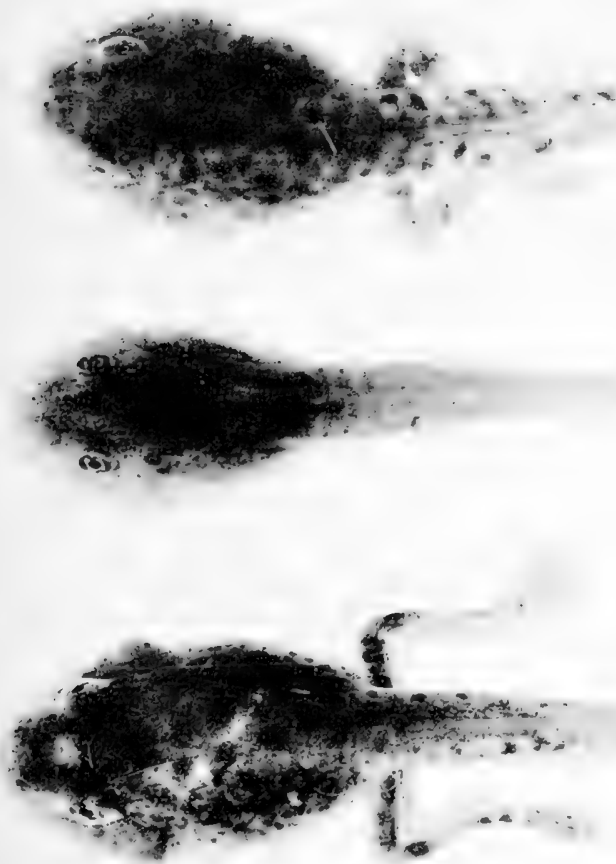

(3)

?.

2. 


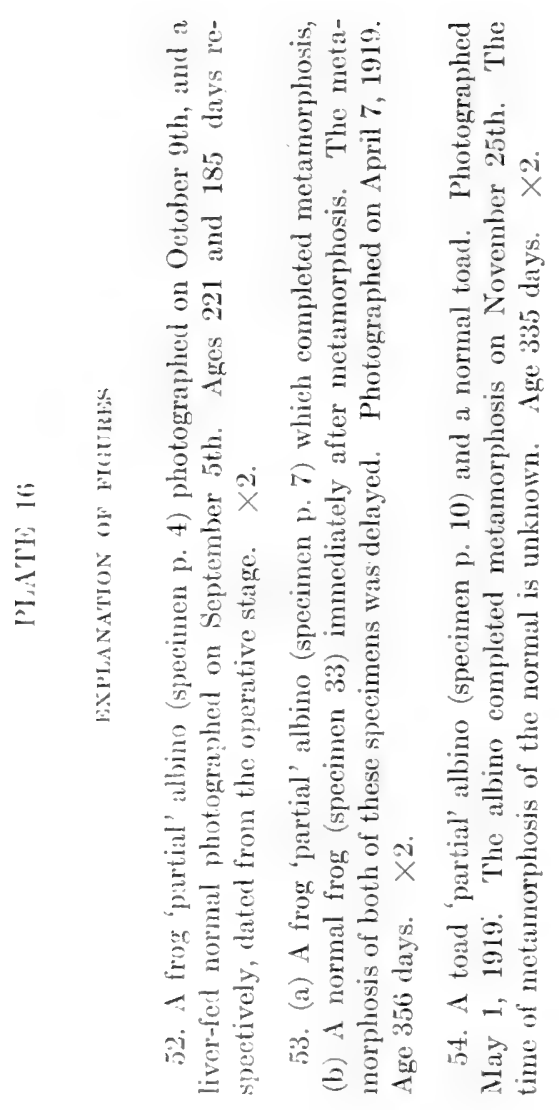


ह

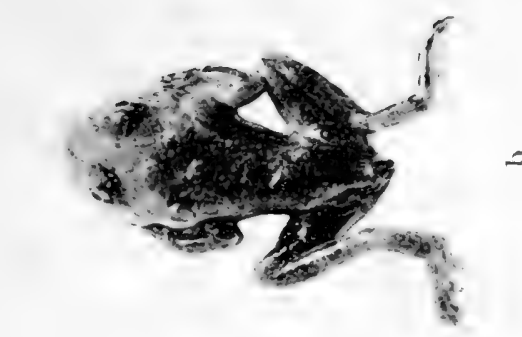

趾
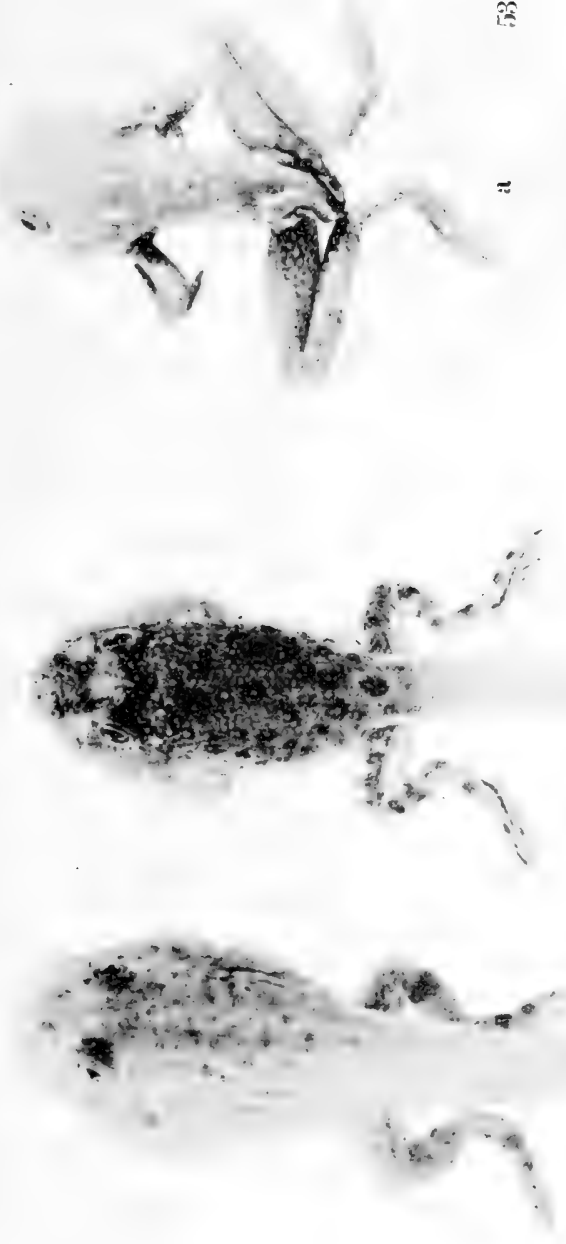

is

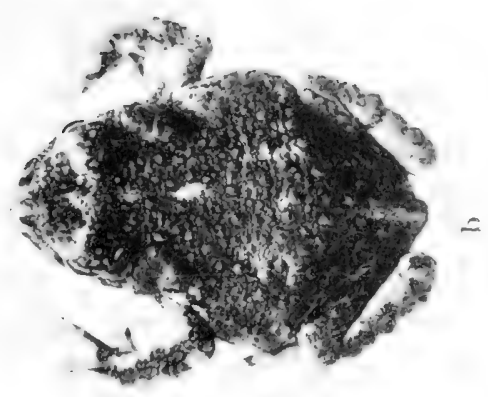

ta

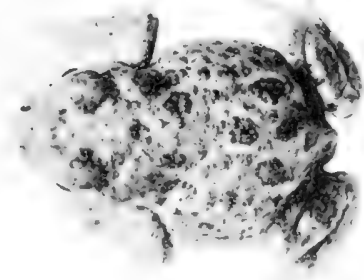$$
\approx
$$ 


\section{PLATE 17}

\section{EXPLANATION OF FIGUMHS}

55. Photographs of a normal and an albinous frog tadpole to show the xantholeucophores. Photographed May 26th. The same specimens as shown in figure 44. $\times 7$.

56. An enlargement of a portion of the dorsal body surface of the specimens shown in figure 55 . 

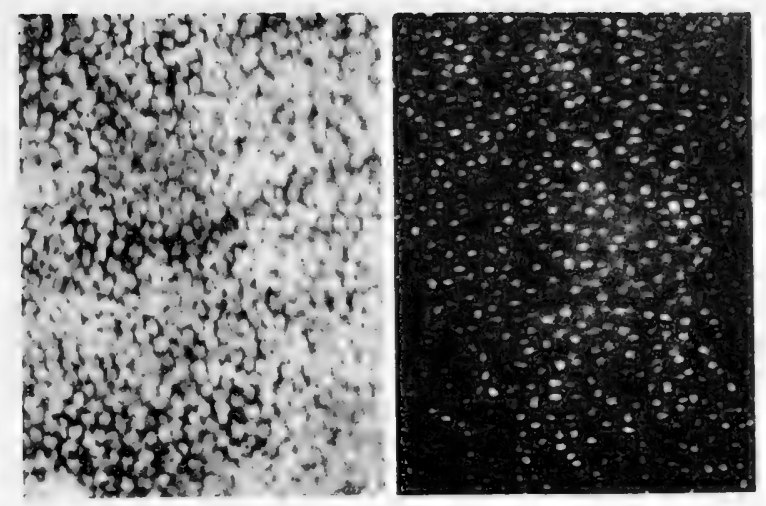

56
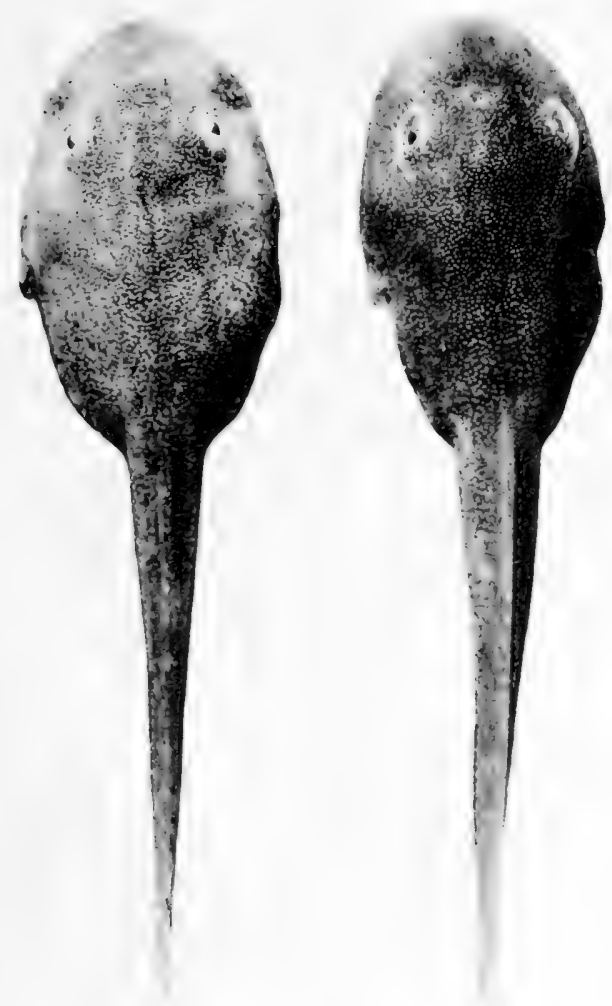
PLATE 18

\section{EXPLANATION OF FIGURES}

57. An albinous and a normal frog tadpole showing reciprocal skin exchanges. Taken four hours after the skin exchange was effected. Age of specimens 70 days, dated from the operative stage. $\times$ n.

58. Enlargements of the skin exchanges and surrounding region of the specimens shown in figure 57 . 

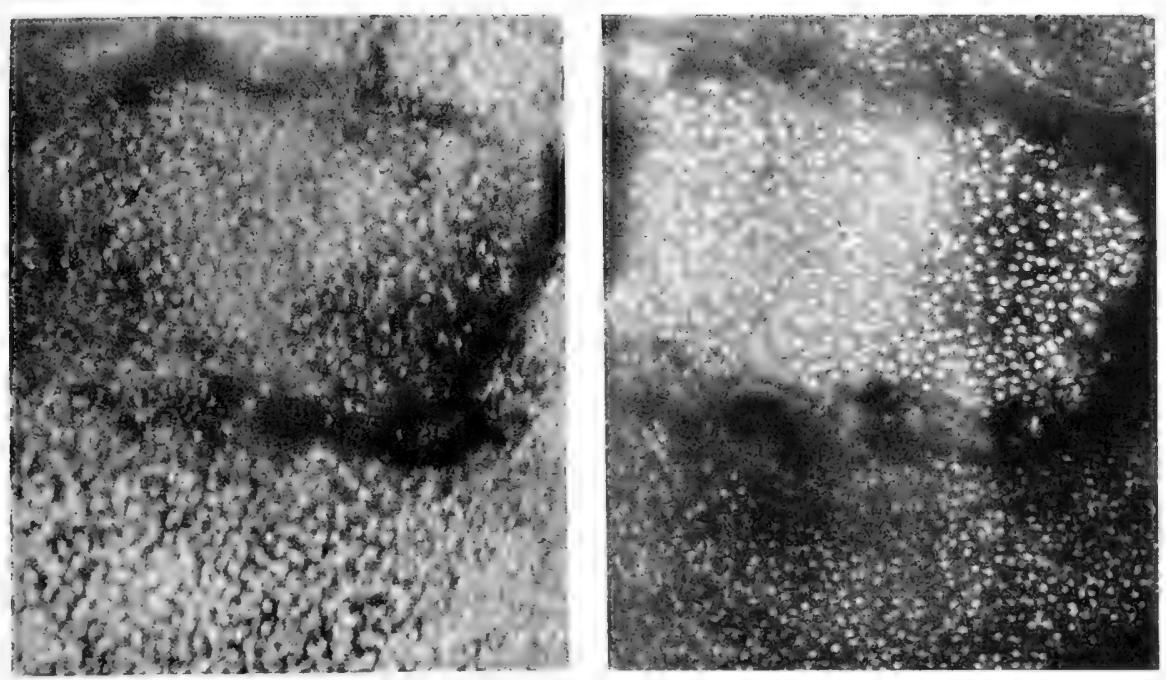

58
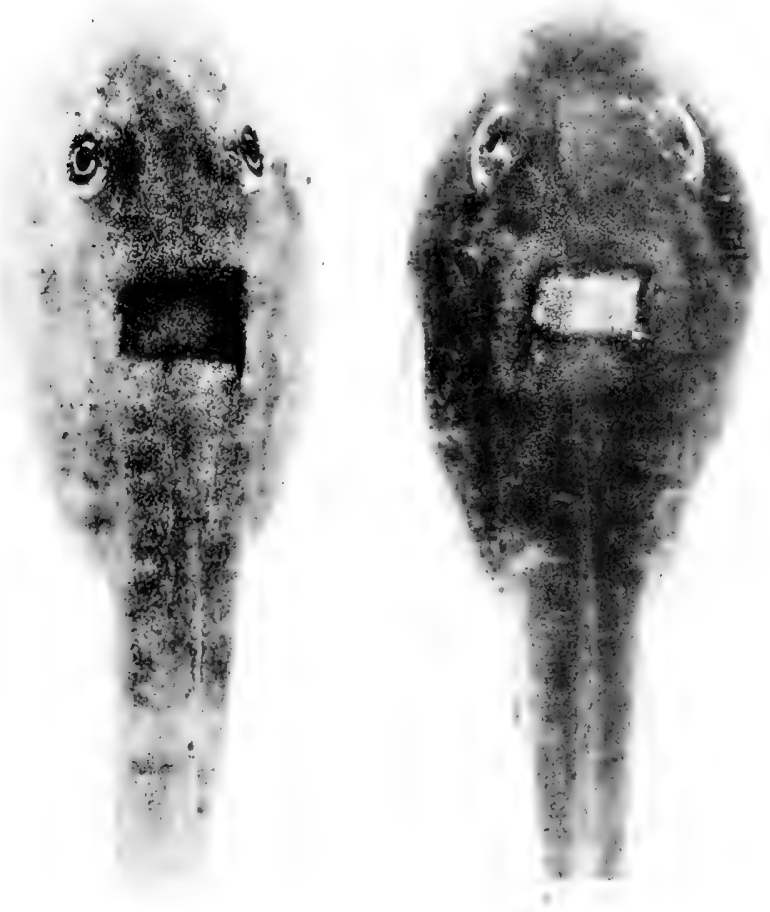
PLATE 19

\section{EXPLANATION OF FIGURES}

59. The mesonephroi and adrenal bodies, fixed in the osmium-bichromate solution. (a) 'Partial' albino young adult frog (specimen p. 7). (b) Normal young adult frog (specimen 33). (c) Albinous frog larva. Age of specimens 356 days. Specimens $\mathrm{a}$ and $\mathrm{b}$ are shown in figure 53 .

60. An albinous (a) and a thyroidless (b) frog tadpole photographed to show the fat-bodies. Taken immediately after death. These specimens had been subjected to inanition for six weeks prior to death. Age 335 days. $\times 2$. 


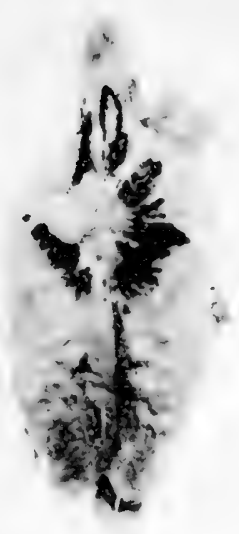

a

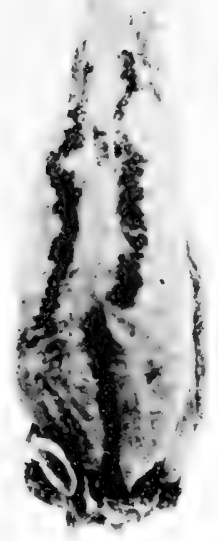

b

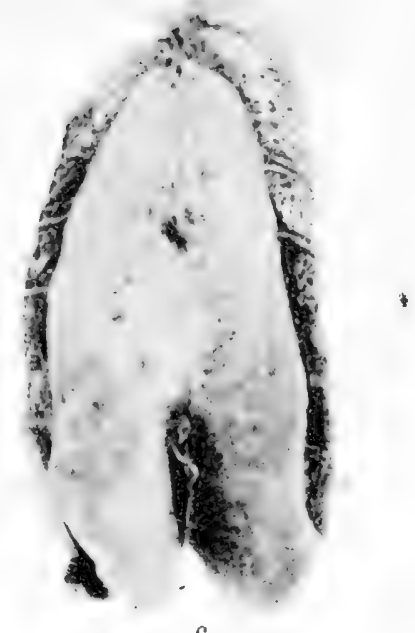

59

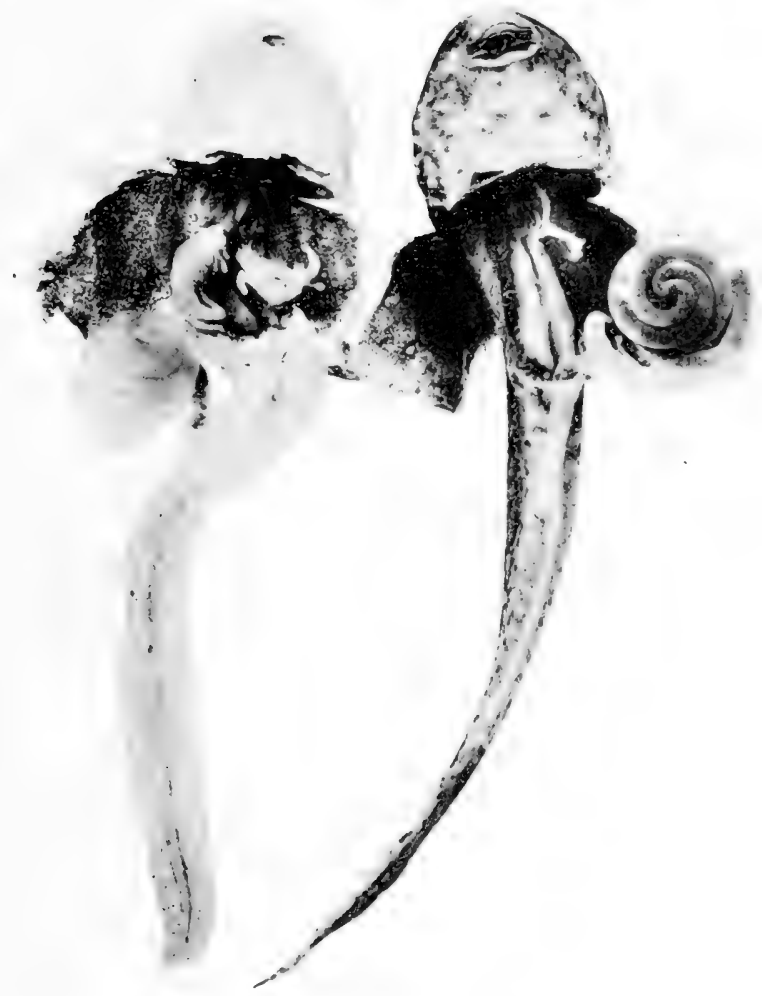

60 



\section{THE AMERICAN ANATOMICAL MEMOIRS}

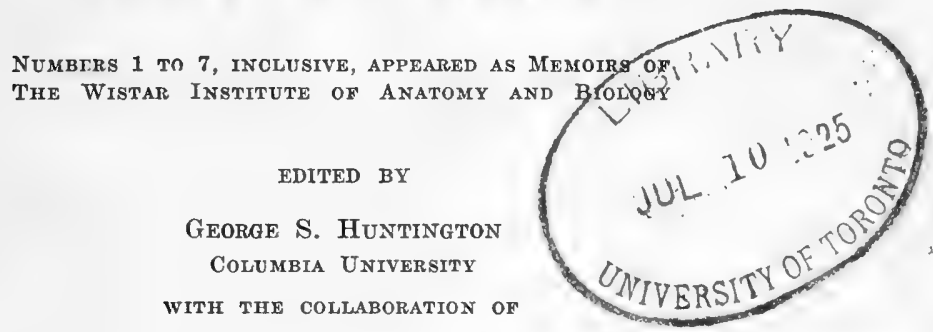

Charles R. Stockard

Cornell UntVkrsity Medical School
AND

HerberT M. Evans

UNIVERSITY OF CALIFORNIA, BERKELEY

AN EXPERIMENTAL ANALYSIS OF OEDEMA IN THE FROG, WITH ESPECIAL REFERENCE TO THE OEDEMA IN RED-LEG DISEASE

CHARLES F. W. MCCLURE LABORATORY OF COMPARATIVE ANATOMY PRINCETON UNIVERSITY

TUBLISHED BY THE WISTAR INSTITUTE OF ANATOMY AND BIOLOGY PHILADELPHIA, PA., U.S.A. 


\section{THE AMERICAN ANATOMICAL MEMOIRS}

This series of Monographs was begun for the purpose of presenting the results of original investigations which were too extensive for incorporation in the current periodicals.

Since the early issues of the series the demands of biological science in our country for a publication of this type have become more urgent and more clearly defined.

This series is open to all qualified investigators in Anatomy. The journal is edited by Dr. George S. Huntington with the collaboration of Dr. Charles R. Stockard and Dr. Herbert M. Evans.

The publication will appear as consecutive numbers of varying sizes issued at irregular intervals, each number containing but one monograph. Bibliographic cards, with authors' abstracts, are issued in advance of each number.

The first seven numbers of the series appeared under the title of "Memoirs of The Wistar Institute of Anatomy and Biology."

They are as follows:

No. 1. The anatomy and Development of the Systejejc Lymphatio Vessels tn the Domestio CAT, by George S. Huntington, Professor of Anatomy, Columbia University, New York City. 175 pages of text, 8 text figures (two in color), 254 photomicrographs and 21 colored plates. $\$ 5.00$.

1911

No. 2. CONTRIBUTION TO THE STUDY OF THE HYPOPHYSIS CeREBRI WITH ESPEOLAL REFERENCE TO ITs Comparative Histology, by Frederick Tilney, Associate in Anatomy, Columbia University, New York City. 72 pages of text, 2 text figures, 60 photomicrographs and plates. (Out of print.)

No. 3. Early Stages of Vasculogenesis in The Cat (Ferrs domestica) Witi Especiat, RefERENCE TO THE MESENCHYMAL ORIGIN OF ENDOTHELIUS, by H. von W. Schulte, Department of Anatomy, Columbia University, New York City. 90 pages of text and 33 figures, of which 14 are in colors. $\$ 1.50$.

1914

No. 4. The DevelopMent of The LYMrhatio SysteM IN Fishes, With Espectal Referenoe to ITS DEvelopMENT IN THE TrouT, by C. F. W. Afclure, Department of Comparative Anatomy, Princeton
University. 140 pages, 41 figures, 11 of which are in colors. $\$ 2.50$. 1915

No. 5. The Developacent of THE Albino RAT, MUs NoRvegrous ALBINUS, by G. Carl Huber, Department of Anatomy, University of Michigan, and The Wistar Institute of Anatomy and Biology,
Philadelphia. 142 pages of text and 42 figures from drawings by the author. (Out of print.)

No. 6. THE RAT, compiled and edited by Henry H. Donaldson. Reference tables and data for the Albino Rat (Mus norvegicus albinus), and the Norway Rat (Mus norvegicus). Second edition. 483 pages. 212 tables, 72 charts, 13 figures, Bibliography of 2329 titles. $\$ 5.00$, bound in cloth.

No. 7. AN EXPERIMENTAL ANALYSIS OF THE ORIGIN OF BLOOD AND VASCULAR ENDOTHELIUM, by Charles R. Stockard, Department of Anatomy, Cornell University Medical School, New York City. 174 pages. $\$ 2.50$.

No. 8. ON THE BehavioR OF BUFo AND RANa TOWAED Collomal Dyes of THE ACID Azo GRoup (trypan blue and dye no. 161), by Charles F. W. McClure; Laboratory of Comparative Anatomy, Princeton University. 64 pages. $\$ 1.25$.

No. 9. The Morphologx and Evolutional Significance of the PrNeal Body, by Frederick Tilney, M.D., Ph.D., Professor of Neurology, Columbia University, New York, and Luther F. Warren, A.B., M.D., Professor of Medicine, Long Island College Hospital, New York. Part 1. A contribution to the study of the epiphysis cerebri with an interpretation of the morphological, physiological, and clinical evidence. 258 pages, 97 text figures. Price, \$3.00.

1919

No. 10. ANATOMical AND PHysiological STUdies ON THE GrowTH OF THE INNER EAR OF THE Alabino RAT, by Tokujiro Wada, The Wistar Institute of Anatomy and Biology. 174 pages, 124 tables, 12 charts, 12 figures, 2 plates. Price, $\$ 4.00$.

No. 11. The Pigmentary, Growth, and ENDocrine. Disturbanoes INduced in the ANuran

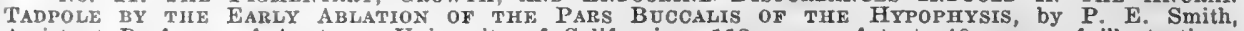
Assistant Professor of Anatomy, University of California. 112 pages of text, 40 pages of illustrations, including 2 colored figures and 7 Heliotype plates. $\$ 3.00$. 12 pages of texh 40 pages of illustrations,

No. 12. AN Experiarfital ANALTSis of OEDEMa iN the Frog, with Special Referenoe to the Oedeara iN RED-LEG Disease, by Charles F. W. McClure, A.M., Sc.D., Professor of Comparative Anatomy, Princeton University. 40 pages, 3 figures. Price, $\$ 1.00$.

No. 8 of the series is the first to appear under the new title.

The price of each number will vary with its size and the number and kind of illustrations contained.

The actual printing cost of each paper has been paid by the author or his laboratory, while The Wistar Institute has managed the details of publication and distribution, using its organization for placing the publication in the public and private libraries of the world.

The extensive distribution enjoyed by all other publications of The Wistar Institute will

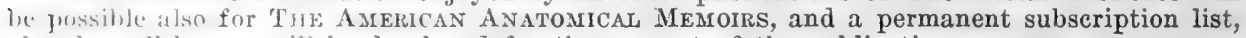
already' well begun, will be developed for the support of the publication.

l'apers intended for publication in The American ANatomical Memorrs should be submitted to the Editor, Dr. George S. Huntington, College of Physicians and Surgeons, 437 West 59th Street, New York City, or to either of the Collaborators, Dr. Charles R. Stockard, Cornell University Medical College, 28th Street and First Avenue, New York City, and Dr. Ilerbert M, Evans, University of California, Berkeley, California.

\section{THE WISTAR INSTITUTE OF ANATOMY AND BIOLOGY}


THE AMERICAN ANATOMICAL MEMOIRS

AN EXPERIMENTAL ANALYSIS OF OEDEMA IN THE FROG, WITH ESPECIAL REFERENCE TO THG OEDEMA IN RED-LEG DISEASE

CHARLES F. W. MCCLURE

LABORATORY OF COMPARATIVE ANATOMY, PRINCETON UNIVERSITY

1925

PUBLISHEI) BY

THE WISTAR INSTITUTE OF ANATOMIY AND BIOLOGY PHILADELPHIA 


\section{AN EXPERIMENTAL ANALYSIS OF OEDEMA IN THE FROG, WITH ESPECIAL REFERENCE TO THE OEDEMA IN RED-LEG DISEASE}

The determination of the causation of oedema, which is associated with such a variety of pathological conditions, would appear to be a highly complex problem. Attempts have been made to show that there is but one primary cause which accounts for its presence whenever and however it manifests itself; on the other hand, there have not been a few investigators who have claimed that it is due, not to a single cause, but to a number of causes.

Oedema is defined as the excessive accumulation of lymph in the tissues and cavities of the body. When the excess of lymph is generally distributed throughout the bodr, we speak of a generalized oedema; when the excess is confined to a single locality or organ, the oedema is localized. The amount of lymph in the tissues of an animal may at different times vary considerably; it is only when the accumulation is clearly greater than normal that we have an oedematous, or pathological condition. To the attainment of this, water is essential. On account of the habits of the frog, and the free and continuous passage of water through its integument, this animal is a particularly favorable object for an experimental study of oedema.

Former investigations have given us, regarding the frog, many facts pertinent to the present study. We know that it is through osmosis (Maxwell, '13) that water is constantly and continuously driven through the integument into the subcutaneous lymph sinuses (Volhard, '12), and that at high temperatures it is driven through more rapidly than at low. We know also that when the normal frog remains in water at a temperature within the range of that of its natural 
environment, a halance is soon established between the amount of water driven through the integument into the subcutaneous lymph simuses and that excreted by the kidneys (Overton, '04), so that the relatively large amount of free water contimuously added to the lymph does not aceumulate in the body in excess. A normal frog ${ }^{1}$ transferred from water at one temperature to water at another ordinarily either loses in weight or remains stationary; and in the cases where it gains weight, the gain is never so continuous through an extended period of time as to produce an oedema. It is therefore evident that when lymph continues to accumulate in the body in excess of normal, the gradual and continuous increase in body weight must be attributed to some factor or factors other than normal, which inhibit the establishment of the balance normally existing in the body between the flow of incoming and outgoing water. Whatever it may be in other animals, the explanation of oedema in the frog depends on the determination of such factor or factors.

In its passage through the capillary vessels of the bloodvascular system, some of the plasma escapes, or transudates, through the capillary walls into the tissue spaces, where it is either taken up by the tissues or returned to the lymphatics. The transudate constitutes what is ordinarily regarded as the lymph concerned in oedema; and all existing theories of oedema attempt to explain the process by which this lymph accumulates and is retained in excess of normal in the tissues and cavities of the body. An oedema of this character may be spoken of as an intracellular (interstitial ?²) oedema, since, owing to the presence of the lymph in excess of normal in the tissue cells, tissue spaces, and cavities of the body, the oedema is evidenced chiefly by a swelling of the tissues in which the lymph has accumulated. Under certain pathological conditions, this form of oedema occurs in the frog,

${ }^{2}$ Lnless otherwise stated, Rana pipiens (Sereber) is the species of frog used in all the experiments of this investigation.

It may be regarded as largely an academic question whether the oedema is purely intracelular or interstitial in character; while without doubt it is largely interstitial, it must to some extent also be intracellular. 
as in all other vertebrates. In the frog, however, oedema manifests itself in yet another form.

When the water is driven by osmosis through the integument of the frog into the subcutaneous lymph sinuses, it there mixes with the lymph already present, received from the tissue spaces, and with the chyle received from the intestinal lymphatics. Through the lymph hearts the lymph thus formed finally reaches the blood-vascular system, where it mixes with the blood plasma. When for any reason more water enters the subcutaneous lymph sinuses than can be simultaneously excreted by the kidneys, free lymph will accumulate in excess of normal in these simuses. In the frog the subcutaneous oedema is always accompanied by the intracellular (interstitial?) form, and vice versa. The problem before us is the determination of the factors which in each instance account for the gradual accumulation of lymph in the body-that is, for the oedematous condition.

Let us first consider those factors which might account for the subcutaneous oedema already described.

Experiments previously made by the writer in 1919 have shown that the generalized oedematous condition of the body observed in certain young frog larvae developed under experimental conditions, resulted from a deficiency in development of the kidneys (pronephroi), which, therefore, were unable, within a given time, to excrete as much water as simultaneously entered the body through the integument. The result was that lymph, in excess of normal, accumulated in the body. The investigations of Howland ('16), and especially those of Swingle ('19), bear out these results in a most striking manner, by showing that an oedematous condition of the body invariably results in young amphibian larvae after the kidneys (pronephroi) have been extirpated.

It has also been demonstrated by the writer ('19) that when the ureters of adult frogs and toads have been ligated and the animals remain in water, a general oedematous condition of the body gradually develops and, as shown in table 1 , the rate at which lymph then accumulates in the body is 
greater at a high than at a low temperature. In experiments of this character in which the oedema was pronounced, the subeutaneous lymph sinuses all over the body were greatly distended with lymph, and in many cases it was observed that the excess of lymph had filtered into the abdominal carity (ascites).

A generalized subcutaneous oedema results when the ureter's have been ligated and the frog remains in water; a localized oedema of exactly the same character is produced when the leg. of a frog has been ligated. In such cases water is constantly and continuously being driven by osmosis through the skin of the leg into the subcutaneous lymph sinuses, as is the case with the skin in all regions of the body when the frog is submerged in water. In the case of the ligated leg, however, lymph gradually accumulates, in excess of normal, in the lymph sinuses distal to the ligature, solely for the reason that the local efferent drainage system of the ligated leg has been completely shut off from the general circulation, through which the oedematous fluid would otherwise reach the renal vessels and the excess of free water in the blood become available for excretion by the kidneys. In proof of the fact that this localized subcutaneous oedema of the leg results from a local mechanical block in the drainage system, one may remove the ligature from the leg and, after placing the frog in water, one will see that gradually the limb regains its normal proportions. Furthermore, it is possible simultaneously to produce a localized and generalized subeutaneous oedema in the same frog by ligating the leg as well as the ureters. After a localized swelling of the leg sinuses has developed, as well as a generalized swelling of the rest of the body, if the ligature is removed from the ureters and the frog is placed in water, the generalized swelling of the body will gradually subside and only the local swelling on the leg will persist. If the leg ligature is then removed, the localized subeutaneous oedema of the leg will gradually subside, for the excess of lymph in the leg now has free access to the general circulation, and the excess of free water 
added to the lymph is thereby made available for excretion by the kidneys.

The chief significance of the above-mentioned experiments is that we have demonstrated by experiment that a subcutaneous oedema can be produced in a frog by a purely mechanical block in the drainage system, and that the location of the block determines the place and extent of the oedema.

The writer has found that a subcutaneous oedema is invariably accompanied by the intracellular (interstitial?)

\section{TABLE 1}

Showing gain (per cent) in body weight in same living frog or toad, in which the ureters have been ligated, when successively placed in tap-water at different temperatures

\begin{tabular}{|c|c|c|c|}
\hline & $12{ }^{\circ} \mathrm{C}$. & ${ }_{222}^{\circ} \mathrm{C}$. & $82^{\circ} \mathrm{C}$ \\
\hline Toad (June) & Per cent & $\begin{array}{c}\text { Per cent } \\
5.33 \text { (1 hour) }\end{array}$ & Percent \\
\hline Toad (July) & & $6.2+(1$ hour $)$ & 11.5 ( 1 hour) \\
\hline Toad (July) & & 4.8 ( 1 hour) & 19.9 (1 hour) \\
\hline Toad (July) & & 4.71 (2 hours) & 31.7 (2 hours) \\
\hline Frog (March) & 3.2 (3 hours) & $11 . t$ (3 hours) & \\
\hline Frog (March) & 1.1 (3 hours) & 3.3 (3 hours) & 25.0 (3 hours) \\
\hline Frog (April) & 2.9 (3 hours) & 6.4 (3 hours) & $2 \cdot 2.0$ (3 hours) \\
\hline Frog (July) & & 1.7 (1 hour) & 4.8 (1 hour) \\
\hline Frog (July) & & 2.82 (1 hour) & 6.3 (1 hour) \\
\hline Frog (July) & & 1.8 (1 hour) & 8.6 (1 hour) \\
\hline Frog (July) & & 2.7 (1 hour $)$ & 6.32 (1 hour) \\
\hline
\end{tabular}

Percentages based on original weight of frogs and toads.

oedema, in which lymph accumulates, in excess of normal, in or among the cells of the tissues. After a frog, whose leg has been ligated, has remained for about twenty-four hours in water, the gastrocnemius muscle of the ligated leg may be greatly swollen and, when removed from the body, is found to weigh considerably more than that of the leg which has not been ligated. The abnormal increase in size and weight of the muscle from the ligated leg, over that of the muscle from the leg not ligated, is undoubtedly due to the presence of lymph in excess of normal, which, in some manner, has 
been taken up and held by the muscle tissue. An explanation of the process by which this has come about constitutes, in the frog at least, the problem of intracellular (interstitial?) oedema. Two leading theories have thus far been advanced in explanation of the causation of this form of oedema. These are the osmotic pressure theory, as advanced by J. Loeb ('98), and the colloid-chemical theory of Martin Fischer ('15).

We may state at the beginning that an experimental analysis of the conditions found in the frog decidedly indicates that the production of the intracellular (interstitial?) form of oedema is owing to differences which can be demonstrated to exist between the osmotic pressure of the oedematous lymph in the subcutaneous lymph sinuses and hence in the blood plasma, and that of the lymph in normal muscle tissue.

Let us first consider different experiments made upon the same living frog placed in water after the osmotic pressure of its body fluids has been raised beyond a point we may ordinarily regard as normal. We know that when a normal frog remains out of water for a considerable time, or is placed in a hypertonic saline solution, a loss in body weight follows owing to a loss of water from the body. When such a desiccated frog is placed in water, immediately it begins to gain in weight, and continues to do so until water has been driven by osmosis through the integument into the subcutaneous lymph sinuses sufficient in amount to restore the osmotic pressure of the body fluids to a point that may be regarded as normal. When this condition has been established, the normal frog either begins to lose in weight or else for a considerable time remains stationary; from this time on, however, it never gains weight continuously. Three experiments of this character-experiments in which the same frog, after desiccation, was successively placed in water at $17^{\circ}, 23^{\circ}$, and $32^{\circ} \mathrm{C}$ - - are illustrated by curves 1,2 , and 3 in figure 1 . The hroken lines in the figure indicate the loss in body weight which resulted during the period the frog remained out of water; and the continuous lines, the subsequent behavior of the frog when placed in water. Such curves, denoting the 
behavior of the frog, may be spoken of as desiccation recovery curves (D.R.C. in figure), and represent in a typical manner the general behavior of normal frogs observed under similar experimental conditions.

The three desiccation recovery curves $(1,2$, and 3 in fig. 1) show that, immediately following the suspension of the desiccated frog in water, it gains weight continuously for a period varying between two and four hours. This signifies that during this time more water enters the subcutaneous lymph sinuses through the integument than is simultaneously excreted by the kidneys. On the other hand, when the body fluids have regained their normal osmotic pressure, the loss in body weight which follows (curve 1, fig. 1) signifies that more water is then being excreted by the kidneys than simultaneously enters the subcutaneous lymph sinuses-a cireumstance which may possibly be explained on the grounds that free water has been released from the tissue colloids and has become available for excretion by the kidneys. As shown by the desiccation recovery curve 2 in figure 1 , the amount of water driven through the integument into the subeutaneous lymph sinuses may, in course of time, be equibalanced by that excreted by the kidneys. At such a time, slight fluctuations in body weight ean be temporarily produced by raising or lowering the temperature of the water. As thus far observed by the writer, frogs usually gain slightly in weight when transferred from water at a high to water at a lower temperature, and lose in weight when transferred from water at a low to water at a higher temperature. Such fluctuations in body weight would appear to be due to a temporary gain or loss of water by the tissue colloids rather than to fluctuations in kidney function, since it can be demonstrated that in the normal frog the kidneys serve as passive agents, and are more than capable of excreting any excess of free water in the body made available to them, when the frog is in water at any temperature within the range of that of its natural environment. 
Having considered the osmotic reactions which result when a normal desiceated frog is placed in water, we may now compare these reactions with those obtained when the same frog has again been desiccated and, before being put into water, has had injected into its subeutaneous lymph sinuses a hypertonic saline solution.

After injecting a hypertonic saline solution into the subcutaneous lymph sinuses of a normal desiceated frog and then placing the frog in water, we should expect to obtain a desiccation recovery curve of the same general character as that obtained on a desiccated frog that had not been injected. The only difference we should expect to find would be that in the case of the injected frog the curve would have a greater maximum height, owing to an increase in the osmotic pressure of the body fluids beyond that resulting from desiccation. Such a curve (4) is shown in figure 1, which illustrates the behavior of this frog, which had been desiccated by remaining twelve hours out of water, and into the subcutaneous lymph sinuses of which, before it was placed in water, 1 ce. of a 2.97 per cent solution of $\mathrm{NaCl}$ had been injected. The maximum height obtained by this $\mathrm{NaCl}$ eurve (4, fig. 1) is observed to be much greater than that of any one of the three control curves (1,2, and 3, fig. 1) obtained when, before being placed in water, the desiccated frog had not been injected with a hypertonic solution.

This increase in height of the NaCl curve (4, fig. 1) over that of the controls (1,2, and 3 , fig. 1 ), in which the desiccated frog had not been injected with the hypertonic saline solution, indicates that an increased amount of water is driven through the integument by the increased osmotic pressure of the lymph in the subeutaneous lymph sinuses of the injected frog. () $n$ this same frog was made another experiment differing from the former only by the fact that the frog was not desic('ated before 1 ce of a 2.97 per cent $\mathrm{NaCl}$ solution was injected, and the frog put into water. In this experiment the behavior of the frog is illustrated by curve 5 in figure 1, which shows that for the body fluids to regain their average normal osmotic 
pressure less water was required than when the frog had been desiccated prior to the injection.

The above experiments show the general osmotic reactions which take place in a living frog placed in water after the concentration of salts in the body and, consequently, the

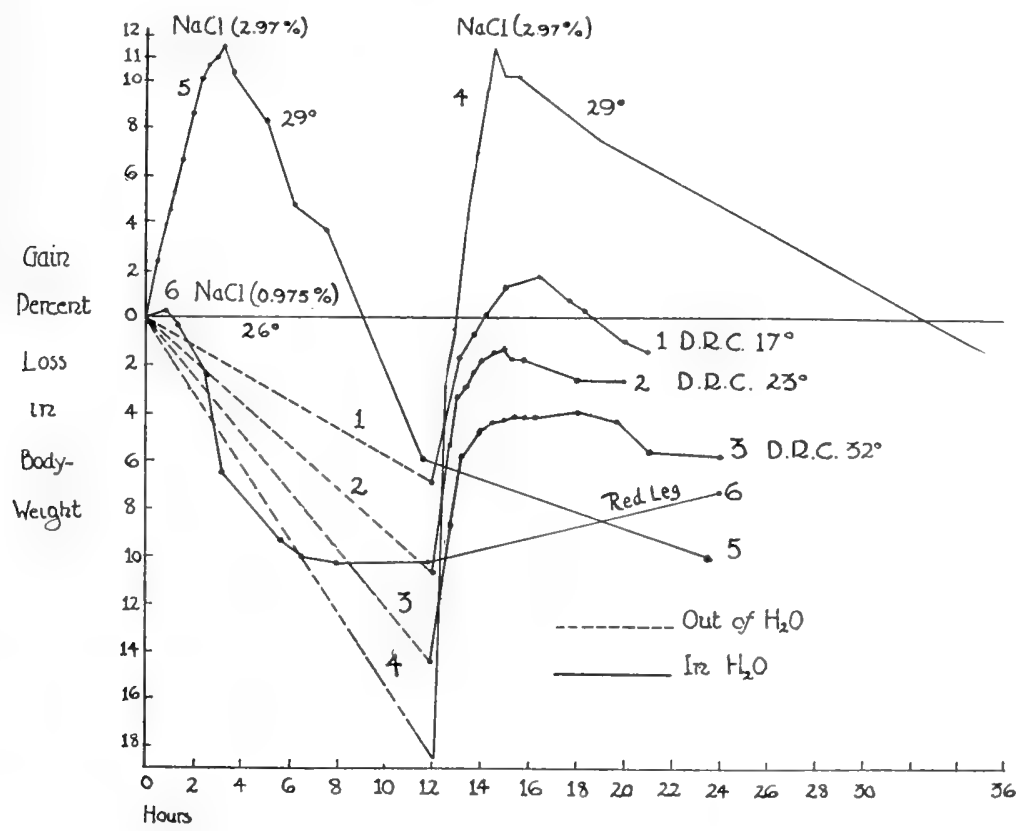

Fig. 1 Behavior of a normal desiccated frog when placed in water at different temperatures (curves 1, 2 , and 3 ) ; behavior of same frog when desiceated, after a saline solution has been injected into the subcutaneous lymph sinuses and the frog placed in water (eurve 4); behavior of same frog, not desiceated, after a saline solution has been injected into the subcutaneous lymph sinuses and the frog placed in water (curve 5); behavior of same frog which has contracted red-leg disease during the course of the experiment (curve 6).

osmotic pressure of the body fluids have been raised above normal. Let us now consider the behavior of muscles taken from desiccated frogs when these muscles are immersed in a Ringer's solution approximately isotonic with muscles of a normal, healthy frog that has not been desiccated.

It has long been recognized that the weight of a resting muscle taken from a normal healthy frog remains practically 
stationary when placed in an isotonic saline solution, and that the same muscle would gain weight if placed in a hypotonie, and lose weight if placed in a hypertonic, saline solution. A solution of $\mathrm{NaCl}$ isotonic with frog's muscle has been estimated to vary between 0.6 (Nasse, '69) and 0.8 per cent at room temperature (Cooke, '98). Overton ('02) observed it to be 0.65 to 0.725 per cent, and Fletcher ('04) found 0.75 per cent to be the approximate value for the gastrocnemius at $17^{\circ} \mathrm{C}$., when no fibrillary twitchings occur. It is thus evident that slight variations exist in the osmotic pressure of normal resting muscles taken from frogs of the same or of different species. A possible explanation of these slight rariations, said by observers to exist in the osmotic pressure of normal resting muscles taken from frogs of the same or different species, may be due to the fact that they did not follow a uniform procedure prior to removing the muscles from the frogs. We know that when a frog remains out of water its body loses water; if this is not immediately replaced through the ordinary channels, there results an increase in the osmotic pressure of the body fluids. Experiments of the writer have shown that, in determining the osmotic pressure of frog's muscle, he can obtain uniform results only from the muscles of frogs which he has left in water a sufficient length of time to insure that through the agency of the kidneys a normal balance has been established between the incoming and outgoing flow of water. Only in such frogs could he insure against some degree of desiceation and be certain that the osmotic pressure of the body fluids was average and normal. It is therefore evident that muscles taken from frogs which are of the same species, but which may have come from different environmental conditions, will almost certainly show slight variations in osmotic pressure.

The $\triangle$ or freezing-point depression of a Ringer's solution approximately isotonic with normal resting gastrocnemius muscle taken from a frog which has remained in water at room temperature for at least twelve hours prior to the 
removal of the muscle has been found to be approximately $0.445^{\circ}$. In the following pages such a solution will be spoken of as an isotonic Ringer's solution.

The following experiments show the behavior of muscles of desiccated frogs, when these muscles are immersed in the isotonic Ringer's solution above mentioned. In these experiments and all similar ones the writer removed the muscles from the body without injury to the tissues and followed a uniform procedure in drying the muscles with filter-paper before placing them on the balance. The experimental error involved in weighing the gastrocnemius muscle was found to be about 5 milligrams. Since in all of the experiments about to be mentioned the purpose was primarily to observe whether the muscles, when immersed in lymph or in the isotonic Ringer's solution, lost or gained weight continuously through a considerable period of time, weighings carried through two decimal places gave the facts with sufficient accuracy.

Two healthy normal frogs, originally weighing, respectively, 18.38 (A) and 28.7 grams (B), were kept out of water until A showed a loss in body weight amounting to 30 per cent and $\mathrm{B}$ a loss in body weight of 32.2 per cent. The four gastrocnemius muscles of these frogs were then carefully removed from the body without injury to the tissues, and each was placed at room temperature in a separate covered dish containing 20 ce. of the isotonic Ringer's solution. The behavior of each desiccated muscle of frogs $A$ and $B$ is shown in table 2, and can be compared with that of two gastroenemius muscles similarly taken from a normal healthy frog (C) not desiccated, and immersed in 20 ce. of isotonic Ringer's solution at room temperature (control, table 2). It will be observed that the muscles taken from the desiccated frogs (A and B) gained weight continuously for a considerable period of time, and that in each instance before an equilibrium had been established, the amount of water absorbed was essentially equivalent to that which had been lost by desiccation. Other similar experiments in which the frogs had been desiccated to a lesser degree gave essentially the same re- 
sults. It is therefore clear that the loss of water in desiccated frogs has been from tissues throughout the body, and has not been a loss merely from the lymph of the subeutaneous lymph sinuses. When we compare the behavior of the desiccated muscles with that of the controls, we observe that the weight of the muscle which had not been desiceated has remained practically stationary for a period of twenty-two hours. The above experiments on desiccated muscles, like those made on the living frog (fig. 1), clearly indicate that when the osmotic pressure of the muscle has been raised above that of the fluid in which the muscles are immersed, the muscles will gain weight by absorbing water and will continue to do so until an equilibrium is established.

Let us now see how we may apply the results obtained by the above experiments to the muscles taken from oedematous frogs, in which an oedema has been experimentally produced by ligating either the leg or the ureters.

We know that lymph in the subcutaneous lymph sinuses gains access to the blood plasma through the lymph hearts and that some of this plasma escapes, as lymph, through the capillary walls of the blood vessels into the tissue spaces, where it becomes available for absorption by the muscles and other tissues. If the osmotic pressure of the lymph in the subcutaneous lymph sinuses of an oedematous ligated frog should, by the gradual addition to the lymph of water through the integument, become lower than that of a resting normal muscle, we should expect that in time the osmotic pressure of the lymph escaping into the tissue spaces would also become lower than that of normal resting muscle, so that, in rirtue of differences in osmotic pressure, normal resting muscles would gain weight when immersed in lymph taken from an oedematous frog and oedematous muscles would lose weight when immersed in a Ringer's solution isotonic with normal resting muscle.

On a priori grounds one might expect that when water is constantly and continuously entering the subcutaneous lymph simuses of a frog in water, and that when all means of egress 
of lymph from the ligated area has been discontinued, the concentration of salts in the lymph of the ligated area would gradually become lowered, as would likewise its osmotic pressure. The following experiments show that such has

\section{TABLE 2}

Behavior of gastrocnemius muscles from desiccated frogs ( $A$ and $B$ ) in Ringer's solution approximately isotonic with normal resting muscle.

Control: Behavior of gastrocnemius muscles of nomal healthy frog (C) in Ringer's solution approximately isotonic with normal resting muscle.

Ringer's solution: $\Delta=0.445^{\circ}-p H$, r.0. Hoom temperature.

\begin{tabular}{|c|c|c|c|}
\hline EXPERIMENT & Hocrs & $\begin{array}{l}\text { LEFT GASTROCNEMIUS OF } \\
\text { DESICCATED FROG }\end{array}$ & $\begin{array}{l}\text { CONTRO.: RIGHT GASTROCNEMITS OH } \\
\text { DESICCATED FROG }\end{array}$ \\
\hline \multirow{10}{*}{$668(A)$} & & Gram (per cent) & Gram (perecent) \\
\hline & 0. & $0.445 \quad(0)$ & $0.445 \quad(0)$ \\
\hline & 1.00 & $0.49 \quad(+10.1)$ & $0.49 \quad(+10.1)$ \\
\hline & 2.00 & $0.50 \quad(+12.3)$ & $(1.50)(-12.3)$ \\
\hline & 4.00 & $0.52 \quad(+16.8)$ & $(1.52) \quad(+16.8)$ \\
\hline & 5.00 & $0.53 \quad(+19.0)$ & $(1.58)(-19.01)$ \\
\hline & 7.00 & $0.54 \quad(+21.3)$ & $0.54 \quad(+21.3)$ \\
\hline & 8.00 & $0.56 \quad(+26.0)$ & $0.56 \quad(-26.0)$ \\
\hline & 21.00 & $0.57 \quad(+28.0)$ & $0.57 \quad(+28.0)$ \\
\hline & 26.00 & $0.57 \quad(+28.0)$ & $(1.57 \quad(-28.0)$ \\
\hline \multirow[t]{11}{*}{$669(\mathrm{~B})$} & 0 & $0.26 \quad(0)$ & $(1.25 \quad(0)$ \\
\hline & 1.00 & $0.29 \quad(+11.5)$ & $11.28 \quad(+12.0)$ \\
\hline & 2.00 & $0.30 \quad(+15.3)$ & $0.30 \quad(+20.0)$ \\
\hline & 3.00 & $0.31 \quad(+19.2)$ & $(1.31 \quad(-24.0)$ \\
\hline & 4.00 & $0.31 \quad(+19.2)$ & $(1.82) \quad(-28.01)$ \\
\hline & 5.00 & $0.31 \quad(+19.2)$ & $11.3 * \quad(+28.0)$ \\
\hline & 6.00 & $0.31 \quad(+19.2)$ & $11.32 \quad(+28.0)$ \\
\hline & 7.00 & $0.32 \quad(+23.0)$ & $11.33 \quad(+32.0)$ \\
\hline & 8.00 & $0.32 \quad(+23.0)$ & $0.33 \quad(+32.0)$ \\
\hline & 10.00 & $0.333 \quad(+27.0)$ & $11.33 \quad(+32.0)$ \\
\hline & 12.00 & $0.33 \quad(+27.0)$ & $11.333 \quad(+32.0)$ \\
\hline $670(\mathrm{C})$ & 0 & $0.3+\quad(0)$ & $11.3 \pm \quad(0)$ \\
\hline \multirow[t]{9}{*}{ Control } & 1.00 & $0.34 \quad(0)$ & $11.34 \quad(0)$ \\
\hline & 2.00 & $0.35 \quad(+3.0)$ & $0.35 \quad(+3.0)$ \\
\hline & 3.00 & $0.35 \quad(+3.0)$ & (1.35 $\quad(+3.0)$ \\
\hline & 4.00 & $0.35 \quad(-3.0)$ & $11.35 \quad(+3.0)$ \\
\hline & 5.00 & $0.35 \quad(+3.0)$ & $0.35 \quad(+3.0)$ \\
\hline & 7.00 & $0.35 \quad(+3.0)$ & (1..3 $(-3.11)$ \\
\hline & 10.00 & $0.35 \quad(+3.0)$ & $(1.23) \quad(-3 .(1)$ \\
\hline & 12.00 & $0.35 \quad(+3.0)$ & $(1.35) \quad(+3.0)$ \\
\hline & (22.00 & $0.35 \quad(+3.0)$ & $(1.35 \quad(+3.0)$ \\
\hline
\end{tabular}


been found to be the case with lymph taken from the subcutaneous lymph sinuses of the leg of a frog in which an oedema has been experimentally produced as the result of ligation.

The legs of three large bullfrogs ( $R$. catesbiana) were ligated near the thigh, and the frogs were placed in water. At the end of forty-eight hours, 30 cc. of bloody lymph was remored from the subcutaneous lymph sinuses of the legs of the three frogs and $30 \mathrm{cc}$. of clear straw-colored lymph was obtained from the coelom (ascites) of one of the three.

The $\triangle$ or freezing-point depression of this lymph, as well as its hydrogen-ion concentration, were kindly determined for me by my colleague, Doctor Marshall, of the Department of Physical Chemistry. They were as follows:

Leg lymph, obtained from three frogs, $\Delta=0.394^{\circ}-\mathrm{pH}, 4.97$

Coelom lymph, obtained from one frog, $\Delta=0.368^{\circ}-\mathrm{pH}, 7.60$

The freezing-point lowerings are correct within 0.005 of a degree.

From the above determinations it is evident that the osmotic pressure of lymph obtained from the oedematous area is lower than that of Ringer's solution $\left(\triangle=0.445^{\circ}\right)$ which has been found to be approximately isotonic with the resting muscle of a normal frog.

The following type experiments tabulated in tables 3 and 4 fully bear out the views previously expressed - that the resting muscle of a normal frog (table 3) should gain weight when immersed in lymph obtained from the subcutaneous lymph sinuses of an oedematous area, and that an oedematous muscle (table 4) should lose weight when immersed in Ringer's solution, approximately isotonie with resting muscle taken from a normal frog.

The type of experiment shown in tables 3 and 4 has been repeatedly made on frogs of different speeies and with lymph taken at different times from different frogs. We therefore helieve it may be stated that the differences in weight of the muscles ohserved in these experiments result from differences in osmotic pressure which exist in the intermuscular 
and intramuscular fluids, and in the fluids in which the muscles are immersed.

In two of the ligated bullfrogs it is interesting to note the presence of an abnormal and excessive accumulation of lymph in the coelom, a portion of the body not shut off by a ligature from the general circulation. Such an accumulation of lymph

TABLE 3

Behavior of gastrocnemius muscles from normal healthy frogs, in lymph from oedematous subcutaneous lymph sinuses of ligated legs of other frogs.

Control: Behavior of gastrocnemius muscles from same frogs, in Ringer's solution approximately isotonic with normal resting muscle.

Ringer's solution: $\Delta=0.445^{\circ}-p H, 7.0$. Room temperature.

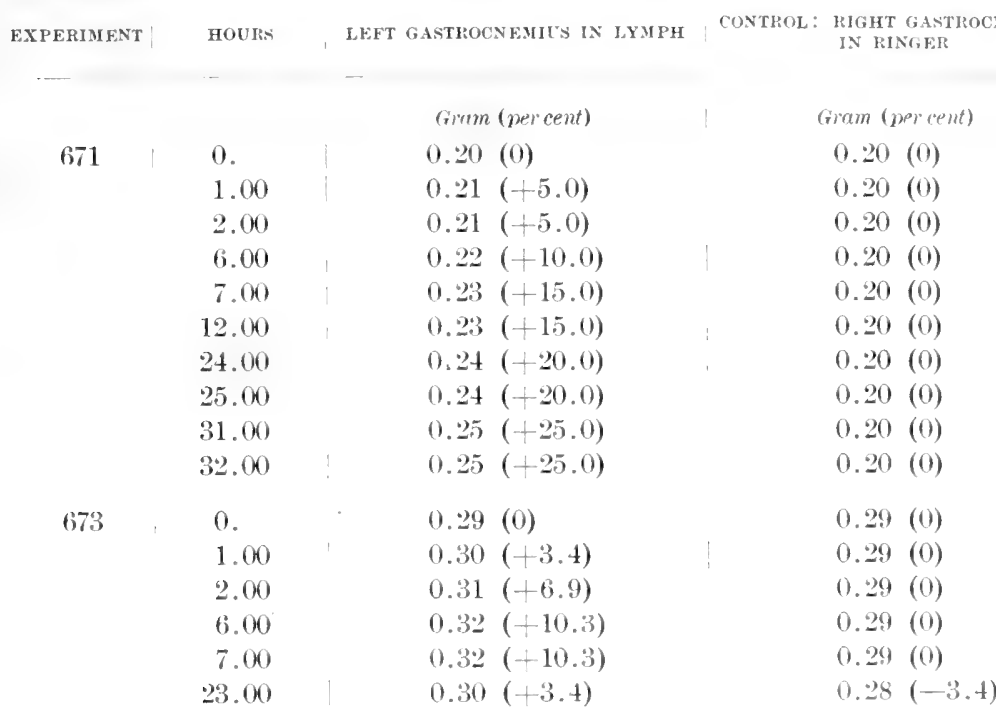

in the coelom (ascites) indicates that, in addition to the oedema in the leg, an oedematous condition has been established throughout the remaining' portion of the body. 'This implies that more water is entering the subcutaneous lymph sinuses through the integument than can simultaneously be excreted by the kidneys. In these frog's the osmotic pressure of the lymph would necessarily be below what we ordinarily regard as normal. 
A marked difference is observed also between the $\mathrm{pH}$ value of the lymph obtained from the ligated legs and that found in the coelom. The greater acidity of the lymph from the ligated area $(\mathrm{pH}, 4.97)$ is apparently associated with metaholic changes in the muscles, which for a considerable period of time have been completely shut off from the general circulation. The $\mathrm{pH}$ value of the coelom lymph was found to he essentially normal ( $\mathrm{pH}, 7.60)$; the reason for this is, appar-

TABLE 4

Behavior of oclematous gastrocnemius muscle from ligated leg of frog, in Ringer's solution approximately isotonic with normal resting muscle.

Control: Behavior of gastrocnemius muscle from unligated leg of same frog, in. Ringer's solution approximately isotonic with normal resting muscle.

Ringer's solution: $\Delta=0.445^{\circ}-p H, 7.0$. Room temperature.

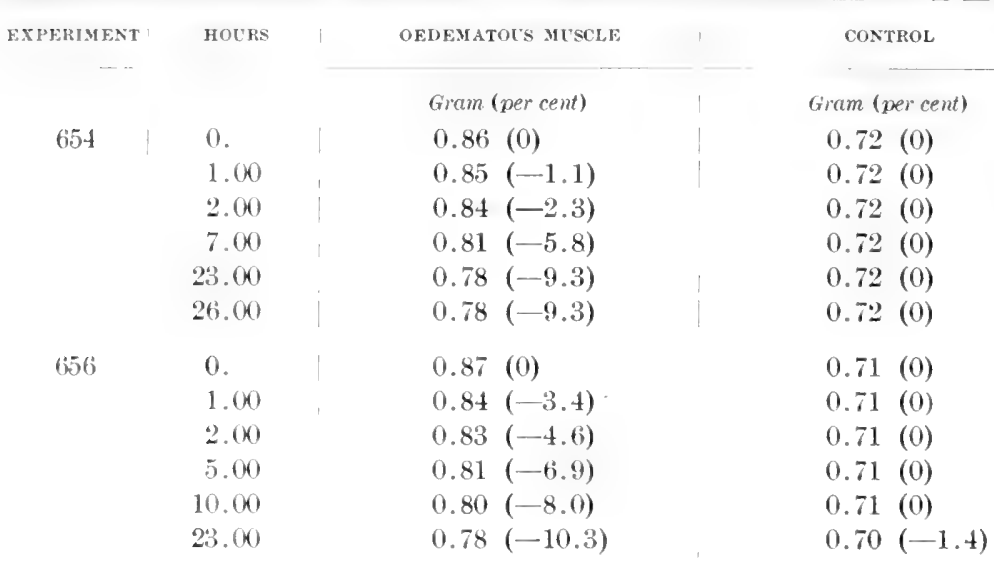

ently, that in all parts of the body not shut off by a ligature from the general circulation, waste products are eliminated in the usual way. The fact that lymph taken from one part of an oedematous frog gives an essentially normal reaction, while lymph taken from another part of the same frog gives an acid reaction, is evidence of the fact that acidity does not in all forms of oedema invariably play the essential rôle, as is maintained by Martin Fischer. From the investigations of Loeb (9.98) we know that muscles may swell and increase in 
weight when immersed in an isotonic saline solution acidulated with lactic acid; but we can nevertheless show by experiment that no increase in weight occurs when normal resting muscle is immersed in an acidulated isotonic Ringer's solution having a $\mathrm{pH}$ value of 4.8. As shown in table 5, the weight of such muscles remains practically stationary for a period of twenty-three hours, and in this respect their behavior resembles that of normal resting muscles immersed in isotonic Ringer's solution having a pH value of 7.0. We may therefore conclude that the swelling of muscles, or the

TABLE 5

Behavior of normal resting gastrocnemius muscles from three different frogs $(A, B$, and $C$ ), when muscles are immersed in the isotonic Ringer's solution acidulated with lactic acid.

Isotonic Ringer's solution: $\triangle=0.445^{\circ}-p H, 4.8$. Room temperature.

\begin{tabular}{c|c|cc}
\hline GOURS & \multicolumn{3}{|c}{ GRAM (PER CENT) } \\
\hline & A & B & C \\
\hline 0. & $0.21(0)$ & $0.24(0)$ & $0.34(0)$ \\
1.00 & $0.21(0)$ & $0.25(+4.1)$ & $0.35(+3.0)$ \\
2.00 & $0.21(0)$ & $0.25(+4.1)$ & $0.35(+3.0)$ \\
5.00 & $0.21(0)$ & $0.25(+4.1)$ & $0.35(+3.0)$ \\
8.00 & $0.21(0)$ & $0.25(+4.1)$ & $0.35(+3.0)$ \\
23.00 & $0.22(+4.7)$ & $0.25(+4.1)$ & $0.35(+3.0)$
\end{tabular}

intracellular (interstitial?) form of oedema observed in ligated oedematous frogs, is not necessarily associated with an overproduction of acid in the tissues, but results rather from differences in osmotic pressure that exist in the tissue fluids, and in the lymph in the tissue spaces from which the cells of the tissues constantly receive their lymph supply.

Under normal conditions, it is through the agency of the vascular system that an excess of free water in the body is made available to the kidneys, and is by them excreted. In the case of an oedema resulting from the ligation of the leg or the ligation of the ureters, this means of eliminating free water from the body is either locally or generally discon- 
tinued. The principle involved is purely mechanical. We know that when normal frogs are placed in water at any temperature within the range of that of their natural environment, a balance is soon established in the body between the incoming and outgoing flow of water, so that free water in excess of normal does not accumulate in the body. Furthermore, we know that the rate at which water is transported through the integument into the subcutaneous lymph sinuses increases with the temperature, so that more water enters the sinuses at high than at low temperatures. This has been demonstrated in table 1 , in which is shown the behavior of those frogs and toads whose ureters have been ligated when placed in water at different temperatures. If the ureters of these same frogs and toads had not been ligated, any increase in the amount of water entering the body at the higher temperatures would have been almost simultaneously excreted by the kidneys, and a normal balance would thereby have been established between the incoming and outgoing flow of water. This still further emphasizes the fact, maintained also by others, that the kidneys serve chiefly as passive agents in the sense that they do not seek water, but excrete only that amount made available to them through the agency of the vascular system. If at higher temperatures the increased amount of water entering the subcutaneous lymph sinuses through the integument is, through the agency of the vascular system, almost simultaneously excreted by the kidneys, it is evident that the rate at which this free water is supplied to the kidneys is correspondingly accelerated. If this were not the case, free water would gradually accumulate in the body in excess of normal, for the reason that less water would then be able to reach the kidneys than was simultaneously being transported through the integument into the subentaneous lymph sinuses. The question therefore arises whether it would be possible by gradually raising the temperature of the water to reach a point at which, within a given time, more water actually entered the body than could simultaneously be conveyed to the renal circulation for ex- 
cretion by the kidneys. If such a condition could be brought about, it is plain that in course of time water would accumulate in the body in excess of normal.

Experiments of this character made by the writer have shown that when normal frogs are transferred from water at room temperature to water at $36^{\circ} \mathrm{C}$, such frogs, after remaining in water at this higher temperature for about thirty minutes, almost invariably show a slight loss in body weight. As a matter of fact, it has been observed by the writer that, within limits of temperature ordinarily consistent with their natural environment, frogs at first usually lose weight when taken from water at a low temperature to water at a higher temperature, and gain weight when taken from water at a high to water at a lower temperature. In the average normal frog' the power of the kidneys to maintain at $36^{\circ} \mathrm{C}$. a normal balance between the incoming and outgoing flow of water signifies in the kidneys not only increased action, but also a reserved functional capacity to meet quite unusual conditions. While the behavior necessarily differs in different cases, $36^{\circ} \mathrm{C}$. is about the average limit at which, in a normal frog, a normal balance can be maintained between the incoming and outgoing flow of water, provided, however, the duration of the experiment is not too extended.

If we may regard $36^{\circ} \mathrm{C}$. as about the average limit of temperature at which the kidneys can maintain a normal balance between the incoming and outgoing flow of water, what conditions are met with when frogs are placed in water at still higher temperatures? While it has thus far proved impossible to determine for all cases the exact limits of temperature at which the kidneys cease to meet the normal requirements of excreting water, it has nevertheless been possible to demonstrate that when frogs are placed in water at a temperature somewhere between $36^{\circ}$ and $39^{\circ} \mathrm{C}$, a slight gain in body weight immediately follows. And, furthermore, this gain in weight, slight though it may be, is within a short time invariably accompanied by coma and cardiac inefficieney. The result is that the rate of flow in the vascular chamnels is 
correspondingly diminished, so that through the agency of the rascular system less water reaches the kidneys than simultaneously enter's the body through the integument. Such conditions obtain when frogs are subjected to these high temperatures; since, however, frogs are unable for any extended period to endure them, an actual oedematous condition of the body camnot be experimentally produced in the living frog by thus increasing the temperature of the water.

Under natural conditions of environment, however, oedematous frogs with red-leg disease do continue to live a considerable time after cardiac inefficiency is manifest. The writer will show later that this inefficiency prevents the establishment of the normal balance between the incoming and outgoing flow of water, and so is itself a contributing factor of the oedema. Moreover, dead frogs, when placed in water at any temperature, gain weight continuously through a considerable period of time. This is because though after death water continues to be transported in the usual manner through the integument, this water, owing to a complete cessation of circulation, cannot be transported to the kidneys. These two observations indicate the relation that exists between cardiac inefficiency and oedema.

A brief résumé of the chief observations made in the preceding pages leads us to the following conclusions:

1. Oedema manifests itself in the frog in two forms which we may distinguish as subcutaneous and intracellular (interstitial?).

2. Any factor, either local or general, which may prevent the establishment of a normal balance between the incoming and outgoing flow of water, such as a deficiency in the development of the kidneys, ligation of a limb, ligation of the ureters, or cardiac inefficiency, will serve as a contributing cause of oedema.

3 Subentaneous oedema is an excessive aceumulation of Iymph in the subcutaneous lymph sinuses and is invariably accompanied by an intracellular (interstitial?) oedema or swelling of the tissues, which results from differences in os- 
motic pressure existing in the tissues and in the lymph which escapes through the capillary walls of the blood vessels into the tissue spaces.

It has occurred to the writer that these same principles are active in the causation of the oedema which accompanies a disease very common among frogs known as red-leg. To this we shall now turn our attention.

ON THE OEDEMA WHICH IN FROGS ACCOMPANIES RED-LEG DISEASE

According to Emerson and Norris ('05), red-leg disease, which is widely distributed throughout North America and Europe, is due to the presence in the frog of Bacillus hydrophilus fiscus. ${ }^{3}$ They state that the predisposing causes of the disease are lower resistance from heat, anemia, and lesions of the skin, which seems to be the portal of entry of the infeetion. The symptoms which characterize the disease are congestion of the ventral surface of the body and more or less ulceration in and haemorrhage beneath the skin. In advanced cases of red-leg, the abdominal viscera, and especially the stomach and intestines, may become greatly congested, as may also the muscles of the body in general. As the disease progresses and congestion becomes more general, it may be accompanied by more severe haemorrhages and by degenerative changes in the tissues. The disease is usually fatal, and a gradual failure to respond to stimuli is followed by coma and death. The oedema which accompanies red-leg disease may be either localized or generalized in character. It may be confined to one or to both hind limbs, and either to the entire limb or to the limb above or below the knee-joint. When the oedema is generalized in character, the entire body, including the limbs, may be generally and uniformly swollen.

Figure 2 is a photograph of a frog with red-leg disease, in which a rather intense form of localized subcutaneous oedema of the right thigh has developed. Figure 3 also is a photograph of a frog with red-leg disease, but here there is a local-

\footnotetext{
${ }^{3}$ Cultures were made by Mr. Vincent Gregg, who identified the bacillus mentioned.
} 
ized swelling of the right leg, and in addition the entire body is generally and uniformly swollen. In the latter, therefore, we have a case in which a localized as well as a generalized subentaneous oedema has been developed in the same indiridual-a condition which, as previously mentioned, can be simultaneously produced in the living frog by applying a

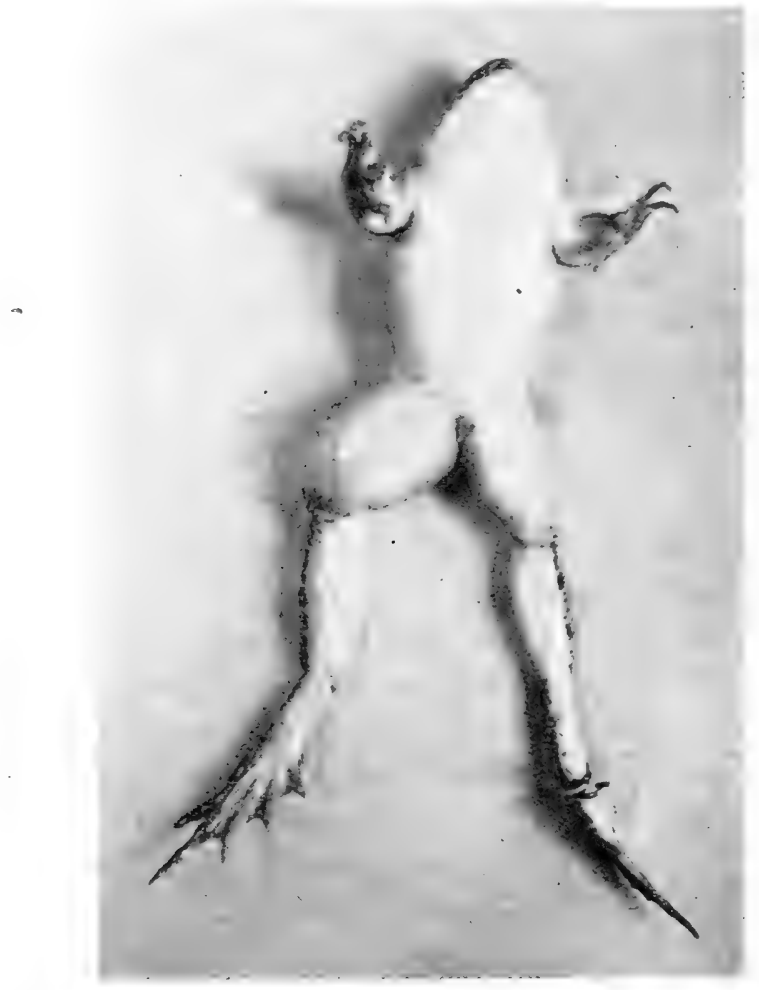

Fig. 2 Plotograph of a frog with red-leg disease, showing a localized subcutimeous oedema of right thigh.

ligature to the thigh and by ligating the ureters. The prescnce of a localized and a generalized oedema in the same individual suggests the possibility that, as in the case of the double-ligation experiment, the cause of the localized swelling may be influenced by local rather than by general conditions; otherwise the lymph would be more uniformly distributed throughout the subeutaneous lymph sinuses. 
A normal healthy frog, when transferred from water at one temperature to water at another or when left a long: period of time in water at one temperature, usually either loses, or remains practically stationary in weight. Should

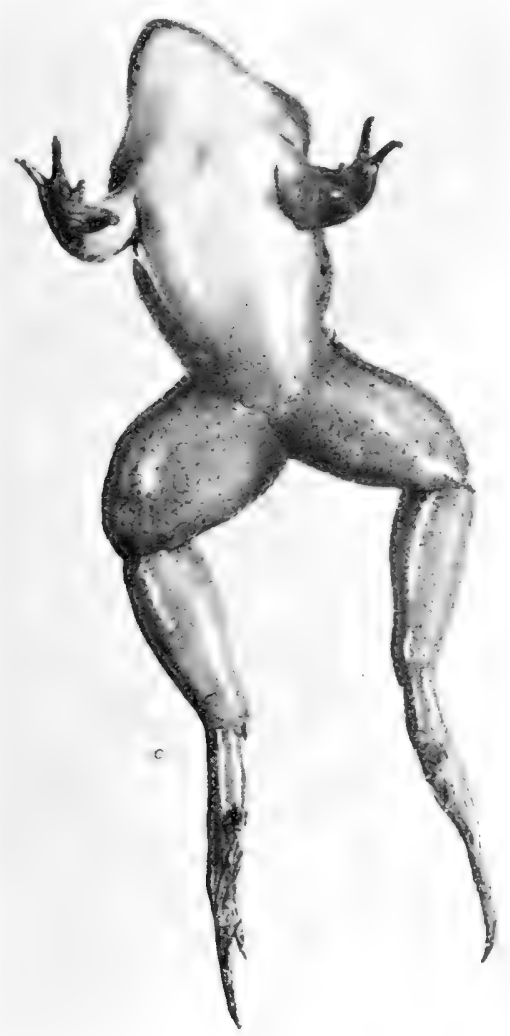

Fig. 3 Photograph of a frog with red-leg disease, showing a localized subcutaneous oedema of right leg and a generalized subcutaneous oedema of the rest of the body.

it gain weight, the gain is only temporary, and never does the gain continue through an extended period. On the other hand, when frogs with well-defined external symptoms of red-leg disease remain in water at any temperature within the limits of that of their natural environment, they immediately begin 
to gain in weight, and continue to do so as long as the disease is progressive. This continuous gain indicates that more water is being transported through the integument into the subcutaneous lymph sinuses than is simultaneously being excreted by the kidneys, and leads to the gradual production of a localized or generalized oedema, subcutaneous as well as intracellular (interstitial?) in character.

In table 6 is shown a number of experiments which bear out the above statement that if frogs with well-defined symptoms of red-leg disease remain in water, they gain weight continuously. As the disease progresses, it will be observed that, in course of time, the frogs become weak and sluggish and react slowly to stimuli. This condition is succeeded by coma and death follows. The disease is usually fatal at room temperature; Emerson and Norris state, however, that at low temperatures its progress may be arrested.

In experiment 161 (table 6) an apparently healthy frog, showing no external symptoms of red-leg, and selected for the purpose of studying its normal behavior, was observed to lose weight continuously during a period of about four hours, after being transferred from water at room temperature to water at $33^{\circ} \mathrm{C}$. Up to this point, the behavior of the frog was normal in respect to the balance that had been established between the incoming and outgoing flow of water. After the fourth hour, however, external symptoms of redleg made their appearance, and after this time the weight of the frog increased continuously.

The selection for experiment of frogs which one would commonly regard as healthy and free from red-leg has proved in some cases a difficult matter. While the character of its desiccation recorery curves (curves 1, 2, and 3 in fig. 1) and its beharior when placed in water generally indicate whether a frog is in healthy condition, the unexpected appearance of red-leg in frog's that in these respects give normal reactions is by no means an uncommon occurrence in the experience of the writer. An example of this is well illustrated by curve 6 in figure 1. The frog from which this curve was obtained 
had previously been used for a number of experiments extending over a considerable period of time. It had therefore become extremely thin and weak at the time of this last experiment. After injecting into the subcutaneous lymph sinuses 1 ce. of a 0.975 per cent solution of $\mathrm{NaCl}$, the writer put the frog into tap-water at $26^{\circ} \mathrm{C}$. Curve 6 in figure 1 shows us that, after a slight gain which was followed by a considerable loss in weight, the frog began to gain weight continuously. This gain was accompanied by red-leg symptoms which unexpectedly made their appearance some time between the eighth and twelfth hours of the experiment.

Having considered the general symptoms of red-leg disease in frogs and the general behavior in water of frogs so afflicted, let us now attempt to explain the presence of the oedema, both localized and generalized, associated with this disease, on the basis of those factors involved in the production of oedema which we have outlined in the preceding pages.

We may state that the presence in fiogs of a localized oedema indicates the probability, at least, that the oedema of this character is not due to inefficiency in kidney function. As a matter of fact, an examination of the urine of frogs in which the oedema is localized has shown that the oedema is not always accompanied by albuminuria. Albuminuria is of frequent occurrence in red-leg disease, however, when congestion has become general.

If, by the aid of a binocular microscope, we follow the progress of congestion in a case of red-leg in which at first the web of the foot is alone congested, we meet with conditions which we have the right to assume represent a typical elinical pieture of what may similarly occur elsewhere in the body when congestion has become more general. The condition which we actually observe in the foot is the establishment of a localized mechanical block in the vascular system, predisposing to the establishment of a typical case of localized subcutaneous oedema of exactly the same character as that which would have been formed had the foot of the frog been ligated. If we follow the progress of the disease as it spreads 


\section{TABLE 6}

Showing behavior of living frogs with red-leg disease, when frogs are placed in finger-bowls containing $100 \mathrm{cc}$. of tap-water

\begin{tabular}{|c|c|c|c|}
\hline EXPERIMEXT & WEIGHT OF FROG & HOIRS IN WATER & $\begin{array}{c}\text { TEMPERATLRE OF } \\
\text { WATER (C.) }\end{array}$ \\
\hline 597 & $\begin{array}{l}\text { Gram (percent) } \\
55.95(0) \\
56.85(+1.6) \\
58.98(+5.4) \\
59.15(+5.7) \\
59.63(+6.5) \\
61.35(+9.6) \\
\text { Frog, sluggish. } \\
63.55(+13.5) \\
\text { Dead. }\end{array}$ & $\begin{array}{c}0 . \\
1.00 \\
46.00 \\
52.00 \\
53.00 \\
57.00 \\
69.00\end{array}$ & $\begin{array}{l}30 \\
15\end{array}$ \\
\hline 598 & $\begin{array}{l}52.53(0) \\
53.99(+2.7) \\
57.55(+9.5) \\
\text { Frog, comatose. } \\
58.00(+10.4) \\
\text { Dead. }\end{array}$ & $\begin{array}{l}0 . \\
6.30 \\
24.00 \\
30.00\end{array}$ & 23 \\
\hline 600 & $\begin{array}{l}25.08(0) \\
27.44(+9.4) \\
\text { Frog, sluggish. Killed. }\end{array}$ & $\begin{array}{c}0 . \\
23.00\end{array}$ & 23 \\
\hline $6+1$ & $\begin{array}{l}36.25(0) \\
34.07(-7.7) \\
40.32(+11.2) \\
42.55(+17.3) \\
\text { Frog, sluggish }\end{array}$ & $\begin{array}{c}0 . \\
2.2 .30 \\
31.00 \\
45.00\end{array}$ & 21 \\
\hline fit2 & $\begin{array}{l}22.97(0) \\
23.48(+2.2) \\
25.55(+11.2) \\
27.45(+19.5) \\
\text { Frog, comatose. Killed. }\end{array}$ & $\begin{array}{c}0 . \\
22.00 \\
33.00 \\
45.00\end{array}$ & 21 \\
\hline (itis & $\begin{array}{l}18.95(0) \\
19.8(+4.4) \\
20.20(+6.5) \\
22.67(+19.6) \\
\text { Frog, comatose. Killed. }\end{array}$ & $\begin{array}{c}0 . \\
11.00 \\
24.00 \\
47.00\end{array}$ & 21 \\
\hline $1 i 44$ & $\begin{array}{l}33.37(0) \\
35.24(+5.6) \\
\text { Froge, comatose. Killed. }\end{array}$ & $\begin{array}{l}0 . \\
8.45\end{array}$ & 21 \\
\hline $6 i 45$ & $\begin{array}{l}19.67(0) \\
21.7(-10.3) \\
\text { Frog, active. Killed. }\end{array}$ & $\begin{array}{c}0 . \\
23.00\end{array}$ & 21 \\
\hline
\end{tabular}


TABLE 6-Continued

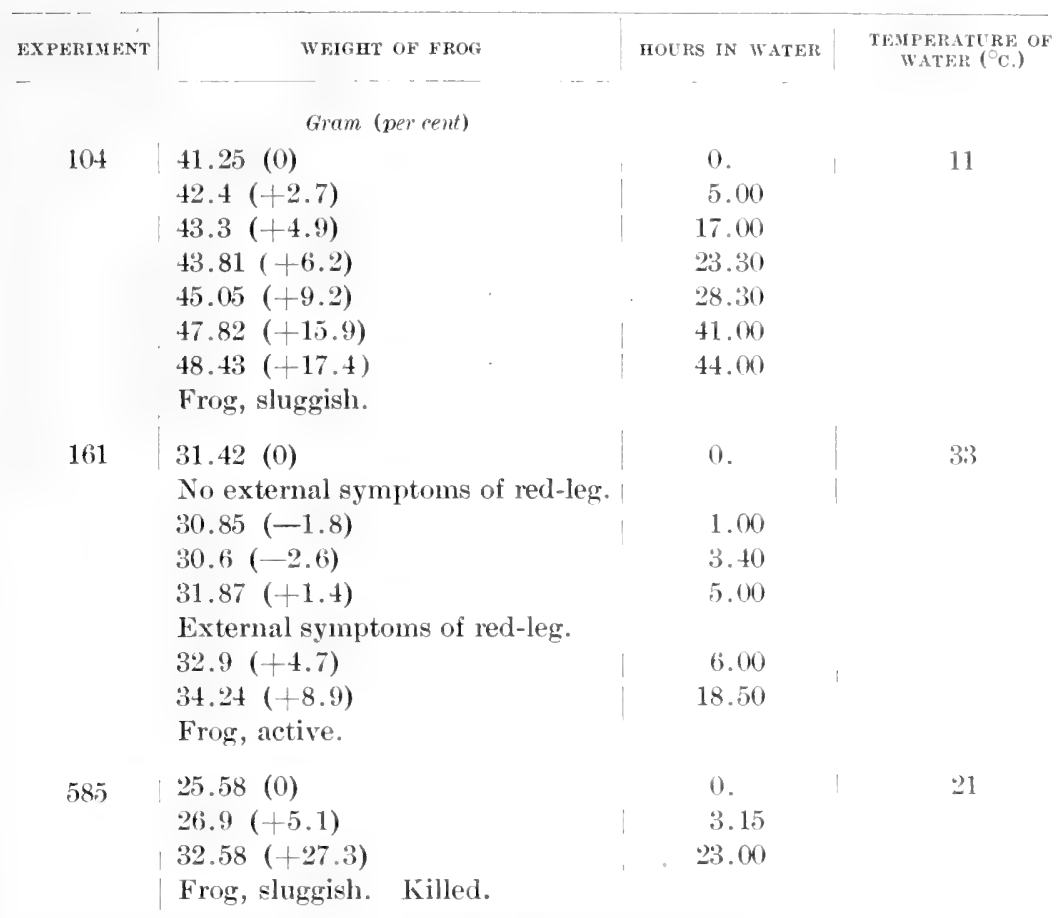

from the foot to the leg, we observe that soon the latter becomes swollen. When, in addition to the foot and leg, the abdominal region becomes affected, a similar swelling of this region becomes evident, and thus the entire body presents the appearance of being swollen generally. The variable manner in which localized oedema manifests itself is essentially indicative of the variable manner in which local conditions may arise, predisposing to its establishment.

Frogs usually remain active and respond to stimuli when the oedema is purely localized in character, as when one or both legs are affected. As soon, however, as congestion becomes more general, and especially when the gastro-intestinal tract is involved, the frogs become weak and shuggish, and soon coma follows. At this time, owing to cardiac inefficieney, the oedema becomes general throughout the body. The ex- 
planation of this is that at this stage more free water is cenerally being added to the lymph in the subeutaneous lymph sinuses than can simultaneously be transported to the kidneys through the agency of the heart and systemic blood vessels. Lrmph therefore gradually accumulates in the subcutaneous lymph sinuses of the body, while formerly its accumulation was regulated and controlled by local conditions. As stated above, the oedematous condition of the body which results when dead frogs remain in water is owing to the fact that, while water still continues to be transported through the integument into the subcutaneous lymph sinuses, all means of transportation to the kidneys by the vascular system has been discontinued. In advanced stages of red-leg disease, cardiac inefficiency similarly acts as a leading factor in rendering it impossible for as much free water to reach the kidneys and to be excreted by them as simultaneously enters the subcutaneous lymph sinuses through the integument, so that lymph generally accumulates in the body in excess of what experiment has shown us to be normal.

Up to this point we have considered certain causes which may account for the occurrence of localized and generalized oedema commonly associated with red-leg disease. We have found also that in frogs whose legs or ureters have been ligated, the resulting subcutaneous oedema is accompanied by an intracellular (interstitial?) oedema; the same is the case in red-leg disease. We, therefore, come now to an analysis of the behavior of muscles from frogs with red-leg disease, under experimental conditions similar to those used in our study of muscles from frogs whose legs or ureters had been ligated.

Should oedema of muscles in red-leg disease be due to an osmotic reaction, we should predict that muscles of a normal healthy frog would gain in weight when immersed in lymph obtained from a frog with red-leg disease; and, conversely, that the muscles of a frog with red-leg disease would lose in weight when immersed in a Ringer's solution, isotonic with normal resting muscle. The reason for this would be that 
such behavior would result if the osmotic pressure of lymph and of muscle in red-leg disease were lower than that of normal resting muscle. That these predictions have been fulfilled is shown by the following experiments.

In table 7 are shown experiments in which the left gastrocnemius muscles of three normal healthy frogs were im-

TABLE 7

Behavior of gastrocnemius muscles from normal healthy frogs, in lymph from subcutaneous lymph sinuses of frogs with red-leg disease.

Controls: Behavior of gastrocnemius muscles of same frogs, in Ringer's solution approximately isotonic with normal resting muscle.

Ringer's solution: $\Delta=0.445^{\circ}-p H$, \%.0. Room temperature.

\begin{tabular}{|c|c|c|c|}
\hline EXPERIMENT & HOURS & LEFT GASTROCNEMIUS IN LYMPH & $\begin{array}{l}\text { CONTHOL: RIGHT GASTROCNEMILS } \\
\text { IN RINGER }\end{array}$ \\
\hline \multirow{3}{*}{657} & & Gram (per cent) & Giram (per cent) \\
\hline & 0 & $0.48 \quad(0)$ & $0.49(0)$ \\
\hline & 1.00 & $0.51(+6.2)$ & $0.49(0)$ \\
\hline \multirow{7}{*}{660} & 2.00 & $0.52(+8.3)$ & $0.49(0)$ \\
\hline & 7.00 & $0.53(+10.4)$ & $0.49(0)$ \\
\hline & 23.00 & $0.53(+10.4)$ & $0.49(0)$ \\
\hline & 0 . & $0.45(0)$ & $0.45 \cdot(0)$ \\
\hline & 1.00 & $0.48(+6.6)$ & $0.45(0)$ \\
\hline & 2.00 & $0.49(+8.8)$ & $0.45(0)$ \\
\hline & 7.00 & $0.51(+13.3)$ & $0.45(0)$ \\
\hline \multirow{6}{*}{681} & 23.00 & $0.52(+15.5)$ & $0.45(0)$ \\
\hline & 26.00 & $0.52(+15.5)$ & $0.45 \quad(0)$ \\
\hline & 0. & $0.29(0)$ & $0.29(0)$ \\
\hline & 1.00 & $0.30(+3.4)$ & $0.29 \quad(0)$ \\
\hline & 4.00 & $0.31(+7.0)$ & $0.29 \quad(0)$ \\
\hline & 8.00 & $0.32(+10.3)$ & $0.29 \quad(0)$ \\
\hline
\end{tabular}

mersed in lymph from frog's with red-leg disease, and the right gastrocnemius muscles (control) of the same frogs were immersed in Ringer's solution approximately isotonic with normal resting muscle. In each instance the muscle immersed in lymph gained weight while the weight of the muscle in isotonic Ringer's solution remained stationary. Also, as shown by the controls in tables 8,9 , and 10 , it will be observed that muscles from frogs with red-leg disease lost 
weight when immersed in Ringer's solution approximately isotonic with normal resting muscle. As stated above, this behavior would be expected, provided that in red-leg disease the osmotic pressure of the lymph were lower than that of normal resting muscle. An examination of the lymph has shown such to be the case.

The $\triangle$ or freezing-point depression and hydrogen-ion concentration of lymph obtained from frogs (Rana catesbiana) with red-leg disease have been determined by my colleague, Doctor Marshall, to be as follows:

$$
\begin{aligned}
\text { Frog } \mathrm{A}, \triangle & =0.330^{\circ} \pm 0.010^{\circ} \mathrm{C} . \\
\mathrm{PH} & =7.5 \\
\text { Frog } \mathrm{B}, \triangle & =0.29^{\circ} \pm 0.010^{\circ} \mathrm{C} .
\end{aligned}
$$

The value of $\triangle$ in frog $B$ is for a partially coagulated lymph, and may differ from the original value for the same, owing to the absorption of electrolytes from the solution in the process of coagulation.

A number of other experiments have been made which still further bear out the view that the oedema which accompanies red-leg disease can be explained on the grounds that muscles take up and hold water as long as the osmotic pressure of the lymph supplied to the muscles continues to remain lower than that of the muscles.

In table 8 two experiments are shown in which the gastrocnemius muscle of a frog with red-leg disease was immersed in lymph obtained from the subcutaneous sinuses of the ligated leg of a normal frog. In one instance (experiment 654) the osmotic pressure of the muscle was higher than that of the lymph, and the muscle gained 13.9 per cent in weight before an equilibrium was established. In the other experiment (experiment 659) the lymph was essentially isotonic with the red-leg muscle, and the weight of the latter remained practically stationary. The behavior of the controls-redleg muscles immersed in Ringer's solution approximately isotonic with normal resting musele-was typical of that of all such muscles when observed under similar experimental 
conditions. These muscles lost weight when immersed in Ringer's solution approximately isotonic with normal resting muscle.

In table 9 are shown experiments in which the gastrocnemius muscles of a frog with red-leg disease were immersed in lymph obtained from the same frog. In one experiment (experiment 661) the lymph was taken from the subcutaneous lymph sinuses, and in the others from the coelom. It will be

TABLE 8

Behavior of gastrocnemius muscles from frogs with red-leg disease, in lymph from subcutaneous sinuses of ligated legs of normal healthy frogs.

Controls: Behavior of gastrocnemius muscles from same red-leg frogs, in Ringer's solution approximately isotonic with normal resting muscle.

Ringer's solution: $\triangle=0.445^{\circ}-p H$, \%.O. Hoom temperature.

\begin{tabular}{|c|c|c|c|}
\hline \multirow{2}{*}{ EXPERIMENT } & - & $-\cdots$ & $-\quad-$ \\
\hline & Hours & LEFT GASTROCNEMIUS IN LYMPH & $\begin{array}{l}\text { CONTROL: RIGHT GAETROCNEMIUS } \\
\text { IN RINGER }\end{array}$ \\
\hline \multirow{7}{*}{654} & & Gram (per cent) & Gram (per cent) \\
\hline & 0 . & $0.43(0)$ & $0.45 \quad(0)$ \\
\hline & 1.00 & $0.45(+4.6)$ & $0.44(-2.2)$ \\
\hline & 2.00 & $0.45(+4.6)$ & $0.44(-2.2)$ \\
\hline & 7.00 & $0.48(+11.6)$ & $0.39 \quad(-13.3)$ \\
\hline & 23.00 & $0.49(+13.9)$ & $0.35(-22.2)$ \\
\hline & 26.00 & $0.49(+13.9)$ & $0.35(-22.2)$ \\
\hline \multirow[t]{2}{*}{659} & 0 . & $0.35(0)$ & $0.34(0)$ \\
\hline & 1.00 & $0.35(0)$ & $0.33(-2.9)$ \\
\hline \multirow[t]{5}{*}{ - } & 2.00 & $0.35 \quad(0)$ & $0.33(-2.9)$ \\
\hline & 7.00 & $0.34(-2.8)$ & $0.31 \quad(-8.8)$ \\
\hline & 24.00 & $0.3+(2.8)$ & $0.30(-11.7)$ \\
\hline & 26.00 & $0.34(-2.8)$ & $0.30(-11.7)$ \\
\hline & & & \\
\hline
\end{tabular}

observed that the museles when first placed in lymph either gained slightly or remained stationary in weight, and that the controls lost weight when placed in Ringer's solution approximately isotonic with normal resting muscle.

- Jacques Loeb ('98) has stated that when a frog's muscle is immersed in a 0.7 per cent solution of $\mathrm{NaCl}$, to which a trace of acid has been added, the muscle takes up and holds water. This phenomenon forms the central idea of the colloid-chemical theory of Martin Fischer; hence it is inter- 
esting to observe the effects produced on muscles obtained from oedematous red-leg frogs, when immersed in an acidulated Ringer's solution approximately isotonic with normal resting muscle.

TABILE 9

Behavior of gastrocnemius muscles from frogs with red-leg disease, in lymph obtained from same frogs.

Controls: Bchavior of gastrocnemius muscles from same frogs, in Ringer's solution approximately isotonic with normal resting muscle.

Ringer's solution: $\Delta=0.445^{\circ}-p H$, \%.o. Room temperature.

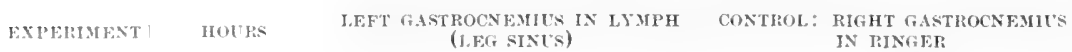

\begin{tabular}{l|ll} 
& Grom (percent) & Gram (per cent) \\
0.00 & $0.50(0)$ & $0.49(0)$ \\
1.00 & $0.51(+2.0)$ & $0.48(-2.0)$ \\
2.00 & $0.51(+2.0)$ & $0.47(-4.0)$ \\
6.00 & $0.52(+4.0)$ & $0.43(-12.2)$ \\
23.00 & $0.52(+4.0)$ & $0.41(-16.3)$ \\
25.00 & $0.50(0)$ & $0.41(-16.3)$
\end{tabular}

Lymph (coelom)

682

\begin{tabular}{l|ll}
0. & $0.62(0)$ & $0.60(0)$ \\
1.00 & $0.62(0)$ & $0.59(-1.6)$ \\
2.00 & $0.62(0)$ & $0.58(-3.3)$ \\
24.00 & $0.62(0)$ & $0.55(-8.3)$ \\
26.00 & $0.62(0)$ & $0.55(-8.3)$
\end{tabular}

Lymph (coelom)

(18.5) $\begin{array}{lll}0 . & 0.31(0) & 0.31(0) \\ 1.00 & 0.31(0) & 0.30(-3.2) \\ 4.00 & 0.31(0) & 0.29(-6.4) \\ 0.00 & 0.29(-6.4) & 0.28(-9.6) \\ 21.00 & 0.27(-12.9) & 0.28(-9.6)\end{array}$

Four experiments of this character are shown in table 10. In two of the experiments, the $p H$ value of the Ringer's solution was 6.5 and in the remaining two it was 4.8. In each cxperiment the muscles were taken from the same frog. The writer found that the behavior of the muscles in acidulated Ringer was the same as that of the controls which were im- 
mersed in Ringer's solution approximately isotonic with normal resting muscle, but having a pH value of 7.0. Thile we may recognize the fact that under certain conditions acidity plays a definite rôle in causing muscles to take up water, it is

TABLE 10

Behavior of gastrocnemius muscles from frogs with rel-leg disease, in Ringer's solution approximately isotonic with normal resting muscle and acidulated with lactic acid.

Controls: Behavior of gastrocnemius muscles from same frogs, in Ringer's solution approximately isotonic with normal resting muscle. $\Delta=0.445^{\circ}$. Room temperature.

\begin{tabular}{|c|c|c|c|c|}
\hline FXPERIMENT & HOURS & LEFT & $\begin{array}{l}\text { GASTROCNEMHLS IN RIAGER } \\
(\mathrm{pH}, 6.5)\end{array}$ & $\begin{array}{l}\text { CONTROL : RIGHT (AASTROCN) } \\
\text { IN RINGER (pH, 7.0) }\end{array}$ \\
\hline & & & Gram (per cent) & Grum (per cent) \\
\hline \multirow[t]{5}{*}{662} & 0. & & $0.52(0)$ & $0.495 \quad(0)$ \\
\hline & 1.00 & & $0.48 \quad(-7.6)$ & $0.46 \quad(-7.0)$ \\
\hline & 4.00 & & $0.42(-19.2)$ & $0.40 \quad(-19.1)$ \\
\hline & 22.00 & & $0.37(-28.8)$ & $0.37 \quad(-25.2)$ \\
\hline & 46.00 & & $0.35 \quad(-32.6)$ & $0.35 \quad(-29.3)$ \\
\hline \multirow[t]{6}{*}{6663} & 0. & & $0.43(0)$ & $0.44 \quad(0)$ \\
\hline & $1 .(K)$ & & $0.42(-2.3)$ & $0.44 \quad(0)$ \\
\hline & 4.00 & & $0.40(-7.0)$ & $0.43 \quad(-2.2)$ \\
\hline & 21.00 & & $0.38(-11.6)$ & $0.39 \quad(-11.3)$ \\
\hline & 22.00 & & $0.38 \quad(-11.6)$ & $0.39 \quad(-11.3)$ \\
\hline & 46.00 & & $0.35 \quad(-18.6)$ & $0.36 \quad(-18.1)$ \\
\hline . & & & RINGER $(\mathrm{pH}, 4.8)$ & \\
\hline \multirow{4}{*}{665} & 0. & & $0.57 \quad(0)$ & $0.58 \quad(0)$ \\
\hline & 1.00 & & $0.55 \quad(-3.5)$ & $0.55 \quad(-5.1)$ \\
\hline & 4.00 & & $0.49(-14.0)$ & $0.48 \quad(-17.2)$ \\
\hline & 23.00 & & $0.42(-26.3)$ & $0.42 \quad(-27.5)$ \\
\hline \multirow[t]{4}{*}{666} & 0 . & & $0.39 \quad(0)$ & $0.39 \quad(0)$ \\
\hline & 1.00 & & $0.36(-7.7)$ & $0.38 \quad(-2.5)$ \\
\hline & 4.00 & & $0.32(-17.9)$ & $0.34 \quad(-12.8)$ \\
\hline & 23.00 & & $0.30(-23.0)$ & $0.31 \quad(-20.5)$ \\
\hline
\end{tabular}

evident that, within the limits indicated, its presence has no material effect of this sort on the oedematous muscles from red-leg frogs. It has already been pointed out by Henderson ('18), Crozier ('18), and other's that, on account of the limited hydrogen-ion concentration in the body, the colloid-chemical theory of Fischer is untenable. 
Owing to a possible inefficiency in kidney function, due to the presence of albumin in the urine, albuminuria has been regarded as a cause of oedema. In the frog it can be demonstrated by experiment that an oedema does result both when there is a deficiency in development of the renal tubules ( $\mathrm{Mc}-$ Clure, '19) and when the kidneys of a larval frog have been extirpated (Howland, '16, and Swingle, '19). Of this there can be no question. The point at issue at present, however,

TABLE 11

Behavior of a frog, not afflicted with red-leg disease but in which an acute nephritis has been experimentally developed, when placed in tap-water at $99^{\circ}$ and $16^{\circ} \mathrm{C}$.

\begin{tabular}{|c|c|c|}
\hline $\begin{array}{l}\text { HOURS IN } \\
\text { WATER }\end{array}$ & WEIGHT OF FROG & $\begin{array}{l}\text { TEMPERATURE } \\
\text { OF WATER }\end{array}$ \\
\hline \multicolumn{3}{|c|}{ Gram } \\
\hline 0. & 27.95 & \multirow[t]{3}{*}{$29^{\circ} \mathrm{C}$} \\
\hline 1.25 & $\begin{array}{l}\text { Frog sluggish, albumin present, casts in abundance. } \\
\qquad 27.8\end{array}$ & \\
\hline 4.00 & $\begin{array}{l}26.5 \\
\text { Frog sluggish, albumin present, casts still abundant. }\end{array}$ & \\
\hline 0. & 26.5 & \multirow[t]{5}{*}{$16^{\circ} \mathrm{C}$} \\
\hline 1.00 & $\begin{array}{l}\qquad 27.5 \\
\text { Frog active, albumin and casts present. }\end{array}$ & \\
\hline 2.00 & $\begin{array}{l}\text { Frog active, albumm and casts present. } \\
\qquad 27.45\end{array}$ & \\
\hline $13 .(x)$ & 26.65 & \\
\hline 15.40 & $\begin{array}{l}\text { Frog active, trace of albumin, no casts observed. } \\
\qquad 26.8 \\
\text { Frog active, trace of albumin. }\end{array}$ & \\
\hline
\end{tabular}

is whether in red-leg disease the presence of albuminuria causes an actual inefficiency in kidney function sufficient to account in this disease for the gradual and excessive accumulation of lymph in the body (table 6). Frog's with red-leg disease are much less resistant than normal frogs and when placed in water at temperatures beyond the range of their natural environment, almost immediately fall into a comatose condition which is accompanied by cardiac inefficiency. Since cardiac inefficiency is in itself a cause of oedema, one is unable 
in these cases to determine in red-leg disease the effect of albuminuria on the efficiency of the kidneys.

In order to test the efficiency of the kidneys in frogs which are not afflicted with red-leg disease, but in which an acute nephritis had been developed, the following procedure was adopted:

Normal frogs were transferred alternately to and fro from water at room temperature to water at $38^{\circ} \mathrm{C}$., until an acute nephritis had been developed with albumin and abundant casts showing in the urine. The nephritis apparently resulted from an overfunctioning of the kidneys. This procedure often required several days, and in order not to kill the frog during the experiment, the writer immediately revived a frog as soon as it appeared sluggish or slightly comatose by placing it in water at a much lower temperature. In table 11 we have the behavior of such a frog, which was placed first in water at $29^{\circ}$ and later in water at $16^{\circ} \mathrm{C}$. During the twenty hours that the frog was in water at $29^{\circ}$ and $16^{\circ} \mathrm{C}$., there was no gain in weight of any significance; obviously, the albuminuria did not cause any inefficiency in kidney functioning, as a normal balance was maintained in the body between the incoming and outgoing water. ${ }^{4}$

\section{SUMMARY}

Oedema, both localized and generalized, manifests itself in red-leg disease in two forms which we may designate as subcutaneous and intracellular (interstitial?) oedema.

A localized and excessive accumulation of lymph in the subcutaneous lymph simuses results from a local block in the efferent drainage chamels. As water is being constantly driven by osmosis through the integument into the subcutaneous lymph sinuses, lymph gradually accumulates in the latter, distal to the block and locally in the sinuses. The osmotic pressure of this oedematous lymph is lower than that of normal resting muscle.

${ }^{4}$ I wish to express my thanks and appreeiation to my colleague, Prof. E. Newton Harvey, for the many favors extended to me during the course of this investigation; my thanks are also due Mr. W. P. Agnew for his kindness in preparing the photographs for me. 
A generalized and excessive accumulation of lymph in the subcutaneous lymph sinuses is associated chiefly with eardiac ineficiency, as the result of which, when the frog remains in water, more free water continuously enters the subcutaneous lymph sinuses through the integument than can simultaneously be transported to the kidneys through the ageney of the vascular system. Hence, lymph gradually accumulates in the subcutaneous lymph sinuses in excess of normal and causes a general distention of the sinuses. The osmotic pressure of this lymph is lower than that of normal resting muscle.

A swelling of tissues accompanies the subcutaneous oedema. This is brought about by differences in osmotic pressure which exist between the fluid within and that supplied to the tissues. 


\section{BIBLIOGRAPHY}

Cooke, E. 1898 Experiments upon the osmotic properties of living frog's muscle. Jour. Physiol., vol. 23.

Crozier, W. J. 1916 Cell penetration by acids. Jour. Biol. Chem., vol. 24.

- 1918 On indicators in animal tissues. Jour. Biol. Chem., vol. 35.

Durig, A. 1901 Wassergehalt und Organfunction. Pflüger's Archiv., Bd. 85.

Fischer, M. 1915 Oedema and nephritis. New York.

Emerson, H., AND Norris, C. 1905 'Red-leg.' An infectious disease in frogs. Jour. Exper. Med., vol. 7.

Fletcher, W. M. 1904 Osmotic properties of muscles and their modifications in fatigue and rigor. Jour. Physiol., vol. 7 .

Hendersen, L. J., and Cohn, E. J. 1918 On the swelling of protein colloids. A reply to Professor Martin II. Fischer. Jour. Amer. Chem. Soc., vol. 40 .

Howland, R. B. 1916 On the effect of the removal of the pronephros of the amphibian cmbryo. Proe. Nat. Acad. Sei, vol. 2.

LoEB, J. 1898. Physiologische Untersuchungen über Ionenwirkungen. Zur Theorie des Oedems. P'flüger's Archiv., Bd. 71.

Maxwell, S. S. 1913 On the absorption of water by the skin of the frog. Amer. Jour. Physiol., vol. 32.

MCClure, C. F. W. 1919 On the experimental production of edema in larval and adult anura. Jour. Gen. Physiol., vol. 1.

Moore, A. R. 1915 An analysis of experimental edema in the frog. Amer. Jour. Physiol., vol. 37.

Nasse, O. 1869 Pfliger's Archiv. Quoted from Fletcher, '04.

Overton, E. 1902 Beiträge zur allgemeinen Muskel- und Nervenphysiologie. Pflüger's Archiv., Bd. 92.

Overton, E. 1904 Neununddreissig 'Thesen über die Wasserökonomie der Amphibien und die osmotischen Eigenschaften der Amphibienhaut. Verhl. d. Phys.-med. Ges. zu Würzburg, N.F., Bd. 36.

DE SousA, D. H. 1909 The effects of temperature on the osmotic properties of muscles. Quart. Jour. Exper. Physiol., vol. 2.

Swingle, W. W. 1919 On the experimental production of edema by nephrectomy. Jour. Gen. Physiol., vol. 1.

Volhard, F. 1912 Physikochemische Beiträge zur Ödemfrage. Verhand. d. deutsch. Kóngress f. inn. Med., Bd. 29. 
$u^{\circ}$ 


QL

948

W33

BioMed
Wada, Tokujiro

Anatomical and physiological studies on the growth of the inner ear of albino rat
PLEASE DO NOT REMOVE CARDS OR SLIPS FROM THIS POCKET

UNIVERSITY OF TORONTO LIBRARY 
